\title{
Targeting Reserve Growth Opportunities in the Northern Gulf of Mexico Basin: Transferring Secondary Gas Recovery Technology to the Offshore Environment
}

\section{Technical Progress Report}

September 30, 1998 through September 30, 2002

by

Tucker F. Hentz, Lesli J. Wood, Michael V. DeAngelo, Hongliu Zeng, Mark H. Holtz, Shirley P. Dutton, Ke-Sheng Chan, Claudia Rassi, Javier Garcia, Eugene M. Kim, Dallas B. Dunlap, Robert E. Barba, and Paul R. Knox

December 2002

DOE Award No. DEFC26-98FT40136

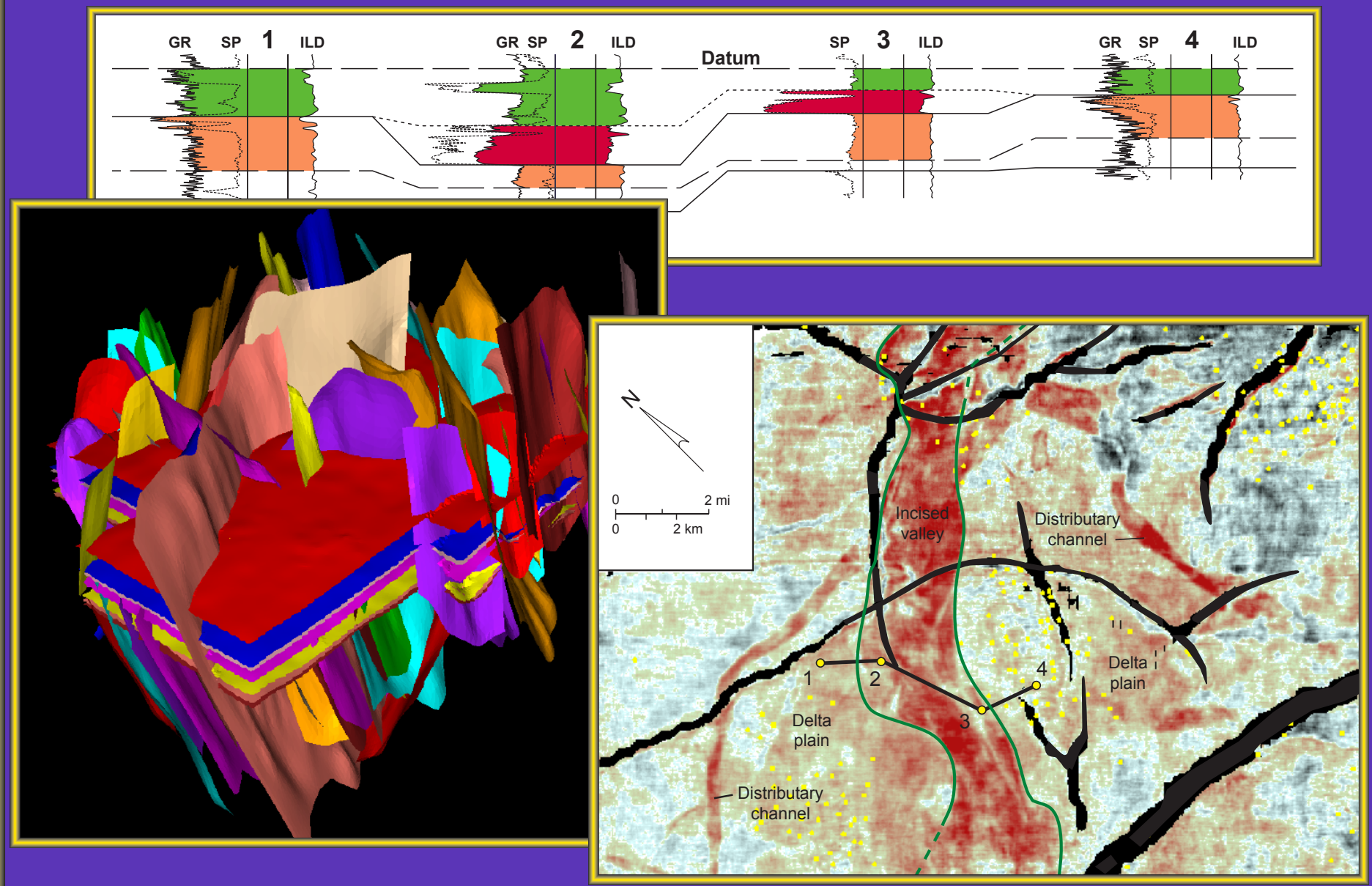

B ureau of Economic Geology scott W. Tinker, Director John A, and Katherine G. J ackson School of Geosciences The University of Texas at Austin DO ${ }^{\circledR}$ NETL Austin, Texas 78713-8924 


\section{Targeting Reserve Growth Opportunities in the Northern Gulf of Mexico Basin: Transferring Secondary Gas Recovery Technology to the Offshore Environment}

Technical Progress Report

September 30, 1998 through September 30, 2002

Tucker F. Hentz, Lesli J . Wood, Michael V. DeAngelo, Hongliu Zeng, Mark H. Holtz, Shirley P. Dutton, Ke-Sheng Chan, Claudia Rassi, Javier Garcia, E ugene M. Kim, Dallas B. Dunlap, Robert E. B arba, and Paul R. Knox

Bureau of E conomic Geology Scott W. Tinker, Director John A. and Katherine G. J ackson School of Geosciences The University of Texas at Austin Austin, Texas 78713-8924

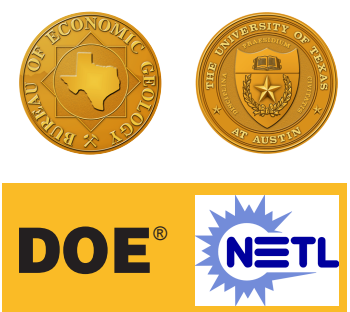




\section{EXECUTIVE SUMMARY}

The Bureau of Economic Geology's Offshore Secondary Gas Recovery research program was a 4-year project funded by the U.S. Department of Energy, whose goals are to research new techniques in defining the structure, stratigraphy, and hydrocarbon character in mature areas in the northern Gulf of Mexico; to utilize those multidisciplinary techniques to identify additional gas resources; and to predict regional trends in hydrocarbon accumulation. By latest estimates, Miocene-age strata of the northern Gulf of Mexico shelf are thought to contain 12.7 Tcf of remaining gas, which represents 41 percent of the total remaining proven recoverable reserves. A study area was chosen in the Vermilion Block 50 and South Marsh Island Areas of offshore Louisiana. This area included two major producing fields, Starfak and Tiger Shoal, that provided more than 150 logging suites, detailed rockproperty measurements, and whole and sidewall core, all of which were integrated with a high quality 3-D seismic survey to construct a detailed sequence-stratigraphic framework for the study area. Analyses were done within the context of this framework for researchers to better understand stratigraphic and structural controls on resource distribution and to plan the pursuit of new opportunities.

Specific objectives of the project were to (1) increase reserves, (2) prioritize newly identified development opportunities, (3) develop and apply new technologies, (4) create transferable knowledge, and (5) achieve these objectives using quality products in a timely fashion. These objectives have been reached through the following series of accomplishments:

(1) Increase reserves

- On the basis of research analysis and preliminary drilling results, a 50-percent probability exists that the opportunities delineated within the study area contain 1 trillion standard feet of gas.

- Mean unrisked potential reserve additions are $623 \mathrm{Bcf}$.

- Mean risked potential reserve additions are 146 Bcf.

- Seismic analysis has identified several deep (below $3.0 \mathrm{sec}, \sim 12,000 \mathrm{ft}$ ) structural closures, and petrophysical and petrographic analyses show that as much as 27 percent porosity and $766 \mathrm{md}$ of permeability exist in the Miocene units below 14,000 ft. Both observations suggest significant deepreserves potential throughout the area.

(2) Prioritize newly identified development opportunities

- Fifty-four potential resource-addition opportunities were identified, classified according to their geologic play type, and risked. Moreover, their resources, in place and recoverable, were calculated at certainty and at risk.

- Three different trap styles among the 54 identified opportunities - three-way structural closure, pure stratigraphic trap, and a combination stratigraphic-structure trap-were drilled by industry partner, Texaco, and all were successful.

(3) Develop and apply new technologies

- The first-ever, high-resolution sequence-stratigraphic framework of the northern Gulf of Mexico Miocene reservoirs was created. 
- The first extensive Root-Mean Squared Amplitude mapping for targeting resource-addition opportunities was applied.

- The first stratal-slicing technology in an offshore shelf setting to enhance seismic extraction of geomorphic elements and map depositional features was used.

- The first successful neural-network-assisted, multiattribute transform of seismic data into a 3-D petrophysical volume was used that can accurately predict lithology, thickness, and porosity.

- The first use of neural networks to automate seismic-facies analysis using geomorphic form was applied.

- A comprehensive, user-friendly, Excel-based program to manage complex resource opportunity portfolios was designed.

(4) Create transferable knowledge

- Seven manuscripts are in publication or in press in major refereed scientific journals.

- Sixteen oral or poster presentations have been made at national and international scientific meetings.

- Five extended abstracts have been published.

- A short course will be presented to the public in September 2002 in collaboration with the Petroleum Technology Transfer Council.

- Three Ph.D. dissertations and two Master's theses were completed.

- Four internal presentations were made to staff and scientists at The University of Texas at Austin.

- An extensive public Website with downloadable publications has been made available.

(5) Achieve these objectives using quality products in a timely fashion

- The OSGR project was completed on time and within budget.

- All project deliverables were completed before the project deadline.

- Numerous manuscripts have been published in peer-reviewed journals of the highest standard. 


\section{CONTENTS}

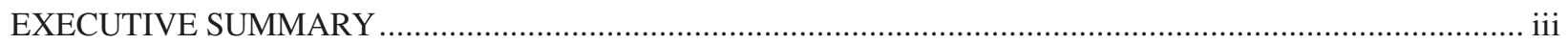

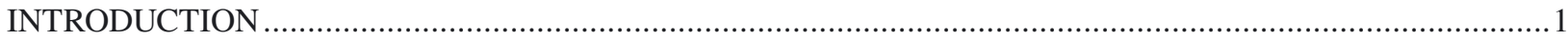

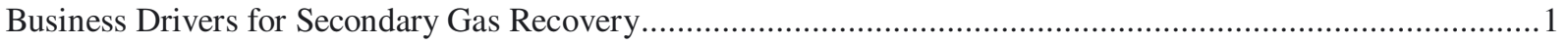

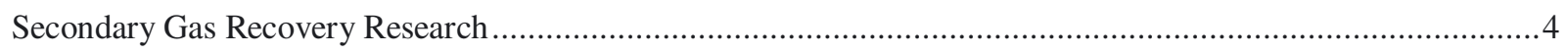

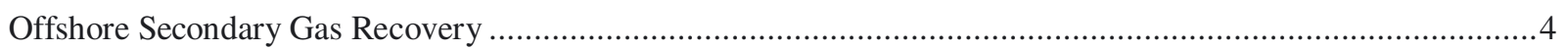

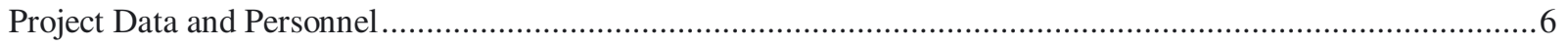

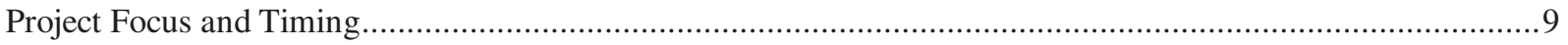

PREVIOUS WORK

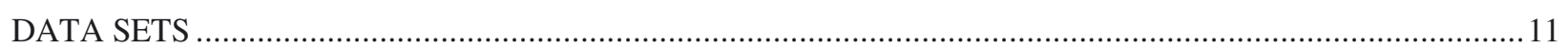

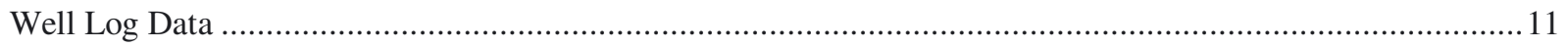

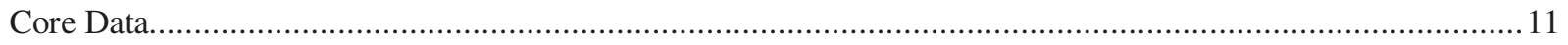

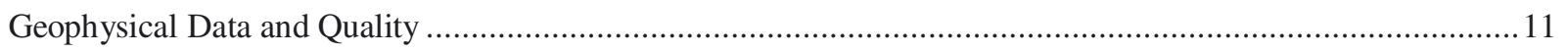

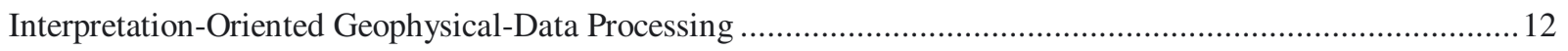

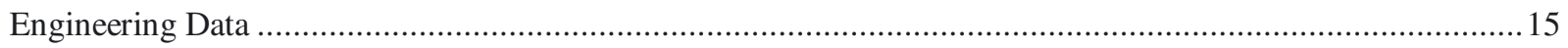

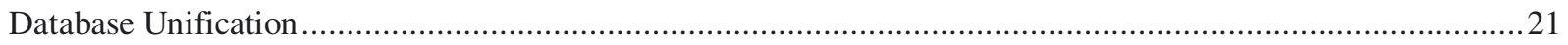

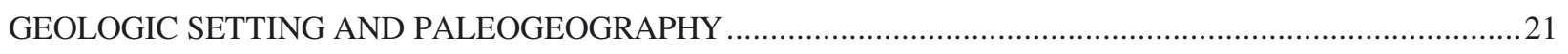

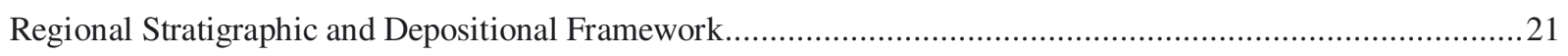

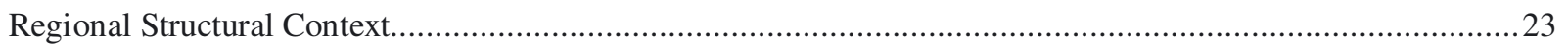

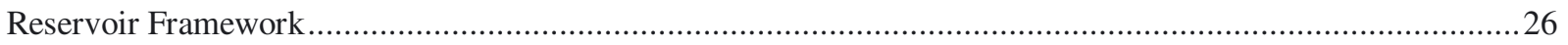

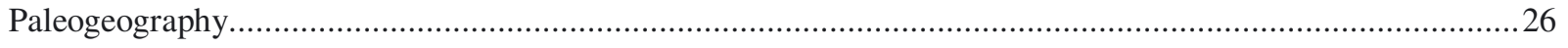

IMPROVING RESOURCE RECOVERY IN THE MIOCENE, NORTHERN GULF OF MEXICO ......................28

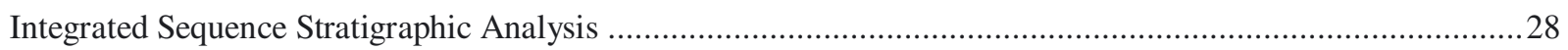

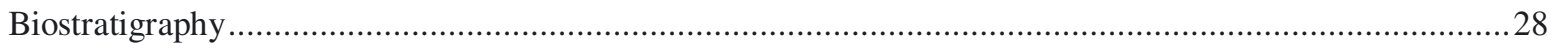

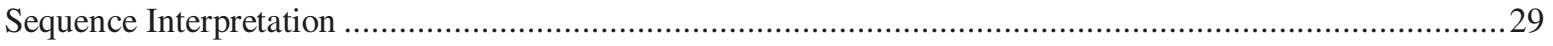

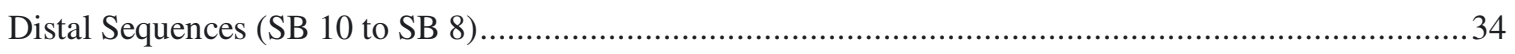

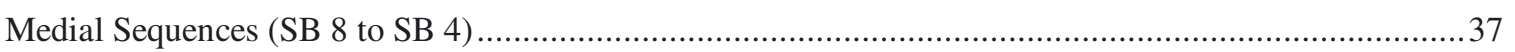

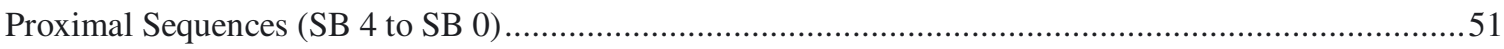

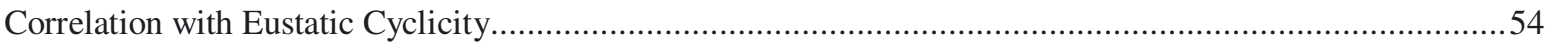

Hydrocarbon Distribution within Third-Order Systems Tracts ................................................................5

Rock Properties and Production Distribution within Fourth-Order Systems Tracts ......................................58

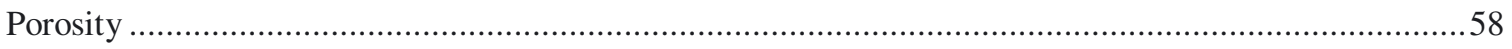

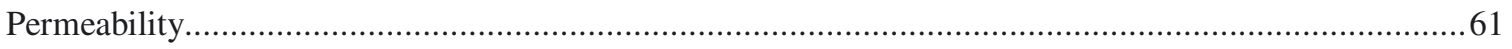

Production Behavior: Production Rates and Cumulative Production of Selected Sequences ......................61

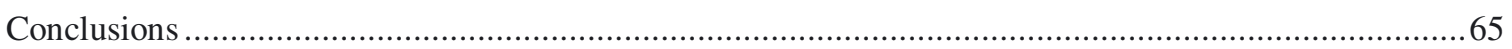

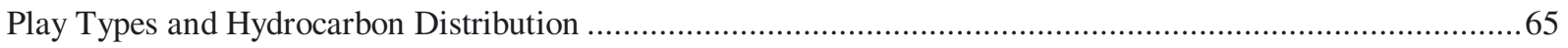

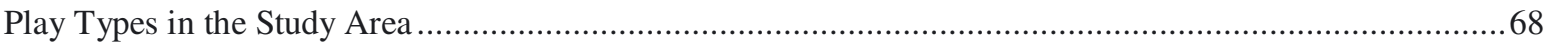




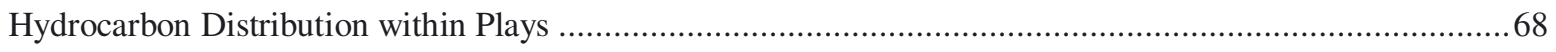

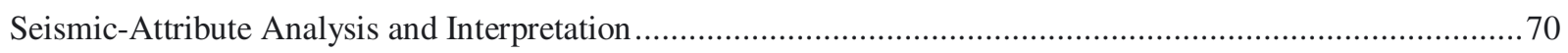

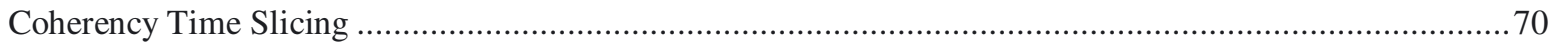

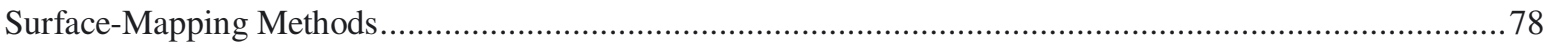

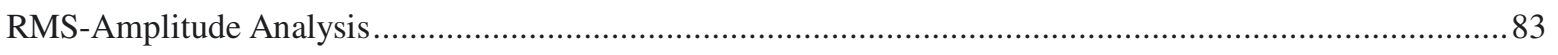

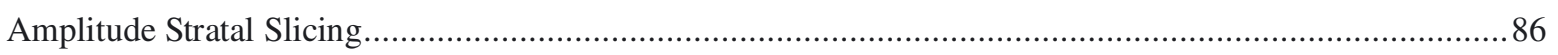

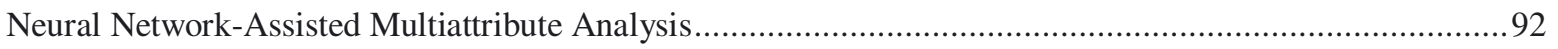

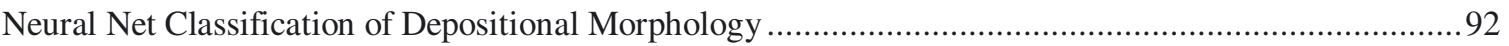

Neural Net Prediction of Petrophysical-Log Properties ........................................................................96

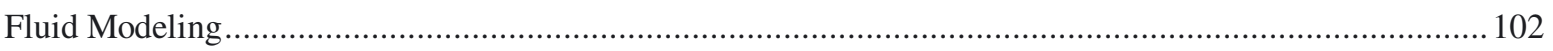

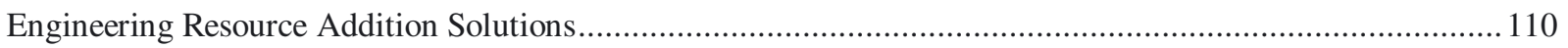

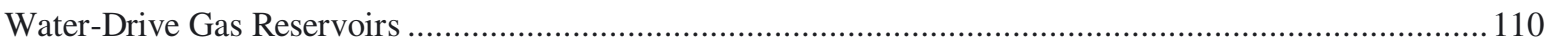

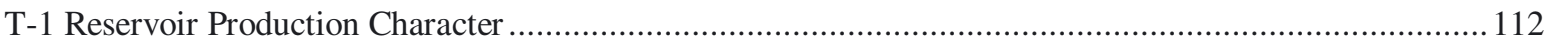

Petrophysical Input to the Reservoir-Characterization Process .............................................................. 114

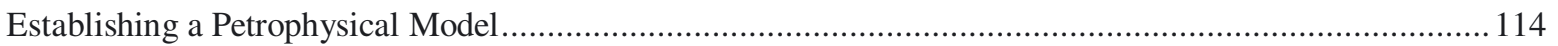

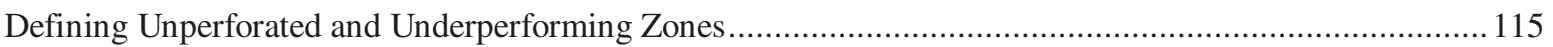

Underperforming Pay: Example of the Y Sand in Blocks 30 and 31 .................................................. 116

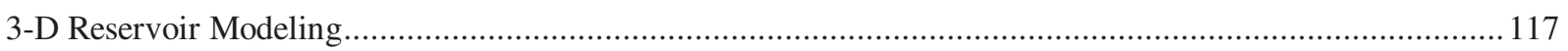

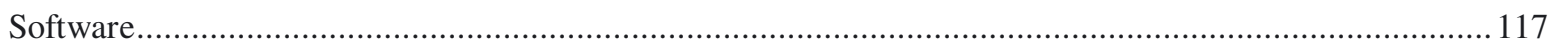

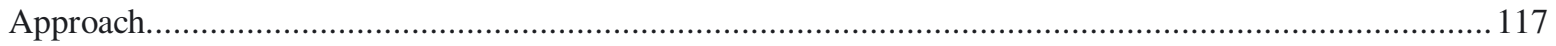

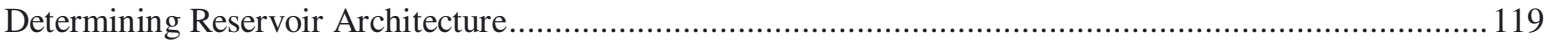

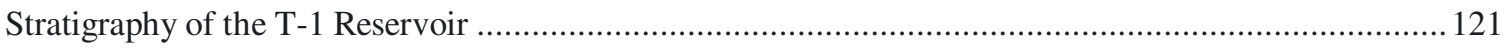

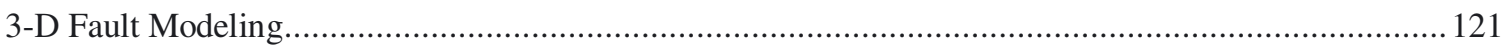

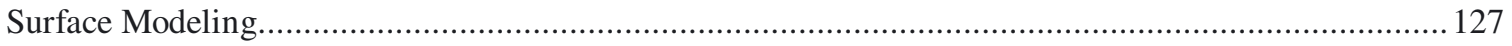

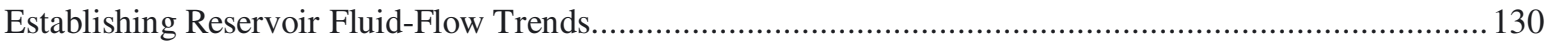

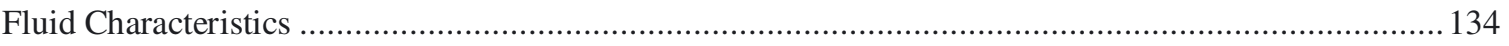

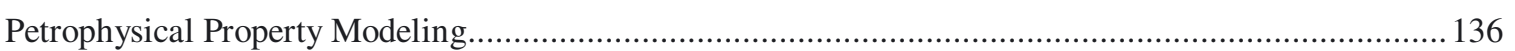

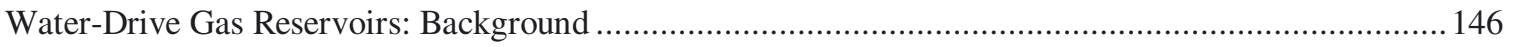

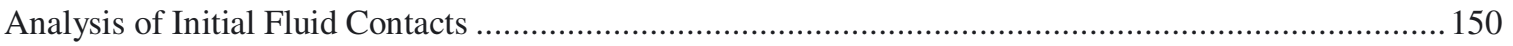

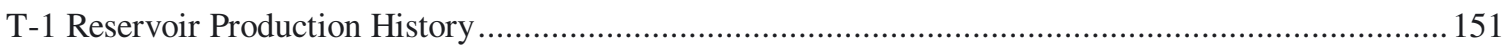

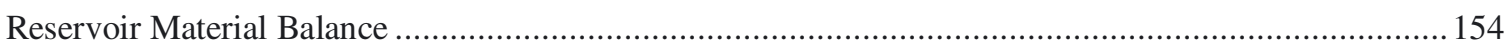

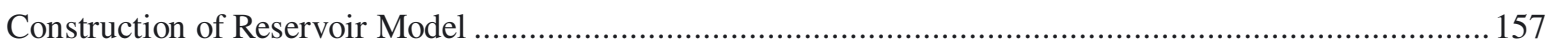

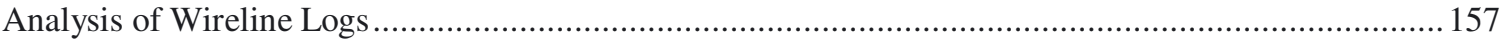

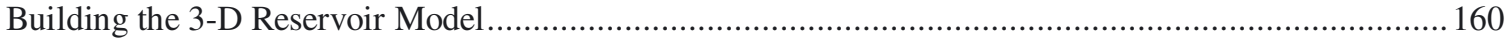

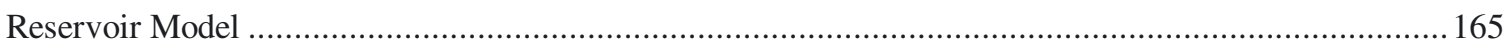

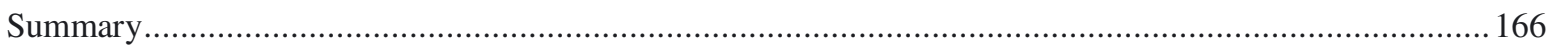

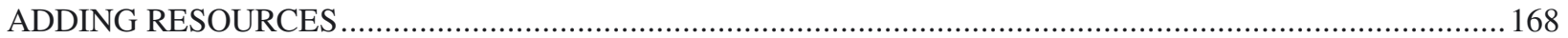




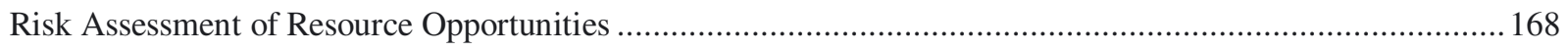

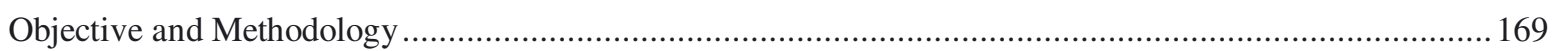

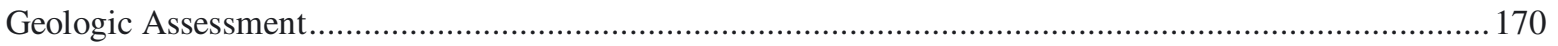

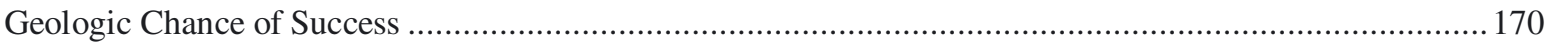

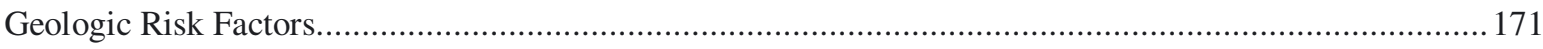

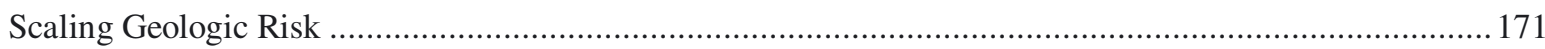

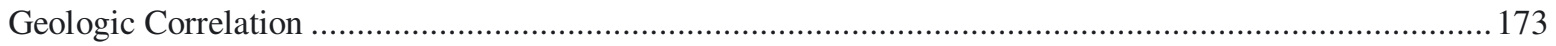

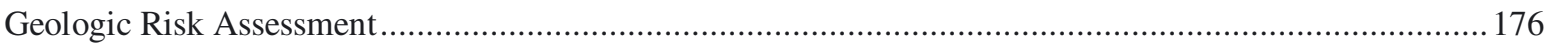

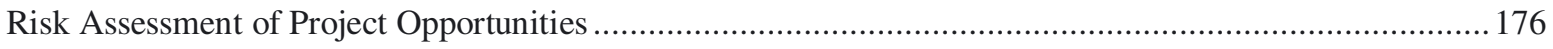

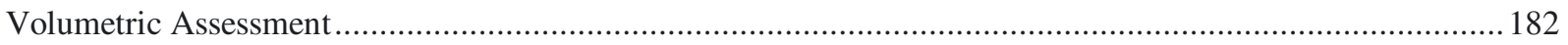

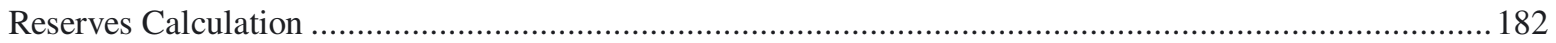

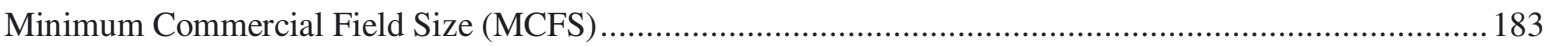

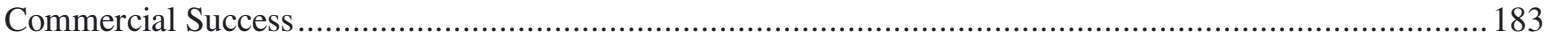

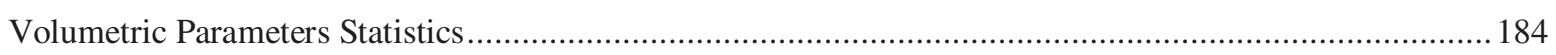

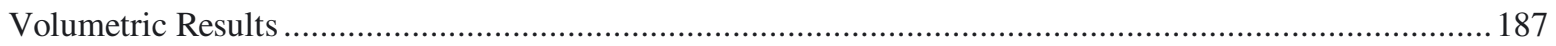

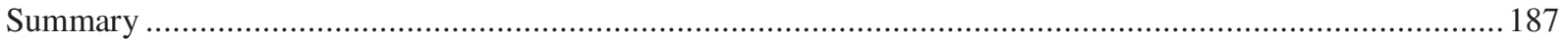

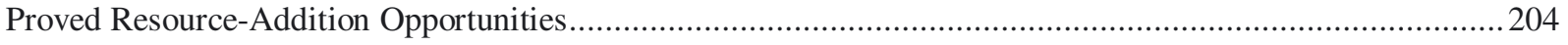

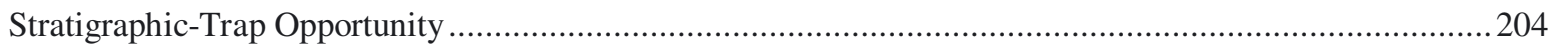

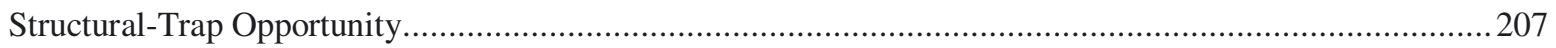

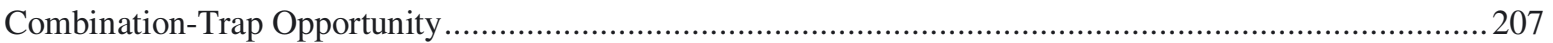

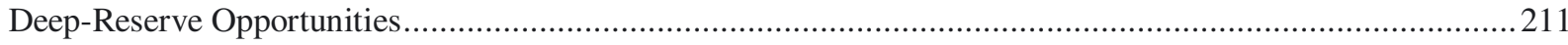

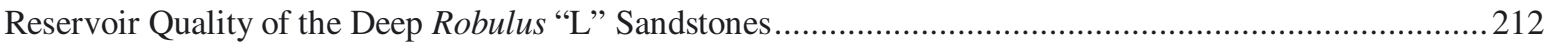

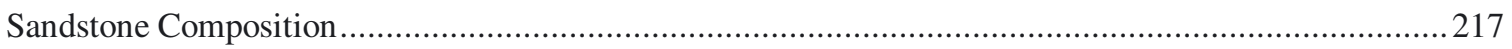

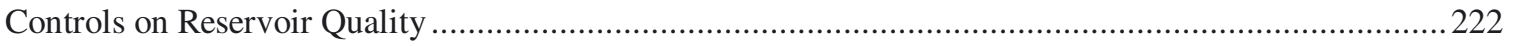

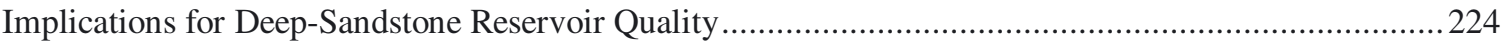

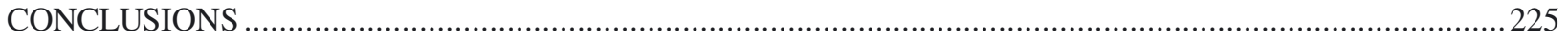

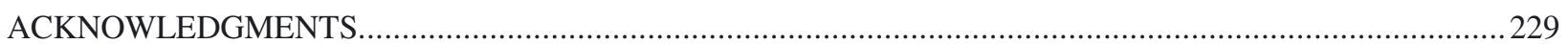

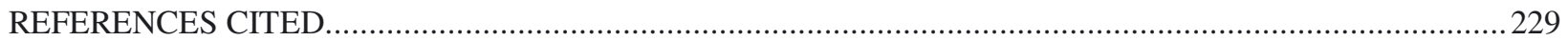

Figures

1. U.S. natural gas demand and production forecasts showing a widening gap between demand and production, indicating needed growth in either imports or domestic production to fill demand.

2. Pie-chart diagrams showing state of hydrocarbons in the GOM on the shelf, where 55 percent is nonassociated gas, to the deepwater, where only 36 percent is gas and 25 percent is associated with oil

3. Production profiles from seven previous SGR field studies, revealing incremental production responses ..............5

4. Simplified Gantt chart of project timeline showing key project phases and events ............................................. 7 
5. Map of Vermilion and South Marsh Areas showing the study's primary target fields, Starfak and Tiger

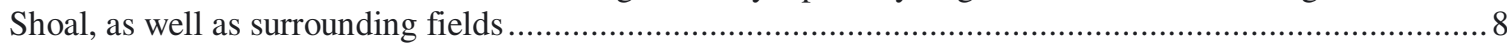

6. Close-up map of study area identifying outlines of the two major 3-D seismic surveys used in this project ......... 13

7. Northwest-southeast regional strike-oriented seismic profile across Starfak and Tiger Shoal fields illustrating good tie between well $\operatorname{logs}$ and nearby seismic traces ........................................................ 14

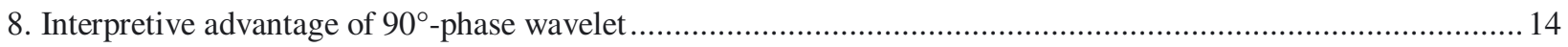

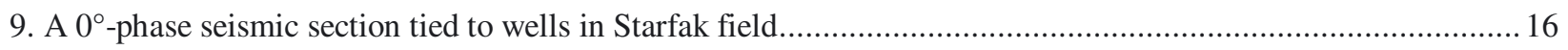

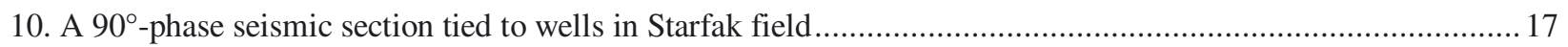

11. Continuity time slice at 2,100 ms showing a sharp and complete regional fault system in the shallower

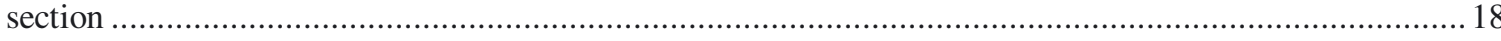

12. Continuity time slice at 3,700 ms illustrating numerous small, subtle faults in the area between Starfak and Tiger Shoal fields and to the northwest of Starfak field in the deeper section..................................... 19

13. Spectral balancing of deep data (a) before processing and (b) after processing..............................................20

14. Composite type log of Starfak and Tiger Shoal fields that displays gross stacking patterns, reservoir nomenclature, extinction horizons of invertebrate paleofauna, and stage boundaries ................................ 22

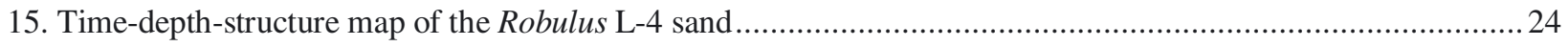

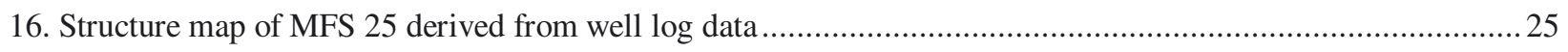

17. Ranges of paleobathymetric zones recorded within the study interval.......................................................... 31

18. Third-order sequence boundaries and maximum flooding surfaces and representative curves of total foraminifera abundance and diversity within the study interval ........................................................ 32

19. Relative positions of distal, medial, and proximal third-order sequences and systems tracts in a

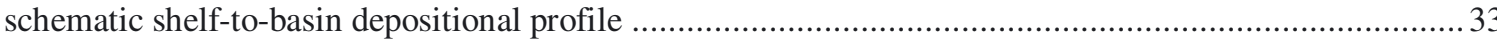

20. Dip cross section of distal third-order Sequence 10, Starfak field, representing the most distal of third-

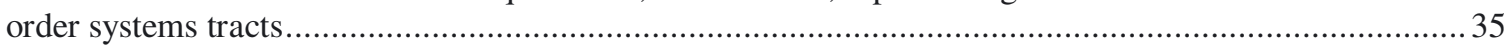

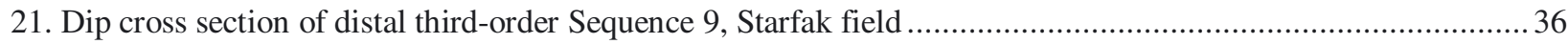

22. Amplitude stratal slice and well log expression of the uppermost fourth-order prograding wedge in

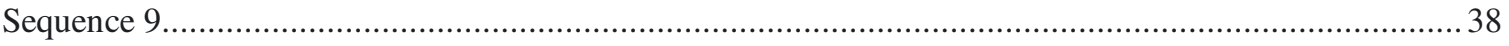

23. Dip cross section of medial third-order Sequence 8 (middle Miocene), Starfak field....................................... 39

24. Dip cross section of medial third-order Sequence 7, Starfak field .................................................................. 40

25. Dip cross section of medial third-order Sequence 6, Starfak field ................................................................ 41

26. Dip cross section of medial third-order Sequence 5, Starfak field ................................................................. 42

27. Depositional-dip-oriented seismic profile of the third-order prograding complex in Sequence .......................44

28. (a) Isochore maps of the incised-valley-to-prograding-wedge transition in the third fourth-order sequence from the bottom of third-order Sequence 7, middle Miocene, Starfak field, and (b) of the fourth-order HST that directly underlies, and was partially incised by, the valley/wedge complex ......

29. Isochore map of the incised-valley system at the base of third-order Sequence 5, middle Miocene, Starfak and Tiger Shoal fields

30. Representative amplitude stratal slices of lowstand incised-valley fills characteristic of the third-order medial and proximal sequences

31. Representative amplitude stratal slice of part of a digitate highstand delta system characteristic of the third-order medial and proximal sequences.

32. Dip cross section of proximal third-order Sequence 4, Starfak field. 
33. Dip cross section of proximal third-order Sequence 3, Starfak field.

34. Dip cross section of proximal third-order Sequence 2, Starfak field

35. Dip cross section of proximal third-order Sequence 1, Starfak field.

36. Comparison of the coastal-onlap curve of the study area (offshore Louisiana), the transgressiveregressive cycles of Hardenbol et al. (1998) for European basins, and the global curve of Haq et al. (1988).

37. Bar graphs of cumulative gas, oil, and hydrocarbon production from the 10 third-order LST's in Starfak and Tiger Shoal fields ......

38. Bar graph of average LST porosities of fourth-order LST's. .59

39. Bar graph of average TST porosities of fourth-order TST's 59

40. Bar graph of average HST porosities of fourth-order HST's

41. Histograms of relative frequency of porosities within fourth-order LST's, TST's, and HST's

42. Bar graph of average permeabilities of fourth-order LST's.

43. Bar graph of average permeabilities of fourth-order TST's. .62

44. Bar graph of average permeabilities of fourth-order HST's

45. Average monthly percentage of gas production from the four fourth-order sequences that had production in each of the three systems tracts.....

46. Average monthly percentage of oil production for the four fourth-order sequences that had production in each of the three systems tracts.

47. Average monthly percentage of water production for the four fourth-order sequences that had production in each of the three systems tracts.....

48. Percentage of cumulative gas production contributed by each of the three systems tracts within the four sequences.

49. Percentage of cumulative oil production contributed by each of the three systems tracts within the four sequences.

50. Percentage of cumulative water production contributed by each of the three systems tracts within the four sequences

51. Coherency time slice generated at 2,000 ms revealing areal distribution of faults throughout the 3-D seismic study area

52. Conventional time slice extracted from the 3-D seismic amplitude volume.

53. Seismic profile showing structural, stratigraphic, and fault interpretations of first- and second-order normal faults

54. Vertical seismic section of an undrilled structural lead, characterized by a strong amplitude anomaly terminating against a normal fault. 75

55. Vertical seismic profile showing an hourglass feature associated with transecting faults 76

56. Time-structure map of the Robulus L-4 sand with associated second-order fault swarms in Starfak field. . .77

57. Squash-plot cross section showing seismic expression of lowstand prograding wedge 79

58. Time-structure map of MFS 2 depicting the subsurface topography associated with the five major producing fields

59. Time-structure map of the Robulus L-4 sand with associated second-order fault swarms in Starfak field.

60. Root-mean-squared amplitude map of D-sand interval extracted from 3-D seismic data set over study area. 
61. Root-mean-squared amplitude map from F-sand interval extracted from the 3-D seismic data set over

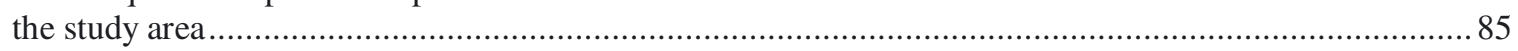

62. Acoustic impedance as an indicator of lithology

63. North-south-oriented cross section A-A' of Starfak field showing well-to-seismic correlation in twoway traveltime

64. Amplitude stratal slices showing a Pliocene coastal plain, upper Miocene incised-valley fill, and an

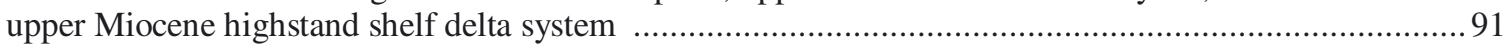

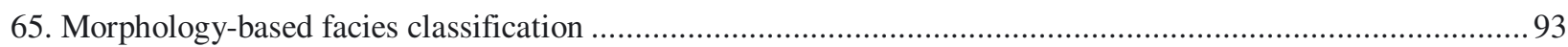

66. Amplitude stratal slices of three fluvial systems and related channel waveforms............................................ 94

67. Morphology-based facies classification of three fluvial systems ................................................................ 95

68. Morphology-based volume classification of incised-valley fill, fluvial channels, and floodplain ...................... 97

69. Generalized forward-feed model used in neural network training for this study ........................................... 98

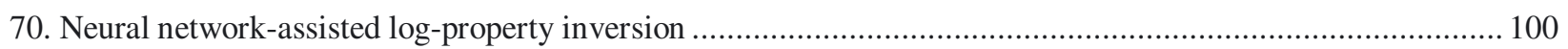

71. Sand content predicted from multiple seismic attributes by Neural-Net-assisted attribute analysis .................. 101

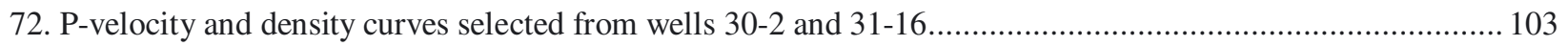

73. P-velocity of clean sandstone and shale against depth with trend lines.......................................................... 104

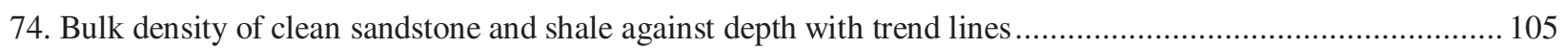

75. Acoustic impedance trend lines of brine-saturated sandstones, shale, and hydrocarbon-saturated sandstones ......

76. Reflection coefficient trend lines related to brine-saturated sandstones and hydrocarbon-saturated sandstones

77. Pressure-depletion, gas-reservoir, and ultimate-recovery efficiency for U.S. reservoirs based on data from the Department of Energy's Gas Information System database

78. Aquifer-drive, gas-reservoir, and ultimate-recovery efficiency for U.S. reservoirs based on data from the Department of Energy's Gas Information System database

79. Production history of the Starfak T-1 reservoir showing multiple pulses of decreasing gas-production rate and increasing water-production rate.

80. Methodology of reservoir characterization to identify reserve growth potential, which is a four-step process, at times iterative, that integrates geologic, geophysical, and engineering information

81. Stratigraphic position of the Starfak T-1 sandstone .

82. RMS amplitude map, with faults interpreted from lineations and offset of maximum flooding surfaces in cross-lines

83. EW4 depth fault sticks penetrating MFS 30 surface.

84. Derivation of MFS 30 fault lines for fault EW4 by extrapolating the associated cutoff lines onto the fault surface......

85. Results of truncating fault D2 against larger fault EW4

86. Revised MFS 30 structural surface that is consistent with both fault model and surface picks from well

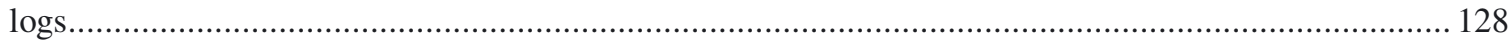

87. Stratigraphic modeling input—revised MFS 30 and MFS 32 surfaces ..

88. Time vs. depth from checkshot data results in a strong linear relationship 
89. Stratigraphic modeling results displaying final MFS 30, T-1, T-2, and MFS 32 surfaces subparallel to each other and offset at the faults

90. 3-D seismic T-1 picks overlain on the T-1 seismic surface.

91. Stratigraphically calculated vs. seismically interpreted T-1 surface .......................................................... 133

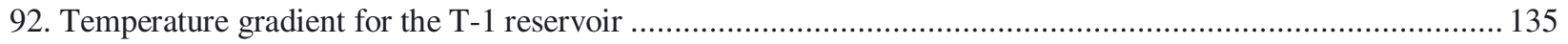

93. Taking the highest pressures as representative of the initial reservoir pressure results in a reasonable

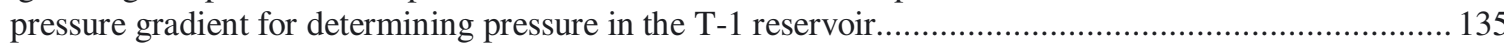

94. Three possible models indicate how a wetting phase can trap a nonwetting phase as a result of variations in pore geometry

95. Relationship between capillary number and nonwetting phase residual saturation showing how Sgrm will decrease as Nvc increases

96. Power-law equation giving strong empirical fit to Starfak porosity and permeability data

97. Capillary-pressure curves display a strong correlation with $\log (\mathrm{k})$ : $\phi$ ratios because they reflect pore type and geometry.

98. An empirical power-law fit between $\log (\mathrm{k})$ : $\phi$ and Swirr results in a strong predictive tool because it takes into account pore-geometry variation

99. Residual gas saturation displays an inverse linear relationship with porosity.....

100. Shape of initial residual wetting-phase saturation curves displays effect of rock type

101. Unconsolidated sandstones display lower Sgrm values than consolidated sandstones, and initial gas saturation is inversely related to Sgrm

102. Sgrm model results in values ranging from 0.37 to 0.12 , with Sgrm rapidly increasing as porosity and Sgi decrease and then taper off.

103. From empirically derived equations, initial residual nonwetting phase curves can be generated to display petrophysical rock character at varying rock quality ............................................................... 144

104. Capillary pressure curves can be grouped together and averaged together.................................................. 145

105. Estimated gas-water relative permeability for low-quality reservoir rock .................................................. 147

106. Estimated gas-water relative permeability for medium-quality reservoir rock ............................................. 147

107. Estimated gas-water relative permeability for high-quality reservoir rock .................................................. 148

108. U.S. ultimate recovery efficiency in pressure-depletion-drive gas reservoirs based on data from U.S. Department of Energy's Gas Information System database ............................................................... 148

109. U.S. ultimate recovery efficiency of aquifer-drive gas reservoirs based on data from U.S. Department of Energy's Gas Information System database.....

110. Initial fluid contacts indicate fluid-flow barriers at time of gas migration

111. Production history of the Starfak T-1 reservoir.

112. Well 50-D4(12) was drilled and logged after wells 50-B2(4), 50-B1(9), and 50-B1(2) had watered out at the same structural level

113. Wells logged before and after aquifer encroachment display significantly different gas-saturation values .......

114. Water-swept zones follow porosity-Sgrm trend predicted by the Sgrm model and differ from that of initial conditions

115. Pressure history indicates that the reservoir is functioning as two separate fault-bounded compartments 
116. Relationship between wireline-log-calculated porosity and bulk-volume shale displays general linear trend

117. Relationship between porosity, impedance, and lithology

118. Higher amplitudes in the seismic align with Vsh calculated from wireline logs.

119. High seismic amplitudes coincide with the distribution of sandstone within the T-1 reservoir... 162

120. Resulting seismic-derived T-1 3-D shale volume 163

121. Example cross section of the final model showing distribution of sandstone between wells and in the intrawell space

122. Normal distribution of risk-assessment levels 167

123. Parameters used to determine geologic chance of success ..... 175

124. Geologic-correlation-factor matrix for geologic-risk parameters... 180

125. Temperature correlation used in resource calculations 181

126. Pressure correlation used in resource calculations..... 185

127. Specific-gas-gravity distribution for play MM4 P.1. 186

128. Specific-gas-gravity distribution for play MM7 P.1B . 188

129. Specific-gas-gravity distribution for play MM7 R.1B. 188

130. Specific-gas-gravity distribution for play MM9 P.1B 189

131. Specific-gas-gravity distribution for play UM1 P.1B. 189

132. Specific-gas-gravity distribution for play UM3 P.1B. 190

133. Gas-saturation distribution for play MM4 P.1 190

134. Gas-saturation distribution for play MM7 P.1B. 191

135. Gas-saturation distribution for play MM7 R.1B 191

136. Gas-saturation distribution for play MM9 P.1B. 192

137. Gas-saturation distribution for play UM1 P.1B 192

138. Gas-saturation distribution for play UM3 P.1B 193

139. Porosity distribution for play MM4 P.1. 193

140. Porosity distribution for play MM7 P.1B 194

141. Porosity distribution for play MM7 R.1B 194

142. Porosity distribution for play UM9 P.1B. 195

143. Porosity distribution for play UM1 P.1B. 195

144. Porosity distribution for play UM3 P.1B. 196

145. Recovery-factor distribution for play MM4 P.1 196

146. Recovery-factor distribution for play MM7 P.1B 197

147. Recovery-factor distribution for play MM7 R.1B. 197

148. Recovery-factor distribution for play MM9 P.1B . 198

149. Recovery-factor distribution for play UM1 P.1B... 198

150. Recovery-factor distribution for play UM3 P.1B. 199

151. Probability distribution of unrisked reserves displaying a lognormal-like tail 199 201 
152. Probability values for geologic chance, minimum commercial field size, and commercial success

153. Root-mean-squared (RMS) amplitude map from F-sand interval extracted from 3-D seismic data set over the study area

154. Gamma-ray and resistivity log from well 206 drilled by Texaco in 2001 to test the Opportunity 50 stratigraphic trap.

155. Depth-structure map of MFS 42, showing location of Opportunity 8 within the structural saddle between Starfak and Tiger Shoal fields

156. Two arbitrary seismic lines, $\mathrm{H}-\mathrm{H}^{\prime}$ and $\mathrm{H} 1-\mathrm{H} 1^{\prime}$, through the Opportunity 8 structural closure, showing the high-amplitude anomaly associated with the target......

157. A 3-D RMS amplitude map of the N-sand reservoir interval (Opportunity 29).....

158. Seismic line that illustrates structural nature of the section below 3.0 seconds (below $\sim 15,000 \mathrm{ft}$ subsea)

159. Structure map of MFS 48, which occurs below $15,000 \mathrm{ft}$, showing several deep structural closures

160. Cross section of Starfak field, showing distal third-order Sequence 10

161. Cored intervals in the Robulus L-2 and L-5 sandstones in wells 31-6 and 31-7

162. Core description and interpreted depositional and systems-tract setting of the Robulus L-5 sandstone in well 31-6

163. Compositional classification of the Robulus L-2 and L-5 sandstones

164. Photomicrographs of fine-grained, proximal-delta-front sandstones from the Robulus L-2 interval, well 31-6

165. Photomicrographs of very fine grained Robulus L-5 sandstones .

166. Plot of core-analysis porosity versus permeability for Robulus L-2 and L-5 sandstones

Tables

1. Distribution of reserves and production data by geologic age for the Gulf of Mexico, showing the

Miocene-age reservoir resources leading all categories, including remaining proved reserves

2. Texaco-designated sandstone-body reservoirs in Starfak and Tiger fields

3. Characteristic paleobathymetric indicator fossils (foraminifera) in the Miocene section of Starfak and

Tiger Shoal fields.

4. Play types within Starfak and Tiger Shoal fields based on play designations of Hentz and others (1997)

and Seni and others (1997)

5. Hydrocarbon properties from production data. 106

6. Brine and rock properties 106

7. Petrophysical properties for three rock-quality groups

8. Volumetric results for three different weighted-average scenarios, indicating that a 30-70 seismic-to-log scenario is most appropriate 
9. Summary of geological risk factors by different authors.

10. Risk categorization matrix.

11. Risk-assessment scaling table with normal-distribution factors.

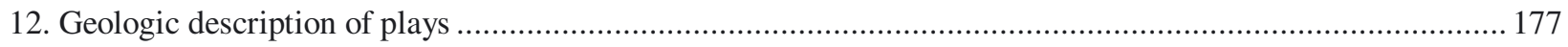

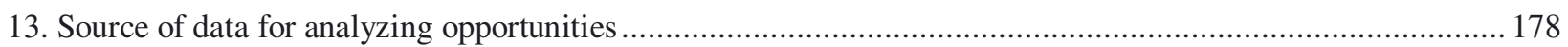

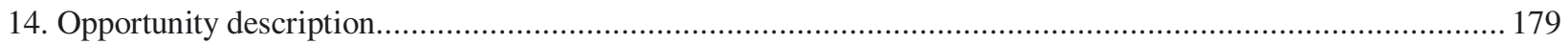

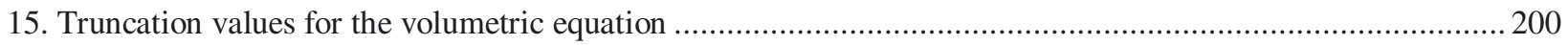

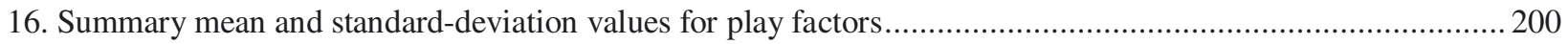

17. Summary of the best-fitting probability distributions for reservoir properties by play ............................. 200

18. Original gas in place and reserves values for unrisked, geologically risked, and commercial risked reserves.

Plates

1. Gantt chart of project timeline showing key project phases and events IN POCKET

2. Subregional, dip-oriented seismic profile of Starfak field. IN POCKET 


\section{INTRODUCTION}

\section{Business Drivers for Secondary Gas Recovery}

Natural gas is projected by many analysts to surpass oil and liquid gas and become the dominant product in the United States' energy market within the next decade, if not sooner (Hefner, 1993; Fisher, 1999). Recent projections by Lore and others (1999) show U.S. natural-gas demand reaching approximately $32 \mathrm{Tcf}$ by 2015 . Although production is also expected to increase, the gap between demand and production that must be filled by imports is projected to continue to widen throughout the next several decades (fig. 1). Projected declines in natural-gas production indicate that existing gas reserves in proven fields on outer continental shelf (OCS) lands will be nearly depleted by 2020. In the absence of significant changes in resource estimates, technology, investment or discovery sizes, the U.S. Mineral Management Service has projected that the Federal OCS will be unable to maintain its current level of contribution toward meeting the Nation's demand for natural gas past the year 2020 (Lore and others, 1999).

The Gulf of Mexico (GOM) currently provides more than one-quarter of the natural gas produced in the United States and is projected to contain approximately 16 percent of the proven natural gas reserves nationwide (Lore and others, 1999). Within the GOM, Miocene-age strata contain the dominant share of original and remaining proven gas reserves (table 1; Lore and others, 1999). Of the 67.3 Tcf discovered to date, 54.6 Tcf has been produced and another 12.7 Tcf remains to be recovered from Miocene strata. These reserves represent 41 percent of the total remaining proven recoverable reserves in the GOM and constitute a significant proven reserve waiting to be recovered. These Miocene-age resources are found almost exclusively in shelf water depths of less than $200 \mathrm{~m}$ amid existing infrastructure. Recent declines in per capita performance on the GOM shelf and improvements in deep-drilling technology have spurred large companies to search for hydrocarbons in deep water. Oil is the dominant product in deep-water provinces, the majority of gas found in association with oil (fig. 2). Therefore, although 80 to $140 \mathrm{Tcf}$ of gas is potentially producible over the next $50 \mathrm{yr}$ from fields located in deep-water regions, its association with oil complicates the economics, cycle time, needed technology, and infrastructure associated with its development (Lore and others, 1999). Although a larger share of overall gas demand is expected to be met by deepwater fields over the next $15 \mathrm{yr}$, there is a significant need to arrest the slow decline in shelf-bound gas production if the OCS is to continue viably contributing to the Nation's energy future. With more than 41 percent of proven, recoverable GOM natural-gas resources remaining to be produced from shelf-bound Miocene fields and more remaining to be booked as resources, there is a strong need for new play concepts to revitalize existing fields on the modern shelf. In addition, new process designs and imaging tools for reducing uncertainty in exploration and production will enable small and large companies to arrest the decline in capital performance on the GOM shelf and maintain their interests. Such objectives are inherent in the goals of the Secondary Gas Recovery research program. 


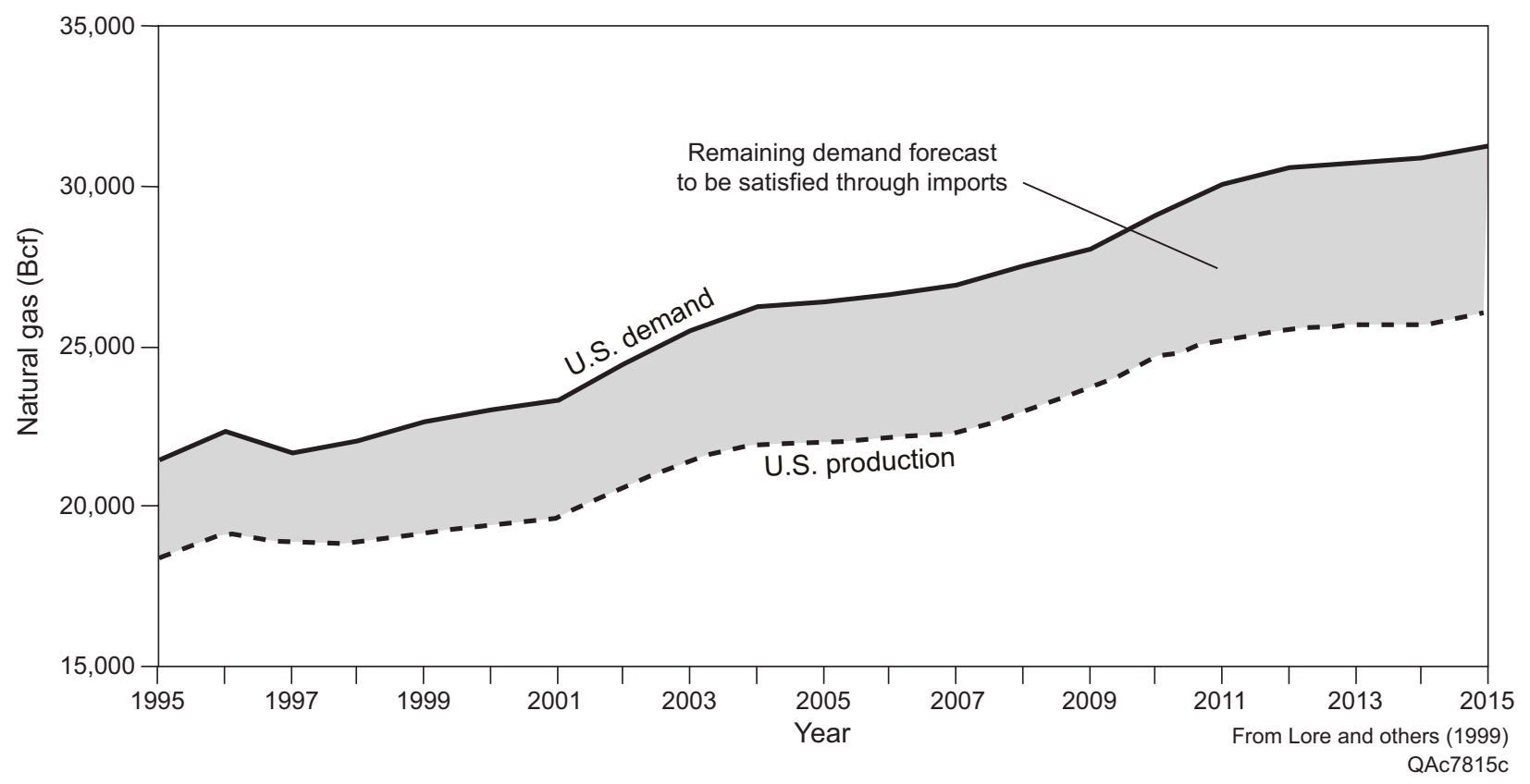

Figure 1. U.S. natural gas demand and production forecasts showing a widening gap between demand and production, indicating needed growth in either imports or domestic production to fill demand. 
Table 1. Distribution of reserves and production data by geologic age for the Gulf of Mexico, showing the Mioceneage reservoir resources leading all categories, including remaining proved reserves. From Lore and others (1999).

\begin{tabular}{|c|c|c|c|}
\hline Age & $\begin{array}{c}\text { Original proved } \\
\text { reserves } \\
\text { (percent) }\end{array}$ & $\begin{array}{c}\text { Cumulative } \\
\text { production } \\
\text { (percent) }\end{array}$ & $\begin{array}{c}\text { Remaining proved } \\
\text { reserves } \\
\text { (percent) }\end{array}$ \\
\hline Pleistocene & 40 & 41 & 37 \\
\hline Pliocene & 16 & 16 & 16 \\
\hline Miocene & $\mathbf{4 2}$ & $\mathbf{4 3}$ & $\mathbf{4 1}$ \\
\hline $\begin{array}{c}\text { Oligocene, Cretaceous, } \\
\text { and Jurassic }\end{array}$ & 2 & 0 & 6 \\
\hline
\end{tabular}
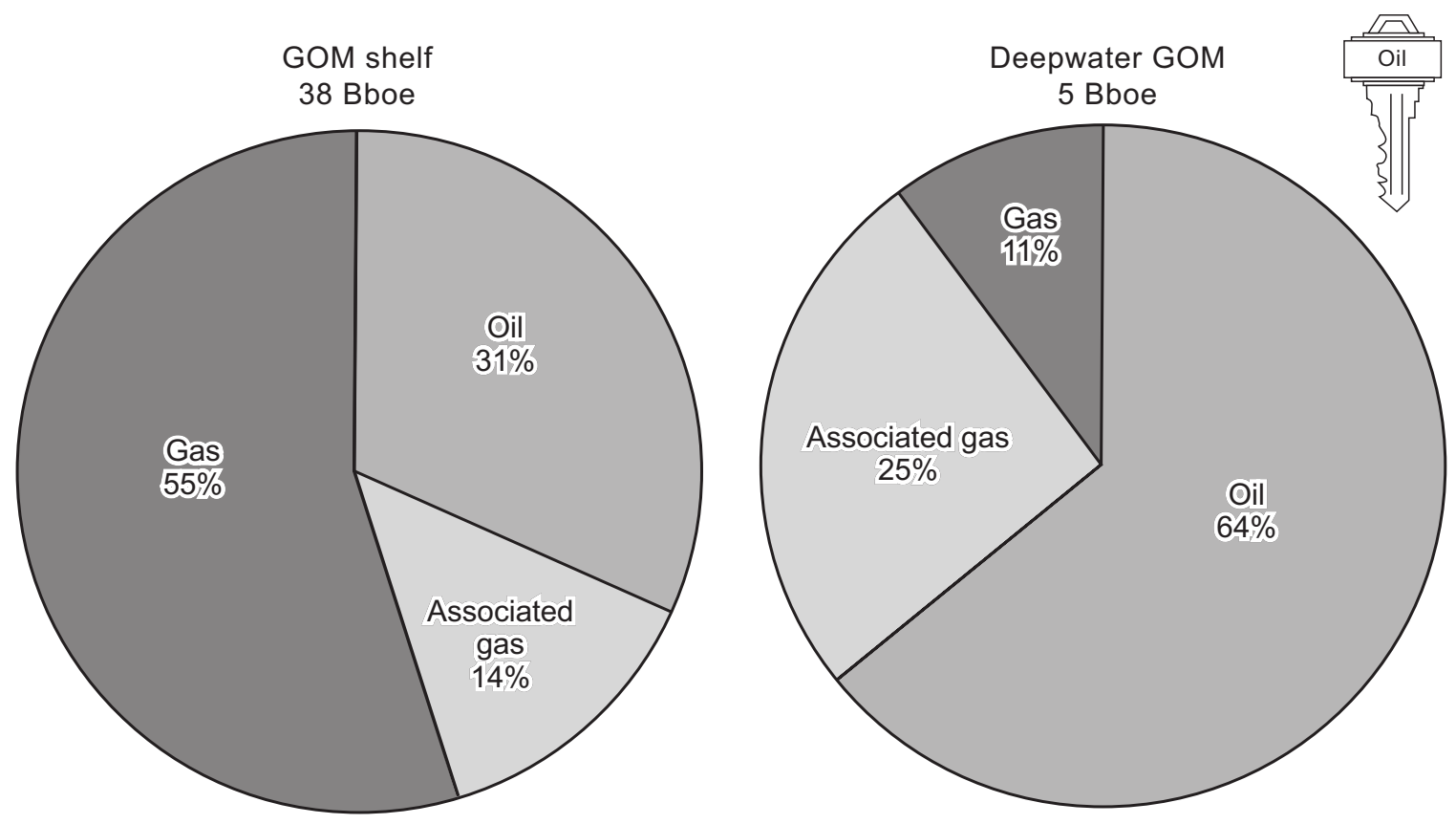

Ultimate recovery anticipated, 70 percent oil

From Lore and others (1999) QAc7827c

Figure 2. Pie-chart diagrams showing state of hydrocarbons in the GOM on the shelf, where 55 percent is nonassociated gas, to the deepwater, where only 36 percent is gas and 25 percent is associated with oil. 


\section{Secondary Gas Recovery Research}

The Bureau of Economic Geology, The University of Texas at Austin, has been working to improve gasrecovery efficiency in complex onshore reservoirs since 1988 through Secondary Gas Recovery (SGR) research sponsored by the U.S. Department of Energy, with secondary sponsorship by the Gas Research Institute. The results of a quantitative assessment of the benefits of SGR technology provide striking evidence of the success of the research project and the comprehensive technology transfer strategy, as well as the financial success producers have experienced in application of that technology. Over the period 1988 through 1998, incremental gas production in seven fields previously studied by the SGR program is projected to total $231 \mathrm{Bcf}$ (fig. 3). Assuming \$2/Mcf, total economic value resulting from the incremental production equals $\$ 462$ million. Operator surveys collected from previous SGR short-course participants reveal a 25-percent market penetration rate of SGR technologies. Multiplying the economic value by the market penetration rate, the value of historical SGR field studies approximates \$116 million (fig. 3). The investment of \$30 million by DOE and GRI in the research study of these seven fields has yielded a benefit/cost ratio of 4:1. Application of research results has resulted in incremental proved gas reserves of 4 Tcf (Office of Fossil Energy, U.S. Department of Energy website and http://www.fe.doe.gov/techline/tl_beg98.html).

SGR projects in onshore Gulf Coast sandstones, sandstones of the Fort Worth Basin, and karsted carbonate reservoirs of the Permian Basin have successfully defined secondary, or incremental, gas recovery on the basis of targeting reservoir heterogeneity. These heterogeneities have largely been stratigraphic and diagenetic rather than structural, given that fault compartmentalization of reservoirs is a well-known barrier to completion of hydrocarbon recovery. Past projects have been collaborative, with industry partners ranging from majors, such as Shell and Mobil, to midsize companies, such as Oryx and Union Pacific Resources, to small independents. In 1998, The University of Texas at Austin Bureau of Economic Geology decided to pursue a similar research strategy that would demonstrate secondary gas recovery principles and practices in an established natural gas field in the Federal offshore of the Gulf of Mexico.

\section{Offshore Secondary Gas Recovery}

The Offshore Secondary Gas Recovery (OSGR) project began October 1998 as a 4-year joint research venture between the Bureau of Economic Geology (BEG) and the U.S. Department of Energy (DOE). The project was an outgrowth of a previous DOE -sponsored BEG project that produced the Atlas of Northern Gulf of Mexico Gas and Oil Reservoirs, Volumes 1 (Seni and others, 1997) and 2 (Hentz and others, 1997). The OSGR project focused on practical application of products from the atlas study, providing owners of offshore Gulf of Mexico leases a process road map for increasing hydrocarbon reserves and their asset base. The goal of the OSGR project was to identify additional natural gas resources in a major field in the northern Gulf of Mexico through multidisciplinary 

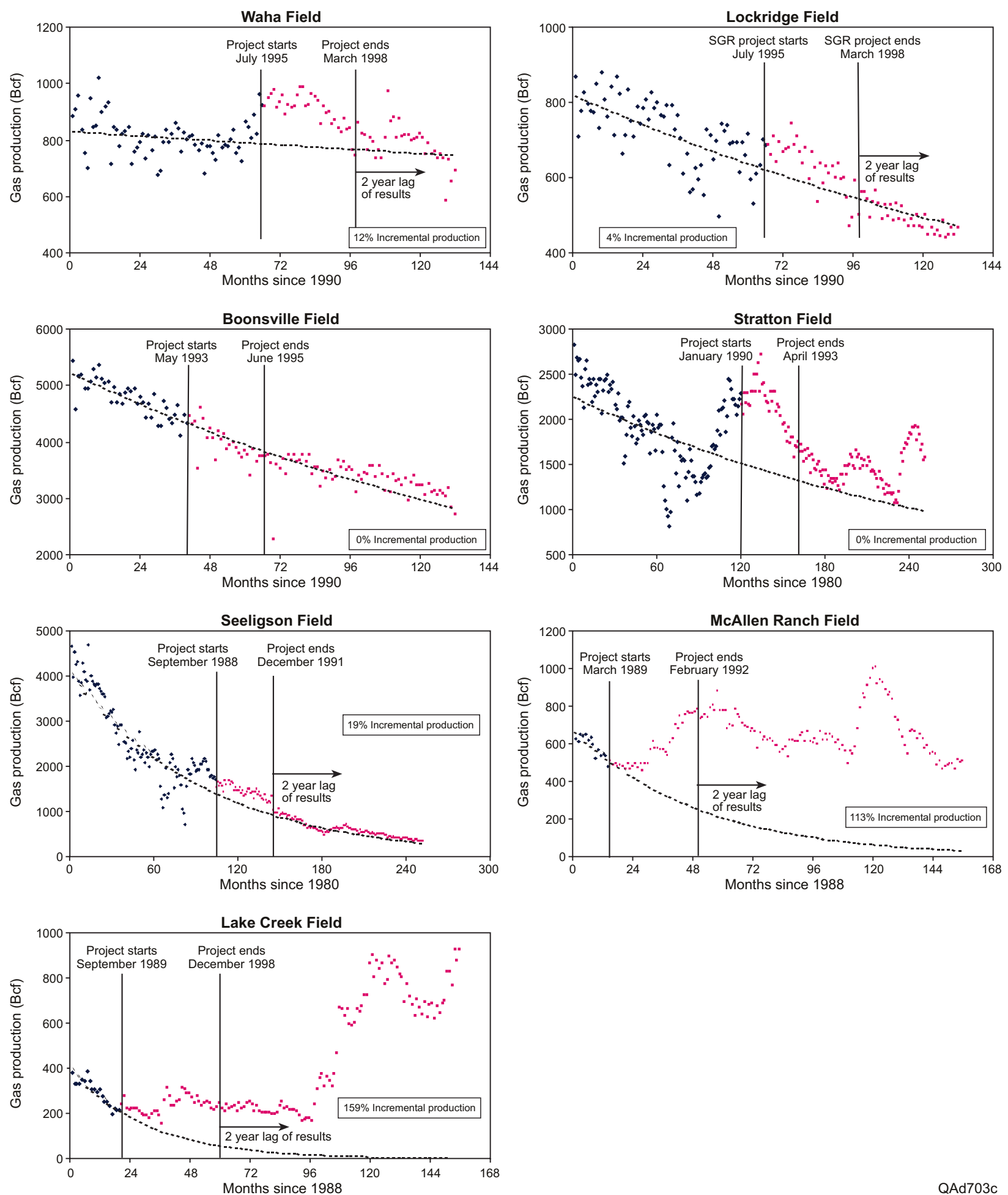

QAd703c

Figure 3. Production profiles from seven previous SGR field studies, revealing incremental production responses. As with all applications of technology, incremental production responses range from excellent (Lake Creek and McAllen Ranch) to good (Seeligson and Waha) to marginal (Lockridge) to insignificant (Boonsville and Stratton). Overall SGR technologies in these fields yielded an incremental production response of $231 \mathrm{Bcf}$. 
field- and reservoir-characterization study. Broader objectives were to create exploration and production models using the project data, which allowed explorationists and producers to target their efforts in the most productive intervals and stratigraphic levels of the Gulf of Mexico Miocene. The specific objectives of the project were to (1) increase reserves, (2) prioritize newly identified development opportunities, (3) develop and apply new technologies, (4) create transferable knowledge, and (5) achieve these objectives using quality products in a

timely fashion. The objectives of the project were achieved through completion of a nine-phase work plan and the tasks associated with that work plan (fig. 4; plate 1).

Siliciclastic Miocene strata are currently the most productive of all chronostratigraphic units in the northern Gulf of Mexico (GOM) outer continental shelf, accounting for $40 \%$ of all hydrocarbons produced and $40 \%$ of all remaining proved reserves. Most of these Miocene resources (99\% of cumulative production, $61 \%$ of remaining proved reserves) are restricted to the present continental shelf (Crawford and others, 2000), where the majority of active fields are considered mature. These statistics indicate that significant potential exists for interfield and intrafield development in the shelf area ( $<650 \mathrm{ft}$ water depth). Moreover, deep Miocene strata $(>15,000 \mathrm{ft}$ subsea) below established reservoirs in the shelf area hold the promise of additional resources. Only 5\% of all wells drilled on the GOM shelf have penetrated strata below $15,000 \mathrm{ft}$, in which there is an estimated $10.5 \mathrm{Tcf}$ of deep gas recoverable resources (Minerals Management Service, 2001).

The OSGR study area included two major producing fields, Tiger Shoal and Starfak fields in the Vermilion Block 50 and South Marsh Island Areas, northern GOM (fig. 5). Although originally designed to look at data from a single field, the project evolved to encompass two fields in detail, as well as to consider surrounding fields of Mound Point, Lighthouse Point, and Amber. This evolution reflected the need to consider more regional applicability of research results: to move from the postage-stamp application of research results from a single field to the broader distribution of observations throughout the GOM Miocene. The study area contains predominantly progradational deposits consisting of upward-coarsening deltaic deposits, as well as distributary- and fluvial-channel deposits. The study area as noted in the offshore atlas (Seni and others, 1997) is included in four large gasdominated plays. The combination of asset size and potential, regional productivity of the field intervals, and data availability and quality made this an excellent area for pursuing the objectives of the OSGR program.

\section{Project Data and Personnel}

In support of the research project, Texaco contributed the in-kind value of all field data, such as well log data, production histories, sample and core data, and, most important, a 3-D seismic survey. In 1998, this survey had been acquired and processed but not yet interpreted. The Bureau field study incorporated 3-D seismic interpretation; geologic-facies, structural, and well log analysis; petrophysical interpretation; and a reservoir-engineering study. The objective was to make industry as a whole aware of the potential for incremental natural gas recovery and the revitalization of mature natural gas fields. The result, summarized in detail in the following section, includes the definition of specific drilling and recompletion opportunities for additional gas recovery, as well as new approaches, technologies, and paradigms for exploration in Miocene strata across the Gulf of Mexico. 


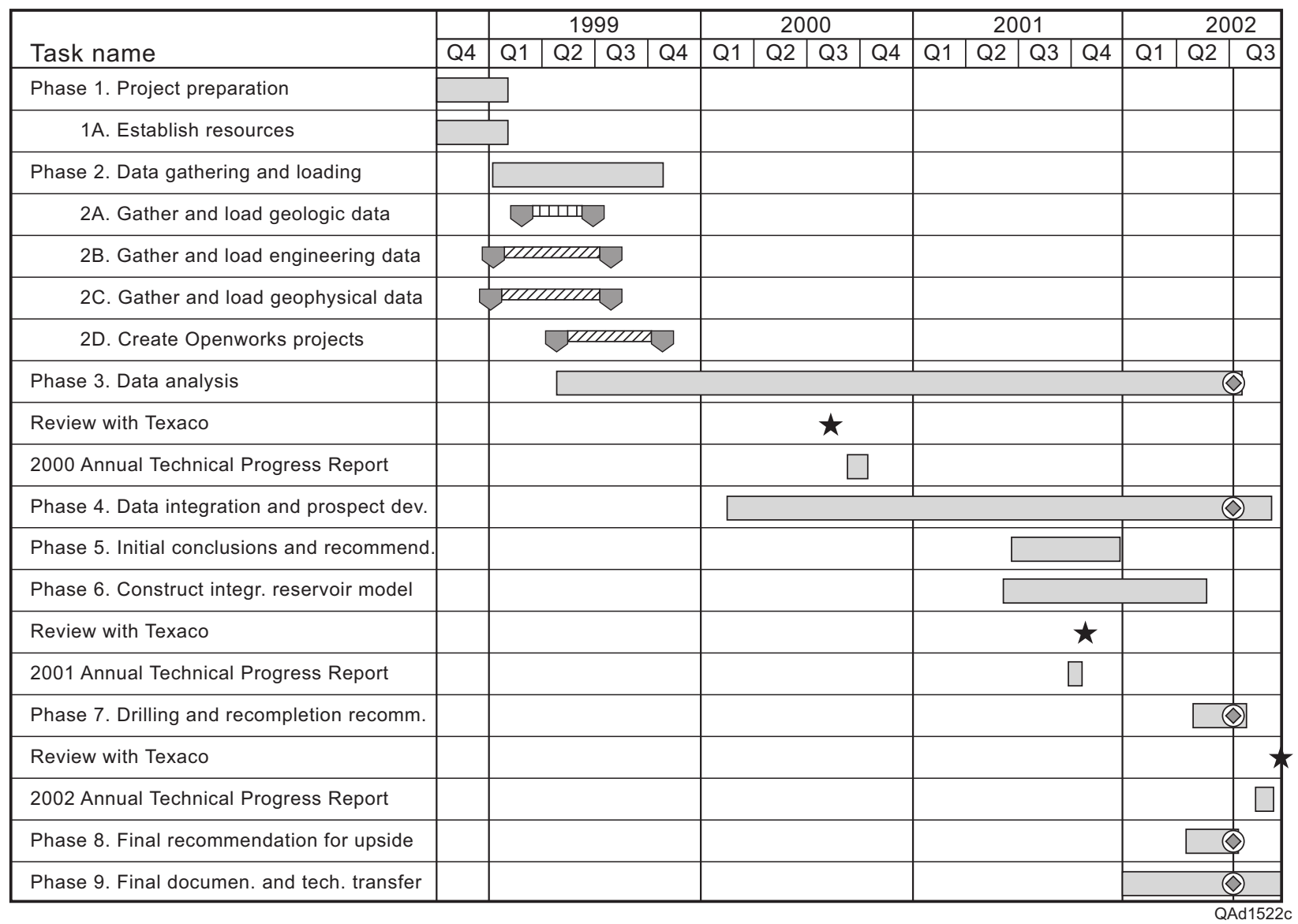

Figure 4. Simplified Gantt chart of project timeline showing key project phases and events. 


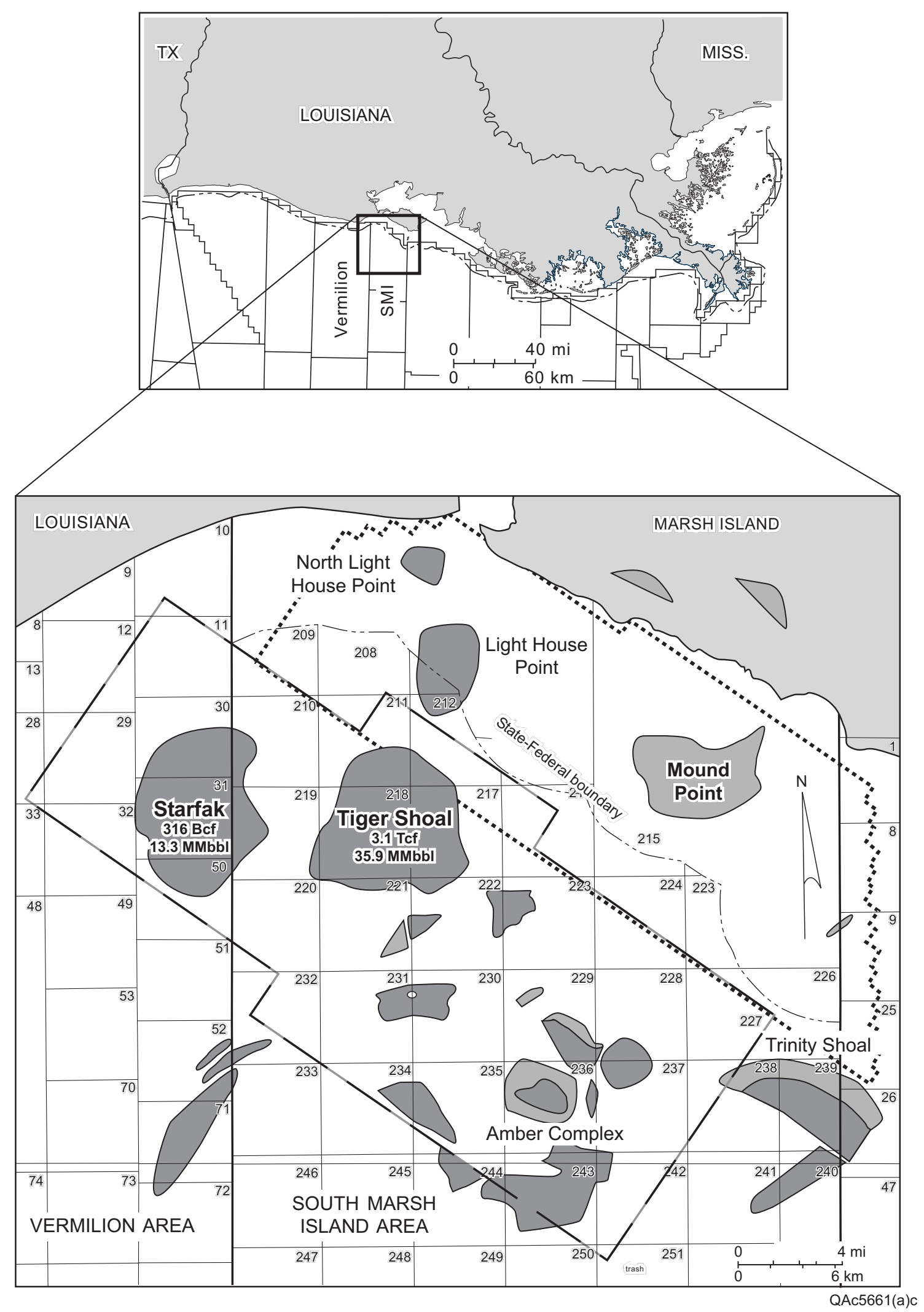

Figure 5. Map of Vermilion and South Marsh Areas showing the study's primary target fields, Starfak and Tiger Shoal, as well as surrounding fields. 
The project had four full-time geoscientists staffing it, as well as a quarter-time engineer and a quarter-time petrophysicist. In addition to the professional staff, the project had three Ph.D. students addressing some aspect of the data evaluation as part of their dissertation research. Their work was conducted in tandem with the overall project time line to maximize the value that their work brought to the project. Some of the student work was supported through grants outside the OSGR funding. The theses from this student research will be available to the general public, and thesis titles and authors, as well as several publications resulting from the student's research are listed at the end of this report in the publications compilation. Leveraging DOE's research dollars with such supplemental secondary research grants and graduate student thesis study is beneficial for all participants.

\section{Project Focus and Timing}

The project's technical analysis was completed on schedule in nine phases: (1) PROJECT PREPARATION, (2) DATA GATHERING AND LOADING, (3) DATA ANALYSIS, (4) DATA INTEGRATION AND RESOURCE ADDITION DEVELOPMENT, (5) INITIAL CONCLUSIONS AND RECOMMENDATIONS, (6) CONSTRUCTION OF INTEGRATED RESERVOIR ARCHITECTURE MODEL, (7) FINAL RECOMMENDATION FOR DRILLING AND RECOMPLETIONS, (8) FINAL RECOMMENDATIONS FOR UPSIDE POTENTIAL, and (9) FINAL DOCUMENTATION AND TECHNOLOGY TRANSFER. The initial phase included creating and populating a master Access database for the project. From previous observation it was known that the time taken to organize and quality check such a database pays off in future cycle time reduction. The project's Gantt chart (plate 1) was designed to insure an accounting for all tasks associated with each phase of the process, as well as to enable the team to plan their research time to achieve the ambitious research goal of the project. The Gantt chart for the project was a living document that provided a template of process and graphic display of duration and deadlines for all aspects of the project. As information became available from the chosen study areas, adjustments were made in the work plan to accommodate changing data availability and new scientific developments. In many instances research tangential to the main goal of the original project was completed, such as neural network analysis of seismic geometries or detailed biostratigraphic analysis of all available well data. Such tangential work is not a bad thing, because, as the project proceeded, new directions in reservoir analysis or opportunities to apply new techniques in geologic and geophysical assessment presented themselves. These directions were pursued, and excellent publications and results were produced in part achieving the goal of identifying new technologies to apply in secondary gas recovery assessment.

Several general targets of potentially untapped reserves across the study area were identified:

(1) Additional structural traps newly imaged on the new 3-D seismic data and located within the immediate area of production,

(2) Possible deep closures and structural traps beneath existing production,

(3) Structural traps that extend into the structural "saddle" between Starfak and Tiger Shoal fields and widespread stratigraphic and combination stratigraphic/structural traps that exist across the study area. 
All viable new opportunities were mapped and analyzed and were proposed by the research group to industry partner, Texaco, for inclusion in its drilling program. During the course of the study, three of these opportunities-a structural, a stratigraphic, and a combined stratigraphic/structural opportunity—were tested by Texaco in three separate wells. The results of these wells, all of which were successful tests, are incorporated into the resource assessments here, both directly as recoverable resources and indirectly as ground truth to the assessment of riskweighted resources in other new opportunities across the area. These tests provide invaluable information to groundtruth technical risk assessment, in-place and recoverable resource calculations, reservoir petrophysical character, and the accuracy of seismic detection.

\section{PREVIOUS WORK}

Since the early 1980's, stratigraphic analysis of the Miocene Series of the northern GOM has focused on the regional-scale depositional history (e.g., Winker, 1982; Galloway and others, 1986; Morton and others, 1988), genetic stratigraphy of low-frequency cycles (Galloway, 1989; Galloway and others, 2000), and definition of primarily low-order sequences based on basinwide correlation of biozones (Styzen, 1996; Lawless and others, 1997; Fillon and Lawless, 1999, 2000). Play atlases of the northern Gulf of Mexico (Bebout and others, 1992; Seni and others, 1997) classified Miocene reservoir-bearing strata within broad groupings based on chronozone and depositional style. In all these approaches, however, details of the genetic stratal architecture, systems tracts, and the pattern of hydrocarbon distribution within this framework were beyond their scope. These topics will be addressed herein.

Published studies of Starfak and Tiger Shoal fields do not exist, and there is a paucity of detailed lithostratigraphic, sequence-stratigraphic, and structural data for the Miocene Series near the study area. Van Wagoner and others (1990) presented a regional cross section of middle Miocene fourth-order sequences of onshore south-central Louisiana. However, the authors cited no published study for this work to enable access to primary data. Using seismic data, Wagner and others (1994) examined the lower Miocene sequence stratigraphy of the nearshore West Cameron and East Cameron Areas in the Federal Outer Continental Shelf 25 mi west of Starfak field. Wells in Starfak and Tiger Shoal fields do not penetrate the portion of the lower Miocene examined by these authors; however, seismic coverage of the lower Miocene in the study area is available, and their conclusions were useful in the deep seismic interpretation. Luo (2000), who studied the same 3-D seismic data set in her thesis work, provided insight into the regional history of growth-fault development. Paleontological studies of foraminiferal abundances (Rosen and Hill, 1990), general calcareous nannofossil diversity (Jiang and Watkins, 1992; Jiang, 1993), and basin-scale faunal zones (Lawless and others, 1997) of the northern GOM provided critical constraints on absolute ages of the Miocene succession in Starfak and Tiger Shoal fields. 


\section{DATA SETS}

\section{Well Log Data}

Tiger Shoal field, considerably older than Starfak field, has been producing since 1958 from 103 total oil and gas wells. Almost every Tiger Shoal well is vertical, a few wells at the margins of the field being deviated. Oilproducing wells were drilled to depths shallower than those of the gas-producing wells, and they are located exclusively on the east side of the field, mainly in Block 217. A limited number of data were recorded from the logged wells, mostly as resistivity and SP curves. A few of the oil wells have sonic and porosity logs; however, no open-hole gamma-ray logs exist from the oil-producing, east part of Tiger Shoal field. Gas-producing wells, relatively deeper penetrations, have more complete log suites than do the field's oil wells. The gas wells, mostly in Block 218, display a more areally diffuse distribution than do the oil-producing wells. Use of the gamma-ray curve was crucial to precise identification of sequence-stratigraphic boundaries and the accurate depiction of sandstone $\log$ facies. Its absence from most wells in Tiger Shoal field is a limitation of this field's well log database.

Starfak field, discovered in 1975, has a total of 53 wells, and 8 of them are deviated. The log suites from this field are significantly more complete than those of Tiger Shoal field. More than half of the Starfak wells have gamma-ray, neutron-porosity, bulk-density, and sonic logs. Log suites from most Tiger Shoal wells do not include these log types, a significant limitation of this well-data subset. No shear-wave sonic logs are available from Starfak or Tiger Shoal fields.

\section{Core Data}

Texaco provided sidewall-core data for 41 vertical and sidetrack wells in Starfak field and for 58 wells in Tiger Shoal field. Between approximately 10 and 160 sidewall cores, representing one to several sand-body reservoirs, were taken from each well. Spreadsheet databases were constructed that contain all laboratory-derived measurements: permeability (some cores measured for both air and oil permeability), porosity, porosity saturation (oil), porosity saturation (water), percent volume of oil, and percent volume of gas.

Texaco archives yielded only one whole-core description of an 82-ft interval in the Texaco No. 6, Block 31 well. Texaco conducted special core analysis of this interval (Robulus L-2 sand) by recording pressure-volumetemperature (PVT) data and permeability, porosity, and relative permeability values. McBride and others (1988) documented the existence of at least four conventional cores from Starfak field; however, all efforts failed to locate these whole cores for description and analysis as part of this project.

\section{Geophysical Data and Quality}

The 3-D seismic data were acquired between 1994 and 1995 in an area approximately $352 \mathrm{mi}^{2}$. The data were merged from two surveys, OCS 310 (southwest) and SL 340 (northeast), covering five of Texaco's offshore fields: Starfak, Tiger Shoal, Mound Point, Light House Point, and North Light House Point (fig. 6). Both surveys are 
oriented NW-SE in the inline direction and SW-NE in the crossline direction. Western Geophysical Corporation (WGC) of New Orleans conducted the acquisition by using a cable crew with an air-gun source. Both WGC and Texaco's New Orleans office were involved in the data processing. Although some acquisition problems (dead cable, time breaks, etc.) resulted in difficulties and delays, there is no evidence of significant problems in quality in the final product (Texaco Exploration and Production Inc., 1996).

From an interpreter's point of view, the 3-D seismic data set is of good quality. Dominant frequency varies from $40 \mathrm{~Hz}$ in the shallow section to $20 \mathrm{~Hz}$ in the deep section, many of the gas reservoirs or reservoir groups being clearly resolved. Visible direct seismic indicators of gas-bearing zones include bright spots on structural highs and against faults and a significant velocity sag observed in the gas-bearing area of Tiger Shoal field. The signal-to-noise ratio is high, with no multiples or other coherent noises, and no migration problems are apparent. The merged data volume, however, does show some subtle differences in dynamic characteristics between the OCS 310 and SL 340 subvolumes. The potential effect of this difference on the project should, however, be minimal because both Starfak and Tiger Shoal fields are well within the OCS 310 subvolume.

Attention has been paid to tying wells accurately to seismic data. Five checkshots in Starfak field were loaded into the database. Analysis of the checkshot curves resulted in an allocation of different time-depth (T-D) curves to different wells on the basis of their distance from checkshot wells and structural location. Although most sonic and density log curves are partly spurious because of borehole washout, sonic/density logs in two wells were able to be edited to produce good-quality synthetic seismograms that show a reliable tie between well logs and nearby seismic traces. A constant shift was applied to the log curves from all other wells to match the tie with the two wells with good synthetics (fig. 7; plate 2). Available log-interpreted picks of sequence boundaries and tops of main reservoir units (mainly in Starfak field) were then loaded into the database and checked for consistency in correlation.

\section{Interpretation-Oriented Geophysical-Data Processing}

\section{Three types of poststack processing were applied to the 3-D volume to improve interpretability of data.}

First, a $90^{\circ}$-phase shift was applied to the original, approximately zero-phase data. Shape of seismic wavelet determines which part of the wavelet is the most important for seismic response. It is well known that the zero-phase wavelet is symmetrical and has maximum energy in its central part. Its small side lobes make it better than minimum- and maximum-phase wavelets of the same frequency for detecting reservoirs vulnerable to the geological noise from both above and below. But the main problem for interpreters is that for a single reservoir (layer), two seismic events (one peak and one trough) can be seen, which may cause confusion in identifying sandstones from shales when multiple reservoirs are involved in the interval of interest. In fact, for seismically thin layers, $90^{\circ}$-phase wavelet is better than its zero-phase counterpart for interpretation (fig. 8). For $90^{\circ}$-phase wavelet, one reservoir is reflected by one seismic event, a peak or trough, depending on sand-shale acoustic relationship. It occurs at the middle of the reservoir, having two weak side lobes, making more sense for a geologist because the seismic 


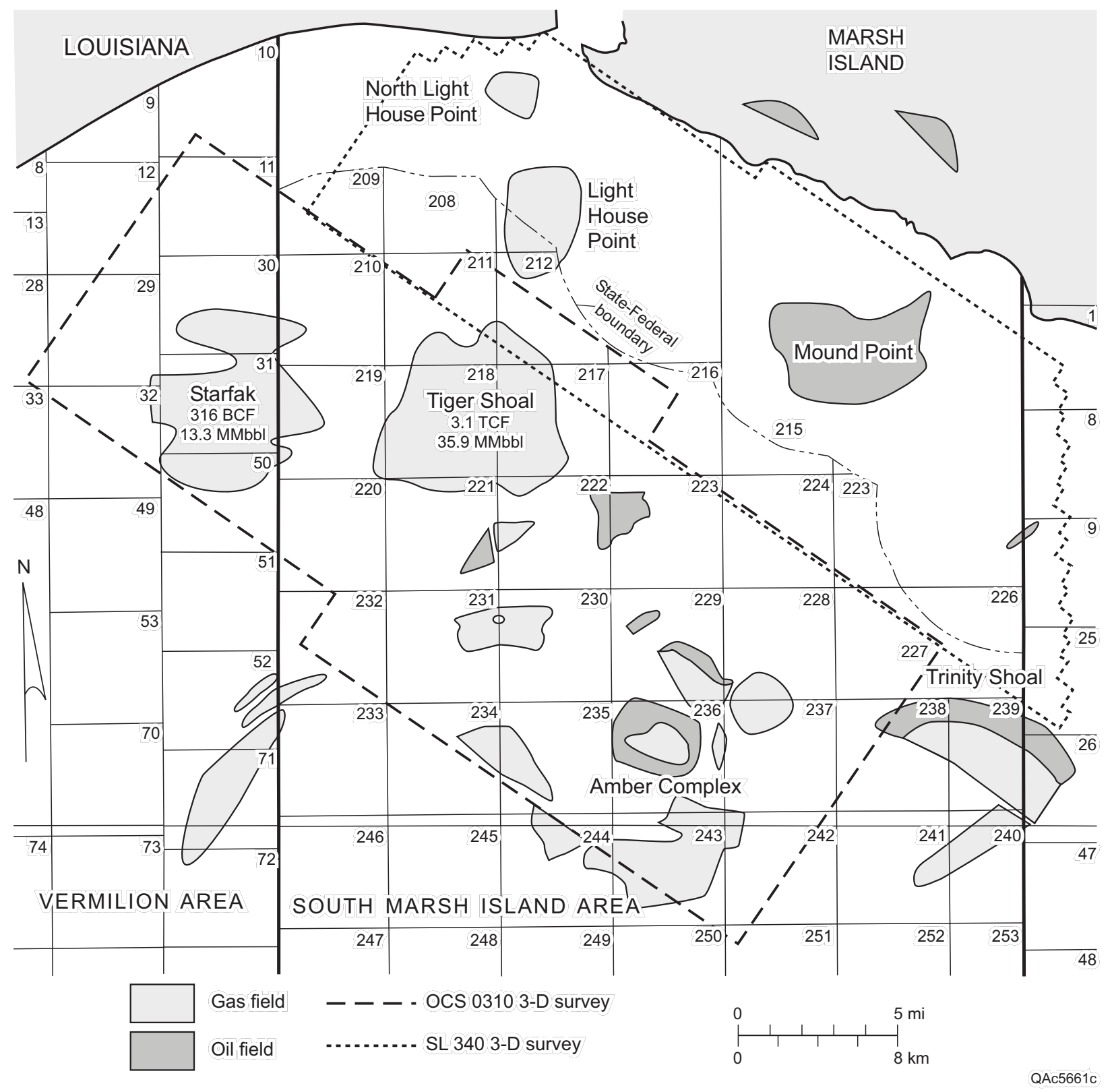

Figure 6. Close-up map of study area identifying outlines of the two major 3-D seismic surveys used in this project. 


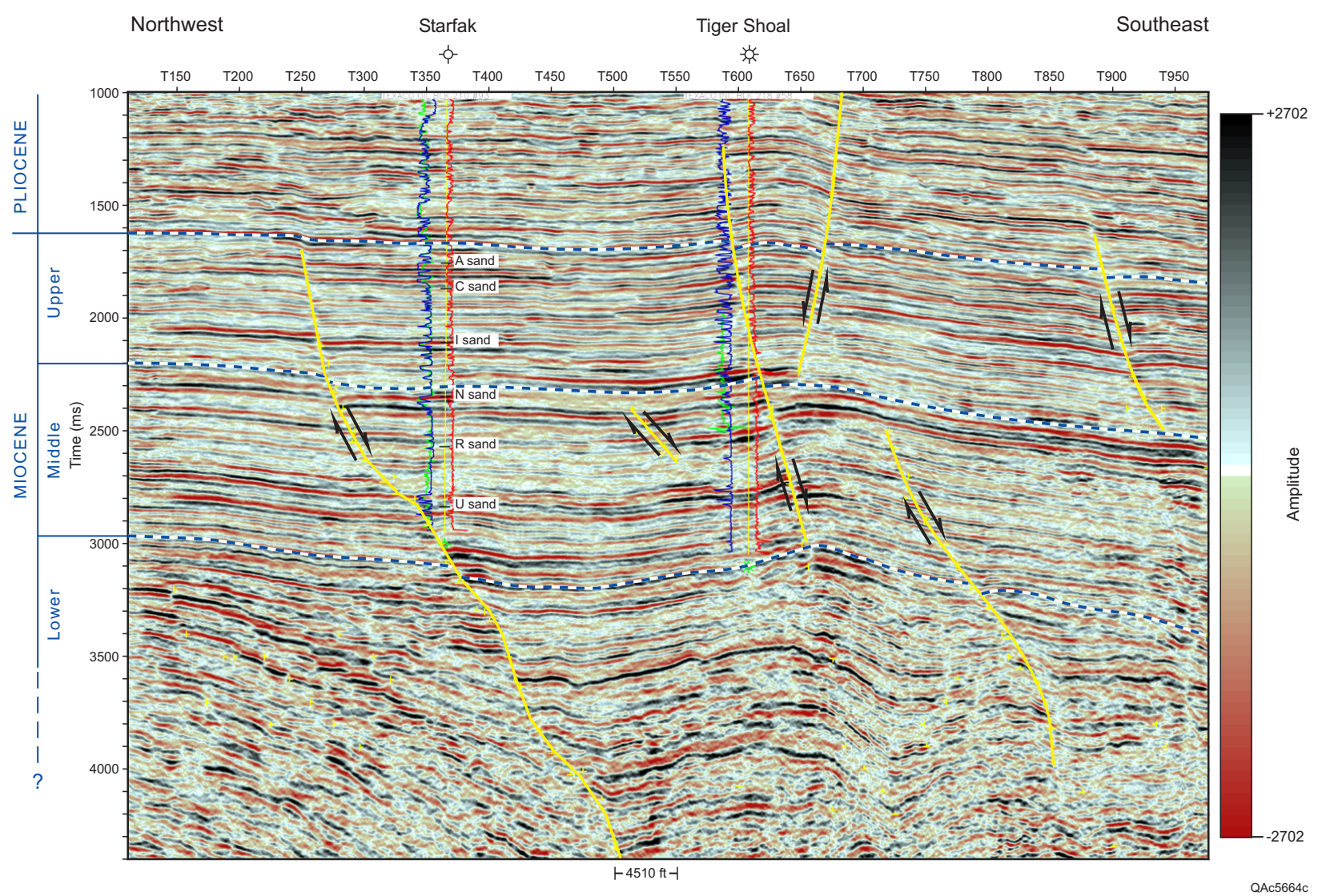

Figure 7. Northwest-southeast regional strike-oriented seismic profile across Starfak and Tiger Shoal fields illustrating good tie between well logs and nearby seismic traces.

Lithology

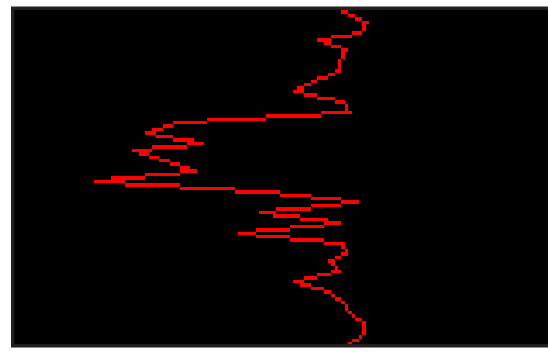

$0^{\circ}$ Ricker

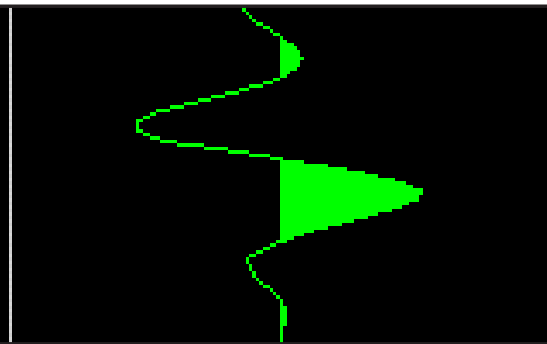

$90^{\circ}$ Ricker

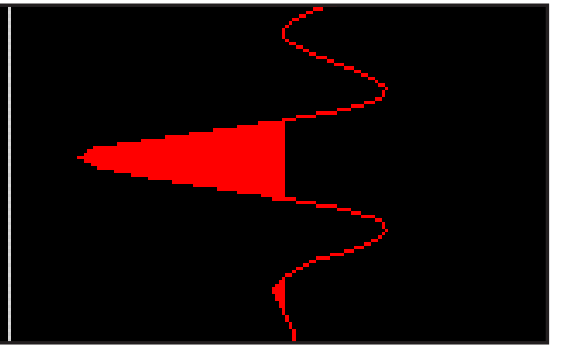

QAc7910c

Figure 8. Interpretive advantage of $90^{\circ}$-phase wavelet. For seismically thin layers, one reservoir is reflected by one trough (peak) at top and one peak (trough) at base with $0^{\circ}$-phase wavelet, but only one main trough (peak) at middle if a $90^{\circ}$-phase wavelet is involved. 
section of $90^{\circ}$ phase best matches its "inversion" or impedance section without an inversion actually being done. The resulting $90^{\circ}$-phase data, therefore, coincide better with impedance logs and, in turn, with gamma-ray, SP, and resistivity curves - those with which geologists are most familiar. For this reason, a $90^{\circ}$-phase data set was selected for most of the seismic interpretation in the project. The difference between the data of two phases and their influence on well-seismic correlation is shown in figures 9 and 10.

The second type of poststack processing that was applied involved calculating continuity (Landmark) cubes from the original data to aid in fault interpretation and identification of stratigraphic features. The project's primary benefit of these cubes is that they can image numerous faults of different scales (from regional [tens of miles] to local [hundreds to thousands of feet]) and resolve important depositional features (for example, channel systems and slope fans). Benefit of the processing can easily be seen in continuity time slices (figs. 11, 12), which show a sharp and complete regional fault system in the shallower section (fig. 11, 1 to $3 \mathrm{~s}$ ) and many small, subtle faults in the area between Starfak and Tiger Shoal fields and to the northwest of Starfak field in the deeper section (fig. 12, 3 to $4.5 \mathrm{~s}$ ), which are otherwise difficult to pick.

Thirdly, a processing of spectral balancing was conducted on deep data (3 s and deeper) to improve vertical seismic resolution. The deep section is an important hydrocarbon-producing zone (U-Y sands, $12000 \mathrm{~A}$ and B sands and Robulus "L" sands) and one of the critical targets of this research. However, compared with the higher frequency, shallower data (30- to 40-Hz dominant frequency in interval of 1 to $3 \mathrm{~s}$ ), deeper data are characterized by a significantly lower dominant frequency $(\sim 20 \mathrm{~Hz})$ and therefore much lower vertical resolution. To improve the interpretability of the seismic data, the amplitude level of higher frequency components was enhanced in the data, while the lower, originally dominant frequency components were kept intact. The range and enhancing scale of the higher frequency components were carefully selected and tested to avoid overamplifying the noise level of the data. The processing moved the dominant frequency of the data to the 30- to $40-\mathrm{Hz}$ level (comparable to the frequency of the shallower data). The resulting data reveal more stratigraphic details vertically (compare fig. 13, especially the lowstand prograding wedge). Judging by the good and sometimes even better correlation between well logs and seismic events in the processed data, these improvements are real and come from originally masked higher frequency signals.

\section{Engineering Data}

Engineering data provided by Texaco formed a firm basis for reservoir-specific analyses. Production-history data include cumulative production; monthly production values for oil, gas, and water; and starting/ending dates of production for each reservoir and reservoir segment. All perforation intervals provided by Texaco were individually tied to production history in the company's Oil Field Manager (OFM) data. These data were supplemented with perforation information from hard-copy well log annotations, well-history files, and well-bore schematics. Reservoir-gas composition and pressure/volume/temperature (PVT) analyses from four wells in Tiger Shoal field have also been provided. There are 14 water analyses from Tiger Shoal field and 3 analyses from Starfak field. Two wells from Starfak field have yielded pressure-buildup test data. Numerous bottom-hole pressure (BHP) tests are available from various wells, reservoirs, and reservoir segments throughout their production history. 


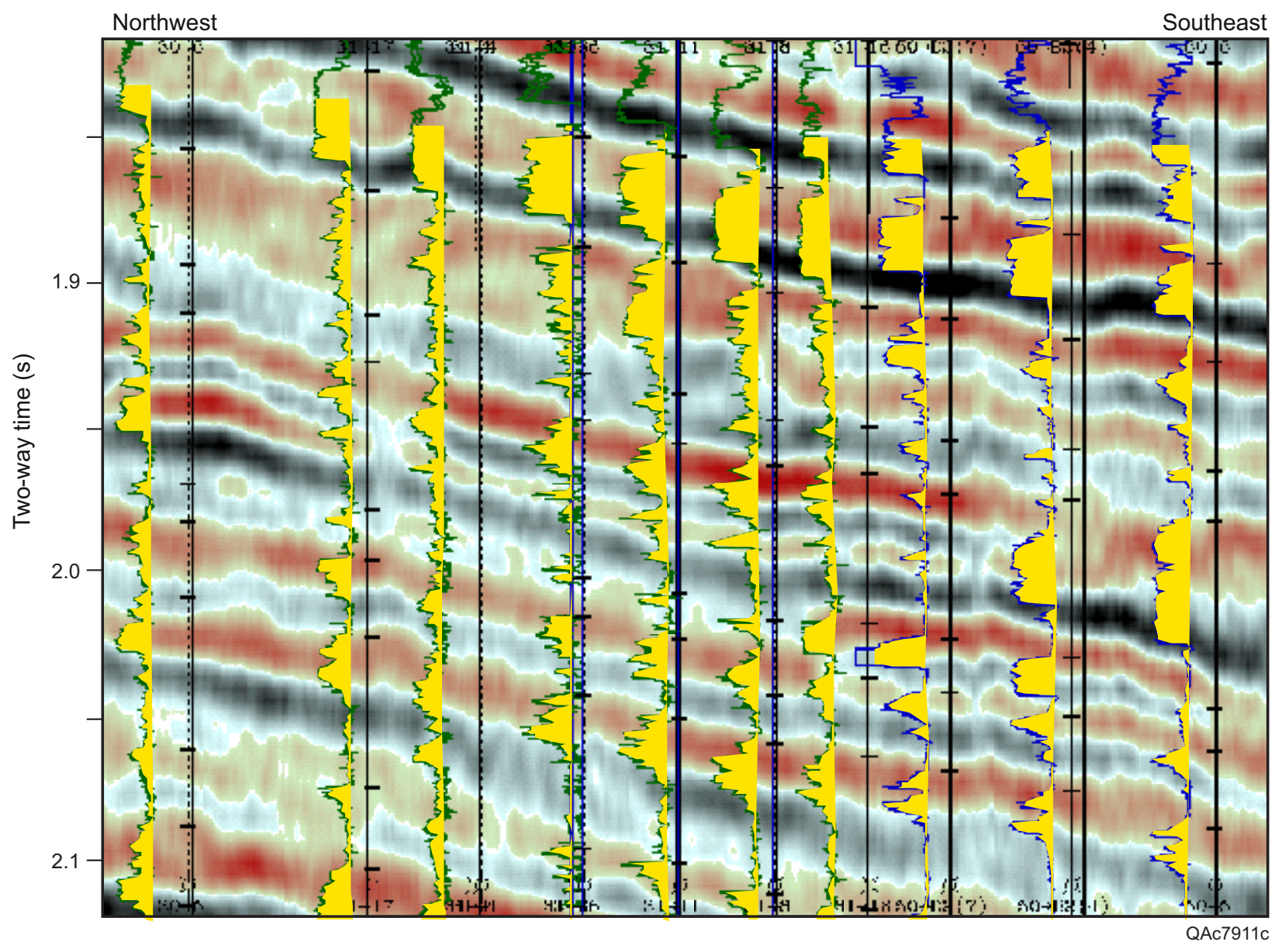

Figure 9. A $0^{\circ}$-phase (original) seismic section tied to wells (GR/SP) in Starfak field. Each sandstone ties to a pair of seismic events (trough or red at top and peak or black at bottom). 


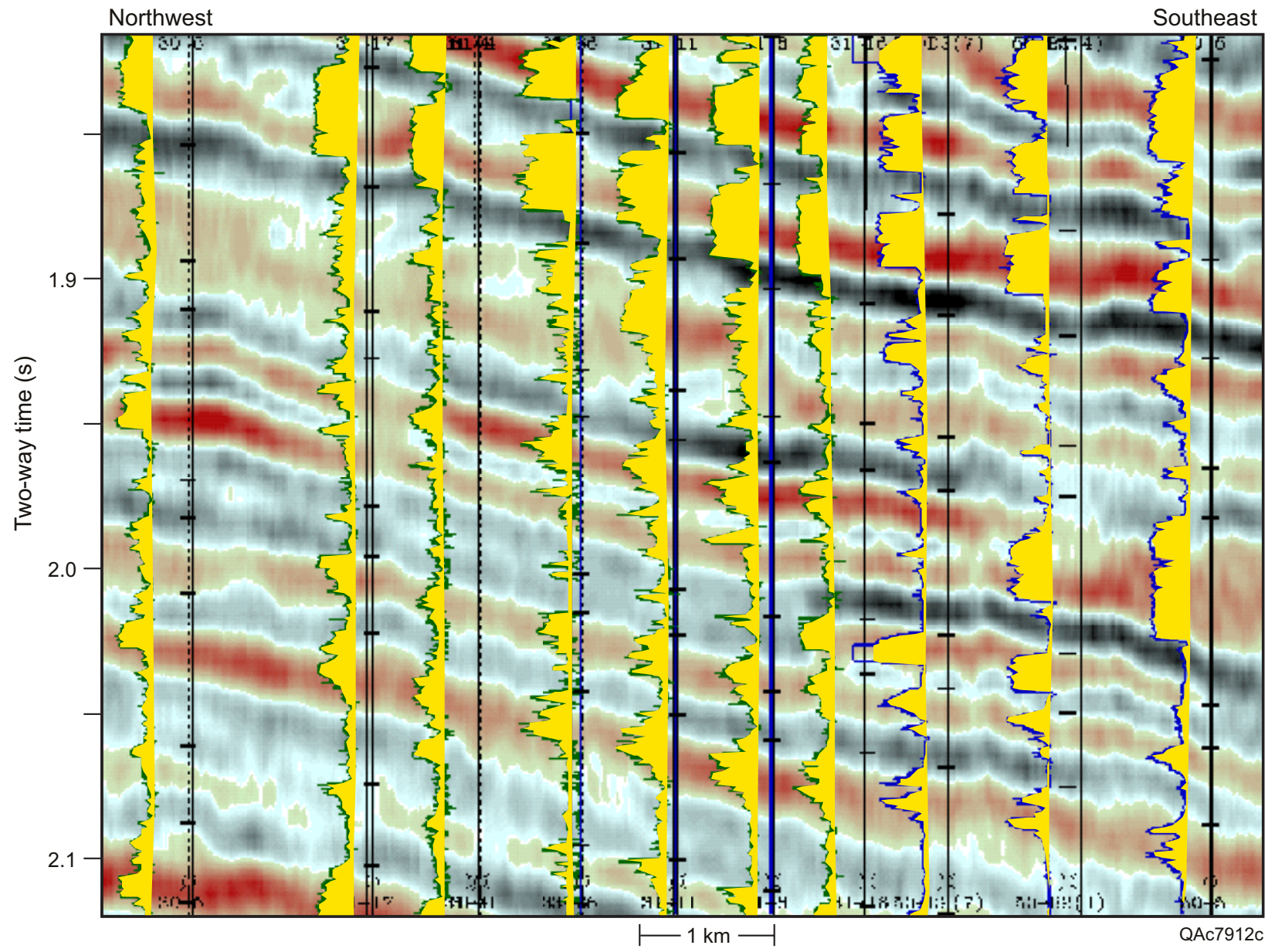

Figure 10. A $90^{\circ}$-phase (reprocessed) seismic section tied to wells (same as figure 9). Each sandstone ties to one seismic event (trough or red at middle). 


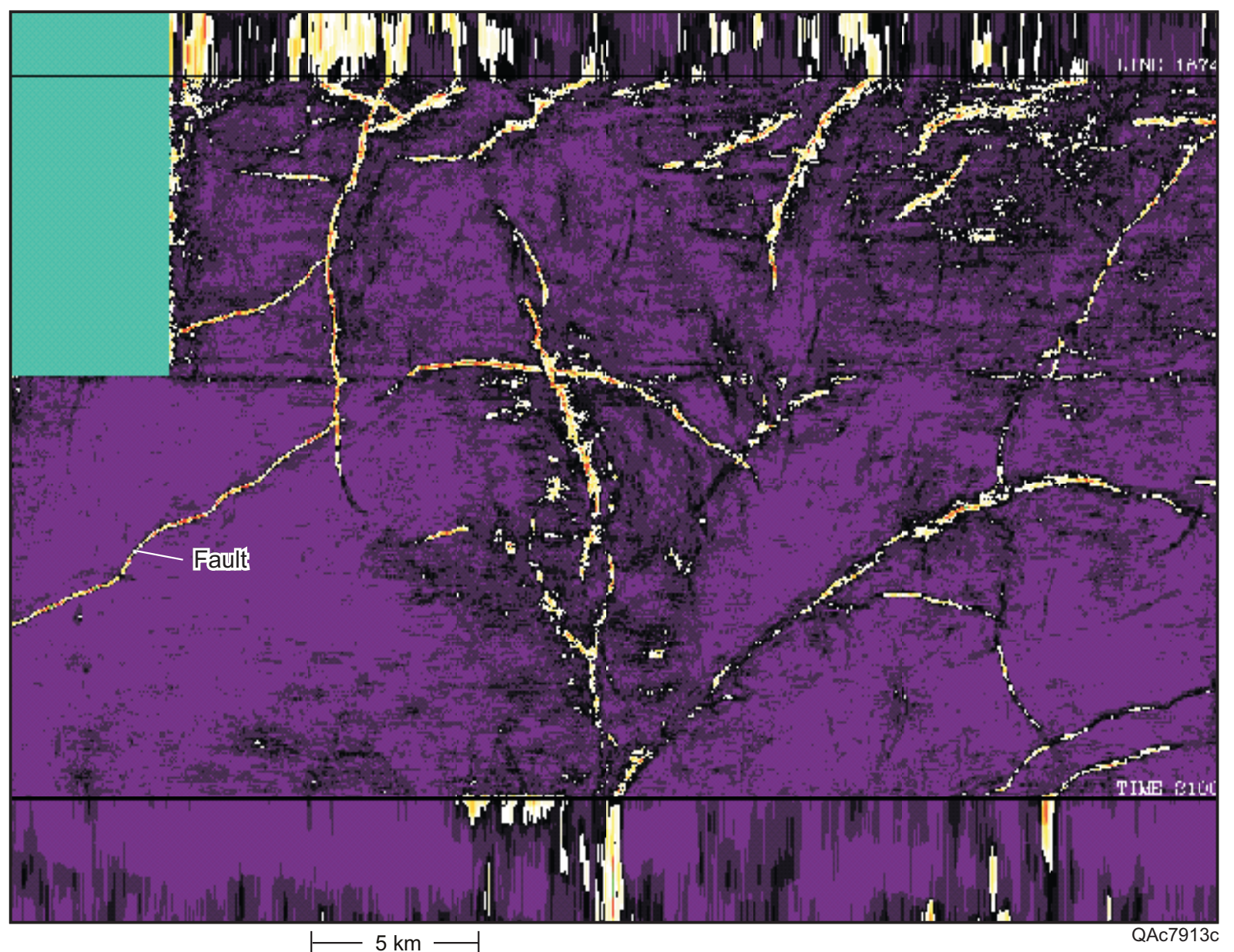

Figure 11. Continuity time slice at $2,100 \mathrm{~ms}$ (in chair map view) showing a sharp and complete regional fault system in the shallower section. 


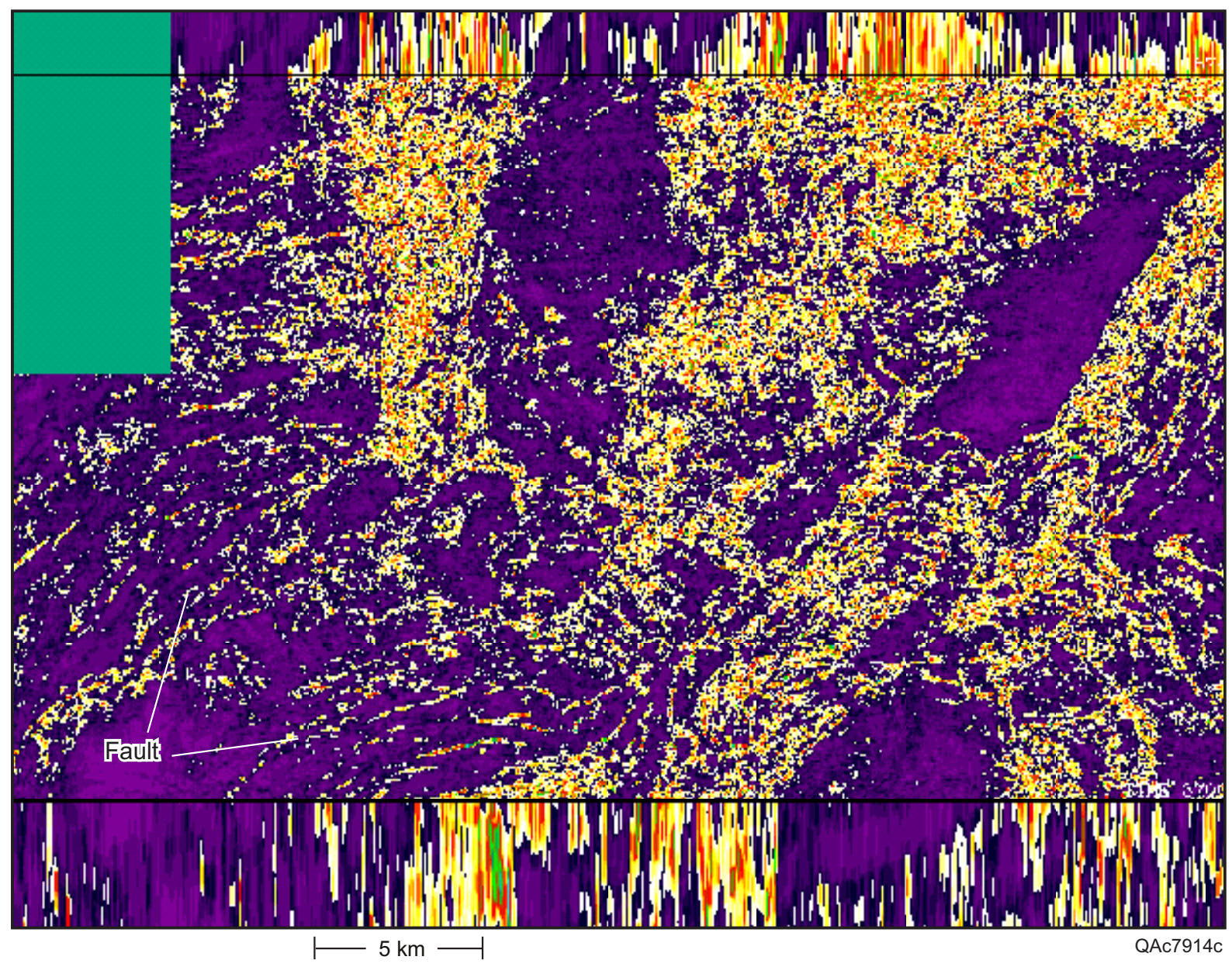

Figure 12. Continuity time slice at 3,700 ms (in chair map view) illustrating numerous small, subtle faults in the area between Starfak and Tiger Shoal fields and to the northwest of Starfak field in the deeper section. 
(a)

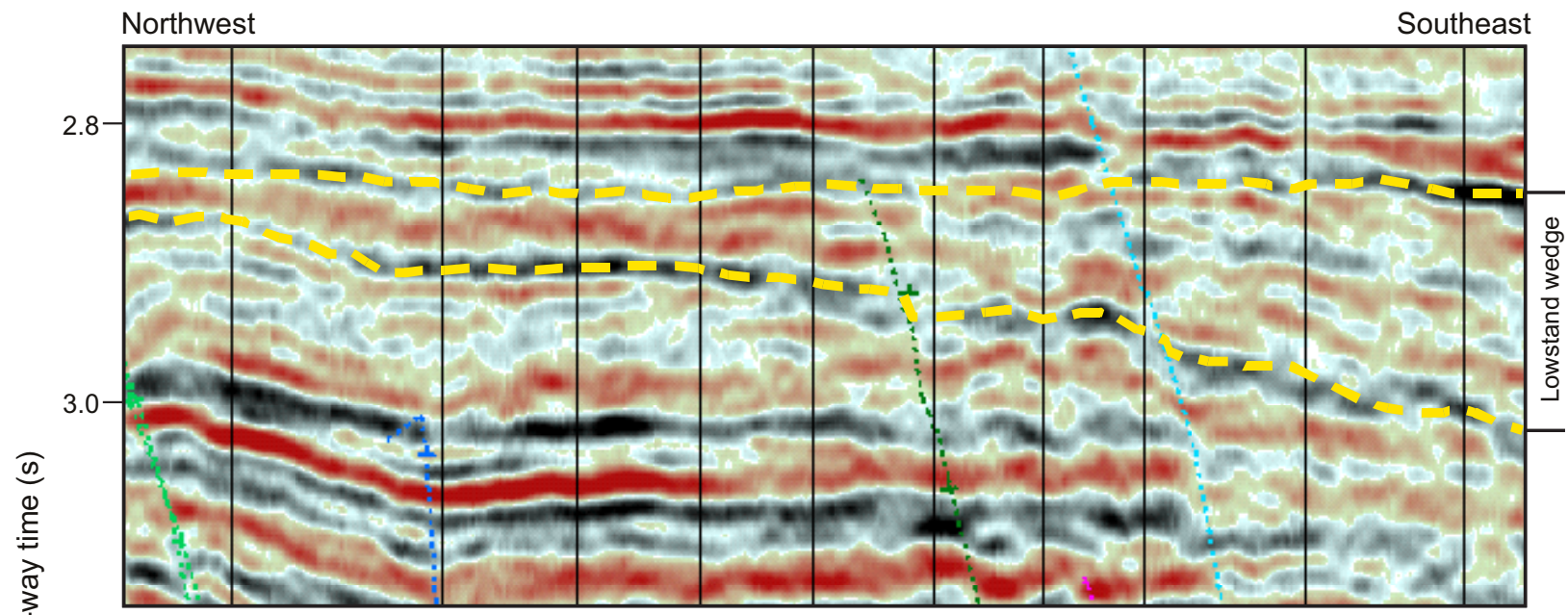

(b)

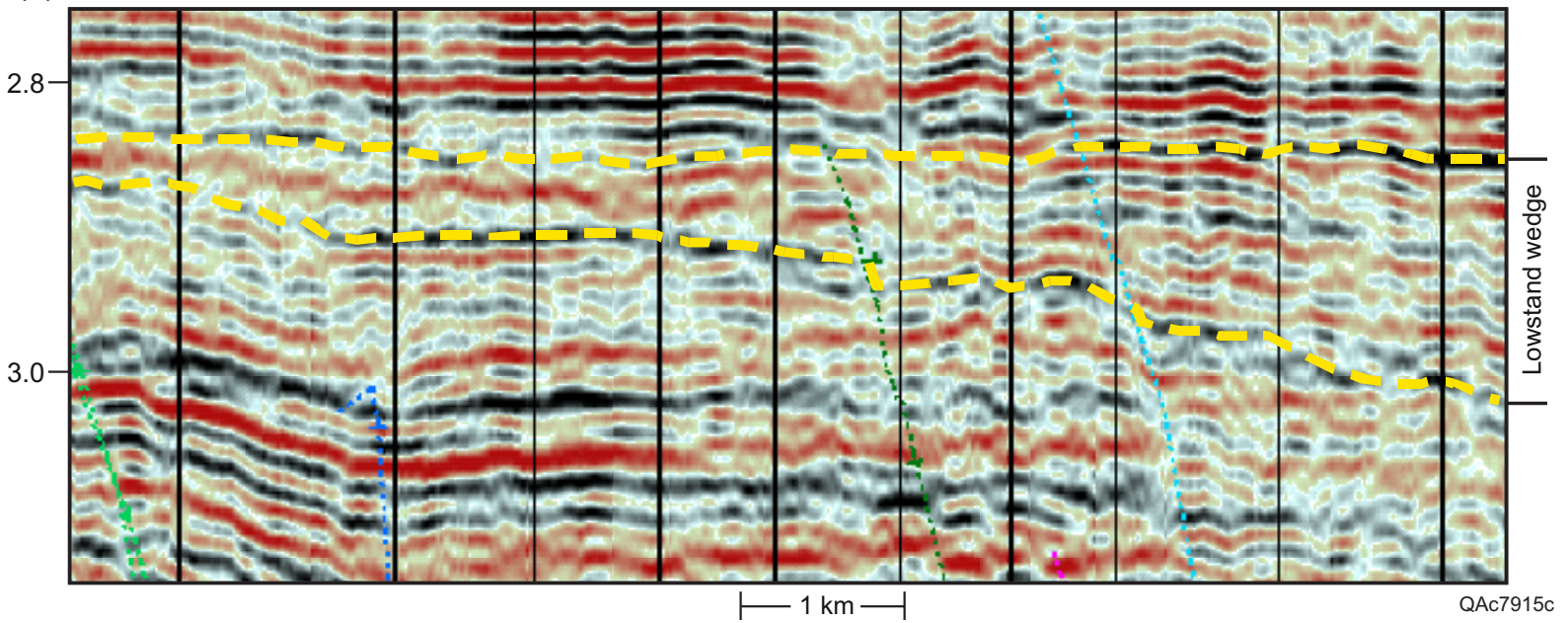

Figure 13. Spectral balancing of deep data (a) before processing and (b) after processing. 


\section{Database Unification}

Texaco provided the project with abundant seismic, geologic, engineering, and production data for the Miocene reservoirs in the two fields. Early in the project, separate databases were constructed for both fields that were fully populated with (1) geologic-marker picks derived from well log correlation (reservoir tops, fault locations), (2) all perforated and completed intervals, (3) inventory of all digitized well log curves, (4) inventory of hard copies of well logs, (5) core-analysis data, (6) cumulative oil/water/gas-production data, (7) geographic coordinates and elevations of surface (kelly bushing) and bottom-hole (for deviated and sidetrack wells) locations, and (8) azimuths and deviation directions for all deviated and sidetrack wells. Moreover, sequence-stratigraphic data, depositional-facies data, and quantitative petrophysical data derived from in-house well $\log$ analysis were added, as well as other Texaco data (for example, results of well-completion tests) as separate data sets. These separate databases were populated in a variety of applications: Landmark's Seisworks and Stratworks, Zmap, GeoGraphix Exploration System (GES), Petcom, Prizm, Oil Field Manager (OFM), and Roxar's Reservoir Modeling System (RMS). These databases were then unified into a master Access database, which is designed to be an integrated, comprehensive data platform from which disparate software will draw the most current data for analysis.

Our well log database was moved to Prizm and Openworks so that log analyses could be easily transferable among seismic interpreters and geologists. The GES project aided in the visualization and interpretation of production data for reservoir modeling.

\section{GEOLOGIC SETTING AND PALEOGEOGRAPHY}

\section{Regional Stratigraphic and Depositional Framework}

Starfak and Tiger Shoal fields produce hydrocarbons from sandstones in most of the Miocene Series (upper lower to upper Miocene), which in the two fields forms a dominantly regressive, progradational succession as much as 10,000 ft thick (fig. 14). The lower part of the reservoir-bearing interval (upper lower Miocene) is characterized by approximately 3,000 ft of mostly slope and basinal depositional facies: lowstand basin-floor fan, slope-fan, and lowstand-deltaic-wedge depositional facies. Shale-dominated slope-fan deposits, each deposit as much as $\sim 1,000 \mathrm{ft}$ thick, compose the major portion of this lower zone. At $\sim 13,000 \mathrm{ft}$, this succession is overlain by a 7,000-ft-thick upper zone of mostly on-shelf and significant, but volumetrically minor, off-shelf, lowstand depositional elements that exhibit a grossly increasing abundance of sandstone upward (middle and upper Miocene). Cyclic distal highstand, distal transgressive, and lowstand prograding-wedge and distal incised-valley-fill facies in the basal part of this upper zone grade upward into progressively more proximal, cyclic highstand, transgressive, and incisedvalley-fill facies. A thick succession of aggradational fluvial coastal-plain deposits occurs only a few hundred feet above the reservoir-bearing study interval. This upward-shallowing trend of depositional facies coincides with that 


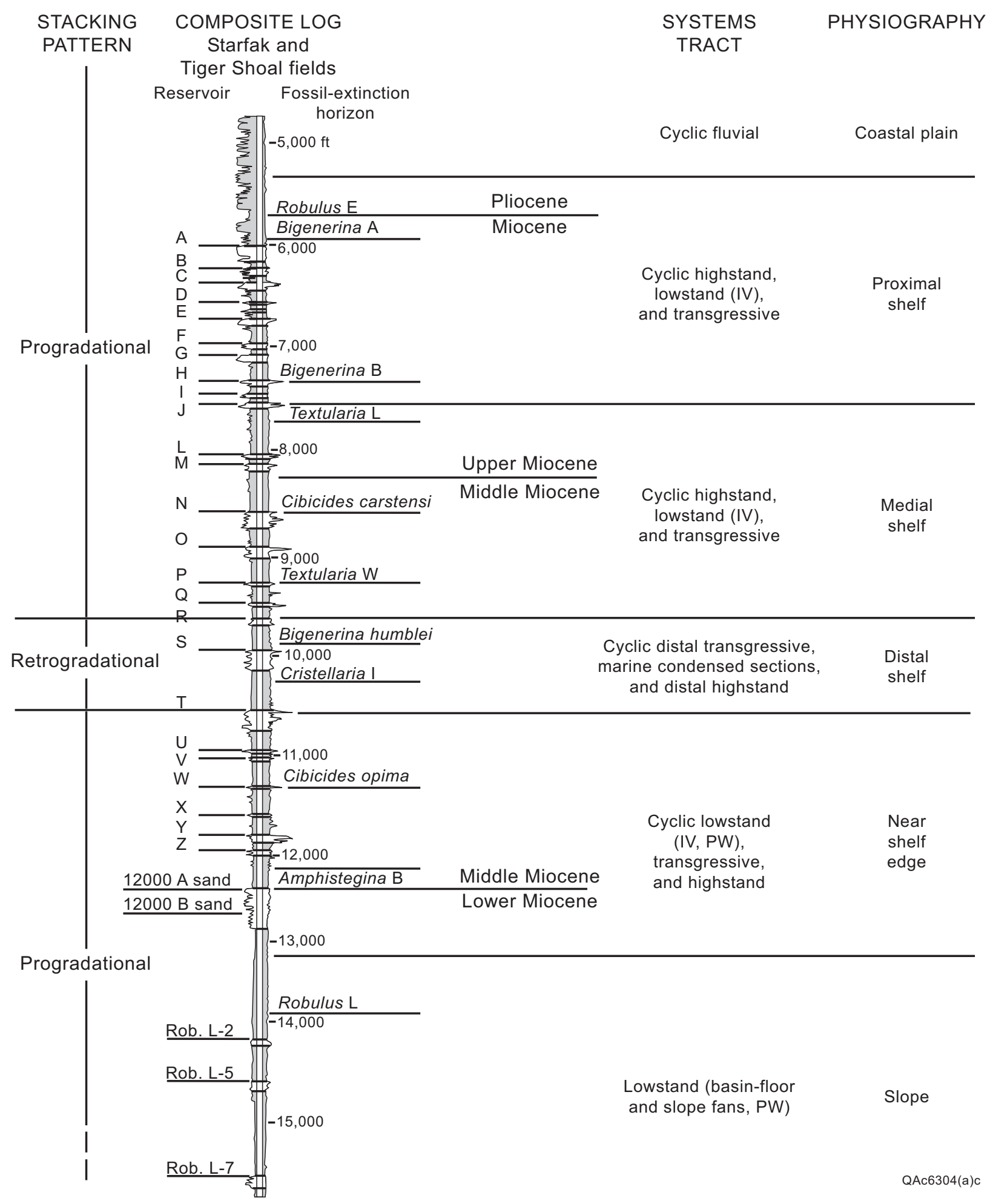

Figure 14. Composite type log of Starfak and Tiger Shoal fields that displays gross stacking patterns, reservoir nomenclature, extinction horizons of invertebrate paleofauna, and stage boundaries. Stage boundaries are approximate and are based on microfossils from several wells in each field. Interpretation of systems tracts and paleophysiography is based on wireline-log facies, inferred lateral facies relationships, facies-stacking patterns, and mapping using seismic data (primarily time-depth-structure and isochron maps and amplitude stratal slices). 
of the entire Miocene interval in the offshore northern Gulf of Mexico (Seni and others, 1997). Paleontological data from selected wells indicate that the 10,000-ft section from the oldest reservoir (Robulus L-8 sand) at the base of the study interval to the Pliocene/Miocene boundary just above the uppermost reservoir (A sand) represents 11.2 m.y. (discussed later in the "Biostratigraphy" section).

\section{Regional Structural Context}

Starfak and Tiger Shoal fields are located in the Oligocene-Miocene Detachment Province of the northern Gulf Coast continental margin (Diegel and others, 1995). This region is generally characterized by large-displacement, dominantly down-to-the-basin, listric growth faults that sole on a regional detachment zone above the Oligocene section. Regional deformation is a product of salt mobilization from the level of the autochthonous Jurassic Louann Salt, or it is a result of detachment and growth-fault development along a salt weld that formerly contained a thick, allochthonous salt body (Diegel and others, 1995; Luo, 2000). A characteristic feature of this province is the great thickness of deltaic and other on-shelf sediments above the detachment zone, typically exceeding $3 \mathrm{mi}$. This remarkable succession of thick Miocene on-shelf, shelf-edge, and slope siliciclastics accumulated during a period of generally high sedimentation rates. These sediments were generated by rejuvenation of continental highlands, particularly the southern Appalachians during the middle to late Miocene (Boettcher and Milliken, 1994; Galloway and others, 2000), and help make this region one of the world's great high-quality petroleum reservoir provinces. Starfak and Tiger Shoal fields lie within the heart of this region.

Geologic conditions in the greater two-field study area are structurally simple compared with those of the complex, diapirically deformed strata that occur to the south. The two fields are associated with several subregional normal growth faults and related ancillary faults that cause additional structural partitioning. One first-order growth fault transects Starfak and Tiger Shoal fields; however, at least five first-order, large-displacement faults occur in the entire area of seismic coverage. First-order growth faults, as opposed to second-order faults, are characterized by large apparent offsets (>500 ft of maximum offset), and they extend from near the seafloor to below the maximum depth of seismic coverage (4.4 s, 18,000 ft). Second-order faults occur having both growth and nongrowth geometries and in typically much shorter segments having smaller amounts of apparent offset. A first-order, broadly arcuate, west-east-trending growth fault cuts the north part of the two fields and acted as a primary control on basin geometry and depositional-systems-track development during the early Miocene (figs. 15, 16). A narrow zone of second-order, north-south-trending growth faults roughly bisects Tiger Shoal field, generally separating primarily gas producing reservoirs in the west part of the field from primarily oil reservoirs in the east (fig. 16). Second-order, deep-seated, east-west-trending faults extend from Starfak field into a broad structural low (saddle) between the two fields (fig. 15).

Structurally, Starfak field is characterized by (1) the first-order, arcuate, west-east-trending growth fault with approximately $600 \mathrm{ft}$ of apparent offset in the field and (2) the deep-seated, east-west-trending faults that bound rotated fault blocks. The up-section termination of these smaller, lower offset faults is generally at $\sim 11,500 \mathrm{ft}$; the basal soles of these normal faults are deeper than the range of seismic coverage. Structurally trapped 


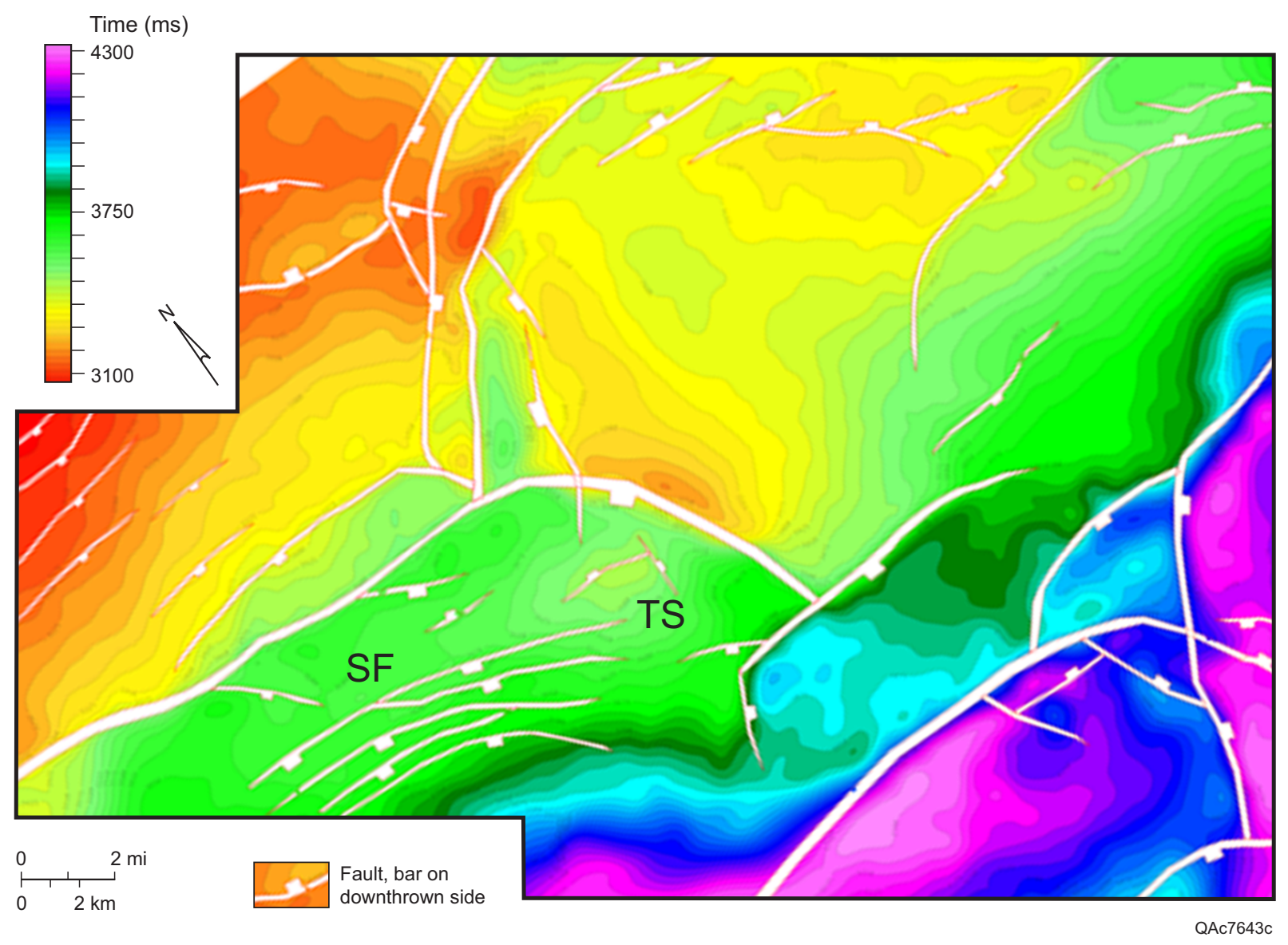

Figure 15. Time-depth-structure map of the Robulus L-4 sand. This unit occurs at approximately $14,700 \mathrm{ft}$ in Starfak (SF) field. Note that the regional fault distribution varies from that of the shallower MFS 25 horizon (fig. 16). In particular, the deep-seated, east-west-trending faults that extend from Starfak field toward Tiger Shoal (TS) are absent at the shallower horizon. 


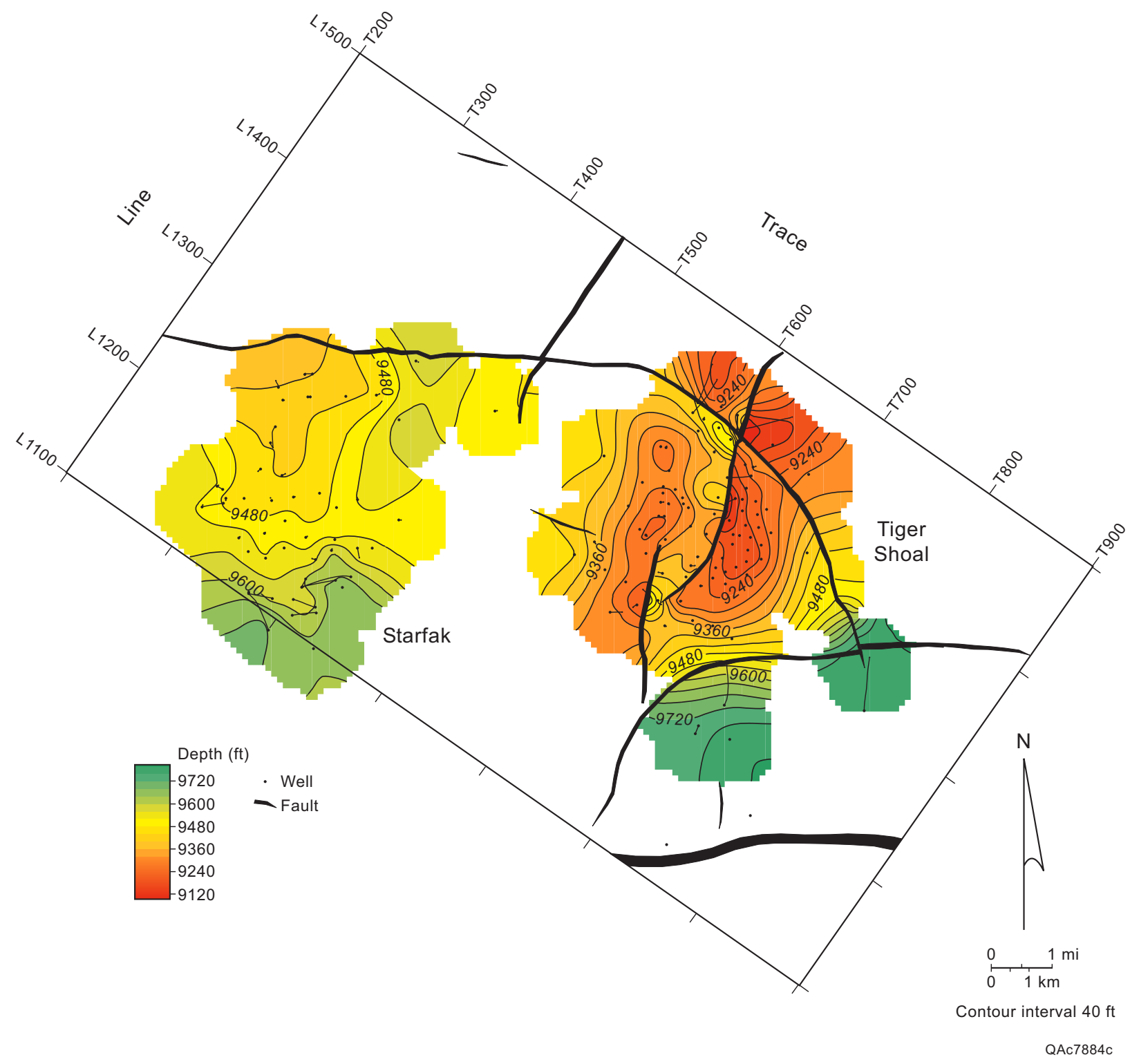

Figure 16. Structure map of MFS 25 (between O and P sands) derived from well log data. Fault traces derived from 3-D seismic interpretation. 
hydrocarbons are being produced from rollover anticlines against the first-order growth fault and from deep zones in the rotated fault blocks. In contrast, structural traps in Tiger Shoal field are generally anticlines cut by the second-order, north-south-trending faults.

\section{Reservoir Framework}

In all, 62 Texaco-designated gas and oil reservoirs occur within Starfak and Tiger Shoal fields: 15 in Starfak and 47 in Tiger Shoal (table 2). In accordance with Texaco's established reservoir nomenclature, these sandstonebody reservoirs are named, in descending order, A through Z sands (some are variously subdivided using alphanumeric designations, such as T-1 sand and M-1 [lower] sand), $12000 \mathrm{~A}$ sand, $12000 \mathrm{~B}$ sand, and the Robulus L-1 through Robulus L-8 sands (fig. 14). Reservoir sandstones range in depth from 6,200 to 16,200 ft in Starfak field and $\sim 6,000$ to $15,400 \mathrm{ft}$ in Tiger Shoal field. The two fields are currently operated by Chevron-Texaco. Tiger Shoal has produced gas and oil from 103 wells and was discovered in 1958, whereas Starfak field, discovered in 1975, comprises 53 wells, mostly gas producers. Sixty-two gas and oil reservoirs occur within Starfak and Tiger

\section{Shoal fields: 15 in Starfak and 47 in Tiger Shoal.}

Although surfaces on or within many of the Texaco-designated reservoir sandstones typically coincide with key sequence-stratigraphic boundaries, vertical reservoir boundaries are nongenetic. Among other benefits, this coincidence greatly aided in the precise correlation of sandstone-bearing intervals across the 4-mi undrilled saddle between Starfak and Tiger Shoal fields (fig. 15). With only two exceptions, Texaco-designated reservoir sandstones are approximately correlative between the fields. The Texaco-designated E and L sand reservoirs in Starfak and Tiger Shoal fields are not time-stratigraphic equivalents between the two fields, although the true equivalents are within only 100 to $150 \mathrm{ft}$ of the miscorrelated intervals.

\section{Paleogeography}

The study area lies within part of the ancestral Mississippi River depocenter (McGookey, 1975), most recently designated the Central Mississippi sediment-dispersal axis by Galloway and others (2000). As defined by Galloway and others (2000), the Central Mississippi and East Mississippi dispersal axes produced a composite delta system that dominated the paleogeography of the entire Gulf Coast margin. They coincide with the western and central parts of the modern Mississippi-delta complex, respectively. 
Table 2. Texaco-designated sandstone-body reservoirs in Starfak and Tiger fields.

$\begin{array}{ll}\text { Starfak } & \text { Tiger Shoal } \\ \text { M } & \text { A Stray } \\ \text { N } & \text { B upper } \\ \text { P } & \text { Big B-4 } \\ \text { T-1 } & \text { Big C } \\ \text { T-1A } & \text { C } \\ \text { T-1B } & \text { D } \\ \text { T-2A } & \text { E } \\ \text { U } & \text { E-1 } \\ \text { W } & \text { E-2 } \\ \text { X } & \text { F } \\ \text { Y } & \text { G } \\ \text { 12000 A } & \text { G Stray } \\ \text { ROB L-1 } & \text { H } \\ \text { ROB L-2 } & \text { I } \\ \text { ROB L-5 } & \text { J } \\ & \text { K-1 } \\ & \text { K-2 } \\ & \text { L } \\ & \text { M upper } \\ & \text { M-1 } \\ & \text { M-1 lower } \\ \text { M-2 } \\ \text { M-2 lower } \\ \text { N } \\ \text { N-1 } \\ \text { N-1 middle } \\ \text { N-1 upper } \\ \text { N-2 } \\ \text { N-3 } \\ \text { O } \\ \\ \text { O-2 } \\ & \text { P } \\ & \text { P-2 } \\ & \text { Q-1 } \\ & \text { Q-2 } \\ & \text { R } \\ & \text { S-2 B } \\ & \text { T-1 } \\ & \text { T-2 } \\ & \text { U } \\ \text { V } \\ \text { W } \\ \text { Y } \\ \end{array}$




\title{
IMPROVING RESOURCE RECOVERY IN THE MIOCENE, NORTHERN GULF OF MEXICO
}

\author{
Integrated Sequence Stratigraphic Analysis
}

The sequence-stratigraphic interpretation techniques used in this project are discussed in Van Wagoner and others (1990) and Mitchum and others (1993). This approach enabled construction of a genetic context for all phases of study of the Miocene succession (Hentz and others, 2000, 2001, 2002; Zeng and others, 2000a, 2001a-c; Badescu and Zeng, 2001; DeAngelo and Wood, 2001; Rassi and Hentz, 2001; Zeng, 2001; Rassi, 2002a-c; Zeng and Wood, 2002; Hentz and Zeng, in press). Moreover, it establishes the groundwork for investigations of reservoir-specific attributes and the identification of previously undetected hydrocarbon resources within the two-field area, this project's 3-D seismic volume, and adjacent on-shelf areas.

\section{Biostratigraphy}

Faunal data from unpublished Texaco paleontological reports from 15 wells in both fields indicate that the $\sim 10,000$-ft section from the oldest reservoir (Robulus L-8 sand) at the base of the study interval to the Pliocene/Miocene boundary just above the uppermost reservoir (A sand) represents $\sim 11.2$ m.y. of deposition. The study interval ranges in age from latest early Miocene (late Burdigalian, 17.3 m.y.) to the end of the Miocene (early Messinian, 6.1 m.y.). The Miocene stage boundaries used by Texaco have been employed: the extinction horizons of Robulus "L" (top of lower Miocene), Cibicides carstensi (top of middle Miocene), and Robulus "E" (top of upper Miocene) (R. G. Lytton III, personal communication, 2001). Fourteen regional GOM foraminiferal biozones (Picou and others, 1999) occur within the study interval, ranging from the Cibicides "38" and Robulus "L" zones ( 16.5 m.y.) to the Robulus "E" zone ( 6.1 m.y.) at the top of the Miocene Series. However, lower Miocene strata in deep wells in nearby North Light House Point and Mound Point fields (fig. 5) record the regional Operculinoides zone (extinction horizon of Robulus "54-B"), the next-oldest regional GOM biozone (at 18.0 m.y.), occurring $\sim 600$ to $700 \mathrm{ft}$ below the base of the deepest well log section in the two project fields. Ages of regional biozones in the project were initially derived from Lawless and others (1997), who used the time scale of Berggren and others (1985); these ages were "converted" to the revised chronology of Berggren and others (1995).

In most instances, the top of each regional biozone is chronostratigraphically well constrained in Starfak and Tiger Shoal fields, with 40 to $100 \mathrm{ft}$ of vertical variance for the top of each zone among the 15 wells having fossil data. These zones consistently extend across the same flooding shales in the 15 wells. However, the variation in the highest occurrences of Cibicides opima and Bigenerina "B" (within shales and overlying sandstones) is not as well constrained, most likely because of changing environmental conditions coinciding with pronounced changes in depositional facies. However, highest occurrences of both taxa within sandstones may also be a result of redeposition of fossils above unconformities. Owing to this uncertainty of the positions of extinction horizons, these biozones are depicted within chronostratigraphic ranges. 
Paleobathymetric indicator fauna, benthic organisms that lived within certain ranges of water depth (Picou and others, 1999), enabled reconstruction of water depths during deposition of reservoir-scale (fourth-order) systems tracts (table 3). Several of the Texaco paleontological reports include complete faunal-count lists recorded by the well-site paleontologists. In most wells, samples were recorded every $30 \mathrm{ft}$ from immediately above the study interval to TD. These lists provide an accounting of fossil assemblages, abundances of individual species, and stratigraphic positions of major faunal "floods." Indicator fossils within faunal floods, which typically coincide with the marine condensed sections, can be used to estimate the paleobathymetric conditions under which the sediments containing the fossils were deposited. The indicator fossils record an overall upward-shallowing trend within the entire study interval (fig. 17), coinciding with the overall regressive stratal-stacking pattern. Information provided by the indicator fossils also offers corroborative evidence for the interpretations of systems tracts, which are discussed in following sections.

\section{Sequence Interpretation}

The $~ 10,000-\mathrm{ft}$ Miocene succession in Starfak and Tiger Shoal fields comprises 10 third-order sequences and no fewer than 58 fourth-order sequences, which average $\sim 1.1$ and $\sim 0.19$ m.y. in duration, respectively. The average duration of the third-order sequences, composed of fourth-order sequence sets (Mitchum and Van Wagoner, 1990), is comparable to that of the Miocene Series measured in basins worldwide (Haq and others, 1988; Hardenbol and others, 1998). The average duration of the fourth-order sequences is also comparable to that of other Miocene fourth-order sequences of the Gulf Coast Basin (Van Wagoner and others, 1990). Because the data set does not allow observation of the full shelf-to-basin profile of the Miocene sequences, relative positions of coastal onlap can only be inferred. However, the third-order sequences exhibit an upward-thinning trend (fig. 18), the upsection occurrence of progressively shallower water benthic-fossil assemblages (fig. 17), decreasing fossil abundance and diversity (fig. 18), and a generally upward thinning of lowstand systems tracts (LST's), collectively indicating the progressive upsection coastal offlap of the Miocene succession.

Conceptually, stratal stacking patterns within third-order systems tracts vary relative to their position in the shelf-to-basin depositional profile (Mitchum and Van Wagoner, 1990; Mitchum and others, 1993). Furthermore, these variations coincide with changes in stratal attributes of the component fourth-order systems tracts. Therefore, the study interval is divided into distal, medial, and proximal parts (fig. 19), each of which share sequencestratigraphic characteristics, to systematically document larger scale stratal and depositional trends within the $\sim 10,000$-ft study interval. 
Table 3. Characteristic paleobathymetric indicator fossils (foraminifera) in the Miocene section of Starfak and Tiger Shoal fields (after Picou and others, 1999).

Marginal marine

Ammonia beccarii

Elphidium spp.

Inner neritic $(0-60 \mathrm{ft})$

Bifarina vicksburgensis

Buccella hannai

Buccella mansfieldi

Cibicides concentricus

Eponides spp.

Nonionella spp.

Reusella spp.

Middle neritic (60-300 ft)

Bolivina floridana (rare)

Cancris sagra

Cibicides carstensi

Cibicides floridanus

Gyroidina hannai

Uvigerina peregrina (rare)

Outer neritic (300-600 ft)

Ammobaculites nummus

Bolivina floridana (common to abundant)

Chilostomella spp.

Cibicides opima

Gaudryina atlantica

Gyroidina scalata

Liebusella spp.

Pullenia salisburyi

Textularia barretti

Uvigerina altacostata (rare)

Uvigerina carapitana

Uvigerina howei

Uvigerina lirettensis

Uvigerina peregrina (common to abundant)

Valvulinaria spp.

Upper bathyal (600-1,500 ft)

Anomalina alazanensis

Cibicides matanzanensis

Cyclammina cancellata

Liebusella pozonensis

Planulina harangensis

Uvigerina altacostata (common to abundant) 


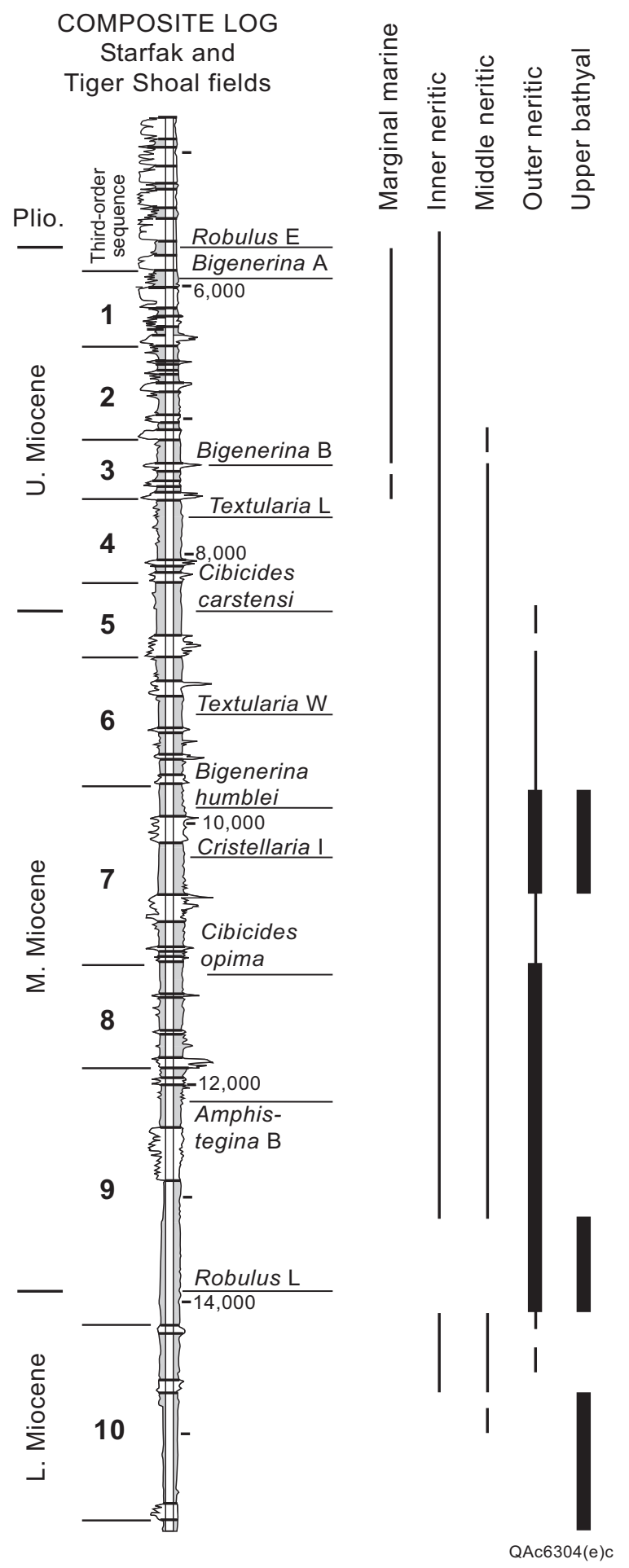

Figure 17. Ranges of paleobathymetric zones recorded within the study interval. Widest portions of zone bars represent stratigraphic intervals of particularly abundant indicator fauna. Many sandstones and immediately subjacent shaly strata in the lower two-thirds of the study interval were deposited under marginal-marine conditions; however, indicator fossils of this environment are sparsely preserved. Marginal marine $=$ shallow, brackish conditions; inner neritic $=\sim 0-60 \mathrm{ft}$; middle neritic $=\sim 60-300 \mathrm{ft}$; outer neritic $=\sim 300-600 \mathrm{ft}$; and upper bathyal $=$ $\sim 600-1,500 \mathrm{ft}$. Lists of indicator fossils used in this study are from Picou and others (1999). 


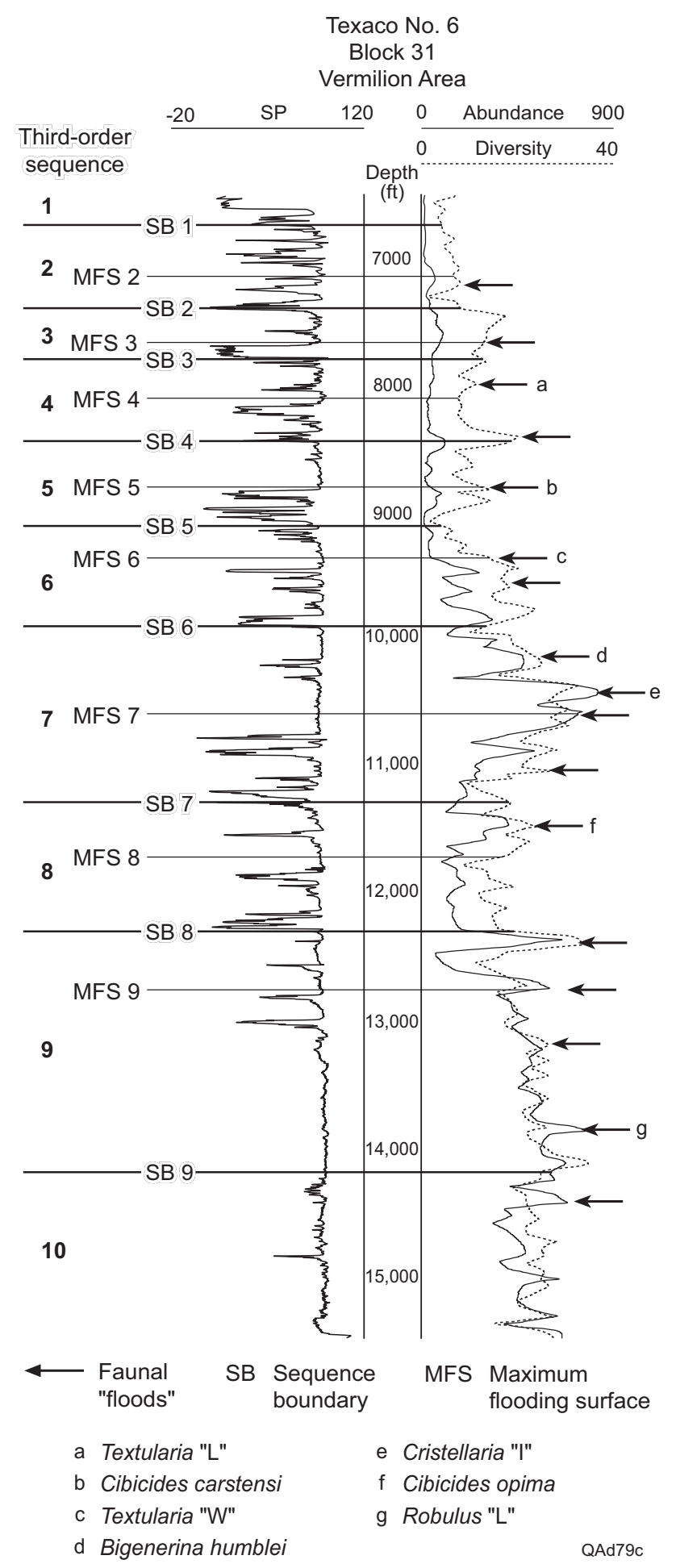

Figure 18. Third-order sequence boundaries and maximum flooding surfaces and representative curves of total foraminifera abundance and diversity within the study interval. The chronostratigraphic positions of depicted major and minor faunal "floods," derived from fossil summaries of paleontological reports from 15 wells from Starfak and Tiger Shoal fields, are very consistent among wells. Regional GOM biozones that coincide with floods are also depicted. Note that most third-order MFS's coincide with faunal floods; other floods mark prominent fourth-order MFS's. MFS 1 (not shown) coincides with the Bigenerina "A" extinction horizon (fig. 35). 


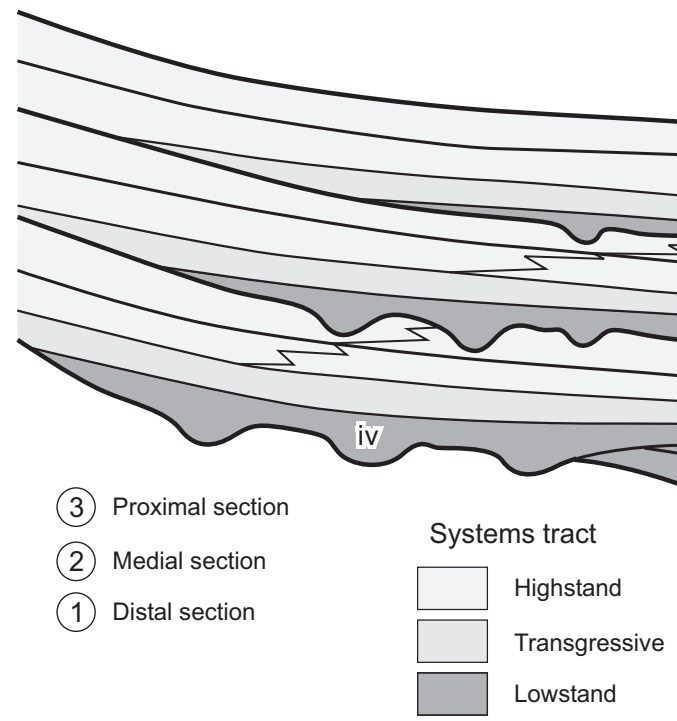
sequence boundary

Figure 19. Relative positions of distal, medial, and proximal third-order sequences and systems tracts in a schematic shelf-to-basin depositional profile. The Miocene study interval comprises two distal, four medial, and four proximal third-order sequences; iv = incised valley, $\mathrm{pw}=$ prograding wedge, $\mathrm{sf}=$ slope fan, and bff = basin-floor fan. 


\section{$\underline{\text { Distal Sequences (SB } 10 \text { to SB 8) }}$}

Stratal characteristics. Third-order Sequences 10 and 9 (lower and middle Miocene) extend from SB 10 near the base of the study interval to SB 8, just above the regional Amphistegina "B" biozone (figs. 20, 21). The sequences are comparable in thickness, ranging between $\sim 1,600$ and 1,800 ft. Both sequences are characterized by thick (as much as $\sim 1,100 \mathrm{ft}$ ) shale-dominated sections in their lower parts. These thick basal shales contain periodic, interbedded shaly sandstones within thin zones of several tens of feet that exhibit both upward-fining and upwardcoarsening trends. The basal contact of Sequence 10 differs from that of Sequence 9 by exhibiting thick (each as much as $\sim 250 \mathrm{ft}$ ) single or multiple, blocky-serrate, aggradational sandstone units that record little or no incision (fig. 20, 15,700-15,900 ft in Texaco No. 3).

In both sequences, the thick shale interval is overlain by a series of interstratified upward-coarsening, progradational shale-and-sandstone units, totaling $\sim 580$ to $770 \mathrm{ft}$, with each unit as much as $\sim 200 \mathrm{ft}$ thick. Thin (as much as $\sim 40 \mathrm{ft}$ ), typically poorly developed retrogradational sections overlie the progradational units. These progradational/retrogradational pairs stack to form a progradational set characterized by a general upsection trend of coarsening sandstones (the "Robulus 'L' sands" of Texaco) within the pairs (fig. 20, 14,200-14,930 ft in Texaco No. 3; fig. 21, 12,780-13,500 ft in Texaco No. 4). Hart and others (1989) also recognized this overall regressive trend from paleoecologic data. Unlike Sequence 10, Sequence 9 contains blocky, blocky-serrate, and, more rarely, upward-fining aggradational sandstone units as thick $\sim 120 \mathrm{ft}$ (fig. 21, 13,000 ft) within this progradational set. These units have sharp erosional bases that incise correlated shale marker beds.

Also in contrast to Sequence 10, the upper part of Sequence 9 comprises a second progradational set of stacked upward-coarsening units (fig. 21, 12,330-12,820 ft in Texaco No. 17). A thin ( 10-50 ft) retrogradational interval overlies each upward-coarsening unit. The set ranges from 400 to $500 \mathrm{ft}$ in thickness, with each unit ranging from $\sim 60$ to $160 \mathrm{ft}$ in thickness. The upper progradational units of both progradational sets within the two sequences are capped by thin (as much as $\sim 25 \mathrm{ft}$ ), but locally well developed, sandstones above dominant shale, or they occur as gradually upward coarsening, sandstone-dominated units (fig. 20, particularly at $\sim 14,300-14,440 \mathrm{ft}$ in Texaco No. 3; fig. 21, at $\sim 12,780-12,920 \mathrm{ft}$ in Texaco No. 9).

Systems tracts. All of third-order distal Sequence 10 and the lower two-thirds of Sequence 9 represent thirdorder lowstand prograding complexes and slope-fan complexes. Basin-floor-fan sandstones also occur at the base of Sequence 10. Well log expressions of these lowstand divisions conform to those described in Mitchum and others $(1990,1993)$. Benthic paleofauna indicate that the third-order LST's in the two sequences represent overall upwardshallowing successions that range from basin-floor and lower and upper slope (upper bathyal) deposits at the base to inner-shelf (marginal marine to middle neritic) facies at the top (figs. 17, 20, 21). The third-order sequence boundary of the Sequence 10 prograding complex (fig. 20, at $\sim 15,760 \mathrm{ft}$ in Texaco No. 4 and $\sim 15,890 \mathrm{ft}$ in Texaco No. 3) coincides with the base of a thick, blocky-serrate, basin-floor-fan sandstone deposited in an upper bathyal environment. The base of another well-developed basin-floor-fan sandstone 150-200 ft below SB 10 (fig. 20, at $\sim 16,150 \mathrm{ft}$ in Texaco No. 3) in a few deep wells may represent another third-order sequence boundary near the 


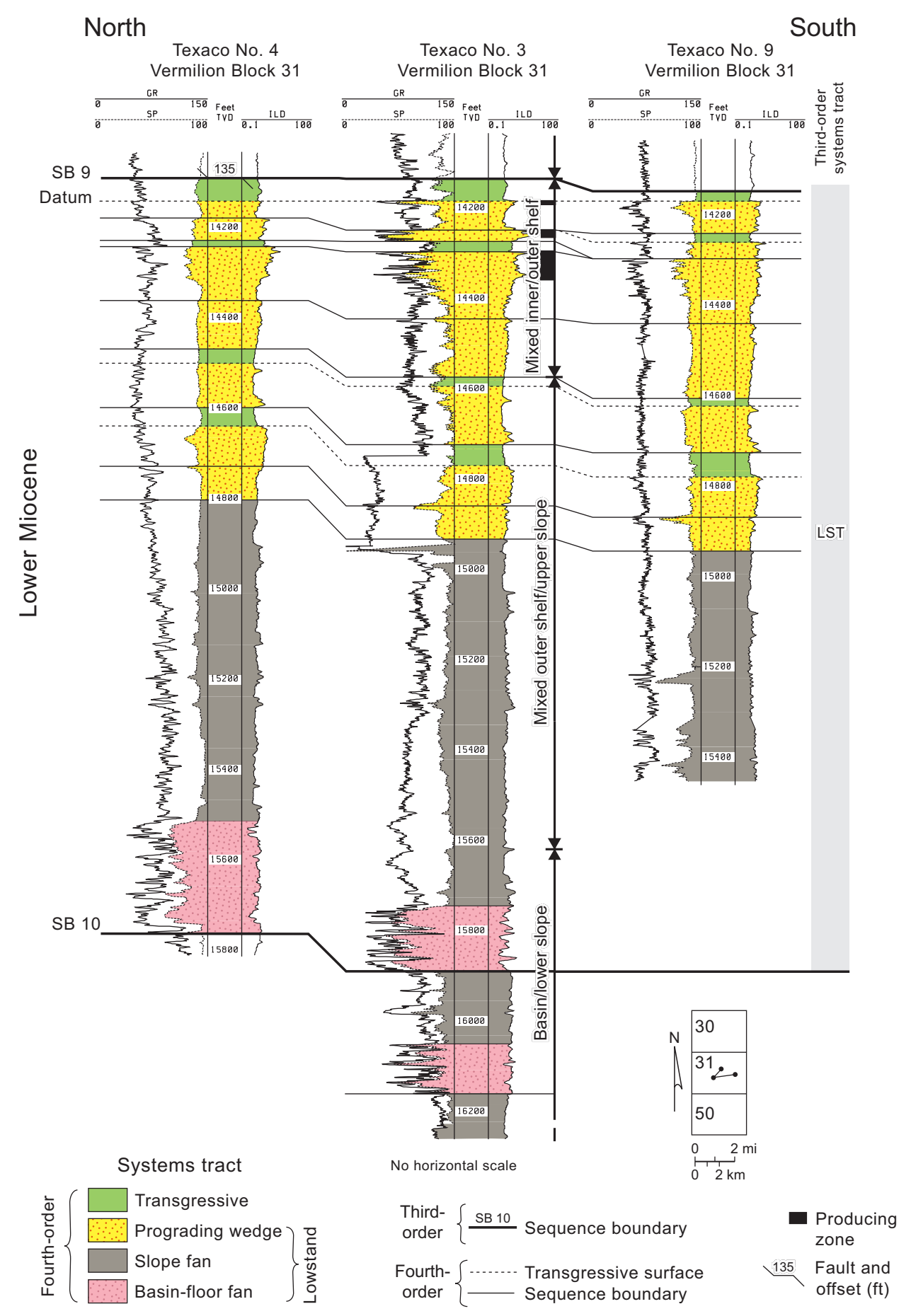

QAc9199(nc)c

Figure 20. Dip cross section of distal third-order Sequence 10 (lower Miocene), Starfak field, representing the most distal of third-order systems tracts. Third-order transgressive and highstand shales probably exist in uppermost Sequence 10; however, consistent well-to-well log patterns identifying these deposits are not evident. Fourth-order prograding-wedge sandstones compose the hydrocarbon reservoirs. Only three wells penetrate this deep zone in Tiger Shoal field because prospective prograding-wedge sandstones are poorly developed there. In the thick shale intervals, grain-size trends are best recorded by the deep induction log (ILD). Because of caving of shales in the borehole, the gamma-ray log is an unreliable record of lithology in these deep zones. Paleobathymetric interpretations are based on benthic fossil assemblages: basin and slope $=$ upper bathyal, outer shelf $=$ outer neritic, and inner shelf $=$ middle neritic to marginal marine (table 3$)$. 


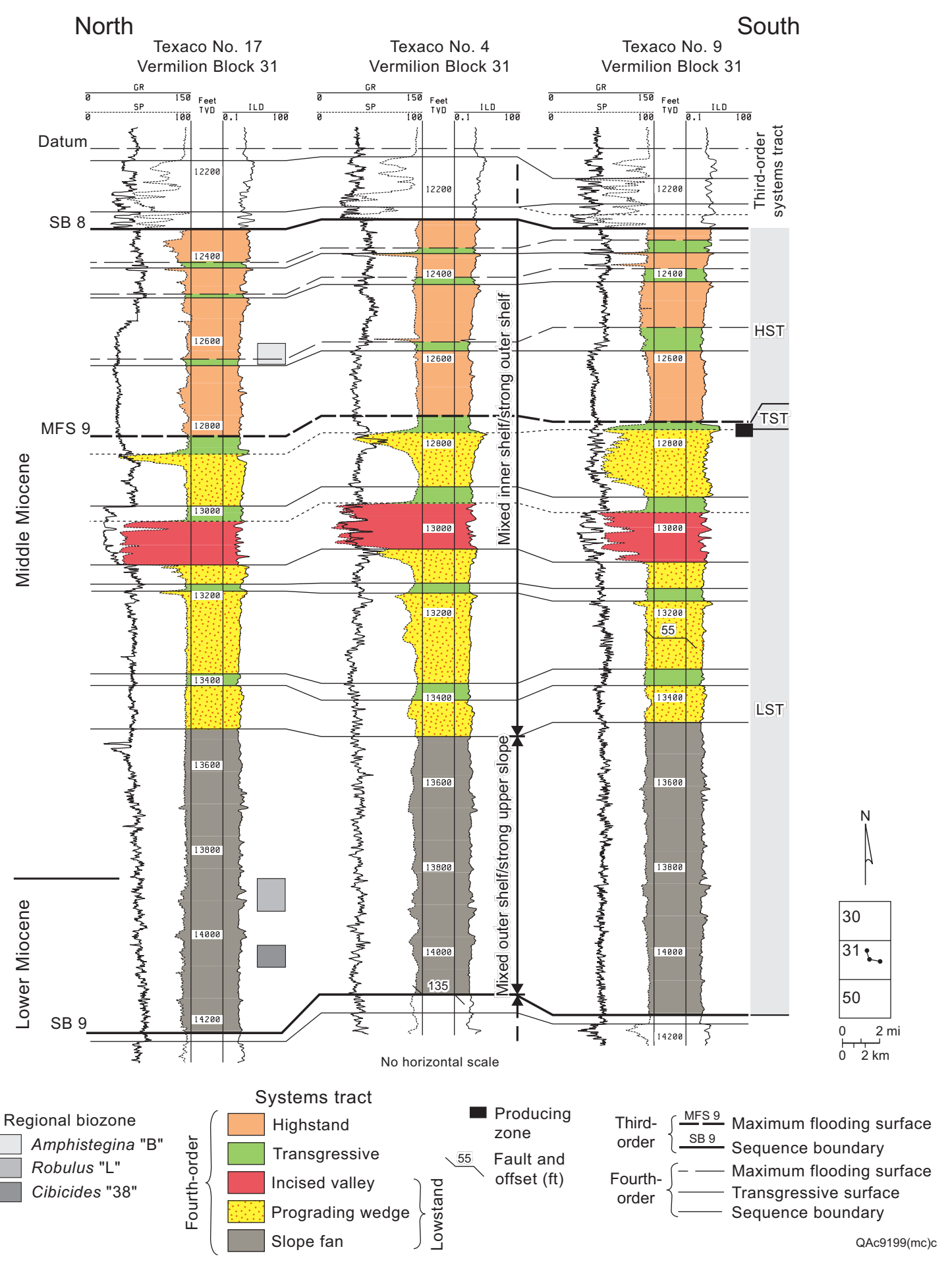

Figure 21. Dip cross section of distal third-order Sequence 9 (lower and middle Miocene), Starfak field. Producing zones occur in fourth-order prograding-wedge and incised-valley-fill sandstones of the third-order LST. Biozone "boxes" record vertical variance for the top of each zone among the wells with fossil data. Paleobathymetric interpretations are based on benthic fossil assemblages: upper slope $=$ upper bathyal, outer shelf $=$ outer neritic, and inner shelf $=$ middle neritic to marginal marine $($ table 3$)$. 
distal margin of an older fan deposit (see figure 19 for schematic representation of possible vertical relation). Fourth-order sequence boundaries of the Sequence 10 prograding complex coincide with the bases of upwardcoarsening prograding-wedge sandstone/shale units (top of sequence) deposited in marginal-marine to middle/outerneritic environments. Hart and others (1989) noted a mix of terrestrial, estuarine, and marine palynomorphs in whole cores from two of the fourth-order prograding wedges in Sequence 10 (basal wedge and fourth wedge from the base in figure 20). They interpreted the depositional setting of the sandstones as outer-neritic shelf, possibly storm or deltaic deposits, but inferred no sequence-stratigraphic context. An internal Texaco report of the lower core from the same well ascribed a similar depositional/paleobathymetric setting. A deltaic setting is reasonable, but the progradational unit represents a range of marginal-marine (sandy top) to possible middle neritic (shaly base) water depths. Seismic imaging of the sandier upper parts of the prograding complexes in distal and medial sequences by amplitude stratal slicing (Zeng and others, 2001a) shows that fourth-order wedges are as much as 9 mi in strike width and $>3 \mathrm{mi}$ in the dip dimension (fig. 22). Third-order prograding complexes (sequence sets) are only marginally wider along depositional strike (as much as $\sim 12 \mathrm{mi}$ ), indicating focused lowstand deltaic deposition within the third-order (1.1 m.y.) time frame. These dimensions contrast markedly with the much greater areal dimensions of the highstand deltas (discussed in "Medial Sequences").

The thick shale intervals in the lower parts of Sequences 10 and 9 represent outer-neritic to upper bathyal (fig. 17) slope-fan deposits. Sandy zones within them probably record midslope turbidites and shingled turbidite channel/levee deposits that mark fourth-order clinoform toes (Erskine and Vail, 1988) or fourth-order basin-floor fans (Mitchum and others, 1993). Fourth-order sequence boundaries could not be systematically correlated through the slope-fan deposits where consistently occurring progradational intervals are not well defined. Mitchum and Van Wagoner (1990) proposed that sequence boundaries are not easily recognized in third-order slope fans because they have no shallow-marine equivalents. The Sequence 9 third-order LST contains inferred incised-valley fills (blocky sandstones) and generally better developed prograding-wedge sandstones in the upper part (figs. 21, 22), and no basin-floor fans at the base. Moreover, unlike Sequence 10, the upper third of Sequence 9 comprises a welldeveloped sequence set of fourth-order highstand (HST) and transgressive (TST) systems tracts that represents the third-order HST, which was deposited in marginal-marine to outer neritic water depths. These features all suggest a more proximal position for Sequence 9 relative to that of Sequence 10.

The inferred third-order TST and maximum flooding surface (MFS) of Sequence 9, which coincides with a major faunal flood (fig. 18), immediately overlies the third-order LST (fig. 21). Relative to the third-order TST's of most overlying, more proximal sequences, this TST is thin (as much as $40 \mathrm{ft}$ ) because of its distal position. Although distal, shaly TST and HST deposits probably overlie the lowstand prograding complex of Sequence 10 (near SB 9), they could not be identified clearly from the well log expression.

\section{Medial Sequences (SB 8 to SB 4)}

Stratal characteristics. Medial third-order Sequences 8 through 5 (middle to upper Miocene, SB 8 to SB 4), which extend from $\sim 300 \mathrm{ft}$ above the regional Amphistegina "B" biozone to $\sim 75 \mathrm{ft}$ above the Cibicides inflata biozone (figs. 23-26), differ from the distal sequences in several ways. Unlike those of the distal successions, the 

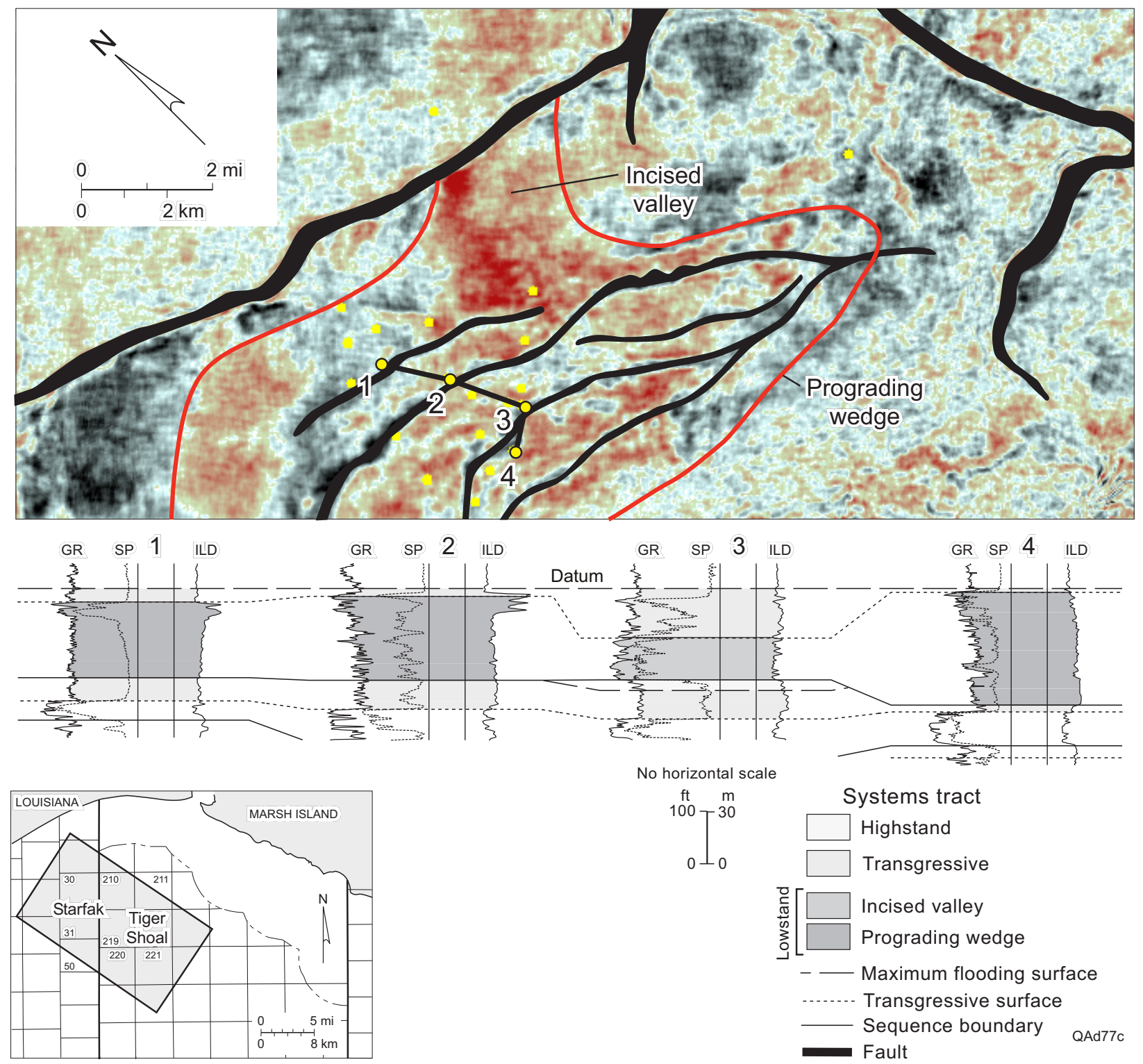

No horizontal scale

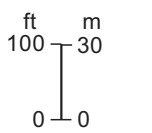

Systems tract
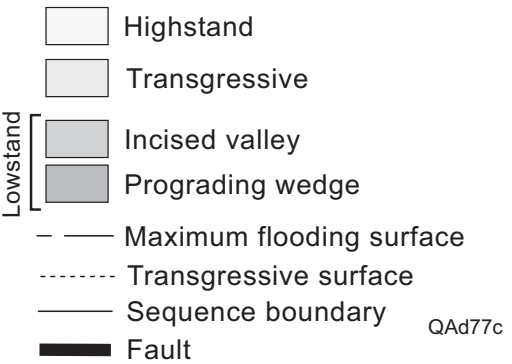

Figure 22. Amplitude stratal slice and well log expression of the uppermost fourth-order prograding wedge in Sequence 9 (fig. 21). Well 1 captures the log expression of the margin of the wedge, whereas wells 2 and 4 exhibit the sandier accumulations within the central portion. Well 3 probably represents fluvial deposition within an incised valley (sharp-based, blocky-serrate sandstone) concurrent with wedge progradation, followed by estuarine and bayhead delta (retrogradational middle portion and upper progradational sandstone, respectively) deposition. Imaging of the distal parts of most wedges is limited by the southwestern boundary of the 3-D seismic data volume. Relief on the first-order growth fault just north of the wedge probably formed the exposed shelf edge below which relative sea level fell during lowstand deltaic deposition. 


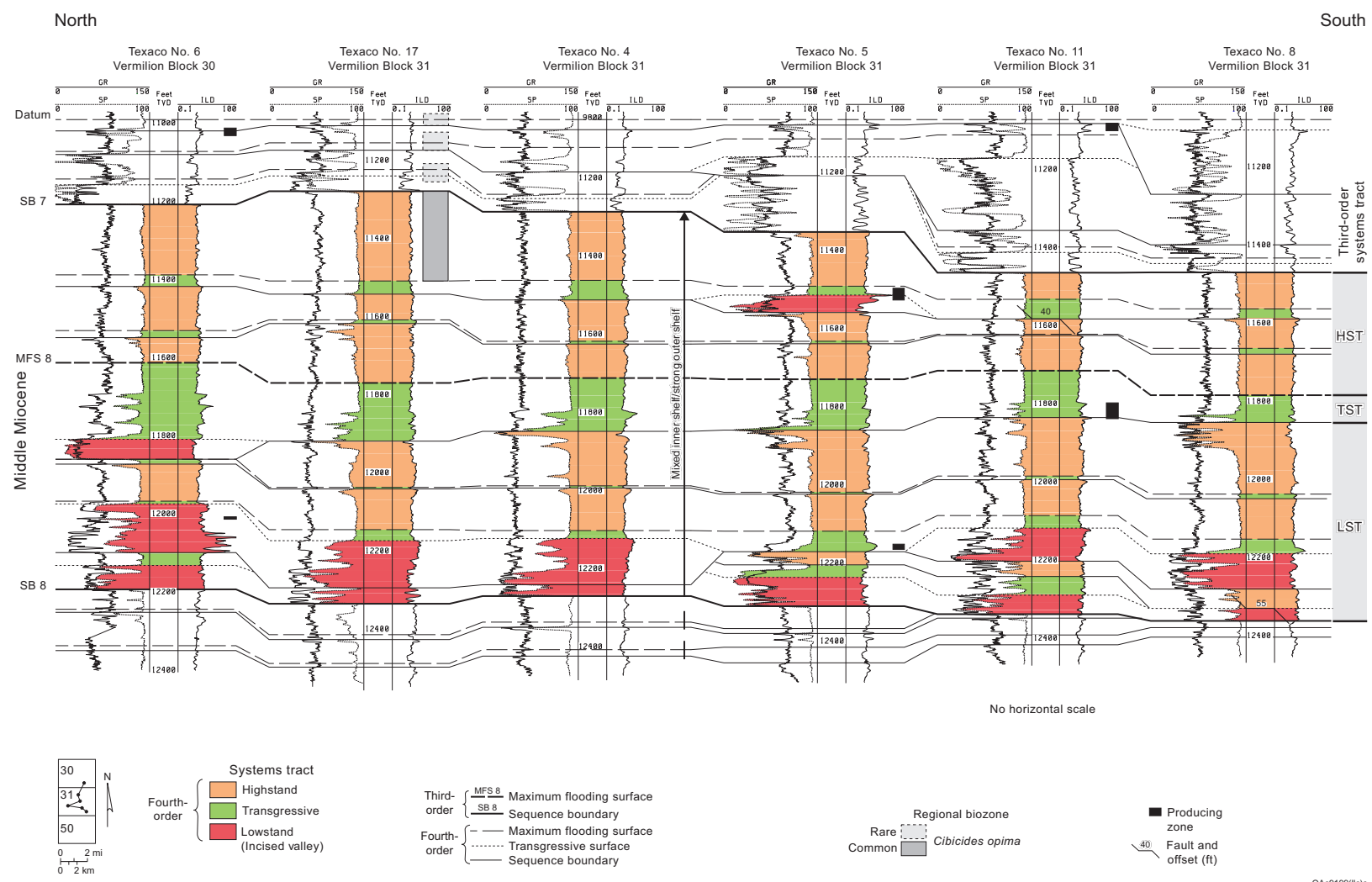

Figure 23. Dip cross section of medial third-order Sequence 8 (middle Miocene), Starfak field. Fourth-order incisedvalley systems in the third-order LST can be correlated to prograding wedges in wells downdip of, and lateral to, those shown in this cross section. Fourth-order incised-valley-fill, transgressive, and highstand deltaic/strandplain sandstones, mostly in the third-order LST produce hydrocarbons. Biozone "boxes" record vertical variance for the top of each zone among the wells with fossil data. Paleobathymetric interpretations are based on benthic fossil assemblages: outer shelf $=$ outer neritic, and inner shelf $=$ middle neritic to marginal marine (table 3 ). 


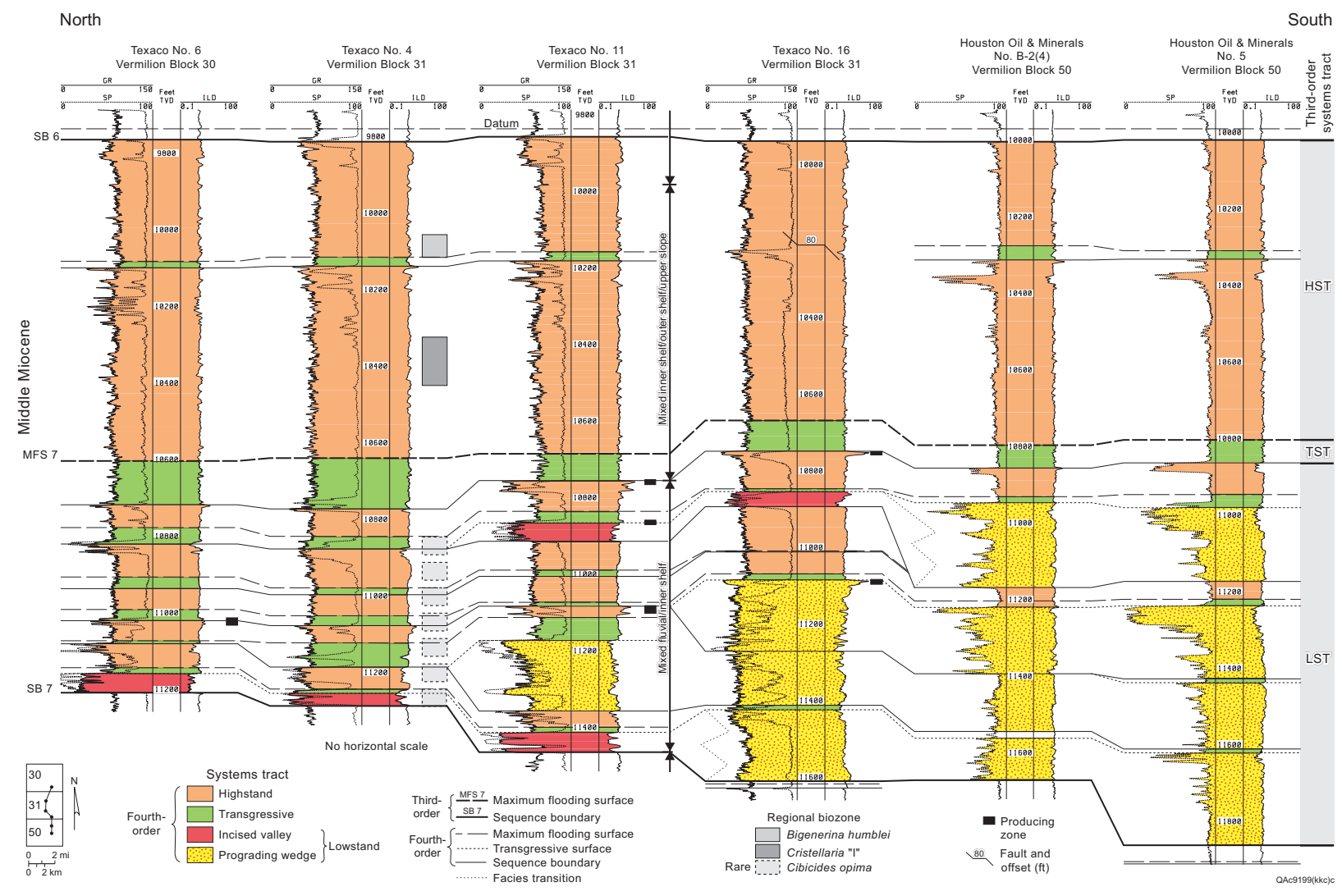

Figure 24. Dip cross section of medial third-order Sequence 7 (middle Miocene), Starfak field. The third-order TST and basal HST record the basinwide Cristellaria "I" transgression event. The lower fourth-order HST of the thirdorder HST may contain additional fourth-order sequences. Fourth-order prograding-wedge, highstand deltaic/strandplain, and transgressive sandstones in the third-order LST compose the hydrocarbon reservoirs. Biozone "boxes" record vertical variance for the top of each zone among the wells with fossil data.

Paleobathymetric interpretations are based on benthic fossil assemblages: upper slope $=$ upper bathyal, outer shelf $=$ outer neritic, and inner shelf $=$ middle neritic to marginal marine (table 3$)$. 


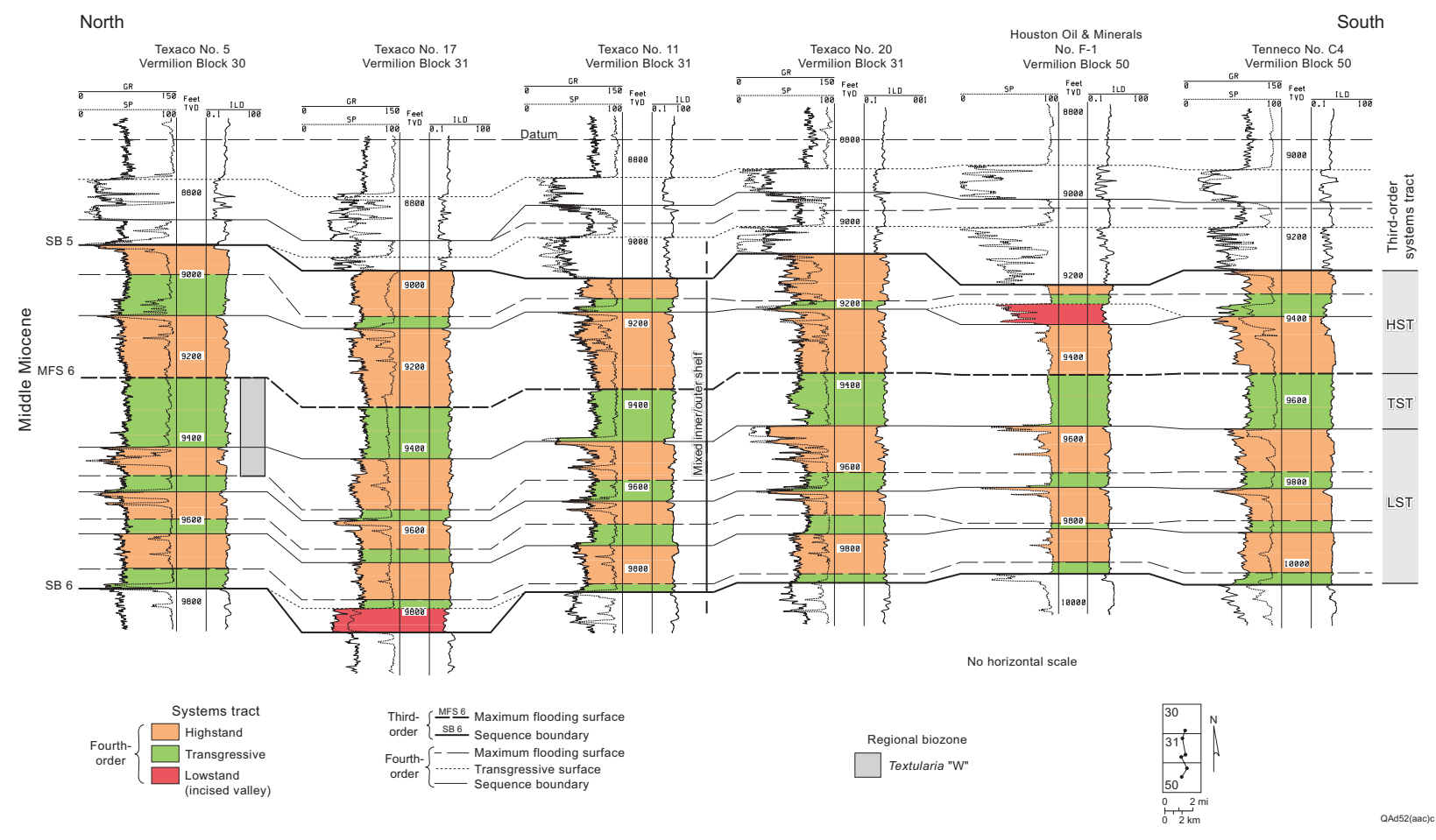

Figure 25. Dip cross section of medial third-order Sequence 6 (middle Miocene), Starfak field. Biozone "box" records vertical variance for the top of the zone among the wells with fossil data. Paleobathymetric interpretations are based on benthic fossil assemblages: outer shelf $=$ outer neritic, and inner shelf $=$ middle neritic to marginal marine (table 3). 


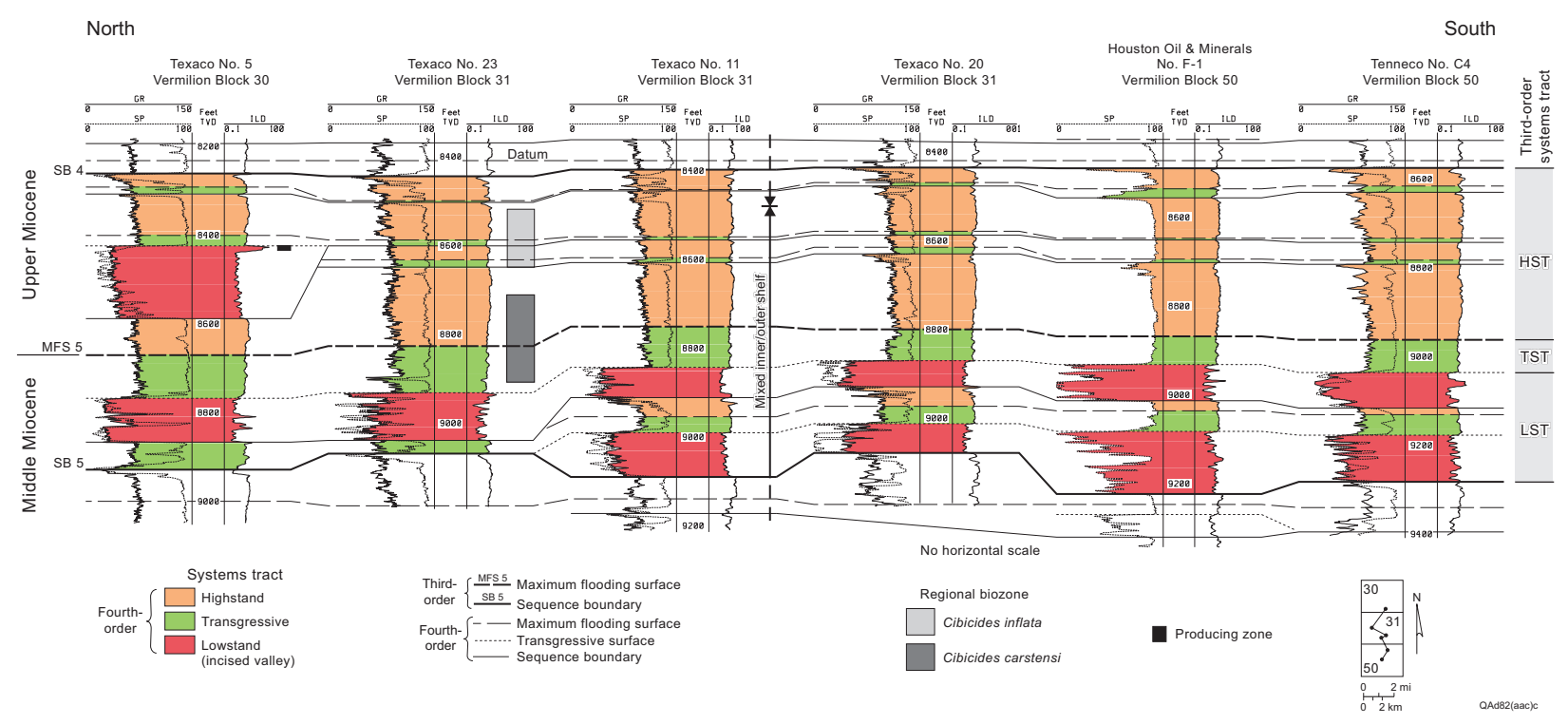

Figure 26. Dip cross section of medial third-order Sequence 5 (middle and upper Miocene), Starfak field. The lower two incised valleys in the third-order LST are parts of the most extensive valley systems in the study area. Biozone "boxes" record vertical variance for the top of each zone among the wells with fossil data. Paleobathymetric interpretations are based on benthic fossil assemblages: outer shelf $=$ outer neritic, and inner shelf $=$ middle neritic to marginal marine (table 3). 
basal third-order sequence boundaries of the medial sequences are locally marked by pronounced erosional contacts overlain by sharp-based, blocky, blocky-serrate, and upward-fining (aggradational) sandstone units ( 40-250 ft thick). In other areas, the basal contacts are conformable, correlating from erosional bases of the sandstone units to the tops of upward-coarsening progradational units. In the lower two medial sequences, erosional contacts also correlate with conformable to slightly erosional bases of thick (as much as $\sim 250 \mathrm{ft}$ ), typically upward coarsening intervals that attain comparable thicknesses (fig. 24, e.g., 11,000-11,850 ft in Houston Oil \& Minerals No. 5). These progradational intervals are restricted to the downdip portion of the area of well control, and their occurrence coincides with marked thickening of the third-order sequence. They differ from the progradational units in the updip areas by being thicker and containing a higher percentage of sandstone, typically composing gradually upward coarsening, sandstone-dominated units with no prominent shale base. In marked contrast to the distal sequences, a thick basal upper-bathyal to outer-neritic shale is not present in the medial sequences.

Each of the medial sequences, which range from 600 to 1,800 ft in thickness, comprises three distinct stratigraphic divisions: (1) a lower succession of two to five aggradational ( 40-250 ft thick) or progradational ( 50-180 ft thick) units; (2) an atypically thick ( 70-190 ft), upward-fining, retrogradational, shale-dominated section in the middle; and (3) an upper section of typically two to four (50-500 ft thick) mostly progradational units of thicker shales and sandstones. Progradational and aggradational units in the lower and upper divisions are interstratified with thinner ( 15-50 ft) shaly retrogradational intervals. Erosionally based blocky, blocky-serrate, and upward-fining sandstone units are more common in the lower succession, whereas upward-coarsening sandstone/shale units dominate the upper division. In the upper division, the progradational/retrogradational pairs stack to form a progradational set characterized by a general upsection trend of increasing sandstone grain size, bed thickness, and number of sandstone beds within the pairs. The middle retrogradational unit only rarely contains sandstone beds, which primarily occur in wells from the updip (northern) parts of the sequences (fig. 23, unit below MFS 8).

Systems tracts. The lower, middle, and upper stratigraphic divisions of the medial sequences represent thirdorder LST's, TST's, and HST's, respectively, that accumulated in upper-slope/outer-shelf to fluvial environments in marine water depths that ranged from upper bathyal to marginal marine, as indicated by fossil data (figs. 17, 23-26). Two to five relatively thin ( 75-100 ft) closely spaced fourth-order sequences form the LST. The third-order LST is overlain by the third-order TST, an atypically thick, shale-dominated retrogradational interval. The upper division, two to four fourth-order HST's (locally incised by valley fills and interstratified with thin TST's) composing a progradational sequence set, forms the third-order HST.

The third-order LST's in lower two medial Sequences 8 and 7 record the transition from upper-slope, proximal portions of fourth-order prograding wedges (downdip) to the on-shelf portions of fourth-order HST deposits locally incised by valley fills that are equivalent to the wedges (updip). This transition is captured in Sequences 7 (figs. 24 27 ) and 8 , although it is present in Sequence 8 in wells downdip of, and lateral to, those shown in figure 23. These third-order proximal prograding complexes represent a continuation of the overall upsection offlapping trend beginning with the distalmost LST deposits of Sequence 10. 

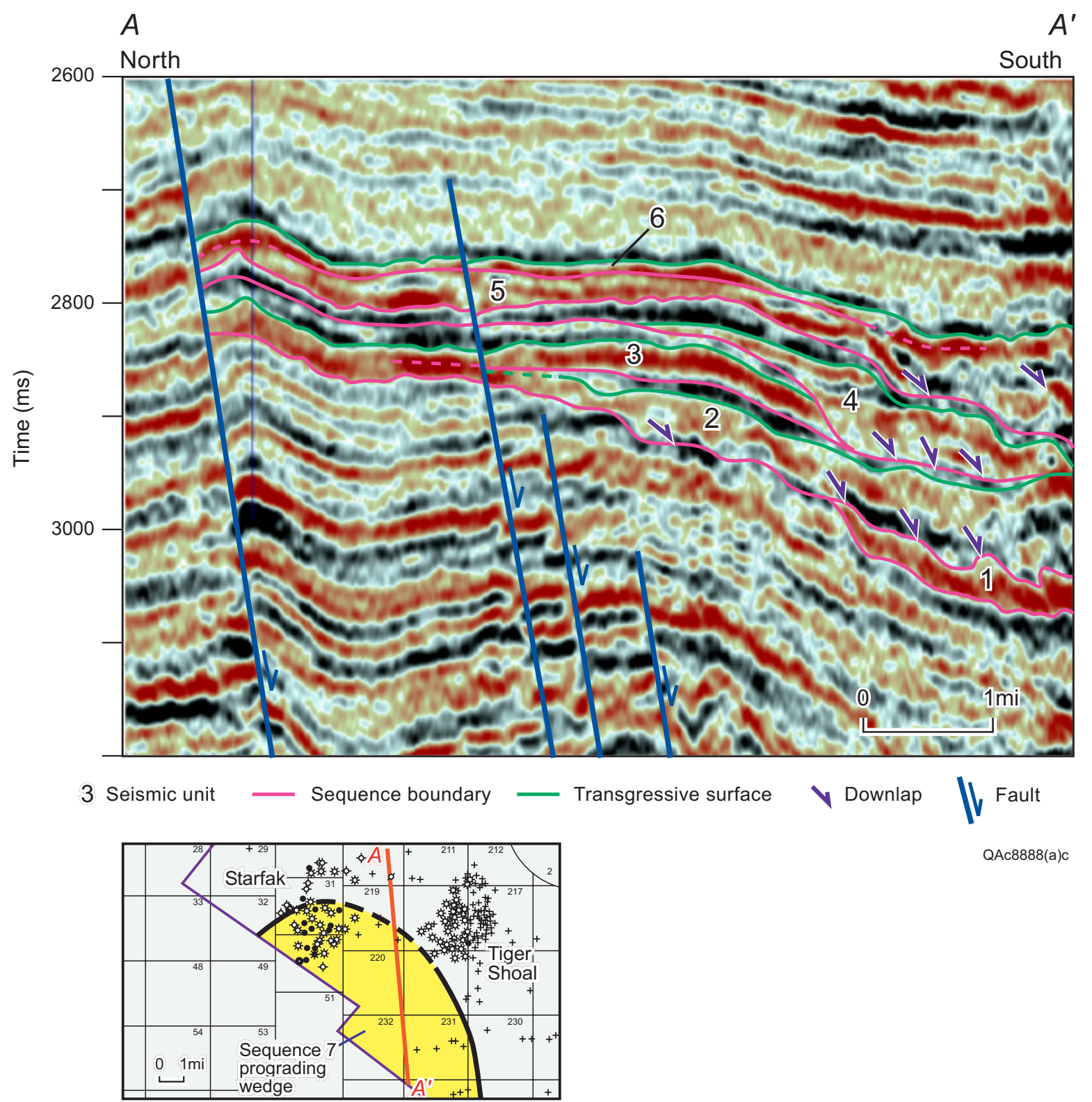

QAc8888(a)c

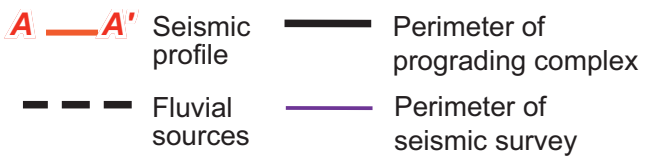

Figure 27. Depositional-dip-oriented seismic profile of the third-order prograding complex in Sequence 7 (fig. 24). Seismic line depicts the wedge complex in an area near the southernmost limit of seismic coverage, therefore showing the most distal extent of the wedge that can be viewed. Seismic units 6, 5, and 4 correspond to the upper three fourth-order sequences defined in the area of well control. However, the seismic stratigraphy of seismic unit 3 is more complex; well log correlation with the seismic indicates that unit 3 comprises the basal two fourth-order sequences in the area of well control. Seismic units 1 and 2 were deposited south and southeast of well control and represent coastally onlapping fourth-order prograding wedges. Third-order SB 7 at the base of the wedge complex was a major sediment-bypass surface across which the sediments in seismic units 1 and 2 were transported. 
In the third-order LST's and much less commonly in the third-order HST's, fourth-order blocky, blocky-serrate, and upward-fining sandstone units record lowstand incised-valley-fill aggradation. They are thickest (as much as $\sim 250 \mathrm{ft}$ ) at the valley-to-wedge transition (fig. 28a), locally incising most or all of the underlying HST (fig. 28). In this transitional zone, the log facies of fourth-order incised-valley sandstones locally depict an aggradational pattern at the base of the unit and a progradational $\log$ trend at the top (e.g., at 11,200 ft in Texaco No. 16 [figs. 22, 24, well 3). These log characteristics suggest fluvial deposition within an incised valley concurrent with wedge progradation, followed by deposition of a sandy bayhead delta during the subsequent transgressive phase. Because of the general difficulty of systematically correlating inferred thin bayhead-delta deposits within individual valley fills, no attempt was made at precise correlation of these facies to differentiate true LST strata from overlying TST sediments in valley fills. However, these upper progradational-sandstone units occur within correlated valley fills in updip wells, supporting inferred bayhead-delta deposition of the TST. Valley-fill channels ( 40-250 ft thick) range between $<0.5$ and $>5 \mathrm{mi}$ in width; one or both margins of the largest valleys cannot be resolved in the seismic volume, and maximum widths therefore cannot be measured. Incised valleys that have been mapped (fig. 29) and/or resolved seismically within the $352-\mathrm{mi}^{2}$ study area (fig. 30 ) commonly compose complex valley-axis systems that are probably widespread along exposure surfaces (sequence boundaries) across the Miocene shelf at the Central Mississippi and East Mississippi sediment-dispersal axes (sensu Galloway and others, 2000). This point is supported by Van Wagoner and others (1990, his figures 22 and 23), who correlated and mapped the distribution of an incisedvalley system (as much as $240 \mathrm{ft}$ thick), which is equivalent to, and updip ( $90 \mathrm{mi}$ northeast) of, a fourth-order valley system near the base of middle Miocene Sequence 7. Within an area of $\sim 1,900 \mathrm{mi}^{2}$ (about five times the size of the seismic area), they resolved a valley system that attains a maximum width of $>40$ mi and displays a complexity of merging valley axes comparable to that in the study area.

The areal dimensions of fourth-order highstand deltas of the medial and proximal third-order sequences (fig. 31) contrast sharply with those of the more areally restricted depocenters of the lowstand deltas (fig. 22). Whereas the perimeters of some lowstand deltas can be resolved in the 352- $\mathrm{mi}^{2}$ study area, the geographic expanse of highstand deltas of third-order LST's and HST's greatly exceeds that of the study area. Typically only one or two distributary lobes of an HST delta can be resolved in stratal slices (fig. 31), even fewer in maps of the areas of well control. The smaller areal dimensions of the lowstand deltas are consistent with more focused sedimentation via the funneling effect of feeder incised valleys (Posamentier and Vail, 1988).

The third-order TST's in the medial sequences are thicker and more easily resolved on well logs than those of the distal sequences. In depositional-dip profile, the TST's decrease in thickness and contain fewer progradational sandstones (of very thin fourth-order systems tracts) distally over a distance of 2 to $4 \mathrm{mi}$ (best shown in fig. 23), reflecting retrogradation and increasing distance from sediment-source areas. Four of the five third-order MFS's in the medial sequences coincide with major faunal floods (fig. 18) recorded in the associated marine condensed sections. The exception, the MFS of Sequence 8, occurs at the base of a broad faunal peak. 

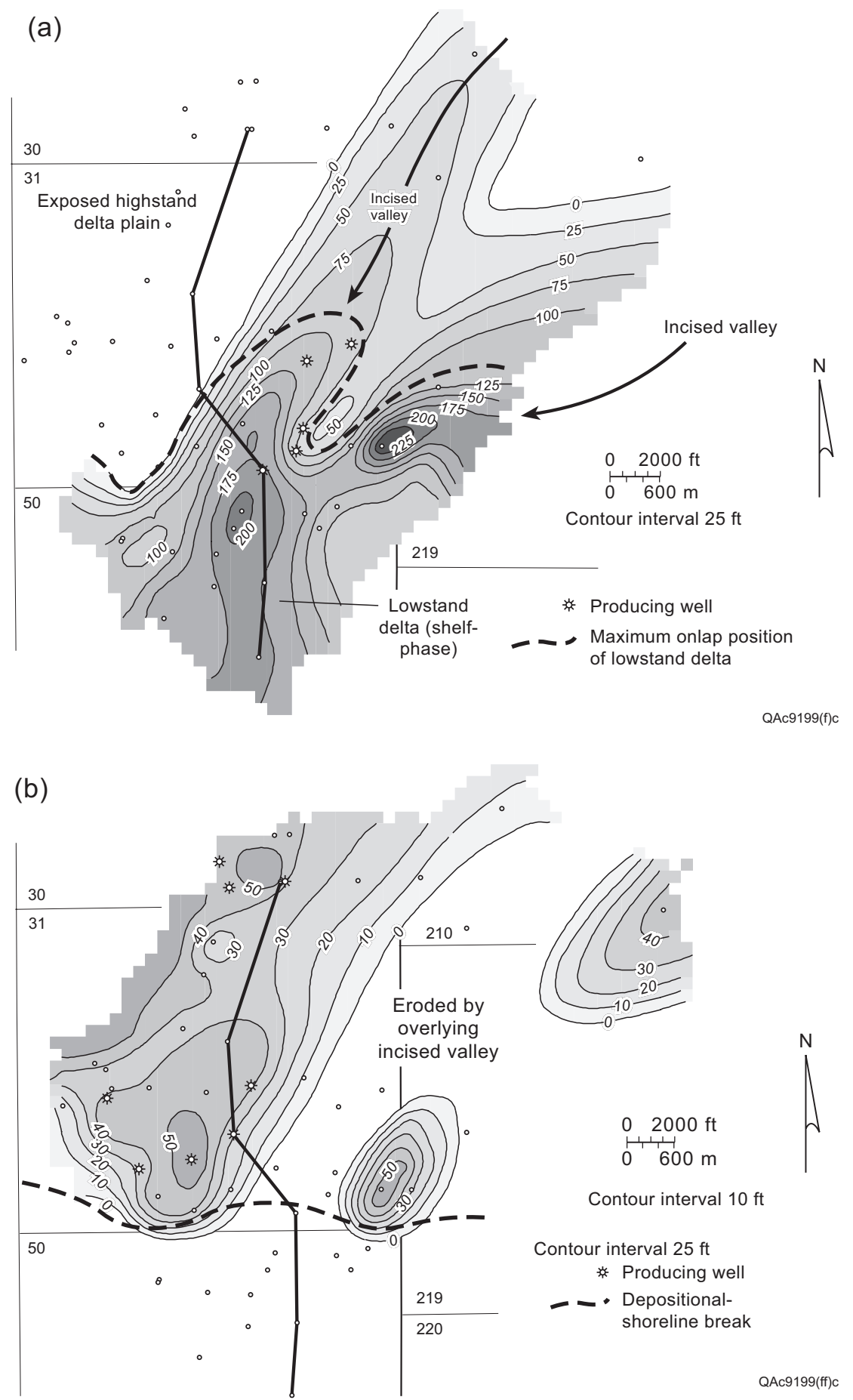

Figure 28. (a) Isochore map of the incised-valley-to-prograding-wedge transition in the third fourth-order sequence from the bottom of third-order Sequence 7 (fig. 24), middle Miocene, Starfak field. Only the most proximal portion of the prograding wedge has been drilled. (b) Isochore map of the fourth-order HST that directly underlies, and was partially incised by, the valley/wedge complex shown in a. There is no evidence of fault control of a shelf break, in contrast to the structural control on Sequence 9 wedge deposition (fig. 22). Instead, this shelf-phase lowstand delta formed basinward of the depositional-shoreline break of the underlying highstand delta platform. Line of section is that of figure 24. Both systems tracts contain productive sandstones; petrophysical and engineering analysis suggests that sandstones of the two systems tracts form separate reservoir compartments. 


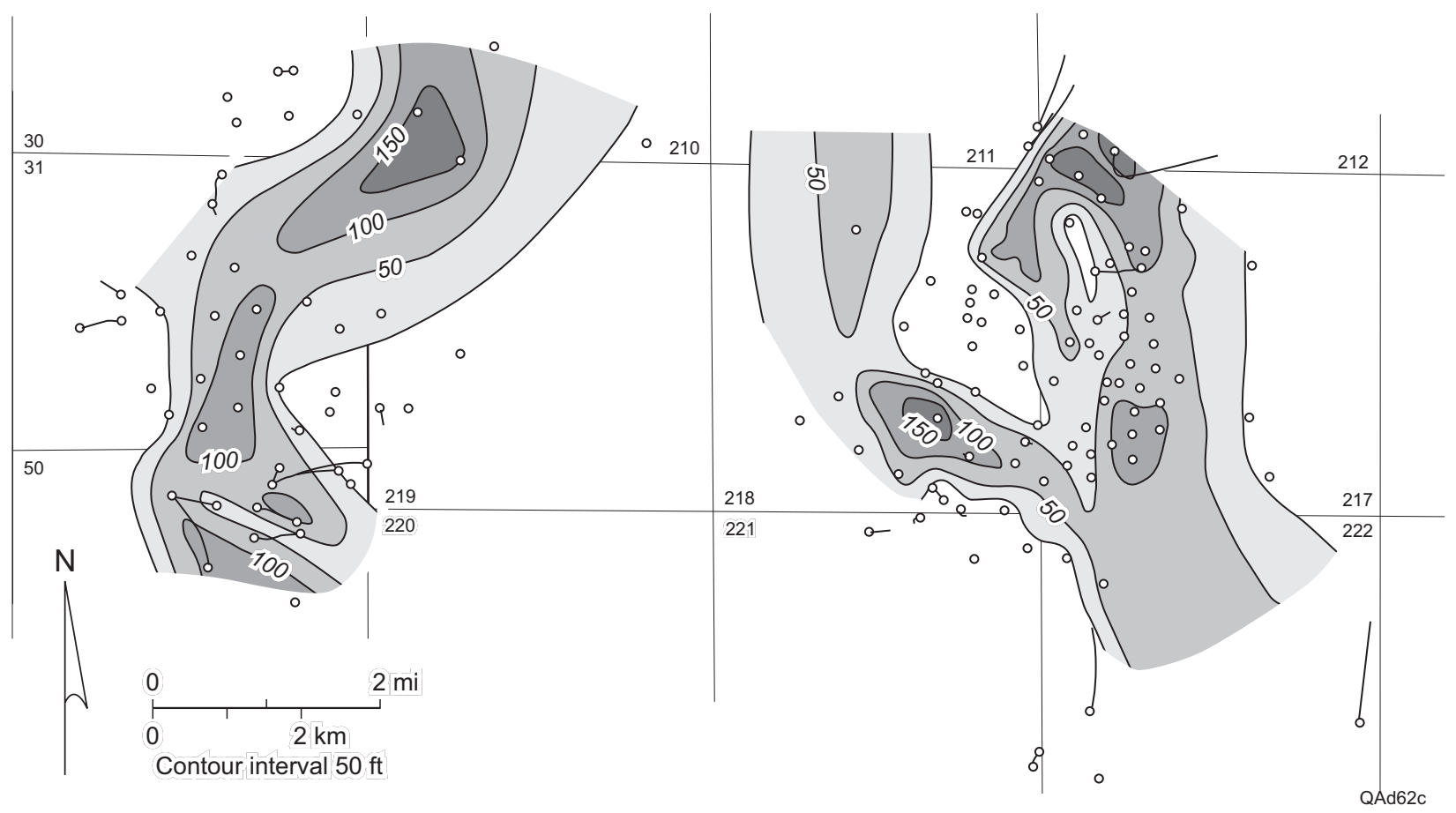

Figure 29. Isochore map of the incised-valley system at the base of third-order Sequence 5 (fig. 26), middle Miocene, Starfak (west) and Tiger Shoal (east) fields. Fault-controlled structural highs in Tiger Shoal field that currently contribute to hydrocarbon trapping also locally influenced the direction of channel pathways during incision and valley-fill aggradation. 

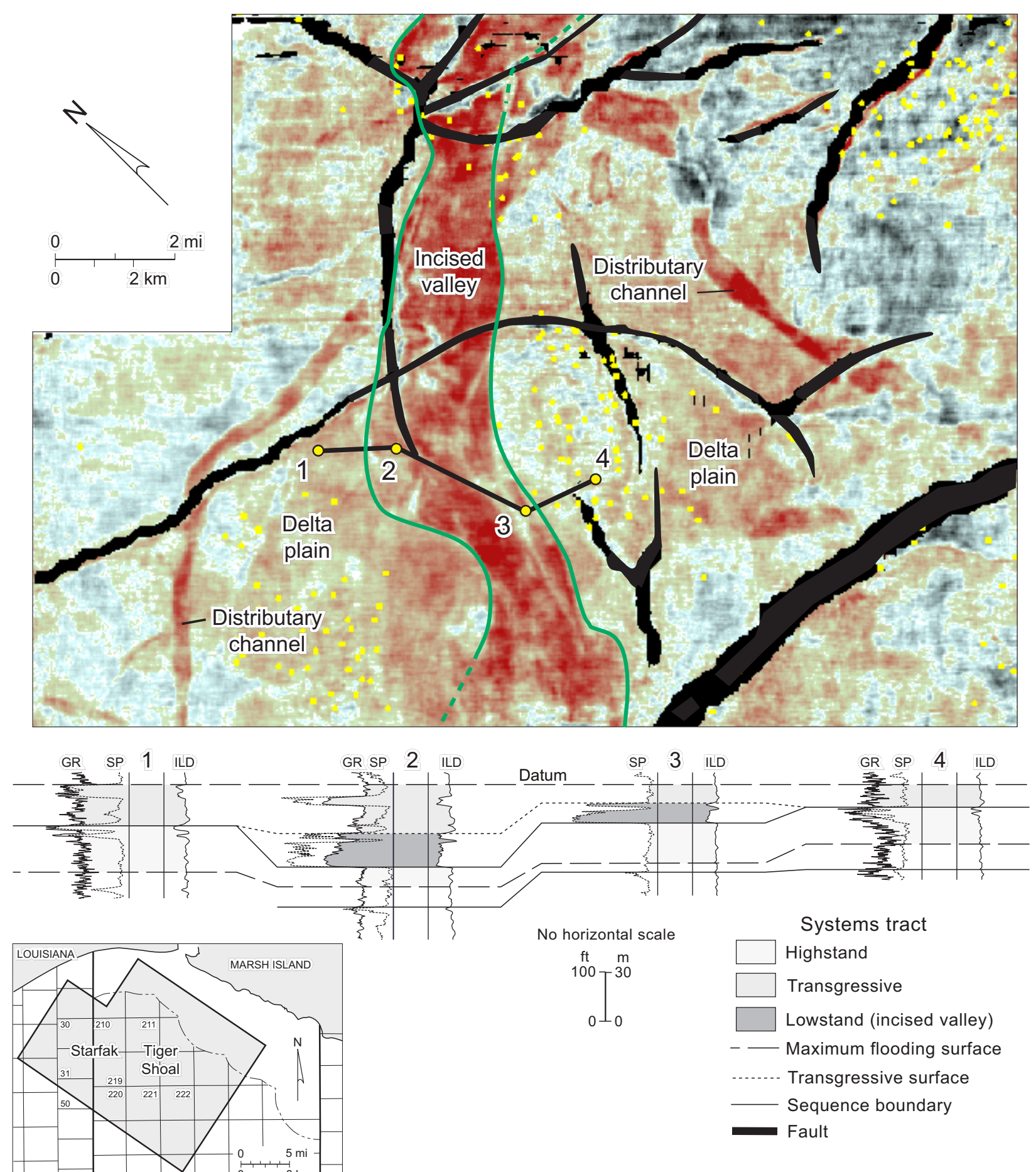

QAd75c

Figure 30. Representative amplitude stratal slices of lowstand incised-valley fills characteristic of the third-order medial and proximal sequences. (a) Amplitude stratal slice and well log expression of a valley fill incising highstand delta-plain deposits (lower part of third-order HST, Sequence 4 [fig. 32]). Note well-developed delta-plain sandstones below sequence boundary (exposure surface) equivalent to that below the valley fills (unconformity) in wells 1 and 4 of a, in contrast to the shaly interdeltaic deposits below the exposure surface in wells 1 and 4 in $b$. 


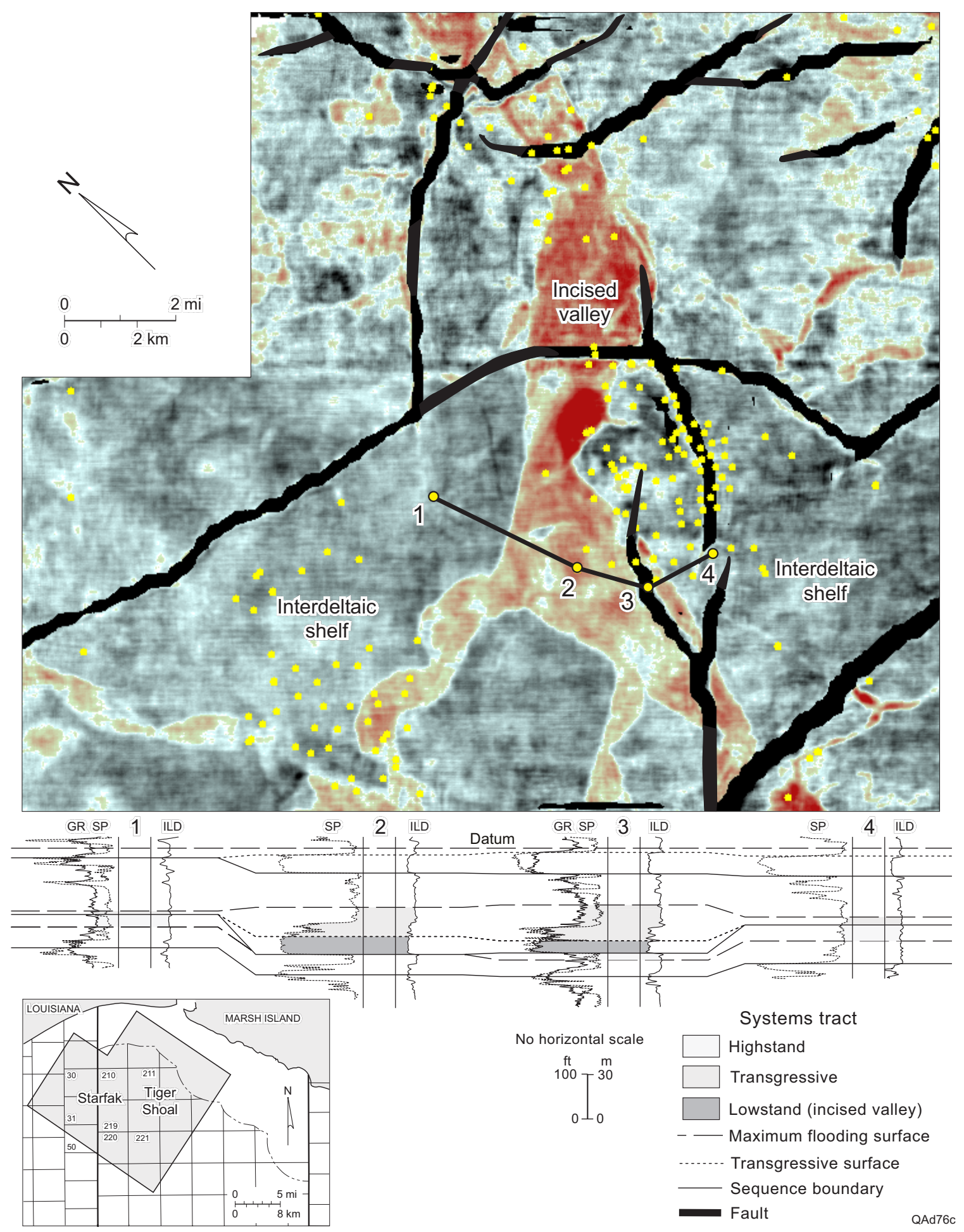

(b) Stratal slice and well log expression of a valley fill incising interdeltaic deposits (upper part of third-order LST, Sequence 2 [fig. 34]). Note well-developed delta-plain sandstones below sequence boundary (exposure surface) equivalent to that below the valley fills (unconformity) in wells 1 and 4 of a, in contrast to the shaly interdeltaic deposits below the exposure surface in wells 1 and 4 in b. 


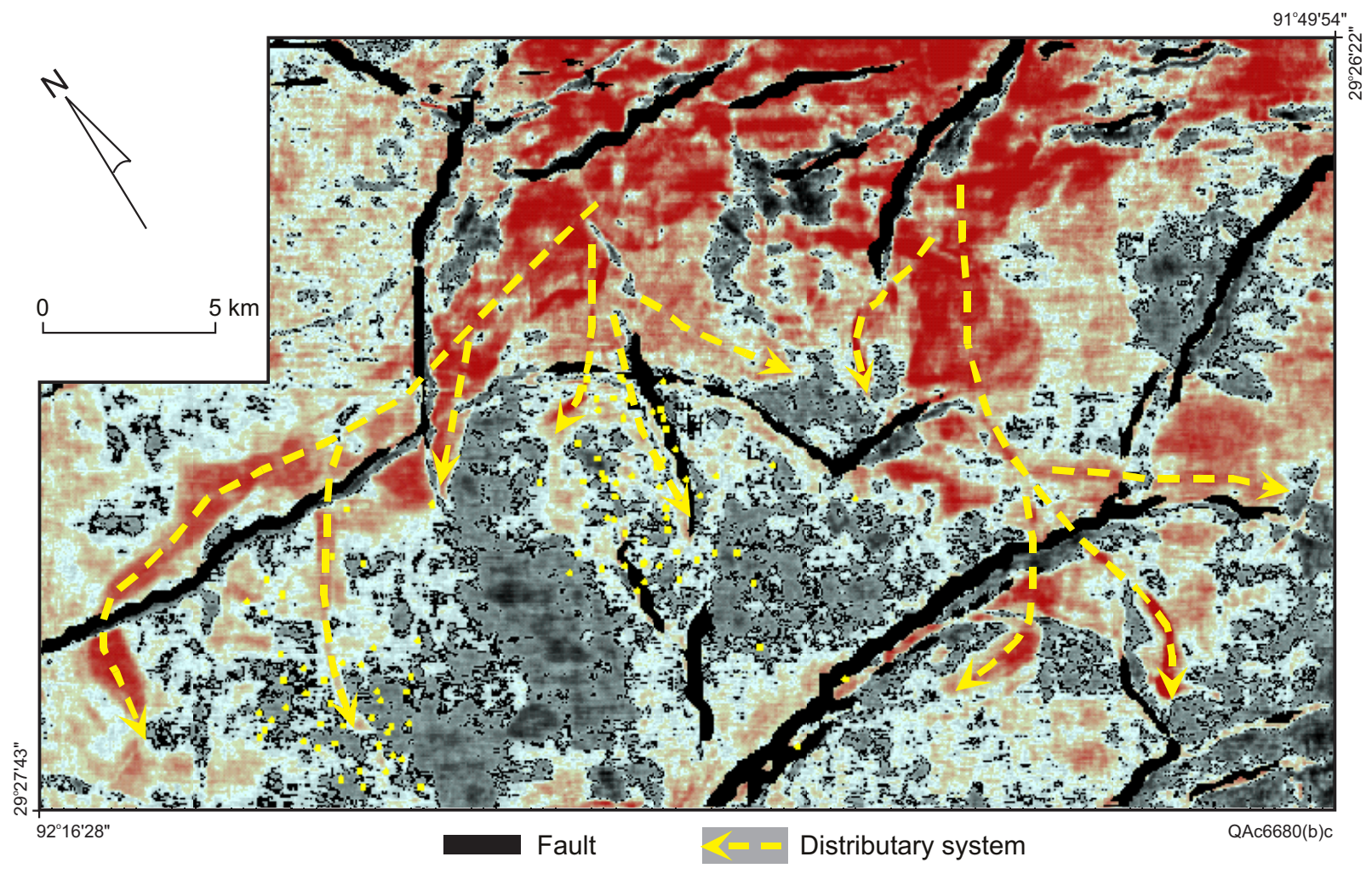

Figure 31. Representative amplitude stratal slice of part of a digitate highstand delta system (upper part of thirdorder HST, Sequence 4 [fig. 32]) characteristic of the third-order medial and proximal sequences. Note probable syndepositional fault control of the western distributary system. Area depicted is that of both seismic surveys shown in figure 6. 


\section{Proximal Sequences (SB 4 to SB 0)}

Stratal characteristics. Proximal third-order Sequences 4 through 1 (upper Miocene, SB 4 to SB 0) extend from $\sim 75 \mathrm{ft}$ above the Cibicides inflata regional biozone to $\sim 150 \mathrm{ft}$ above the Bigenerina "A" biozone (figs. 32-35). These proximal sequences are the thinnest of all 10 third-order sequences, ranging between $\sim 375$ and $700 \mathrm{ft}$ in thickness. Like the medial sequences, each of the proximal sequences comprises three stratigraphic divisions: (1) a lower succession of one to three aggradational ( 40-130 ft thick) or progradational ( 25-80 ft thick) units; (2) a locally thick ( 35-70 ft), upward-fining, retrogradational, shale-dominated section in the middle; and (3) an upper section of typically two to five ( $30-200 \mathrm{ft}$ thick) mostly progradational units of thicker shales and sandstones. Progradational and aggradational units in the lower and upper divisions are interstratified with thinner ( 10-70 ft) retrogradational intervals. However, the proximal sequences are differentiated from the medial ones by having a higher proportion of blocky and blocky-serrate aggradational sandstones and thinner progradational units that contain a higher percentage of sandstone. The retrogradational units in the lower and upper divisions also contain a higher percentage of sandstone than those in the medial sequences but are of comparable thickness.

Systems tracts. The lower, middle, and upper stratigraphic divisions of the proximal sequences represent thirdorder LST's, TST's, and HST's, respectively. These systems tracts accumulated in water environments shallower than those of the medial sequences: inner-shelf to fluvial settings in marine water depths that ranged from middle neritic to marginal marine, as indicated by fossil data (figs. 17, 32-35). One to three relatively thin ( 75-130 ft) closely spaced fourth-order sequences form the third-order LST. The third-order LST is overlain by the third-order TST. The upper division, two to five fourth-order HST's (locally incised by valley fills and interstratified with thin TST's) composing a progradational sequence set, forms the third-order HST. The more abundant valley-fill sandstone units commonly incise the separate progradational and retrogradational units that best define the cyclic stratal patterns within the third-order sequences, making the defining of these proximal third-order sequences more challenging, especially in Sequence 1 (fig. 35).

In the area of well log control and within the area of seismic coverage, the proximal sequences show minimal variation in overall thickness or stratal-stacking patterns ("railroad tracks" on seismic profiles). No lowstand prograding complexes can be resolved on either seismic or well logs in the downdip portions of the study area. In the lower Pliocene succession above Sequence 1, incised-valley sandstones compose an upward-increasing percentage of the section, grading to stacked fluvial channel fills and thin and volumetrically minor overbank and marine-flood shales in a dominantly coastal-plain setting (Zeng and others, 2001a). Third-order MFS's generally coincide with regional faunal-abundance peaks (fig. 18). 


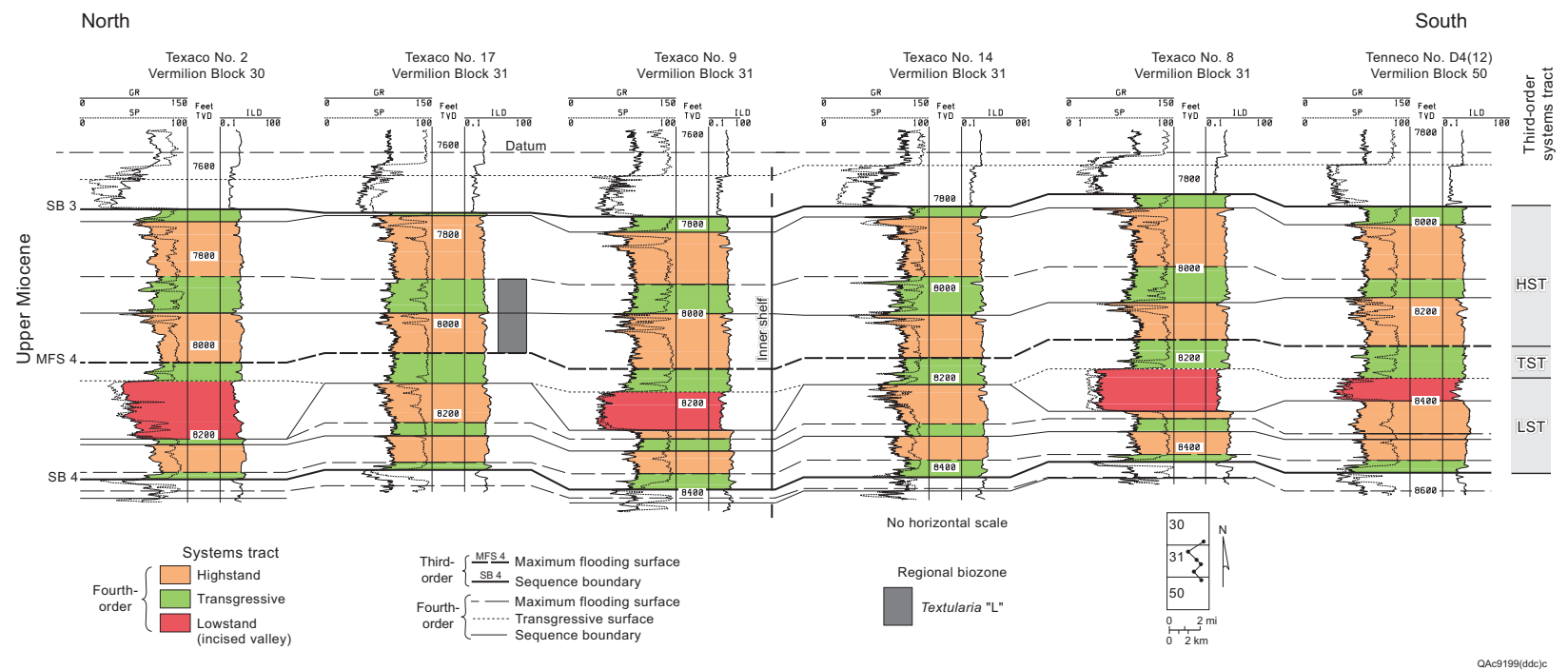

Figure 32. Dip cross section of proximal third-order Sequence 4 (upper Miocene), Starfak field. Biozone "box" records vertical variance for the top of the zone among the wells with fossil data. Paleobathymetric interpretations are based on benthic fossil assemblages: inner shelf = middle neritic to marginal marine (table 3 ).

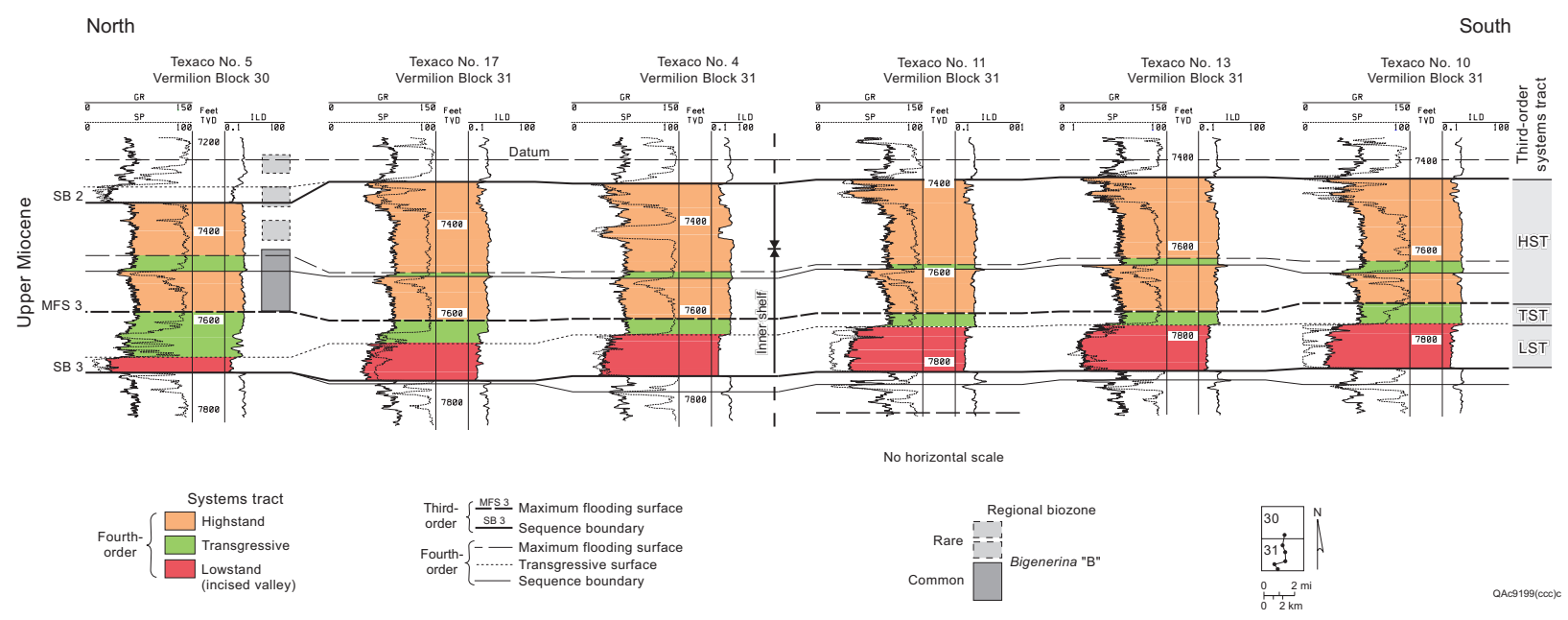

Figure 33. Dip cross section of proximal third-order Sequence 3 (upper Miocene), Starfak field. Biozone "boxes" record vertical variance for the top of each zone among the wells with fossil data. Paleobathymetric interpretations are based on benthic fossil assemblages: inner shelf $=$ middle neritic to marginal marine (table 3 ). 


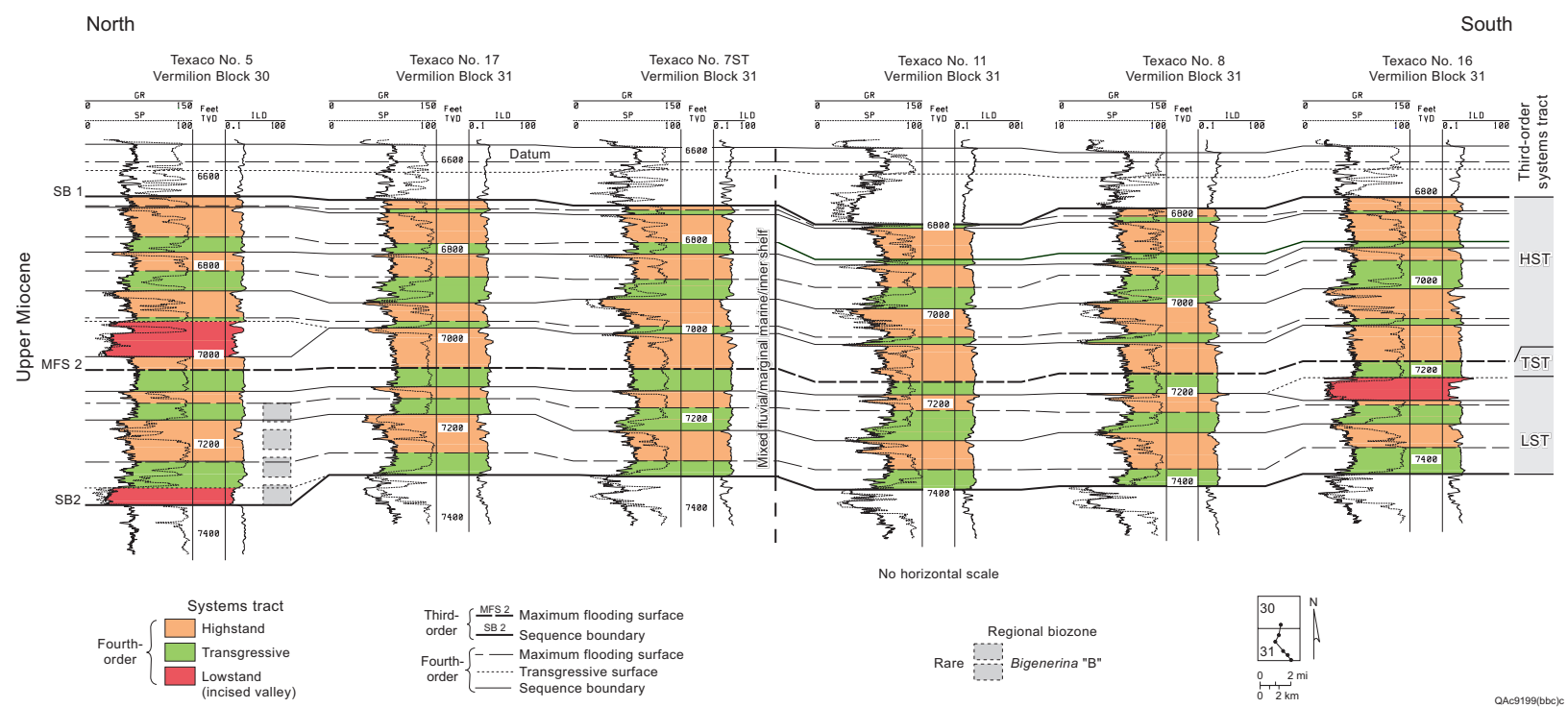

Figure 34. Dip cross section of proximal third-order Sequence 2 (upper Miocene), Starfak field. Biozone "boxes" record vertical variance for the top of each zone among the wells with fossil data. Paleobathymetric interpretations are based on benthic fossil assemblages: inner shelf $=$ middle neritic to marginal marine (table 3 ).

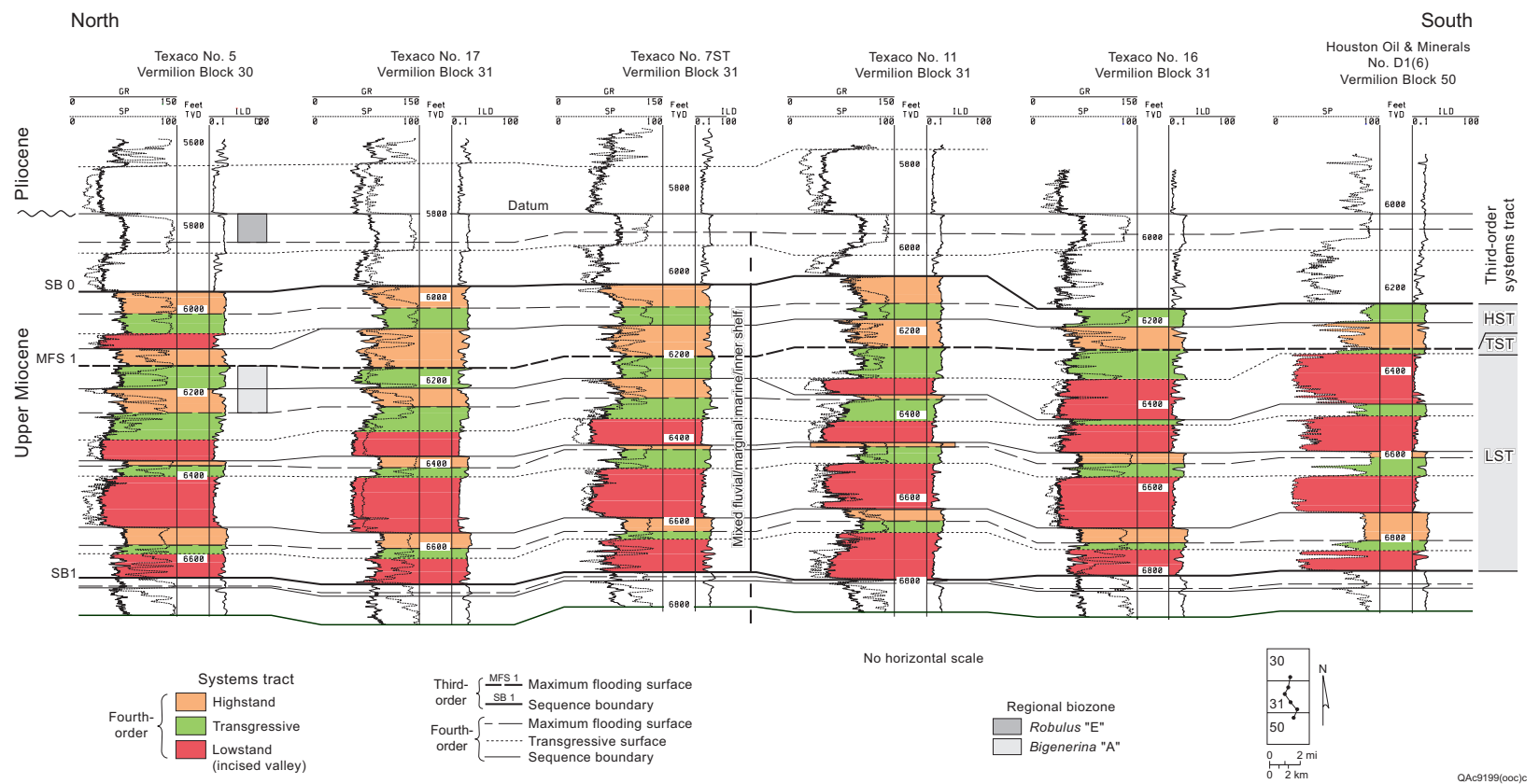

Figure 35. Dip cross section of proximal third-order Sequence 1 (upper Miocene), Starfak field. Biozone "boxes" record vertical variance for the top of each zone among the wells with fossil data. Paleobathymetric interpretations are based on benthic fossil assemblages: inner shelf $=$ middle neritic to marginal marine (table 3 ). 


\section{Correlation with Eustatic Cyclicity}

Although biostratigraphic data show that the absolute ages of the third-order sequence boundaries approximately coincide with those defined by Haq and others (1988), updated with the revised chronology of Berggren and others (1995), the third-order cyclicity interpreted in the study contrasts with Haq's generalized (global) coastal-onlap curve (fig. 36). Whereas the Haq curve shows transgressive trends in the upper lower to lower middle Miocene and throughout the upper Miocene, prominent regressive signatures can be observed in the study area during these periods. In fact, the entire study interval is a regressive succession at the third-order scale. The study area lies within the Miocene Central Mississippi sediment-dispersal axis (Galloway and others, 2000). Therefore, the difference between the "average" global pattern and that of offshore Louisiana is best explained by the basin-specific effects of generally high sediment flux throughout the Miocene in the vicinity of the ancestral Mississippi delta.

In contrast to the global third-order sequences of Haq and others (1988), three third-order cycles were identified between 11.70 and 9.26 m.y., a time interval of 2.44 m.y. that Haq and others (1988) identified as representing one third-order cycle (fig. 36). Styzen (1996) also concluded that there are multiple cycles within this time range, although he did not differentiate between third- and fourth-order sequences. However, the duration of one of his four cycles ( 0.9 m.y.) within this time range is comparable to the duration of Haq's shorter term Miocene third-order sequences (0.9 m.y.), using the updated chronology of Berggren and others (1995). Therefore, Styzen's cycle boundaries of the 11.70- to 9.26-m.y. period probably record at least two third-order sequences.

Our inferred coastal-onlap trend for most of the Miocene of offshore Louisiana more closely coincides with observations presented by Hardenbol and others (1998) for Miocene strata in European basins. In the same time interval, they differentiated parts, or all, of three low-order transgressive-regressive (T-R) facies cycles (fig. 36), which coincide with third-order sequence sets. As in the study interval, long-duration regressive periods dominate. However, unlike offshore Louisiana, the European Miocene regressive succession is punctuated by relatively short lived, but significant (second-order?), transgressive events. The differences among these three cycle schemes probably lie in basin-specific variations in the interaction of eustasy, sediment supply, and subsidence, which control stacking trends of third-order sequences (Hardenbol and others, 1998).

\section{Hydrocarbon Distribution within Third-Order Systems Tracts}

As of 2001, resource-in-place estimates for Starfak are approximately 316 Bcf gas and 13.3 MMbbl oil, and for Tiger Shoal estimates are 3.1 Tcf gas and 35.9 MMbbl oil. Within individual fourth-order systems tracts of Starfak and Tiger Shoal fields, hydrocarbons have been produced from inferred lowstand incised-valley fills, deltaic/strandplain sandstones of late HST's, deltaic sandstones of late lowstand prograding wedges, and transgressive bayhead deltaic sandstones. However, calculation of the vertical distribution of production in Starfak and Tiger Shoal fields indicates that the vast majority of gas and oil production is from the third-order LST's at the bases of the third-order cycles (fig. 37). 
Offshore Louisiana

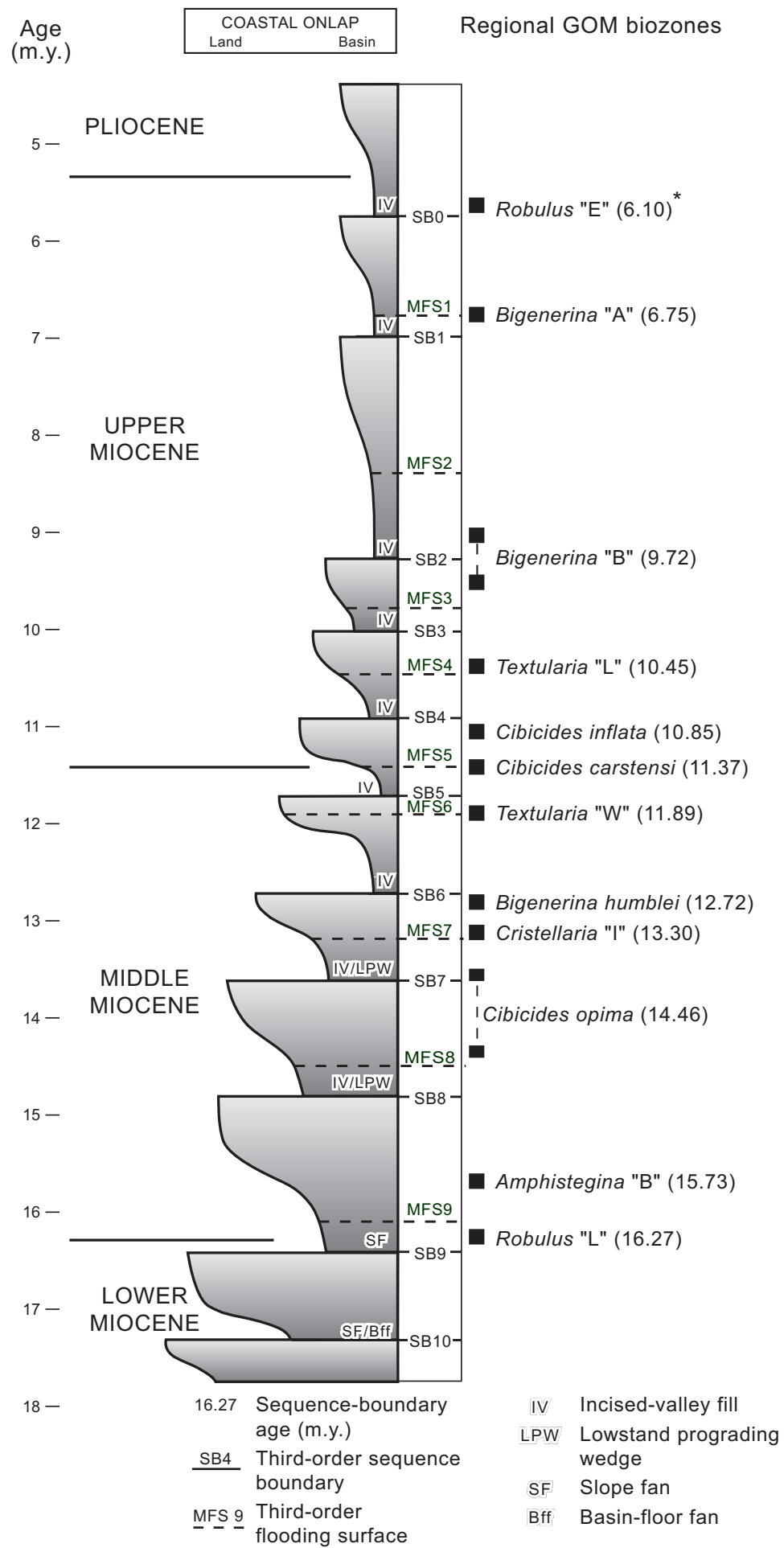

Europe

(Hardenbol et al.,1998)

\section{Global}

(Haq et al.,1988; ages from Berggren et al., 1995)

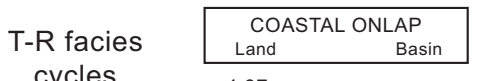

cycles

$\mathrm{T}$
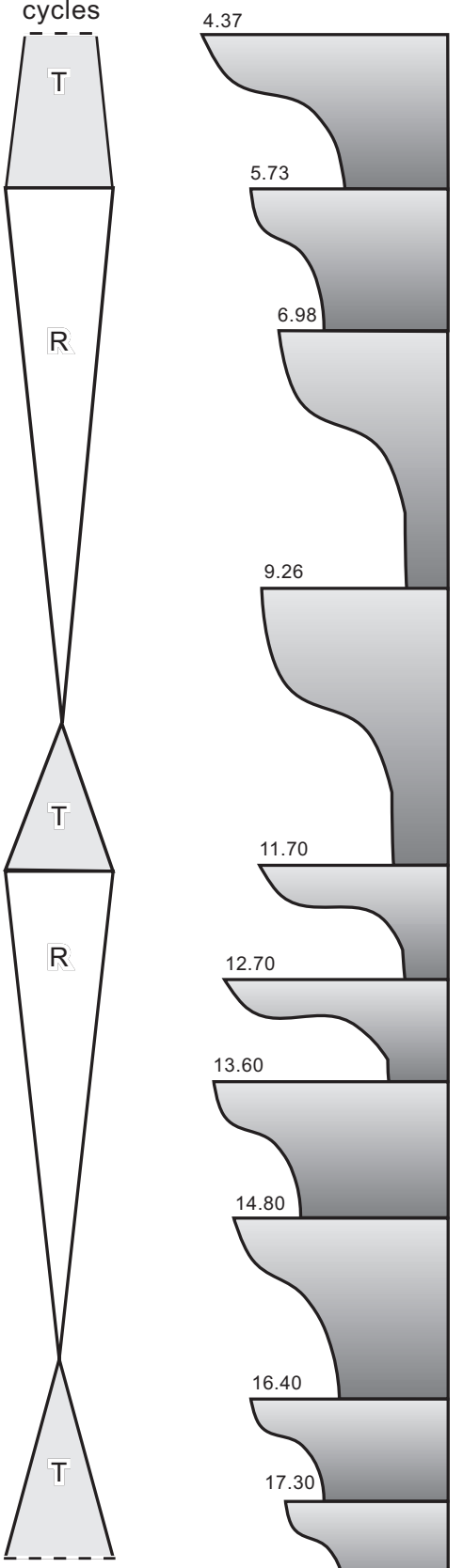

9.26
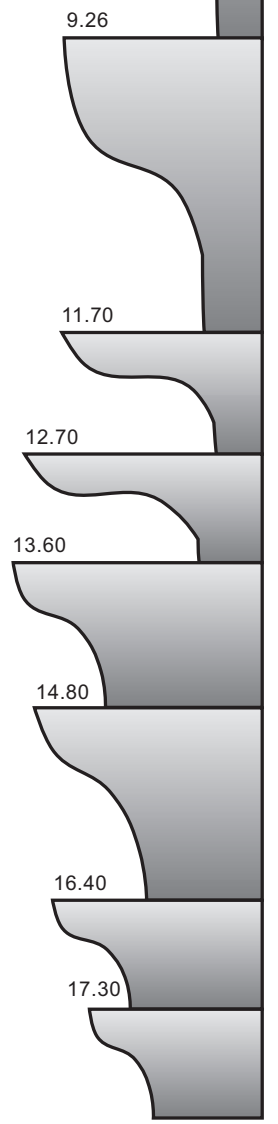

*Ages (m.y.) derived from Lawless et al. (1997)

and converted to those of Berggren et al. (1995)

QAc7050(qa)c

Figure 36. Comparison of the coastal-onlap curve of the study area (offshore Louisiana), the transgressive-regressive cycles of Hardenbol et al. (1998) for European basins, and the global curve of Haq et al. (1988). 
(a)

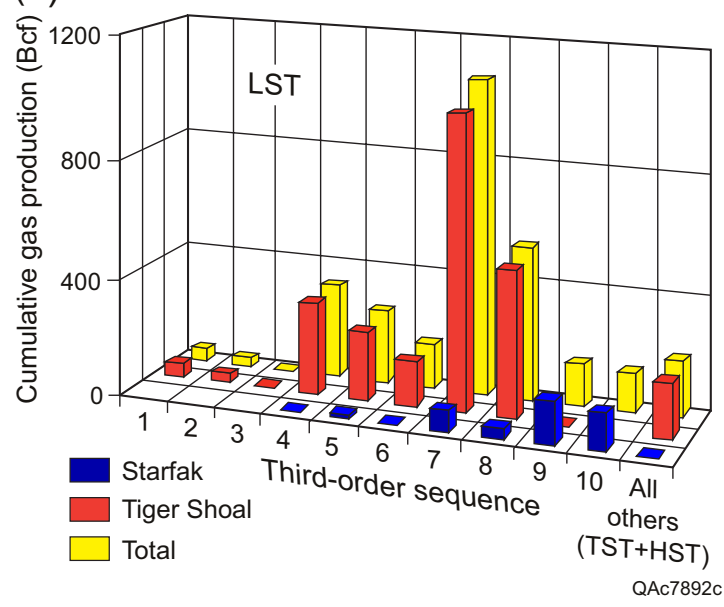

(b)

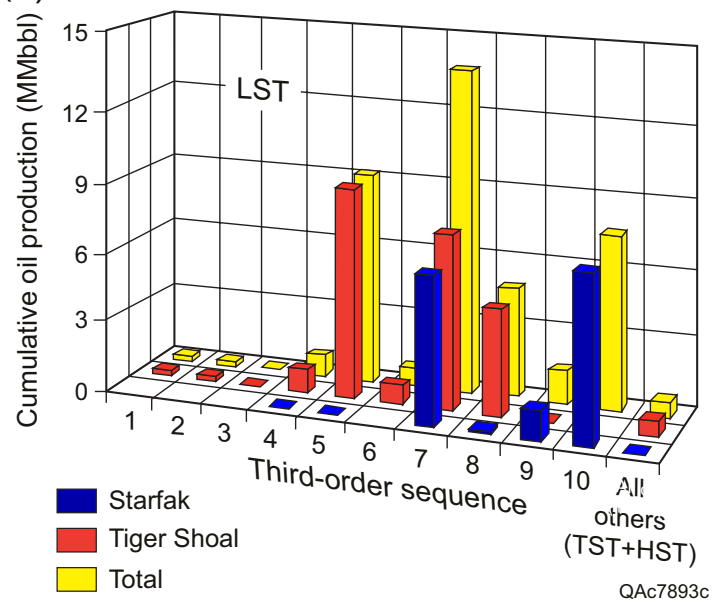

(c)

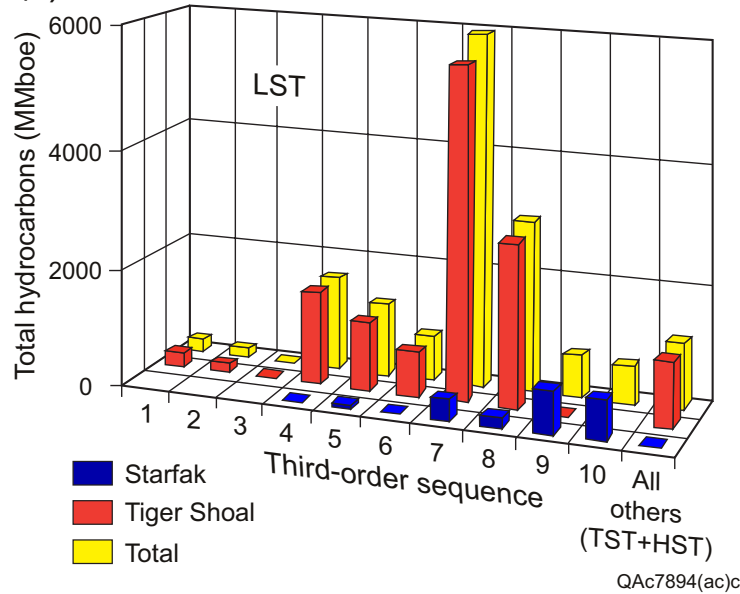

Figure 37. Bar graphs of cumulative hydrocarbon production (through 7/1/00) from the 10 third-order LST's in Starfak and Tiger Shoal fields. The category "All others" represents cumulative production from all third-order HST and TST reservoirs. (a) Cumulative gas. (b) Cumulative oil. (c) Total hydrocarbons. 
Within Starfak and Tiger Shoal fields, reserves are concentrated where fourth-order systems tracts stack to form third-order LST's, which compose $\sim 30$ to 50 percent of the total study interval. Production records through 7/1/00 indicate that 92.6 percent of all gas production, 98.0 percent of all oil production, and 92.6 percent of total hydrocarbon production has come from LST's of the third-order sequences. The third-order LST of Sequence 7 (fig. 24) has produced the majority of total hydrocarbons, followed by the LST of Sequence 8 (fig. 23). However, the prograding-wedge sandstones of Sequence 10 (fig. 20), which are deep targets, have only recently been developed and are currently primary opportunity targets. Although a dominant structural-trapping component is present in the fields (DeAngelo and Wood, 2001), most of the resource distribution can be predicted by understanding its context within a framework of key sequence-stratigraphic surfaces. There is a strong control on hydrocarbon distribution by these key surfaces.

Hydrocarbons are dominantly distributed in third-order LST's because these intervals have optimal reservoirquality, seal, and source juxtapositions. Most reservoirs occur within the third-order LST's for several reasons, considered collectively:

- Prominent thick shales of the third-order TST's and HST's create thick regional hydrocarbon seals over reservoirs within the third-order LST's.

- These thick sealing shales above and below the productive zones minimize the risk of cross-fault juxtaposition of lowstand reservoir sandstones against third-order highstand sandstones that can act as points of leakage.

- Thick, third-order Miocene shales are potential source rocks for hydrocarbons in lowstand sandstones of the overlying third-order sequence (Walters and Cassa, 1985; Mink and others, 1988).

- The common juxtaposition of thick incised-valley sandstones against neritic to shallow-marine shales from lowstand incision creates lateral and upper seals at valley margins (e.g., Bowen and others, 1993).

- The areally restricted distribution of commonly thick, stacked, deltaic-wedge sandstones within slope and basinal shales creates ideal conditions for potential hydrocarbon migration and entrapment.

On the basis of these observations and rationale, it is concluded that there are significant untapped hydrocarbon accumulations in nonstructural traps within the study area. Moreover, hydrocarbon concentrations most likely occur in third-order systems tracts comprising both nonstructured and structured Miocene strata in adjacent on-shelf regions of the northern GOM. This pattern of resource distribution keyed to third-order LST's serves as a guide for more regional resource development. Inspection of limited well log data from surrounding Miocene shelf fields (Light House Point, Mound Point, and South Marsh Island Block 236 [Amber Complex]) indicates that the sequence-stratigraphic framework of the Miocene Series can be tied to these areas (fig. 5). The framework can most likely be readily applied to other surrounding offshore fields, especially if supported by sufficient well log and paleontological data to reinforce correlation confidence. 


\section{Rock Properties and Production Distribution within Fourth-Order Systems Tracts}

As part of this project, rock properties and production performance were linked to fourth-order sequences and their systems tracts. Porosity and permeability of reservoir sandstones vary depending on their occurrence within LST's, TST's, and HST's. Additionally, the production performance of the sequences and their systems tracts were scrutinized to characterize the three systems tracts by their monthly production performance (Rassi, 2002a, b).

A petrophysical model developed by project members (Barba and Kiliç, 2000) served as the basis for this analysis and provided the bulk of the evaluated data. This model enabled estimation of effective porosity, water saturation, permeability to air at surface conditions, permeability to gas at in situ conditions, net feet of permeable interval, and net feet of gas pay. The objective was to calibrate the model to the available core and production data. Most core information was derived from percussion sidewall cores and some log curves. However, because of the different ages of Starfak and Tiger Shoal fields, consistency of data quality from log suites was reduced. Moreover, the open-hole porosity log data of the wells are of poor quality owing to the age of the measurements and hole conditions (Barba and Kiliç, 2000).

The result of this model is generation of a porosity/permeability model curve, which provides values for all systems tracts represented in Starfak and Tiger Shoal fields. An average value for every systems tract was calculated, and the resulting arithmetic averages are presented in graphs. Moreover, all porosity (and permeability) data were tested for their statistical significance (Rassi, 2002a, b).

\section{Porosity}

The fourth-order LST's (fig. 38) within the study interval are represented by 1,576 porosity values. The LST's have the highest porosity values of the three systems tracts, $\sim 28$ percent in the shallowest zone (to $\sim 7,200 \mathrm{ft}$ ), decreasing with depth. At the depth of LST 47 (at $\sim 11,300 \mathrm{ft}$ ), the porosity has been reduced to $\sim 12$ percent. This trend of decreasing porosity with depth is explained by (1) increasing compaction with depth and the resulting loss in pore volume and (2) the abundance of coarser grained fluvial sandstones in the upper parts of the section.

In contrast, the TST's generally have much lower porosities than the LST's. Values in the shallow zone are 20 percent, declining less than the LST's into the deeper section, where the average porosity is reduced by 10 to 15 percent to a minimum value of $\sim 5$ percent. (fig. 39). The number of data points for TST is higher $(\mathrm{n}=2,255)$. HST's ( $n=3,146$ ) have porosities of $\sim 22$ percent in the shallow areas, with a decrease of about 10 percent to values of 12 to 15 percent (fig. 40) (Rassi, 2002b).

Empirical probability-distribution-function (PDF) histograms of the porosity data of the three different systems tracts were created to highlight differences in the three systems-tract populations (fig. 41). After sorting the data in ascending order, a size for porosity classes (or bins) had to be determined. To produce a meaningful graph, a 


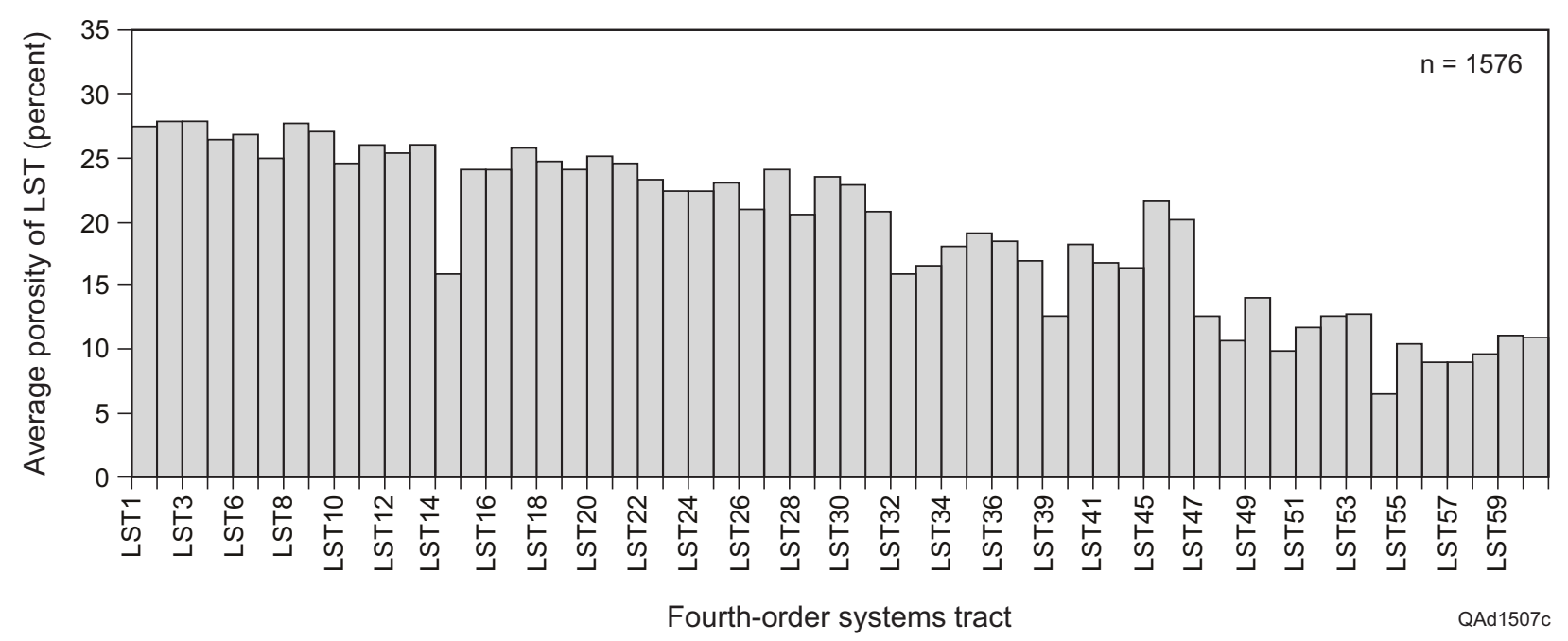

Figure 38. Bar graph of average LST porosities of fourth-order LST's.

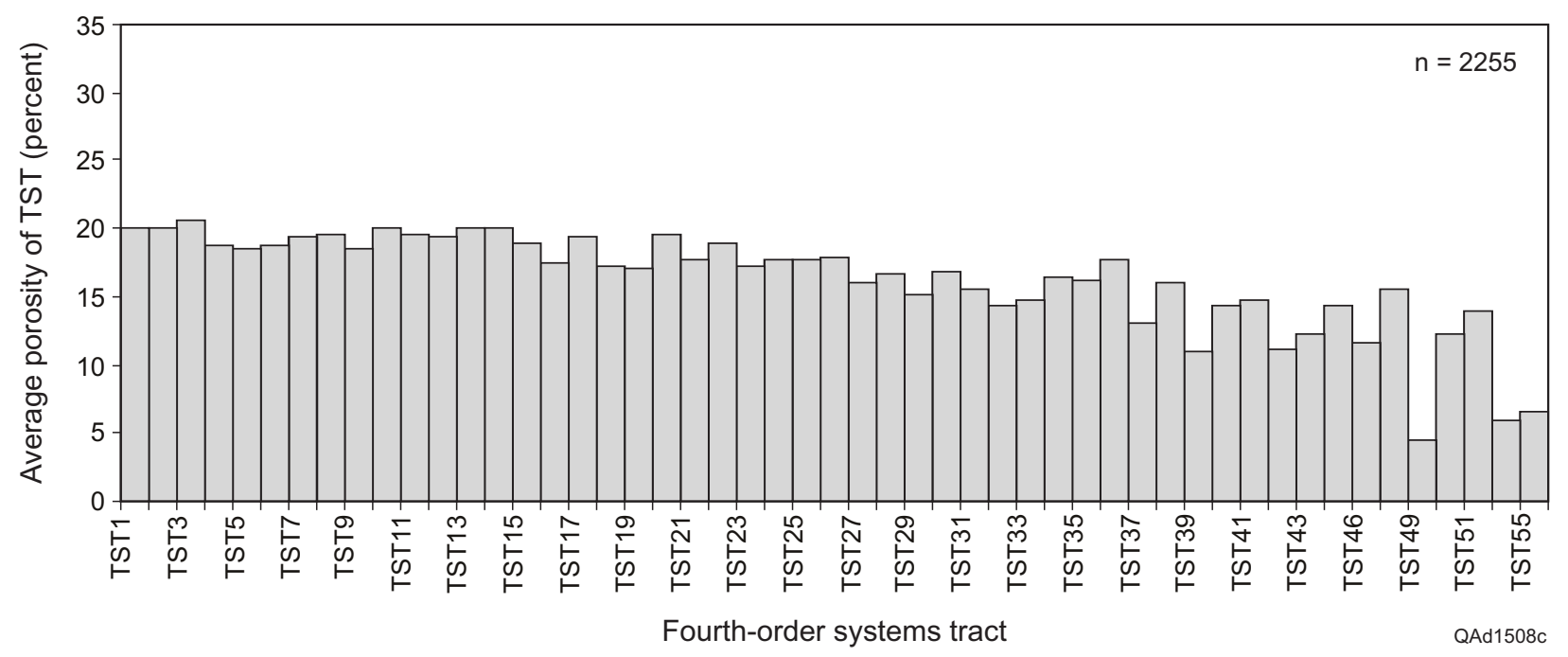

Figure 39. Bar graph of average TST porosities of fourth-order TST's. 


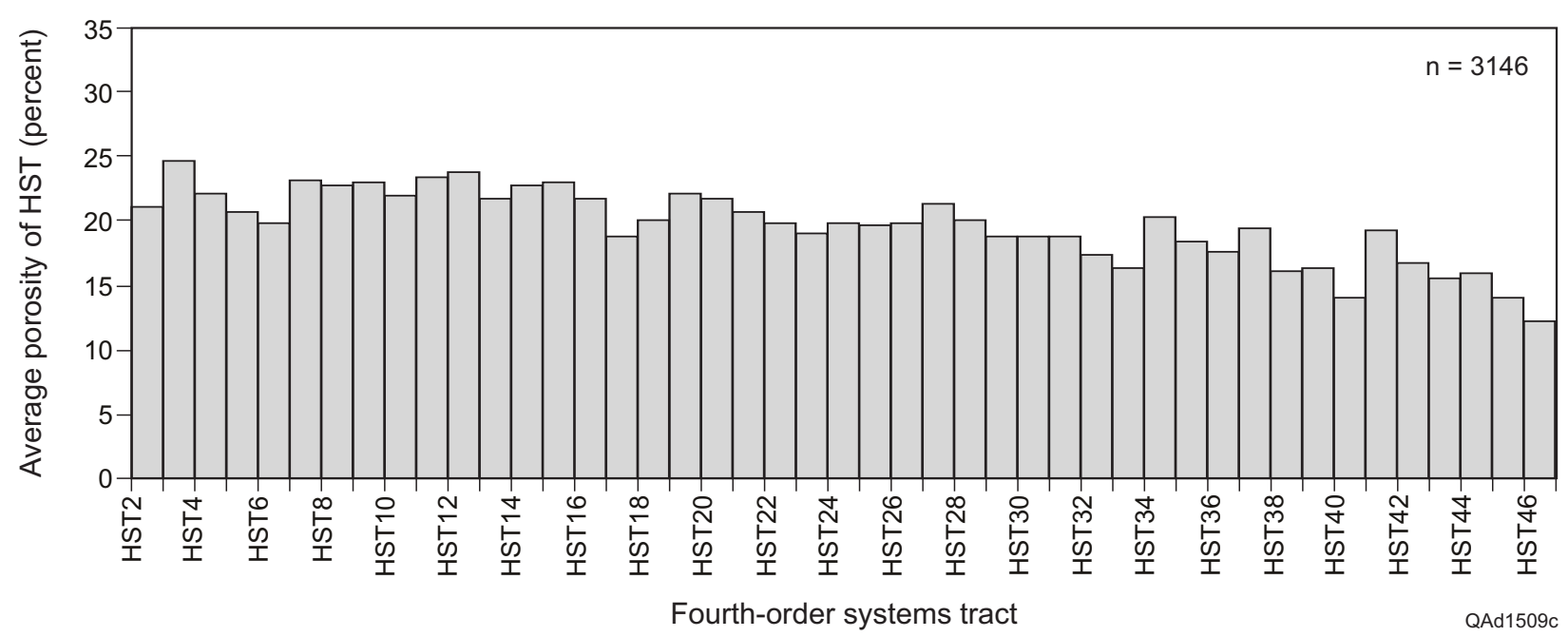

Figure 40. Bar graph of average HST porosities of fourth-order HST's.
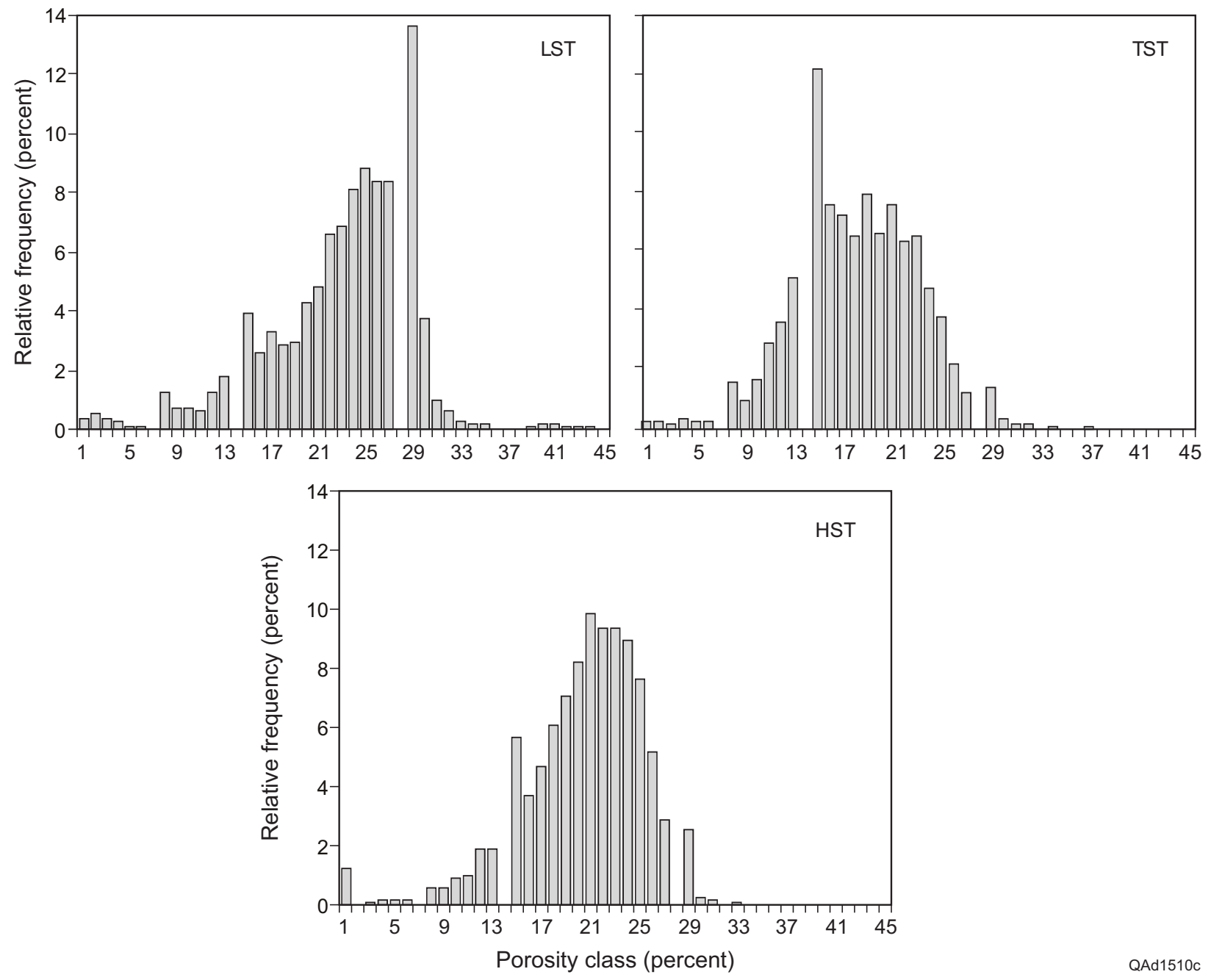

QAd1510c

Figure 41. Histograms of relative frequency of porosities within fourth-order LST's, TST's, and HST's. 
porosity class of 1 percent was found to be sufficient. The number of data points in each class is expressed as a percent value. The data for the three systems tracts produce unimodal histograms; however, the distribution maxima and data ranges for the systems tracts vary. The LST histogram has its peak at porosity values of about 26 to 29 percent, indicating skewness toward the higher values. The TST histogram is skewed toward a highest frequency in the porosity classes of 14 to $19 \%$. The histogram of the HST shows a data-population maximum at 21 to $26 \%$ (Rassi, 2002a).

\section{Permeability}

The range of permeability values is much broader than that of the porosity values. Most of the permeabilities (90-98\%) of the three systems tracts range between 0 and $500 \mathrm{md}$. The y-axes on the three permeability graphs do not show values higher than $700 \mathrm{md}$ to exclude extreme outlying data points, thus enabling the documentation of variations in permeability for data points with lower values.

The charts represent permeability values throughout the entire study interval with increasing depth and indicate that the LST's $(\mathbf{n}=\mathbf{1 , 5 7 6})$ of these two fields have the highest permeabilities, with maximum values exceeding $700 \mathrm{md}$ (fig. 42). The shallower systems tracts have average permeabilities of 300 to $500 \mathrm{md}$. At the depth of LST 18 ( 8,400 ft), average values decrease to 100 to $200 \mathrm{md}$, and from LST 32 to the total depths of wells, permeabilities slowly decline toward very low values. TST's $(n=2,255$, fig. 43$)$ exhibit much lower permeability readings: from the top of the study interval to $\sim$ TST $28(\sim 9,600 \mathrm{ft})$ the values barely exceed $100 \mathrm{md}$ and then steadily decline to 0 to $20 \mathrm{md}$. HST's $(\mathbf{n}=\mathbf{3 , 1 4 6})$ have initial higher permeabilities than those of TST's, but they are still less than the average permeabilities of the LST's (fig. 44). Until HST $20(\sim 8,700 \mathrm{ft})$ the average value is 100 to $200 \mathrm{md}$; they then decline with depth to $\sim 100 \mathrm{md}$. The permeabilities of HST's deeper than HST 30 $(\sim 9,900 \mathrm{ft})$ are reduced to values between 10 and $50 \mathrm{md}$ (Rassi, 2002b).

\section{Production Behavior: Production Rates and Cumulative Production of Selected Sequences}

To compare and contrast production from systems tracts in Starfak and Tiger Shoal fields, the average monthly production per foot perforated in the four fourth-order sequences that produce from all three systems tracts was calculated: sequences 4, 22, 23, and 26. The average monthly production of gas, oil, and water from each of the LST's, TST's, and HST's was divided by the total amount of feet perforated in the specific systems tract. These values are presented in bar charts, thus allowing observation of variations within any one of the four sequences. The resulting rate plots show that monthly gas-production rates of HST's dominate over those of LST's and TST's (fig. 45). However, HST's lead only in gas production; their monthly oil and water yields are insignificant compared with those of the other two systems tracts. The LST's are the strongest producers of water and oil (figs. 46, 47). The TST's of the four sequences produced more oil on a monthly basis than the HST's, but they produced about the same amount of water. HST's have remarkably low oil production. 


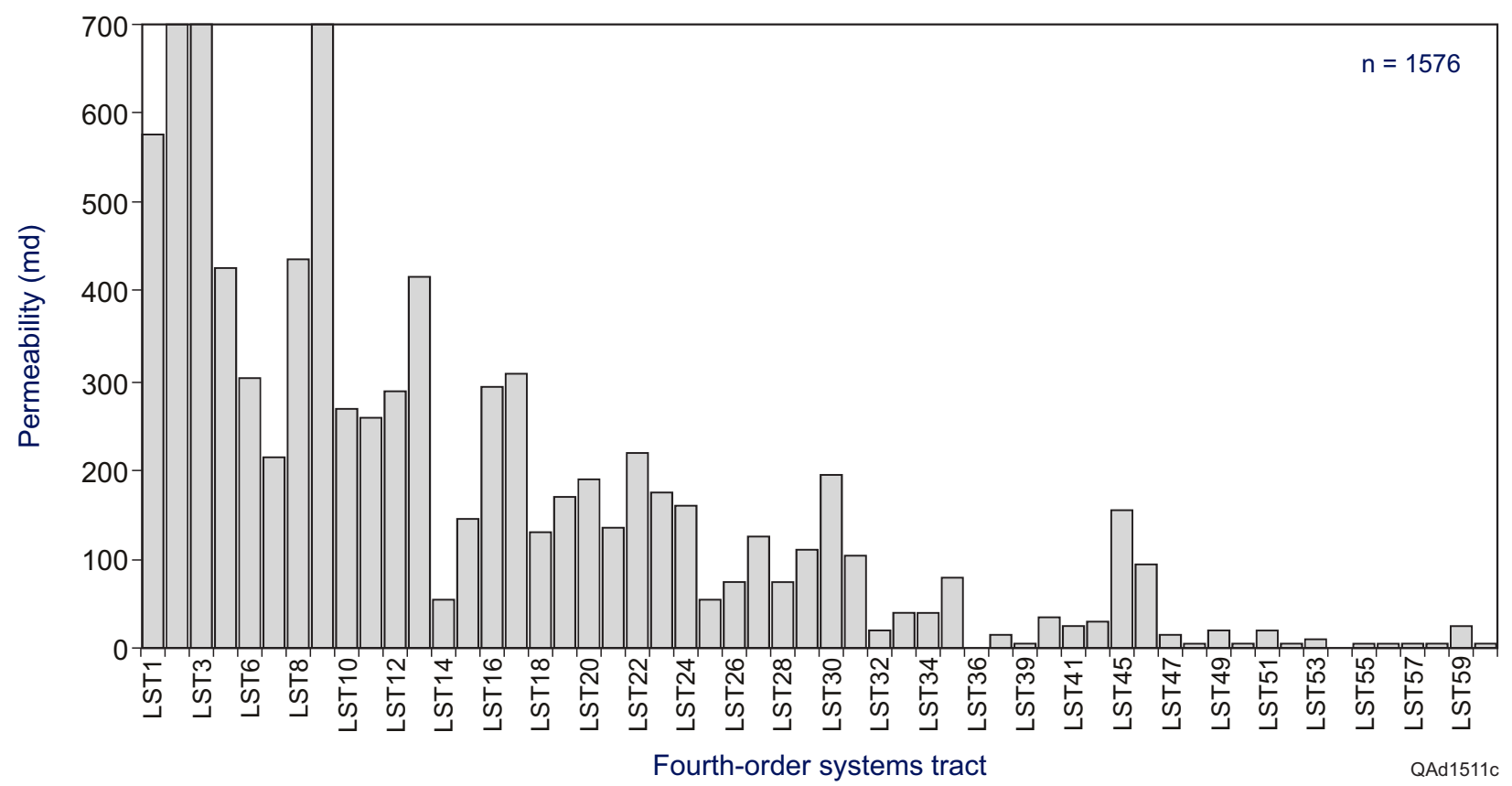

Figure 42. Bar graph of average permeabilities of fourth-order LST's.

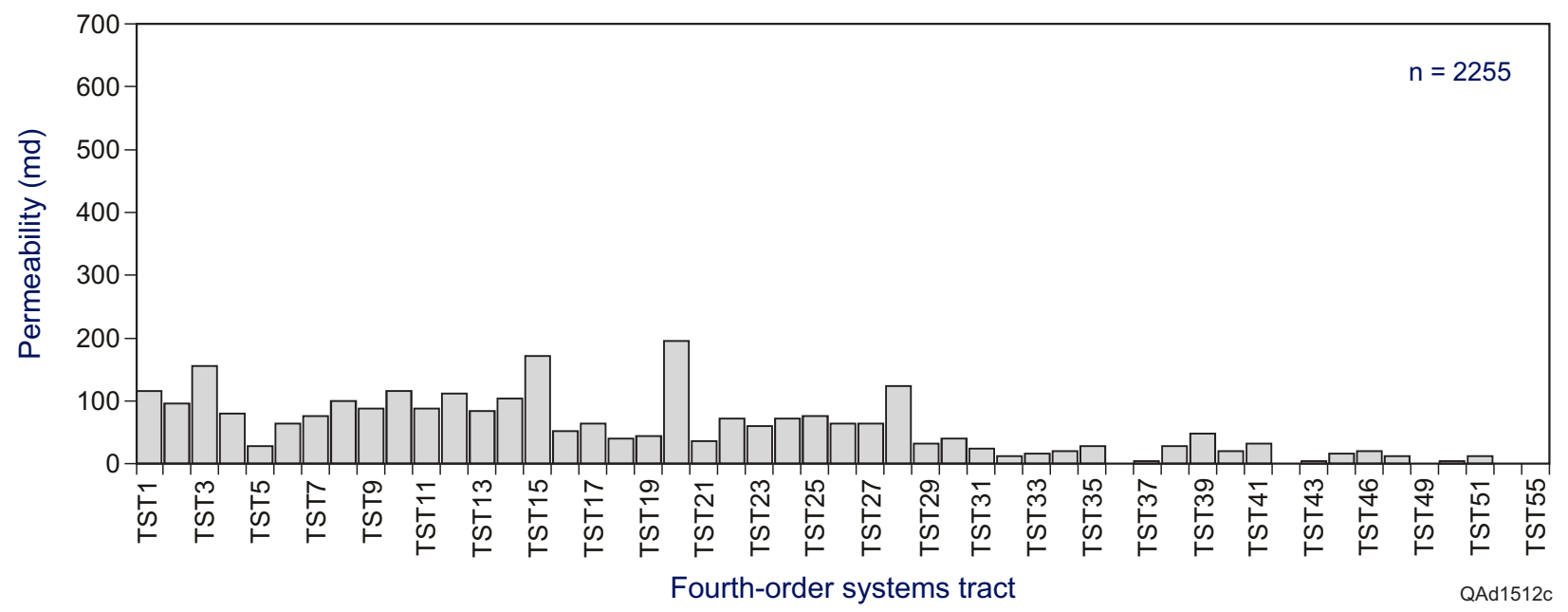

Figure 43. Bar graph of average permeabilities of fourth-order TST's. 


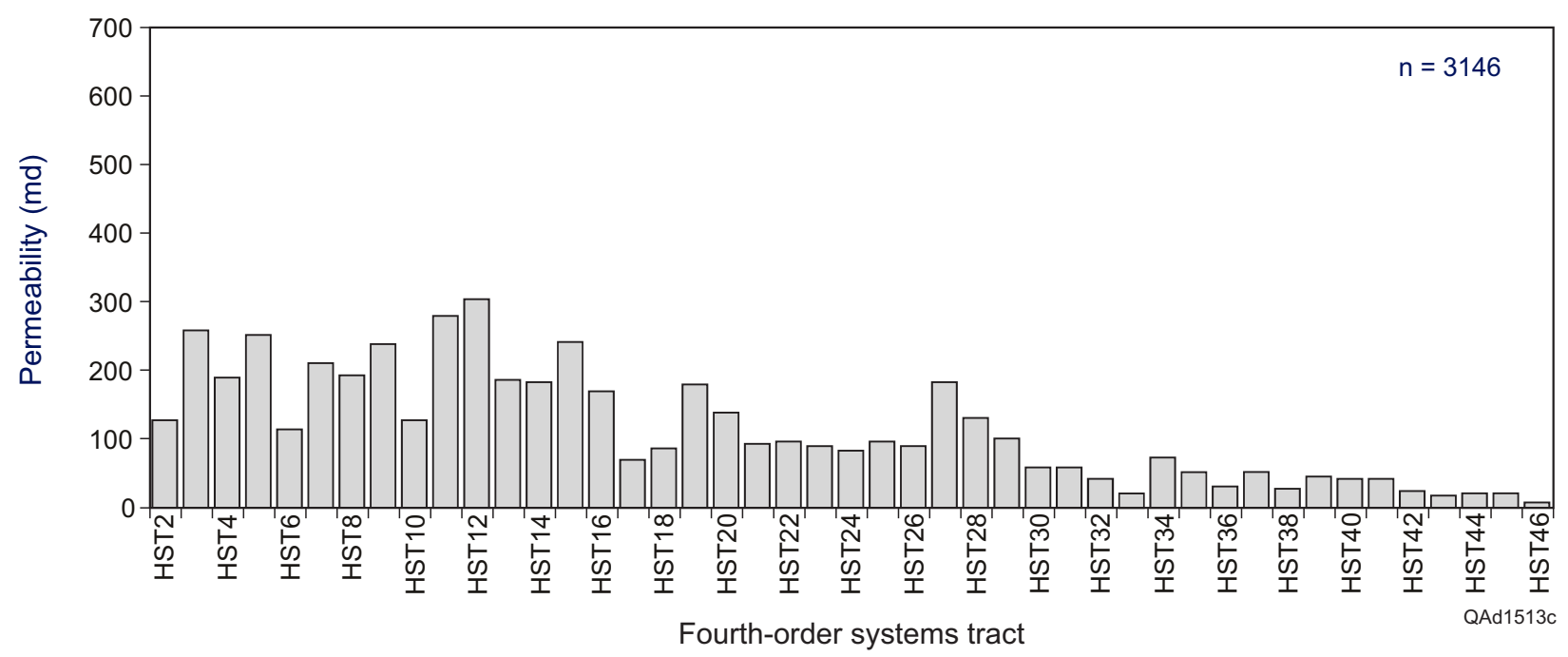

Figure 44. Bar graph of average permeabilities of fourth-order HST's.

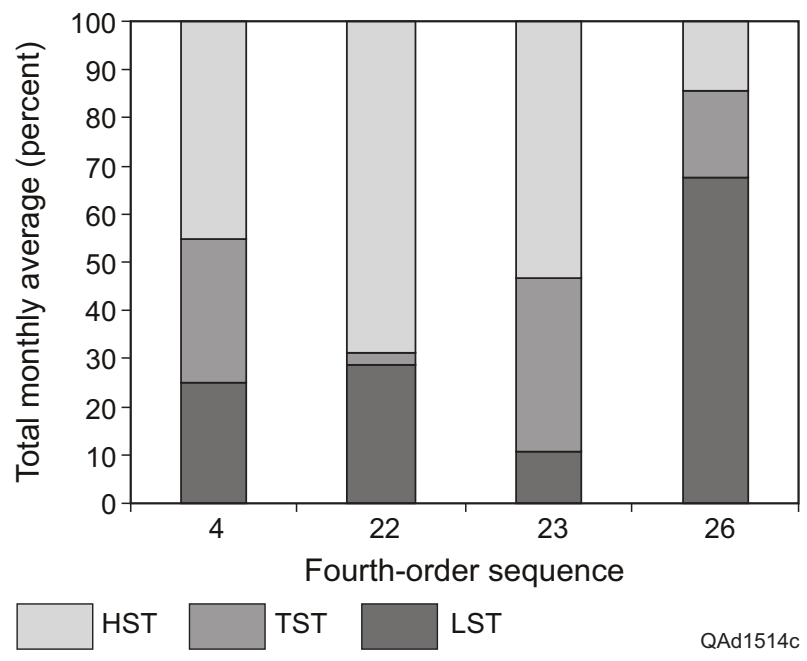

Figure 45. Average monthly percentage of gas production from the four fourth-order sequences that had production in each of the three systems tracts. 


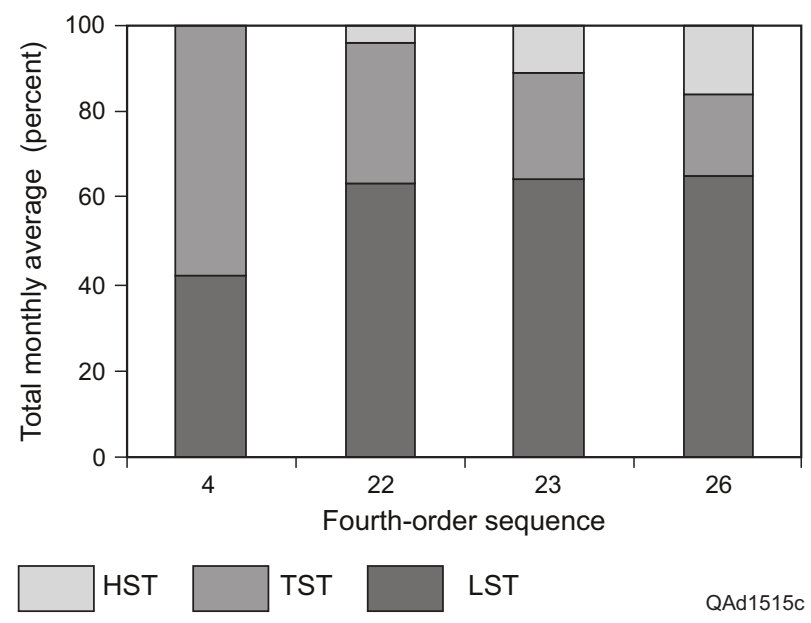

Figure 46. Average monthly percentage of oil production for the four fourth-order sequences that had production in each of the three systems tracts.

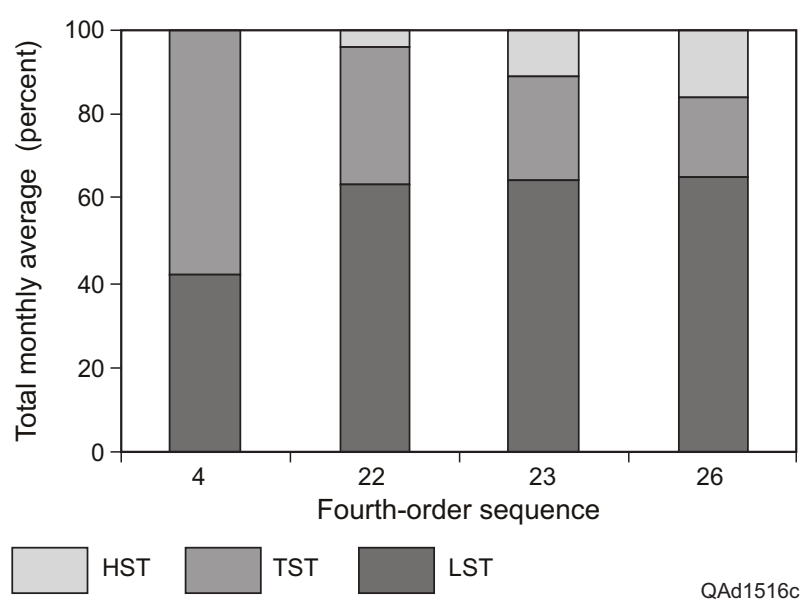

Figure 47. Average monthly percentage of water production for the four fourth-order sequences that had production in each of the three systems tracts. 
Comparison of the cumulative production from each of the same four sequences is necessary to further detail the production behavior of systems tracts. Cumulative gas production is only marginally higher from LST's than from TST's, with HST's producing less than half of each of the other two systems tracts (fig. 48). Cumulative oil production is lowest in HST's, and TST's and LST's have produced more or less equal amounts of total oil (fig. 49). The percentage of cumulative water production from HST's is approximately equal to the amount from LST's, except for sequences 22 and 26 (fig. 50). These two sequences do not have any water production from either HST's (sequence 22) or LST's (sequence 26) (Rassi, 2002b).

\section{$\underline{\text { Conclusions }}$}

The following key points summarize the analysis of the data set:

- Porosities: LST's have the highest average porosity values, especially in the shallow sections. LST porosity is $\sim 28$ percent, compared with 20 percent (TST) and 22 percent (HST).

- Permeabilities: The highest values of permeability are again found in LST's (average in shallow: 300-500 md), followed by HST's (100-200 md) and TST's (<100 md).

- Production rate: The monthly production rate per perforated foot enables comparison of the production behavior of the three systems tracts. In general, average gas production rates are highest in HST's, followed by those in LST's.

- Cumulative production: LST's yield most gas, oil, and water production, followed by TST's.

\section{Play Types and Hydrocarbon Distribution}

Gas and oil atlases of the northern Gulf of Mexico (Hentz and others, 1997; Seni and others, 1997) evaluate reservoirs in the productive areas in the northern Gulf of Mexico by grouping them into play types. Grouping reservoirs into play types offers several advantages. Because of their relatively similar geological, engineering, and production characteristics, reservoirs within the same play tend to have similar production and ultimate recovery growth (URG) patterns. These patterns of better-known, mature reservoirs may be extrapolated with relative confidence to newly discovered reservoirs within the same play. Moreover, production and URG responses to technology may be determined for a representative reservoir and results readily transferred to the larger family of reservoirs that constitute the play. Additionally, knowledge gained from plays can assist in future exploration for similar reservoirs (Galloway and others, 1983). Researchers on the project applied these principles by examining internal anatomy and production characteristics of several play types, examining their similarities and differences, identifying nontraditional targets associated with them, and pinpointing those characteristics that affect reserve 


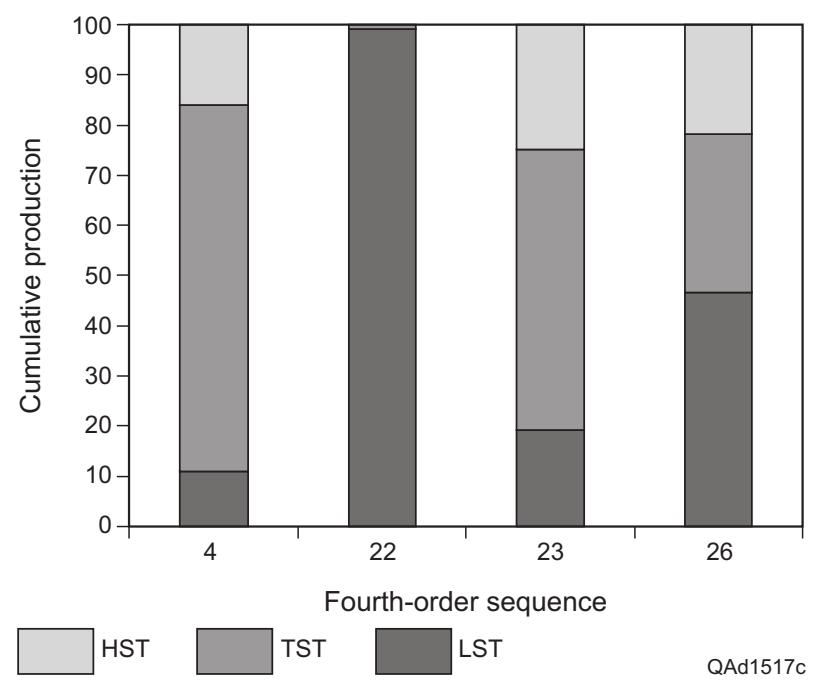

Figure 48. Percentage of cumulative gas production contributed by each of the three systems tracts within the four sequences.

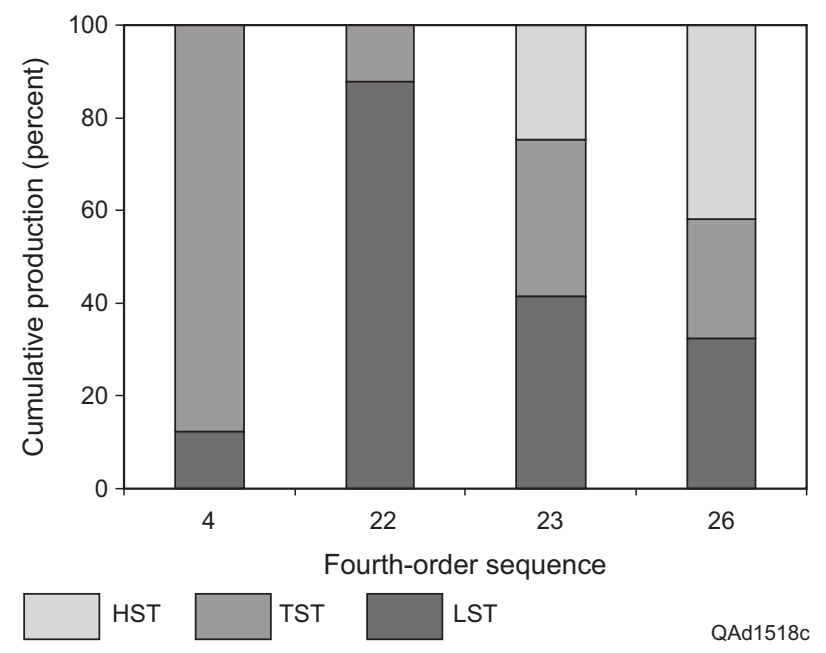

Figure 49. Percentage of cumulative oil production contributed by each of the three systems tracts within the four sequences. 


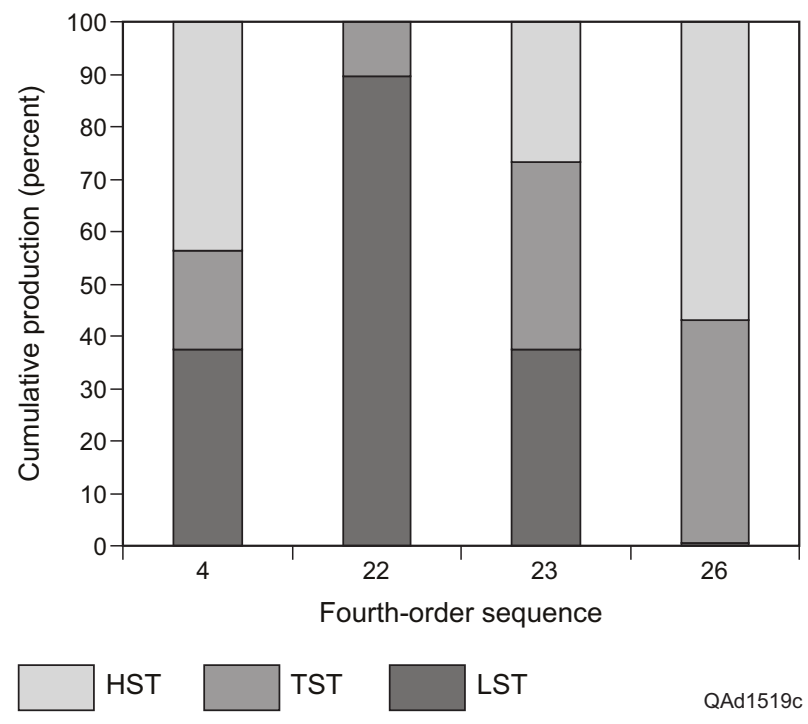

Figure 50. Percentage of cumulative water production contributed by each of the three systems tracts within the four sequences. 
distribution and ultimate recovery from them. These observations could then be upscaled through the hierarchy of play types developed in the 1997 atlases.

Play Types in the Study Area

On the basis of the atlases of the northern Gulf of Mexico (Hentz and others, 1997; Seni and others, 1997), reservoirs in Starfak and Tiger Shoal fields could be classified into several play types. As defined in these atlases, plays are broad groupings of reservoirs based on depositional style from gross well log stacking pattern (aggradational, progradational, retrogradational) and the chronozone in which the reservoirs occur. This approach is necessary to aggregate basinally distributed reservoirs having broadly similar characteristics within a manageable organizational scheme. The system enables the observations and processes defined within a smaller study area to be more broadly applied to regional resource-addition issues.

The 10,000-ft upper-lower through upper Miocene succession in the two fields comprises seven middle and upper Miocene plays, five progradational and two retrogradational (table 4). Rock successions in the progradational plays, typically several thousand feet thick, consist of repeating upward-coarsening intervals representing primarily regressive depositional systems. In contrast, backstepping progradational intervals grouped into a broadly upward fining succession characterize the retrogradational plays, which are typically several hundred feet thick. These successions are further divided into chronozones on the basis of key extinction horizons within the middle and upper Miocene section. Primarily fourth-order on-shelf highstand and lowstand incised-valley sandstones form the framework of the progradational plays in the two fields (2,000 to 6,000 ft thick). The much thinner (100 to $500 \mathrm{ft}$ ) and more localized retrogradational plays are successions of third-order LST's and overlying transgressive systems tracts (TST's) that collectively grade upward from thick fourth-order lowstand progradingwedge and incised-valley sandstones to thinner and finer grained strandplain/deltaic sandstones. Thick shales of third-order TST's and overlying HST's form regional sealing units across the fields, significantly influencing hydrocarbon distribution. Hydrocarbons reside in fourth-order LST's, TST's, and HST's in all plays within the two fields.

\section{Hydrocarbon Distribution within Plays}

Detailed sequence-stratigraphic analysis clarifies the reservoir framework of these plays and enables a focused strategy of exploitation, particularly in mature fields such as Starfak and Tiger Shoal. Hydrocarbons that have been produced from the fields reside in a variety of different traps (DeAngelo and others, 2000); most of these are structural in nature. Abundant undiscovered resources probably lie in stratigraphic traps formed by (1) updip pinch-outs of incised-valley sandstones within shaly highstand strata, (2) local diagenetic pinch-outs of late highstand sandstones that are capped by tight (sealing) zones formed by possible pedogenic cementation developing during lowstand exposure, (3) a variety of potential subregional sandstone pinch-outs within 
Table 4. Play types within Starfak and Tiger Shoal fields based on play designations of Hentz and others (1997) and Seni and others (1997). Note that the two fields share four plays in four different chronozones.*

Starfak

UM1 P.1B Lower Upper Miocene Eastern Progradational Sandstone

MM9 P.1B Upper Middle Miocene Central Progradational Sandstone

MM7 P.1B Middle Middle Miocene Eastern Progradational Sandstone

MM4 P.1 Lower Middle Miocene Progradational Sandstone

Tiger Shoal

UM3 R.2

Upper Upper Miocene Eastern Retrogradational Sandstone

UM3 P.1B

Upper Upper Miocene Eastern Progradational Sandstone

UM1 P.1B

Lower Upper Miocene Eastern Progradational Sandstone

MM9 P.1B

Upper Middle Miocene Central Progradational Sandstone

MM7 R.1B

Middle Middle Miocene Eastern Retrogradational Sandstone

MM7 P.1B

Middle Middle Miocene Eastern Progradational Sandstone

MM4 P.1

Lower Middle Miocene Progradational Sandstone

*Biostratigraphic limits of chronozones:

UM3: extinction horizons of Discorbis "12" (base) and Robulus "E" (top).

UM1: extinction horizons of Bigenerina "2" (base) and Discorbis "12" (top).

MM9: extinction horizons of Bigenerina humblei (base) and Bigenerina "2" (top).

MM7: extinction horizons of Amphistegina "B" (base) and Bigenerina humblei (top).

MM4: extinction horizons of Discorbis "B" (base) and Amphistegina "B" (top).

lowstand prograding wedges, (4) updip pinch-outs of lowstand basin-floor-fan sandstones within slope-fan shales, and (5) updip pinch-outs of locally well-developed sandstones within channel-levee complexes of thick 
lowstand slope-fan successions. It is significant that no lower Miocene plays were defined for the Starfak/Tiger Shoal study by Seni and others (1997) for this interval, even though many of the recent exploration efforts have been concentrated in those deep ( $>15,000-\mathrm{ft})$ strata. This observation is consistent with data recently compiled by the Minerals Management Service (2001) that show that only 5 percent of all wells drilled on the Gulf of Mexico shelf have penetrated strata below $15,000 \mathrm{ft}$, in which there is an estimated $10.5 \mathrm{Tcf}$ of deep-gas recoverable resources.

\section{Seismic-Attribute Analysis and Interpretation}

An integrated interpretational approach was utilized to refine the structural framework and identify potential bypassed hydrocarbon accumulations. In exploration areas, 3-D seismic is an invaluable tool that can provide detailed information about the subsurface geology. In mature fields such as Starfak and Tiger Shoal, 3-D seismic can improve the spatial resolution of the structural framework, image depositional trends of reservoir facies in both profile and plan view, and identify potentially bypassed hydrocarbon accumulations. The 3-D seismic can extend reservoir understanding away from well control by identifying known seismic waveforms at producing reservoirs and then search the entire volume for similar seismic waveforms, which may produce the same results. The interpreter can examine the 3-D seismic volume from many different perspectives, allowing detailed analysis of specific areas of interest.

Methodologies of seismic interpretation employed in the project include (1) coherency analysis primarily for fault identification; (2) surface-mapping methods to deduce regional structure at different stratigraphic levels; (3) analysis of root-mean-squared (RMS) amplitudes to identify stratigraphic, depositional, and hydrocarbon-bearing features; (4) amplitude stratal slicing to image regional depositional systems along single genetic surfaces; (5) neural network-assisted multiattribute analysis for automated depositional-facies recognition and for prediction of log properties from seismic attributes; and (6) analysis of seismic-lithology

relationships. Related methods that were used to clarify the relationship between log-derived attributes and seismic data included (1) analysis of sonic and density logs to reveal the acoustic relationship between sandstone and shale and (2) derivation of acoustic impedance of water- and hydrocarbon-bearing reservoir facies.

\section{Coherency Time Slicing}

Coherence data processing is becoming a common tool for recognizing discontinuities within 3-D seismic data volumes. In cases where conventional attribute-extraction techniques do not provide acceptable image results, faults and some stratigraphic features can be better imaged if a coherence technique is used. For this study, it was determined that construction of coherence time slices would be useful in the initial phase of the research. A major advantage of coherence attributes is that they allow a mathematical assessment of the 3-D seismic data volume without being biased by previous interpretation. Coherence calculations compare waveform similarity between adjacent traces within a specified time window, which are cross-correlated with neighboring traces. The lowest correlation coefficient calculated will be assigned to the central sample. Coherence values can range from +1 to -1 . A value of +1 indicates a perfect match between adjacent traces, which is typical of where rock matrix has no lateral 
variations (no faulting or change in rock type). A value of -1 indicates significant trace similarity if the phase of one of the waveforms is inverted, which could be an indicator of offset (faulting) within the reference window. A coherence value of zero indicates no correlation between seismic reflection characters. Lower coherence values (0 to -1) may indicate significant lateral changes in rock type, pore-fluid content, faulting, or any geologic variation that can affect seismic reflection waveshapes. Fault segments are more pronounced on the coherence time slices (fig. 51) than they are on conventional amplitude time slices (fig. 52). Time slices of the coherency volume, starting at 2,000 ms, were generated at 100-ms intervals. Fault segments were identified and mapped at each 100-ms interval. Vertical sections oriented in dip direction were then extracted from the 3-D seismic amplitude volume for analysis. Afterward the fault segments identified from the coherence time slices were projected onto the extracted dip seismic sections. The interpreter could then determine whether the fault segments could be correlated to a particular fault line in the vertical section (fig. 53).

Analysis of the 3-D seismic volume reveals the presence of numerous $(60+)$ normal faults throughout the study area. There are at least five first-order normal faults ( $>500 \mathbf{f t}$ of maximum offset), extending from near the seafloor to below seismic depth coverage (fig. 53). The first-order growth faults are characterized by increasingly thicker sequences of sediments as depth increases. These five faults have many rollover features at depth, many of which have not been exploited. Rollovers are excellent targets for hydrocarbon accumulations and are the trapping mechanism for several of the opportunity leads generated during this project. These features are commonly found in the deeper portions of first-order growth faults, where fault offset is greatest. The 3-D seismic volume in the northern Gulf of Mexico was examined to pinpoint strong amplitude anomalies (bright spots) terminating against faults that might indicate hydrocarbon accumulations (fig. 54). Numerous (60+) second-order faults were also interpreted. Although second-order faults generally have less maximum offset ( $<200 \mathbf{f t}$ ) compared with that of first-order faults, significant reserve growth opportunities are associated with these important features.

Several hourglass features were observed throughout the study area. Hourglass features are characterized by a crosscutting of fault segments that appear as an $\mathrm{X}$ in a vertical seismic section, which are associated with transecting faults (fig. 55). Hourglass features form good structural traps, with a minimum of two sides bounded by faults. The next phase of study was to map key lithostratigraphic horizons throughout the 3-D seismic volume.

Deep structure below the overpressured zone (at $\sim 11,000 \mathrm{ft}$ in the two study fields) is more complex, and seismic data quality degrades rapidly below this level (typically around -15,000 ft) (fig. 56). Overpressured areas, characterized by an abrupt change in P-wave velocity and bulk density, are thought to strongly influence the quality of deep seismic data. Within the zone of overpressure, seismic attributes do not correlate well with known hydrocarbon-bearing reservoirs. Consequently, seismic-attribute data below this level are unreliable predictors of hydrocarbon trends. 


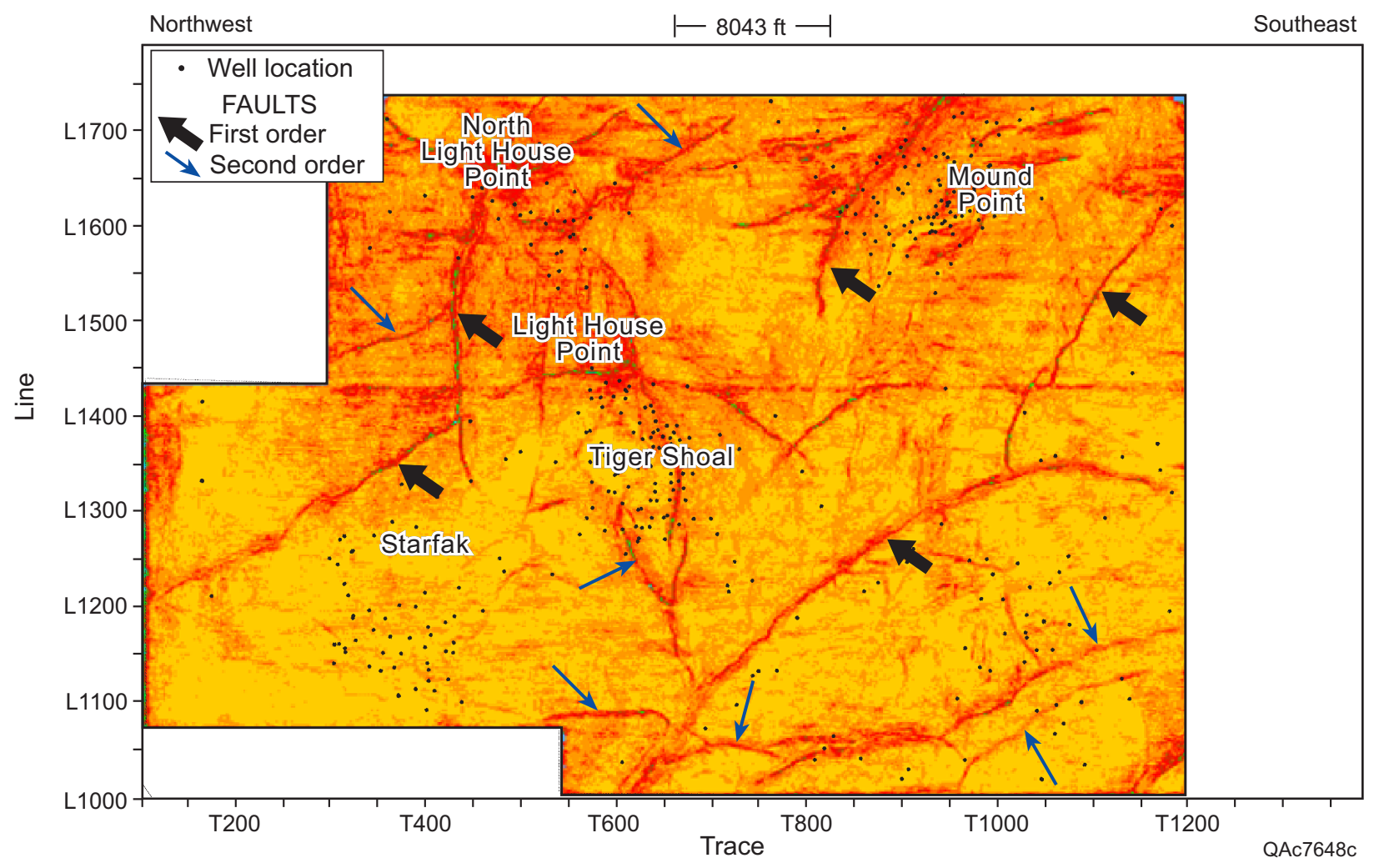

Figure 51. Coherency time slice generated at 2,000 ms revealing areal distribution of faults throughout the 3-D seismic study area. 


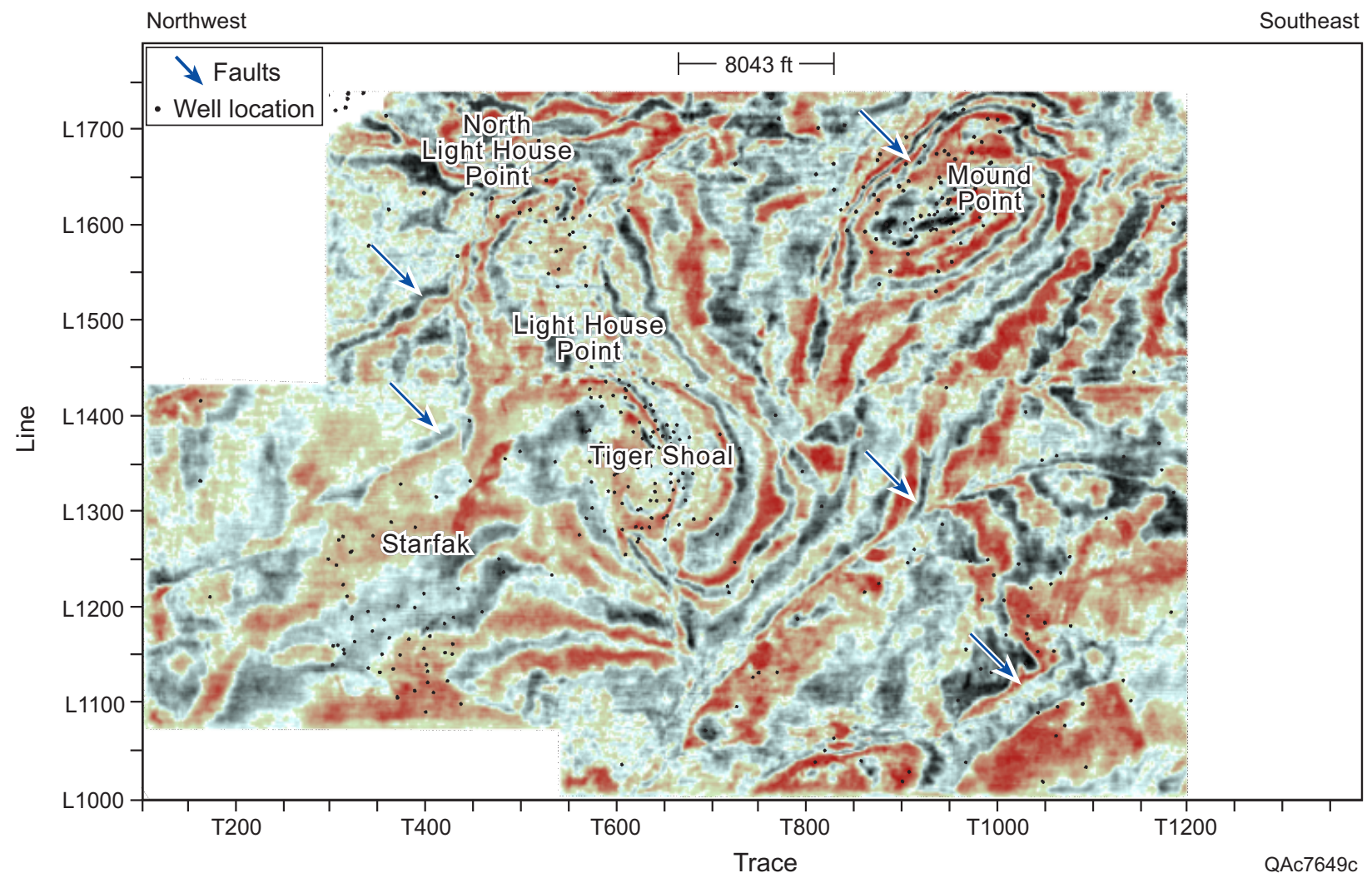

Figure 52. Conventional time slice extracted $(2,000 \mathrm{~ms})$ from the 3-D seismic amplitude volume. 


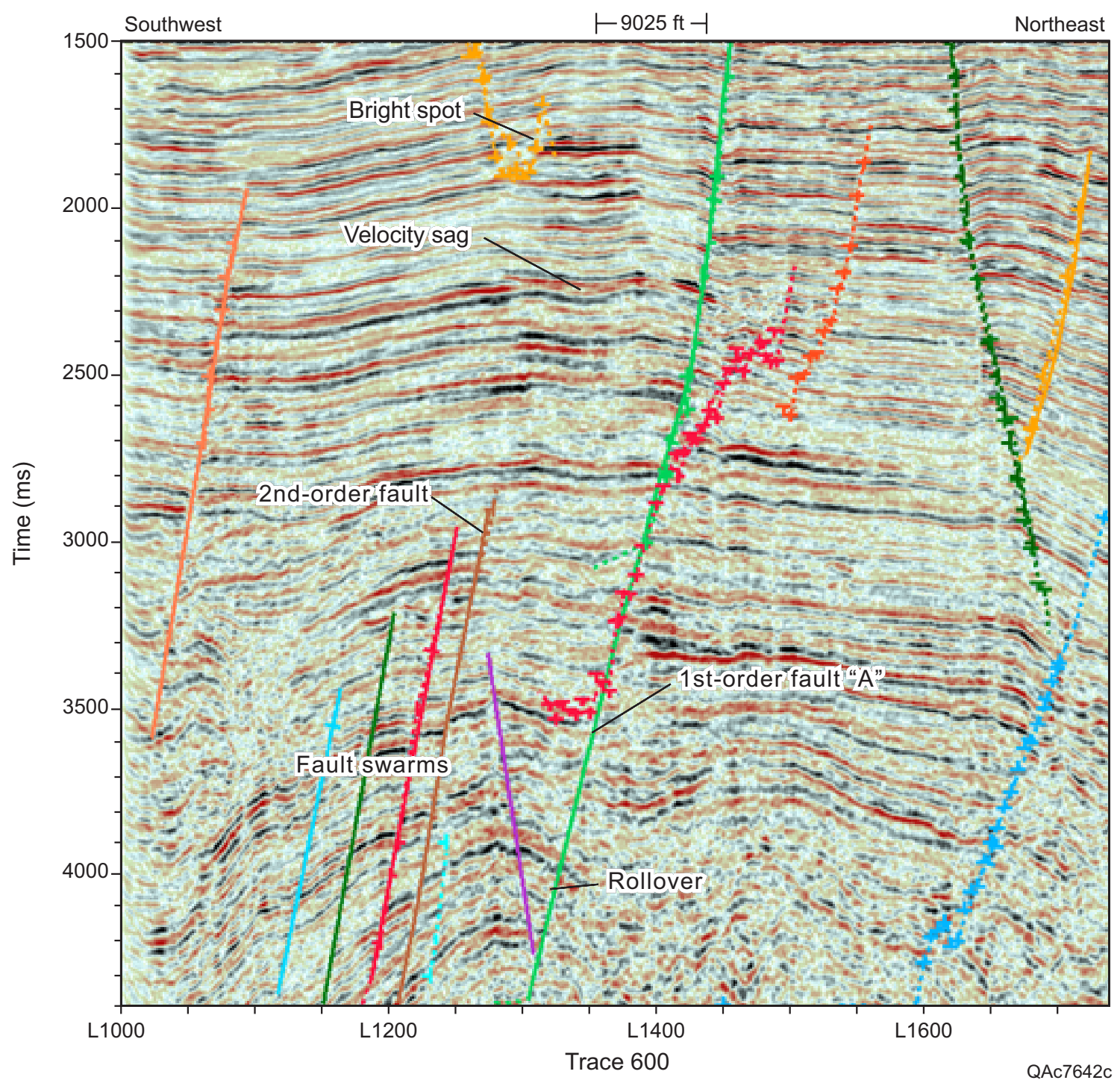

Figure 53. Vertical seismic profile showing structural (rollover), stratigraphic (bright spot), and fault interpretations of first- and second-order normal faults. 


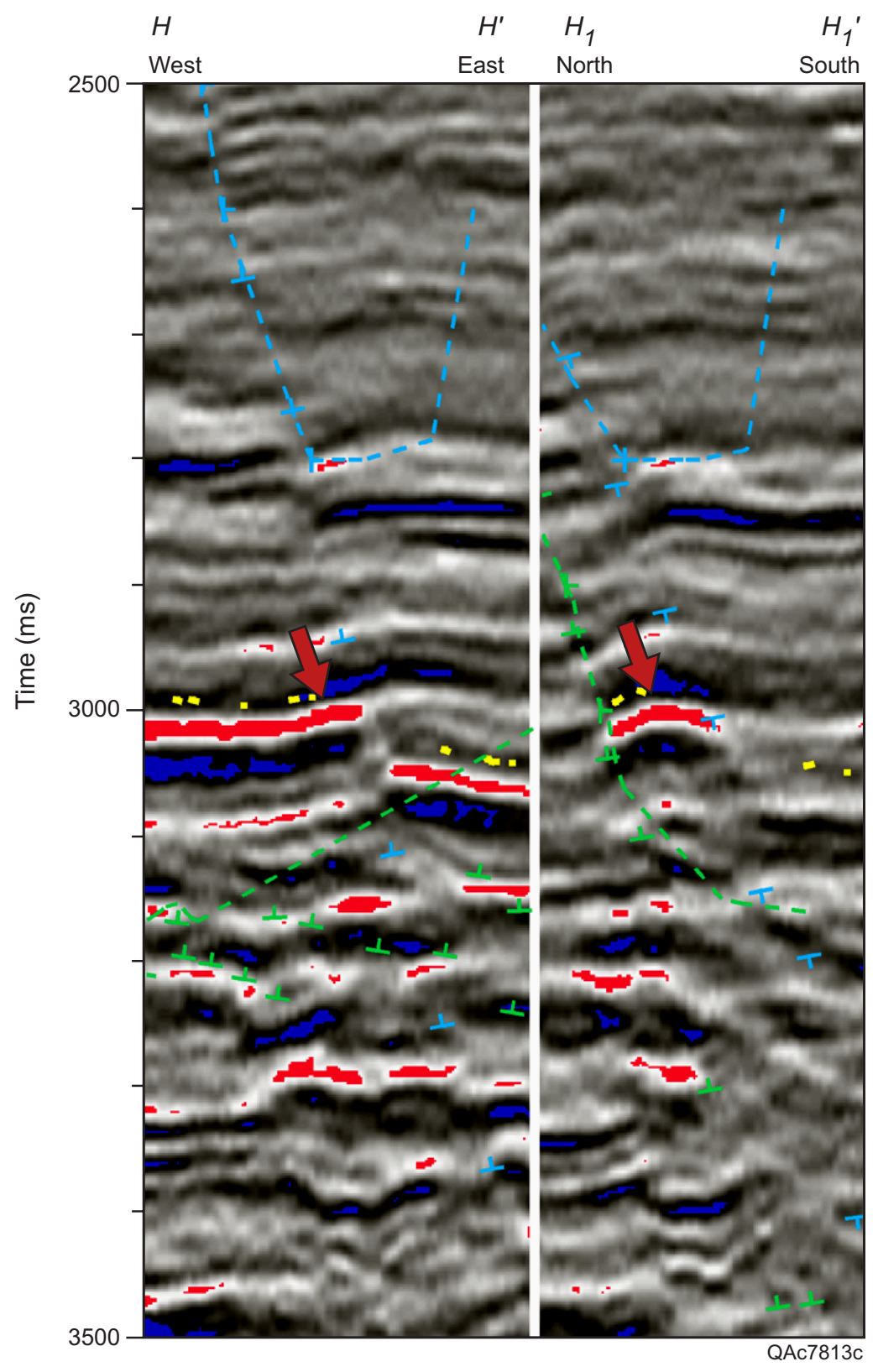

Figure 54. Vertical seismic section (a "squash plot" or horizontally compressed section) of an undrilled structural lead, characterized by a strong amplitude anomaly (arrows) terminating against a normal fault. 


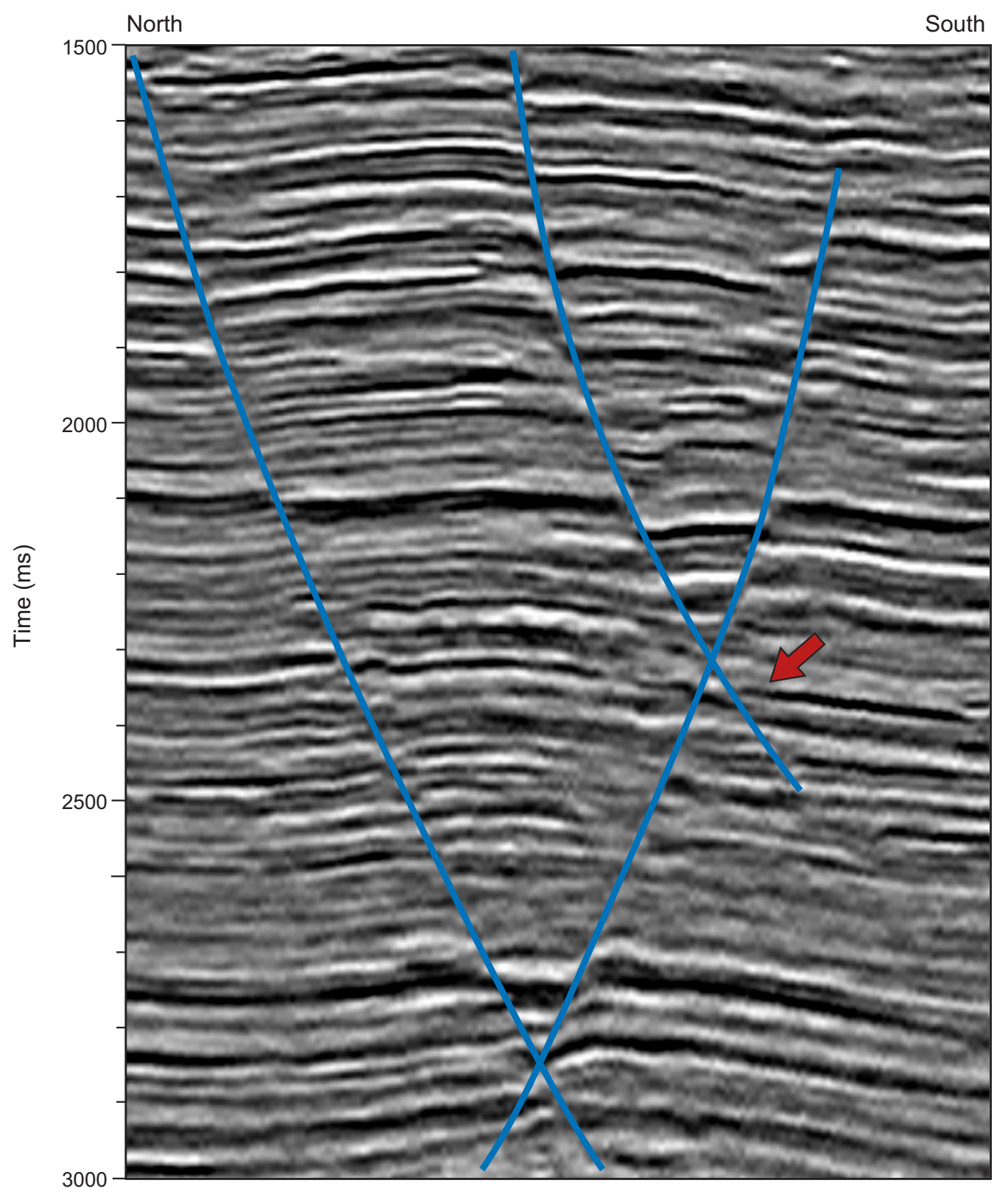

QAc7783c

Figure 55. Vertical seismic profile showing an hourglass feature associated with transecting faults. 


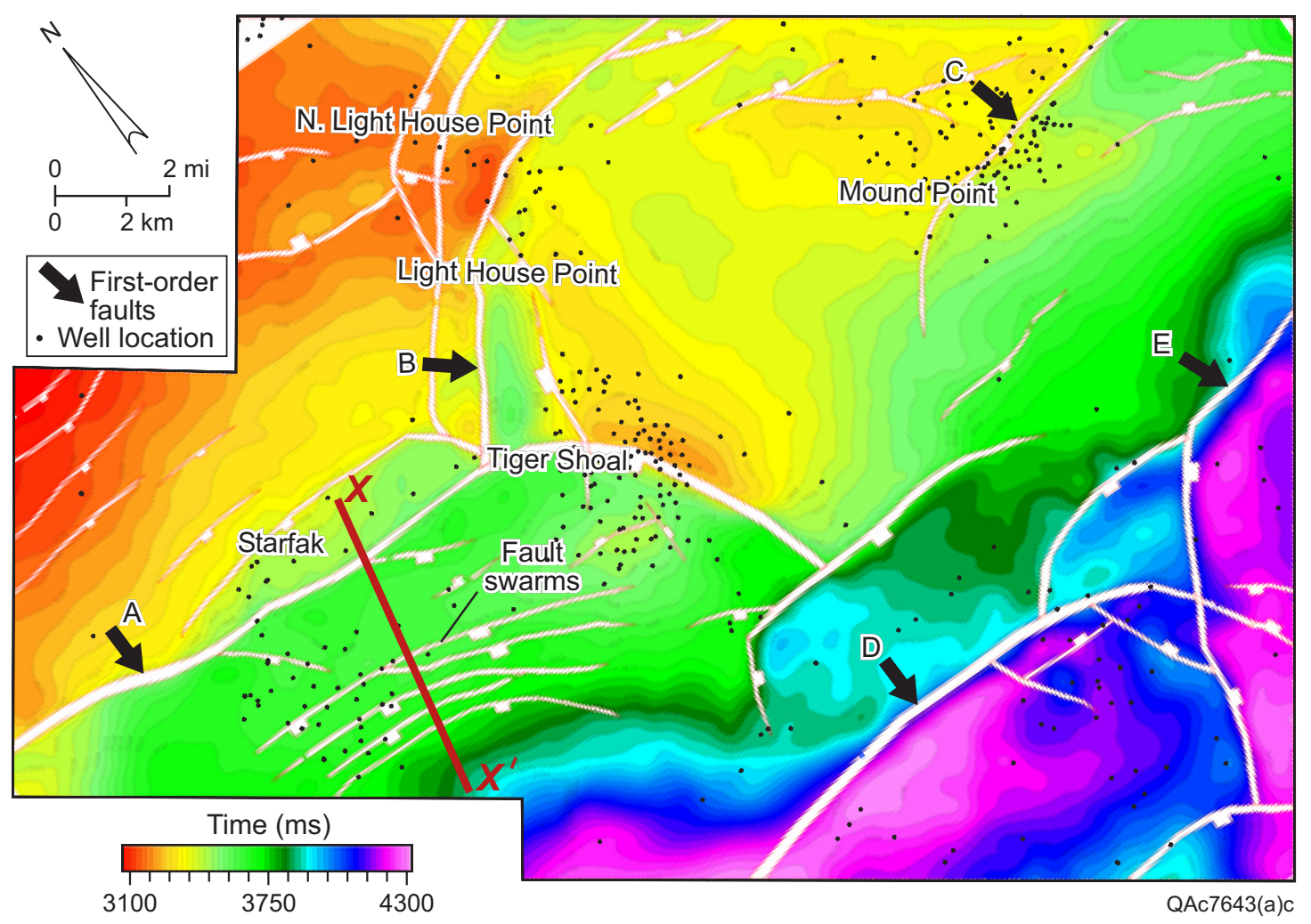

Figure 56. Time-structure map (contour interval $=25 \mathrm{~ms}$ ) of the Robulus L-4 sand with associated second-order fault swarms in Starfak field. Cross section X-X' shown in figure 57. 


\section{Deep segments of first-order growth faults have significant offset (>600 ft), and they syndepositionally}

influenced the distribution of reservoir-quality sediments in the south-southeast part of the seismic coverage area. Sequence-stratigraphic and seismic interpretation reveals several prograding wedges deposited along the south margin of the seismic area during relative sea-level lowstand (fig. 57). Lowstand wedges thicken to the south and form oval thicks that strike east-west. They are bounded at their base by a basal unconformity. This unconformity truncates underlying reflectors and is downlapped by the overlying mounded, chaotic, and sigmoidal seismic reflectors. Progradational wedges downlap onto an underlying correlative conformity and are overlain by a strong, high-amplitude, continuous reflector that represents the flooding surface. Several fault swarms of closely spaced, limited-offset, second-order normal faults cut these lowstand prograding wedge deposits in the south part of Starfak field (fig. 56). These faults most likely have significant influence on hydrocarbon migration and distribution within prograding-wedge reservoir sequences. In some cases, these faults may form seals that impede the flow of hydrocarbons, thus forming effective traps. In other cases, they may allow hydrocarbons to escape progradingwedge systems and move along the faulted rock matrix to shallower reservoir intervals.

\section{Surface-Mapping Methods}

In order to transfer key strata to the proper 3-D image time, several synthetic seismograms were generated for well-to-seismic calibration. Wells with checkshot surveys were used as controls. Checkshot data were available only from wells in Vermilion Block 50 (Starfak) field. The resulting time-depth functions were then applied to the well information for proper well-to-seismic calibration. Key stratigraphic markers were then posted in the 3-D seismic volume. It was decided early in the planning stage that maximum flooding events would be the easiest events to map across the 3-D seismic volume. They are by definition regionally extensive and produce a strong reflection signal that is easily tracked throughout the study area. The structural framework of this study area presented some obstacles for the interpreter. It became apparent early in the study that trying to map surfaces across the large firstorder growth faults associated with paleoshelf edges would be difficult. Most attempts to correlate a largely displaced updip surface with the displaced equivalent downdip surface produced uncertain results. Fault regions of minimum displacement provided the highest level of correlation confidence. Consequently, mapping began in Vermilion Block 50 (Starfak) field, where key horizon correlations had been well established in well log data. The mapping surface was then correlated and mapped throughout Tiger Shoal field. Subsequent mapping continued to the north of the study area and stopped at the major growth fault associated with the shelf edge. The surface was then correlated over the large growth fault in the northeast of the study area. Finally the surface was extended to the south and terminated in the south-central sector of the study area. All surfaces that were mapped in the 3-D seismic data followed this approach, allowing the interpreter to take advantage of areas of minimal offset across the larger first-order faults. 


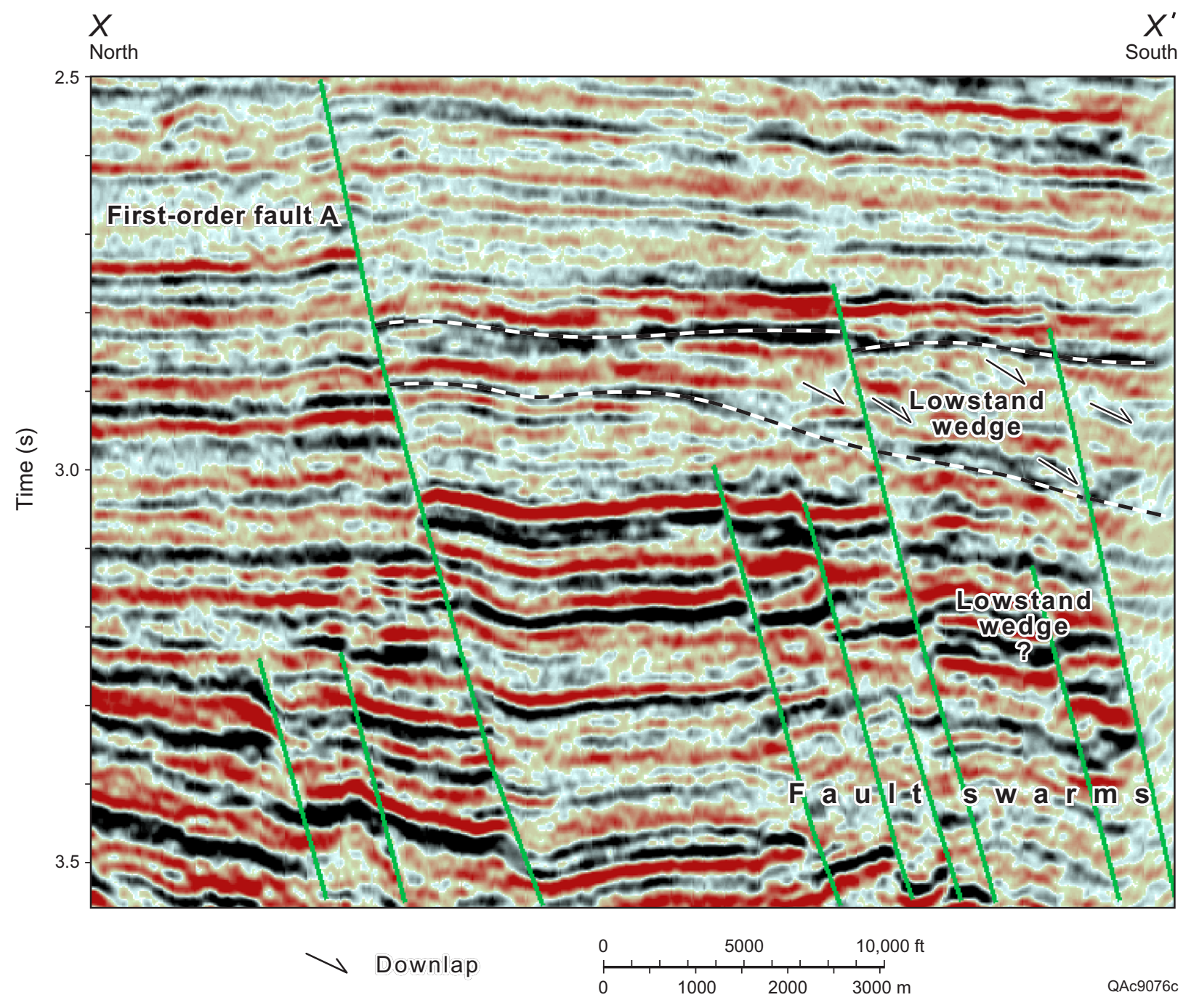

Figure 57. Squash-plot (horizontally compressed) cross section showing seismic expression of lowstand prograding wedge. Location of cross section shown in figure 56. 
Time-structure maps revealed several structural high points within the study area (fig. 58). Tiger Shoal and Mound Point fields are structurally high, with a locally depressed block flanked by faults on each side, examples of classic graben features. Light House Point and North Light House Point dominate the central, northwestern portions of the study area. Within each of these fields normal faults play a significant role in hydrocarbon trapping. In addition, Starfak field is a subregional high point in the south-southwestern portion of the study area. All of these topographical features are conformable to depth, having impact on possible structural plays even at depths corresponding to the Robulus "L" sands. These time-structural highs have been heavily targeted for hydrocarbon exploitation.

The study area is dominated by extensional normal faulting, with no evidence of compression. A significant first-order growth fault (A in fig. 58) runs east to west through the middle of the study area. This fault forms the northern boundary of Starfak and Tiger Shoal fields. In the area north of Starfak field, this fault has offsets greater than $350 \mathrm{ft}$. Producing reservoir sands are on the downthrown side of this fault. In addition, offsets decrease $(<250 \mathrm{ft}$ ) in Tiger Shoal field, with reservoir-quality sands on both sides of the fault. A north-southtrending, first-order fault (B in fig. 58) separates Light House Point and North Light House Point fields. It forms the western boundary of Light House Point field and has offsets greater than $350 \mathrm{ft}$. Mound Point field is bounded on the western edge by a first-order normal fault ( $\mathrm{C}$ in fig. 58). The fault trends from the southwestern portion of Mound Point field and extends to the northeast beyond 3-D seismic coverage. Most reservoir-quality sands are on the downthrown side of the fault. Offsets exceed $350 \mathrm{ft}$ at the $12000 \mathrm{~A}$ sand reservoir interval. Two first-order growth faults (D and E in fig. 58) separate important fault basins located in the southern and southeastern portions of the study area from the five major opportunities within the study area. These two faults, characterized by offsets ( $>500 \mathrm{ft}$ ) increasing with depth and thickening basinward deposits, are thought to define the shelf edge. Downdip deposits may offer good trend plays, targeting stratigraphically trapped (pinch-out) hydrocarbon accumulations that parallel the fault line (strike). Additional fault complexes are evident throughout the study area, each with potentially significant bypassed hydrocarbon accumulations.

First-order growth faults have many associated rollover features (fig. 53). Rollovers are created when active normal faults drag beds of the downthrown block at a rate faster than that of the upthrown block, creating structural closure on a minimum of two sides. Rollovers are excellent targets for hydrocarbon accumulations. These features are commonly found in the lower portions of first-order growth faults, where fault juxtapositioning is greatest.

Structure below maximum flooding surface 45 is more complex. First-order growth faults have significant offset ( $>600 \mathrm{ft}$ ) with depth and influence the channeling of reservoir-quality sediments into the south-southeastern portion of the study area. The seismic data reveal wedges thought to be deposited during a rapid eustatic fall. Several fault swarms (fig. 59) were interpreted in the south part of Starfak field. They are characterized by closely spaced second-order normal faults with limited offset (<100 ft.) Many of the faults impact the lowstand systems tract wedges and may have significant influence on hydrocarbon mobility at these depths. In some cases, where offset is greater than sand thickness, they may form seals that impede the flow of hydrocarbons and form effective traps. In other cases, they may allow hydrocarbons to escape lowstand-wedge systems and move along the faulted rock matrix to shallower reservoir intervals. 


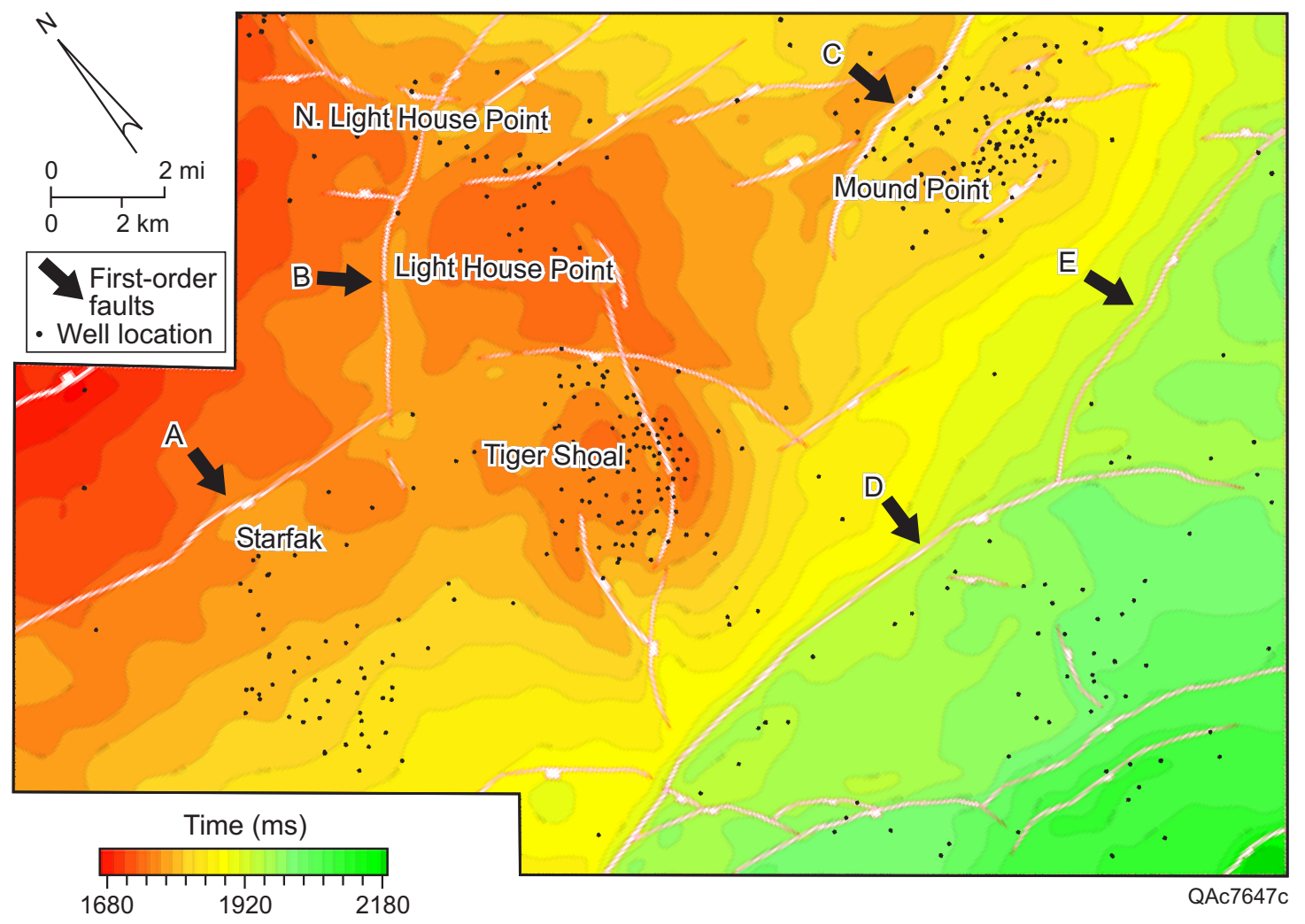

Figure 58. Time-structure map (contour interval $=20 \mathrm{~ms}$ ) of MFS 2 depicting the subsurface topography associated with the five major producing fields. Note the five (A, B, C, D, and E) first-order normal faults. 


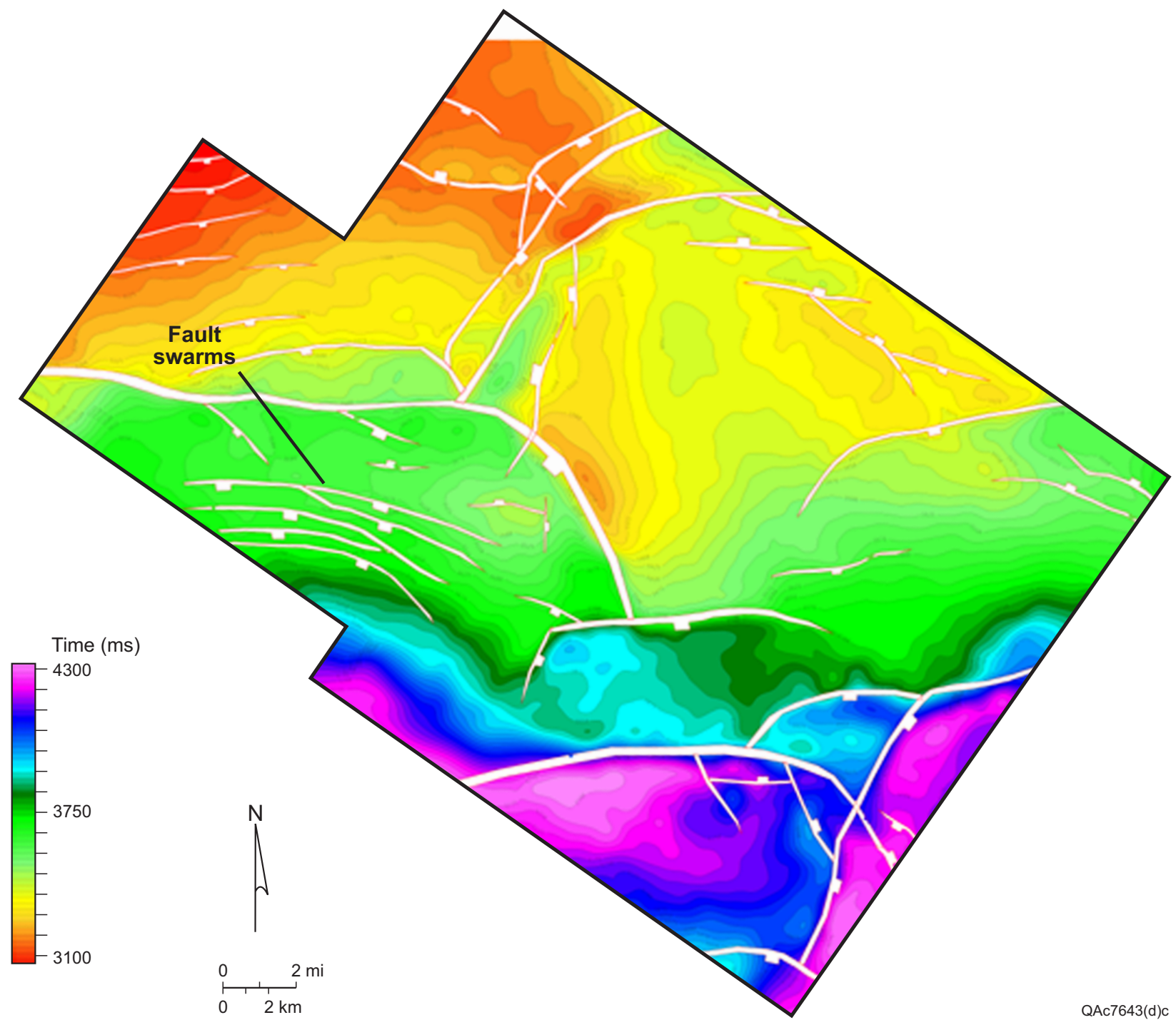

Figure 59. Time-structure map (contour interval $=25 \mathrm{~ms}$ ) of the Robulus L-4 sand with associated second-order fault swarms in Starfak field. 
RMS-Amplitude Analysis

Seismic-reflection-amplitude information can be useful in identifying unconformities, reefs, channel and deltaic sands, lithology, and gas/fluid accumulations. Amplitude anomalies may also be attributed to constructive or destructive interference (tuning effect) caused by two or more closely spaced reflectors, as well as to variations in net sand within a thin-bed unit. Root-mean-squared (RMS) amplitudes are calculated as the square root of the average of squares of amplitudes found within an analysis window. These RMS amplitudes are sensitive to sandstone-bearing depositional systems tracts within the reservoir-bearing successions and help define the spatial distribution of genetically related depositional successions. In the northern Gulf of Mexico Basin, sand-rich, third-order lowstand-systems-tract successions, characterized by high amplitudes, can be distinguished from those having low amplitudes typical of the shale-rich transgressive and early highstand systems tracts. RMS-amplitude maps can also image stratigraphic leads that have been missed by previous exploitation programs.

Several examples of RMS-amplitude maps on which opportunity leads were identified are presented next. Calculating RMS amplitudes between two bounding maximum flooding surfaces generated a map illuminating several depositional elements (fig. 60) associated with the D sand, a lowstand reservoir in the mapped area. On this map, a large lowstand incised-valley system traverses the middle part of the study area. Available well data indicate that this feature has been heavily exploited. Mound Point field, however, has two promising leads previously overlooked by exploitation programs. The northernmost lead (lead 1) has a strong amplitude anomaly located on the downthrown block of a second-order growth fault. The associated faults have more than $100 \mathrm{ft}$ of throw, which is most likely sufficient to seal any hydrocarbon accumulations. The second lead (lead 2) is a sinuous feature interpreted to be remnants of an ancient fluvial system. Its strong amplitudes are on the upthrown block and truncate abruptly against a second-order growth fault.

A second RMS-amplitude map (fig. 61) of the F sand reservoir interval identified three possible additional leads. A strong amplitude anomaly (lead 3) positioned on the downthrown block of a first-order growth fault is an excellent target. The sand body is interpreted to "shale-out" or terminate before it reaches the first-order growth fault. A prominent dark-blue lineation flanks the west edge of this anomaly and is interpreted to be a shale plug. To the immediate south of lead 3, an additional lead (lead 4) was identified. This lead is characterized by a strong amplitude anomaly bounded to the north by a second-order growth fault. Lead 5 is located in Mound Point field. It is characterized by a strong amplitude anomaly located on a graben feature. This sinuous feature is flanked on the north and south by second-order growth faults.

More than 20 stratigraphic leads in the Starfak-Tiger Shoal area were identified with RMS-amplitude maps generated for 18 separate reservoir levels. Commonly, vertical seismic sections fail to clearly identify these important stratigraphic features because they are typically manifested as subtle variations in amplitude strength, 


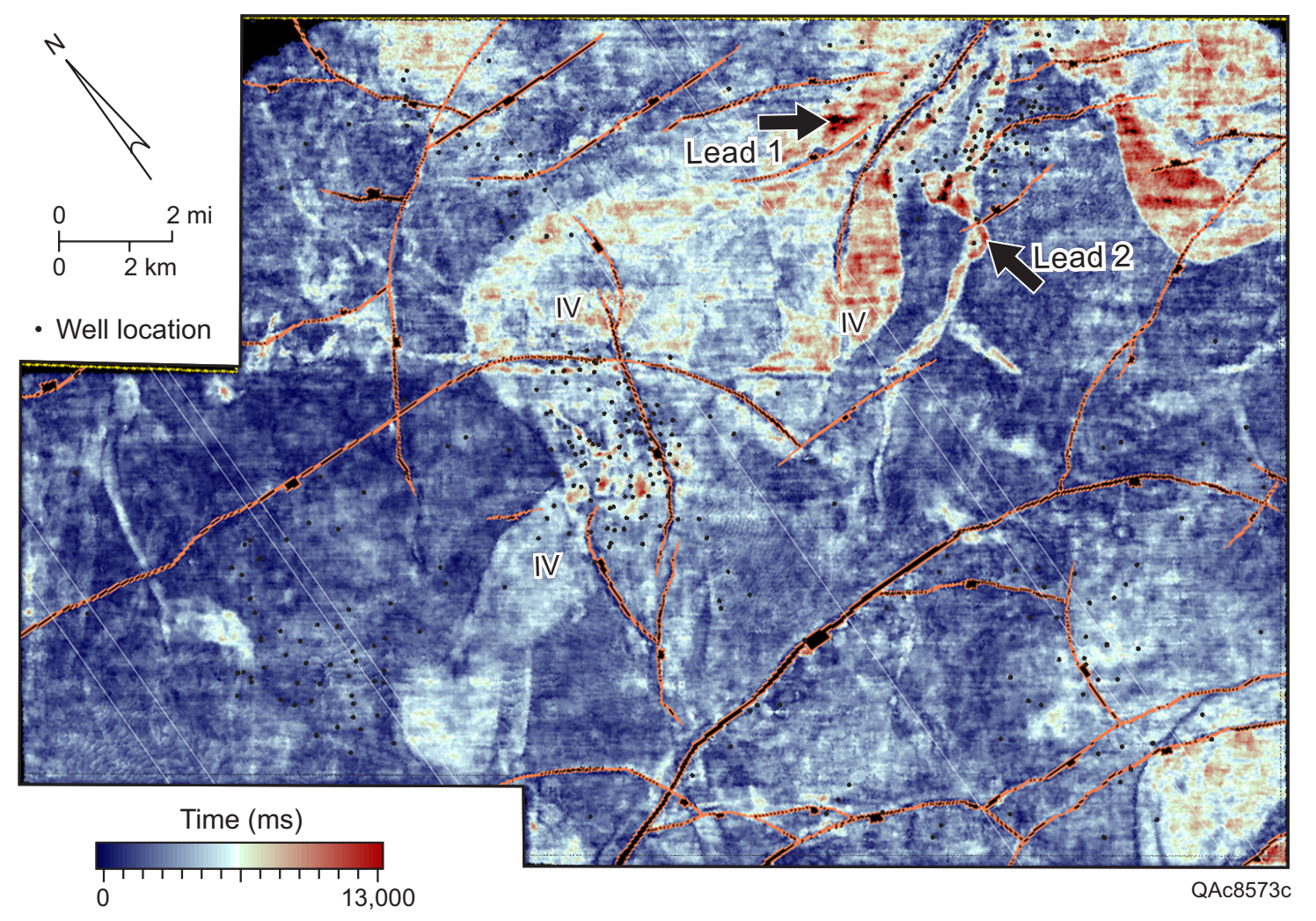

Figure 60. Root-mean-squared (RMS) amplitude map of D-sand interval extracted from 3-D seismic data set over study area. Note large incised valleys (IV), as well as smaller distributary channels. Several stratigraphic fluvial- or distributary-channel opportunities (leads) are shown. 


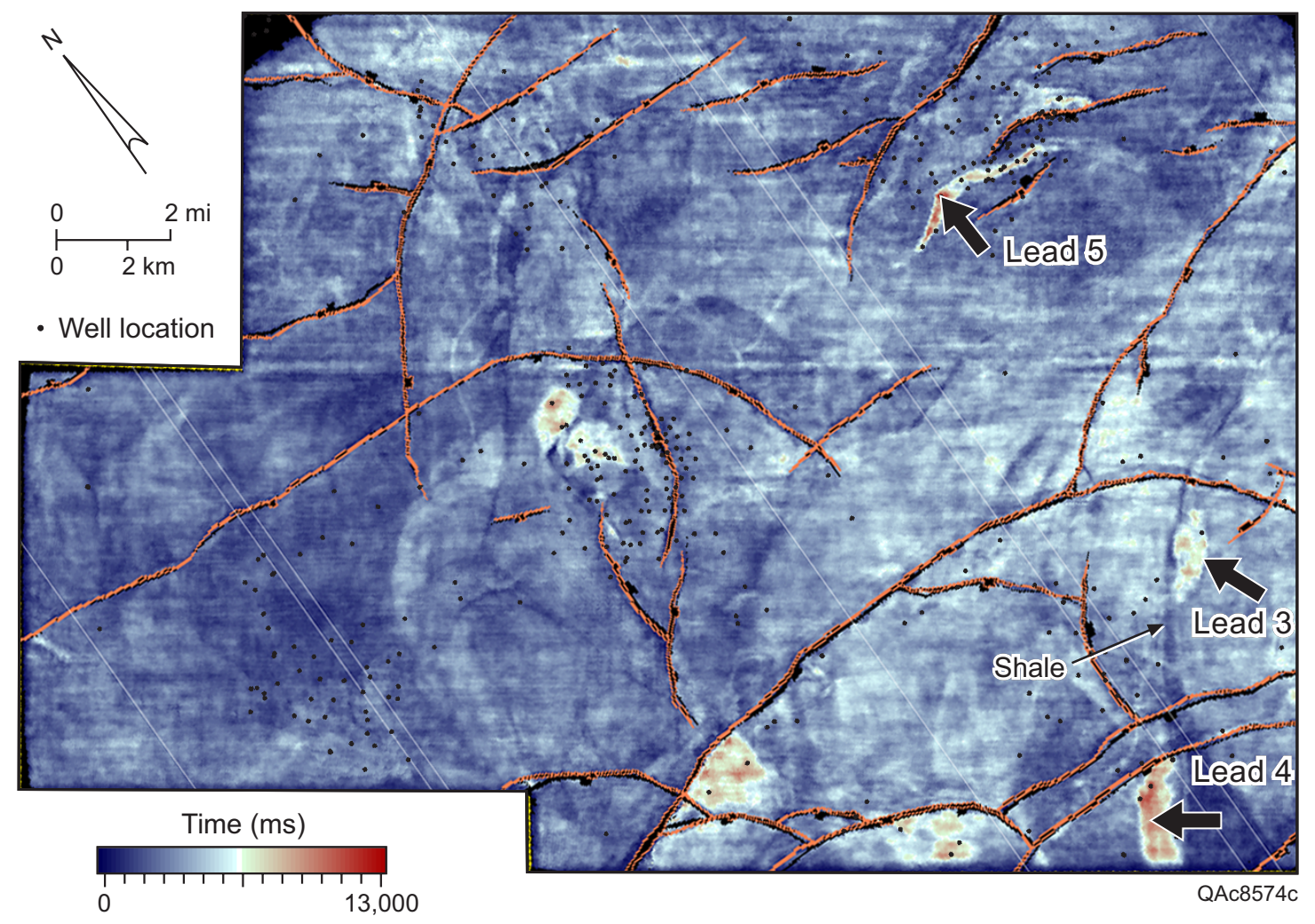

Figure 61. Root-mean-squared (RMS) amplitude map from F-sand interval extracted from the 3-D seismic data set over the study area. The thin orange lines are down-to-the-southeast normal faults. Several stratigraphic fluvial- or distributary-channel leads are pointed out, including the Lead 3 opportunity. This accumulation (red) is limited on its west side by shaly (dark) facies. 
phase shift, or polarity reversal and are easily overlooked by interpreters. Imaging these leads in a horizontal view adds additional information of spatial distribution of important stratigraphic features to the typical seismic crosssectional geometries used to interpret seismic facies. Such spatial-distribution and planform views can be used to interpret depositional patterns that lend insight into the associated reservoir quality. In this study, the sinuous nature of these features can only be seen in such a horizontal view, and well data from the area, as well as analogs from both modern and ancient fluvial systems, indicate that such sinuous features are highly likely to be incised valleys or channel reservoir sands.

\section{Amplitude Stratal Slicing}

In this project, a new seismic-imaging approach called amplitude stratal slicing was applied (Zeng, 1994; Zeng and others, 1995; Posamentier and others, 1996; Zeng and others, 1998a, b) to improve the picking of depositional surfaces in wedge-form and growth-faulted sequences and to increase the preservation of planiform geometry for interpreting reservoir facies. Problems exist in the use of conventional time or horizon slices for imaging geologic-time surfaces. Time slices are extracted from the data volume at a constant traveltime. Likewise, a horizon slice is constructed by extracting a seismic attribute parallel to and away from a picked horizon. For either approach to be accurate, one must assume that the formation being sliced is flat lying or that it has a sheetlike geometry. Most data volumes are characterized by significant thickness changes and faulting, however, that can cause horizon- or time-slice surfaces to sample strata from seismic events of different ages. Surfaceextraction and interpretation tools and methods to ensure accurate extraction of time-equivalent data points are, therefore, needed. These tools should also provide maximum preservation of planiform geomorphic or sedimentologic features, which are so useful in creating an accurate seismic interpretation. Like aerial photographs or satellite pictures of modern depositional systems, stratal slices can be used in sedimentological study of ancient depositional systems. Seismic-attribute patterns on stratal slices help to establish the link between geomorphology and depositional models. The integration of well and regional geologic information further enhances the creditability of the sedimentological interpretation.

A segment (upper Miocene) of sonic and density logs from Starfak well Texaco 30-2 was first converted to an acoustic impedance (AI) log, which was then plotted against the effective porosity $\left(\phi_{\mathrm{e}}\right)$ derived from density and GR $\operatorname{logs}$ (fig. 62). Effective porosity is here an indicator of lithology, with the highest $\phi_{\mathrm{e}}(>0.3)$ being clean sandstone, the lowest $\phi_{\mathrm{e}}(<0.1)$ being shale, and intervening values being shaly sandstone and sandy shale. Notice that statistically, AI decreases linearly with increasing $\phi_{\mathrm{e}}$ (fig. 62). In other words, sandstone is characterized by an AI lower than shale. If bounded by thick shale, the top of the sandstone would be reflected as a seismic trough (zerophase wavelet in polarity reversed from the Society of Exploration Geophysicists standard).

After careful depth-to-time conversion and seismic-phase adjustment, acoustic separation of sandstone and shale on a well-to-seismic-tied section can be shown (fig. 63). More than 90 percent of the sandstones (middle Miocene-Pliocene) are tied to seismic trough events (red) without much ambiguity. Not only are regionally 


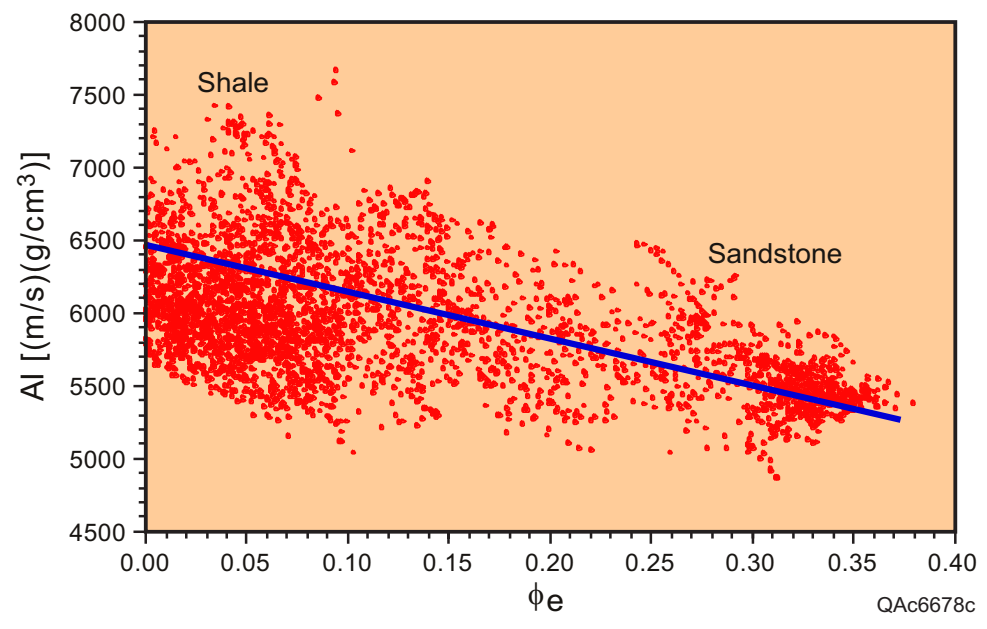

Figure 62. Acoustic impedance (AI) as an indicator of lithology (effective porosity). AI is calculated from sonic and density logs (product of velocity and bulk density), and effective porosity $\left(\phi_{e}\right)$ from density and GR logs (density porosity with clay effect removed). Data are sampled from the 6,550- to 8,850-ft section (upper Miocene) in well $30-2$. 


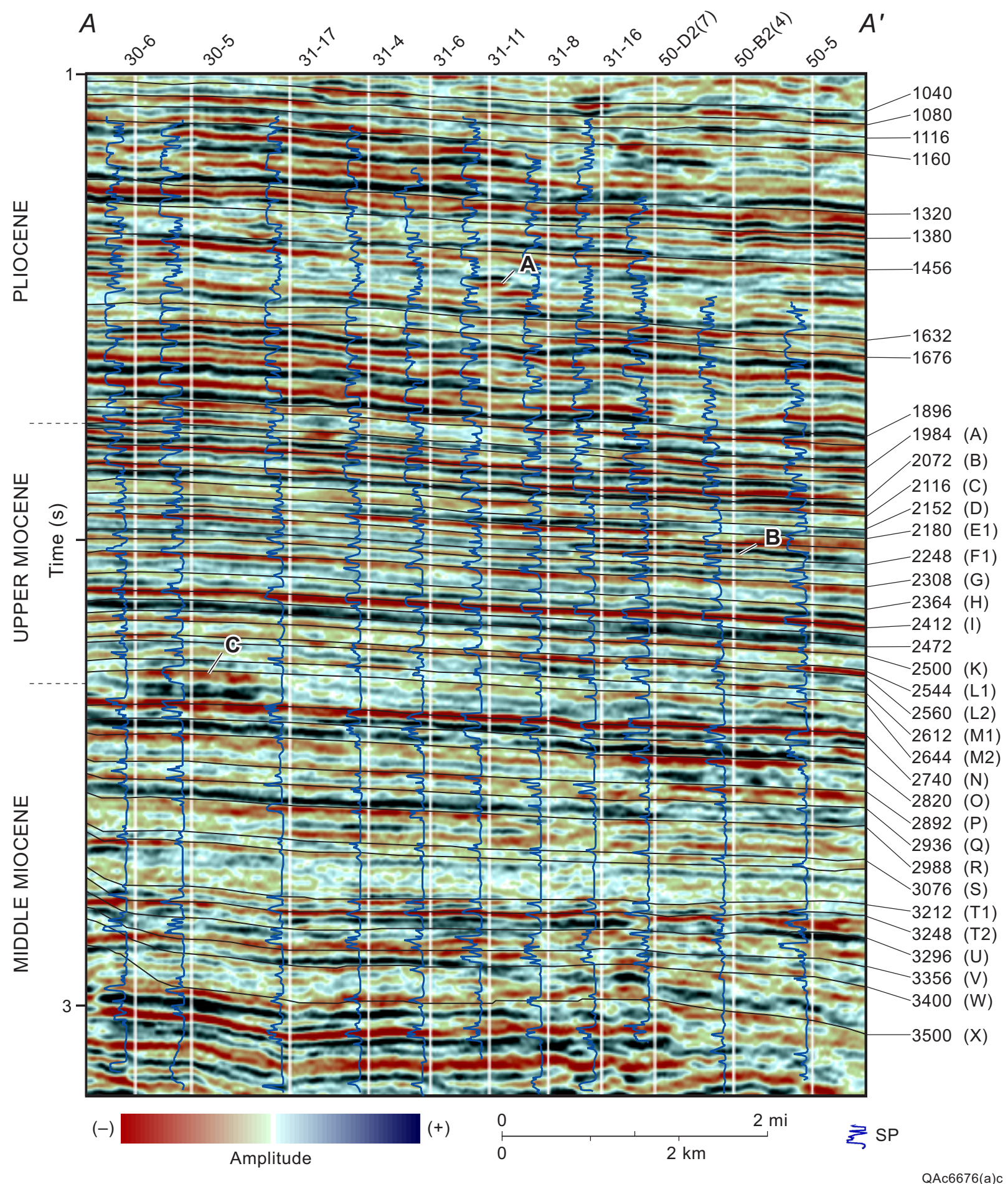

Figure 63. North-south-oriented cross section A-A' of Starfak field showing well-to-seismic correlation in two-way traveltime. Stratal slices are numerically ordered according to increasing geologic time (no scale). Texacodesignated reservoir (lithostratigraphic) units are identified by letters in parentheses. Three lenticular sandstones tied to patchy seismic events are designated by the letters A, B, and C. Numbers represent approximate surface depth in time. See figure 159 for location. 
continuous sandstones confined to continuous seismic trough events (for example, B, I, and N sands in fig. 63), but many lenticular sand bodies also show excellent correlation to patchy seismic events (for example, A, B, and C in fig. 63). In contrast, most of the shales are characterized by seismic peak events (black). The only exceptions are some thick shaly units in the middle Miocene section (R to T-1 sand in fig. 63) that are reflected as complex peaktrough couplets, an indication of internal heterogeneity. With limited well calibration, the seismic amplitude (trough) can be safely used as an indicator of sandstone.

Seismic attributes must be extracted on a depositional surface (geologic time surface) if they are to represent the maximum extent of a depositional unit. Such a seismic-surface display is called a stratal slice. Stratal slicing improves seismic-surface display mainly by making slices linearly between geologic time-equivalent seismicreference events (for example, maximum flooding surfaces). To simplify the discussion it is assumed that such reference events can be picked without difficulty. In doing stratal slicing, it is also assumed that deposition is laterally proportional in thickness for all depositional units. No unconformities (truncations) or other discordant reflections (onlap, offlap, toplap, etc.) can occur between the reference events. However, as shown later, sequence boundaries can be an exception when average erosion along such boundaries is limited to tens of meters and below seismic resolution.

A stratal-slice volume was generated among 13 reference seismic events in the middle Miocene-Pliocene section. Among 776 stratal slices in the roughly 3.0-s data interval, some have been highlighted on the well-toseismic section (fig. 63) to show representative stratal slices in two-way time and their relationship with seismic events, lithostratigraphic units, and well log characteristics. These slices demonstrate typical depositional facies images in different stages of basin development. However, only selected slices are discussed herein for highlighting methodology and interpretation of stratal slices.

The interpretation of stratal slices should be an integrated process that uses all of the available geologic well data in tandem with seismic data. The key component of this process is the use of modern depositional and geomorphic models to guide interpreters in recognizing depositional patterns in seismic-attribute slices. In some cases, patterns alone are enough for accurate facies identification (for example, a meandering fluvial system). In other situations, however, well information such as well log facies or stacking pattern is helpful in deciphering the nature of the depositional feature. In this study, the following pieces of information were used in seismicpattern/depositional-facies conversion:

- Pattern geometry: channel (shoestring), lobe, digitate, sheet/random, etc.

- Pattern texture: smooth, patchy (variable), wormlike, etc.

- GR/SP log pattern: upward fining, upward coarsening, blocky, serrate, straight, etc.

- Amplitude (seismic-lithology relationship): negative (thick/blocky sand), positive (shale/condensed section), low/variable (variable polarity, thin sand/shale), highly negative (gas sand).

- Relationships: regional setting, structure, sea level/systems tract inferred by sequence-stratigraphic study, etc. 
For example, slice 1160 (fig. 64a) illustrates some moderately sinuous, channellike features. Internal amplitudes are smoother than those surrounding the features. Using seismic-lithology modeling, negative amplitudes indicate thick sandstone trends. Wells that penetrate these features show that they are characterized by an upward-fining log pattern, supporting evidence of a fluvial channel fill (fig. 64a, $\log 2$ ). Outside of the channels, wells penetrate shale (fig. 64a, $\log 3$ ). The slice is in the Pliocene section, an interval interpreted by sequence-stratigraphic study as developing primarily in a coastal-plain environment. Therefore, the best interpretation of these features would be that they were formed and filled by tributary streams.

Slice 2248 (fig. 64b) shows a remarkably different channel type. Most of these features, subregional in size, exhibit low sinuosity with local bifurcation downstream. Internally smoothed, negative-amplitude patterns are visually striking as compared with surrounding sheetlike, mostly positive amplitude patterns. These features are composed of sandstones characterized by mostly blocky and fingerlike log patterns in the penetrating wells (fig. 64b, logs 1 and 2). In contrast, the surrounding positive amplitudes are correlated with shale in wells (fig. 64b, $\log 3$ ). Stratigraphically below the Pliocene coastal-plain deposits, these Miocene features represent incised-valley fills (IVF's) that incise exposed shelf facies. The IVF's contain deposits of lowstand and transgressive systems tracts. Similar IVF's can be seen terminating updip in the coastal plain (fig. 64a), indicating that at least some of the IVF's also drain the landwardmost portion of the lowstand coastal plain.

Slice 2472 (fig. 64c) highlights generally lobate and digitate aerial geometries that have negative amplitudes inferred to be thick sandstone bodies. Each fingerlike or channellike feature grades downdip to low-/variableamplitude lobes. Penetrating wells in channels show typical upward-fining, distributary-channel patterns overlying the upward-coarsening, prograding deltaic deposits (fig. 64c, log 1). Delta-front deposits are characterized by thin, interbedded sandstone and shale of upward-coarsening and serrate patterns (fig. 64c, log 2). Sandstone content further decreases in prodelta/shelf environments where the penetrating wells encounter shaly deposits that have weak upward-coarsening trends (fig. 64, $\log 3$ ). On the basis of its highstand position in the sequence-stratigraphic framework, the system has been interpreted as a highstand on-shelf delta.

In the study interval, gas-bearing sandstones commonly show as bright spots. However, condensed sections and salt layers sometimes also generate bright spots that confuse interpreters. Facies analysis on stratal slices can help reduce the ambiguity. For instance, the F-1 sand in Tiger Shoal field produces gas in several wells (fig. 64b, $\log 2$ ). The reservoir is interpreted as an IVF sandstone and is reflected as a bright spot labeled BS I. Although incisedvalley-fill-thickness changes in the sandstone can cause amplitude variability, there is no indication that this sandstone is characterized by any significant thickness change throughout the field area. Therefore, dramatic amplitude change within the system is interpreted to be a function of fluid content and can be used to find new drilling targets. Several such undrilled, high-amplitude IVF segments (labeled as BS II-IV) are shown associated with the F-1 sand interval (fig. 64b). They appear bounded updip by faults, creating possible structural/stratigraphic gas traps. Among them, BS II has been drilled recently and proved gas productive. 


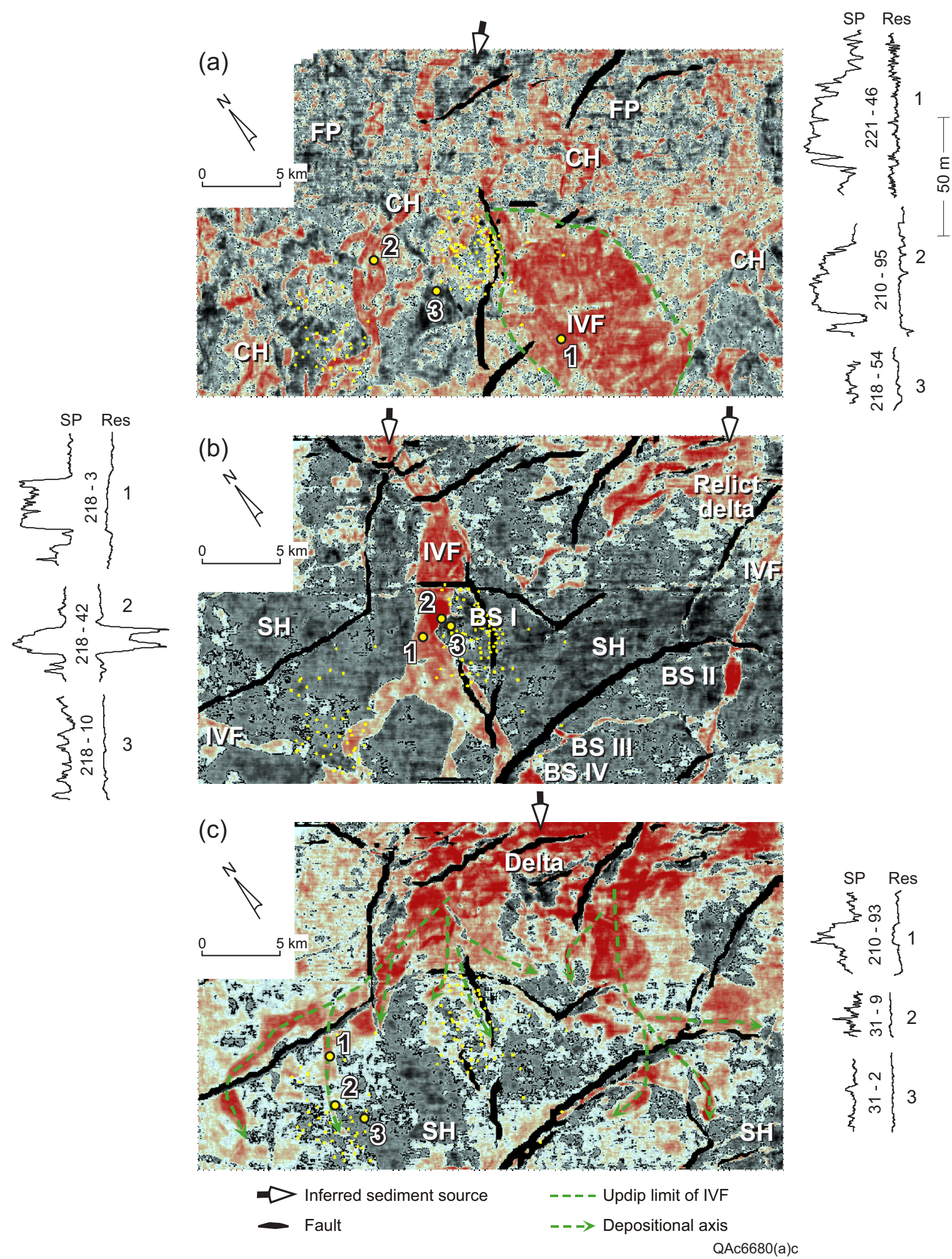

Figure 64. Amplitude stratal slices showing (a) a Pliocene coastal plain (slice 1160), (b) upper Miocene incisedvalley fill (slice 2248), and (c) an upper Miocene highstand shelf delta system (slice 2472). See figure 63 for stratigraphic position. $\mathrm{CH}=$ channel; FP = floodplain; IVF = incised-valley fill; $\mathrm{SH}=$ shelf; BS I-IV = bright spots. 


\section{Neural Network-Assisted Multiattribute Analysis}

\section{Neural Net Classification of Depositional Morphology}

Interpretation of depositional morphology and reservoir geobodies from seismic attribute images is a laborintensive and time-consuming process. However, such information collected from slices milliseconds apart can provide an immensely valuable and spatially dense database for assessment of three-dimensional reservoir architecture, as well as aid significantly in reconstruction of depositional systems evolution. The possibility of automating the initial analysis of depositional morphology was examined. A Multilayer Perceptrons (MLP) neural network application (Principe and others, 2000) was selected for (1) supervised classification of the plan-view morphology of various depositional systems on amplitude stratal slices and (2) automated differentiation of the depositional systems in 3-D. In the neural network, each input node takes on the values of one morphologic attribute, and each output node represents one facies class. Neural networks are considered superior to standard statistical classifiers for the present study because they do not assume class distribution and can better handle the nonlinearity of seismic data.

What is key is providing the neural network with morphology attributes that can effectively describe different morphology groups (facies) in a statistical sense. Examples include (but are not limited to) size, orientation, geometric tendency (for example, line or circle), and curvature. Supervised learning will involve converting sample depositional facies (visually picked by geologists) into facies categories labeled by arbitrary numbers (1, 2, 3, etc.). If results are satisfactory, the rule learned from the training can then be applied to the whole seismic data set for automated depositional facies mapping.

Figure 65 shows the morphology-based classification of fluvial and deltaic systems. Results clearly identify the systems with straight, sinuous, and anastomosing patterns as different fluvial facies (fig. 65a). Similarly, the morphologic characterization of bird-foot, cuspate, and estuarine shapes leads to the identification of three different deltaic systems (fig. 65b). Waveform (amplitude) is assumed to be insensitive to morphologic variations across facies spectra, and no texture attributes are used.

In the project's 3-D seismic volume, three types of fluvial channels were identified on the basis of the geomorphology on stratal slices (fig. 66): straight, meandering, and anastomosing. The task was to classify them as different seismic facies so that a more quantitative evaluation of the depositional-morphology-reservoir-quality relationship could be performed (Zeng and Wood, 2002). Unfortunately, channels in different facies are characterized by a similar amplitude range. Worse, waveforms of wiggle traces penetrating different-type channels are statistically identical. Their texture attributes (continuity and co-occurrence matrix) also look similar. Consequently, a waveform classification and texture analysis generated poor results. Only a morphology-based neural-network classification (fig. 67) correctly identified the three types of channels as three different facies. The result is not perfect, though, because some minor misclassifications remain in each of the facies maps. The ambiguity that occurs in automated facies mapping has apparently been reduced, but it has not been eliminated. 
(a)

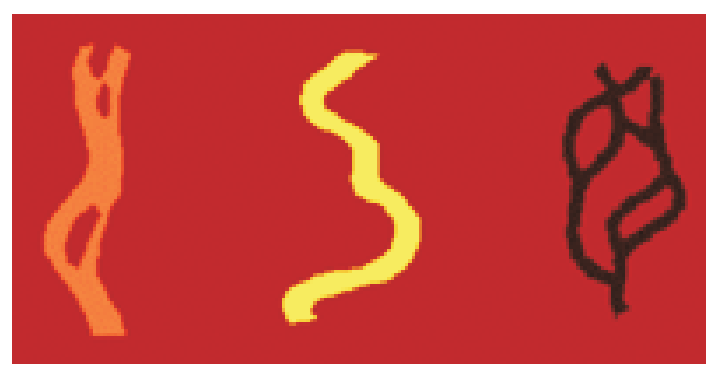

(b)

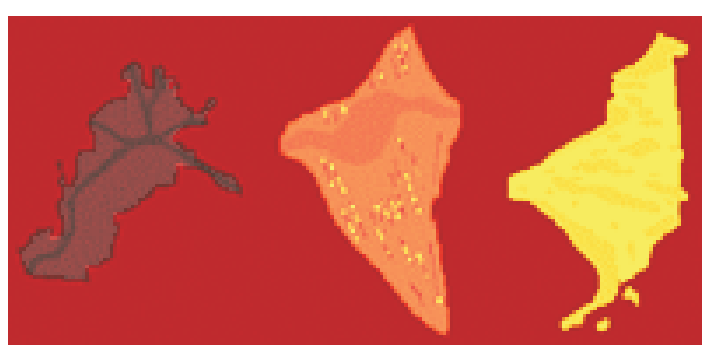

Facies

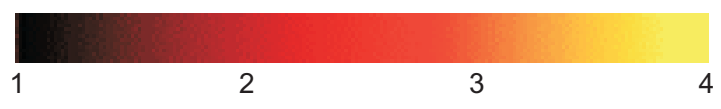

QAd866c

Figure 65. Morphology-based facies classification. (a) Fluvial systems. Facies 1 = anastomosing (suspended-load) channel (black). Facies $2=$ floodplain (not shown). Facies $3=$ straight (bed-load) channel (orange). Facies $4=$ sinuous (mixed-load) channel (yellow). (b) Deltaic systems. Facies $1=$ fluvial-dominated delta (black). Facies $2=$ interdeltaic bay/shelf (not shown). Facies $3=$ wave-dominated delta (yellow). Facies $4=$ tidal delta (orange). 
(a)

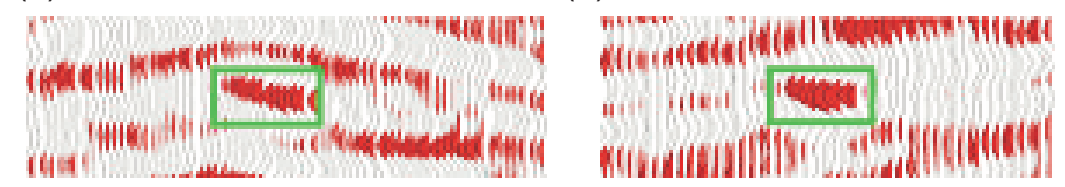

(c)

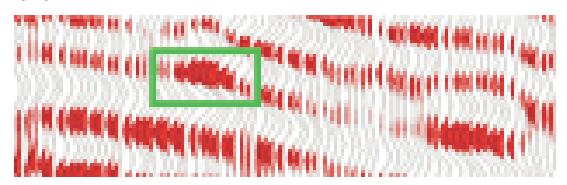

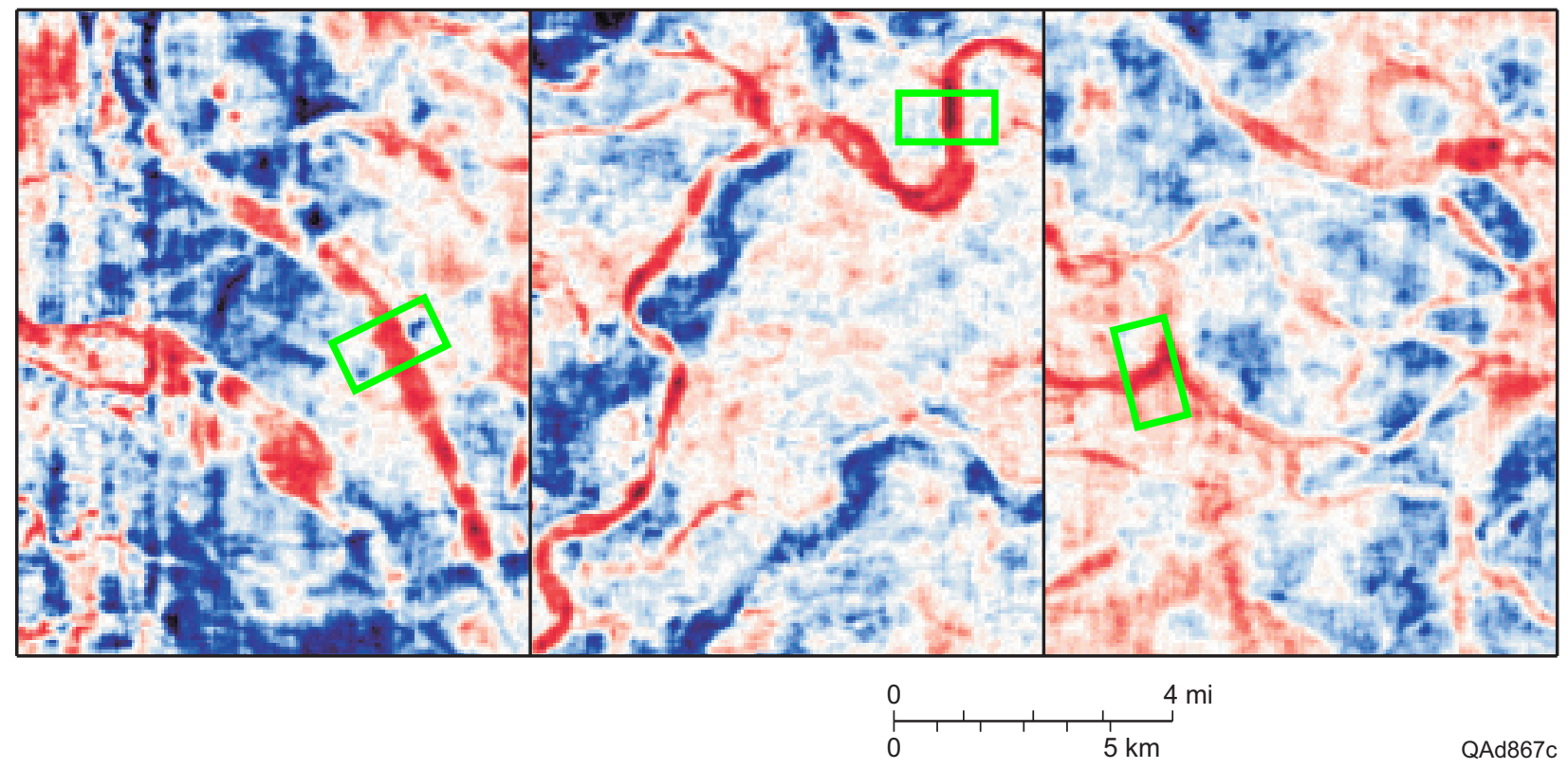

Figure 66. Amplitude stratal slices of three fluvial systems and related channel waveforms. (a) Straight. (b) Meandering. (c) Anastomosing. Although their channel morphologies are different, the three fluvial systems are characterized by similar channel waveform. 
(a)

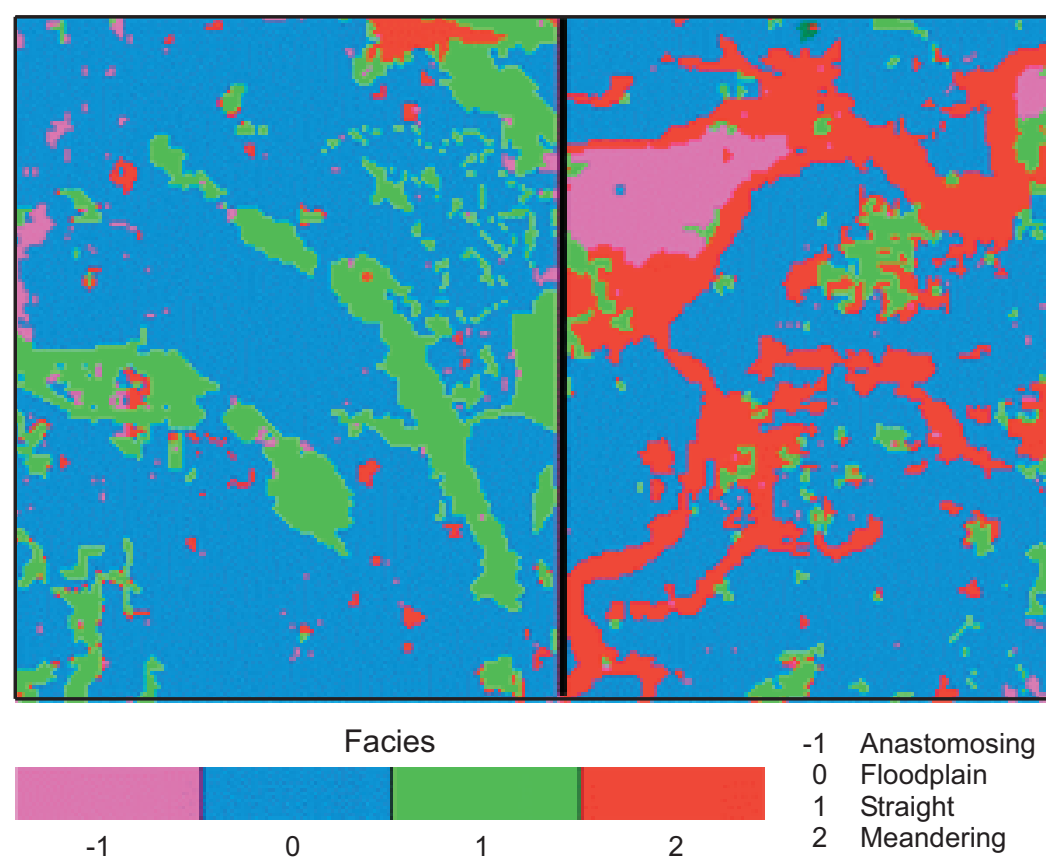

(c)

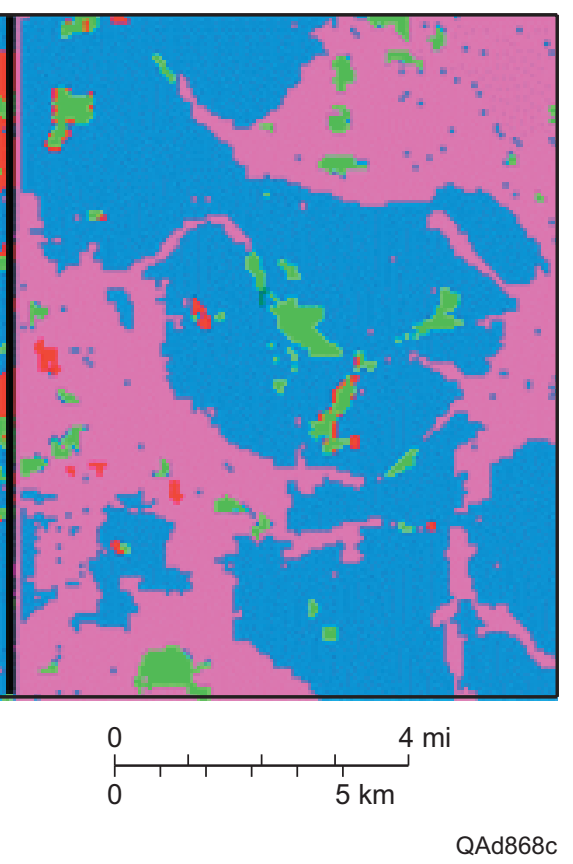

Figure 67. Morphology-based facies classification of three fluvial systems. Facies $-1=$ anastomosing-channel network. Facies $0=$ floodplain. Facies $1=$ straight channel. Facies $2=$ sinuous channel. 
One advantage of morphology-based, automated, seismic facies analysis is the ability to trace depositional (stratigraphic) features in a 3-D seismic mass at great speed and in great detail, even if they do not stand out as seismic amplitude, waveform, or texture anomalies. If a stratigraphic feature is related to potential production, the tool is also useful for developing play and trapping concepts. For example, in a seismic stratal-slice volume (fig. 68a), incised-valley-fill sandstones, fluvial-channel sandstones, and floodplain shale exhibit different geomorphologic characteristics. Amplitude and waveform were not conclusive in the attempt to distinguish sandstones of incised-valley-fill origin from those of fluvial origin. Instead, a slice-by-slice (at a 4-ms sample rate) implementation of the rules learned from morphology-based neural-network training helped to quickly generate a seismic lithofacies volume (fig. 68b), which was then easily subdivided into three subvolumes representing the three lithofacies (fig. $68 \mathrm{c}-\mathrm{e}$ ). Considering that $>90$ percent of the hydrocarbons in the study region has been produced from incised-valley-fill and other lowstand reservoirs, these results will be beneficial for future exploration and infill drilling in the area.

\section{Neural Net Prediction of Petrophysical-Log Properties}

One of the promising developments in reservoir-property inversion in recent years is the use of a multiattribute transform to predict petrophysical-log properties (Schultz and others, 1994; Russell and others, 1997; Zeng and Kerans, 2000; Zeng and others, 2000b; Hampson and others, 2001). Successful use of neural-network-assisted, multiattribute transform of seismic data into a 3-D petrophysical volume that can accurately predict lithology (shaliness or clay content), thickness, and porosity, providing the spatial density of petrophysical data necessary for full-volume reservoir modeling. Directly exploring the correlation between a log property (for example, porosity) and multiple seismic attributes at well locations, shown by

Log property $=\mathrm{C}_{1} *$ Attribute $_{1}+\mathrm{C}_{2} *$ Attribute $_{2}+\ldots+\mathrm{C}_{\mathrm{n}} *$ Attribute $_{\mathrm{n}}$,

where $\mathrm{C}_{1} \ldots \mathrm{C}_{\mathrm{n}}$ are constants, has many advantages over conventional inversion procedures. This kind of exploration can be used to map log properties without previous knowledge of acoustic impedance, it makes use of far more seismic measurements (attributes) beyond amplitude waveform, and there is no need to extract a seismic wavelet. Multiattribute transform can be built as a linear, regression problem or a nonlinear, neural-network problem. The neural-network approach is preferred because it can achieve higher accuracy (smaller error). After multiple tests, a generalized forward-feed model was selected as the neural-network training model (fig. 69). The training was conducted by using NeuroSolutions ${ }^{\circledast}$ (commercial software from NeuroDimension, Inc.).

Thirty-five wells in Starfak field were selected for neural-network training. The petrophysical-log property chosen for inversion is volume of shale (Vsh) that is calculated from gamma-ray/spontaneous potential logs in the wells. Volume of shale is an excellent indicator of lithology in the study area because it easily distinguishes clean sandstone (small Vsh) from shaly sandstone (intermediate Vsh) and shale (large Vsh). Vsh is also a good indicator of reservoir quality by showing a linear relationship to effective porosity: the smaller the Vsh, the larger the porosity 

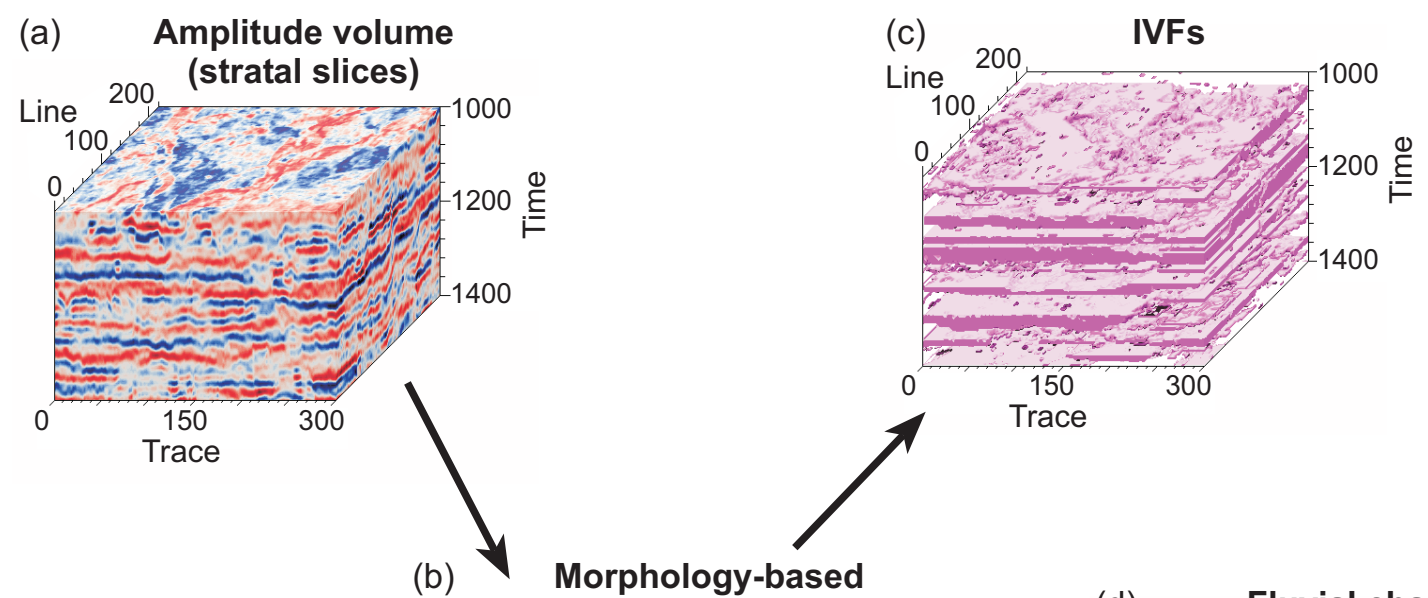

(b)

Morphology-based

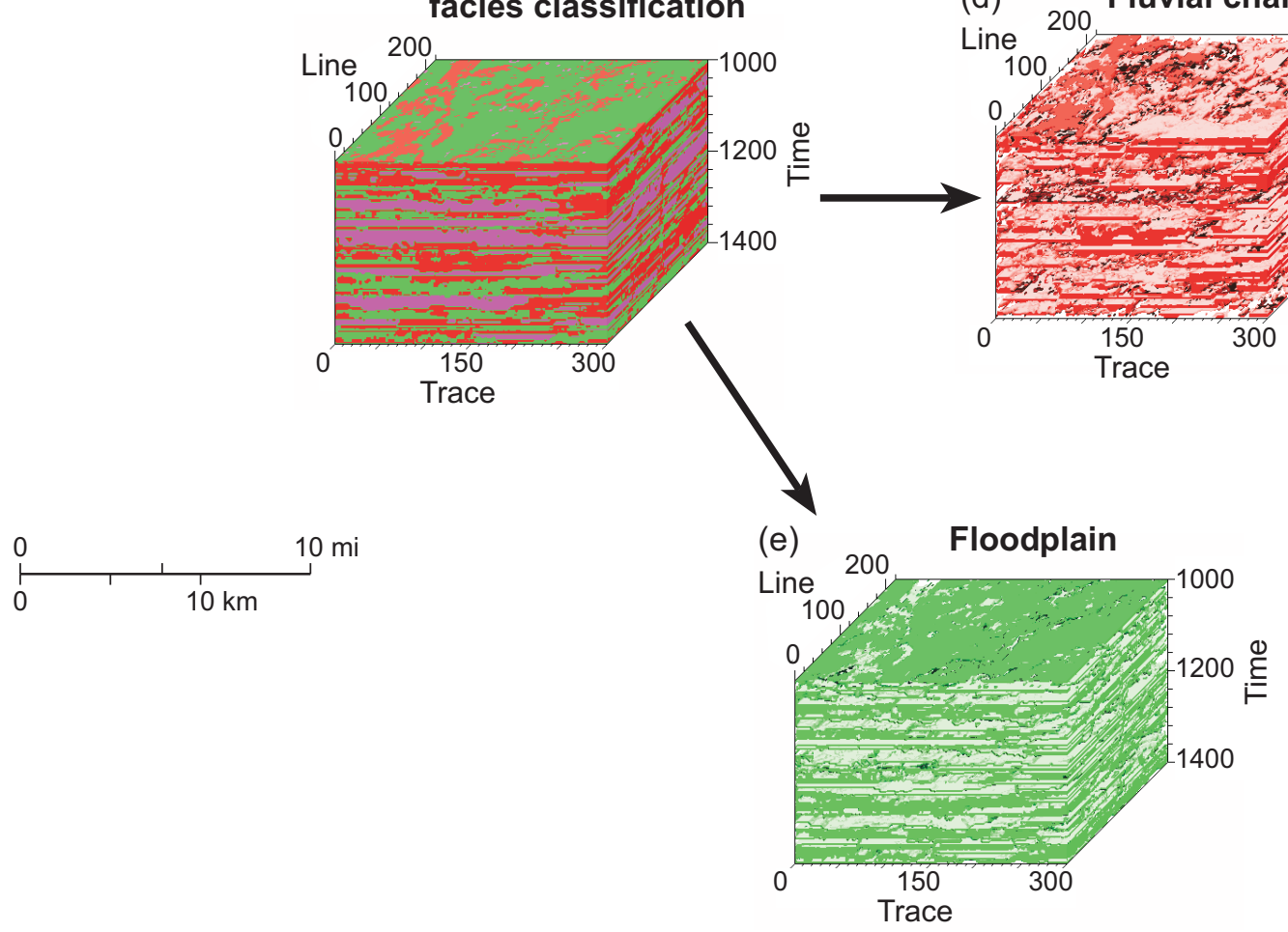
1000

Figure 68. Morphology-based volume classification of incised-valley fill, fluvial channels, and floodplain. 


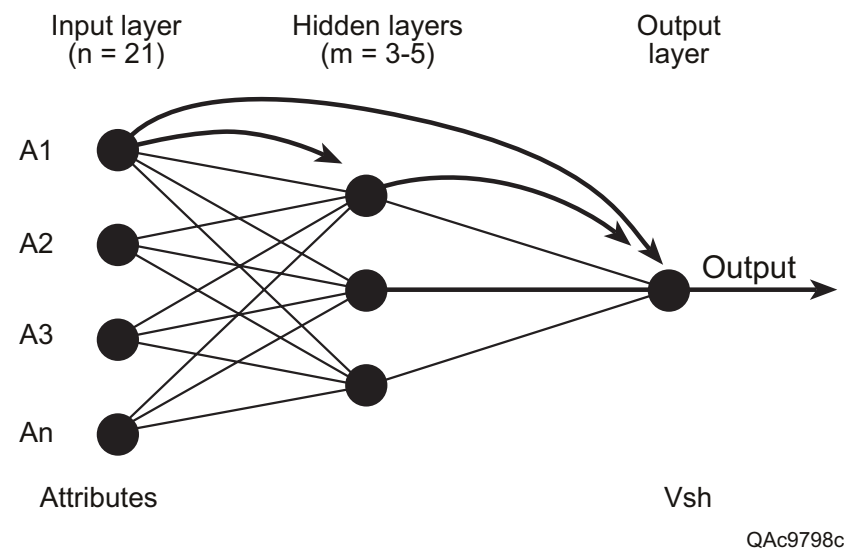

Figure 69. Generalized forward-feed model used in neural network training for this study. 
and the better the reservoir quality. By exploring directly the relationship between Vsh and seismic attributes using a neural network, wavelet extraction and acoustic-impedance calibration that require accurate velocity/density data, as in a conventional inversion, were avoided.

For example, the result in the A-H sand section in Starfak field is shown in figure 70. With nine wells tied to the seismic section, it was observed that in the original data (fig. 70a) most sandstones are tied to amplitude trough (red) in character. However, thickness of the sandstones and shales is not very well defined because of tuning. Some very thin sandstones ( $15 \mathrm{ft}$ or thinner) are simply unresolved. Because of tuning, amplitude is not a good indicator of Vsh and shows a very low correlation between the two ( $R=0.29$ in 35 wells). The work emphasized reducing this seismic thin-bed tuning effect for better resolution of reservoir thickness and porosity. Many Miocene reservoirs in the fields are seismically thin (less than one-quarter wavelength). Tuning is a major source of ambiguity in the interpretation of such reservoirs from poststack seismic data. Because, for a seismically thin bed, seismic amplitude is a function of impedance $\times$ thickness, to solve for impedance (porosity) and thickness separately from amplitude is an underdetermined problem. For example, to solve for acoustic impedance in any poststack inversion scheme, a priori information on thickness is needed. Ambiguity is merely translated to uncertainty in guessing thickness between wells. Additional, independent data are needed to reduce the degree of freedom within the problem.

A new seismic attribute, Amplitude versus Frequency (AVF), can be used to reduce the tuning effect in log-property inversion. Achieved by panel filtering in the effective frequency range of seismic data, AVF reveals the relationship between dominant frequency (filter) and reflection amplitude for a certain thickness, which is an extension and supplement to AVTh (the relationship between thickness and reflection amplitude for a certain frequency component). The attribute makes dynamic use of frequency spectra to release additional, independent information for amplitude detuning, thus helping to reduce the degree of freedom of any thin-bed inversion problem.

Neural-network-assisted attribute analysis (figs. 70, 71) dramatically improves the result by showing (1) much less tuning effect and more vertical and horizontal thickness changes, (2) higher resolution for very thin sandstones that are otherwise unresolved in the original data, and (3) much better fit between Vsh and seismic data ( $\mathrm{R}=0.72$ in 35 wells). Results also show that the 3 -D sand-content volume calculated from well and seismic data demonstrates strong correlation to well logs, high resolution, and cross-field stability, providing the spatial density of petrophysical data necessary for full-volume reservoir modeling.

Similar procedures were conducted for the I-M sand, N-O sand, T-1-T-2 sand, and U-W sand sections, all of which generated satisfactory results that show significant improvement in reservoir delineation and high-frequency sequence-stratigraphic definition. 
(a)

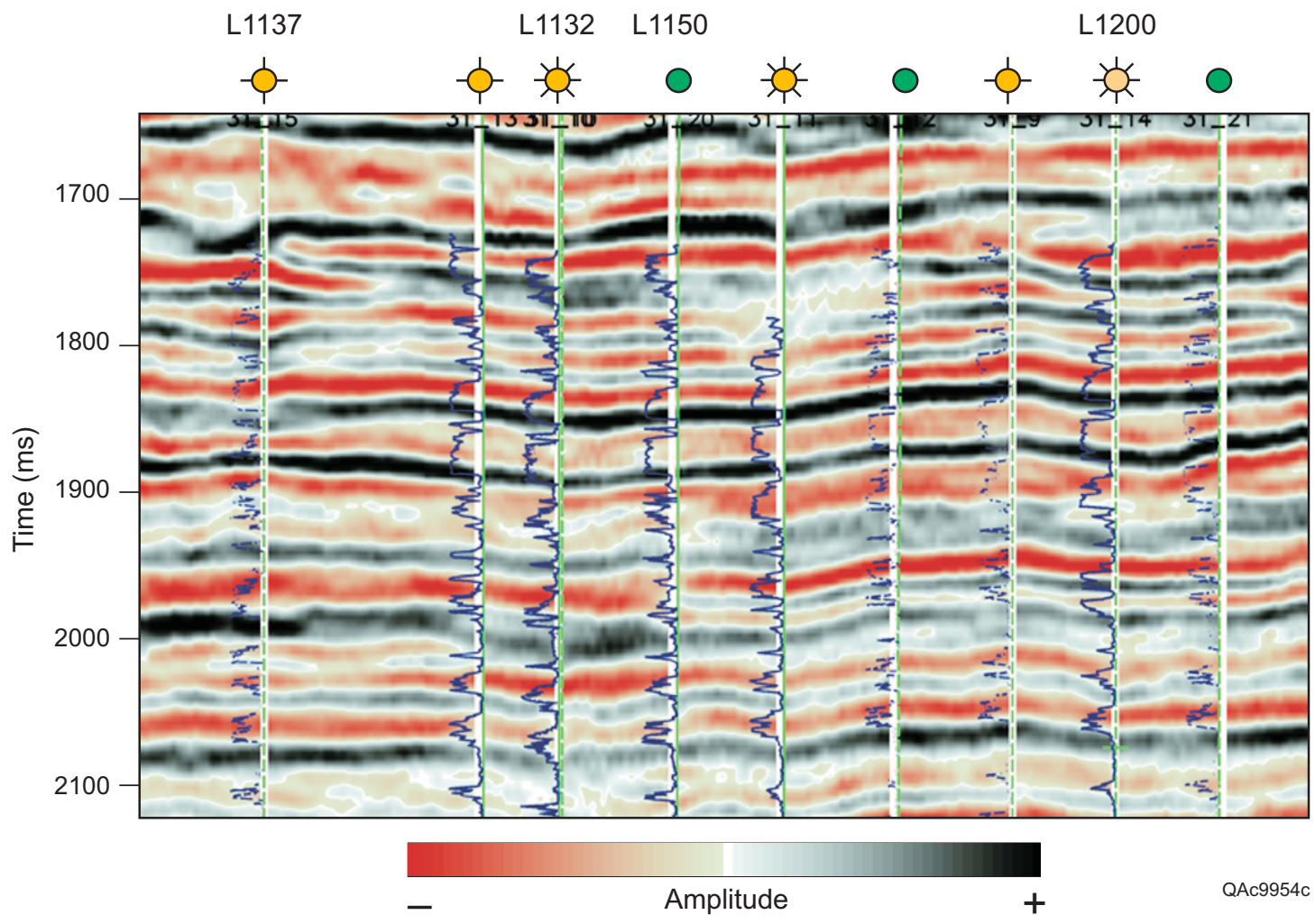

(b)

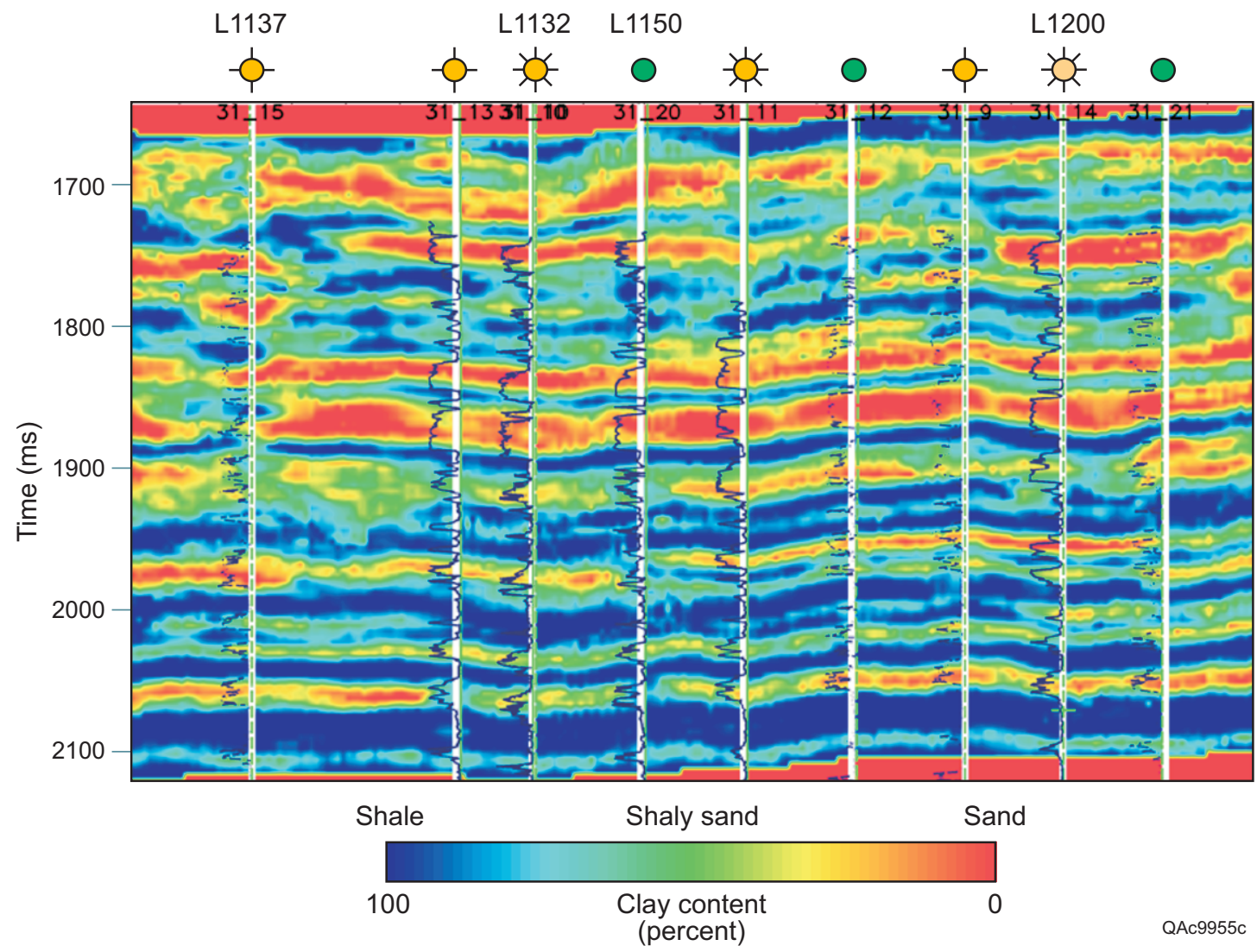

Figure 70. Neural-network-assisted log-property (Vsh) inversion. (a) Original seismic data section tied to nine wells in A-to-H sand interval. (b) Same section after inversion. 
(a) Seismic data
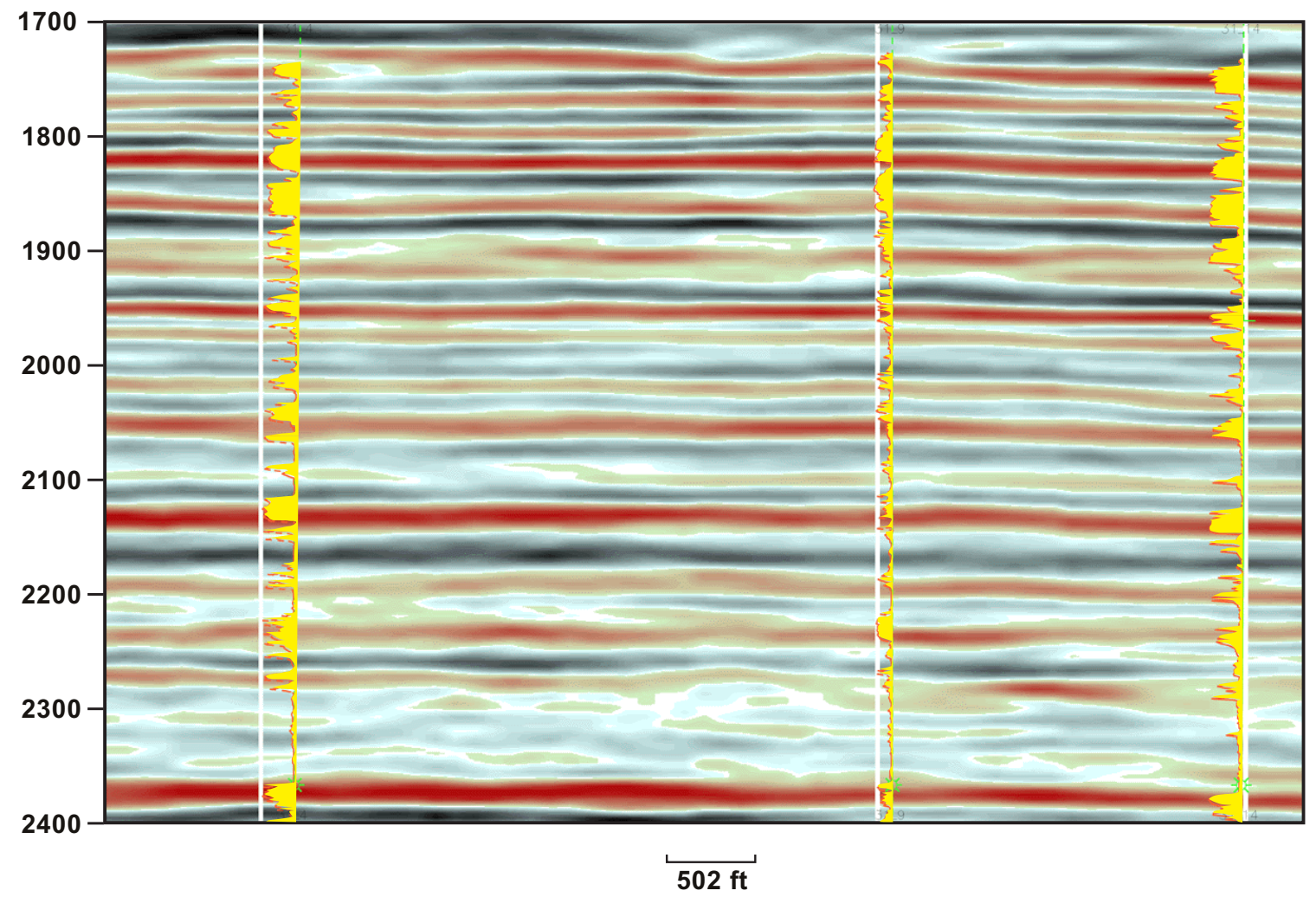

(b) Sand content

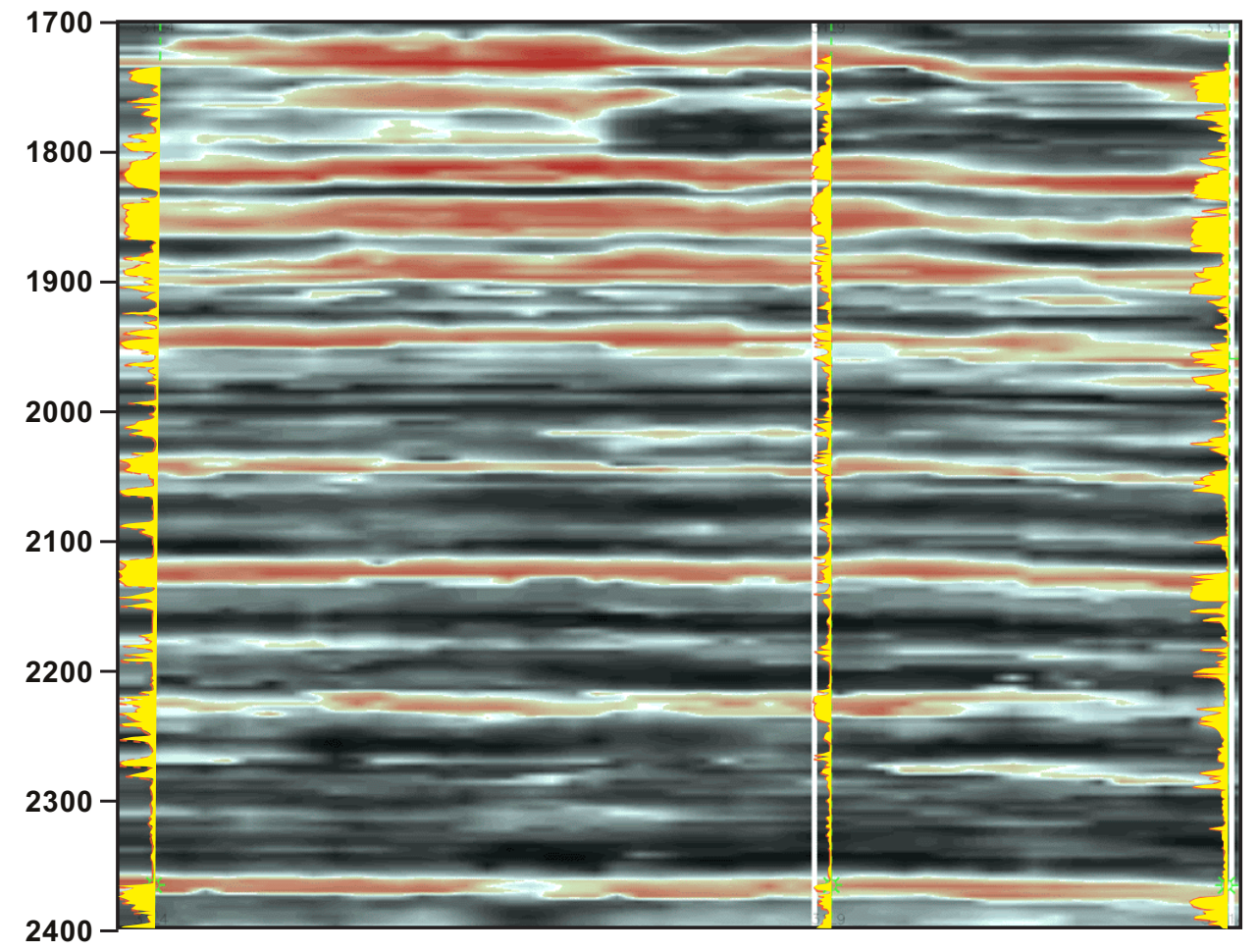

QAc9234C

Figure 71. Sand content predicted from multiple seismic attributes by neural-net-assisted attribute analysis. (a) Original seismic data, with SP logs in three wells superimposed. (b) Sand-content section. 


\section{Fluid Modeling}

The most important data needed to study acoustic behavior of rocks are P-wave velocity and bulk density. Unfortunately, in the study area there is no direct measurement of velocity and rock moduli from core. Therefore, sonic and density logs are the only available sources of data. As a further restriction, only two wells (Texaco $30-2$ and 31-16) have segments of both sonic and density logs of fair quality (fig. 72), with serious borehole washouts in all other wells. As a result, only a sandstone/shale-trend analysis could be conducted. More detailed, layer-by-layer analysis is not realistic until new high-quality well log data are available.

Data (excluding hydrocarbon-saturated sandstones) from the two wells were combined, and P-velocity and bulk density of sand and shale were plotted against depth, with trend lines added (figs. 73, 74). In general, for the interval of interest (6,000 to 15,000 ft, or A sand-Robulus "L" sands), sandstones have higher P-velocity (except where $<7,000 \mathrm{ft}$ deep) and lower bulk density (all depths) than that of shale. The abrupt changes of $\mathrm{P}$ velocity and bulk density around 13,000 ft (above the $12000 \mathrm{~A}$ sand) reflect the top of the overpressure zone in the area. Because these trends are for water-saturated sandstones only, the hydrocarbon effect on response is as yet unknown.

We then used Gassman's Equation to calculate how much velocity change is expected if pore fluid in a sandstone was substituted with gas:

$$
\mathrm{M}=\rho \mathrm{V}_{\mathrm{p}}^{2}=\mathrm{K}_{\mathrm{drf}}+\frac{4}{3} \sigma_{\mathrm{drf}}+\frac{\left(1-\frac{\mathrm{K}_{\mathrm{drf}}}{\mathrm{K}_{\mathrm{ma}}}\right)^{2}}{\frac{1-\phi-\frac{\mathrm{K}_{\mathrm{drf}}}{\mathrm{K}_{\mathrm{ma}}}}{\mathrm{K}_{\mathrm{ma}}}+\frac{\phi}{\mathrm{K}_{\mathrm{fl}}}}
$$

where

$$
\begin{aligned}
& M=\text { P-wave modulus, } \\
& \rho=\text { density of shaly sandstone, } \\
& V_{p}=\text { P-wave velocity, } \\
& \phi=\text { effective porosity, } \\
& K_{d r f}=\text { bulk modulus of dry rock frame, } \\
& K_{m a}=\text { bulk modulus of matrix, } \\
& K_{f l}=\text { bulk modulus of pore fluid, and } \\
& \sigma_{d r f}=\text { Poisson's ratio of dry rock. }
\end{aligned}
$$

On the basis of the production data derived from information for hydrocarbon properties, the $\bullet$ and $\mathrm{K}_{\mathrm{fl}}$ values of gas calculated from Thomas and others (1970), the $\bullet \bullet$ and $\mathrm{K}_{\mathrm{fl}}$ values of oil calculated from Wang and others (1988) (table 5), and some common assumptions of brine and rock moduli (table 6), $\mathrm{K}_{\mathrm{drf}}$ can be calculated first by 


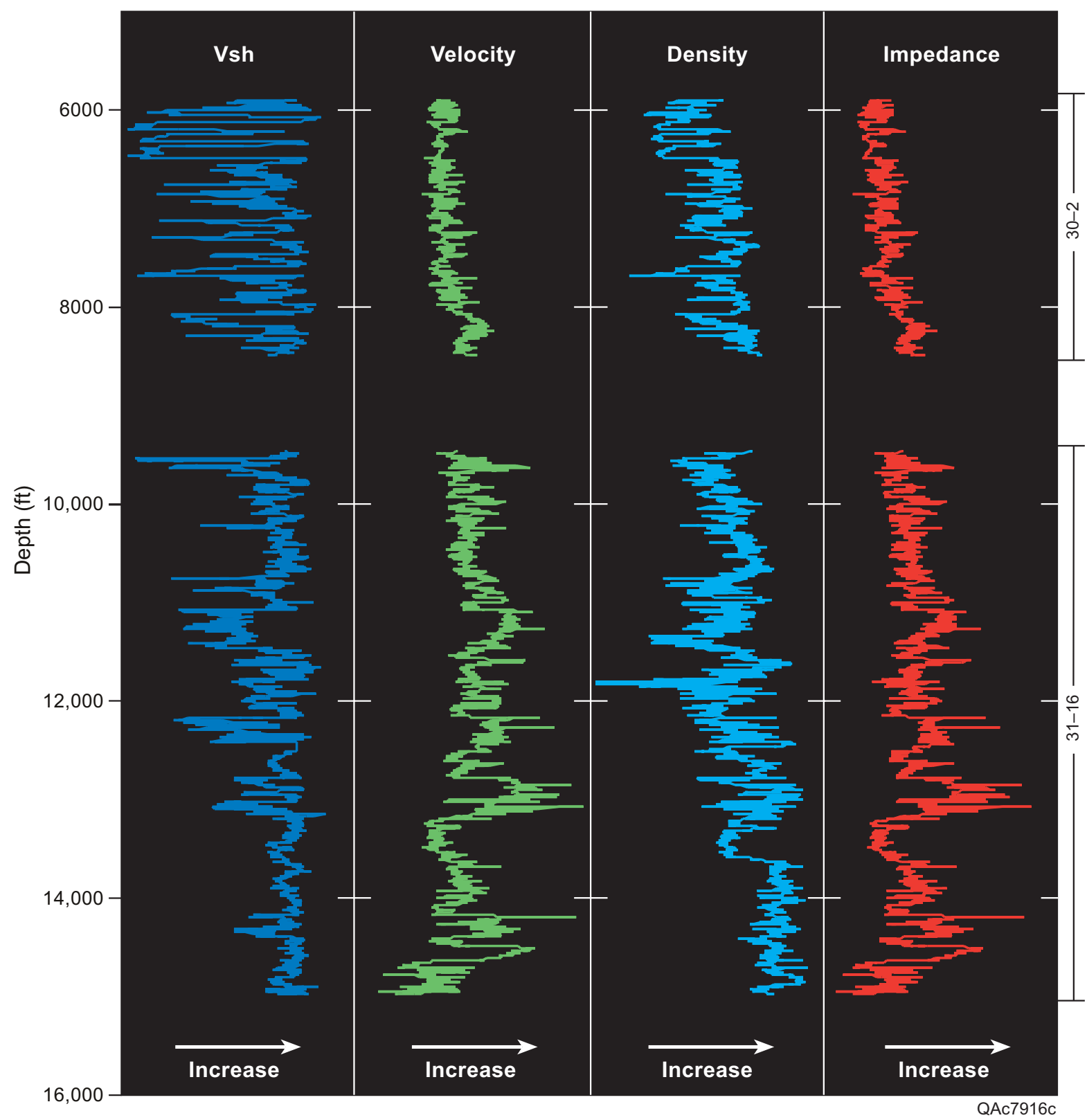

Figure 72. P-velocity (from sonic log) and density curves selected from wells 30-2 and 31-16. 


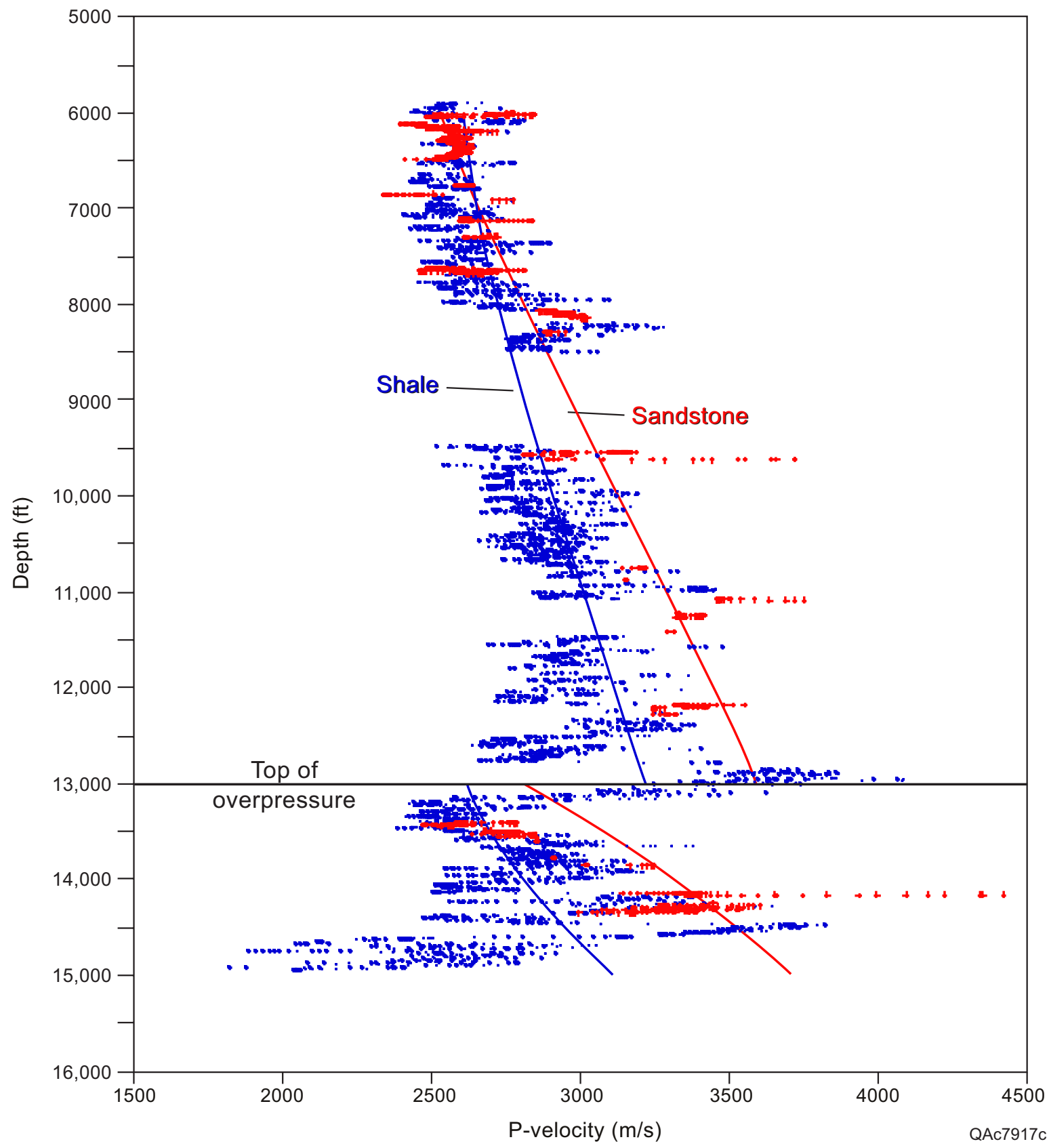

Figure 73. P-velocity of clean sandstone and shale against depth with trend lines. 


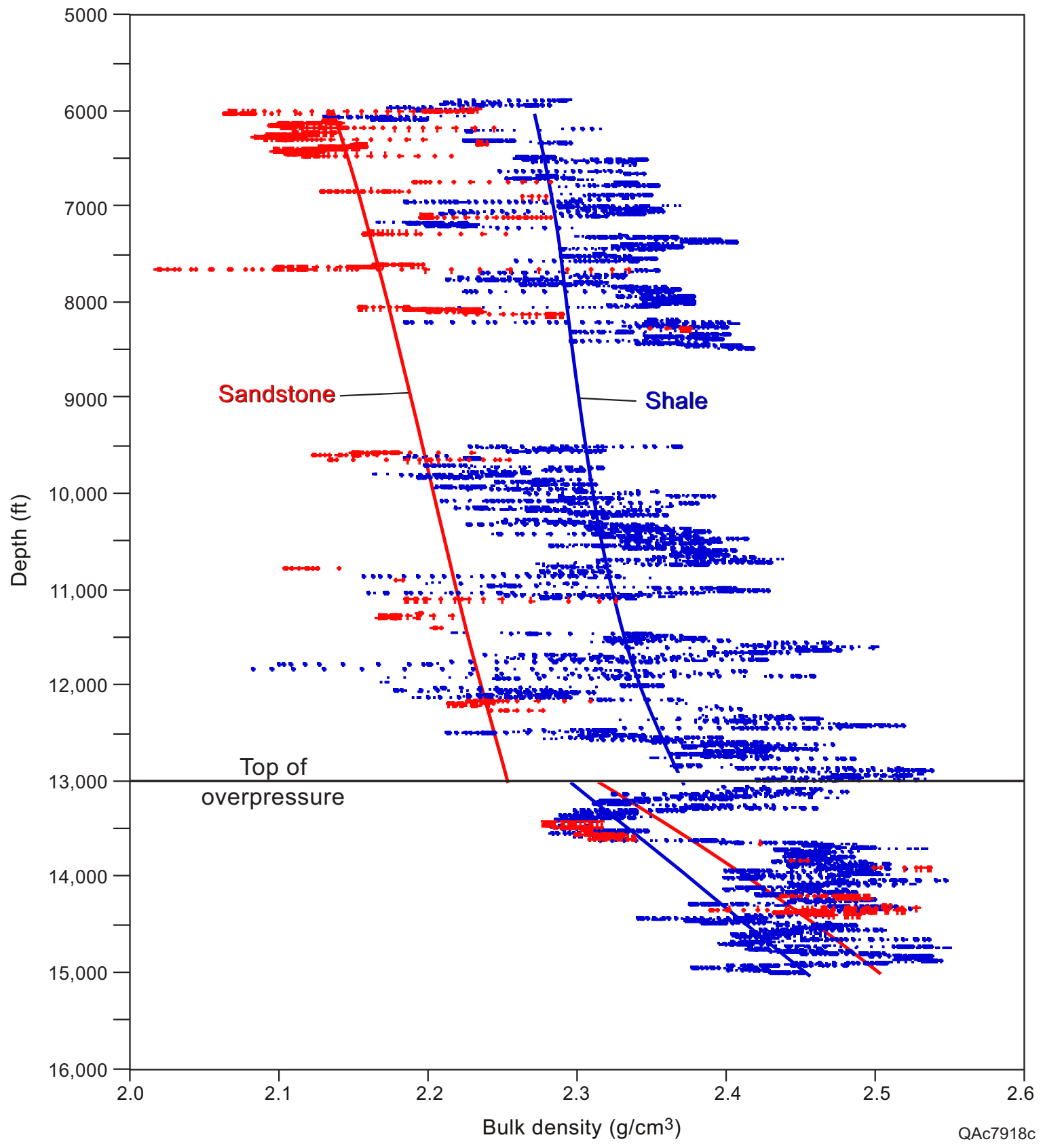

Figure 74. Bulk density of clean sandstone and shale against depth with trend lines. 
Table 5. Hydrocarbon properties from production data.

$$
\begin{aligned}
& \gamma_{\text {gas }}=0.6 \text { (dry gas) } \\
& \gamma_{\text {condensate }}=1.2 \text { (treated as heavy gas) } \\
& \gamma_{\text {oil }}=30^{\circ} \text { API }
\end{aligned}
$$

For depth ranging from 6,000 to $13,000 \mathrm{ft}$ :

$$
\begin{aligned}
& \rho_{\text {gas }}=-0.07392+0.004372 \mathrm{~T}-0.00001804 \mathrm{~T}^{2} \\
& \mathrm{k}_{\text {gas }}=10.602 \mathrm{~T}-199.64 \\
& \rho_{\text {condensate }}=-0.20672+0.012518 \mathrm{~T}-0.000066582 \mathrm{~T}^{2} \\
& \mathrm{k}_{\text {condensate }}=-964.35+57.72 \mathrm{~T}-0.2733 \mathrm{~T}^{2} \\
& \rho_{\text {oil }}=0.81503-0.0019885 \mathrm{~T} \\
& \mathrm{k}_{\text {oil }}=13,798-31.936 \mathrm{~T}
\end{aligned}
$$

For depth ranging from $13,000 \mathrm{ft}$ to $15,000 \mathrm{ft}$ :

$$
\begin{aligned}
& \rho_{\text {gas }}=0.19347+0.00051093 \mathrm{~T} \\
& \mathrm{k}_{\text {gas }}=947.57+4.8926 \mathrm{~T} \\
& \rho_{\text {condensate }}=0.36345+0.00059204 \mathrm{~T} \\
& \mathrm{k}_{\text {condensate }}=6857.4-53.464 \mathrm{~T}+0.1981 \mathrm{~T}^{2} \\
& \rho_{\text {oil }}=0.7032-0.0014527 \mathrm{~T} \\
& \mathrm{k}_{\text {oil }}=-8,682+330.88 \mathrm{~T}-1.2921 \mathrm{~T}^{2}
\end{aligned}
$$

where $\mathrm{T}$ is the formation temperature $\left({ }^{\circ} \mathrm{C}\right)$ and

$$
\mathrm{T}=5 / 9 *[56+0.0139 * \text { depth }(\mathrm{ft})-32] .
$$

Table 6. Brine and rock properties.

$\begin{array}{lcc}\text { Material } & (\mathrm{g} / \mathrm{cc}) & \mathrm{K}(\mathbf{G P a}) \\ \text { Brine } & 1.10 & 3.00 \\ \text { Quartz } & 2.65 & 36.47 \\ \text { Clay } & & 21.42\end{array}$


inputting $\mathrm{V}_{\mathrm{p}}$ and of a brine-saturated sandstone. The $\mathrm{V}_{\mathrm{p}}$ of gas-saturated sandstone is then found by substituting the , $\mathrm{K}_{\mathrm{fl}}$ of brine-saturated sandstone, with that of gas-saturated sandstone. In the input parameters, hydrocarbon saturation was assigned 65 percent, a fair guess from petroleum engineering data.

Shaly sandstone

$$
\begin{gathered}
\frac{1}{\mathrm{~K}_{\mathrm{ma}}}=\frac{\mathrm{V}_{\mathrm{sh}}}{21.42}+\frac{\left(1-\mathrm{V}_{\mathrm{sh}}\right)}{36.47} \\
\sigma_{\text {dry }}= \begin{cases}0.15 & \mathrm{~V}_{\mathrm{sh}} \leq 0.15^{*} \\
0.88 \mathrm{~V}_{\mathrm{sh}}-0.082 & 0.15<\mathrm{V}_{\mathrm{sh}} \leq 0.40 \\
0.83 \mathrm{~V}_{\mathrm{sh}}+0.082 & \mathrm{~V}_{\mathrm{sh}}>0.40\end{cases}
\end{gathered}
$$

* Formulated from Hilterman (1990)

Results were plotted as the acoustic impedance trend lines of hydrocarbon-saturated sandstones, together with brine-saturated sandstones and shale (fig. 75). The most dramatic effect on sandstone impedance comes from gas, shown by the most significant decrease of sandstone impedance compared with that of brine-saturated sandstone. Condensate-saturated sandstone shows a change in impedance very similar to, but slightly weaker than, that of gas-saturated sandstone. Oil saturation has a less sensitive influence on sandstone impedance (about halfway between gas line and water line (fig. 75). All hydrocarbon-saturated sandstones, however, show systematic decrease in magnitude of impedance change owing to the pressure increase with depth, which increases the values of $\mathrm{fl}^{\bullet}$ and $\mathrm{K} f$.

Converted to reflection coefficient (RC) trends (fig. 76), water-saturated sandstones below the shale show normal reflections of $\mathrm{RC}-0.05-0.10$. In contrast, gas-saturated sandstones beneath the shale are characterized by a strong, negative reflection ( $\mathrm{RC}<-0.05$ or bright spots) in most of the depth range, except for 11,500 to $13,000 \mathrm{ft}$ and 13,700 to $15,000 \mathrm{ft}$, where the gas signal becomes insignificant $(\mathrm{RC}-0.05-0.01)$ and is considered undetectable from surrounding reflections. Condensate-saturated sandstones are predicted to behave in a manner very similar to that of gas-saturated sandstones. As a result, they cannot be distinguished from each other in terms of seismic amplitude. The RC trend of oil-saturated sandstones is in between those of gas- and water-saturated sandstones, showing a potential of being bright spots only where it is shallower than 9,000 ft. 


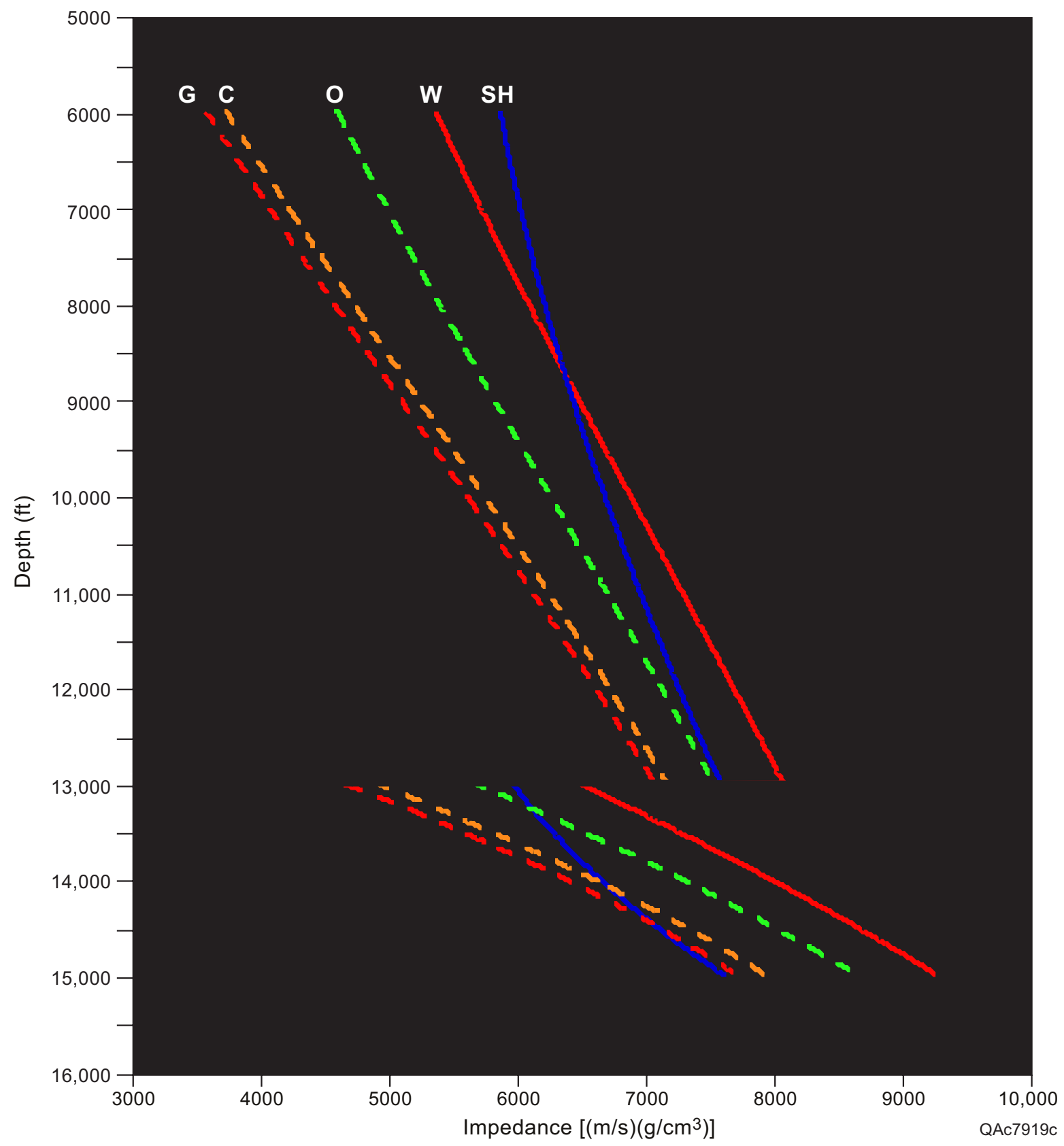

Figure 75. Acoustic impedance trend lines of brine-saturated sandstones, shale, and hydrocarbon-saturated sandstones. $\mathrm{SH}=$ shale, $\mathrm{W}=$ brine, $\mathrm{O}=$ oil, $\mathrm{C}=$ condensate, and $\mathrm{G}=$ gas. 


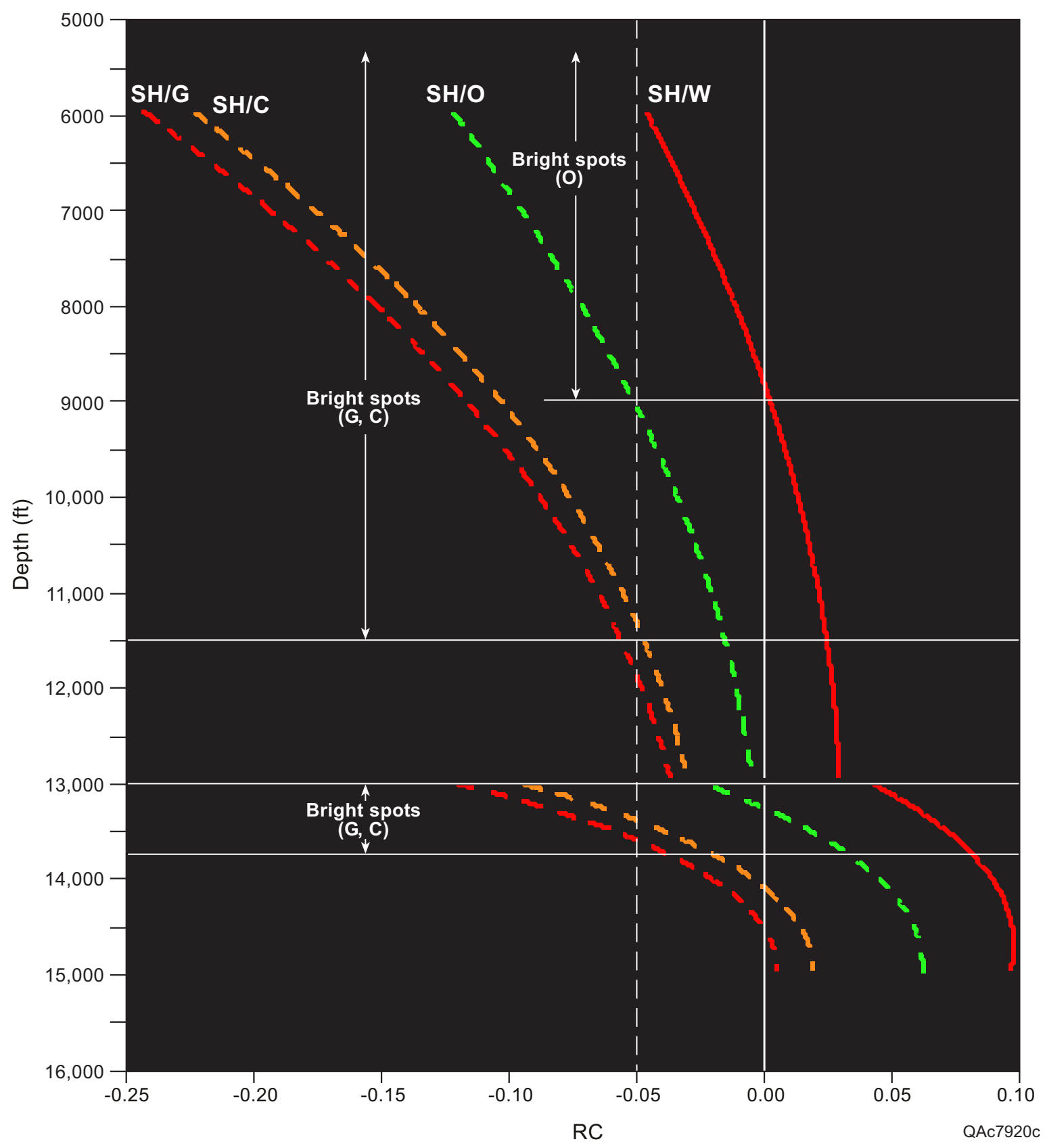

Figure 76. Reflection coefficient (RC) trend lines related to brine-saturated sandstones and hydrocarbon-saturated sandstones. $\mathrm{SH} / \mathrm{W}=$ brine-saturated sandstone below shale, $\mathrm{SH} / \mathrm{O}=$ oil-saturated sandstone below shale, $\mathrm{SH} / \mathrm{C}=$ condensate-saturated sandstone below shale, and $\mathrm{SH} / \mathrm{G}=$ gas-saturated sandstone below shale. 


\section{Engineering Resource Addition Solutions}

\section{Water-Drive Gas Reservoirs}

Water-drive gas reservoirs, such as the T-1 sand (table 2; fig. 14), are by their very nature plagued throughout their lives by water encroachment. Water that maintains reservoir pressure will migrate toward, or "encroach" upon, production wells, commonly trapping residual gas behind the invading waterfront. These effects reduce the volume of gas that will be produced, as compared with conventional pressure depletion. Also, as water volume flowing into the well bore increases, loading can eventually occur, which will effectively kill the free flow of gas, resulting in down time, sporadic well production, costly well maintenance, and, ultimately, abandonment of the well. Additionally, high volumes of produced water can increase disposal costs, rendering a well uneconomic. Careful planning, design, reservoir characterization, and well handling are needed to maximize gas recovery when aquifer encroachment occurs.

Aquifer encroachment decreases ultimate recovery in gas reservoirs. Typical gas reservoir pressure depletion can have recovery efficiencies ranging from 0.75 to 0.9 , whereas aquifer-drive recovery efficiencies are typically in the range of 0.5 (Grab and Smith, 1987; MacKay, 1994). Ancell and Manhart (1987) reported a recovery factor of 0.65 in a 9,100-ft Texas Frio reservoir, and Hower and others (1992) reported a 0.489 recovery for a Gulf of Mexico Miocene reservoir.

U.S. gas-reservoir-production trends display a similar character of lower recovery efficiency for aquifer-drive reservoirs. For all pressure-depletion-drive reservoirs in the U.S. the mean ultimate recovery efficiency is approximately 0.74 (fig. 77), according to data compiled by the U.S. Department of Energy's Gas Information System (GASIS). The distribution of ultimate recovery displays a tail ending at around 0.5 with some outliers at 0.1 and 0.2. These outliers are probably due to data busts within a public database because they lie outside the 5-percent delimiting range. In contrast to the pressure-depletion distribution, the aquifer-drive gas reservoirs display a mean ultimate recovery efficiency of 0.67 (fig. 78). The distribution is bimodal, with a group centered around 0.5 and another around 0.9 . The high-recovery grouping is interpreted to be due to incorrectly distinguishing between aquifer drive and pressure-depletion drive in the public database or from underestimating the original gas in place.

Aquifer and hydrocarbon-reservoir characteristics and production history govern water encroachment, and understanding these factors is critical to optimizing oil and gas recovery. The main aquifer attributes that influence hydrocarbon recovery are aquifer size, pressure, and geologic character. Size and pressure characteristics affect the pressure support transmitted to the hydrocarbon reservoir. The larger the aquifer size relative to the hydrocarbon reservoir (dimensionless radii), the greater and longer the pressure support and the lower the recovery efficiency. A greater pressure differential between the aquifer and a depleting gas reservoir can reduce ultimate recovery. Recovery efficiencies for gas reservoirs and aquifers at lower initial pressures will be less affected by aquifer encroachment, whereas higher pressure systems may result in more rapid water encroachment (Agarwal and others, 


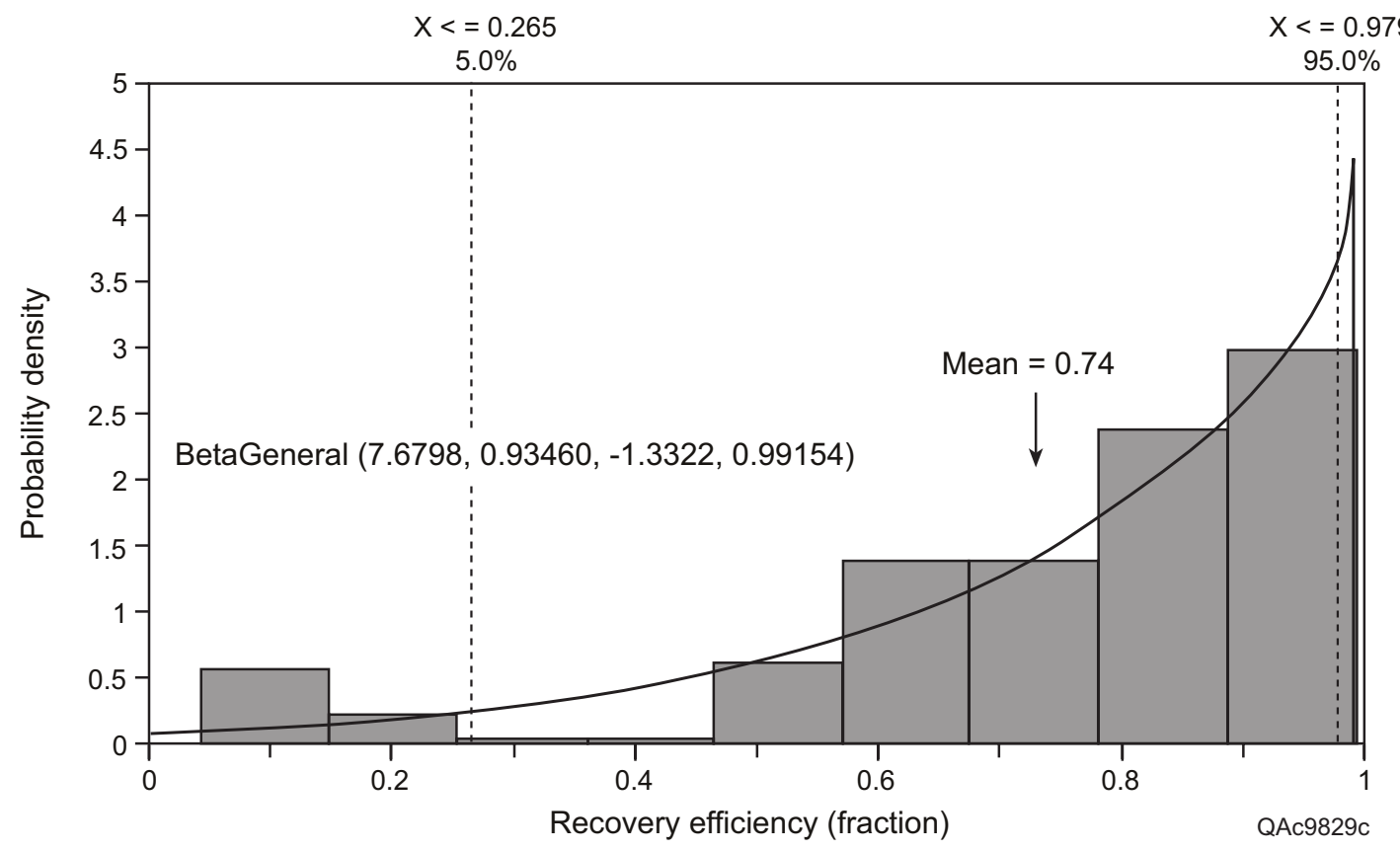

Figure 77. Pressure-depletion, gas-reservoir, and ultimate-recovery efficiency for U.S. reservoirs based on data from the Department of Energy's Gas Information System (GASIS) database.

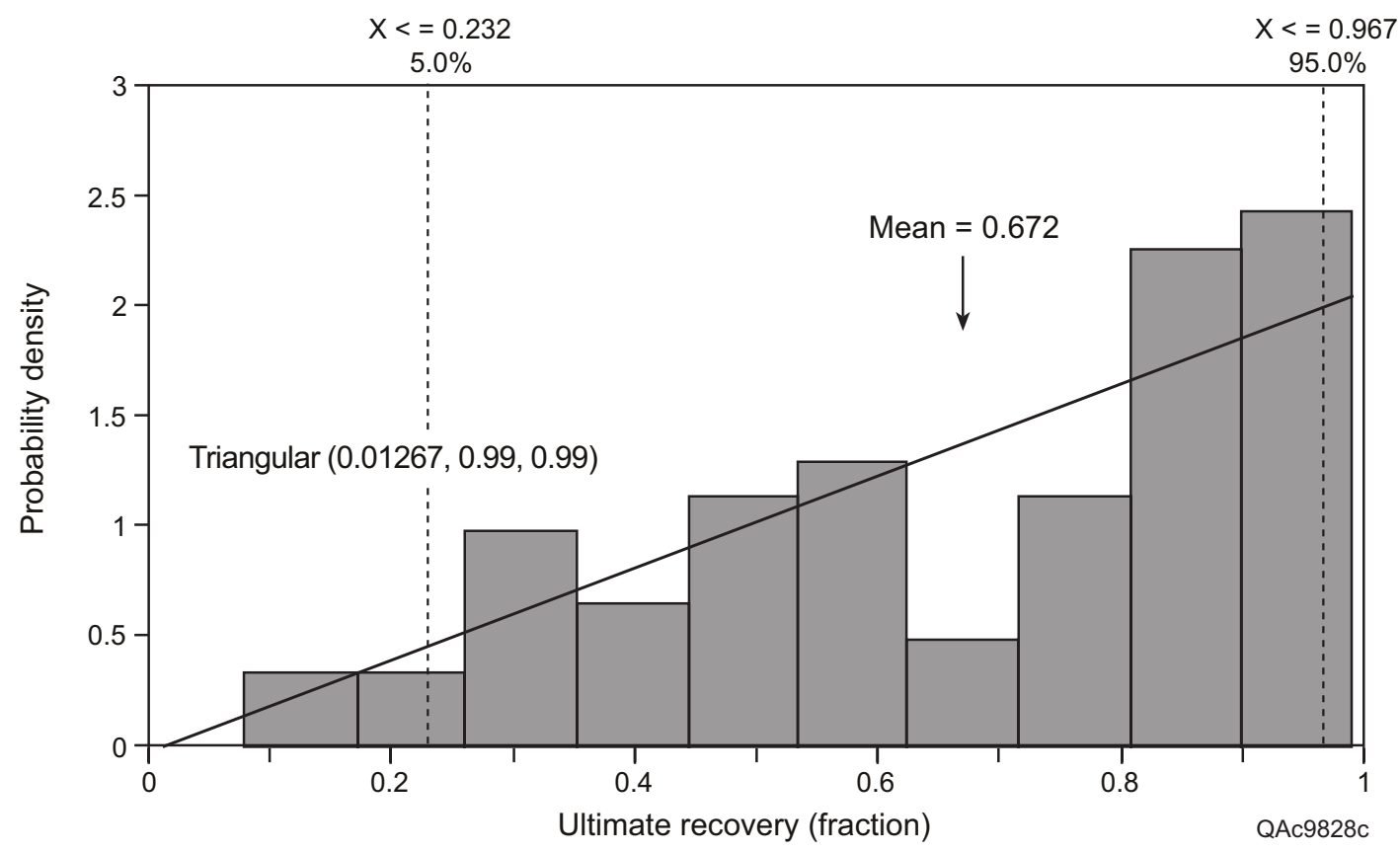

Figure 78. Aquifer-drive, gas-reservoir, and ultimate-recovery efficiency for U.S. reservoirs based on data from the Department of Energy's Gas Information System (GASIS) database. 
1965). Permeable and homogeneous aquifer/gas reservoir systems undergo more rapid water encroachment at higher reservoir pressures and thus have lower gas recovery efficiency. Also, higher residual gas saturation resulting from pore geometry and higher relative permeability to water will lead to lower recovery efficiency. High residual oil saturation occurs when pressure depletion is not uniform in the oil leg and when the oil has high viscosity relative to the encroaching water. Overall, characteristics that promote water influx and decrease a reservoir's incremental pressure cause lower recovery efficiency.

Production history also influences aquifer encroachment. An increased gas production rate can result in an increased recovery of gas (Agarwal and others, 1965; Matthes and others, 1973; Lutes and others, 1977). An increased production rate often leads to greater pressure depletion before wells water out and thus results in greater gas recovery. The performance parameters proposed by Hower and Jones (1991) illustrate the interrelationship between gas flow rate and reservoir characteristics. High production rates, however, must be designed so that no coning or fingering occurs. Relative permeability and residual gas saturation are important in the effectiveness of higher production rates. Permeability, relative permeability, and residual gas saturation affect the broadness of the pressure gradient between gas reservoir and aquifer. A broad pressure gradient will increase the water-invaded zone and result in a larger volume of trapped gas. Oil recovery is increased when reservoir pressure depletion is uniform. Uniform pressure depletion reduces water fingering and, thus, bypassed oil as the aquifer water front encroaches.

\section{T-1 Reservoir Production Character}

The production history of the T-1 sand reservoir (table 2; fig. 14) displays the strong influence of aquifer influx. The reservoir has undergone four pulses of production as wells have been completed and produced in separate fault blocks within the reservoir (fig. 79). Each production pulse is characterized by declining gas production rate, along with a contemporaneous water production increase. The first pulse of production came from Houston Oil \& Minerals Nos. E1, B2, and B1, all Starfak Block 50 wells. These wells produced from the southernmost fault block in the reservoir and produced for an average of 6 years from 6/1/78 to 6/7/84. Water production steadily increased after 1 year of production and essentially killed any steady gas production after 3 years.

The next pulse of production came from wells producing from the next fault block to the north. These wells, including Texaco Nos. 1 and 19 in Block 31, produced for about 7 years. These wells also experienced a steady gasproduction decline and a steady water-production increase. A third pulse came from well 31-11 producing at the high point on the "31" fault block. Well 31-11 experienced a short production life of less than 2 years, with steady gas production decline and water production increase. The fourth and last pulse of production came from well 30-5 positioned in a fault block farthest to the north up against a major regionally extensive, first-order normal fault. This well saw just over 2.5 years of declining gas production and increasing water production. It is clear from the production history of relative reservoir pressure depletion that aquifer encroachment is controlling production character. This conclusion implies that it is likely that only slightly more than half of the original gas in place has been produced, leaving a large gas resource behind. 


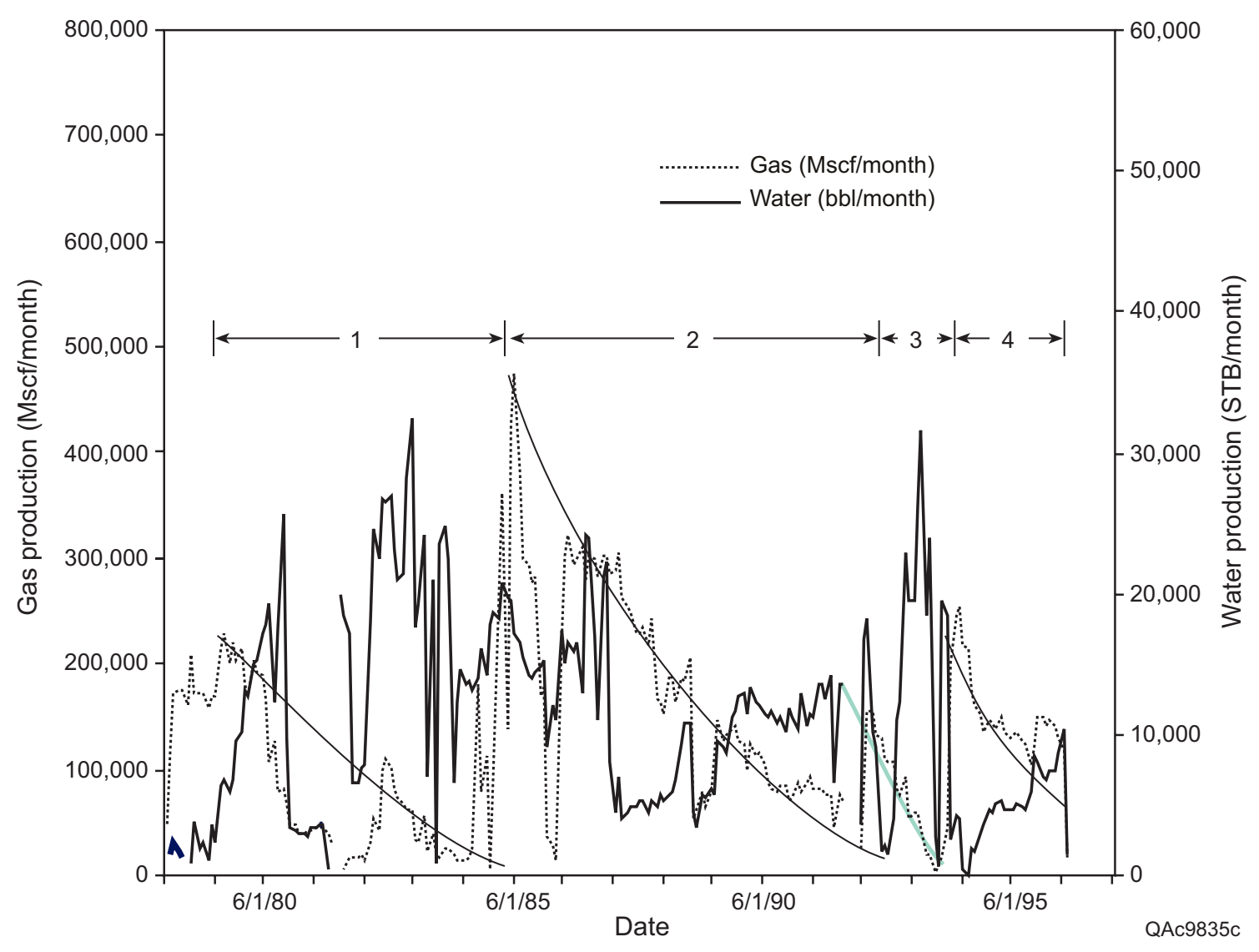

Figure 79. Production history of the Starfak T-1 reservoir showing multiple pulses of decreasing gas-production rate and increasing water-production rate. 
Petrophysical Input to the Reservoir-Characterization Process

The goals of the petrophysical analysis are to

- Identify unperforated zones and zones that are performing below their potential,

- Provide inputs for recompletion or infill-drilling opportunities,

- Examine primary completion designs and suggest improved designs for enhancing recovery, and

- Provide quantitative estimates of petrophysical parameters to aid in mapping and estimate of gas resources.

To achieve these goals, it was necessary to design an integrated petrophysical model that could be used to calculate various parameters on each well. These results were coupled with seismic mapping and adjacent-well and production data to target underperforated and underperforming zones in existing wells.

\section{Establishing a Petrophysical Model}

The petrophysical analysis of the two study fields provides an estimate for each well of effective porosity, water saturation, permeability to air at surface conditions, net feet of permeable interval, permeability of gas at in situ conditions and net feet of gas pay. It is important that the model be calibrated to all available core information. The porosity calculated by the petrophysical model should match core effective porosity, and calculated permeability to air should be equal to core permeability to air. In addition, effective porosity of the model and core should match, the model of Sw should be 100 percent in water zones with no residual hydrocarbons, and the Sw should also be equal to core capillary-pressure data in zones that produce only gas. Finally, the model's permeability to gas should be equal to well-test permeability or net-overburden-stressed Klinkenberg-corrected permeability.

This approach is complicated by several factors in this study. Data from only a single whole core from the study area exist, taken in the Texaco No. 6 (Block 31) well through the Robulus "L" sands. This core has special core analyses (capillary pressure and net overburden permeability) of some samples, but such limited amounts of whole core place some uncertainty on the derived model. These data are supplemented by a significant number of percussion sidewall core samples from area wells. The error bar around percussion core data is somewhat larger than that obtained using conventional or sidewall drilled core; however, this is the best information available in this field. An additional complication in building the petrophysical model is that open-hole porosity log data in the shales are of poor quality universally in all the hole conditions. To mitigate this later problem, the logs were compared with sidewall-core porosities to help normalize the data. Several models were used to estimate porosity in every well, with the model that gave the best agreement with sidewall core porosity being chosen. Models used included density-neutron cross-plot, density, sonic, and an empirical porosity from core data and shale volume. Reasonably good agreement was attainable in all cases. 
The focus of petrophysical work was in Starfak field. Starfak has an excellent distribution of porosity information, with $\operatorname{logs}$ in 56 wells. These data were analyzed and integrated with existing whole and sidewall-core information, as well as a more regional analog data set of Miocene capillary pressure and permeability data, to derive a set of final parameters and equations for calculating petrophysical parameters for Starfak field. These derivations are

- $\quad$ Rw 0.094 ohm-m at 77 F (from SP and Rmf) (northern Starfak wells)

- Rw 0.110 ohm-m at 77 F (from SP and Rmf) (southern Starfak wells)

- $\quad \mathrm{A}=0.81, \mathrm{~m}=2$, and $\mathrm{n}=2$

- Modified Simandoux model

- $\quad$ Temperature $=77+0.01 *$ depth

- $\quad \mathrm{K}^{\mathrm{air}}=10^{(1.663895 \mathrm{E}+01 * \mathrm{PHIEQ} 2.449536)}$

- $\quad \mathrm{K}^{\text {gas }}=\left(\left(35.5 * \mathrm{PHIEQ}^{2} *((\mathrm{PHIEQ}-\mathrm{BVWQ}) / \mathrm{BVWQ})\right)\right)^{2}$

- $\quad$ BVWI $=\left(0.2552 * \mathrm{~K}^{\mathrm{air}-0.2716}\right)$

- $\quad$ SWI = BVWI/PHIEQ

\section{Defining Unperforated and Underperforming Zones}

With the petrophysical model in place, identification of unperforated zones was relatively straightforward. If a zone has indications of reasonable hydrocarbon volume and permeability to hydrocarbons and there are no perforations in the zone within the zone's drainage area, it is unperforated pay. Identification of underperforming perforated zones is somewhat more involved and can be made on two levels. The first level involves the calculation of volumetric reserves for the structural and stratigraphic compartment the completion is draining. A comparison of the current cumulative hydrocarbon production for the compartment with the volumetric reserves originally in place provides a good indication of the compartment's drainage. These reservoirs have welldocumented recovery efficiencies in analog fields for estimating the amount of gas or oil that can be reasonably recovered. This information can be factored into a decision on whether a recompletion of an existing zone can recover the additional hydrocarbons or whether a new well is needed.

The second level of analysis involves a systems approach. The concept of NODAL analysis has been successfully applied in the Gulf of Mexico for the last 20 years. The NODAL process provides an estimate of well performance as a function of drawdown pressure, near-well-bore skin damage, perforation efficiency, and tubing size. The three key inputs to this process are effective permeability to hydrocarbons, reservoir pressure, and the magnitude of well-bore-skin damage. All three of these can be obtained directly from a transient-pressure well test. The most critical of the three is effective permeability to hydrocarbons. With the integration of well-test and well $\log$ data, this effective-permeability value can be estimated from well log porosity and irreducible-water saturation. The output of the analysis is an estimate of what the well should be producing with different completion options. The completion option of choice today in unconsolidated reservoirs is the "frac pack," where a gravel pack assembly is 
run in combination with a hydraulic fracture treatment. This option was not widely used in Miocene strata of the Gulf of Mexico until the early to mid-1990's. At a time when most wells were drilled in Starfak and Tiger Shoal, the standard final completion procedure was either slightly overbalanced perforating in mud or underbalanced perforating. Both techniques have since been shown to be ineffective in removing near-well-bore skin damage. These techniques normally result in high near-well-bore skin damage, with plus 10 to 15 very common. The "frac pack" procedure has resulted in significant productivity increases in high-permeability reservoirs, and it should be the procedure of choice for most of the sandstones in Starfak and Tiger Shoal. Negative skin values can be consistently obtained with this technique. In sands where water contacts are nearby, the preferred technique is extremely overbalanced perforating, with tubing-conveyed perforating guns and resin for consolidation of the sands. This procedure has been successfully implemented on numerous high-permeability wells in the Gulf of Mexico, with significant reductions in skin damage in all cases.

\section{Underperforming Pay: Example of the Y Sand in Blocks 30 and 31}

Many wells with unperforated pay have been identified in Starfak field. A good example is the Y sand in the southern part of Block 30 and the northern part of Block 31. The Y sand is present in most of the wells in the fault block but has only produced from one well (8.5 Bcf from the Texaco No. 6 ST [Block 30] well). This area was the focus of detailed analysis to assess potential resource addition.

During the initial log analysis, it was observed that the Texaco No. 6 (Block 30) well had $59.5 \mathrm{ft}$ of gas pay and the Texaco No. 5 (Block 30) well had $57.5 \mathrm{ft}$ of gas pay, with no recorded production from either well following perforating. Both wells had been completed in late 1984. Upon further analysis, it was observed that the 30-6 sidetrack twin to the 30-6 well completed in 1997 was an excellent producer. The zone averaged $7.8 \mathrm{MMcf} / \mathrm{d}$ over the first 38 months of production and was still making 6.6 MMcf/d with a 675 psi FTP in May 2000. The 30-5 well is 2,300 ft away, and the Y sand is of higher quality than that of the producing 30-6 ST well. The amplitude anomaly extends well to the west of the 30-5, and several locations should be available in addition to a workover in the 30-5. Pay is present in the 31-17 and 31-17ST to the south. The 30-5 has been plugged back to uphole zones; however, it was only making $200 \mathrm{Mcf} / \mathrm{d}$ in April 2000 and may be a workover or sidetrack candidate soon if mechanically feasible.

Initial gas-in-place estimates were refined according to the stratigraphic and structural interpretation. Rough numbers based on the pay thicknesses encountered in the four wells with $Y$ sand pay indicate that between 91 and $259 \mathrm{Bcf}$ of gas could be in place within the 2,050-acre amplitude anomaly. Only one well is currently draining this reservoir in the fault block. With only $8.5 \mathrm{Bcf}$ recovered to date, this total represents between 3.3 and 9.3 percent of original gas in place.

The primary reason that the initial completions did not produce was most likely the failure to remove formation damage. In 1984 the most advanced stimulation practice in the Gulf of Mexico was tubing-conveyed underbalanced perforating. The Y sand has below-average permeability for the Miocene in the Gulf (15 to $25 \mathrm{md}$ ), and it is normally pressured. Underbalanced perforating cannot remove damage in the permeability range observed in the $\mathrm{Y}$ 
sand. Calculations based on laboratory data indicate that between 5,000 and 6,000 psi underbalance would be required to remove damage from the drilling and cementing process. Because these zones have only 5,000-psi reservoir pressure to begin with, such an undertaking would be very difficult. In addition, if more than 500-psi underbalance is placed across unconsolidated sand faces, the formation could collapse. Analysis of production records indicates much sand production from these wells, and it is highly likely that they would not remain competent under the underbalanced conditions required to remove damage.

Modern completion practices include hydraulic fracturing, combined fracturing and gravel packing ("fracpacks"), and extreme overbalanced perforating. The proper stimulation procedure for these zones would depend on the degree of consolidation of the formation and the proximity to water. In any case, the damage can be removed and production maximized.

\section{3-D Reservoir Modeling}

\section{Software}

In evaluating the computational needs for reservoir modeling, several software packages were considered: StrataModel by Landmark ${ }^{\circledR}$, Property3D by GeoQuest ${ }^{\circledR}$, RMS by Roxar ${ }^{\circledR}$, and Gocad by T-Surf ${ }^{\circledR}$. Four critical criteria for were defined determining which software package would be best suited for model construction: ease of use, connectivity with existing geologic databases, flexibility in the model-building process, and quality of the finalized geologic model. Each package has advantages over the others: StrataModel because of the attribute gridding and connectivity, Property3D for its structural framework, and Gocad because of the quality of the geologic model. However, RMS was chosen primarily because it has a well-devised workflow that can be easily adjusted to fit varying modeling needs and because it is straightforward to learn, in contrast to software such as Gocad. Moreover, RMS has optimal deterministic and stochastic modeling capabilities and excellent connectivity with the existing Landmark Oracle database.

\section{Approach}

The approach to identifying and modeling reservoir character involves four principal steps: (1) determining geologic reservoir architecture, (2) establishing fluid-flow trends in the reservoir, (3) integrating reservoir architecture and fluid-flow trends, and (4) identifying reserve-growth potential (fig. 80). These steps 


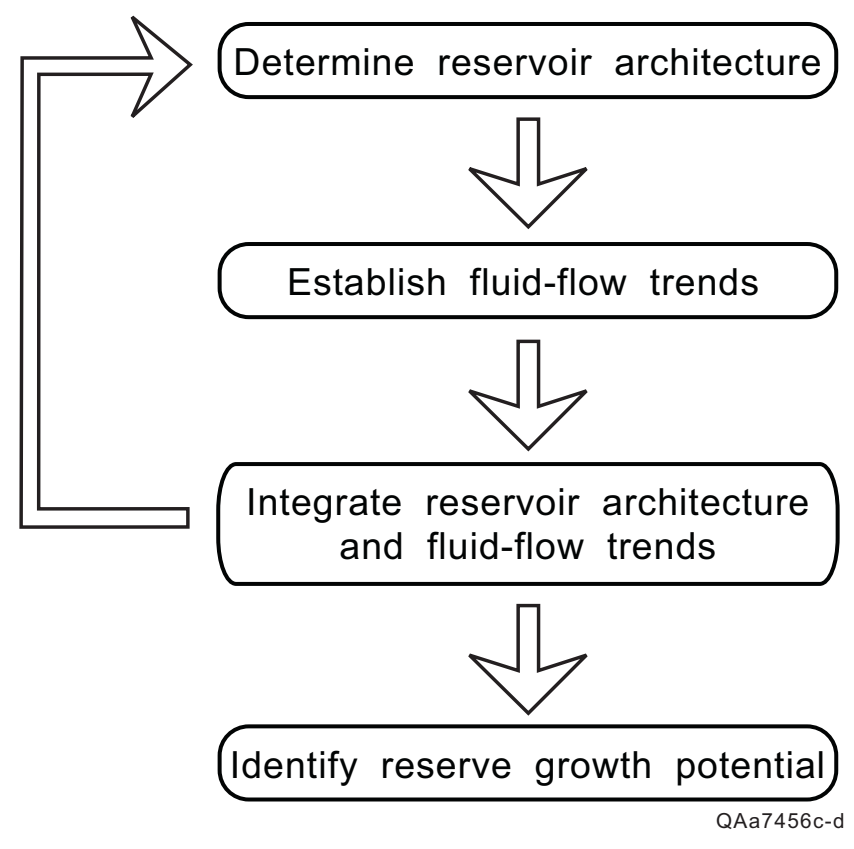

Figure 80. Methodology of reservoir characterization to identify reserve growth potential, which is a four-step process, at times iterative, that integrates geologic, geophysical, and engineering information (Holtz and Hamilton, 1998). 
are interrelated, although determining geologic reservoir architecture is the logical starting point. These four steps are general, and the level of depth to which they can be implemented is heavily dependent on both the time and data available. The characterization methodology is an iterative process, relying on the testing of multiple working hypotheses to determine the most probable reservoir model. The key iterative step is creating a reservoir model by integrating reservoir architecture with fluid-flow trends. This step is commonly the point at which new hypotheses are developed and old hypotheses are disregarded. The goal of the overall methodology is to determine by what means reserve growth can be accomplished. The following discussion details each of the four steps of reservoir characterization, culminating in a 3-D geocellular reservoir-visualization model and the delineation of reserve-growth opportunities.

The Starfak T-1 reservoir is representative of a large group of Miocene water-drive gas reservoirs of the northern Gulf Coast Basin, offshore Louisiana (fig. 5). The T-1 reservoir sandstone occurs immediately below the thick, regional Cristellaria "I" shale (fig. 81).

The Starfak T-1 reservoir has provided a wide variety of data. Over 40 wells have been drilled through the T-1 reservoir during the 1980's and 1990's. The logs taken in these wells are the conventional logs used in the Gulf Coast: SP, gamma ray, resistivity, density-neutron, and sonic. The specific types of logs for each well vary somewhat over the reservoir area. Over 100 sidewall cores have been taken, and standard porosity and permeability measurements have been collected. The 3-D seismic survey enables visualization of the reservoir over the study area; the poststacked volume is available for the project. Additionally, production data, including a limited amount of pressure history, are available. The data are typical of those found in a mature offshore Gulf Coast reservoirs and are sufficient to develop a reservoir model to upscale to a reservoir simulation.

\section{Determining Reservoir Architecture}

The architecture of the T-1 reservoir is determined by the spatial position of faults and stratigraphic surfaces. Positions of faults were interpreted from the integration of 3-D seismic, well log curves, and fluid levels. Regional fault interpretations were downscaled to detail the positions of the reservoir-scale faults needed for reservoir characterization. An amplitude stratal slice map was used in conjunction with a map of initial fluid levels to evaluate possible sealing faults within the T-1 reservoir. Locations on the fluid-level map where inconsistencies exist between wells were interpreted to not be in fluid-flow communication. Fluid-flow boundaries were drawn on the fluid-level map using this interpretation. Next, this map was overlain by an amplitude stratal slice map. Lineations in this map were investigated to see whether they corresponded to interpreted fluid-flow boundaries on the fluid-level map. It was noted that several amplitude trends correspond to fluid-flow boundaries. Both faults and changes in depositional facies were interpreted to define these boundaries.

Examining the 3-D seismic volume further detailed the positions of these faults. Additional, smaller scale faults were identified, and all upper fault terminations were modified within the limits of seismic resolution. 


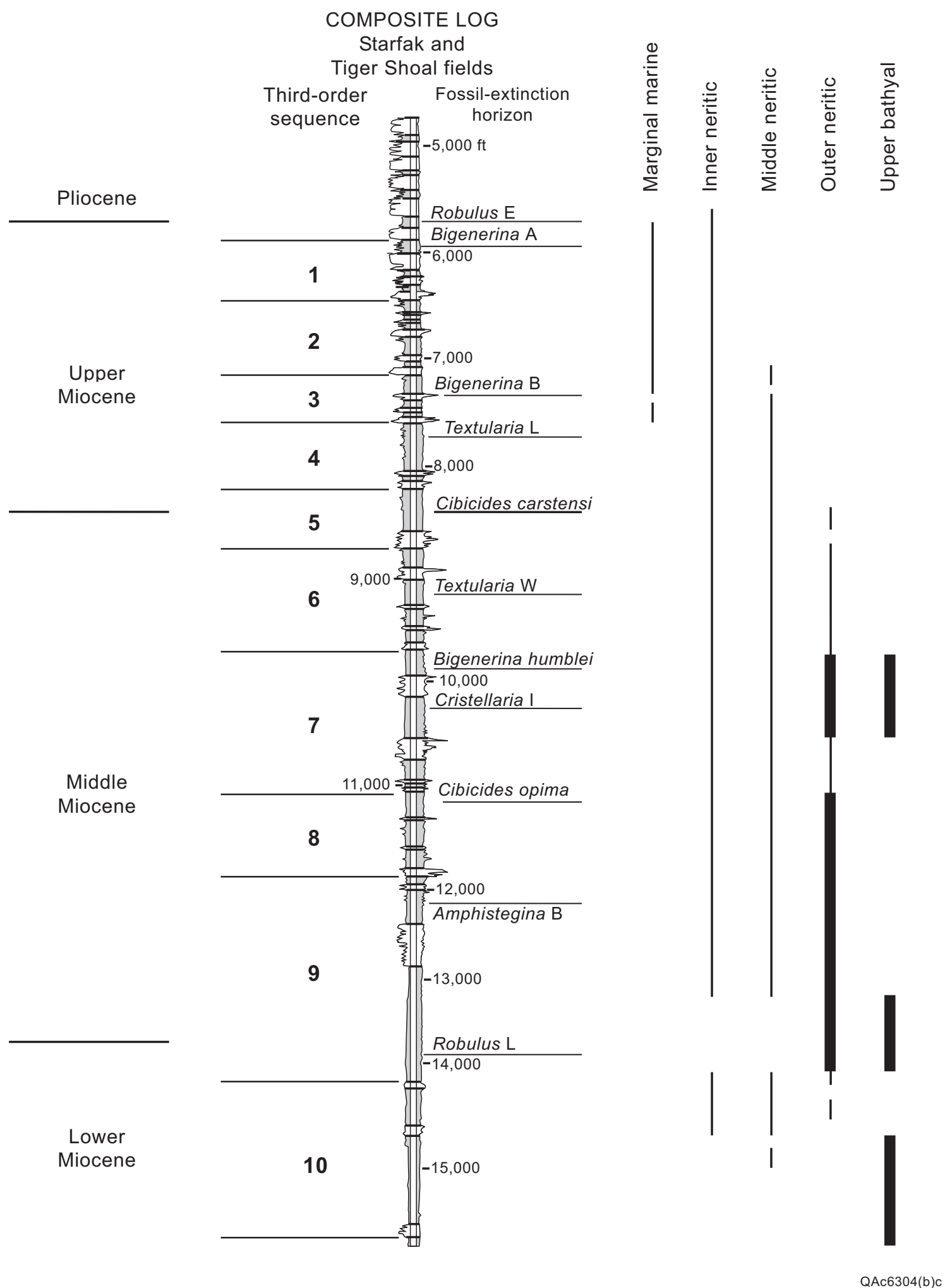

Figure 81. Stratigraphic position of the Starfak T-1 sandstone. 
The T-1 reservoir architecture was constructed in three stages: (1) defining the stratigraphy, (2) constructing fault surfaces, and (3) generating structural surfaces. Next is a detailed, stage-by-stage description of the procedure for building the T-1 reservoir architecture using the RMS reservoir modeling software by Roxar .

\section{Stratigraphy of the T-1 Reservoir}

The T-1 reservoir in Starfak field is part of the Middle Miocene Eastern Retrogradational Sandstone play lying offshore of Texas and Louisiana (Seni and others, 1997). This middle Miocene section contains the Cibicides opima, Cristellaria "I," and Bigenerina humblei regional biozones. Reservoirs in this play are typically gas bearing, formed by normal-faulted anticlines with water drives (Seni and others, 1997). Within the sequence-stratigraphic framework, the T-1 is the uppermost sand in the third-order lowstand systems tract of medial third-order Sequence 7 (fig. 24). The thick Cristellaria "I" shale above the T-1 sand represents deposition in outer neritic (300-600 ft) to upper bathyal (600-1,500 ft) water depths.

The T-1 reservoir comprises two stacked, discontinuous sandstone bodies and a third, thicker sandstone that truncates the others. The two vertically stacked sandstones range from 0 to $20 \mathrm{ft}$ in thickness and are separated by a thin shale that is expressed as a gamma-ray spike of variable amplitude and thickness. Both the upper and lower sandstones display blocky to upward-fining log signatures. The third, thicker sandstone lies on the eastern flank of the reservoir and displays a blocky gamma-ray signature. The lower T-1 sands were deposited in a deltaic/strandplain environment of a highstand systems tract, whereas the upper sand forms the fill of a lowstand incised valley.

\section{3-D Fault Modeling}

The second step in determining the reservoir architecture is building an internally consistent fault model. The fault model is determined by interpreting where faults exist in the reservoir and then modeling the faults' positions and throws in the computer. The position of faults within the reservoir were interpreted from the 3-D seismic volume and fluid-level information calculated from well logs. Offset of maximum flooding surfaces on cross-lines were used to interpret the position and throw of faults. An RMS amplitude map of the T-1 sand provided corroborative data on the areal positions of faults in the study area (fig. 82). Variations in initial fluid levels were also examined to infer the locations of possible sealing faults. This analysis is further described in the "Establishing Reservoir Fluid-Flow Trends" section.

Computer fault modeling consists of constructing a set of fault surfaces along with their associated fault lines. The objective is to build a fault model in which all structural surfaces are consistent with the fault surfaces and in which each pair of fault lines matches the up-thrown and down-thrown sides of the corresponding structural surface. The following inputs and procedures were used to build a consistent fault model for all the various faults that 


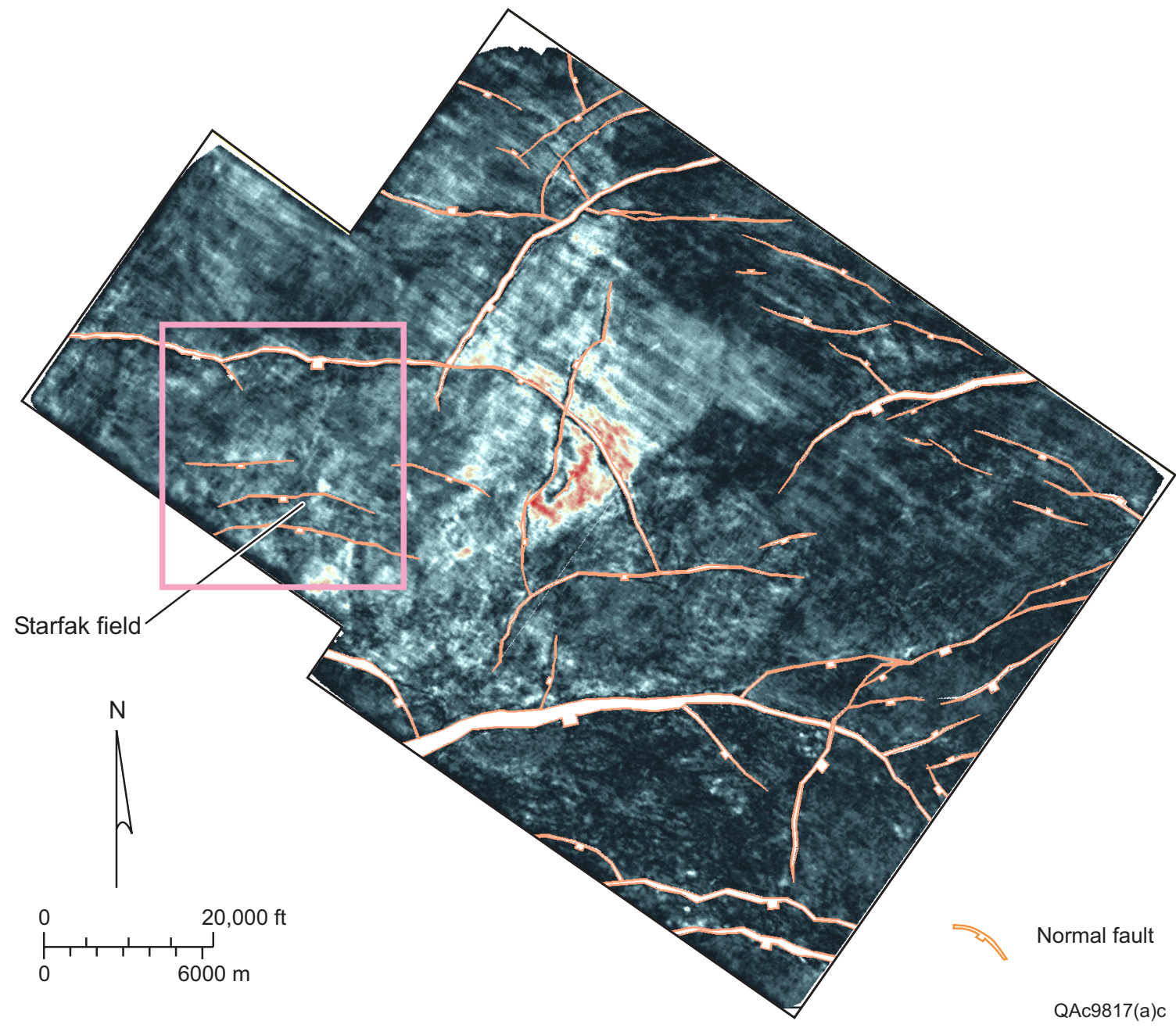

Figure 82. RMS amplitude map, with faults interpreted from lineations and offset of maximum flooding surfaces in cross-lines. Pink box outlines area of detailed reservoir modeling study. 
transect the MFS 30 to MFS 32 stratigraphic intervals (fig. 81) within Starfak field. The resulting fault model was (1) first used to insure proper stratigraphic modeling of the T-1 and T-2 structural surfaces in the faulted areas and (2) later incorporated into the 3-D modeling grids to allow accurate volume calculation.

Fault-modeling input and procedure. Fault modeling requires preparation of three input data sets. First, the picks for maximum $4^{\text {th }}$-order flooding surfaces MFS 30 and MFS 32 for the 47 wells within the Starfak study area were loaded into the Landmark OpenWorks database. Second, 2-D depth surface grids of MFS 30 and MFS 32 that honor both the seismic data and well log observations were created in, and subsequently exported from, Landmark Z-MAP Plus. Third, the fault segments of EW4, D2, D3, D15, and D20 created in Landmark SeisWorks were converted into depth fault sticks and stored in the OpenWorks database.

Fault modeling requires manipulation of these three data sets using the following procedures:

- Import 2-D depth surface grids (500`×500` grid in Z-MAP Plus ASCII format) for MFS 30 and MFS 32 into RMS.

- Reduce the lateral extent of the imported surfaces to that of the RMS project $\left(\mathrm{Xmin}=1,717,500^{\prime}, \mathrm{Xmax}=\right.$ 1,747,500', Ymin = 269,150', Ymax = 299,150`).

- Load MFS 30 and MFS 32 depth surface picks into the RMS project directly from the Landmark OpenWorks database.

- Load depth fault sticks of EW4 (as shown in fig. 83), D2, D3, D15, and D20 into RMS directly from the Landmark OpenWorks database.

- Display and edit the fault sticks as necessary, using the 3-D line editor in RMS.

- Grid the fault surfaces on the basis of the fault sticks (gridding algorithm $=$ smooth; grid increment $=500^{\prime}$ )

- Generate the MFS 30 fault lines for EW4, D2, D3, D15, and D20 using the RMS Fault Modeling tool. As illustrated in figure 84, this step creates a pair of parallel cutoff lines located on opposite sides of the fault. The up-thrown and down-thrown fault lines of MFS 30 are then extrapolated from both cutoff lines on the fault surface (algorithm $=$ smooth extrapolation; cutoff lines' distance to fault $=500^{\prime}$ ).

- Use the same method to generate the MFS 32 fault lines for all the faults.

- Display and edit the fault lines as necessary, using the Fault Editor and 3-D Line Editor in RMS.

- Regrid the fault surfaces on the basis of the modified fault lines and fault sticks (gridding algorithm = horizontal; grid increment $=100^{\prime}$ ).

- Regrid MFS 30 and MFS 32 surfaces using the Mask-method gridding algorithm (grid size = 100` $\times 100^{\prime}$; total grid nodes $=301$ column $* 301$ rows $=90,601)$.

- Regenerate the MFS 30 and MFS 32 fault lines for EW4, D2, D3, D15, and D20 using the new fault surfaces and structural surfaces (algorithm $=$ horizontal extrapolation; cutoff line's distance to fault $=500^{\prime}$ ).

- Truncate D2 against the older first-order fault EW4, as depicted in figure 85 (adjust radius $=500^{\prime}$ ).

- Adjust MFS 30 and MFS 32 surfaces to the EW4, D2, D3, D15, D20 fault lines (influence radius = 1,000'). 


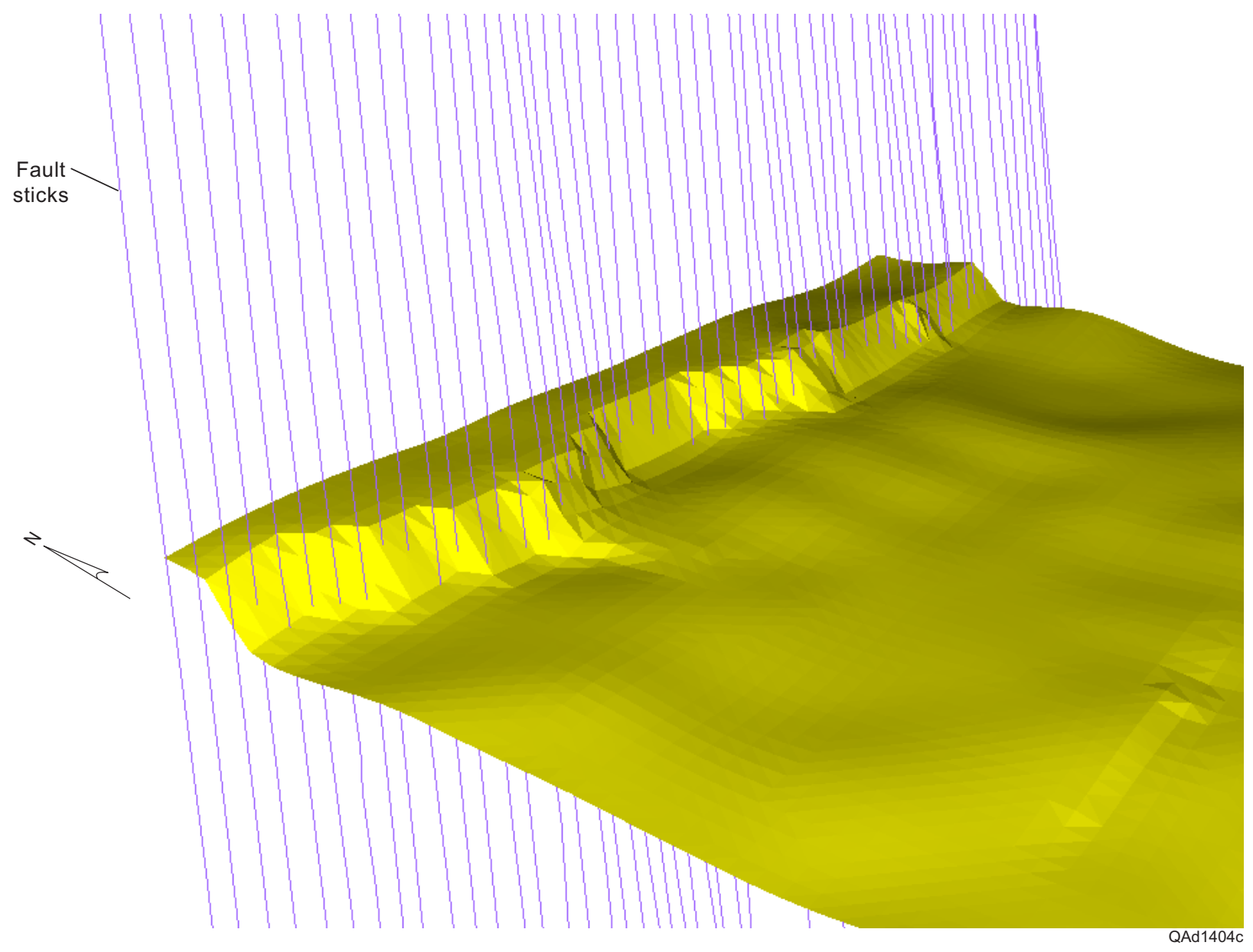

Figure 83. EW4 depth fault sticks penetrating MFS 30 surface. 


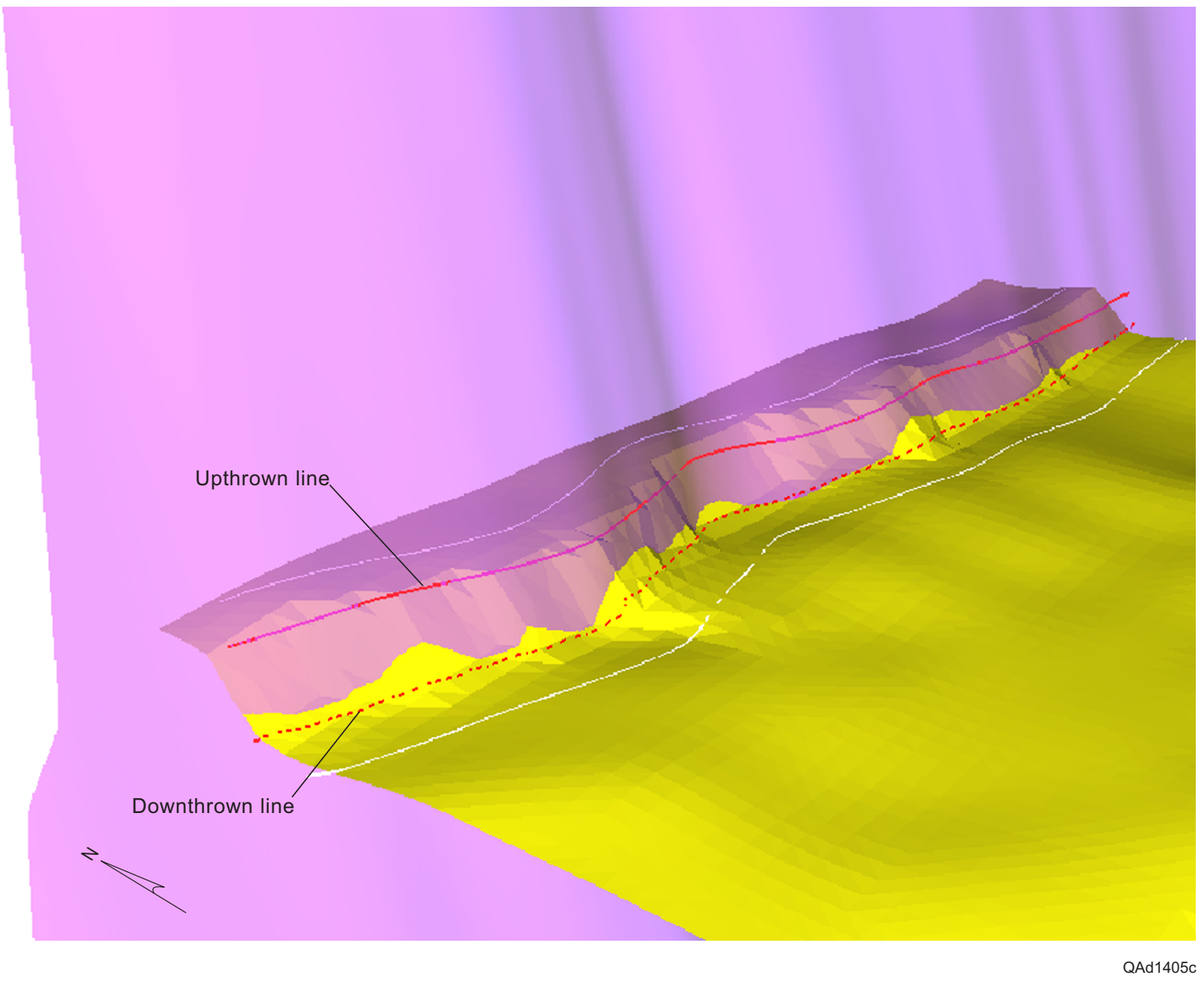

Figure 84. Derivation of MFS 30 fault lines for fault EW4 by extrapolating the associated cutoff lines (white) onto the fault surface. 


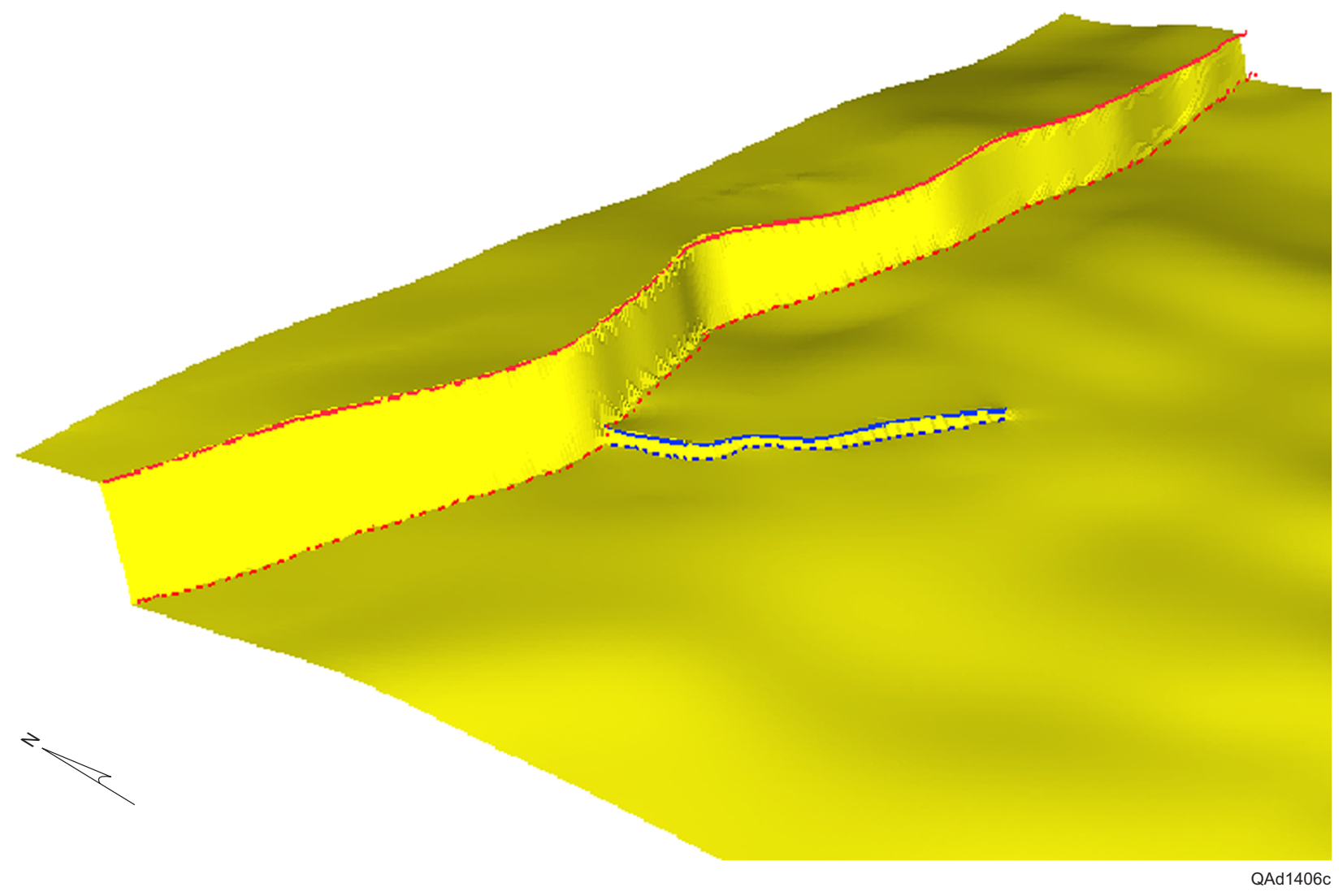

Figure 85. Results of truncating fault D2 (blue) against larger fault EW4. 
- Use the Surface Editor in RMS to manually edit the inconsistent surface grids near the faults.

- Adjust the resulting faulted surface grids to the corresponding depth surface picks of the 47 wells within the Starfak study area.

- Use the Horizon Administration tools in RMS to check whether MFS 30 and MFS 32 surfaces overlap (especially at the fault planes) and, if necessary, adjust them to become internally consistent.

Fault model. The main product of the fault modeling is a consistent fault model representing all the fault surfaces (EW4, D2, D3, D15, and D20) and their associated fault lines. In addition, this step also results in revised MFS 30 and MFS 32 structural surfaces in time (see figure 86) that are consistent with both the fault model and the top picks from well logs.

\section{Surface Modeling}

The third step in constructing the T-1 reservoir architecture is generating the reservoir's structural surface, which defines the top of the 3-D structural model by using the stratigraphic modeling tools in RMS. In essence, stratigraphic modeling in RMS is a process by which surfaces interpreted by seismic and geologically modeled isochores are amalgamated to perfectly fit and build a stratigraphic framework of the reservoir. This process uses interpreted horizon surfaces (such as MFS 30 and MFS 32), geological isochores, and/or surface picks from well logs as the main input data. In addition, the process also considers the existing fault model to insure accurate modeling in the faulted areas. The results are newly calculated horizon surfaces (such as that of T-1) produced by the addition and/or subtraction of isochores from the associated interpreted horizons.

The top of the T-1 surface was then constructed. All well log picks of the T-1 top were reviewed and refined to be consistent with the top of the reservoir interval. Kelly bushing heights were reviewed and adjusted. Deviation surveys were checked on nonvertical wells. Combining these T-1 well picks with the seismically defined MFS 30 and MFS 32 surfaces resulted in the building of a T-1 surface.

Surface model input and procedure. The surface-modeling procedures use two sets of input data. The first set of input data comprises the revised MFS 30 and MFS 32 interpreted horizon surfaces (fig. 87) and the fault model produced by the just-described process. The MFS 30, T-1, T-2, and MFS 32 top picks for the 47 wells within Starfak field provide the second set of input data that are necessary for deriving the T-1 and T-2 calculated horizon surfaces through stratigraphic modeling.

Time-depth conversion was accomplished from checkshot data gathered in well 219-122. A set of 30 data points were measured between the depths of $454 \mathrm{ft}$ and 14,735 ft. These data were analyzed to obtain a function of depth with respect to time in order to make conversions to true vertical depth (fig. 88).

The surface-modeling procedure is as follows: 


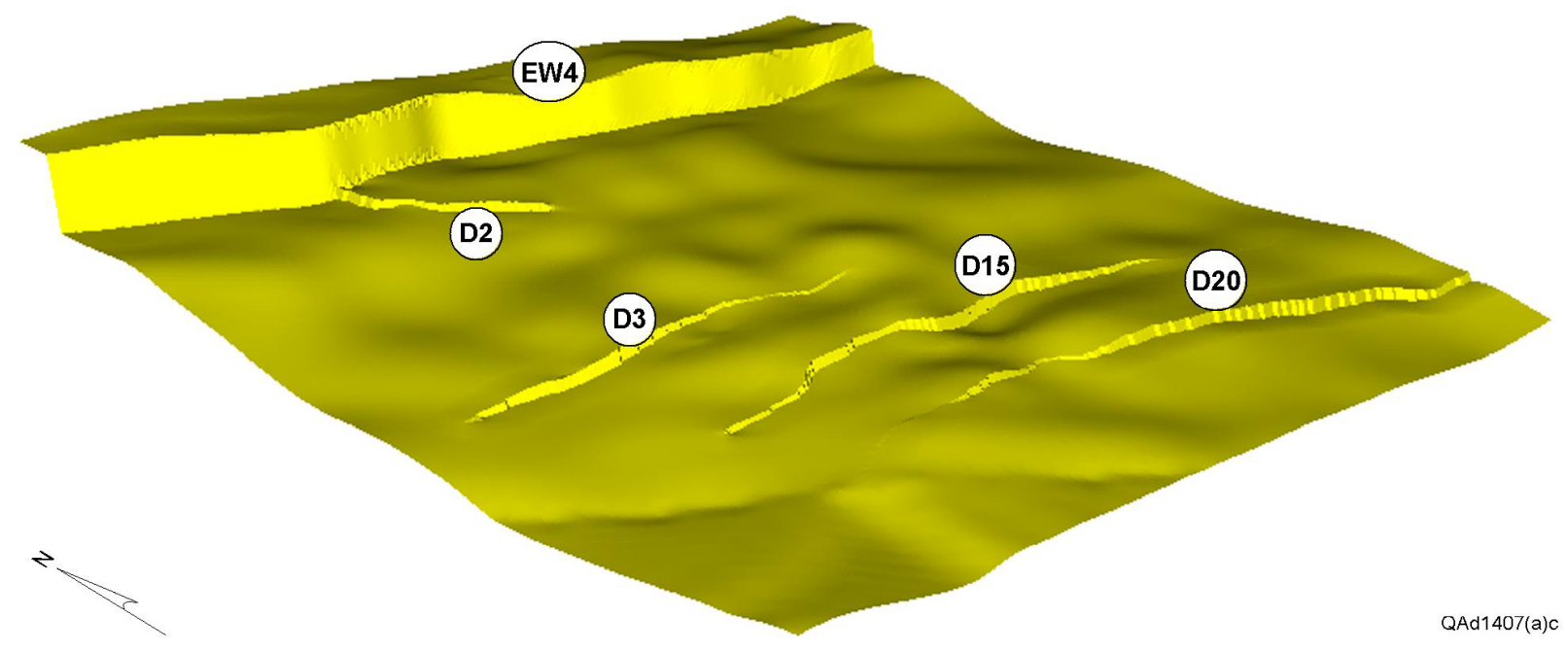

Figure 86. Revised MFS 30 structural surface that is consistent with both fault model and surface picks from well logs. 


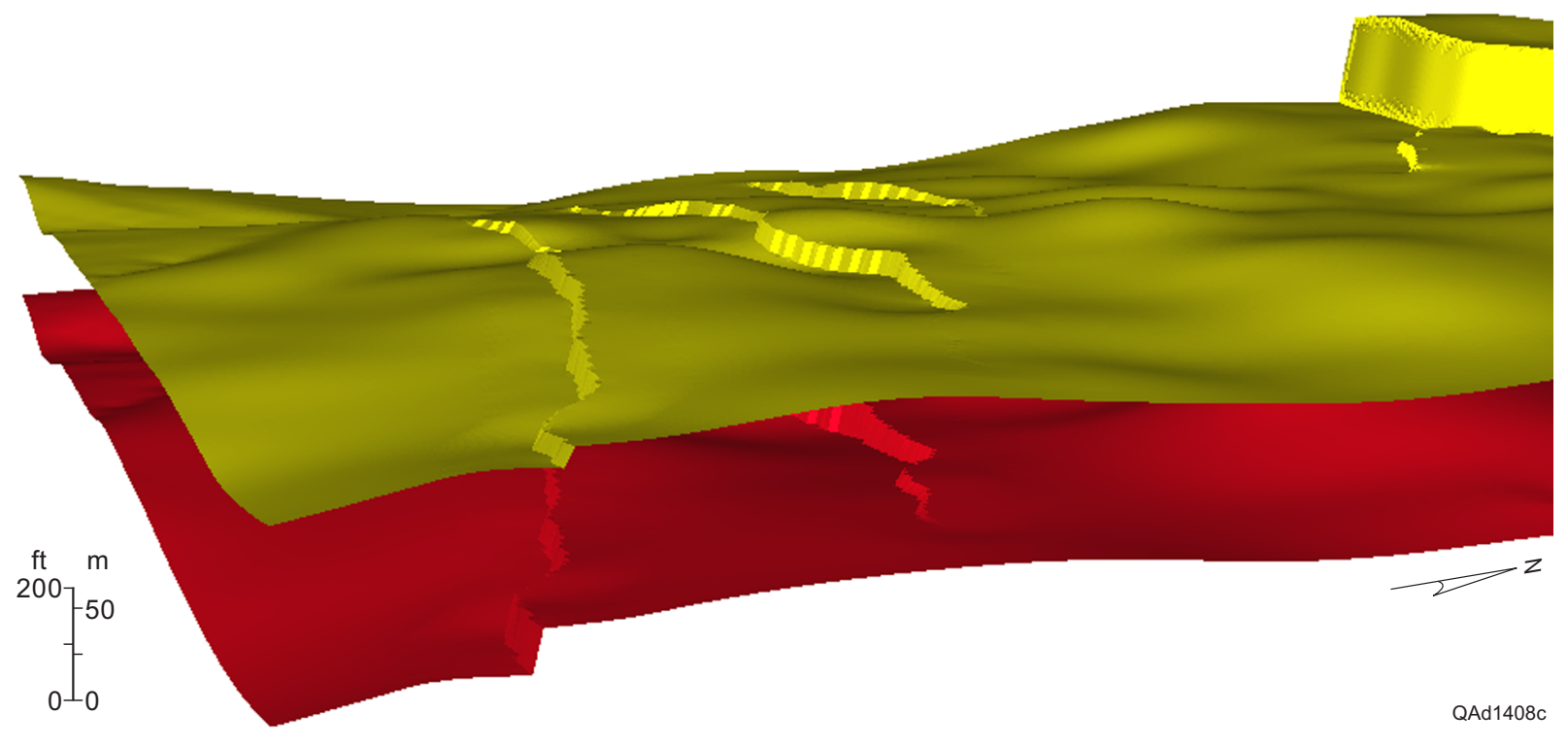

Figure 87. Stratigraphic modeling input—revised MFS 30 and MFS 32 surfaces.

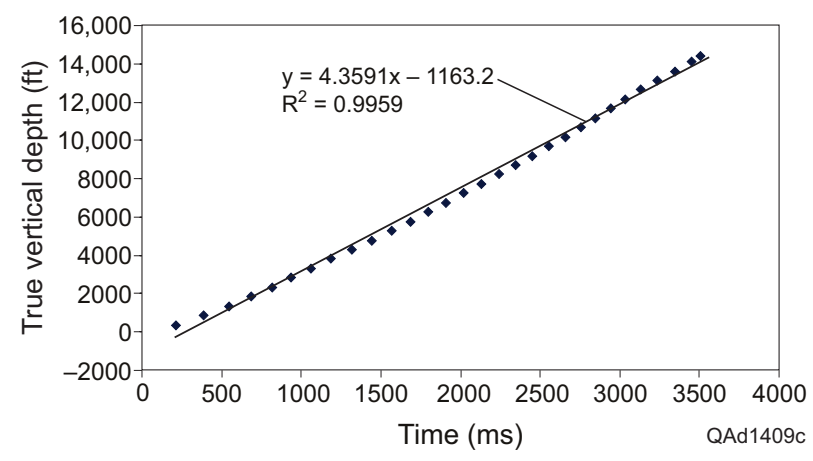

Figure 88. Time vs. depth from checkshot data gathered in Starfak well 219-122 results in a strong linear relationship. 
- Insert an empty T-1 calculated horizon between the MF S30 and MFS 32 interpreted horizons using the Horizon Administration tools in RMS.

- Insert an empty T-2 calculated horizon between MFS 30 and MFS 32.

- Load the T-1 and T-2 top surface pick depths for each well into RMS directly from the Landmark OpenWorks database.

- Run the Stratigraphic Modeling process in RMS to calculate and build T-1 and T-2 horizon surfaces using the following settings:

- $\quad$ Select MFS 30 to MFS 32 as the interval to be modeled.

- Specify the T-1 and T-2 top surface picks as part of the main input used in stratigraphic modeling.

- Set isochore correction method $=$ correct proportional.

- Toggle "use well correction" on, and set algorithm = cosine expansion.

- Toggle "use fault" on to allow accurate stratigraphic modeling in the faulted areas.

- Examine the resulting T-1 and T-2 structural surfaces in the RMS 3-D display window and, if necessary, use RMS Surface Editor to manually edit the inconsistent surface grids near the faults.

- Use RMS Horizon Administration tools to check whether the MFS 30, T-1, T-2, and MFS 32 surfaces overlap (especially at the fault planes) and, if necessary, adjust them to become internally consistent.

Surface model. The surface-modeling procedures resulted eventually in the final MFS 30, T-1, T-2, and MFS 32 structural surfaces (fig. 89). The surfaces are consistent with both the fault model and the corresponding top picks from the well logs.

To insure the accuracy of the final stratigraphically derived T-1 surface, the T-1 top pick of each well was carefully scrutinized for accuracy and consistency before loading it into RMS. Following stratigraphic modeling, the final stratigraphically calculated T-1 surface was contrasted with an equivalent seismically interpreted T-1 surface to show how well they matched, thus providing a way to visually examine the accuracy of the final T-1 stratigraphic surface.

The T-1 seismic surface that was used to triangulate the stratigraphic modeling results was derived from a set of T-1 picks from the 3-D seismic data set (fig. 90) that honor both the well observations and the seismic trend throughout the study area. Because the T-1 stratigraphic and seismic surfaces closely coincide except in areas where seismic data are absent (fig. 91), the final T-1 stratigraphically calculated surface can be considered to be a reasonably accurate model of the "real" T-1 structural surface that defines the top of the T-1 3-D reservoir model.

\section{Establishing Reservoir Fluid-Flow Trends}

Establishing fluid-flow trends in a reservoir is the second step in reservoir characterization. The goal of analyzing these trends is to determine the initial drive mechanism, to explain the effects of previously applied 


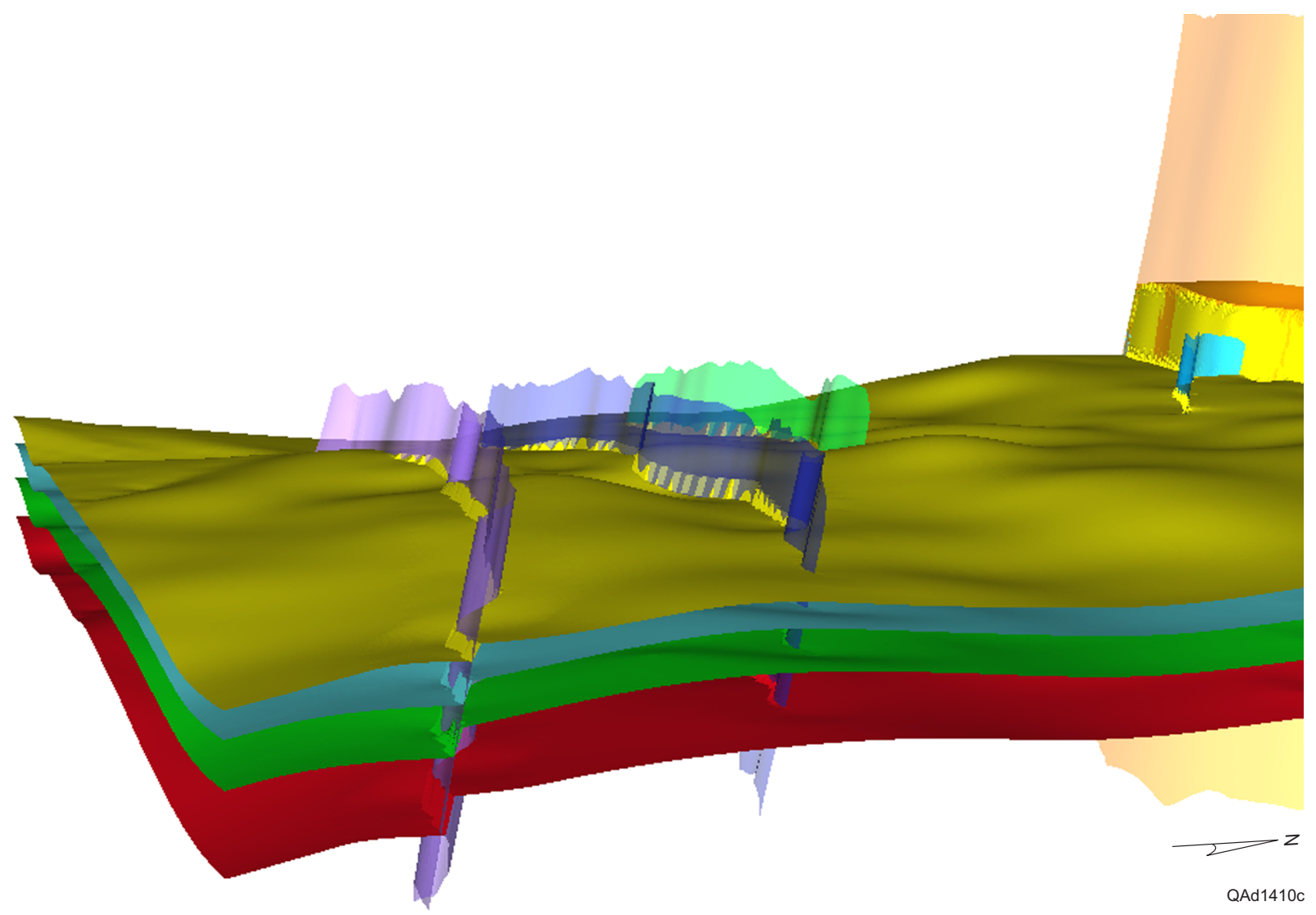

Figure 89. Stratigraphic modeling results displaying final MFS 30, T-1, T-2, and MFS 32 surfaces subparallel to each other and offset at the faults. 


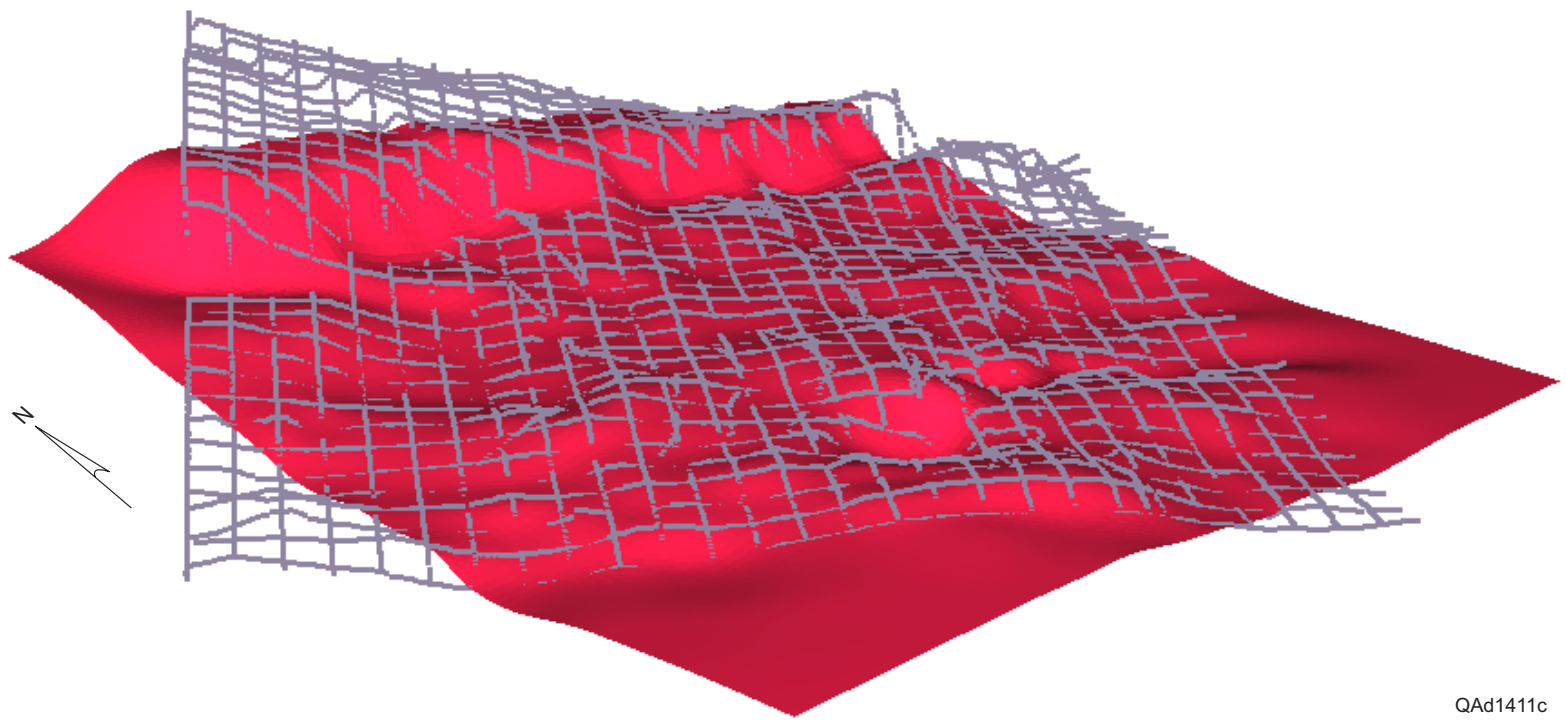

Figure 90. 3-D seismic T-1 picks (gray ) overlain on the T-1 seismic surface. 


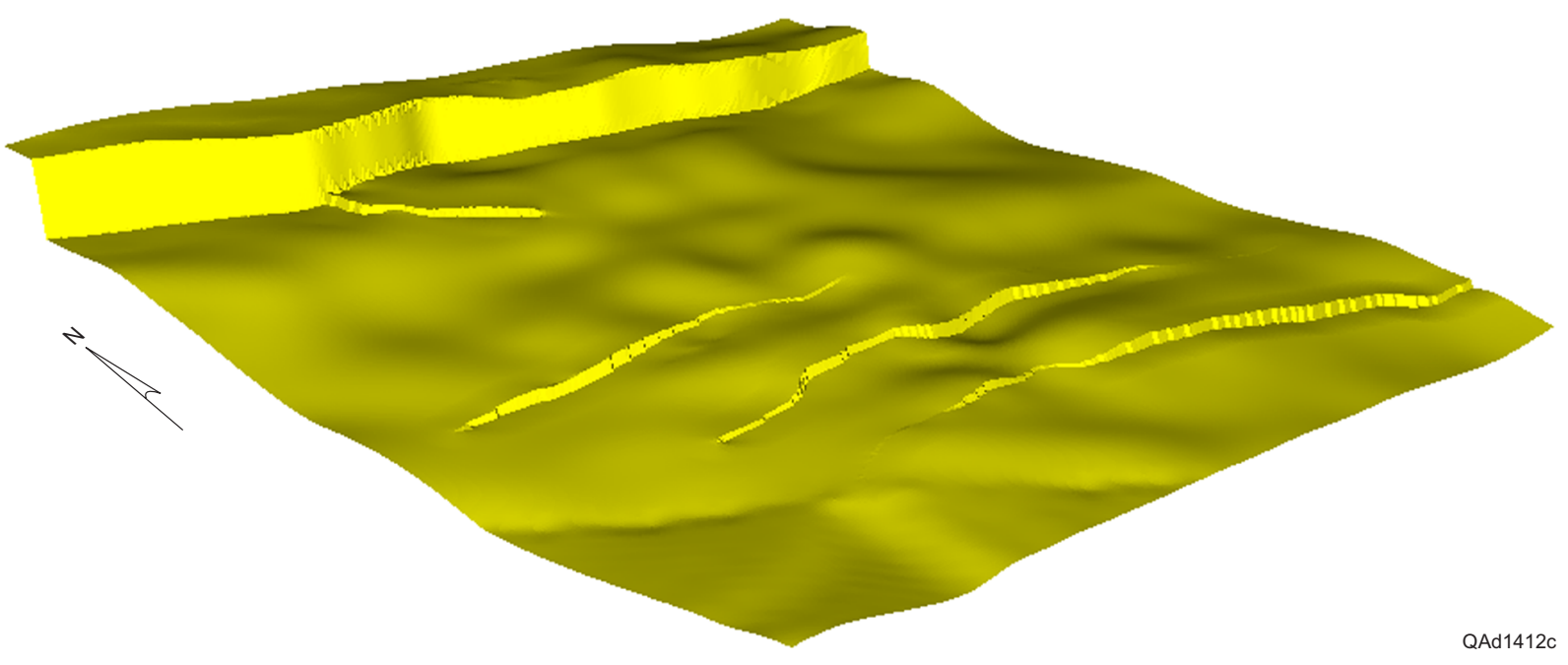

Figure 91. Stratigraphically calculated vs. seismically interpreted T-1 surface. Refer to figure 86 for fault names. 
reservoir-production strategies, and to aid in the design of the reservoir model. Establishing these trends also functions as a production preprocessor to reservoir simulation. This step involves analyzing and incorporating the flow dynamics of the reservoir and depends heavily on reservoir-engineering concepts of storage capacity and fluid flow in a porous medium. The type of fluid-flow characteristics to be analyzed depends on the initial hydrocarbon fluid properties and the determined drive mechanism and on any secondary or tertiary recovery mechanisms applied. Establishing fluid-flow trends is accomplished through four main tasks: (1) ascertaining the initial fluid and properties, (2) constructing rock-fluid property models, (3) assessing well test data, and (4) generating a production-time-series analysis (Holtz and Hamilton, 1998). For this study, data were available for all but step 3.

\section{Fluid Characteristics}

The initial fluid properties give valuable insight into how a reservoir will produce and can help explain production anomalies. The key is to understand how fluid properties will change with changes in reservoir

pressure. Basic hydrocarbon fluid properties needed in reservoir characterization include oil and gas gravity, oil and gas viscosity, formation volume factor, gas-to-oil ratio, bubble-point pressure, water salinity, and initial-water-tooil/gas ratio. The primary source for determining initial hydrocarbon fluid properties is pressure-volumetemperature (PVT) analysis; a secondary source is initial well production and the application of published oil and gas PVT correlations. Additionally it is important to know the initial reservoir temperature and pressure conditions. These conditions have a profound effect on fluid characteristics.

Reservoir initial conditions. Reservoir temperature was analyzed from measurements taken when PVT samples were obtained. The 35 data points range in depth from 8,000 to $15,000 \mathrm{ft}$ and display a strong linear trend with an $\mathrm{R}^{2}$ of 0.833 (fig. 92). The best-fit equation 1 predicts the surface temperature at $65^{\circ} \mathrm{F}$ and has the temperature changing $1.43^{\circ} \mathrm{F}$ per $100 \mathrm{ft}$. The average T-1 reservoir depth is $10,797 \mathrm{ft}$, resulting in an average reservoir temperature of $219^{\circ} \mathrm{F}$.

$$
Y=0.0143 x+65
$$

Plotting reservoir pressure vs. depth indicates a normal pressure gradient in the T-1 reservoir to just below 12,000 ft (fig. 93). Reported initial pressure data are quite scattered. Assuming that the highest values at depth represent true initial pressure and that the lesser values are unrepresentative leads to calculation of a pressure gradient of $0.44 \mathrm{psi} / \mathrm{ft}$ (fig. 93). This pressure gradient compares favorably with a normal water-pressure gradient of $0.433 \mathrm{psi} / \mathrm{ft}$ and suggests that the gas column in which the pressures were measured is short. Wells in which pressures are interpreted as too low may have experienced liquid loading or the test may not have been conducted for a length of time sufficient to build up to reservoir pressure. Applying the average reservoir depth, along with this pressure gradient, results in an average reservoir pressure of 4,791 psi. 


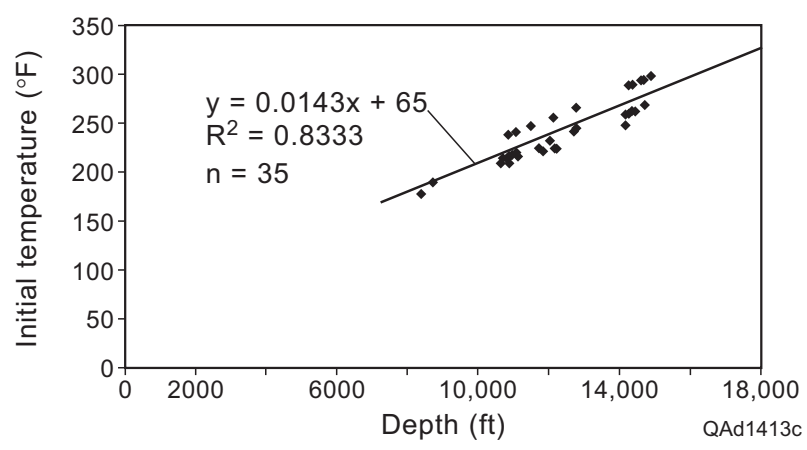

Figure 92. Temperature gradient for the T-1 reservoir.

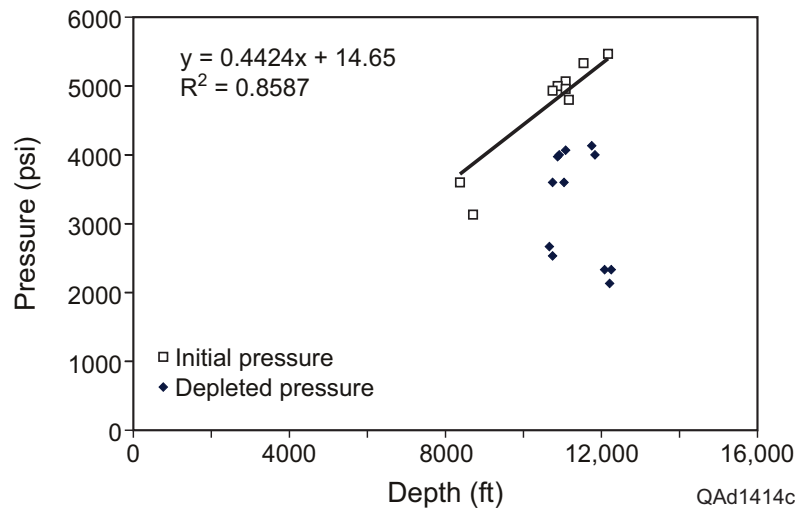

Figure 93. Taking the highest pressures as representative of the initial reservoir pressure results in a reasonable pressure gradient for determining pressure in the T-1 reservoir. 
Gas and water properties. The T-1 reservoir is a dry gas reservoir. Gas gravity is 0.65 and condensate is 50 API. The producing gas:condensate ratio is 69,000 STB. Using the average reservoir conditions and applying the empirical functions of Brill and Beggs (1974), the initial gas properties are a $\mathrm{z}$ factor of 0.91 and a gas formation fraction $(\mathrm{Bg})$ of 0.0048 . No water samples were available for the T-1 reservoir; therefore, water properties were determined from wireline-log Rwa analysis.

\section{Petrophysical Property Modeling}

Petrophysical models consider the interaction between fluid and rock properties. Salient petrophysical properties include porosity, permeability, residual gasloil saturation, capillary pressure, formation resistivity factor, wettability, relative permeability, and initial water saturation. The goal in designing petrophysical models is to devise methods for determining storage capacity, flow capacity, and hydrocarbon pore volume at the smallest common geological scale.

Petrophysical properties are interdependent. Porosity has been related to residual gas saturation, permeability, capillary pressure, and relative permeability such that all petrophysical properties are interrelated. This interrelationship will be applied in the 3-D geocelluar model such that each petrophysical property will have the proper value relative to another for each cell in the model. In the following description the models to calculate properties, and their interrelationship with porosity, are described.

Residual gas saturation model. With water acting as the wetting phase and gas acting as the nonwetting phase, maximum residual gas saturation (Sgrm) results from pore-scale capillary forces. Sgrm is the trapped nonwetting phase when the wetting phase has been imbibed into the rock from a state of irreducible water saturation to a state of zero capillary pressure. The models that describe how this trapping occurs are pore-geometry dependent. Three trapping models are possible (fig. 94). The pore doublet model is more likely to occur in poorly sorted rock or in rock with dual-porosity networks. The pore snap-off and dead-end models are more likely to occur in lower porosity rocks and rocks with greater cementation. The trapping models thus suggest that porosity will have an inverse relationship with Sgrm.

The relationship between capillary number $(\mathrm{Nvc})$ and porosity also illustrates an inverse relationship between porosity and Sgrm. The direct relationship between capillary number and porosity is shown in Equation 2 (Lake, 1996).

$$
\mathrm{Nvc} \geq \frac{\phi}{\mathrm{C}}\left[\mathrm{j} \cos \theta_{\mathrm{A}}-\frac{\cos \theta_{\mathrm{R}}}{(2 \tau)^{1 / 2}}\right]^{2}
$$

As capillary number increases, nonwetting-phase residual saturation decreases (fig. 95). In the case of a watergas system, therefore, Sgrm depends on porosity. Note also how the function is dependent on rock and pore type. As 
(a) Pore doublet model

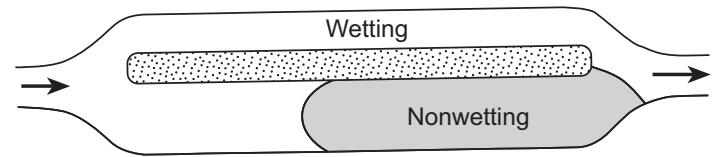

(b) Pore snap-off model
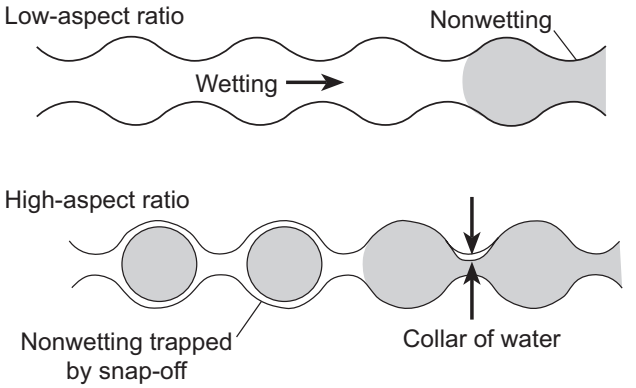

(c) Dead-end model

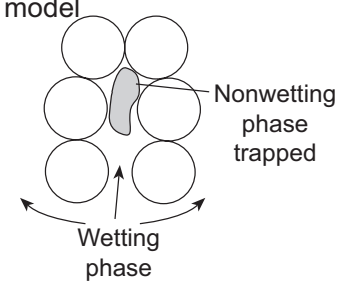

QAd501c

Figure 94. Three possible models indicate how a wetting phase can trap a nonwetting phase as a result of variations in pore geometry (modified from Chatzis and Morrow, 1981).

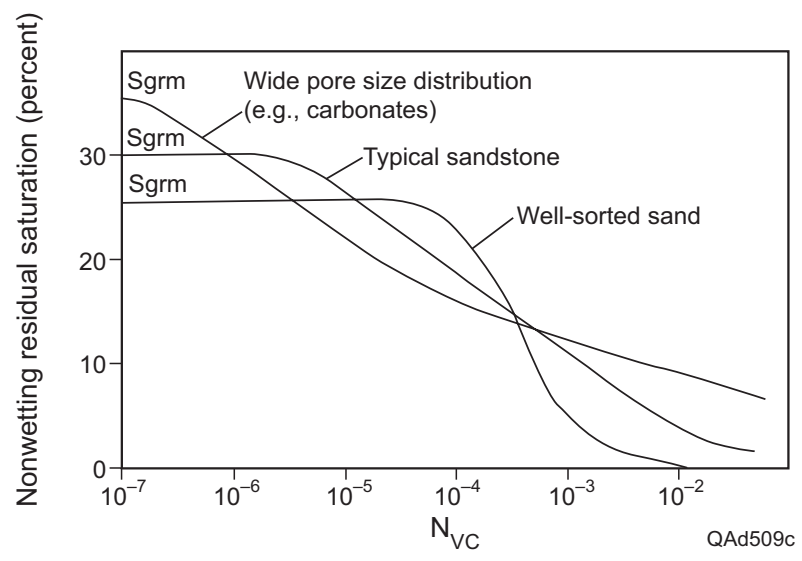

Figure 95. Relationship between capillary number ( $\mathrm{Nvc}$ ) and nonwetting phase residual saturation showing how Sgrm will decrease as Nvc increases (Lake, 1996). 
the pore network becomes more complex from well-sorted sandstone to typical sandstone to wide pore-size distribution, Sgrm increases. Therefore, nonwetting-phase trapping occurs increasingly as porosity decreases and pore-geometry complexity increases.

A methodology has been developed for deriving an empirical model for Sgrm in gas reservoirs. The methodology is based on the concept that petrophysical properties are interrelated and that the interrelationship is a function of the rocks' pore-network geometry. The steps in the methodology are (1) develop a porosity-permeability relationship, (2) develop a function for irreducible water saturation from capillary pressure data, (3) determine a relationship for Sgrm as a function of porosity, and (4) combine equations to obtain Sgrm as a function of initial gas saturation. An example of this methodology's application from the Miocene study section is illustrated next.

The relationship between porosity and permeability was determined by generating a best-fit equation for the two properties. A conventional cross-plot of porosity vs. permeability displays both a strong exponential and powerlaw fit with less than one order of magnitude of variation (fig. 96). Permeability ranged to a high end of $1 \mathrm{D}$ at 0.3 porosity and a low end of $1 \mathrm{md}$ at 0.14 porosity. The power-law equation was chosen, having an $\mathrm{R}^{2}$ of 0.855 , because it more realistically models permeability approaching zero as porosity decreases. Permeability can be predicted from equation 3.

$$
\mathrm{k}=7 \mathrm{E} 7\left(\phi^{9.61}\right)
$$

An expression for initial water saturation is determined by assuming that pore geometry controls petrophysical interrelationships. Because the way a data set radiates out from a low porosity-permeability point is a function of pore geometry, the ratio of $\log (\mathrm{k}): \phi$ should give a measure of the pore geometry as well (Holtz and Major, 2002).

Application of this pore-geometry measure facilitates the development of an equation for initial gas saturation. The $\log (\mathrm{k}): \phi$ value corresponds to variations in capillary characteristics. Capillary-pressure curves that demonstrate low irreducible-water saturations correspond to $\operatorname{larger} \log (\mathrm{k}): \phi$ ratios (fig. 97).

This relationship leads to equation 4 (fig. 98), which is used for calculating irreducible-water saturation (Swirr).

$$
\text { Swirr }=5.159\left(\frac{\log (\mathrm{k})}{\phi}\right)^{-1.559}
$$

A robust model of residual gas saturation was developed from field and published data. A strong relationship is documented between increasing porosity and decreasing residual gas saturation. The trend is linear, and the best fit is represented in equation 5. This relationship predicts an Sgrm lower limit of 0.125, corresponding to a porosity limit of unconsolidated sandstone, an upper limit of 0.5, corresponding to 0.05 porosity, and an Sgrm equal to initial gas saturation (Chierici and others, 1963) (fig. 99). 


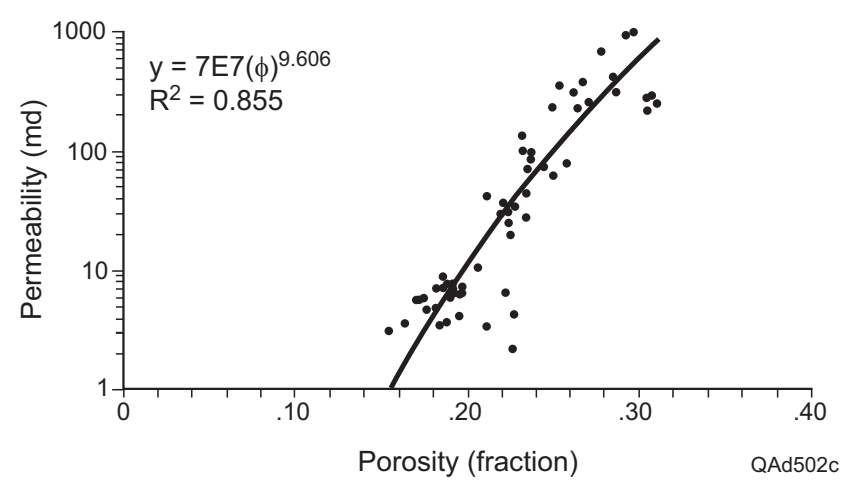

Figure 96. Power-law equation giving strong empirical fit to Starfak porosity and permeability data.

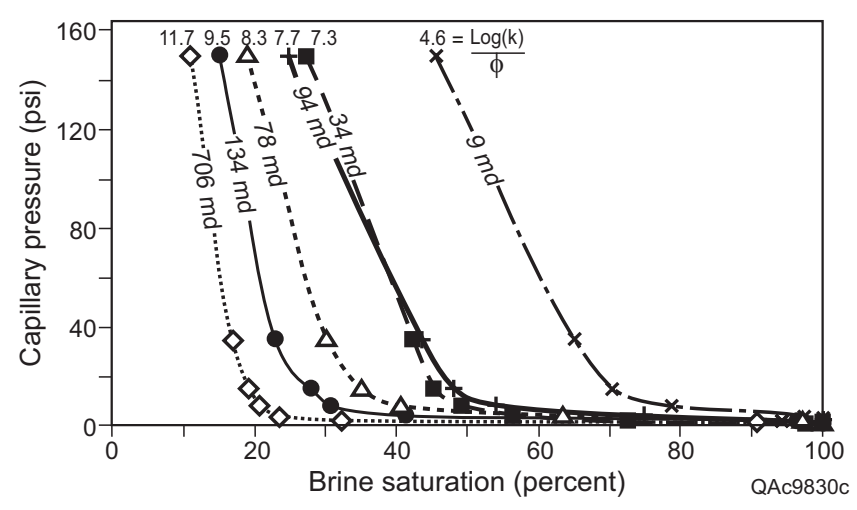

Figure 97. Capillary-pressure curves display a strong correlation with $\log (\mathrm{k}): \phi$ ratios because they reflect pore type and geometry. 


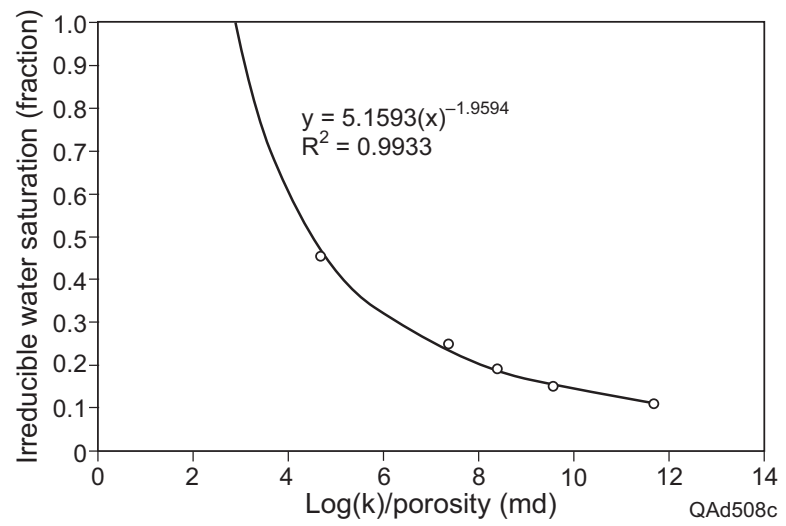

Figure 98. An empirical power-law fit $\left(\mathrm{R}^{2}=0.99\right)$ between $\log (\mathrm{k}): \phi$ and Swirr results in a strong predictive tool because it takes into account pore-geometry variation.

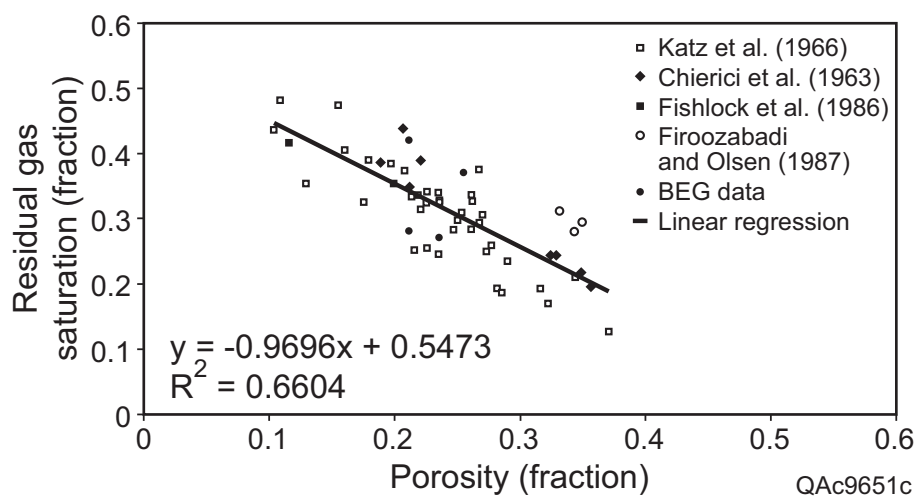

Figure 99. Residual gas saturation displays an inverse linear relationship with porosity. 


$$
S_{\mathrm{grm}}=-0.9696 \phi+0.5473
$$

The final step in developing the Sgrm model is to integrate Equations 2, 3, and 4. They must be integrated in such a way that Sgrm is a function of Swirr so that the initial condition of Sgrm being less than or equal to the initial gas saturation is met. This initial condition is met with the development of an initial-residual [IR] nonwetting phase curve (IR curve). The general shapes of IR curves are shown in figure 100. These curves represent the character of an individual rock sample. The end point to the curve is the Sgrm value. The shape of the initial-residual wettingphase saturation curves displays the effect of rock type. As sandstone becomes cleaner, better sorted, and less cemented (higher porosity), the curves move farther away from the 1-to-1 line and increase in slope, and Sgrm decreases.

The results of Chierici and others (1963) correspond to those of figure 100. They found that unconsolidated sandstones have lower Sgrm values than those of consolidated sandstones and that there is an inverse trend between initial gas saturation (Sgi) and Sgrm (fig. 101). The empirical relationship sought after should therefore follow this trend.

To determine where the trend will intersect the 1-to-1 line, representing the reservoir pay cutoff, equation 6 is applied.

$$
\text { Sgrm }=\text { Sgi }=1-\text { Swirr }
$$

Substituting Sgrm from equation 4 and Swirr from equation 3 and then solving in terms of porosity only by substituting from equation 3 results in an expression that gives the porosity at which equation 6 holds:

$$
\phi-5.32\left[\frac{\log \left(\mathrm{E} 7\left(\phi^{9.6057}\right)\right)}{\phi}\right]^{-1.56}=-.467
$$

The solution to equation 7 results in a porosity of 0.18 and a permeability of $4.9 \mathrm{md}$ at an Sgrm value of 0.37. This Sgrm value represents the highest value expected in the reservoir.

Combining equations 3, 4, and 5 with equation 8 and solving for Sgi in terms of Sgrm results in a function to describe their relationship:

$$
\begin{gathered}
1=\text { Swirr + Sgi } \\
\left.\mathrm{Sgi}=1-\left[5.159 \frac{\left.\log 7 \mathrm{E} 7\left(\frac{\text { Sgrm-0.547 }}{-.9696}\right)^{9.606}\right)}{\left(\frac{\text { Sgrm-.547 }}{-.9696}\right)}\right]\right]^{-1.55}
\end{gathered}
$$




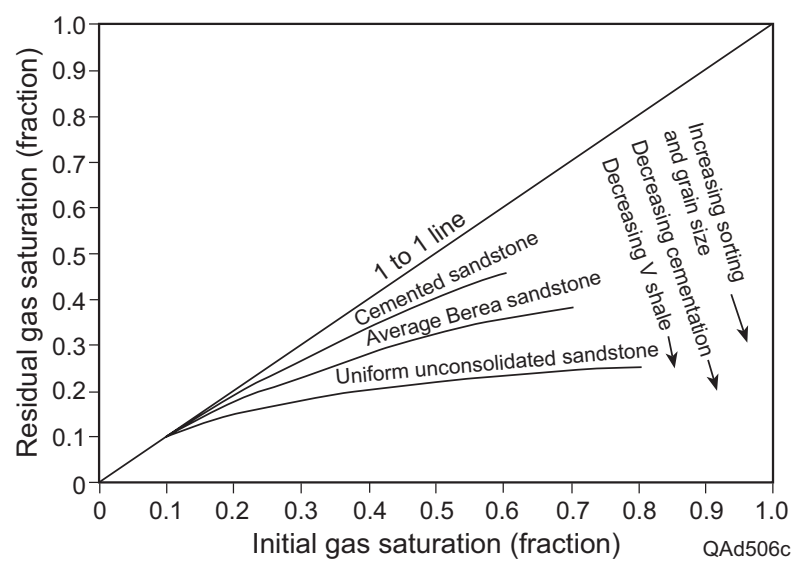

Figure 100. Shape of initial residual wetting-phase saturation curves displays effect of rock type. As sandstone becomes cleaner, better sorted, and less cemented (higher porosity), the curves move farther away from the 1-to-1 line and Sgrm decreases (modified from Lake, 1996).

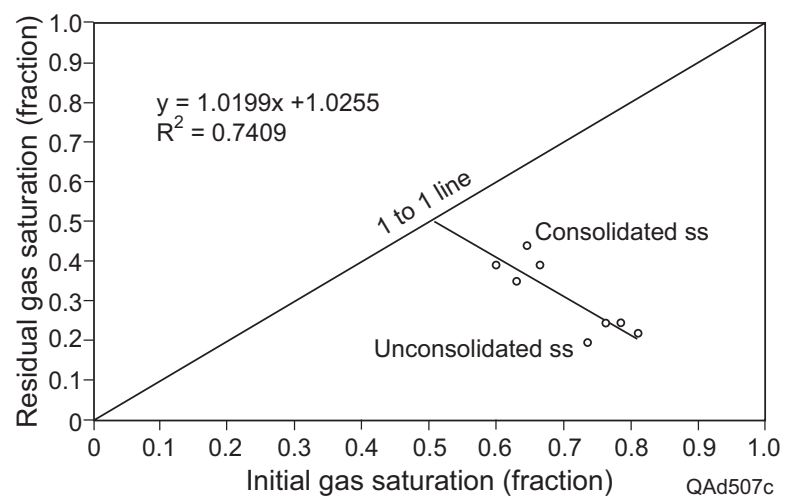

Figure 101. Unconsolidated sandstones display lower Sgrm values than consolidated sandstones, and initial gas saturation is inversely related to Sgrm. 
The relationship between Sgi and Sgrm is a "J" shape lying on its side (fig. 102) and generally corresponds to the curve in figure 101. The interrelationship between porosity, initial gas saturation, and Sgrm can be seen as porosity decreases slowly (along with Sgi) and Sgrm increases rapidly. However, this rapid Sgrm increase tapers off as small increments of porosity result in large increases in Sgi. This relationship represents the end points to a set of IR curves for the varying rock quality within the gas reservoir.

The shapes of the gas-water-system IR curves are illustrated in figures 100 through 102 . The curves must stay below the 1-to-1 line, terminate at a given Sgrm-Sgi position, and decrease in slope with higher quality rock. Equation 9 (modified from Land, 1971) meets these criteria:

$$
\operatorname{Sgr}=1 /\left[\left(\frac{1}{\text { Sgrm }}-1\right)+\left(\frac{1-\text { Swirr }}{\operatorname{Sg}}\right)\right]
$$

Applying equation 9, a set of Swirr-Sgrm values can be determined. Substituting this set of values as constants and applying equation 10 results in a group of IR curves for varying rock quality. This result leads to the curves shown in figure 103. Notice how the ends of each line define the Sgrm line displayed in figure 102. The figure now defines the entire residual gas saturation character of varying rock quality found within the reservoir. Additionally, this curve, along with the capillary pressure curves, can be used to define a capillary desaturation curve (CDC curve) (Lake, 1996), such as the example shown in figure 95.

Capillary pressure and relative permeability. Capillary pressure character displays a consistent change with $\log (\mathrm{k}): \phi$. As this value increases, the capillary pressure entry pressure decreases, the curves become more convex, and the irreducible-water saturation decreases (fig. 97).

The limited capillary pressure data can be grouped into high, medium, and low rock-quality categories. Averaging the capillary pressure data on the basis of their permeability values is key to deriving these reservoirquality groups. The capillary-pressure curve representing less than $10 \mathrm{md}$ became the lowest rock-quality group, curves averaging between 10 and $100 \mathrm{md}$ compose the medium rock-quality group, and curves representing greater than $100 \mathrm{md}$ make up the high rock-quality group. The resultant average capillary pressure curves are illustrated in figure 104.

These rock-quality groupings allow end-point saturations to be determined for each range of rock quality. Table 7 summarizes the petrophysical properties. Porosity was calculated from the aforementioned porosity/permeability relationship after applying an average permeability for the rock group. Residual gas saturation was determined from the porosity/residual gas saturation relationship, and initial water saturation was obtained from the average capillary-pressure curves.

The key to understanding the salient petrophysical properties in water-drive gas reservoirs is the character of the gas-water two-phase flow, which is dictated by a reservoir's relative permeability. Because relative- 


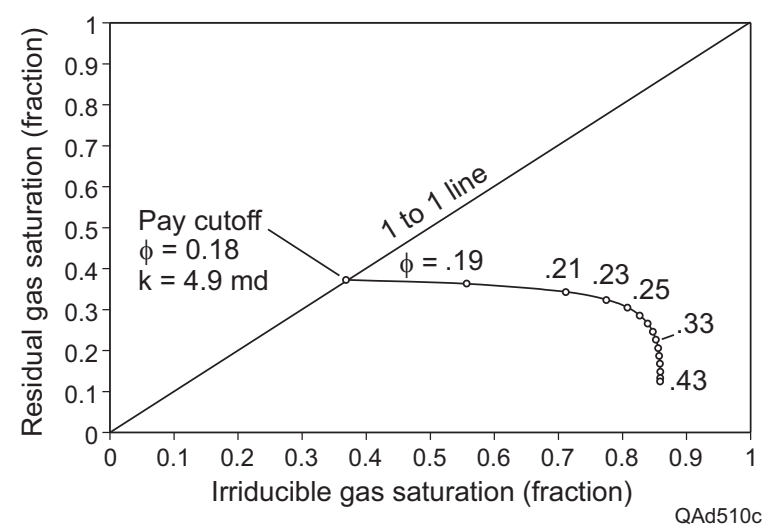

Figure 102. Sgrm model results in values ranging from 0.37 to 0.12 , with Sgrm rapidly increasing as porosity and Sgi decrease and then taper off.

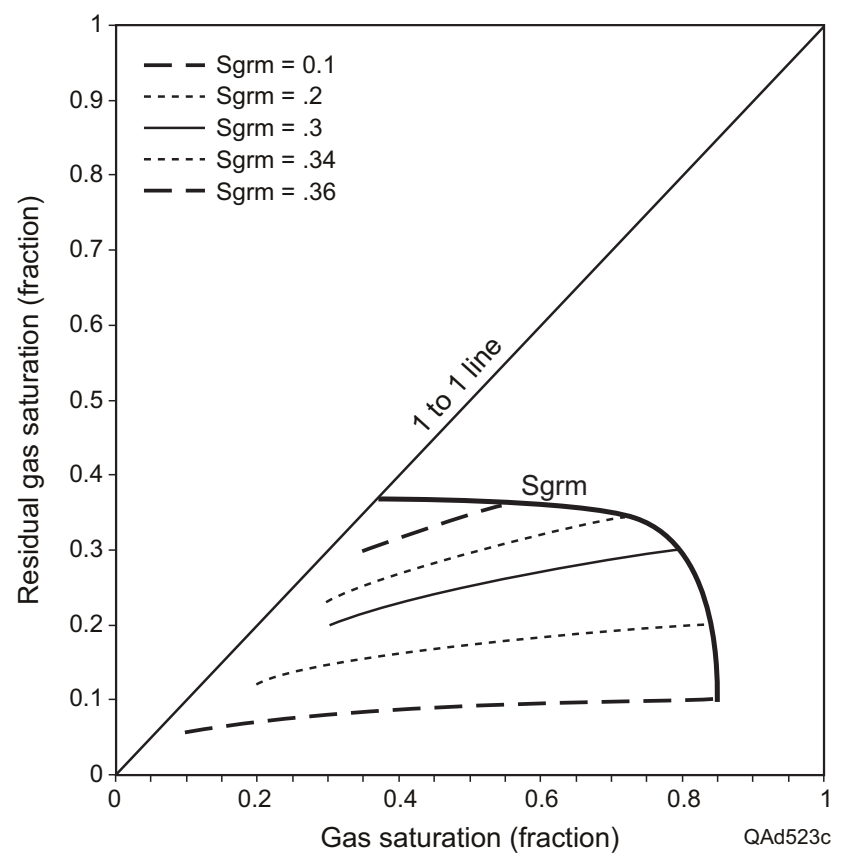

Figure 103. From empirically derived equations, initial residual nonwetting phase curves (IR curves) can be generated to display petrophysical rock character at varying rock quality. 


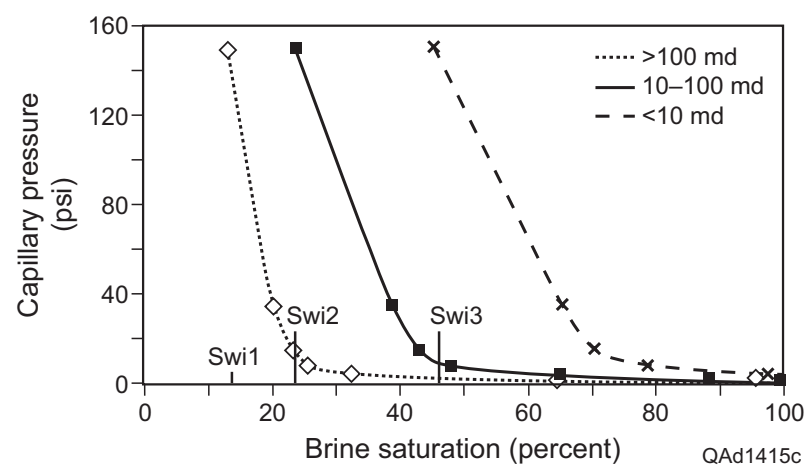

Figure 104. Capillary pressure curves can be grouped together and averaged together. The grouping is based on their $\log (\mathrm{k}): \phi$ values.

Table 7. Petrophysical properties for three rock-quality groups.

\begin{tabular}{|c|c|c|c|c|}
\hline $\begin{array}{c}\text { Rock-quality } \\
\text { group }\end{array}$ & $\begin{array}{c}\text { Porosity average } \\
\text { (fraction) }\end{array}$ & $\begin{array}{c}\text { Permeability } \\
\text { (md) }\end{array}$ & $\begin{array}{c}\text { Residual gas } \\
\text { saturation } \\
\text { (fraction) }\end{array}$ & $\begin{array}{c}\text { Initial water } \\
\text { saturation } \\
\text { (fraction) }\end{array}$ \\
\hline Low & 0.17 & $<10 \mathrm{md}$ & 0.38247 & 0.46 \\
\hline Medium & 0.225 & $10-100 \mathrm{md}$ & 0.32914 & 0.24 \\
\hline High & 0.28 & $>100 \mathrm{md}$ & 0.27581 & 0.14 \\
\hline
\end{tabular}


permeability measurements from any T-1 reservoir samples are unavailable, relative-permeability curves have been developed from initial water saturation and residual gas saturation end points. These end points were used in a Cory relative-permeability model to generate relative-permeability curves.

From the end-point saturations and relative-permeability models, high, medium, and low reservoir-quality groups for relative permeability were established. A set of gas relative permeability $(\mathrm{Krg})$ and water relative permeability (Krw) values were then generated for each of the rock groups (figs. 105-107).

\section{Water-Drive Gas Reservoirs: Background}

Aquifer encroachment decreases ultimate recovery in gas reservoirs. Gas reservoirs affected by pressure depletion typically have recovery efficiencies ranging from 0.75 to 0.9 , whereas aquifer-drive recovery efficiencies are typically in the range of 0.5 (MacKay, 1994; Grab and Smith, 1987). Ancell and Manhart (1987) reported a recovery factor of 0.65 in a 9,100-ft-deep Texas Frio reservoir, and Hower and others (1992) reported a 0.489 recovery factor for a Gulf of Mexico Miocene reservoir.

Gas-reservoir production trends in the U.S. display a similar character of lower recovery efficiency for aquiferdrive reservoirs. For all pressure-depletion-drive reservoirs in the U.S., the mean ultimate recovery efficiency is approximately 0.74 (fig. 108). The distribution of ultimate recovery displays a tail ending at around 0.5 , with some outliers at 0.1 and 0.2 . These outliers are likely due to data busts within a public database because they lie outside the 5-percent delimiting range. In contrast to pressure-depletion gas reservoirs, the aquifer-drive reservoirs display a mean ultimate recovery efficiency of 0.67 (fig. 109). The distribution displays a bimodal distribution, with groups centered around 0.5 and 0.9 . The high recovery grouping is interpreted to be due to an incorrect distinguishing between aquifer drive and pressure depletion drive in the public database or from an underestimating of the original gas in place.

Encroaching water traps residual gas behind the invading water front and maintains reservoir pressure. These effects reduce the volume of gas that will be produced, as compared with conventional pressure depletion. Also, as water volume flowing into the well bore increases, loading can eventually occur, thus effectively killing the free flow of gas, which in turn results in down time, sporadic well production, costly well maintenance, and, ultimately, abandonment of the well. Additionally, high volumes of produced water can increase disposal costs, rendering a well uneconomic. Careful planning, design, reservoir characterization, and well handling are needed to maximize gas recovery when aquifer encroachment occurs.

Aquifer and hydrocarbon reservoir characteristics and production history govern water encroachment, and understanding these factors is critical to optimizing oil and gas recovery. The main aquifer attributes that influence a hydrocarbon reservoir are aquifer size, pressure, and geologic character. Size and pressure characteristics affect the pressure support transmitted to the hydrocarbon reservoir. The larger the aquifer size relative to the hydrocarbon reservoir (dimensionless radii), the greater and longer the pressure support and the lower the recovery efficiency. A greater pressure differential between the aquifer and a depleting gas reservoir can reduce ultimate recovery. 


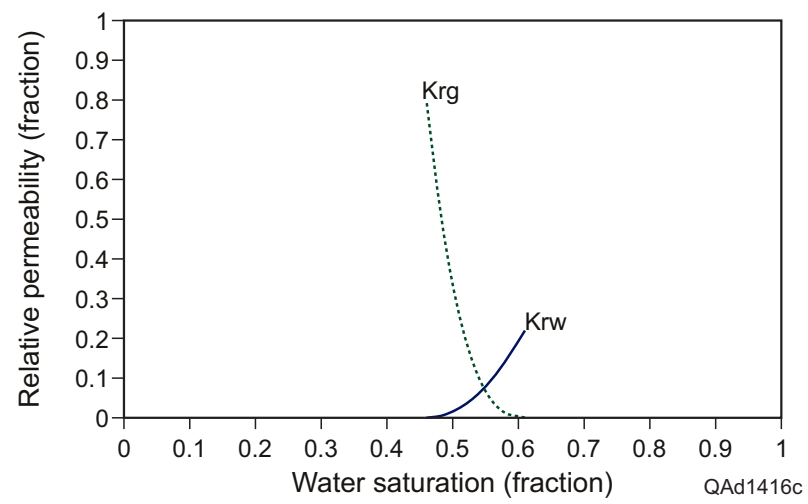

Figure 105. Estimated gas-water relative permeability for low-quality reservoir rock.

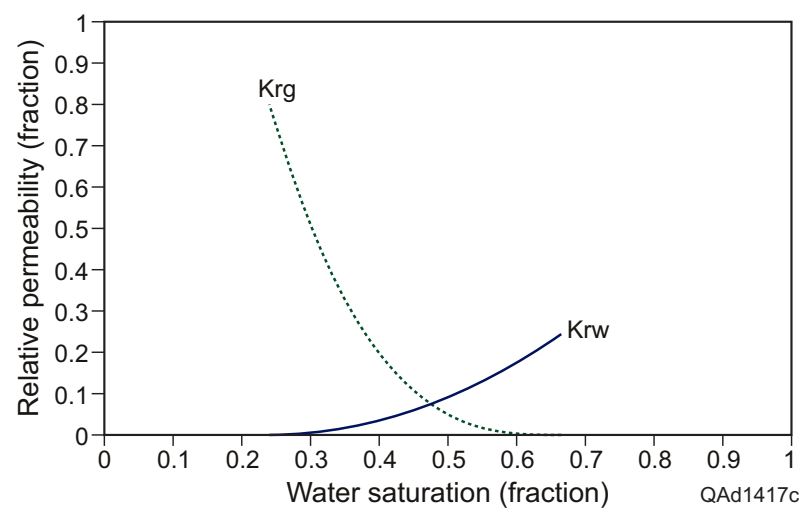

Figure 106. Estimated gas-water relative permeability for medium-quality reservoir rock. 


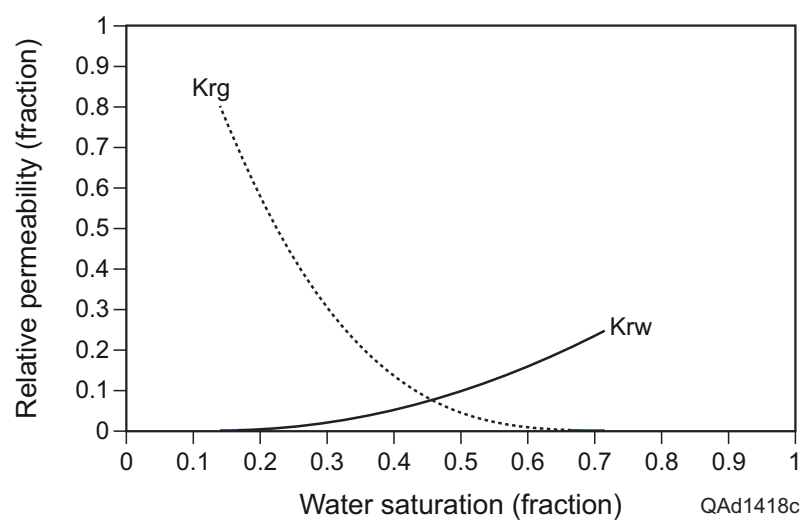

Figure 107. Estimated gas-water relative permeability for high-quality reservoir rock.

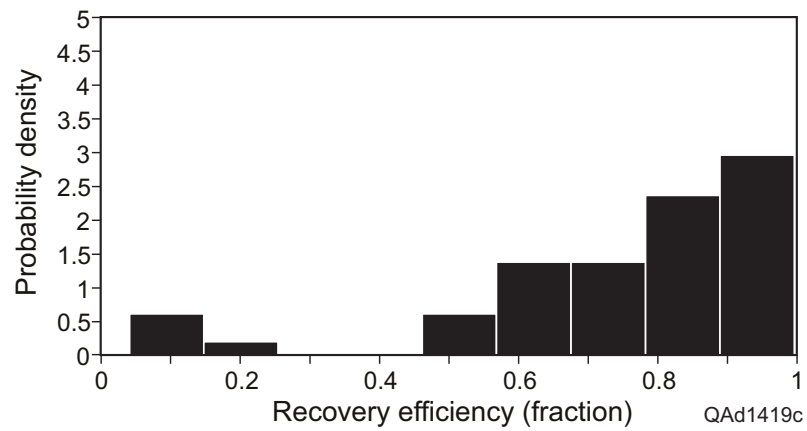

Figure 108. U.S. ultimate recovery efficiency in pressure-depletion-drive gas reservoirs based on data from U.S. Department of Energy's Gas Information System (GASIS) database. 


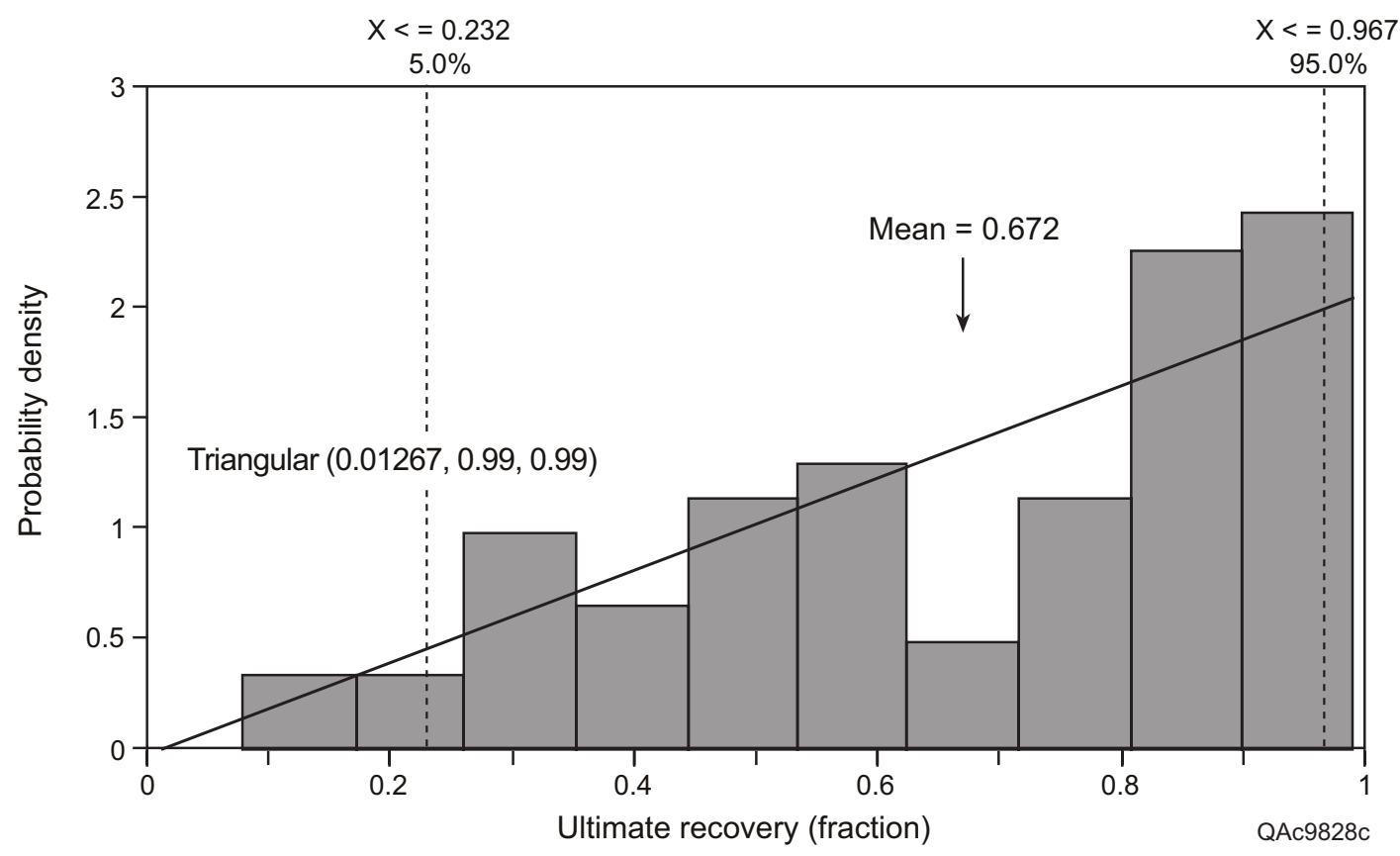

Figure 109. U.S. ultimate recovery efficiency of aquifer-drive gas reservoirs based on data from U.S. Department of Energy's Gas Information System (GASIS) database. 
Recovery efficiencies for gas reservoirs and aquifers at lower initial pressures will be less affected by aquifer encroachment, whereas higher pressure systems may result in more rapid water encroachment (Agarwal and others, 1965). Permeable and homogeneous aquifer/gas reservoir systems undergo more rapid water encroachment at higher reservoir pressures and thus have lower gas recovery efficiencies. Also, higher residual gas saturation resulting from pore geometry and higher relative permeability to water will lead to lower recovery efficiency. High residual oil saturation occurs when pressure depletion is not uniform in the oil leg and when the oil has high viscosity relative to the encroaching water. Overall, characteristics that promote water influx and decrease in incremental pressure drop in gas reservoirs cause lower recovery efficiency.

Production history also influences aquifer encroachment. An increased gas-production rate can result in an increased recovery of gas (Agarwal and others, 1965; Matthes and others, 1973; Lutes and others, 1977). An increased production rate commonly leads to greater pressure depletion before wells water out and thus results in greater gas recovery. The performance parameters proposed by Hower and Jones (1991) illustrate the interrelationship between gas flow rate and reservoir characteristics. High production rates, however, must be designed so that no coning or fingering occurs. Relative permeability and residual gas saturation are important considerations in the effectiveness of higher production rates. Permeability, relative permeability, and residual gas saturation characteristics affect the broadness of the pressure gradient between gas reservoir and aquifer. A broad pressure gradient will increase the water-invaded zone and result in a larger volume of trapped gas. Oil recovery is increased when reservoir pressure depletion is uniform, thus reducing water fingering and, in turn, bypassed oil as the aquifer water front encroaches.

\section{$\underline{\text { Analysis of Initial Fluid Contacts }}$}

Analysis of initial pressure and fluid contacts is a starting point for determining reservoir-production trends. To begin this analysis, the depth and stratigraphic position of data points must be carefully compiled from wellcompletion and workover information. Initial analysis of fluid contacts starts once these data have been compiled on maps, well logs, and graphs.

Under the static conditions normal in a reservoir, initial fluid contacts are controlled by fluid density, with gas over oil and oil over water. Fluid contacts are also horizontal, causing segregation of fluids by depth within a single body of rock (compartment) in which fluids are free to move. The pore pressure is determined by pressure gradients produced by the density of each fluid. At the depth of the hydrocarbon-water contact, the pressure in each fluid is equal.

A significant number of reservoirs contain fluid-flow barriers that segregate the reservoirs into compartments. Because the compartments are not in fluid-flow communication, each can potentially have separate fluid contacts at different depths. The location of fluid contacts within each compartment is controlled by original fluid migration and geologic structure. Each compartment in a reservoir may or may not be filled by hydrocarbons, depending on the amount of fluid migrating and how well it is connected to the source. Additionally, compartments may have different spill points, resulting in different fluid-contact depths. When multiple fluid contacts are present, the reservoir is divided into separate compartments that are defined by the locations of these fluid contacts. 
Original fluid contacts were identified by analyzing completion and test data, wireline logs, and pressure data. Completion and test data establish what type of fluid occurs at what depth. Wireline data are used to calculate the saturation of water and can also be used to detect the presence of hydrocarbons. Initial-pressure data are analyzed to determine the hydrocarbon-water contacts in a normally pressured system.

Completion and test data were evaluated by posting fluid-flow test results at subsea depths on a geologic structure map. The structure map should be drawn on the top of pay for each genetic unit. For each test that flows hydrocarbons, a lowest known oil (LKO) or lowest known gas (LKG) is calculated in subsea depths at the lowest perforation. These values are used to establish the depth of the hydrocarbon interval. For tests that flow water, the highest known water (HKW) is established by calculating the subsea depth at the top of the perforation interval. With this information on a structure map, the depth range in which fluid contacts exist can begin to be delineated.

There are numerous ways to use wireline logs to evaluate the fluid type at any given depth. Resistivity logs can be used to establish water saturation, and neutron and density logs can be used to detect the presence of free gas. Thus, contacts can be established. Importantly, the wireline data should be calibrated with the production test information. Then subsea depth of contacts and LKO, LKG, and HKW determined from the wireline data are posted on the structure map with the test data.

Analyses of wireline calculations indicate where hydrocarbons are present or absent or where a contact between hydrocarbons exists. For the T-1 reservoir, the HKW, LKG (lowest known gas on structure), and gas-water contact (GWC) have been delineated for the two component sandstone bodies (fig. 110). These data indicate that the eastwest-trending faults and the unconformity between the lowstand incised-valley and the deltaic/strandplain highstand facies act as compartmentalizing fluid-flow barriers.

\section{$\underline{\text { T-1 Reservoir Production History }}$}

The production history of the T-1 reservoir records the strong influence of aquifer influx. The reservoir has undergone four pulses of production as wells have been completed and produced in separate fault blocks within the reservoir (fig. 111). Each production pulse is characterized by a declining gas-production rate accompanied by a contemporaneous increase in rate of water production. The first pulse of production came from wells 50-E1, 50-B2, and 50-B1. These wells produced from the southernmost compartment in the reservoir for an average of 6 years from $6 / 1 / 78$ to $6 / 7 / 84$. The rate of water production steadily increased after 1 year of production and essentially terminated any steady gas production after 3 years.

The next pulse of production came from wells producing in the adjacent fault block to the north, including 3119 and 31-1, which produced for $\sim 7$ years. The wells also experienced a steady gas-production decline and waterproduction increase. A third pulse came from well 31-11, which produced from a small structural high adjacent to fault 3 along the north margin of this fault block. It experienced a short production life of less than 2 years, with a 


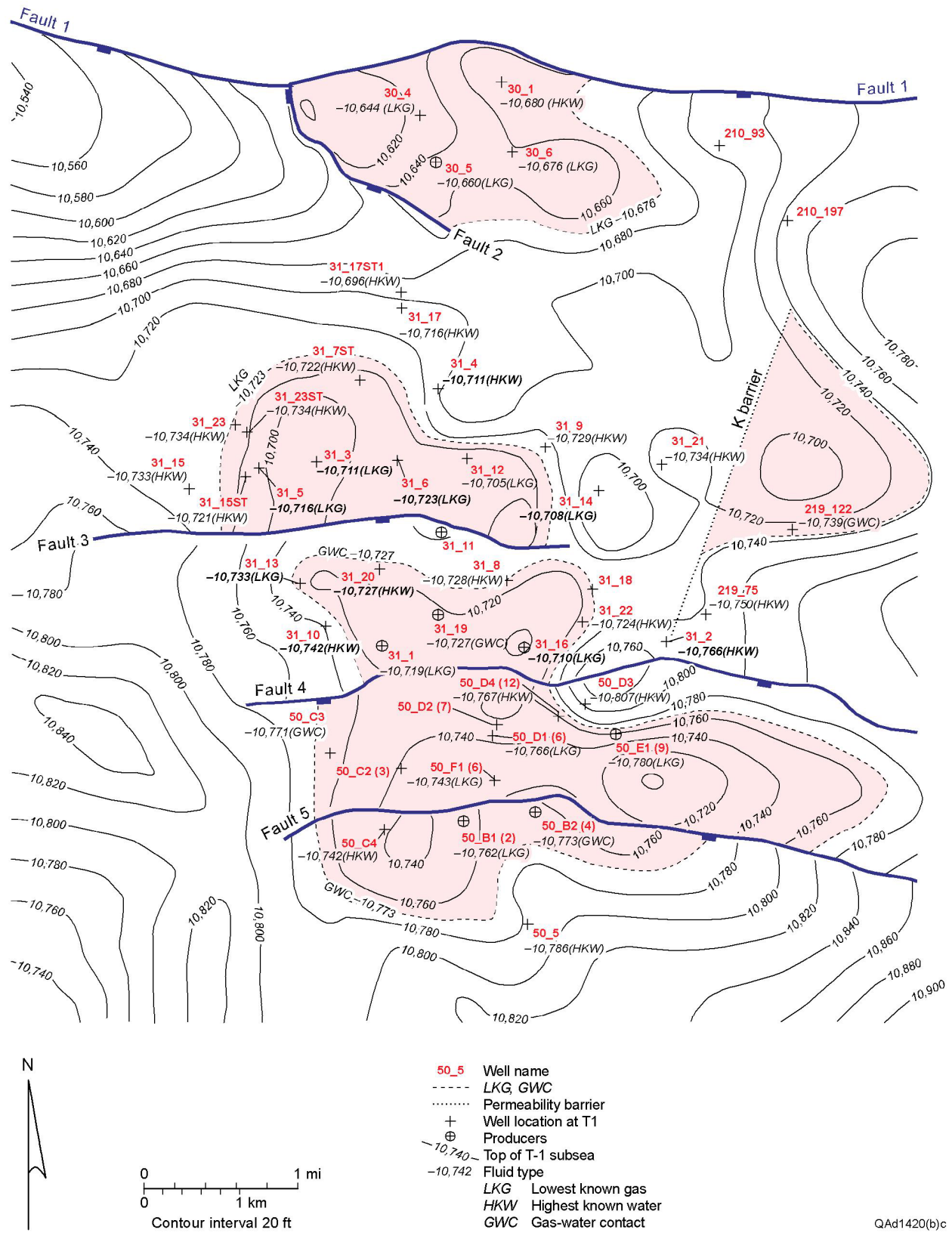

Figure 110. Initial fluid contacts indicate fluid-flow barriers at time of gas migration. 


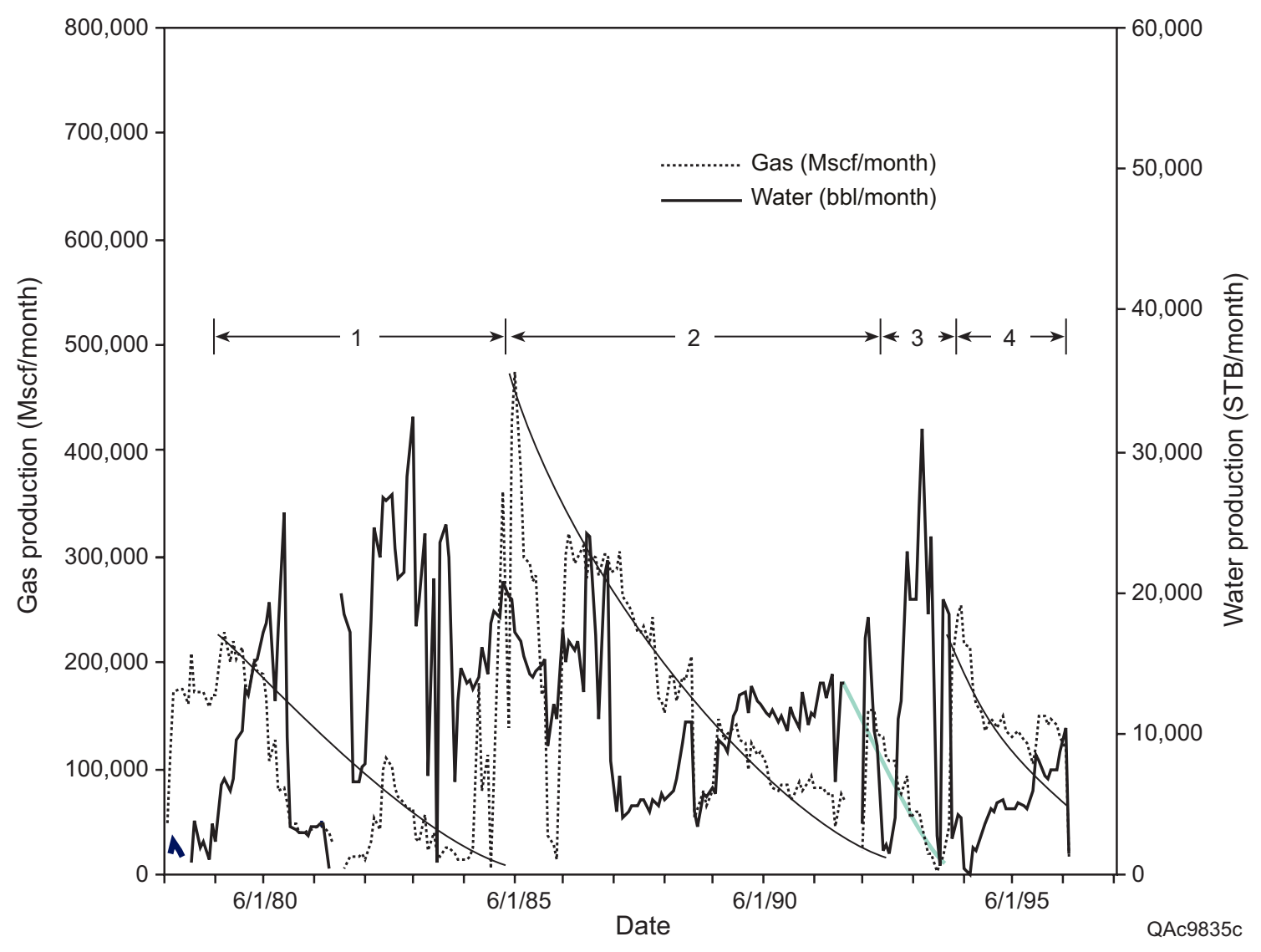

Figure 111. Production history of the Starfak T-1 reservoir. 
steady decline in gas production and an increase in water production. The fourth and last pulse of production came from well 30-5 positioned in the northernmost fault block bordering the regional east-west-trending first-order fault that marks the northern boundary of the field. This well experienced just over 2.5 years of declining gas production and inclining water production. It is clear from the production history, which includes relative reservoir pressure depletion, that aquifer encroachment controlled production. This fact implies that it is likely that just over half of the original gas in place was produced, leaving a large gas resource behind.

The Starfak T-1 reservoir produced from a rollover anticline during the late 1970's and early 1980's. Open-hole $\operatorname{logs}$ were run on newly drilled wells then, concurrently with production (fig. 112). Well 50-D4(12) was logged in April 1984, 4 to 5 years after the three producers had been hit by aquifer encroachment and subsequently shut in. Wells 50-B2(4), 50-B1(9), and 50-B1(2) successively watered-out at the same structural level within the T-1 reservoir that was logged in nearby well 50-D4(12). Well 50-D4(12) is interpreted as water swept when logged because of logging vs. aquifer-encroachment timing.

Wireline gas-saturation calculations also indicate that this well was water swept when logged. Calculated gas saturation in well 50-D4(12) is much lower than in preproduction wells (fig. 113). The calculated gas saturation, which is the Sgrm from forced imbibition due to pressure depletion in the reservoir, averages 0.195 and ranges from 0.064 to 0.376 . These data correspond very well with those that were predicted with the Sgrm model (fig. 102). Additionally they correspond well with Sgrm values reported in the literature (fig. 99).

Comparing the porosity-gas saturation character also indicates that well 50-D4(12) is aquifer swept, thus validating the Sgrm model. The laboratory data indicate that Sgrm increases as porosity decreases because greater trapping mechanisms exist at lower porosity. This trend is recognized in wireline-log-derived $\mathrm{Sg}$ for well 50-D4(12). In contrast to the initial conditions in well 50-B1(2), the Sg-porosity relationship follows an increasing trend, as is expected from the Archie equation (fig. 114). Comparison of the porosity-gas saturation character and the Sgrm model is a method by which swept and nonswept zones can be distinguished.

\section{$\underline{\text { Reservoir Material Balance }}$}

\section{The pressure-depletion histories of wells on either side of the southernmost fault in the T-1 reservoir} (fig. 110) indicate that the reservoir comprises at least two separate fault-block compartments. The wells to the south of fault 4 are in fault block 50, and those to the north are in fault block 31. Both fault blocks had similar initial pressures (fig. 115); however, their pressure-depletion histories are quite different. Block 50 wells were brought on production first and produced for 5 years before production from block 31 occurred. During this time the pressure in fault block 50 decreased by approximately 500 psi relative to that in fault block 31 . After production from block 31 started, the pressure in block 50 decreased rapidly. In contrast, the pressure in block 31 decreased slowly and stabilized, thus recording a significantly different pressure history than that of block 50 .

Several faults were detected within blocks 31 and 50 that are characterized by small-scale offsets ( $\leq 50 \mathrm{ft})$. Closer examination of the varied pressure histories of wells in blocks 31 and 50 indicates that these faults also acted 


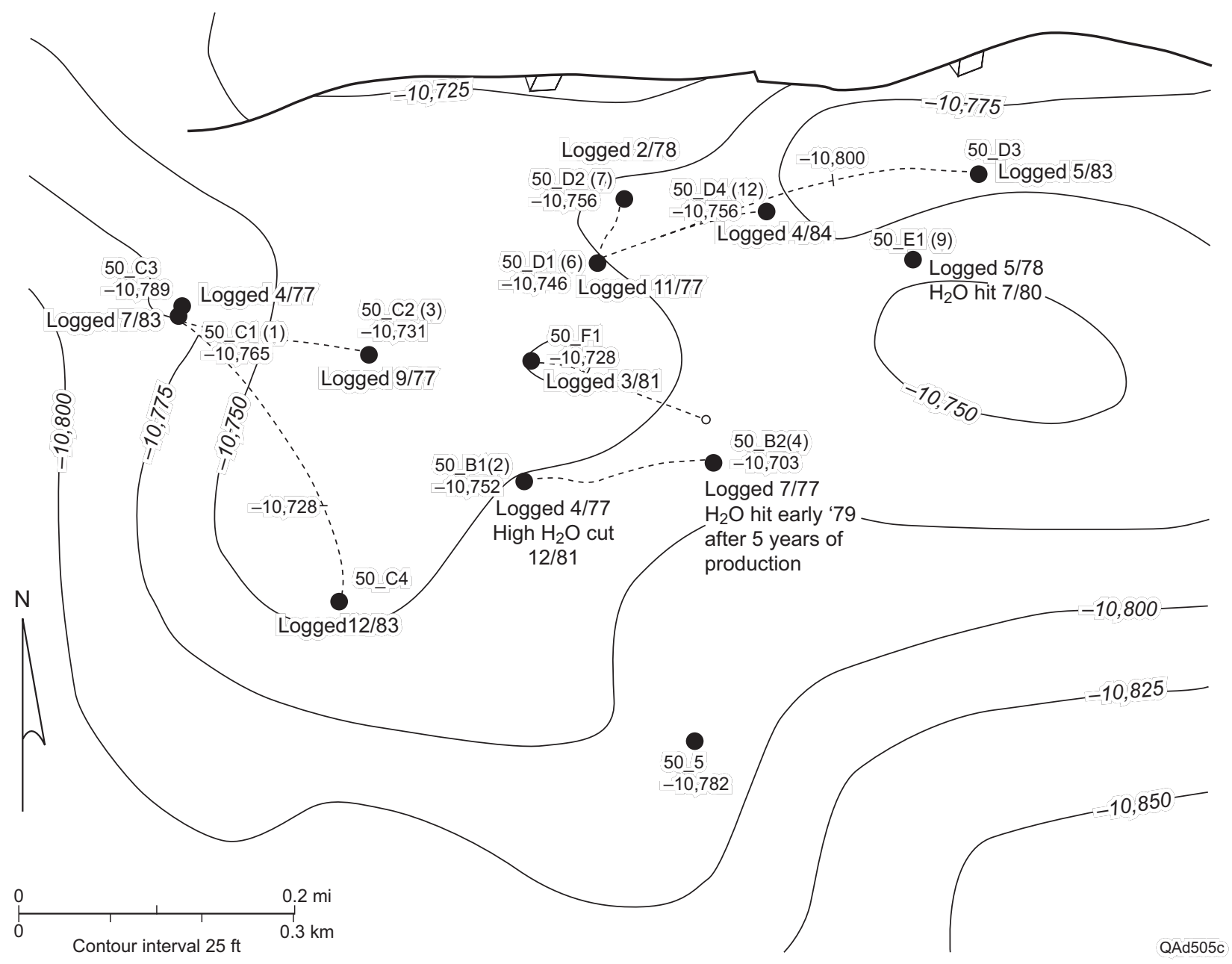

Figure 112. Well 50-D4(12) was drilled and logged after wells 50-B2(4), 50-B1(9), and 50-B1(2) had watered out at the same structural level. 


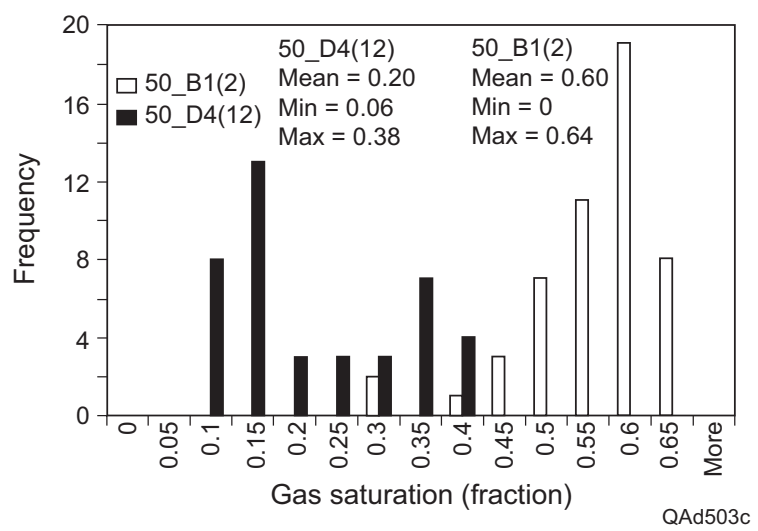

Figure 113. Wells logged before (50-B1(2)) and after (50-D4(12)) aquifer encroachment display significantly different gas-saturation values.

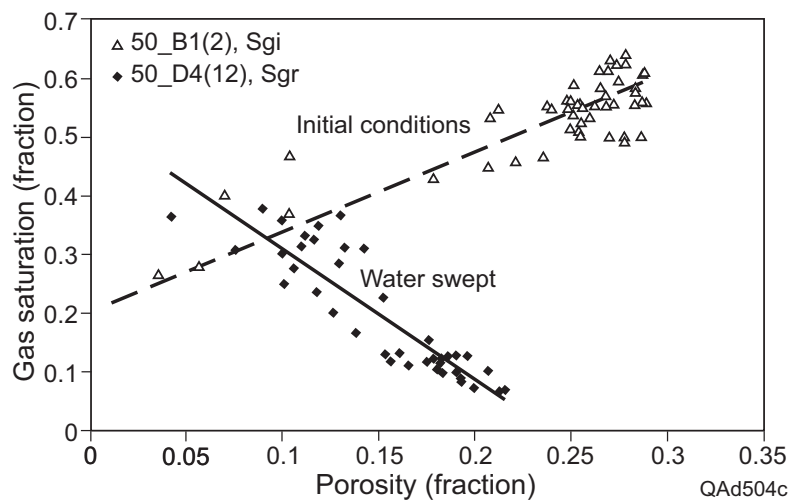

Figure 114. Water-swept zones follow porosity-Sgrm trend predicted by the Sgrm model and differ from that of initial conditions.

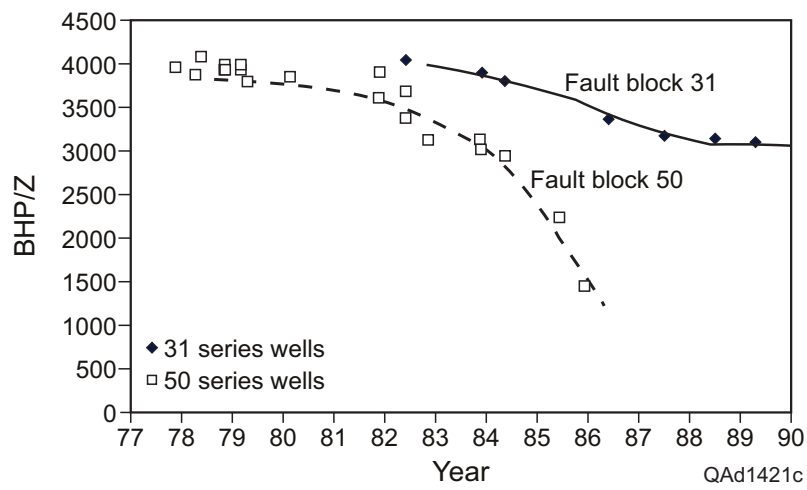

Figure 115. Pressure history indicates that the reservoir is functioning as two separate fault-bounded compartments. 
as pressure seals within the T-1 reservoir. Specifically, distinct differences in initial fluid contacts provide evidence that the faults acted as effective seals to fluid migration. Moreover, because individual sandstone beds are generally thinner than the amount of fault offset, these faults have the potential to juxtapose sandstone against shale and thus form a seal.

Pressure history also suggests differing aquifer dynamics within the fault compartments. The slowly decreasing pressure drop followed by a rapid drop in block 50 (convex shape) is a response typical of a small finiteacting aquifer. The concave pressure response of block 31 is typical of a large infinite-acting aquifer.

\section{Construction of Reservoir Model}

\section{Analysis of Wireline Logs}

A total of 56 wells were incorporated into the reservoir model, the peripheral wells being used to aid in stratigraphic correlation and the wells in the heart on the field having undergone log analysis. Log suites were variable, including 7 wells with SP and IES curves; 10 wells with gamma-ray (GR), BHC sonic, and IES curves; 20 wells with GR, neutron-density, and IES curves; 17 wells with GR, neutron-density, BHC sonic, and IES curves; and 2 wells with GR, neutron-density, BHC sonic, IES, and NGT curves.

Analysis approach. Four-step approach was taken in analyzing the available logs and to calculating petrophysical properties from them. First, the logs were checked for quality. Both the quality of the log digitization and the quality of the data themselves were checked. Next, an overview of the section to be analyzed was undertaken. This step involved checking the log and petrophysical properties to determine what portion of the section could be grouped for detailed wireline-log analysis. The third step defined log-calculation parameters for each of the productive zones identified. Such parameters include those used for determining lithology, porosity, and water saturation. In this analysis the 100-percent-shale point was always taken in the thick shale above the T-1 reservoir to insure maximum consistency in the normalization process. The fourth and final step involved calculating petrophysical properties from the wireline logs, including calculating volume of shale (Vsh), porosity, and water saturation. These steps were followed:

1. Check quality of logs.
A. Determine available logs.
B. Check digital logs against original paper copy to insure correct digitization.
C. Check hole quality by analyzing caliper vs. drill-bit size and looking for abrupt changes in hole size and density corrections.
D. Check cable tension.
E. Check for mud effects on log curves.

2. Review the logged section. 
A. Plot out a quick-look log that includes a track of the (1) gamma-ray curve accompanied by indicators of logging conditions such as tension, caliper, cable speed, (2) resistivity curves, (3) porosity tools (shade the neutron-density crossover), and (4) lithology indicators such as density photoelective effect (PEF), density, and estimated bulk volume shale (Vsh).

B. Determine large-scale geologic markers and stacking patterns to provide a framework for petrophysical analysis. Run a quick-look Vsh, porosity, and Sw from all well log parameters. Obtain gamma-ray maxima and minima from a resistivity vs. gamma-ray plot. Apply a neutron-density cross-plot porosity and an estimated apparent water resistivity (Rwa) from a Pickett plot of likely wet sandstone.

C. Look for overpressured zones; check shale resistivity, density, and sonic transit time vs. depth.

3. Define log-calculation parameters for each of the zones identified.

A. Calculate lithology by using a neutron-density cross plot, deep resistivity (Rt) vs. gamma ray (GR), which allows a gamma-ray maximum and minimum to be picked for a Vsh calculation and a shaleresistivity (Rsh).

B. Use Pickett plot to obtain Rwa, cementation (m), and saturation exponent (n).

4. Calculate petrophysical properties from wireline logs.

A. Calculate Vsh:

$\operatorname{Vshl}[]=\min (1, \max (0,($ ECGR[ ]-GRcln $) /($ GRshl-GRcln $))$, where $\mathrm{ECGR}=$ GR log reading, GRcln = maximum GR value in clean sandstone, and GRshl $=$ GR value of shale.

B. Calculate porosity:

Density porosity: PHID[ ] = (RhoM - RHOZ[] $) /($ RhoM - RhoF $)$, and

Neutron-density average: PHIA [ ] $=(\operatorname{PHID}[]+\mathrm{PHIN}[]) / 2$,

Where RhoM = ss density, RHOZ = density log reading, RhoF = fluid density, and PHIN = neutron log porosity reading. Apparent porosity (PHIA[ ]) is calculated from the neutron and density logs as an average. Density (PHID[ ]) porosity is calculated by applying a matrix density of $2.65 \mathrm{gm} / \mathrm{cm}^{3}$ (quartz) and a fluid density of 1 $\mathrm{gm} / \mathrm{cm}^{3}$ (water). This porosity is used in the Pickett plot analysis for determining the Archie parameters.

C. Calculate water saturation:

$\mathrm{Rwa}[]=\mathrm{AHF90}[]^{*} \mathrm{PHIA}[]^{\wedge} \mathrm{m}$;

$\mathrm{Ro}[]=\mathrm{a} * \mathrm{Rw} /\left(\mathrm{PHIA}[]^{\wedge} \mathrm{m}\right)$, Archie Sw; and

$\operatorname{SwA}[]=\operatorname{sqrt}(\operatorname{Ro}[] / \operatorname{AHF90[}])$, taking $\mathrm{a}=1$,

Where AHF90 $=$ deep resistivity reading and $\mathrm{SwA}=$ apparent water saturation

Wireline-analysis results. Analysis indicated several gas-water contacts within the T-1 reservoir. Pickett plots of water-saturated zones indicated an Rwa of $0.11 \mathrm{ohm}$-meters at $77^{\circ} \mathbf{F}$. A cementation exponent (m) of 2 and a saturation exponent (n) of 2 were also found to be applicable. 
A trend is discernable between wireline-derived porosity and bulk volume shale (Vsh). As porosity decreases, bulk Vsh increases (fig. 116). This is the normal trend seen in Gulf Coast Miocene sandstones. The trend has a strong linear correlation coefficient $(\mathrm{R} 2)$ of 0.91 and predicts zero porosity at a Vsh of 0.79 .

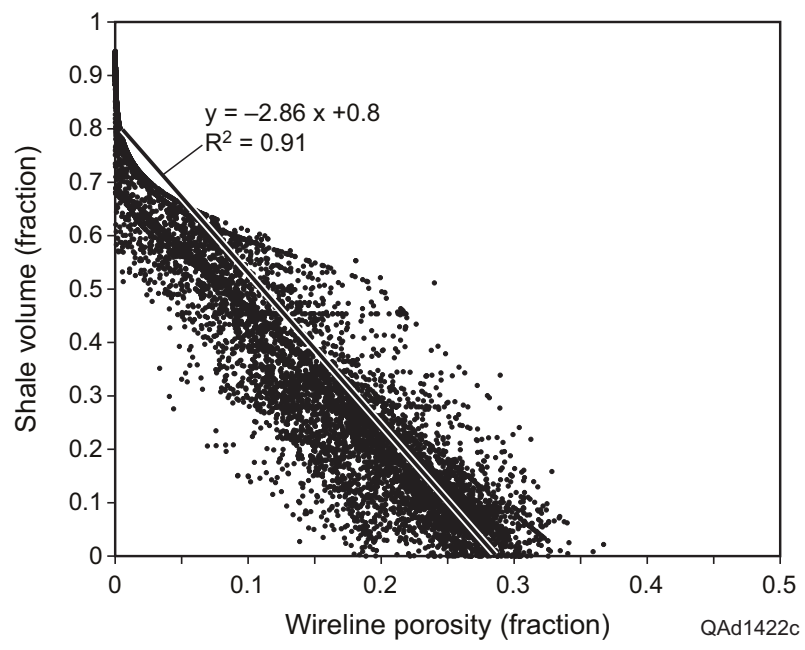

Figure 116. Relationship between wireline-log-calculated porosity and bulk-volume shale displays general linear trend. 


\section{Building the 3-D Reservoir Model}

Constructing the 3-D grid. The third step in constructing the 3-D structural model is building the 3-D grids for the T-1 reservoir according to the fault model and the final T-1 and MFS 32 surfaces that define the volume inside, which was conducted for all 3-D reservoir modeling. The 3-D grids thus created define the 3-D reservoir volume and provide the framework for later petrophysical and facies modeling.

The 3-D modeling of the T-1 reservoir structure uses output from the previous two modeling steps as input. Specifically, this modeling step requires as input both (1) the final T-1 and MFS 32 structural surfaces resulting from the surface modeling process and (2) the consistent fault model created in the fault-modeling step.

\section{Modeling Steps}

- Use the Create Zone tools in RMS to create a new 3-D zone bounded by the T-1 and MFS 32 surfaces.

- Use the Create Modeling Grid tool in RMS to build the 3-D grids that define the volume within the 3-D zone defined earlier, using the following settings:

- $\quad$ Set top of T-1 as the top reference surface and MFS 32 as the bottom reference surface.

- $\quad$ Grid type $=$ corner point; rotation $=0$.

- $\quad$ Grid X increment $=100^{\prime}$; grid Y increment $=100^{\prime}$; cell thickness $=2^{\prime}$.

- $\quad$ Set cell truncation $=$ truncate cells against bounding surfaces

- Toggle on "Use faults" and activate "Incorporate fault throw in 3-D grid."

- Examine the resulting 3-D structural grids in the RMS 3-D display window and use the RMS Show/edit cell content utility to display and/or edit the $\mathrm{x}, \mathrm{y}$, and $\mathrm{z}$ values of the 3 -D grids.

The final result of these modeling steps is a 3-D geocellular structural model of the reservoir volume bounded by the T-1 and MFS 32 surfaces. In this model, the T-1 reservoir structure is represented as a 300 rows $\times 300$ columns $\times 171$ layers 3-D volume, composed of more than ten million $100^{\prime} \times 100^{\prime} \times 2^{\prime} 3-\mathrm{D}$ cells. Because the 3-D grid cells bordering the fault planes are regularized cells that retain their rectangular shape in the modeling process, the resulting fault planes in the 3-D model look like a set of slanted staircases overlain on the original smooth surfaces of the input fault model.

Populating the 3-D grid with petrophysical properties. The 3-D grid was populated with petrophysical properties by using both the 3-D seismic volume and the wireline calculated petrophysical properties. The approach was to change the seismic amplitude data into a rough 3-D Vsh volume. Next, the wireline Vsh data were interpolated throughout the 3-D grid using a reverse distance weighting scheme and a direction bias. The direction bias was chosen to be down the dip axis of the highstand fluvial and lowstand incised-valley systems. Because seismic porosity and impedance are related to Vsh, and wireline porosity is related to Vsh, a Vsh-weighted average 
model was applied. The weighting average model averages seismic and wireline Vsh to obtain a final 3-D Vsh volume, which is then used to populate the 3-D grid with the rest of the petrophysical properties.

A key-attribute approach was chosen to populate the 3-D grid that is based on the concept that all petrophysical properties are interrelated. A key attribute, in this case Vsh, is populated throughout the 3-D grid. Then interrelationships between this key attribute and other petrophysical properties are used to determine their values.

The 3-D seismic volume was used to construct a Vsh volume. Because seismic has a different vertical scale than that of the wireline logs, the seismic Vsh volume is resolved at the 20-ft-thick scale, with the $\mathrm{x}$ and $\mathrm{y}$ dimensions being the same as those of the 3-D grid. Wireline-log analysis indicates that, because impedance is a function of lithology and porosity, as porosity decreases, impedance increases and the lithology changes from sandstone to shale (fig. 117).

Sandstone bodies can be detected and correlated within the seismic volume. Within the T-1 reservoir, higher amplitudes signify sandstone, and the higher sandstone amplitudes can be correlated with the Vsh calculated from wireline logs, thus leading to an enhanced depth-to-seismic tie and definition of the reservoir (fig. 118). Additionally, amplitude stratal slices show where sandstones lie spatially. These amplitude stratal slices were used to determine the northeast-to-southwest dip direction of the fluvial systems. The amplitudes illustrate the thinner, more meandering channels in the center and western portion of the reservoir and the thicker, straighter valley-fill system on the eastern flank (fig. 119).

In preparation for petrophysical-property interpolation, the 3-D seismically derived Vsh volume was time-depth converted and loaded into the grid according to four steps. First, the structural grid (in time) for the 3-D seismic Vsh volume (to be imported) was recreated in RMS. Second, the reproduced Vsh structural grid in RMS was converted from time to depth using a time-depth conversion formula derived from available time-depth measurements. Third, the Vsh values exported from the 3-D seismic volume were loaded into RMS and assigned to their corresponding cells in the RMS 3-D Vsh structural grid (in depth) calculated in the previous step. Finally, using the Resampling Parameter tool in RMS, each grid cell of the existing RMS T-1 reservoir structural model was assigned the Vsh value of its nearest corresponding cell in the imported RMS 3-D seismic Vsh volume obtained using the procedure described earlier (fig. 120).

The final Vsh distribution in the T-1 reservoir was modeled by a weighted average of (1) the seismic Vsh volume and (2) an interpolated Vsh volume calculated by interpolation of blocked and upscaled well log data. The Vsh well data were upscaled to $2 \mathrm{ft}$ on a running-average basis. Then a reverse distance weighting was applied to interpolate the Vsh between wells. A northeast-to-southwest bias was used along with the reverse distance weighting to represent the dip direction of the fluvial systems that controlled deposition of the reservoir sandstone. The resulting Vsh volume was then used to calculate porosity, permeability, and other petrophysical properties needed for reservoir characterization and subsequent flow simulation of the T-1 sand.

The petrophysical interpolation steps are

- Use the Create Interpolated Parameter tool in RMS to derive the interpolated Vsh volume (VCLQ1) with the following settings: 


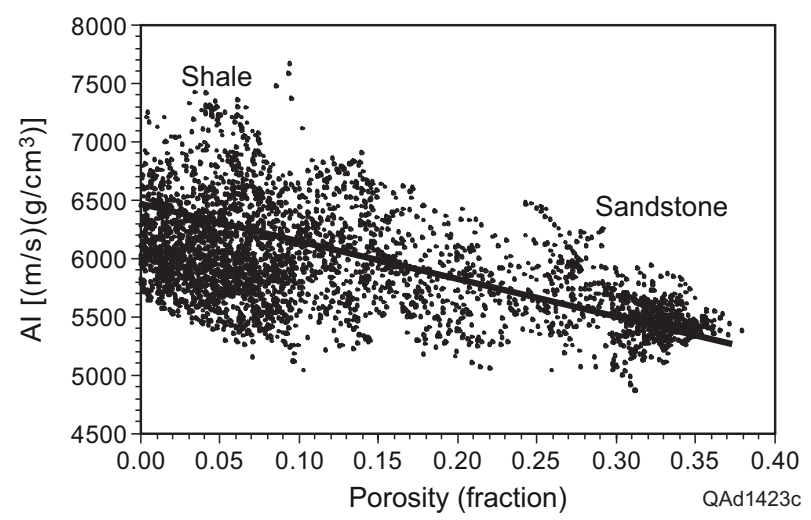

Figure 117. Relationship between porosity, impedance, and lithology.

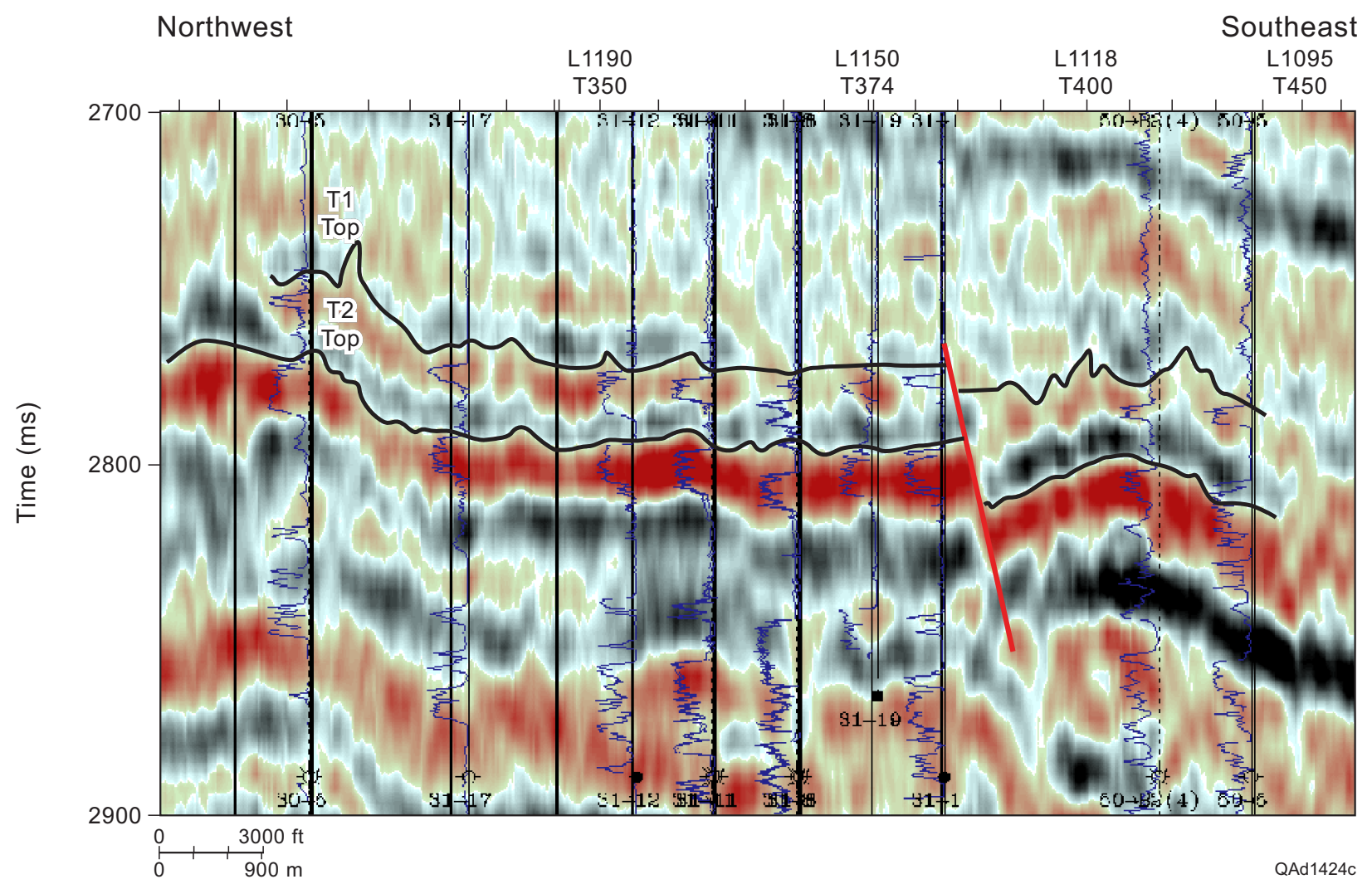

Figure 118. Higher amplitudes in the seismic align with Vsh calculated from wireline logs. 


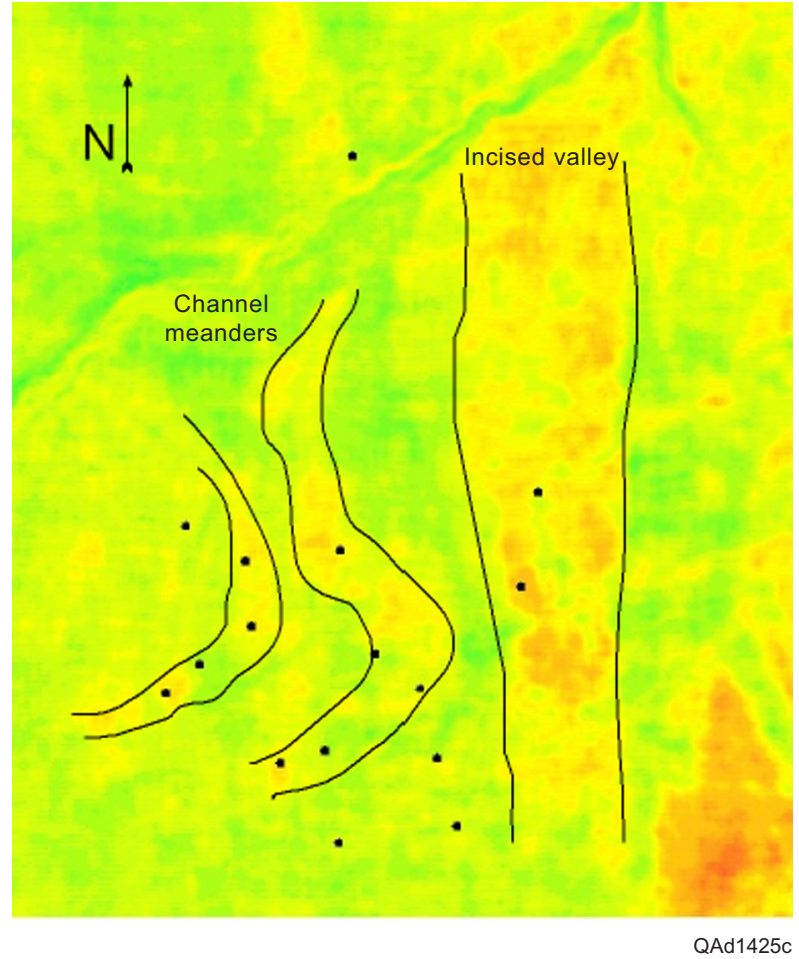

Figure 119. High seismic amplitudes (orange to red) coincide with the distribution of sandstone within the T-1 reservoir. 


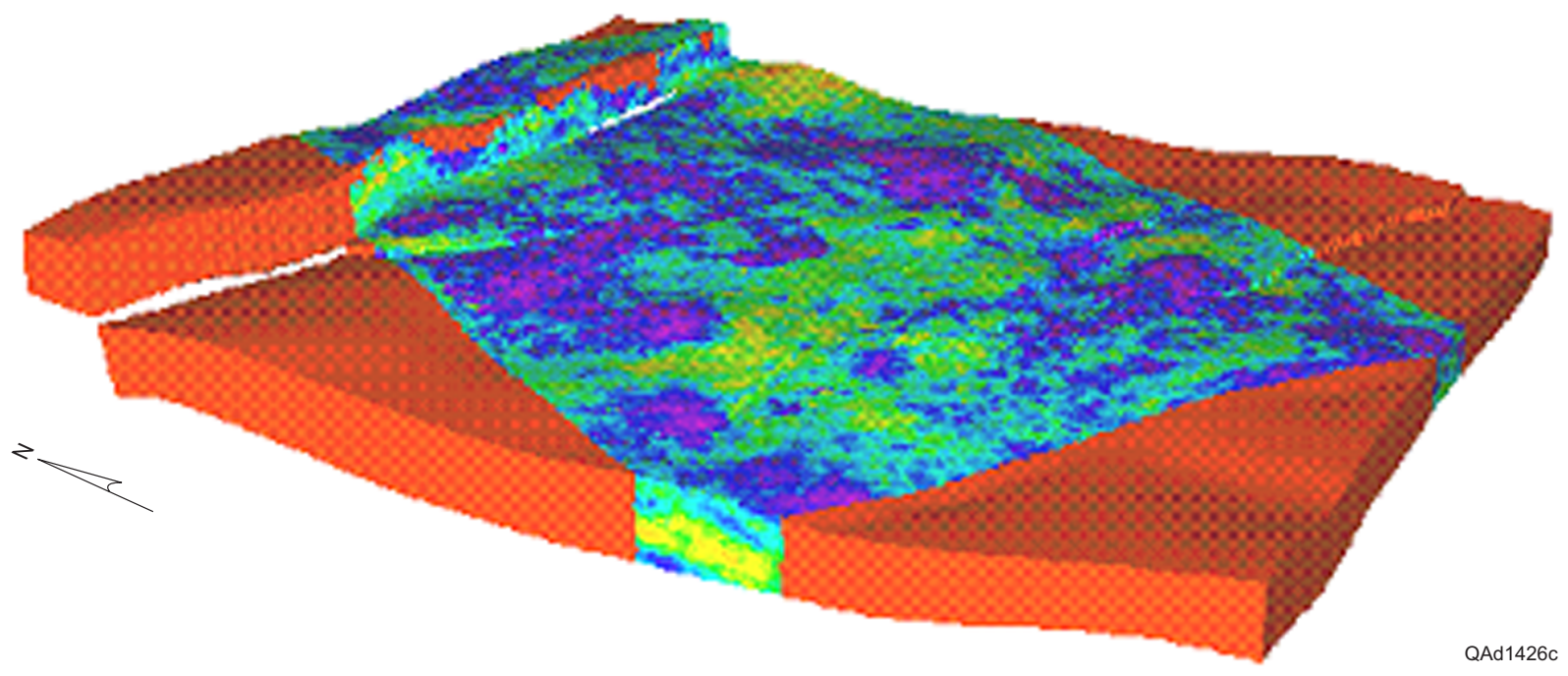

Figure 120. Resulting seismic-derived T-1 3-D shale volume (Vsh). Light colors represent sandstone-rich volumes, whereas darker shades represent shale-rich volumes. 
- In the Framework folder, drop blocked well parameter BW_VCLQ into the blocked wells drop site and then select VCLQ (Vsh curve) as the log data to be interpolated.

- In the Algorithms folder, change the name of the output parameter to VCLQ1.

- Select stratigraphic interpolation as the interpolation mode.

- $\quad$ Set $\mathrm{X}$ influence radius $=100,000^{\prime}, \mathrm{Y}$ radius $=200,000^{\prime}, \mathrm{Z}_{\text {radius }}=4^{\prime}$.

- Set influence orientation $=160^{\circ}$ to align the interpolation with the general direction of Vsh distribution suggested by geological interpretations.

- Use the same tool to calculate the seismic Vsh (VCLQ2) that honors the Vsh derived from well log data with the following settings:

- In the Framework folder, drop blocked well parameter BW_VCLQ into the blocked wells drop site and then select VCLQ (Vsh curve) as the log data to be interpolated.

- In the Algorithms folder, change the name of output parameter to VCLQ2.

- Select stratigraphic interpolation as the interpolation mode.

- $\quad$ Set $\mathrm{X}$ influence radius $=100,000^{\prime}, \mathrm{Y}$ radius $=200,000^{\prime}, \mathrm{Z}^{\prime}$ radius $=4^{\prime}$.

- Set influence orientation $=0^{\circ}$.

- Drop the purely seismic derived Vsh volume 3-D parameter (VSH) into the Trend parameter drop box and set the weighting factor $=1$.

- Use the 3-D Parameter Calculator in RMS to calculate a series of weighted average of VCLQ1 and VCLQ2 on the basis of the following equations:

$$
\begin{aligned}
\mathrm{VSH} 60 & =0.4 \times \mathrm{VCLQ} 1+0.6 \times \mathrm{VCLQ} 2 \\
\mathrm{VSH} 50 & =0.5 \times \mathrm{VCLQ} 1+0.5 \times \mathrm{VCLQ} 2 \\
\mathrm{VSH} 40 & =0.6 \times \mathrm{VCLQ} 1+0.4 \times \mathrm{VCLQ} 2 \\
\mathrm{VSH} 30 & =0.7 \times \mathrm{VCLQ} 1+0.3 \times \mathrm{VCLQ} 2
\end{aligned}
$$

Use the RMS 3-D grid frame player to examine the resulting Vsh volumes (layer by layer, row by row, and column by column), thereby selecting a "final" interpolation scheme that produces the most geologically representative Vsh model. Of the four different weighted averaging schemes listed earlier, the VSH30 produced the best overall result and was therefore chosen as the "final" interpolation scheme to use in subsequent modeling steps.

\section{$\underline{\text { Reservoir Model }}$}

The final output is a 3-D geocellular volume that incorporates both the seismic observation and well log interpolation of the Vsh distribution in the Starfak T-1 reservoir. The seismic Vsh is averaged with wireline Vsh so that the seismic can influence petrophysical properties in the intrawell space. Three different Vsh models were constructed, representing scenarios of different weighted averaging between the seismic and wireline-log Vsh volumes. All the 2-ft-thick blocks were assigned a seismic Vsh value corresponding to the 20 -ft-thick seismic block 
with which they are associated. Various weighted averages were applied to determine the most appropriate influence the seismic Vsh blocks should have on the smaller scale wireline-derived blocks.

From the Vsh values, porosity, permeability, initial water saturation, and residual gas saturation were calculated for each cell. These petrophysical properties were determined from established interrelationships. Porosity was determined first on the basis of the relationship in figure 99. Then permeability, initial water saturation, and residual gas saturation (equations 2,3, and 4) were calculated. The results indicate that a 30 to 70 seismic-log-weighted average has the most correct mass balance of volume produced vs. volume of remaining gas (table 8 ). The other scenarios result in too little initial gas in place when residual gas saturation is accounted for.

Cross sections and map layers indicate that the model contains a Vsh distribution that is consistent with that of the geologic interpolation, which can be seen by inspecting the sandstone distribution between wells. The upper and lower sandstones are correctly interpolated, as seen in figure 121. Where the upper sandstone is present, a continuous sandstone body is present in the model. The lower sandstone pinches out where appropriate, without connection to the upper sandstone.

Table 8. Volumetric results for three different weighted-average scenarios, indicating that a 30-70 seismic-to-log scenario is most appropriate.

\begin{tabular}{|l|c|c|c|}
\hline & $\begin{array}{c}\text { 60-40 Seismic log } \\
\text { weighted average }\end{array}$ & $\begin{array}{c}\text { 40-60 Seismic log } \\
\text { weighted average }\end{array}$ & $\begin{array}{c}\text { 30-70 Seismic log } \\
\text { weighted average }\end{array}$ \\
\hline Produced gas (Bscf) & 29 & 29 & 29 \\
\hline Original gas in place (Bscf) & 47 & 67 & 78 \\
\hline Residual gas in place (Bscf) & 30 & 40 & 45 \\
\hline Remaining mobile gas (Bscf) & -12 & -3 & 4 \\
\hline Sweep efficiency & 1.71 & 1.10 & 0.89 \\
\hline Recovery factor & 0.62 & 0.44 & 0.38 \\
\hline
\end{tabular}

\section{Summary}

The Starfak T-1 reservoir is a fluvial-dominated, water-drive reservoir. Wireline correlations interpreted with seismic-amplitude maps display a distinctive fluvial system within a highstand systems tract. These meanderbelts are incised by a lowstand valley system. A strong impedance constant between sandstone and shale allows the recognition of the sandstone bodies. This impedance contrast is a result of both lithology and porosity. As sandstone bulk volume increases, porosity increases, resulting in porous sandstone having seismic amplitudes greater than those of tight shale.

The Sgrm model used in constructing the 3-D reservoir model enabled delineation of practical relationships between petrophysical properties and useful wireline techniques for determining aquifer-swept zones. Applying 


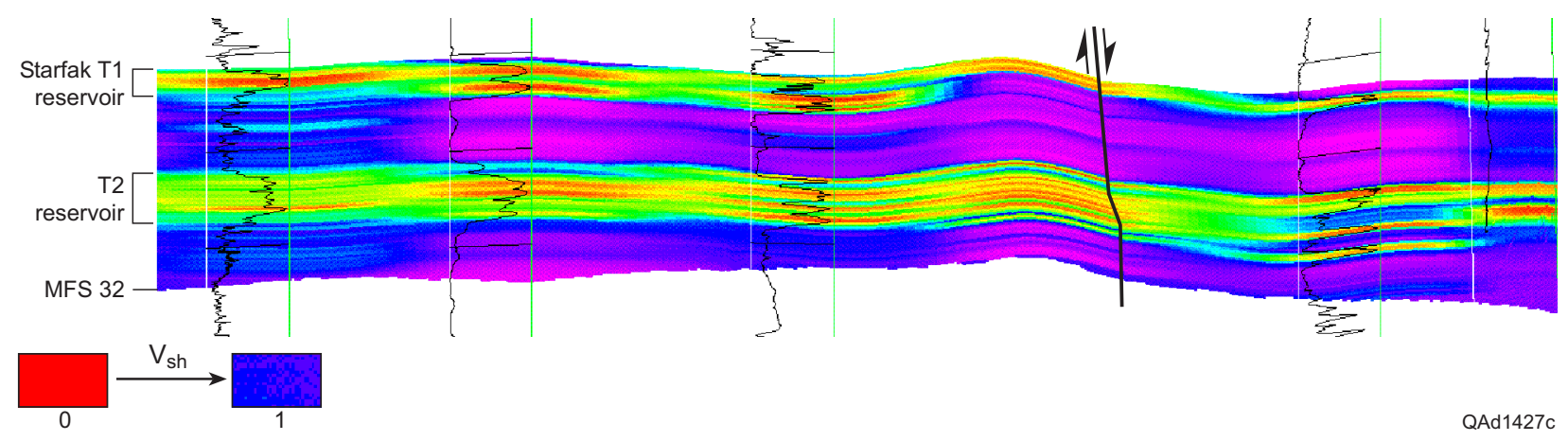

Figure 121. Example cross section of the final model showing distribution of sandstone between wells and in the intrawell space. 
interrelated petrophysical functions allows fine-tuning of petrophysical properties within a 3-D geocellular model and facilitates populating the 3-D grid with all necessary properties for volumetric calculation. Following are the most salient conclusions:

1. Increasing Sgrm with decreasing porosity functions as a viable relationship for use in characterization of Miocene Gulf Coast gas reservoirs.

2. The $\log (\mathrm{k}): \phi$ ratio results in a useful measure of pore type and pore geometry.

3. Combining empirical permeability, porosity, and capillary-pressure equations results in a useful model for determining Sgrm.

4. Wireline log calculations in zones that have been water swept result in Sgrm values very similar to those used in the initial residual model.

5. Similar Sgrm values and porosity-Sgrm trends derived from wireline logs aid in validating the Sgrm model.

6. The linear inverse relationship between Sgrm and porosity contrasts with the direct relationship between Sgi and porosity. This contrast in trends aids in the determination of aquifer-swept zones from wireline-log calculations.

7. By incorporating Sgrm properties into the 3-D model, a more robust model results because petrophysical properties are interrelated and a material balance is achieved.

The Starfak T-1 reservoir has produced less than half of the original gas in place (OGIP). The sweep efficiency in the reservoir has been high, however, because it was abandoned at pressures that are greater than half of the original pressure. A significant volume of gas remains as residual gas. Several techniques can be applied to reduce the abandonment pressure before water encroachment kills production. These strategies center on reducing the reservoir pressure as much as possible before the onset of water encroachment or production of high volumes of water (Schafer and others, 1993). Increasing the rate of gas production can produce more gas and effectively reduce the reservoir pressure before water hits the well bore. Recompletion of existing wells higher in the reservoir or infill drilling of wells higher in the same structure can prolong production life at lower water cuts. High water-cut production, by adding compression and artificial lift, allows a greater decrease in reservoir pressure and thus increased recovery. Additionally, decreasing tubing size increases the velocity of gas and water in the tubing, lifting water at greater water cuts and in turn extending the life of the reservoir.

\section{ADDING RESOURCES}

\section{Risk Assessment of Resource Opportunities}

In past decades, much work has been conducted in the development and application of analytical techniques in prospect analysis. Otis and Schneidermann (1997) described a procedure to calculate geologic success and to analyze the volumetric and economic factors that determine this success. White (1993) provided a risking guide to 
evaluate exploration opportunities. Rose (2001) analyzed a complete procedure for exploration play analysis. In their publications on decision analysis, Newendorp and Schuyler (2000) and Megill (1977) combined exploration risk analysis with economic evaluation.

Risk analysis and portfolio management are widely used in the oil and gas business because of the inherent uncertainty involved in hydrocarbon exploration and development. Whereas risk analysis targets individual projects, portfolio management expands this view to the effects and contributions that individual projects will have on the investor's entire portfolio. Portfolio analysis has been used in the financial sector, and its application to the oil and gas industry is becoming popular. Orman and Duggan (1998) explained the application of portfolio optimization in exploration and production projects. Hightower (1991) described a portfolio-modeling method that includes a semivariance model. DuBois (2001) applied Monte Carlo simulation to portfolio management. Clemen and Reilly (2001) explained decision analysis and risk tolerances. Reilly and others (1997) described the portfolio financial theory and the concept of the efficient frontier. Many practitioners use play analysis and probabilistic evaluation of exploration opportunities, whereas others work with portfolio evaluation using modern portfolio theory adapted to oil and gas projects. Although high-resolution 3-D seismic surveys are now available for many prospective areas (and, as a result, the average success rate for drilled opportunities has increased), significant uncertainty regarding not only the volume of hydrocarbons within opportunities but also the presence of hydrocarbons still exists.

This project focused on risking geologic opportunities and applying simulation to replicate the uncertainty inherent to geologic interpretation, as well as to the data. Volumetric valuation was performed by using probabilistic tools such as Monte Carlo simulation to calculate expected reserves and the perceived risk or uncertainty for each of the natural-gas opportunities identified in this project.

\section{Objective and Methodology}

In addressing one of the primary objectives of this project— to identify additional potential reserves in the mature gas province of the offshore Louisiana shelf-a portfolio of 54 exploration opportunities was compiled within the area encompassed by the 3-D seismic volume. In the section "Proved Resource-Addition Opportunities" three of the opportunities are described: stratigraphic, structural, and stratigraphic-structure combination traps that have been drilled and tested by Texaco. However, it is first necessary to detail the methodology of how the degree of risk associated with each of the 54 opportunities was assessed. This methodology comprises two main elements: simulation and optimization. In the simulation stage, geologic risk is evaluated and reserve volumes are calculated. Risk assessment of an opportunity assigns a probability of success on the basis of an analysis of four fundamental characteristics of the geologic play in which the opportunity occurs: reservoir characteristics (for example, porosity and specific gas gravity), trap, source, and hydrocarbon dynamics (migration and timing). In addition, probabilistic volumetric distributions were calculated for each opportunity using historical play data and the interpreted parameters from geologic and 3-D seismic interpretation of that opportunity. Expected reserves values were obtained with volumetric inputs. Monte Carlo simulation was used to calculate the 
mean value and the standard deviation of several play-derived reservoir characteristics for each opportunity. Details of the procedure are described next.

In the optimization stage, the output from simulation is used as the input for the spreadsheet solver optimization routine that calculates optimal portfolios by minimizing the standard deviation. Linear programming was used to arrive at a set of portfolio values, subject to constraints of the risk tolerance. The application builds efficient portfolios by varying ownership-interest percentages for each of the opportunities in the study.

Efficient Frontier is a risk analysis tool that was employed that shows the limit for optimal portfolios by calculating the mean value and the inherent risk of any combination of opportunities that are limited by companies' requirements of capital or reserves. Risk attitudes were defined for different investor risk tolerances to obtain the optimal portfolio that fits each investor's characteristics.

\section{Geologic Assessment}

Fifty-four potential opportunities were defined and those prospects were identified by their geologic play type. A geologic play comprises a family of reservoirs sharing a geologic history (Seni and others, 1997; Hentz and others, 1997). A probabilistic play model was developed, and it was used to obtain a composited geologic chanceof-success for each opportunity (that is, the chance that hydrocarbon accumulations are present when a well is drilled).

\section{Geologic Chance of Success}

Risk is defined as the opportunity for loss, and chance is defined as the likelihood of a successful outcome. Under conditions of success, uncertainty defines a range of possible outcomes (Rose, 1987). Geologic chance of success is the probability that a producible hydrocarbon accumulation exists and that there is a stabilized flow of hydrocarbons on test. Oil and gas shows, as well as flows of hydrocarbons without pressure stabilization, are not considered successful. Moreover, very low permeability reservoirs, reservoirs of limited areal extent, biodegraded oils in reservoirs, and other marginal cases are excluded as examples of geologic success (Otis and Schneidermann, 1997).

Play-prospect assessment helps address two of the most important questions in portfolio management regarding areas to be selected for the most profitable exploration at a given risk. What is the average chance of prospect discovery in the future, and what is the expected size range of these future discoveries? In risk assessment, there are many nongeologic factors that may influence prospect ranking, such a personal bias, salesmanship, too much optimism or pessimism, company politics, and fear of the unknown (White, 1993). 


\section{Geologic Risk Factors}

For hydrocarbons to accumulate, certain geologic conditions must exist. A successful discovery requires that a hydrocarbon trap be present, that the objective formation have sufficient thickness and porosity, and that the formation have sufficient permeability so hydrocarbons can be readily transferred to the well bore. To achieve success, all of these conditions must be satisfied. Assuming that these conditions are independent, the probability of discovery is the product of each of the individual factors (Newendorp and Schuyler, 2000).

White (1993) described the geologic risk of a hydrocarbon-bearing prospect as the chance that some combination of geologic risk factors is absent in a significantly sized field. The minimum size of such a field is controlled by the size of mappable structural closures (geologic traps), which, practically speaking, is the economic minimum for the area. White thought that the definition of minimums in terms of hydrocarbon flow or detectable or measurable quantities of mobile hydrocarbons is too vague. He pointed out that there is neither a correlation between flow rate and field size nor between flow rate and volumetric risk. He defined geologic success as the coincidence of four groups of factors: (1) trap/seal/timing, (2) porosity and permeability, (3) source, maturation, and migration, and (4) hydrocarbon quality/recovery.

Otis and Schneidermann (1997) defined four independent factors as being necessary for a prospect to contain recoverable hydrocarbons. Those four factors are source rock, reservoir, trap, and timing and migration. They defined geologic success as "having a sustained, stabilized flow of hydrocarbons on test."

Most authors mention between four and five geologic characteristics as being pertinent to hydrocarbon exploration. Table 9 summarizes the opinion of various authors as to the most important risk factors.

For this project, a combination of five geologic chance factors were used: (1) source rock, (2) reservoir rock, (3) trap, (4) timing/migration, and (5) seal. These geologic characteristics appear to be common to most risk-assessment studies, and they compose the essential geologic controls on hydrocarbon accumulation.

\section{Scaling Geologic Risk}

Assigning a numeric probabilistic chance of geologic success to an oil and gas opportunity requires a risking scale. Typical scales involve qualitative judgment and assign a probability of occurrence. Different authors have created qualitative scales to assign geologic risk.

There are several types of deterministic risking schemes. Otis and Schneidermann (1997) proposed assessment of the elements of the risk factors using a verbal scale with the correlating probability range: unfavorable—direct data (0.01-0.3), questionable—indirect data (0.3-0.5), neutral—no data (0.5), encouraging —indirect data $(0.5-0.7$, and favorable—direct data (0.7-0.99).

White (1993) described a procedure of risk analysis using a numerical scale from 0 to 1 . He defined geologic chance as the perceived probability of the existence of a significant field (or related opportunity volume factor) that is larger than a specified practical minimum size (size of small but mappable closures). Ideally, the minimum size equals the economic minimum for the area. 
Table 9. Summary of geological risk factors by different authors.

\begin{tabular}{|c|c|}
\hline Author & Geologic risk factors \\
\hline Otis and Schneidermann (1997) & $\begin{array}{ll}\text { 1. } & \text { Source rock } \\
\text { 2. } & \text { Reservoir } \\
\text { 3. } & \text { Trap } \\
\text { 4. } & \text { Timing/migration }\end{array}$ \\
\hline White (1993) & $\begin{array}{ll}\text { 1. } & \text { Trap/seal/timing } \\
\text { 2. } & \text { Reservoir/porosity/permeability } \\
\text { 3. } & \text { Source/maturation/migration } \\
\text { 4. } & \text { Hydrocarbon quality/recovery }\end{array}$ \\
\hline Megill (1977) & $\begin{array}{ll}\text { 1. } & \text { Trap closure } \\
\text { 2. } & \text { Reservoir } \\
\text { 3. } & \text { Porosity } \\
\text { 4. } & \text { Source } \\
\text { 5. } & \text { Recovery } \\
\end{array}$ \\
\hline Rose and Brown (2001b) & $\begin{array}{ll}\text { 1. } & \text { Source rock } \\
\text { 2. } & \text { Migration/timing } \\
\text { 3. } & \text { Reservoir rock } \\
\text { 4. } & \text { Closure } \\
\text { 5. } & \text { Containment } \\
\end{array}$ \\
\hline USGS (1997) & $\begin{array}{ll}\text { 1. } & \text { Source rock } \\
\text { 2. } & \text { Timing } \\
\text { 3. } & \text { Migration } \\
\text { 4. } & \text { Reservoir } \\
\text { 5. } & \text { Trap } \\
\end{array}$ \\
\hline
\end{tabular}


To Rose (2001), a successful prospect is one that contains at least flowable hydrocarbons. He described a scale of subjective probabilities: will occur (1.0), virtual geologic certainty (0.9-1.0), reasonable geologic confidencemore likely to be present than absent (0.6-0.8), "toss-up"—significant uncertainty $(0.4-0.6)$, fairly unlikely—less likely to be present than absent $(0.2-0.4)$, high-risk geologic factor $(0-0.2)$, and will not occur $(0.0)$. He also specified the probability of geological occurrence in a more specific form using a Chance Adequacy Matrix. This matrix relates both confidence in the data to be interpreted and confidence in the geology to assign risk.

Otis and Schneidermann (1997), after reviewing many projects, calculated a table of general results of assessment or "rules of thumb" that help reduce impractical arguments and characterization of risk (table 10).

The geologic chance of success can be ranked on a verbal ranking system according to the number and quality of data and the decision criteria of the geologist (Likert, 1932):

1. Strongly unfavorable to the concept

2. Somewhat unfavorable to the concept

3. Undecided

4. Somewhat favorable to the concept

5. Strongly favorable to the concept

Sources of uncertainty are the amount and quality of information. Uncertainty is lower when there is good information and much data. It becomes larger when information is sparse and poor. The maximum error occurs in the middle range of uncertainty because judgment is more reliable because more information and data of better quality are available. This uncertainty can be modeled by different values of the standard deviation, assuming a normal distribution curve and using Monte Carlo simulation, which covers all values in the scale from 0 to 1 . The distribution of these uncertainties at each of the five verbal levels is displayed in table 11 and figure 122 .

\section{Geologic Correlation}

To use Monte Carlo simulation in the most efficient way, dependency among the risk-assessment factors should be modeled. Correlation-factor values occur within a range of -1 to 1 . A value of $r$ equal to -1 corresponds to a perfect negative correlation, whereas a value of +1 indicates perfect positive correlation. A correlation coefficient factor of 0 means that the points in question are not correlated. Whenever a data pair exhibit a linear dependency or strong dependency, it is necessary to find a correlation coefficient (Murtha, 1995).

Geologic correlation is evaluated among opportunities within the same play only because they have similar geological history and characteristics. For each of the five geologic factors, correlation matrices are developed on the basis of the seismic and geologic information of each of the opportunities. Opportunities in different plays are modeled with no correlation. Geologic correlations are stronger for opportunities in the same sand-body reservoir. 
Table 10. Risk categorization matrix (Otis and Schneidermann, 1997).

\begin{tabular}{|c|c|l|l|}
\hline $\begin{array}{c}\text { Geologic } \\
\text { risk level }\end{array}$ & $\begin{array}{c}\text { Probability of } \\
\text { geologic } \\
\text { success } \\
\text { (Pg) }\end{array}$ & \multicolumn{1}{|c|}{ Risk factors } & \multicolumn{1}{c|}{ Play characteristics } \\
\hline $\begin{array}{c}\text { Very low } \\
\text { risk }\end{array}$ & $0.5-0.99$ & $\begin{array}{l}\text { All risk factors are } \\
\text { favorable }\end{array}$ & $\begin{array}{l}\text { Same play, adjacent structure: wells that test } \\
\text { proven plays adjacent to (within <5 km of) } \\
\text { existing production }\end{array}$ \\
\hline Low risk & $0.25-0.50$ & $\begin{array}{l}\text { All risk factors are } \\
\text { encouraging to favorable }\end{array}$ & $\begin{array}{l}\text { Same play, nearby structure: wells that test } \\
\text { proven plays near (within 5-10 km of) existing } \\
\text { production }\end{array}$ \\
\hline $\begin{array}{c}\text { Moderate } \\
\text { risk }\end{array}$ & $0.125-0.25$ & $\begin{array}{l}\text { Two or three risk factors } \\
\text { are encouraging to } \\
\text { favorable; one or two are } \\
\text { encouraging or neutral }\end{array}$ & $\begin{array}{l}\text { New play, same trend and old play, new trend: } \\
\text { wells that test new plays in producing basins or } \\
\text { proven plays far from (within }>10 \text { km of) } \\
\text { existing production }\end{array}$ \\
\hline $\begin{array}{c}\text { High risk } \\
\text { encong }\end{array}$ & $\begin{array}{l}\text { One or two risk factors } \\
\text { are encouraging; two or } \\
\text { three risk factors are } \\
\text { neutral or encouraging to } \\
\text { neutral }\end{array}$ & $\begin{array}{l}\text { New play, same trend and old play, new trend: } \\
\text { wells that test new plays in producing basins far } \\
\text { from (within }>20 \text { km of) existing production or } \\
\text { proven plays in an unproved area }\end{array}$ \\
\hline $\begin{array}{c}\text { Very high } \\
\text { risk }\end{array}$ & $0.01-0.063$ & $\begin{array}{l}\text { Two to three risk factors } \\
\text { are no better than } \\
\text { neutral, with one or two } \\
\text { factors questionable or } \\
\text { unfavorable }\end{array}$ & $\begin{array}{l}\text { New play, new basin or play with negative data: } \\
\text { wells that test new plays in an unproved area far } \\
\text { from (within }>50 \text { km of) existing production }\end{array}$ \\
\hline
\end{tabular}

Table 11. Risk-assessment scaling table with normal-distribution factors.

\begin{tabular}{|l|c|c|}
\hline \multicolumn{1}{|c|}{ Chance assessment } & Mean normal distribution & $\begin{array}{c}\text { Standard deviation normal } \\
\text { distribution }\end{array}$ \\
\hline High chance & 0.9 & 0.1 \\
\hline Moderate high chance & 0.7 & 0.15 \\
\hline Moderate chance & 0.5 & 0.2 \\
\hline Moderate low chance & 0.3 & 0.15 \\
\hline Low chance & 0.1 & 0.1 \\
\hline
\end{tabular}




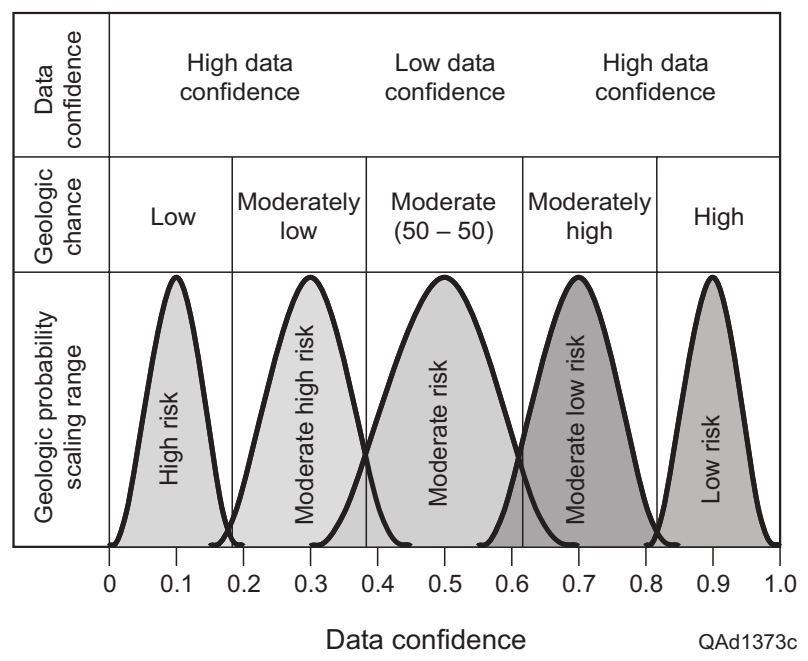

Figure 122. Normal distribution of risk-assessment levels. 


\section{Geologic Risk Assessment}

The procedure followed for the determination of geologic risk involved several steps. First, identify the play in which the opportunities occur. Second, identify the different independent factors that are assumed to control the presence or absence of hydrocarbons for each of the opportunities. This judgment is based on the quality and quantity of data and on the interpretation of the presence of hydrocarbons given by the geologist and geophysicist. Third, multiply the probabilities of all geologic risk factors by the play success chance (because the plays are already "proven," the success chance is assigned a value of 1) to obtain the chance of prospect success (Baker and others, 1984). Each distribution is evaluated in combination with the geologic correlation matrix for opportunities in the same play. The steps for risking geologic success are:

1. Identify the play that corresponds to an opportunity.

2. Identify the five geologic chance factors.

3. Evaluate/rank the geologic success chance of each one of the geologic factors.

4. Evaluate the geologic correlation matrix for opportunities in the same play.

5. Evaluate the play's geologic success.

6. Multiply each of the geologic chance-of-success factors and the play's geologic success factor to obtain the probability of geologic success for each of the opportunities.

\section{Follow the same procedure for the next play.}

The probability of geologic success $(\mathrm{Pg})$ for each opportunity is obtained by multiplying the probabilities of occurrence of each of the five independent geologic factors. This technique is called decomposition, as defined by Newendorp and Schuyler (2000).

$\mathrm{Pg}\left\{\begin{array}{l}\text { Geo log ic } \\ \text { Success }\end{array}\right\}=\mathrm{P}\left\{\begin{array}{l}\text { Source } \\ \text { Rock }\end{array}\right\} \times \mathrm{P}\left\{\begin{array}{l}\text { Reservoir } \\ \text { Quality }\end{array}\right\} \times \mathrm{P}\left\{\begin{array}{l}\text { Trap } \\ \text { Ru }\end{array}\right\} \times \mathrm{P}\left\{\begin{array}{l}\text { Closure } \\ \text { Rigration }\end{array}\right\} \times \mathrm{P}\left\{\begin{array}{l}\text { Timing/ } \\ \text { Ming }\end{array}\right\}$

\section{Risk Assessment of Project Opportunities}

The 54 opportunities delineated within the bounds of the project's 3-D seismic volume occur within six upper and middle Miocene plays of the northern Gulf of Mexico (Seni and others, 1997) (table 12). 
Table 12. Geologic description of plays (Seni and others, 1997).

\begin{tabular}{|l|l|l|l|l|}
\hline \multicolumn{1}{|c|}{ Chronozones } & \multicolumn{1}{c|}{ Location } & \multicolumn{1}{c|}{ Depositional style } & \multicolumn{1}{c|}{ Lithology } & \multicolumn{1}{c|}{ Play name } \\
\hline Lower Middle Miocene 4 & Eastern & Progradational & Sandstone & MM4 P.1 \\
\hline Middle Middle Miocene 7 & Eastern & Progradational & Sandstone & MM7 P.1B \\
\hline Middle Middle Miocene 7 & Eastern & Retrogradational & Sandstone & MM7 R.1B \\
\hline Middle Middle Miocene 9 & Central & Progradational & Sandstone & MM9 P.1B \\
\hline Lower Upper Miocene 1 & Eastern & Progradational & Sandstone & UM1 P.1B \\
\hline Upper Upper Miocene 7 & Eastern & Progradational & Sandstone & UM3 P.1B \\
\hline
\end{tabular}

The data used for the risk assessment come from different sources, such as historical play information, seismic information, petrophysical and stratigraphic analysis, data from Texaco geologists, and the overall judgment of team geoscientists (table 13). Table 14 shows the size and depth of the 54 opportunities currently identified for the area in the study.

The scale that was used to define the geologic risk of the opportunities is based on the previously described model developed to simulate the uncertainty of information (fig. 123). Five geologic chance factors were evaluated: (1) source rock, (2) reservoir rock, (3) trap, (4) timing and migration, and (5) seal. The specific criteria used for ranking the 54 opportunities are described as follows (fig. 124).

Opportunities 1 through 21 were initially identified by a search of the seismic data volume for overlooked structural components (anticlines, rollovers, faults, etc.) that could act as hydrocarbon traps. Such opportunities that showed structural-trap development by no direct hydrocarbon indicators of fluid presence (that is, bright spots) were given moderate chance-of-success (COS) rankings. However, structural components with amplitude bright spots, indicating the probable presence of hydrocarbon fluids, were given high COS rankings.

Root-mean-squared amplitude maps were generated at all reservoir intervals and combined with the sequencestratigraphic analysis to identify opportunities 22 through 42 . These opportunities comprise high-amplitude ("bright") anomalies associated with geological features (for example, sandstone-rich lowstand incised-valley fills) that strongly suggest the presence of reservoir-quality sandstone; moreover, these opportunities have not been penetrated by previous drilling. Because bright amplitudes have historically been good indicators of hydrocarbon presence in the section down to the 12000 A and B sands, lower COS's were assigned opportunities throughout this interval that showed minimal amplitude response. Reservoirs below the 12000 sands, primarily the Robulus "L" sands, generally do not have amplitude responses indicative of reservoir quality; therefore, little or no weighting was given to the presence or absence of amplitude anomalies in these reservoirs. Here opportunities that were interpreted to contain quality reservoir rock and are associated with structural closure or trapping (faults, rollover anticlines, domes) were assigned a high COS. Opportunities showing only bright spots with no association with structural components (possible stratigraphic traps) were given medium COS rankings. In general, all four-way structural closures merited a high COS ranking within the trap-risk-factor category (fig. 123). Reservoirs capped by thick sealing shales (for example, the basinwide "Cristellaria "I" shale above the T-1 reservoir) have high COS ranking. 
Table 13. Source of data for analyzing opportunities.

\begin{tabular}{|l|l|}
\hline \multicolumn{1}{|c|}{ Parameter } & \multicolumn{1}{c|}{ Source of data } \\
\hline Temperature & Correlation with play data \\
\hline Pressure & Correlation with play data \\
\hline Source rock & Regional analysis \\
\hline Timing/migration & Regional analysis \\
\hline Reservoir quality & 3-D seismic, log, and sequence analysis \\
\hline Trap & 3-D seismic interpretation \\
\hline Seal & 3-D seismic, log, and sequence analysis \\
\hline Depth & 3-D seismic and log analysis \\
\hline Pay thickness & 3-D seismic interpretation \\
\hline Area & 3-D seismic interpretation \\
\hline Gas gravity & Play analysis distribution \\
\hline Water saturation & Play analysis distribution \\
\hline Porosity & Play analysis distribution \\
\hline Recovery factor & Play analysis distribution \\
\hline Gas formation volume factor & Beggs and Brill correlation \\
\hline Minimum commercial field size & Economic analysis \\
\hline
\end{tabular}


Table 14. Opportunity description (DeAngelo, 2002).

\begin{tabular}{|c|c|c|c|c|c|}
\hline Play name & Sand & $\begin{array}{c}\text { Opportunity } \\
\text { name }\end{array}$ & $\begin{array}{c}\text { Estimated } \\
\text { depth } \\
\text { (ft) }\end{array}$ & $\begin{array}{c}\text { Size } \\
\text { (acres) }\end{array}$ & $\begin{array}{c}\text { Estimated } \\
\text { average net } \\
\text { pay thickness } \\
\text { (ft) }\end{array}$ \\
\hline \multirow{17}{*}{ MM4 P.1 } & \multirow{4}{*}{ Robulus L-2 } & 5 & 14,150 & 250 & 30 \\
\hline & & 12 & 12,300 & 215 & 25 \\
\hline & & 16 & 13,400 & 420 & 50 \\
\hline & & 17 & 12,500 & 390 & 30 \\
\hline & \multirow{2}{*}{ Robulus L-2/4 } & 48 & 14,200 & 75 & 40 \\
\hline & & 3 & 14,250 & 85 & 40 \\
\hline & \multirow{5}{*}{ Robulus L-4 } & 4 & 14,400 & 65 & 30 \\
\hline & & 54 & 14,600 & 105 & 30 \\
\hline & & 53 & 13,950 & 65 & 30 \\
\hline & & 52 & 14,100 & 1,100 & 110 \\
\hline & & 9 & 14,500 & 120 & 30 \\
\hline & Robulus L-6 & 6 & 14,100 & 60 & 40 \\
\hline & Robulus L-8 & 51 & 13,500 & 330 & 40 \\
\hline & \multirow{4}{*}{$12000 \mathrm{~A} / \mathrm{B}$} & 47 & 12,425 & 50 & 20 \\
\hline & & 46 & 12,300 & 135 & 20 \\
\hline & & 45 & 12,650 & 155 & 20 \\
\hline & & 20 & 14,550 & 85 & 20 \\
\hline \multirow{3}{*}{ MM7 P.1B } & \multirow{3}{*}{$\mathrm{Y}$} & 8 & 12,200 & 215 & 50 \\
\hline & & 18 & 12,350 & 120 & 35 \\
\hline & & 42 & 12,200 & 280 & 45 \\
\hline & \multirow{3}{*}{$\mathrm{T}$} & 49 & 10,575 & 102 & 40 \\
\hline \multirow{4}{*}{ MM7 R.1B } & & 7 & 10,340 & 195 & 60 \\
\hline & & $10 \mathrm{~A}$ & 10,380 & 90 & 65 \\
\hline & \multirow{2}{*}{ V } & 10B & 11,180 & 45 & 55 \\
\hline & & 41 & 11,160 & 60 & 55 \\
\hline \multirow{12}{*}{ MM9 P.1B } & \multirow{6}{*}{ Q } & 2 & 11,230 & 50 & 20 \\
\hline & & 15 & 9,590 & 295 & 20 \\
\hline & & 21 & 11,080 & 395 & 40 \\
\hline & & 34 & 11,810 & 65 & 30 \\
\hline & & 35 & 11,180 & 112 & 40 \\
\hline & & 36 & 11,260 & 145 & 30 \\
\hline & \multirow{2}{*}{$\mathrm{N}$} & 29 & 9,375 & 300 & 35 \\
\hline & & 30 & 10,480 & 220 & 25 \\
\hline & \multirow{4}{*}{$\mathrm{O}$} & 11 & 9,340 & 430 & 45 \\
\hline & & 31 & 9,590 & 255 & 45 \\
\hline & & 32 & 9,380 & 125 & 45 \\
\hline & & 33 & 11,150 & 240 & 35 \\
\hline \multirow{14}{*}{ UM1 P.1B } & \multirow{4}{*}{$\mathrm{L}$} & 1 & 7,680 & 550 & 20 \\
\hline & & 13 & 8,765 & 50 & 30 \\
\hline & & 14 & 8,720 & 155 & 40 \\
\hline & & 25 & 7,970 & 250 & 30 \\
\hline & $\mathrm{J}$ & $19 \mathrm{~B}$ & 7,750 & 130 & 20 \\
\hline & \multirow{3}{*}{ F-1 } & 50 & 8,020 & 376 & 25 \\
\hline & & $22 \mathrm{~A}$ & 7,240 & 385 & 30 \\
\hline & & 23 & 7,080 & 410 & 30 \\
\hline & $\mathrm{F}-2$ & 24 & 8,550 & 665 & 45 \\
\hline & \multirow{3}{*}{ M } & 26 & 8,220 & 145 & 40 \\
\hline & & 27 & 8,180 & 315 & 40 \\
\hline & & 28 & 9,750 & 142 & 45 \\
\hline & $\mathrm{H}$ & 39 & 7,560 & 60 & 20 \\
\hline & & 40 & 7,715 & 100 & 25 \\
\hline & B & $19 \mathrm{~A}$ & 6,130 & 110 & 30 \\
\hline UM3 P 1B & & $22 \mathrm{~B}$ & 6,925 & 300 & 30 \\
\hline (1) & D & 37 & 7,000 & 83 & 30 \\
\hline & & 38 & 6,880 & 490 & 30 \\
\hline
\end{tabular}




\begin{tabular}{|c|c|c|c|c|c|c|c|c|c|c|c|c|c|c|c|c|c|c|c|c|c|c|c|c|}
\hline \multirow{2}{*}{$\begin{array}{l}\text { Play } \\
\text { name }\end{array}$} & \multirow[t]{2}{*}{ Sand } & \multirow{2}{*}{$\begin{array}{l}\text { Opportunity } \\
\text { name }\end{array}$} & \multirow{2}{*}{$\begin{array}{l}\text { Geologic } \\
\text { chance of } \\
\text { success }\end{array}$} & \multicolumn{4}{|c|}{$\begin{array}{c}\text { Source } \\
\text { rock }\end{array}$} & \multicolumn{4}{|c|}{$\begin{array}{l}\text { Reservoir } \\
\text { rock }\end{array}$} & \multicolumn{5}{|c|}{ Trap } & \multicolumn{4}{|c|}{$\begin{array}{l}\text { Timing/ } \\
\text { migration }\end{array}$} & & & Seal & \\
\hline & & & & $\mathrm{L}$ & $M L$ & \begin{tabular}{l|l}
$\mathrm{M}$ & $\mathrm{N}$ \\
\end{tabular} & \begin{tabular}{l|l|}
$\mathrm{MH}$ & $\mathrm{H}$ \\
\end{tabular} & $\mathrm{L}$ & $\begin{array}{ll}M L \\
\end{array}$ & $\mathrm{M} \mid \mathrm{M}$ & $\mathrm{HH}$ & $1 \mathrm{~L}$ & $\begin{array}{ll} \\
\end{array}$ & & \begin{tabular}{l|l}
$1 \mathrm{MH}$ \\
\end{tabular} & $\mathrm{H}$ & $\mathrm{L}$ & $\mathrm{ML}$ & \begin{tabular}{|l|l|}
$\mathrm{M}$ & $\mathrm{MH}$ \\
\end{tabular} & $\mathrm{H}$ & $\mathrm{L}$ & $\mathrm{ML}$ & $\mathrm{M} \mathrm{N}$ & $\mathrm{MH}$ \\
\hline & & 5 & 0.14 & & & & & & & & & & & & & & & & & & & & & \\
\hline & Robulus L-2 & 12 & 0.28 & & & & & & & & & & & & & & & & & & & & & \\
\hline & 1 & 16 & 0.36 & & & & & & & & & & & & & & & & & & & & & \\
\hline & & 17 & 0.14 & & & & & & & & & & & & & & & & & & & & & \\
\hline & Robulus & 48 & 0.29 & & & & & & & & & & & & & & & & & & & & & \\
\hline & $\mathrm{L}-2 / 4$ & 3 & 0.20 & & & & & & & & & & & & & & & & & & & & & \\
\hline & & 4 & 0.10 & & & & & & & & & & & & & & & & & & 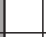 & & & \\
\hline & Robulus L-4 & 54 & 0.23 & & & & & & & & & & & & & & & & & & 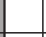 & & & \\
\hline MM4 P.1 & & 53 & 0.23 & & & & & & & & & & & & & & & & & & & & & \\
\hline & & 52 & 0.23 & & & & & & & & & & & & & & & & & & & & & \\
\hline & & 9 & 0.04 & & & & & & & & & & & & & & & & & & & & & \\
\hline & Robulus L-6 & 6 & 0.14 & & & & & & & & & & & & & & & & & & & & & \\
\hline & Robulus L-8 & 51 & 0.23 & & & & & & & & & & & & & & & & & & & & & \\
\hline & & 47 & 0.13 & & & & & & & & & & & & & & & & & & & & & \\
\hline & $12.000 \mathrm{~A} / \mathrm{B}$ & 46 & 0.13 & & & & & & & & & & & & & & & & & & & & & \\
\hline & $12,000 \mathrm{~A} / \mathrm{D}$ & 45 & 0.13 & & & & & & & & & & & & & & & & & & & & & \\
\hline & & 20 & 0.28 & & & & & & & & & & & & & & & & & & & & & \\
\hline & & 8 & 0.36 & & & & & & & & & & & & & & & & & & & & & \\
\hline MM7 P.1B & $\mathrm{Y}$ & 18 & 0.20 & & & & & & & & & & & & & & & & & & & & & \\
\hline & & 42 & 0.36 & & & & & & & & & & & & & & & & & & & & & \\
\hline & & 7 & 0.26 & & & & & & & & & & & & & & & & & & & & & \\
\hline & $\mathrm{T}$ & 49 & 0.25 & & & & & & & & & & & & & & & & & & & & & \\
\hline MM7 R.1B & & $10 \mathrm{~A}$ & 0.46 & & & & & & & & & & & & & & & & & & & & & \\
\hline & V & $10 \mathrm{~B}$ & 0.46 & & & & & & & & & & & & & & & & & & & & & \\
\hline & $\mathrm{v}$ & 41 & 0.33 & & & & & & & & & & & & & & & & & & & & & \\
\hline & & 2 & 0.14 & & & & & & & & & & & & & & & & & & & & & \\
\hline & & 15 & 0.15 & & & & & & & & & & & & & & & & & & & & & \\
\hline & & 21 & 0.20 & & & & & & & & & & & & & & & & & & & & & \\
\hline & Q & 34 & 0.20 & & & & & & & & & & & & & & & & & & & & & \\
\hline & & 35 & 0.28 & & & & & & & & & & & & & & & & & & & & & \\
\hline & & 36 & 0.36 & & & & & & & & & & & & & & & & & & & & & \\
\hline IMIVIY P.TB & & 29 & 0.36 & & & & & & & & & & & & & & & & & & & & & \\
\hline & $\mathbf{N}$ & 30 & 0.14 & & & & & & & & & & & & & & & & & & & & & \\
\hline & & 11 & 0.20 & & & & & & & & & & & & & & & & & & & & & \\
\hline & O & 31 & 0.26 & & & & & & & & & & & & & & & & & & & & & \\
\hline & 0 & 32 & 0.28 & & & & & & & & & & & & & & & & & & & & & \\
\hline & & 33 & 0.18 & & & & & & & & & & & & & & & & & & & & & \\
\hline & & 1 & 0.26 & & & & & & & & & & & & & & & & & & & & & \\
\hline & & 13 & 0.10 & & & & & & & & & & & & & & & & & & & & & \\
\hline & L & 14 & 0.10 & & & & & & & & & & & & & & & & & & & & & \\
\hline & & 25 & 0.15 & & & & & & & & & & & & & & & & & & & & & \\
\hline & $\mathrm{J}$ & $19 \mathrm{~B}$ & 0.28 & & & & & & & & & & & & & & & & & & & & & \\
\hline & & 50 & 0.25 & & & & & & & & & & & & & & & & & & & & & \\
\hline UM1 P 1B & $\mathrm{F}-1$ & $22 \mathrm{~A}$ & 0.36 & & & & & & & & & & & & & & & & & & & & & \\
\hline UIVI P. ID & & 23 & 0.36 & & & & & & & & & & & & & & & & & & & & & \\
\hline & $\mathrm{F}-2$ & 24 & 0.36 & & & & & & & & & & & & & & & & & & & & & \\
\hline & & 26 & 0.36 & & & & & & & & & & & & & & & & & & & & & \\
\hline & M & 27 & 0.28 & & & & & & & & & & & & & & & & & & & & & \\
\hline & & 28 & 0.28 & & & & & & & & & & & & & & & & & & & & & \\
\hline & $\mathrm{H}$ & 39 & 0.36 & & & & & & & & & & & & & & & & & & & & & \\
\hline & $\Pi$ & 40 & 0.20 & & & & & & & & & & & & & & & & & & & & & \\
\hline & $\mathrm{B}$ & $19 \mathrm{~A}$ & 0.33 & & & & & & & & & & & & & & & & & & & & & \\
\hline UM3 P1B & & $22 \mathrm{~B}$ & 0.14 & & & & & & & & & & & & & & & & & & & & & \\
\hline שת & D & 37 & 0.28 & & & & & & & & & & & & & & & & & & & & & \\
\hline & & 38 & 0.20 & & & & & & & & & & & & & & & & & & & & & \\
\hline
\end{tabular}

Figure 123. Parameters used to determine geologic chance of success for Opportunities 1 through 54. 


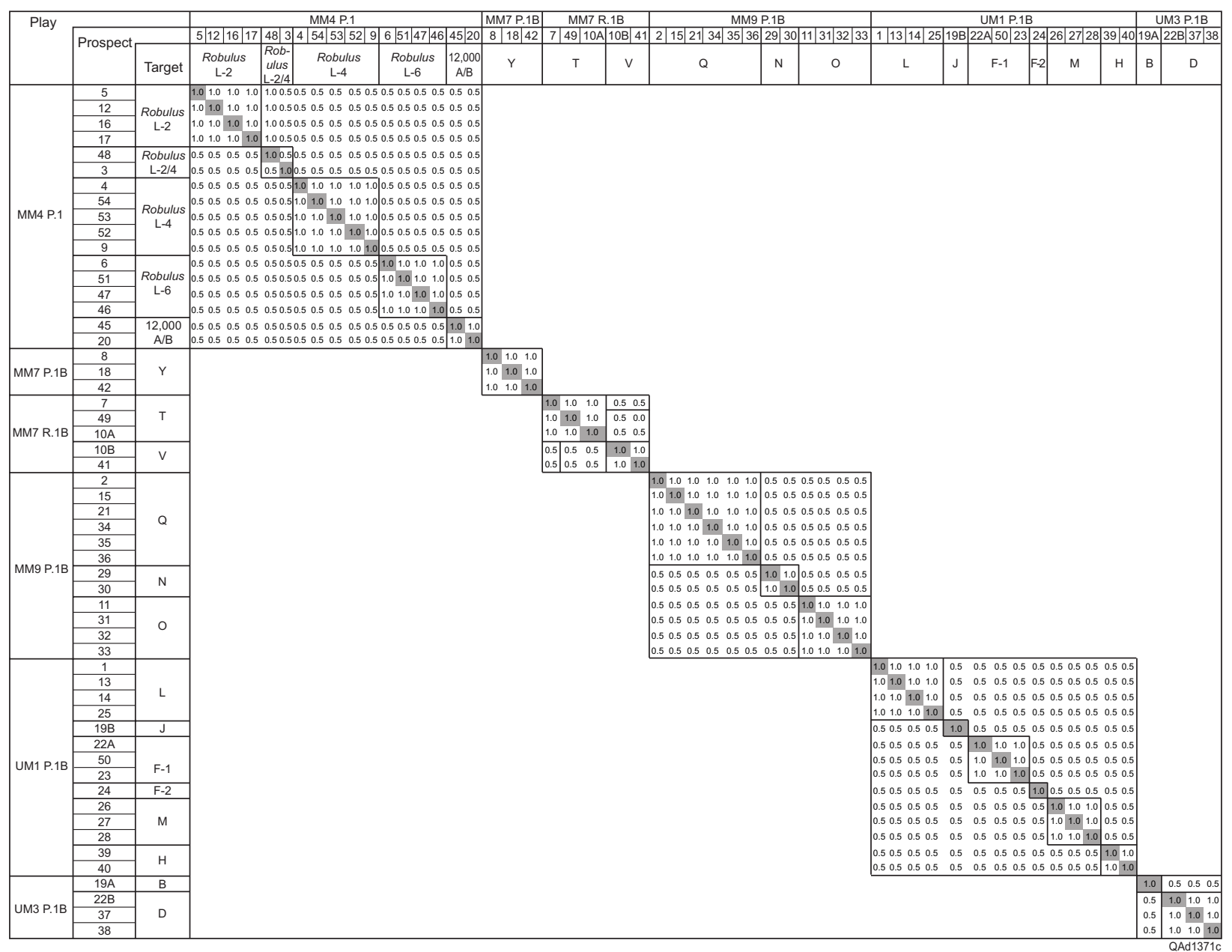

Figure 124. Geologic-correlation-factor matrix of geologic-risk parameters used in assessing Opportunities 1 through 54 . 
The rankings for seal associated with other opportunities range from medium low to medium high, depending on the thickness of sealing shales above the prospective reservoir sand.

High COS rankings to all opportunities in the timing/migration and source-rock ranking categories were assigned primarily because producing reservoirs of Miocene through Pleistocene age already exist in the immediate area and the opportunities are part of proven plays of regional extent.

Overall ranking analysis of the opportunities indicates an average geologic chance of success of 25 percent and a standard deviation of 10 percent. The minimum value was 4 percent, and the maximum was 46 percent.

A geologic correlation matrix was applied to the opportunities to obtain the covariance necessary to take into account geologic dependency. A correlation factor of 1 was assigned to opportunities in the same sandstone interval. For opportunities in different intervals but in the same play, a value of 0.5 was assigned. Opportunities in different plays have no correlation (correlation factor value of 0) (fig. 124).

\section{Volumetric Assessment}

All reserves calculations involve some degree of uncertainty. The uncertainty assigned by the geoscientist to a specific opportunity depends chiefly on the number of reliable geologic and engineering data available at the time of the estimate and the interpretation of these data. A reserve estimation is described as "deterministic" if it is a single best estimate that is based on known geological, engineering, and economical data. When these data are used to generate a range of estimates along with their respective probabilities, "probabilistic" reserve estimations result. To obtain a range of outcomes, the parameters used in the volumetric equation below were calculated as probabilistic distributions on the basis of data from the active plays and 3-D seismic information.

\section{Reserves Calculation}

Volume of recoverable hydrocarbons is determined in a general form by two volumetric equations that consider reservoir area, net pay, petrophysical parameters, and a hydrocarbon-recovery factor. These equations determine how much of the hydrocarbon in a reservoir of a certain size can be produced. The first equation is used to calculate the original gas in place (OGIP):

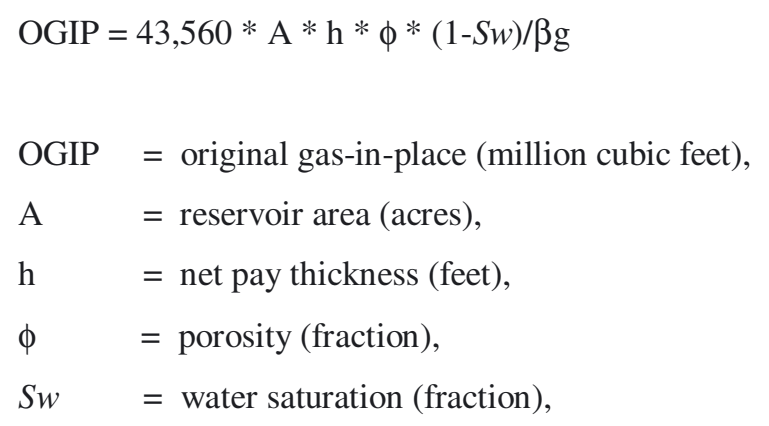


$\beta \mathrm{g}=$ gas formation volume factor $\left(\right.$ reservoir $\left.\mathrm{ft}^{3} / \mathrm{ft}^{3}\right)$

Recoverable reserves are then calculated as a probability distribution with a degree of uncertainty. The recovery factor predicts the amount of hydrocarbon that can be produced at the surface. This value of reserves is called unrisked reserves:

Unrisked reserves $=$ OGIP $*$ recovery factor

The accuracy of these values depends on the quality and quantity of geologic information and on information from adjacent fields. Each value has a level of uncertainty that can be represented by a probabilistic distribution. Each of the variables' probabilistic distribution is truncated at a minimum and maximum to enable calculation of realistic values. In the exercise, distribution represents the range of recoverable hydrocarbons (or "reserves" in the most general sense) expected to be found when a well is drilled, assuming geologic success (stabilized flow of hydrocarbons on test [Otis and Schneidermann, 1997]). Monte Carlo simulation was then applied to combine property distributions and produce final reserve distributions. A summary of the assumptions applied are:

- $\quad$ Drainage area $=200$ acres per well

- $\quad$ Minimum commercial field size $=2 \mathrm{Bcf}$

- Geologic correlation factor $=1$ for opportunities in same play and same stratigraphic unit

- Geologic correlation factor $=0.5$ for opportunities in same play and different stratigraphic unit

- $\quad$ Geologic correlation factor $=0$ for opportunities in different play

\section{Minimum Commercial Field Size (MCFS)}

Selection of the minimum field-size cutoff is important because it affects every major factor in the assessment: opportunities to be counted, success and risk levels, and average field size. Normally the minimum size is the same as, or slightly less than, the assumed commercial minimum for the area. This approach insures that all opportunities of real interest are included (Baker and others, 1984).

\section{Commercial Success}

In opportunity evaluation, the operative decision to complete a well is made after the well has been drilled, and it is based on the Minimum Commercial Field Size (MCFS). The decision is also based on a consideration of all prior costs (such as sunk costs), depending only on whether the costs of completion and operation allow an acceptable profit-making investment within the context of future cash flows (Rose and Brown, 2001a). An 
opportunity is declared a commercial success if the cash flows generated from the discovered volume will cover and exceed project costs, which do not include the exploration costs that are all ready spent and therefore considered sunk costs.

The probability of commercial success (Pc) involves the geological chance of success, and the percentage of an opportunity reserves distribution may be larger than the MCFS. To determine whether an opportunity is greater than the MCFS, drilling a number of wells (trials) may be necessary. The number of trials is the number of exploratory wells that is drilled before the opportunity is abandoned. This value is calculated by dividing the opportunity acreage by the drainage area in acres per well. Commercial success and risked reserves are calculated from

\author{
$\mathrm{Pc}=\left(1-\left(1-\left(\mathrm{Pg} * \mathrm{P}_{\mathrm{MCFS}}\right)\right)^{\text {No.Trials }}\right)$ \\ where \\ $\mathrm{Pc}=$ Probability of commercial success \\ Pg $=$ Probability of geologic success \\ $\mathrm{P}_{\mathrm{MCFS}}=$ Percentage of reserves larger than the MCFS \\ No. trials $=$ Number of exploratory wells drilled before opportunity is abandoned
}

Risked reserves $=$ unrisked reserves $*$ probability of commercial success.

\title{
Volumetric Parameters Statistics
}

In order to simulate the uncertainty of values interpreted from the 3-D seismic cube, probability distributions were considered. For area, the values were estimated with a margin of error of 10 percent in a normal probability distribution, which is reflected in the standard deviation as percentage of the mean value. Net thickness has more uncertainty, and it was assigned a lognormal probability distribution with a standard deviation of 30 percent of the mean value.

Initial temperature and pressure conditions are critical in determining opportunity resources. Reservoirtemperature (fig. 125) and -pressure (fig. 126) values were calculated on the basis of a correlation developed using all data for plays in the study area (Seni and others, 1997).

\footnotetext{
Temperature $\left({ }^{\circ} \mathrm{F}\right)=0.014 *$ depth $(\mathrm{ft})+60$

Pressure $(\mathrm{psi})=0.477 *$ depth $(\mathrm{ft})+14.7$
} 


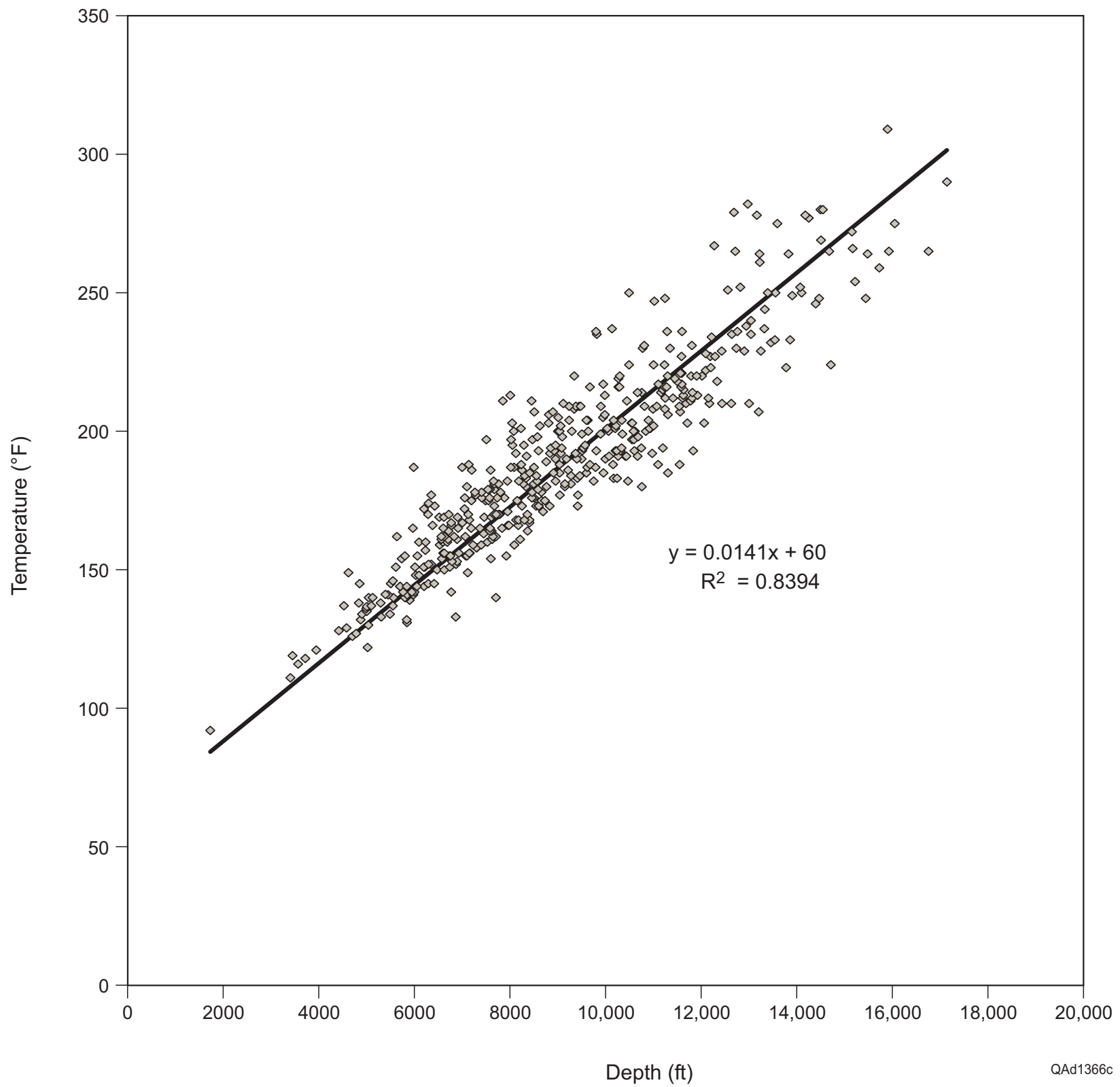

Figure 125. Temperature correlation used in resource calculations. 


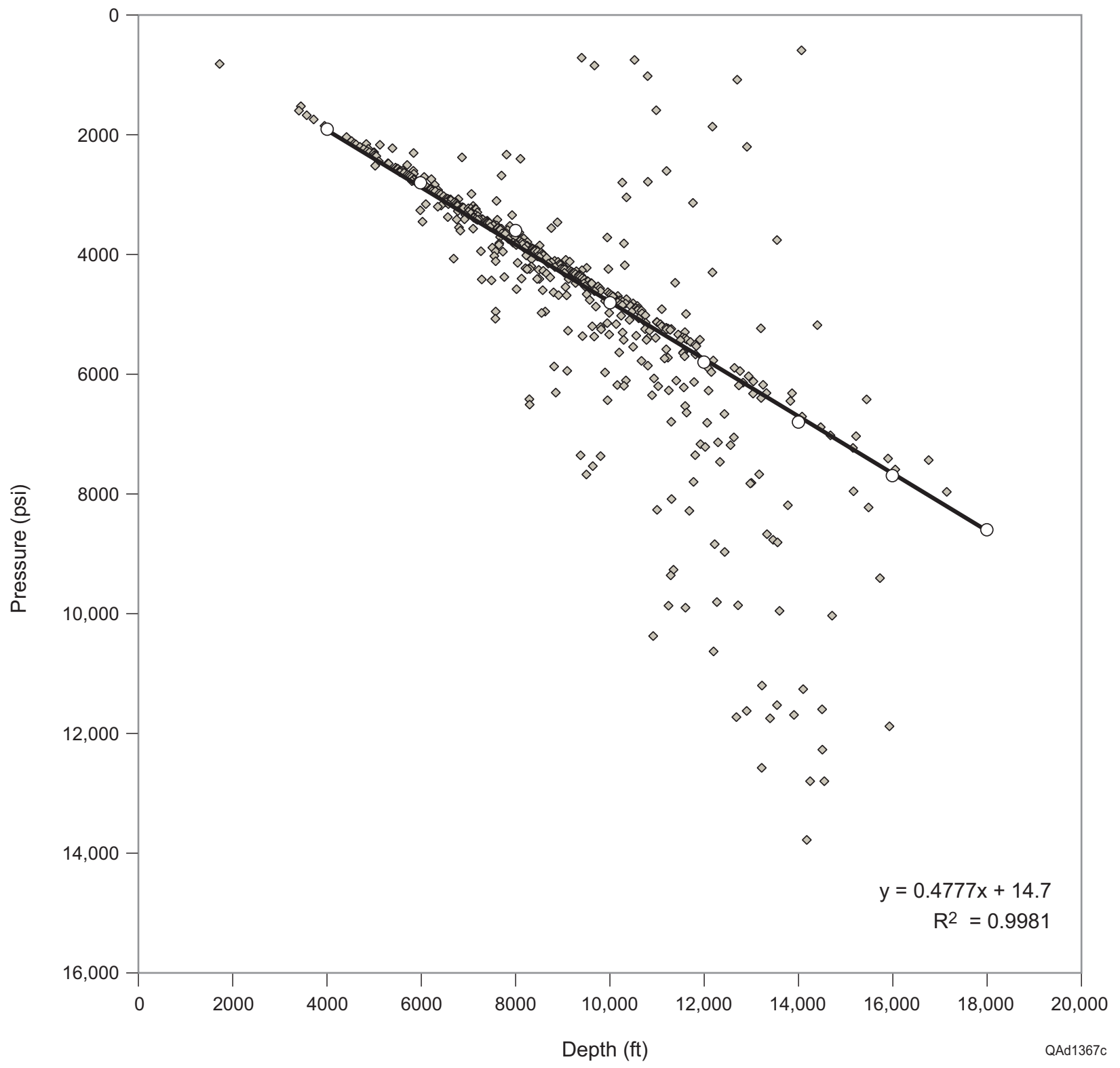

Figure 126. Pressure correlation used in resource calculations. 
Data for play-analysis probability distribution were obtained from Seni and others (1997) for play parameters: (1) specific gas gravity, (2) gas saturation, (3) porosity, and (4) recovery factor. Specific-gasgravity distributions show an average mean value of 0.6 and standard deviation of 0.026 (figs. 127-132). Gassaturation distributions are skewed to the right, with an average of 71 percent and standard deviation of 8 percent (figs. 133-138). Mean value of porosity distribution for all plays is 27 percent, with a standard deviation of 3 percent and a range from 15 to 36 percent (figs. 139-144). Recovery factor has an average mean value of 0.6 and standard deviation of 0.17 (figs. 145-150)

The Monte Carlo simulation used 5,000 iterations for calculated gas-in-place. Input probability distributions for the volumetric calculation were obtained from historical data from plays (table 15) and from the interpretation of 3-D seismic information as shown in play/opportunity descriptions (table 14). The probabilistic distributions that best fit the data were applied, along with maximums and minimums (tables 16, 17).

\section{Volumetric Results}

\section{A 50-percent probability exists that the opportunities delineated within the study area contain 1 trillion} standard feet (Tscf) (table 18). Twenty-five percent of this volume lies within opportunity 52. The six next largest compose another 25 percent of the resources. Thus seven opportunities, or 15 percent by number, account for a full one-half of the possible resources.

Mean unrisked reserves are 623 Bcf (table 18). At 90-percent probability of occurrence, unrisked reserves are $342 \mathrm{Bcf}$, or just over one-third of the mean OGIP. At 10-percent probability of occurrence, unrisked reserves are $933 \mathrm{Bcf}$; therefore, there is a lognormal-like, skewed, unrisked-reserves distribution (fig. 151). Mean risked reserves are $146 \mathrm{Bcf}$ (table 18).

Monte Carlo simulation calculates the probability for each opportunity to contain more hydrocarbons than the MCFS for the area. The MCFS distribution calculated for this project is 2 Bcf. This probability is multiplied by the probability of geologic success to obtain the probability of commercial success (fig. 152).

\section{Summary}

Substantial unexploited gas resources lie within the study area. There is a 50-percent probability that more than $1 \mathrm{Tcf}$ of original gas in place and $623 \mathrm{Bcf}$ of gas reserves (unrisked) are present in the 54 opportunities that were identified during the course of the project (table 18). Importantly, a large portion of this resource is contained within a small percentage of the opportunities, resulting in the testing of these volumes more efficiently. 


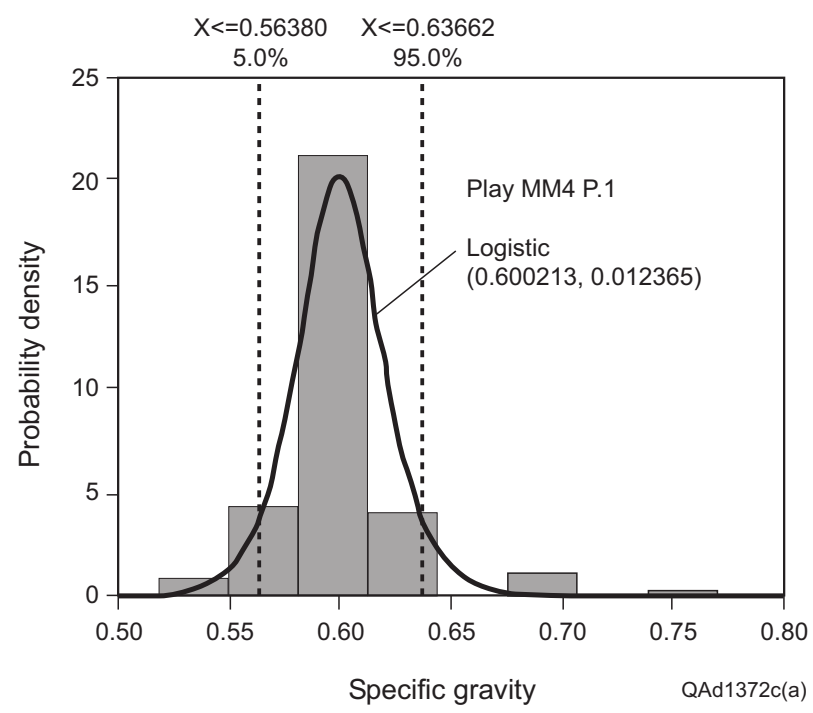

Figure 127. Specific-gas-gravity distribution for play MM4 P.1.

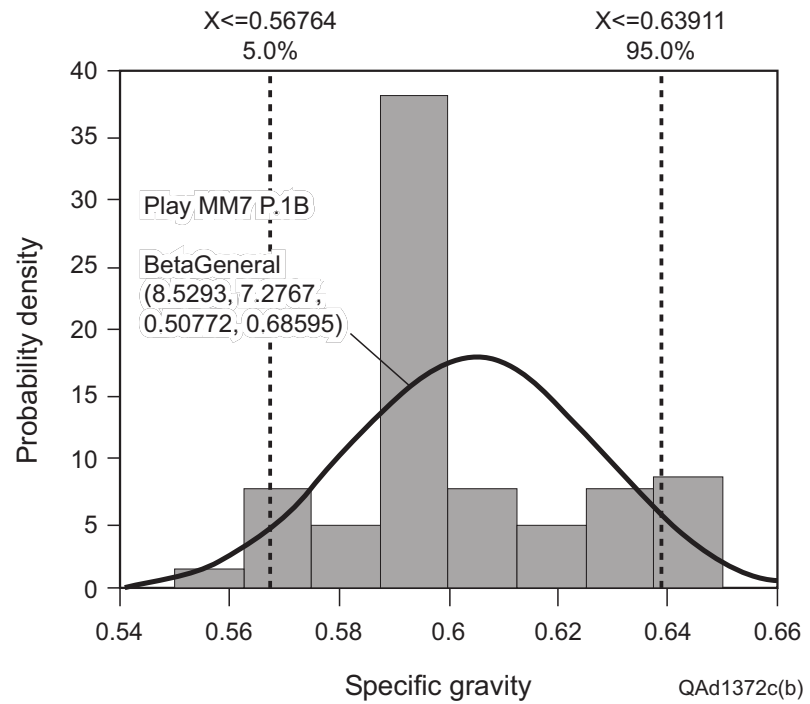

Figure 128. Specific-gas-gravity distribution for play MM7 P.1B. 


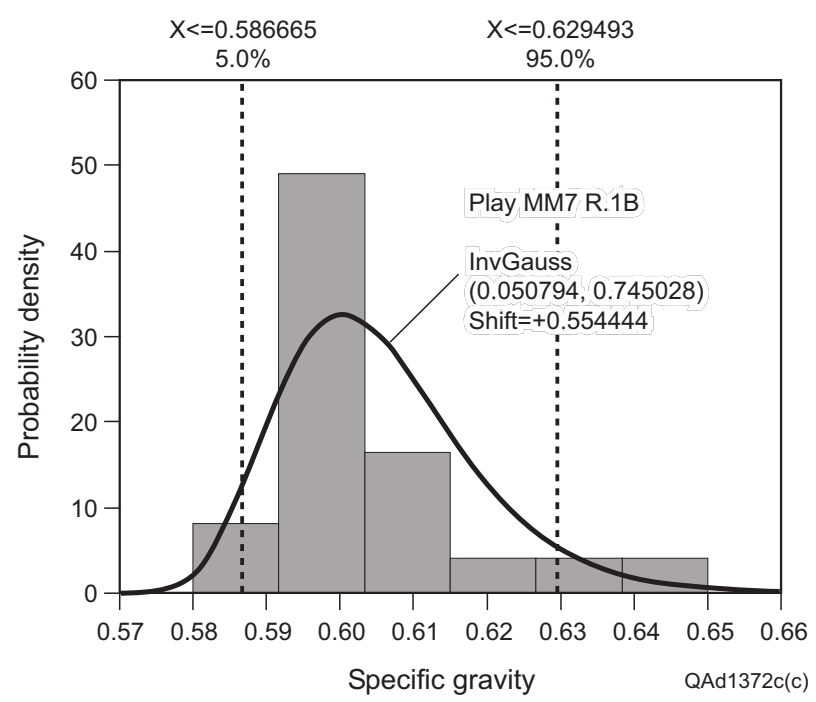

Figure 129. Specific-gas-gravity distribution for play MM7 R.1B.

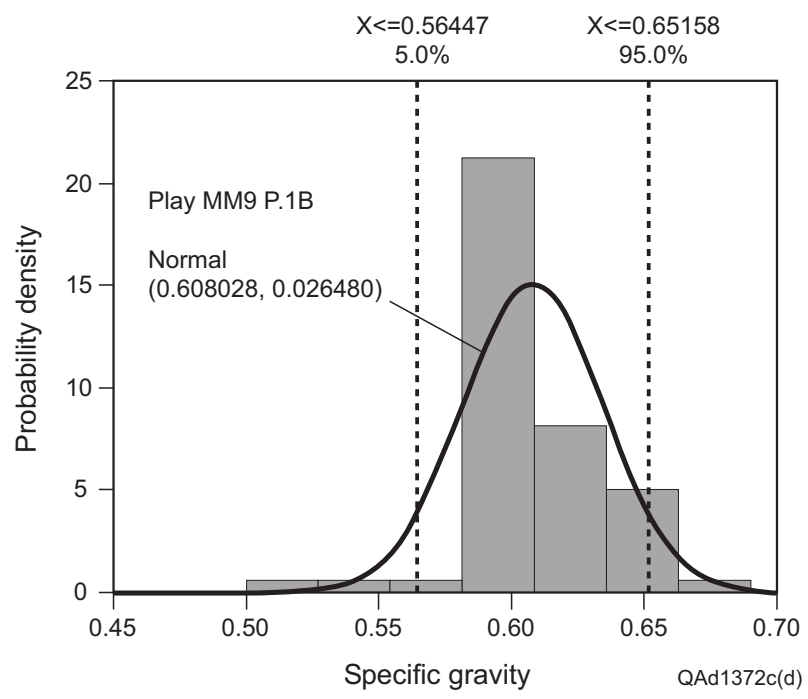

Figure 130. Specific-gas-gravity distribution for play MM9 P.1B. 


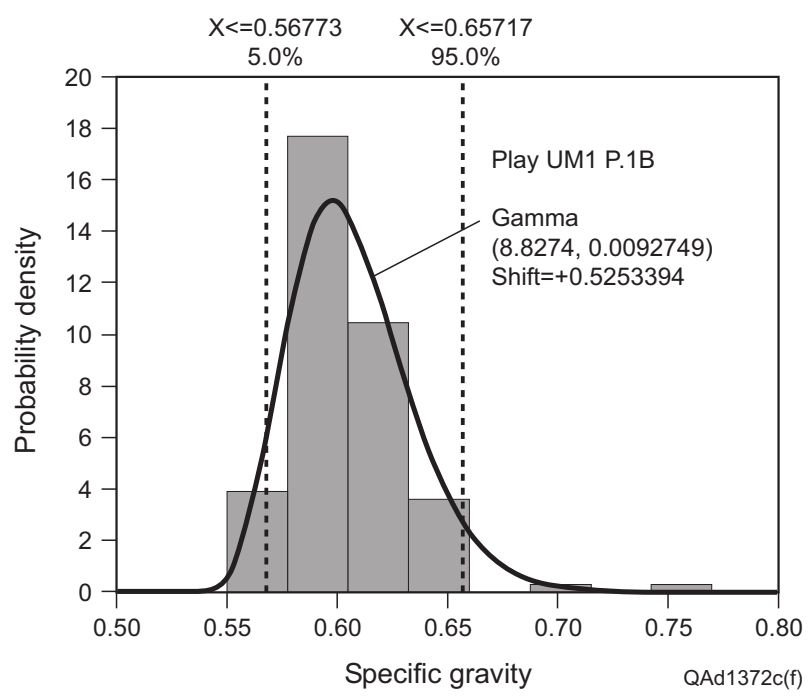

Figure 131. Specific-gas-gravity distribution for play UM1 P.1B.

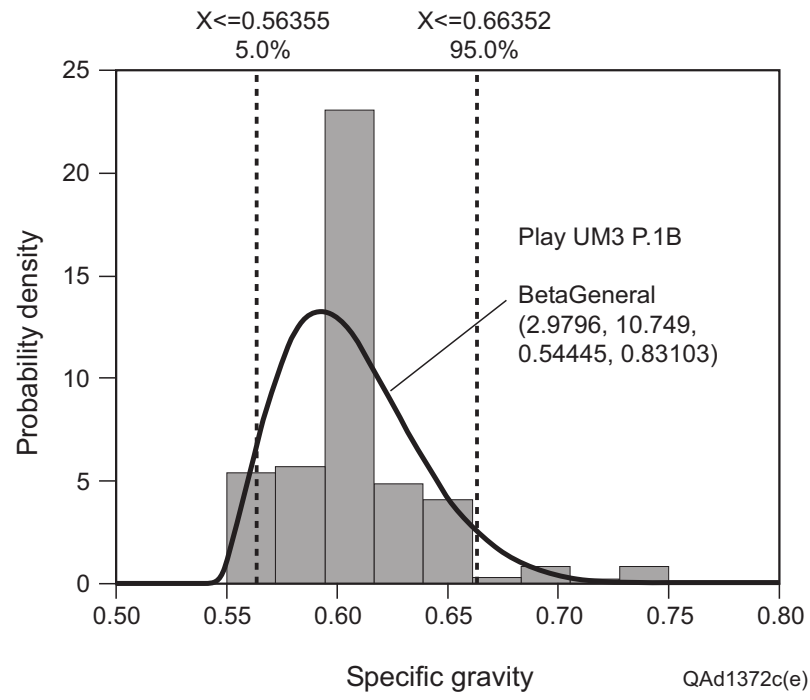

Figure 132. Specific-gas-gravity distribution for play UM3 P.1B. 


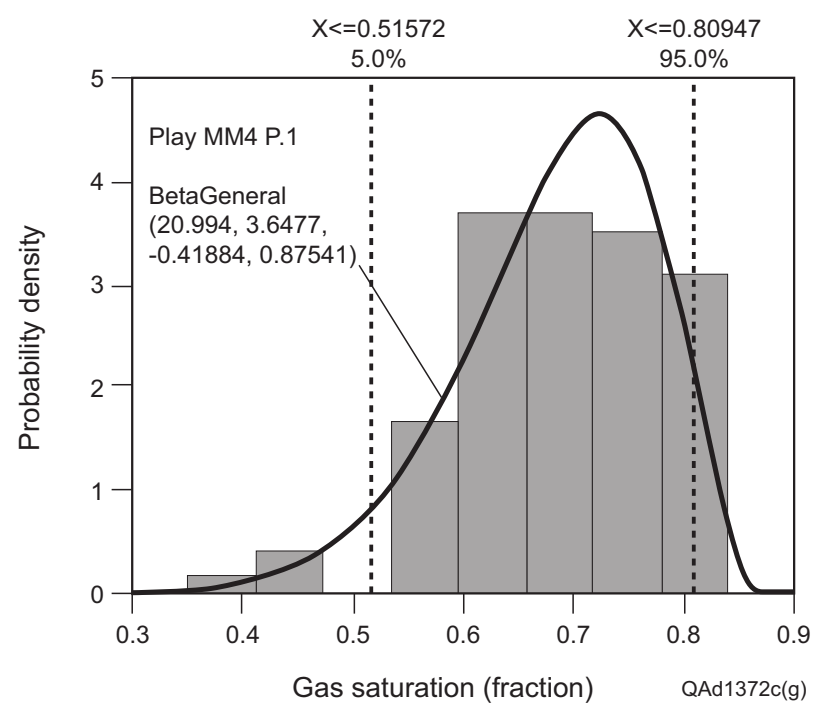

Figure 133. Gas-saturation distribution for play MM4 P.1.

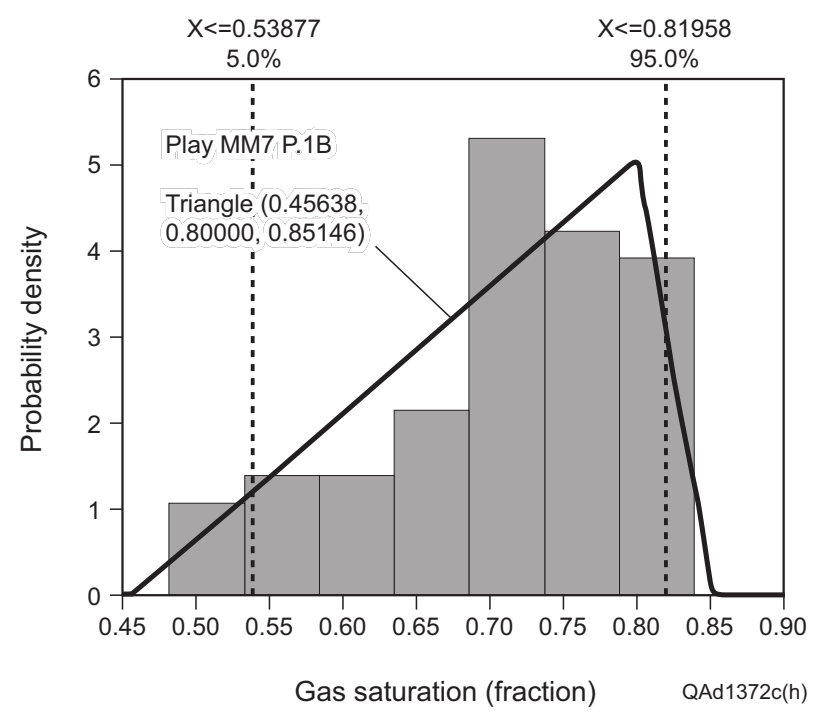

Figure 134. Gas-saturation distribution for play MM7 P.1B. 


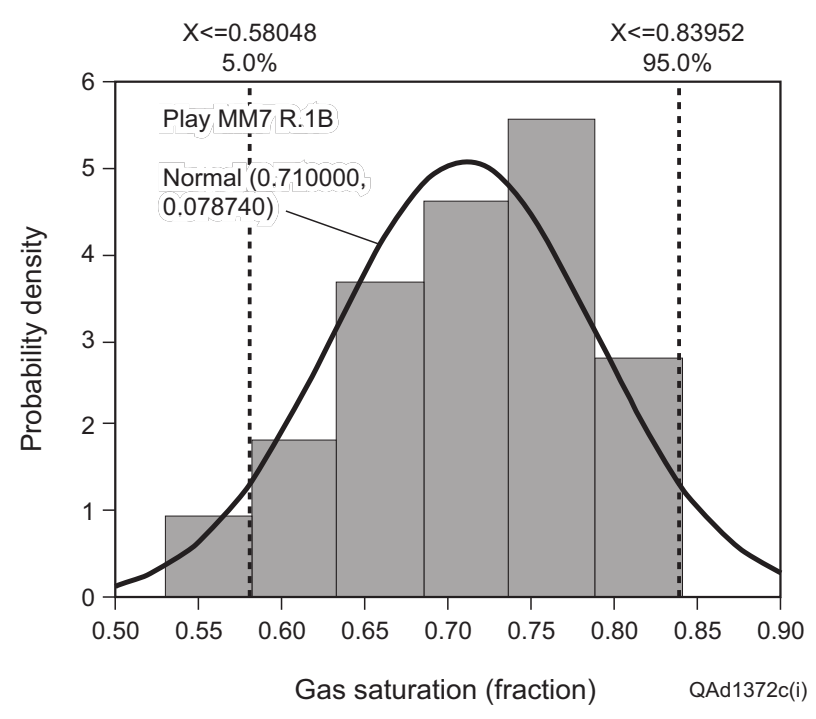

Figure 135. Gas-saturation distribution for play MM7 R.1B.

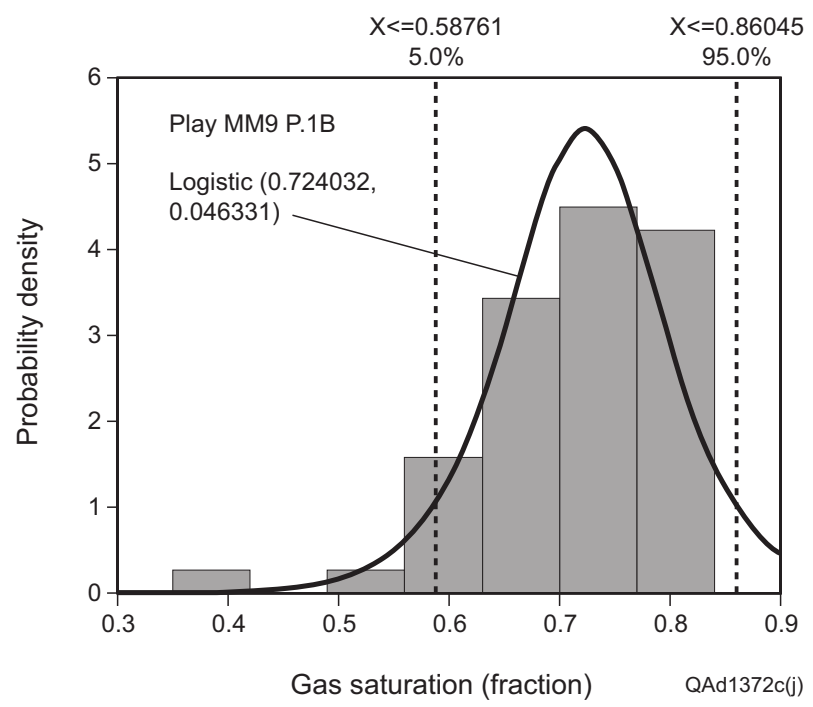

Figure 136. Gas-saturation distribution for play MM9 P.1B. 


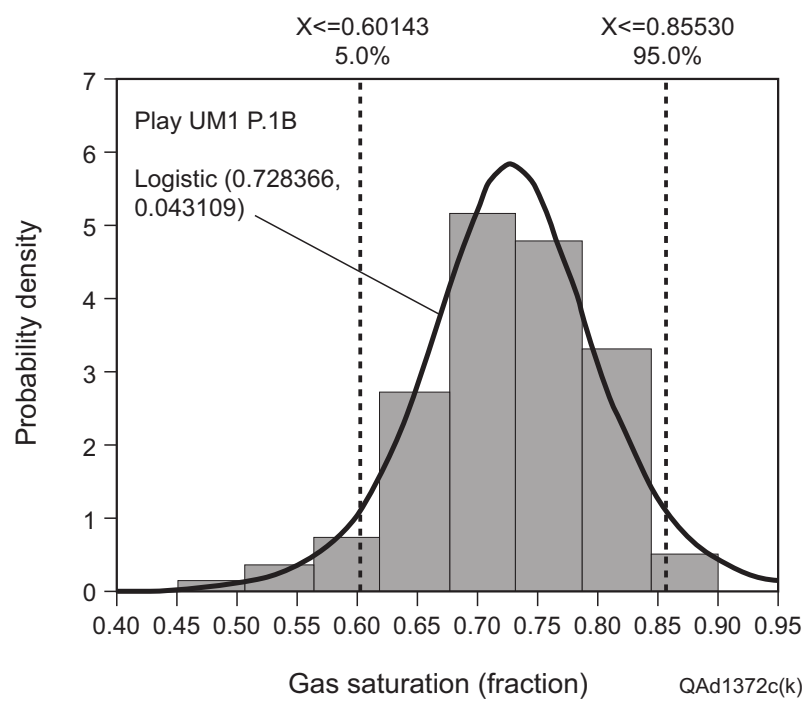

Figure 137. Gas-saturation distribution for play UM1 P.1B.

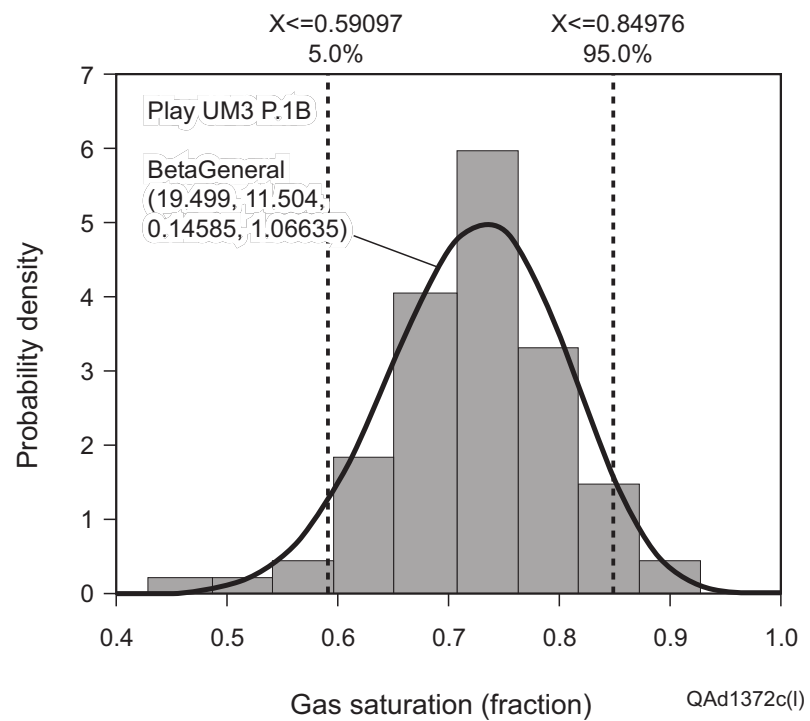

Figure 138. Gas-saturation distribution for play UM3 P.1B. 


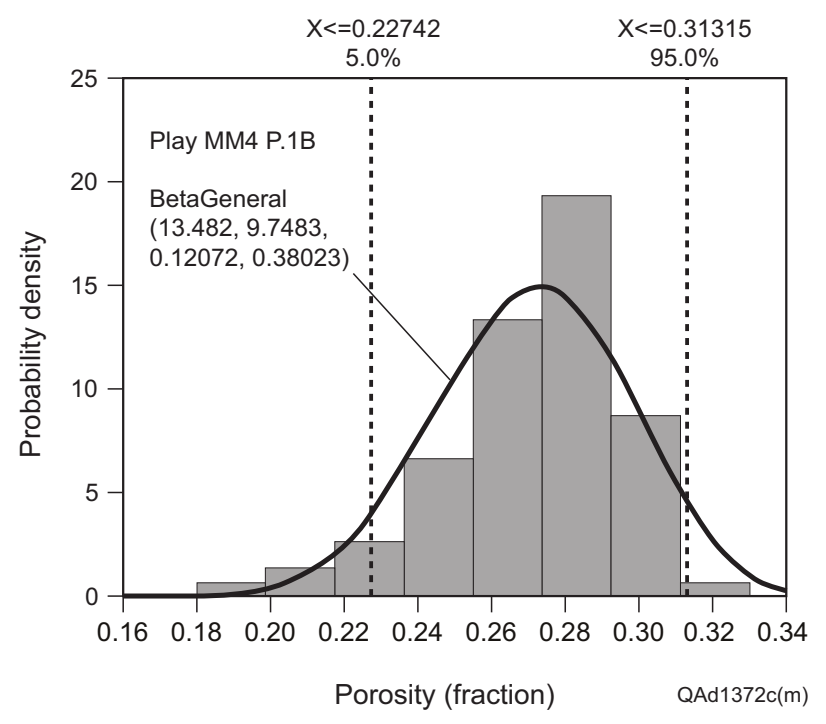

Figure 139. Porosity distribution for play MM4 P.1B.

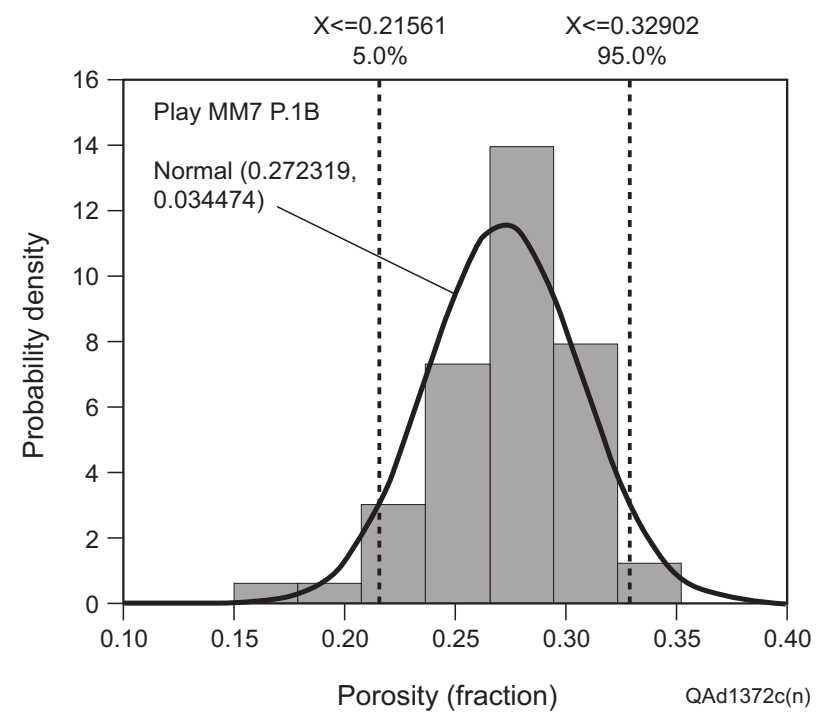

Figure 140. Porosity distribution for play MM7 P.1B. 


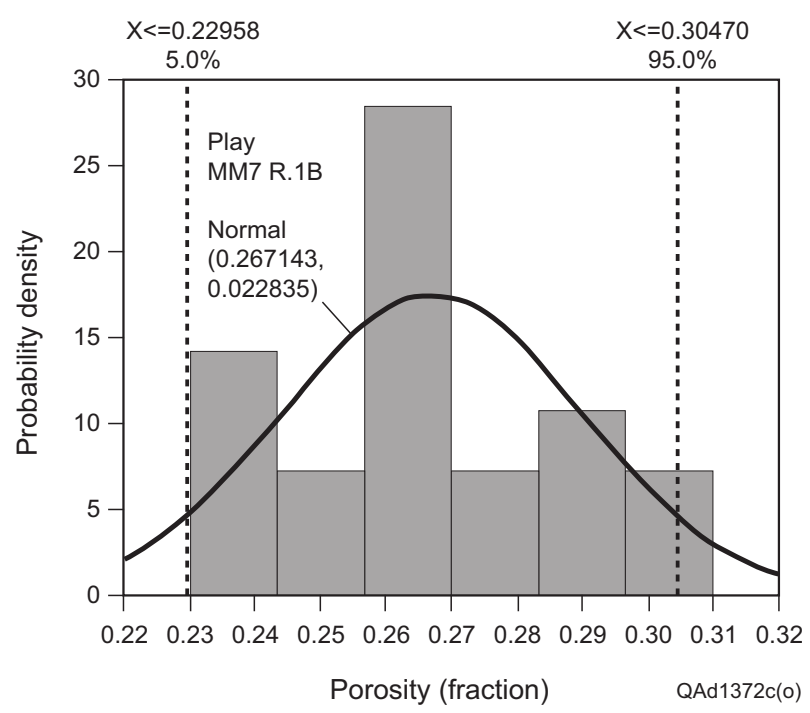

Figure 141. Porosity distribution for play MM7 R.1B.

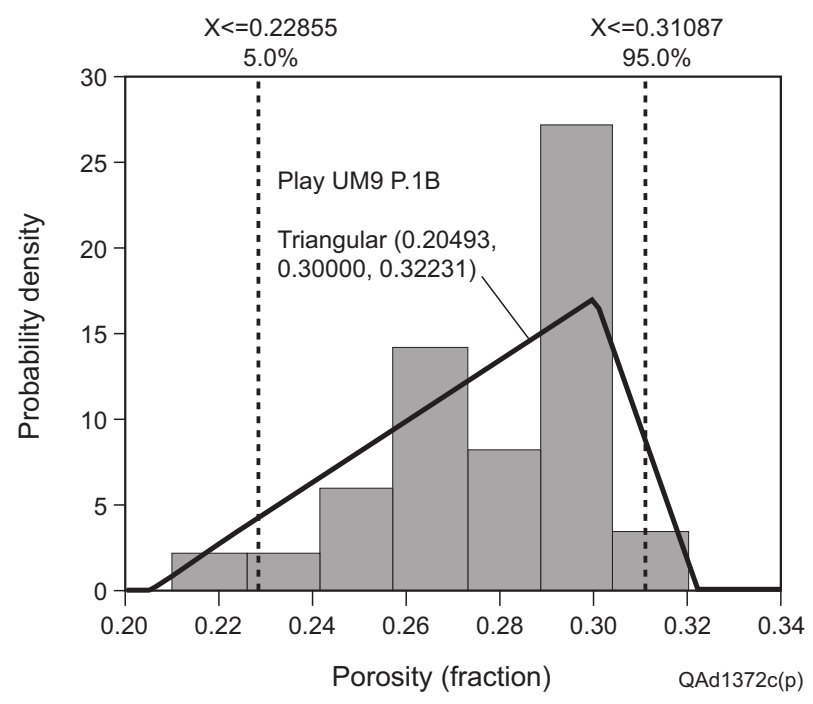

Figure 142. Porosity distribution for play UM9 P.1B. 


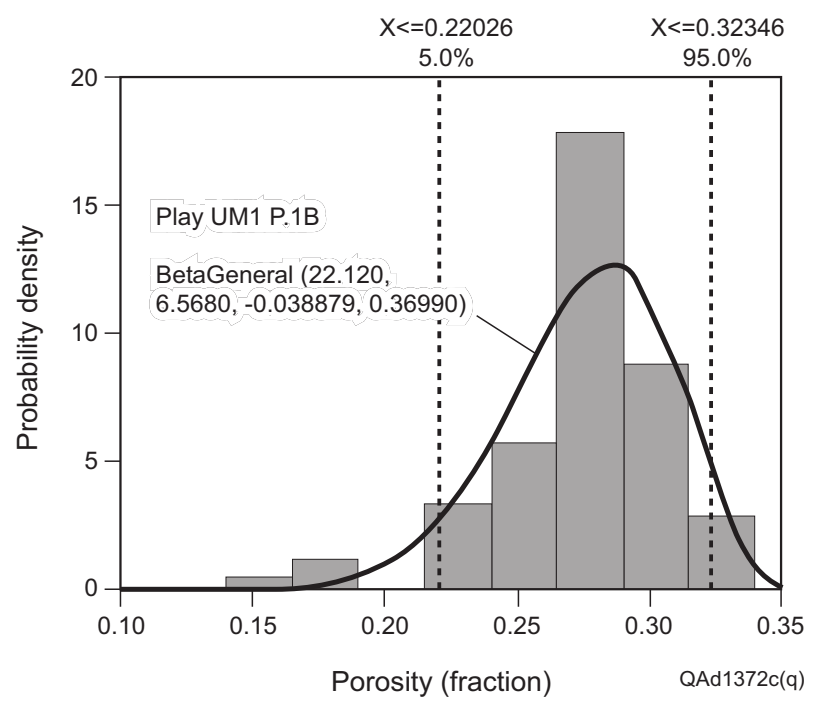

Figure 143. Porosity distribution for play UM1 P.1B.

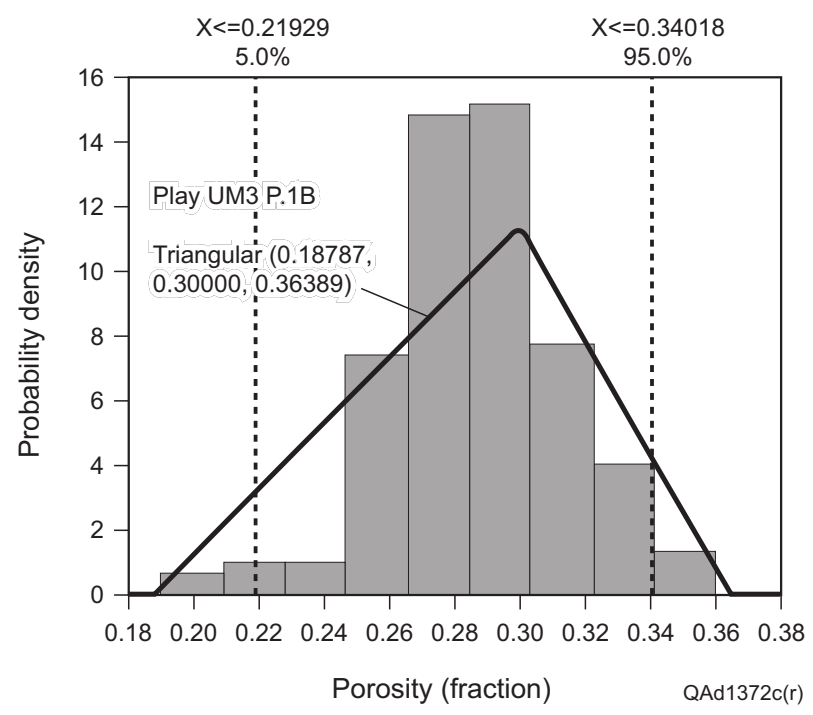

Figure 144. Porosity distribution for play UM3 P.1B. 


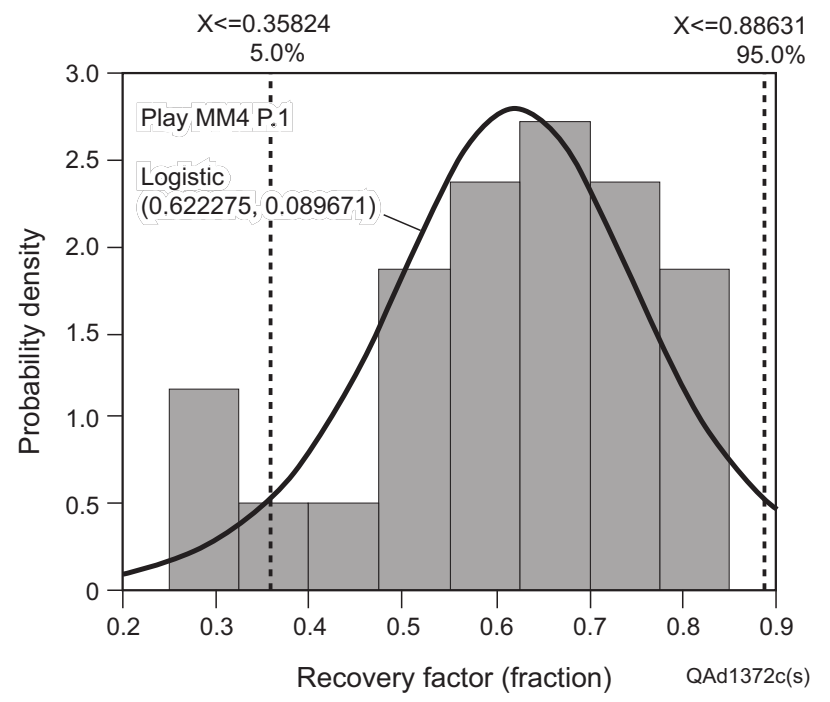

Figure 145. Recovery-factor distribution for play MM4 P.1.

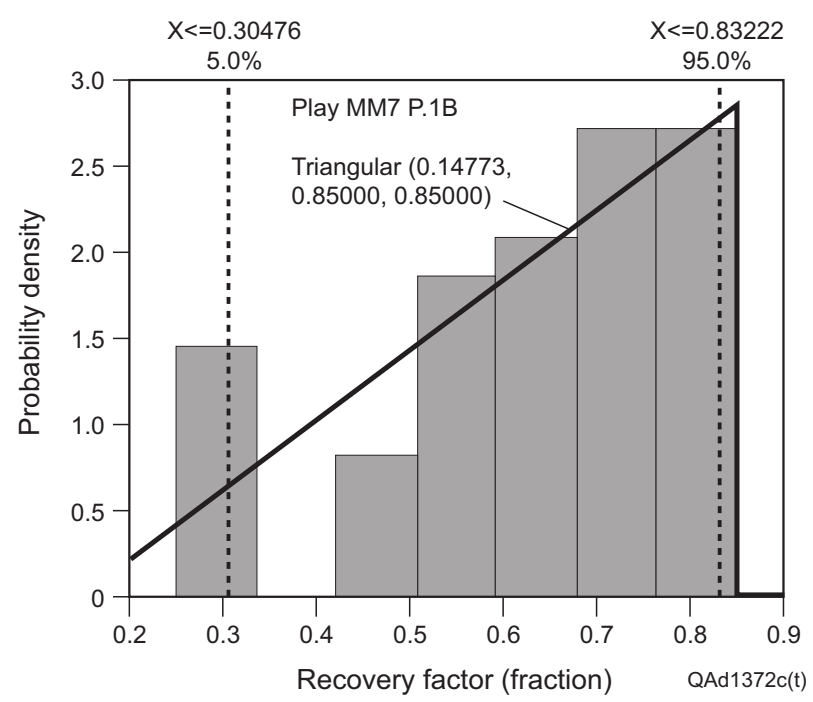

Figure 146. Recovery-factor distribution for play MM7 P.1B. 


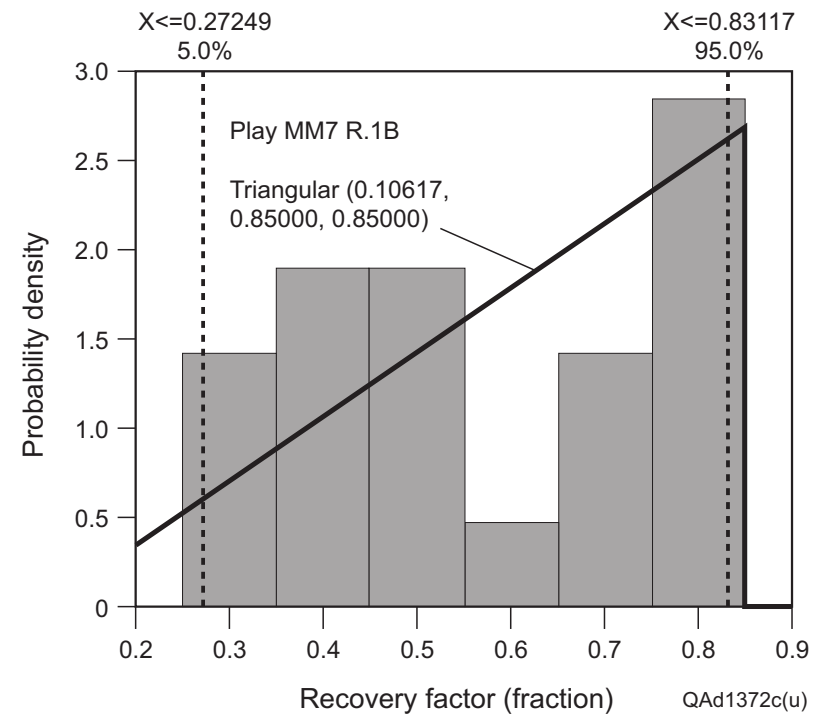

Figure 147. Recovery-factor distribution for play MM7 R.1B.

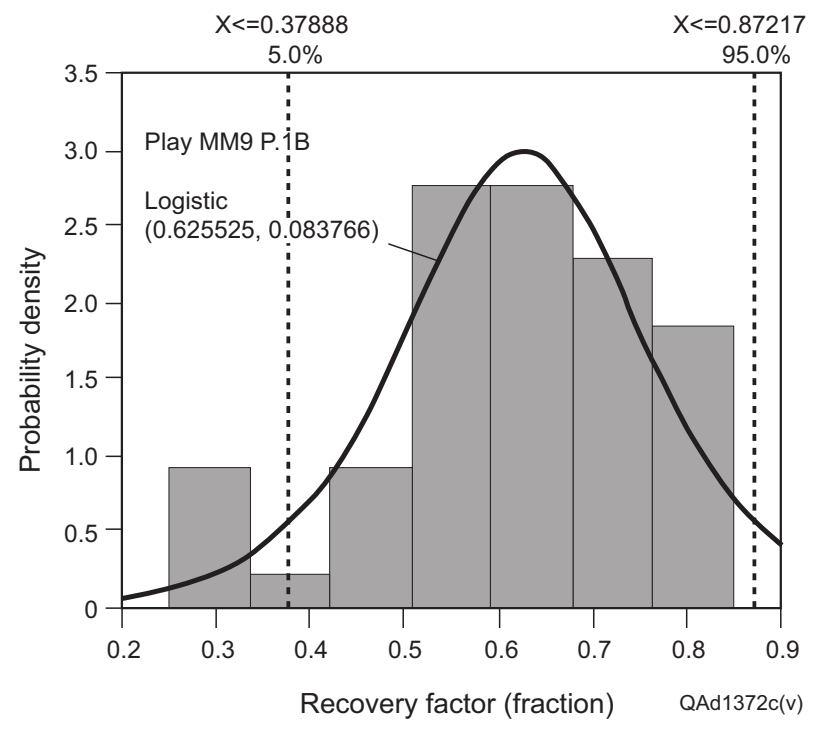

Figure 148. Recovery-factor distribution for play MM9 P.1B. 


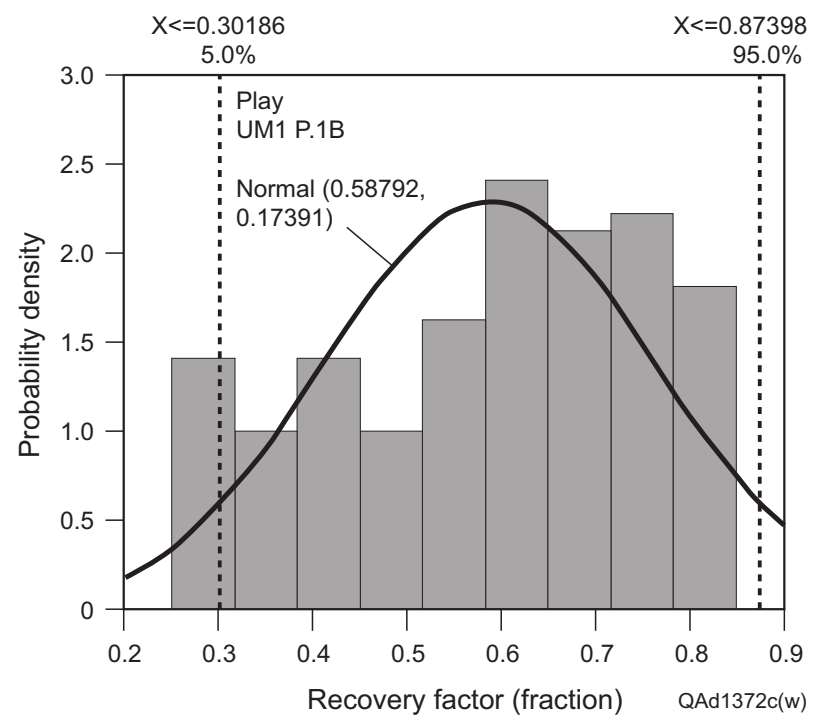

Figure 149. Recovery-factor distribution for play UM1 P.1B.

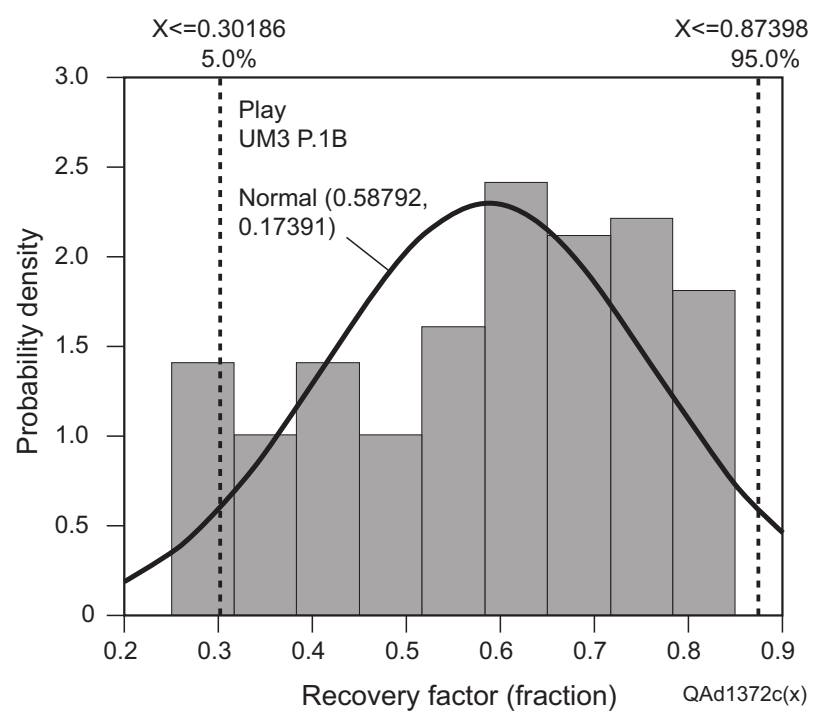

Figure 150. Recovery-factor distribution for play UM3 P.1B. 
Table 15. Truncation values for the volumetric equation.

\begin{tabular}{|l|c|c|}
\hline Variable & Minimum & Maximum \\
& & \\
\hline Temperature $\left({ }^{\circ} \mathrm{F}\right)$ & 100 & 300 \\
\hline Pressure $(\mathrm{psi})$ & 2,000 & 8,000 \\
\hline Gas gravity & 0.5 & 0.75 \\
\hline Gas saturation & 0.35 & 0.90 \\
\hline Porosity & 0.15 & 0.35 \\
\hline Recovery factor & 0.25 & 0.85 \\
\hline Area (acres) & $\mu-10$ percent & $\mu+10$ percent \\
\hline Net pay (ft) & 3 & $\mu+30$ percent \\
\hline
\end{tabular}

Table 16. Summary mean and standard-deviation values for play factors.

\begin{tabular}{|l|c|c|c|c|c|c|c|c|}
\hline & \multicolumn{2}{|c|}{ Porosity } & \multicolumn{2}{c|}{ Gas saturation } & \multicolumn{2}{c|}{ Recovery factor } & \multicolumn{2}{c|}{ Specific gas gravity } \\
\hline & Mean & $\begin{array}{c}\text { Standard } \\
\text { deviation }\end{array}$ & Mean & $\begin{array}{c}\text { Standard } \\
\text { deviation }\end{array}$ & Mean & $\begin{array}{c}\text { Standard } \\
\text { deviation }\end{array}$ & Mean & $\begin{array}{c}\text { Standard } \\
\text { deviation }\end{array}$ \\
\hline MM4 P.1 & 0.272 & 0.026 & 0.684 & 0.091 & 0.610 & 0.159 & 0.603 & 0.030 \\
\hline MM7 P.1B & 0.272 & 0.034 & 0.704 & 0.088 & 0.625 & 0.175 & 0.604 & 0.022 \\
\hline MM7 R.1B & 0.267 & 0.023 & 0.710 & 0.079 & 0.579 & 0.194 & 0.605 & 0.014 \\
\hline MM9 P.1B & 0.279 & 0.024 & 0.715 & 0.090 & 0.617 & 0.151 & 0.608 & 0.026 \\
\hline UM1 P.1B & 0.277 & 0.033 & 0.726 & 0.078 & 0.588 & 0.174 & 0.607 & 0.029 \\
\hline UM3 P.1B & 0.288 & 0.029 & 0.725 & 0.079 & 0.588 & 0.174 & 0.606 & 0.032 \\
\hline Average & $\mathbf{0 . 2 7 6}$ & $\mathbf{0 . 0 2 8}$ & $\mathbf{0 . 7 1 1}$ & $\mathbf{0 . 0 8 4}$ & $\mathbf{0 . 6 0 1}$ & $\mathbf{0 . 1 7 1}$ & $\mathbf{0 . 6 0 6}$ & $\mathbf{0 . 0 2 6}$ \\
\hline
\end{tabular}

Table 17. Summary of the best-fitting probability distributions for reservoir properties by play.

\begin{tabular}{|c|c|c|c|c|c|c|}
\hline Property & MM4 P.1 & $\begin{array}{c}\text { MM7 } \\
\text { R.1B }\end{array}$ & MM7 P.1B & MM9 P.1B & UM 1 P.1B & UM 3 P.1B \\
\hline $\begin{array}{c}\text { Specific gas } \\
\text { gravity }\end{array}$ & Logistic & $\begin{array}{c}\text { Beta } \\
\text { general }\end{array}$ & InvGauss & Normal & Gamma & $\begin{array}{c}\text { Beta } \\
\text { general }\end{array}$ \\
\hline $\begin{array}{c}\text { Gas } \\
\text { saturation }\end{array}$ & $\begin{array}{c}\text { Beta } \\
\text { general }\end{array}$ & Triang. & Normal & Logistic & Logistic & $\begin{array}{c}\text { Beta } \\
\text { general }\end{array}$ \\
\hline Porosity & $\begin{array}{c}\text { Beta } \\
\text { general }\end{array}$ & Normal & Normal & Triang. & $\begin{array}{c}\text { Beta } \\
\text { general }\end{array}$ & Normal \\
\hline $\begin{array}{c}\text { Recovery } \\
\text { factor }\end{array}$ & Triang. & Triang. & Triang. & Logistic & Logistic & Normal \\
\hline
\end{tabular}




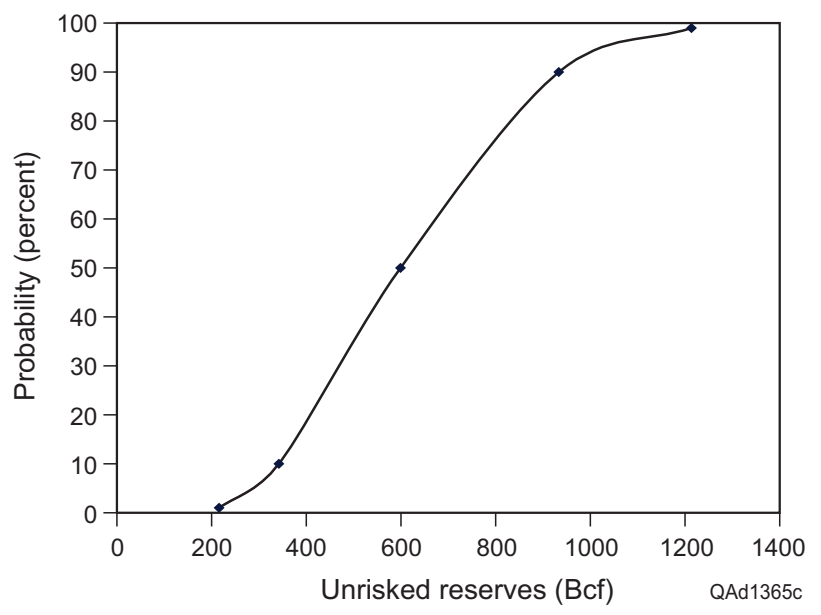

Figure 151. Probability distribution of unrisked reserves displaying a lognormal-like tail.

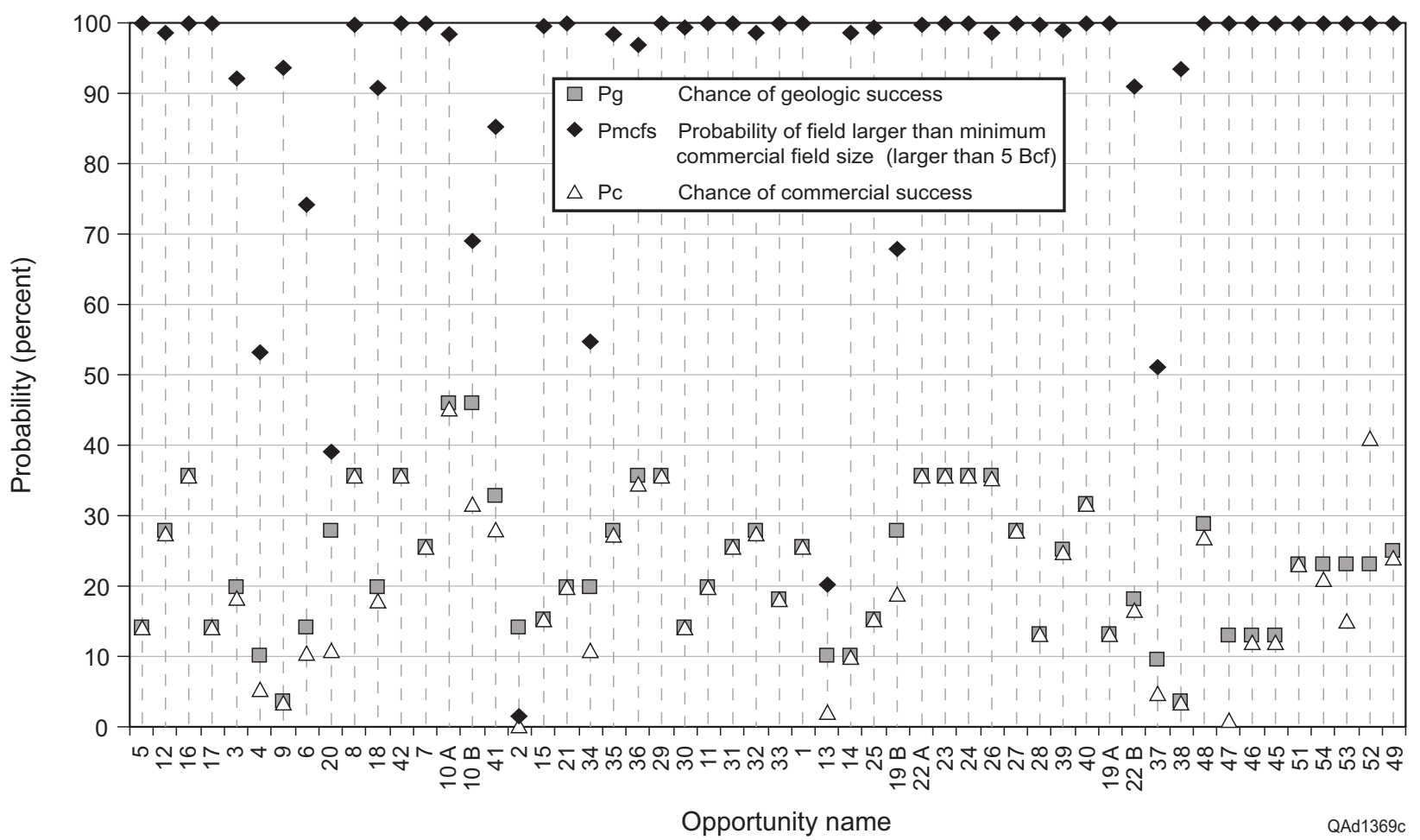

Figure 152. Probability values for geologic chance, minimum commercial field size, and commercial success. 
Table 18. Original gas in place and reserves values for unrisked, geologically risked, and commercial risked reserves.

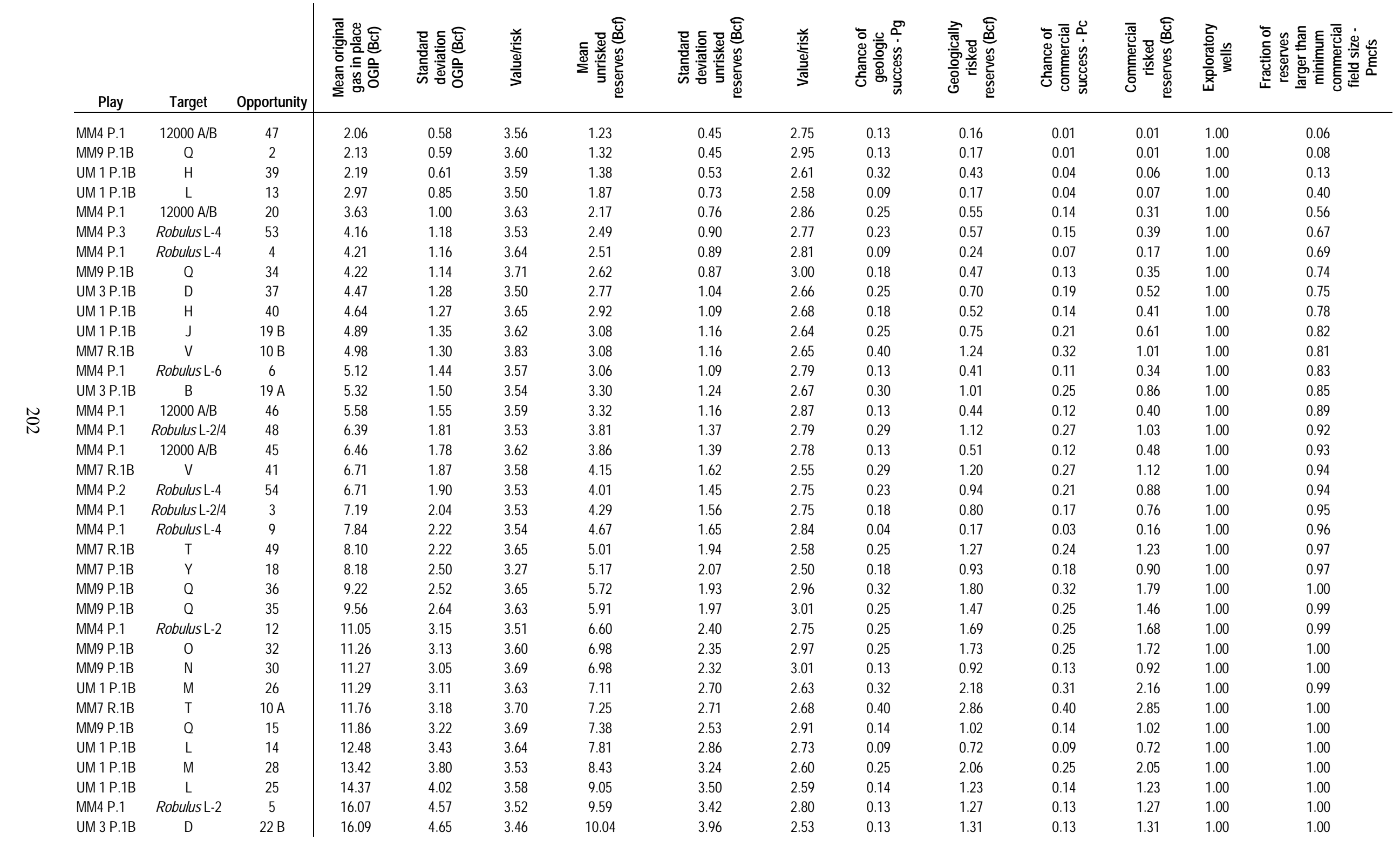




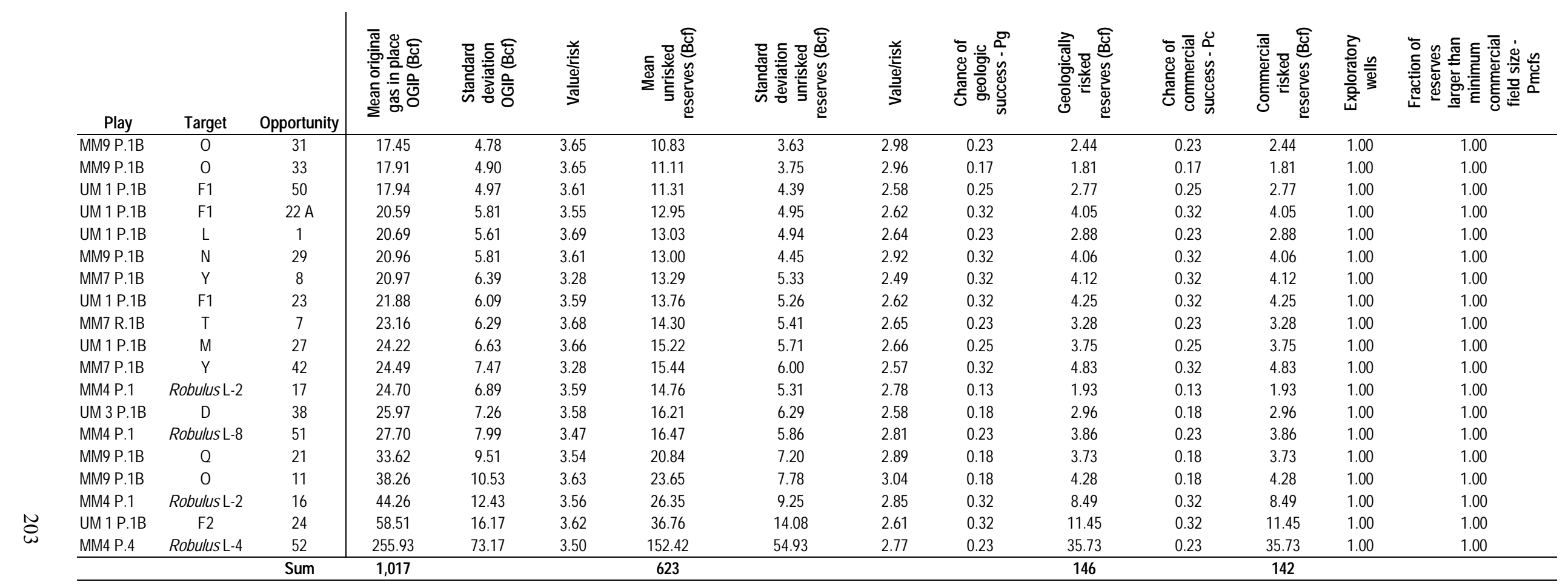




\section{Proved Resource-Addition Opportunities}

The 54 total opportunities identified (DeAngelo and others, 2000; Wood and others, 2001) include rollovers, bright spots terminated against faults, flat spots, untested fault blocks, faulted anticlines, and pure stratigraphic traps. Three of these opportunities have been successfully drilled and tested by Texaco during the term of the project. Drilling of other opportunities from the portfolio is currently being planned by Texaco. The three completed wells involved a stratigraphic trap, structural trap, and a stratigraphic/structural combination trap.

\section{Stratigraphic-Trap Opportunity}

The successful exploration test of a sand-rich, incised-valley, stratigraphic trap opens up an enormous possibility for new reserves in similar stratigraphic features on the Gulf of Mexico shelf. The Miocene deposits beneath the modern Gulf of Mexico (GOM) shelf are an architecturally complex mix of deep-marine slope and basin-floor fan, lowstand prograding-wedge, incised-valley, and associated highstand, distributary, and deltaic deposits. The entire section is rife with opportunity for stratigraphic traps. However, industry management tends to shy away from stratigraphic traps, perceiving too much uncertainty involved in their exploration and exploitation. Yet much potential for gas-resource additions exists in the stratigraphic traps of the GOM shelf.

Through an integrated process of sequence stratigraphy, stratal slicing, and stratal-surface analysis, the team developed several opportunities for Texaco to consider as tests for the viability of smaller incised-valley stratigraphic traps across the study area. Opportunity 50 was chosen as a drill location for Texaco's development program. The lead was initially visible on stratal slices as a low-sinuosity, high-amplitude anomaly composing the F-1 sand in Amber Complex. The anomaly was thought to terminate updip in a fault closure against a firstorder growth fault. However, RMS amplitude mapping was better able to define the internal fill and image a shaly portion of the fill, limiting the updip extent of the reservoir prior to the fault and defining a true stratigraphic trap (fig. 153). Texaco's OCS-G-0310 Well No. 206 was spudded in $17 \mathrm{ft}$ of water to test the stratigraphic trap. The well was optimally located within the high-amplitude portion of this incised, low-sinuosity, seismic geomorphic feature. Well results at the amplitude depth indicate a sharp-based, upward-fining, gamma-ray signature for the F-1 sand, which is interpreted to represent a 50-ft-thick package of basal fluvial fill overlain by an upper portion of estuarine fill (fig. 154). This fill was overlain sharply by high-gamma-ray, sealing shales of the overlying marine flooding event. The upper $21 \mathrm{ft}$ of the F-1 reservoir interval was gas filled, producing 3,500 Mcf/d with no condensate. Volumetrics subsequent to drilling indicate that the reservoir extent is actually limited to the north and west by lithologic pinch-out, suggesting that RMS amplitude maps are an accurate indicator of reservoir extent. Total resources for this stratigraphic trap are calculated by Texaco to be $\mathbf{8}$ Bcf of original gas in place and calculated reserves of 4 Bcf (B. Bergquist, personal communication, 2002). 


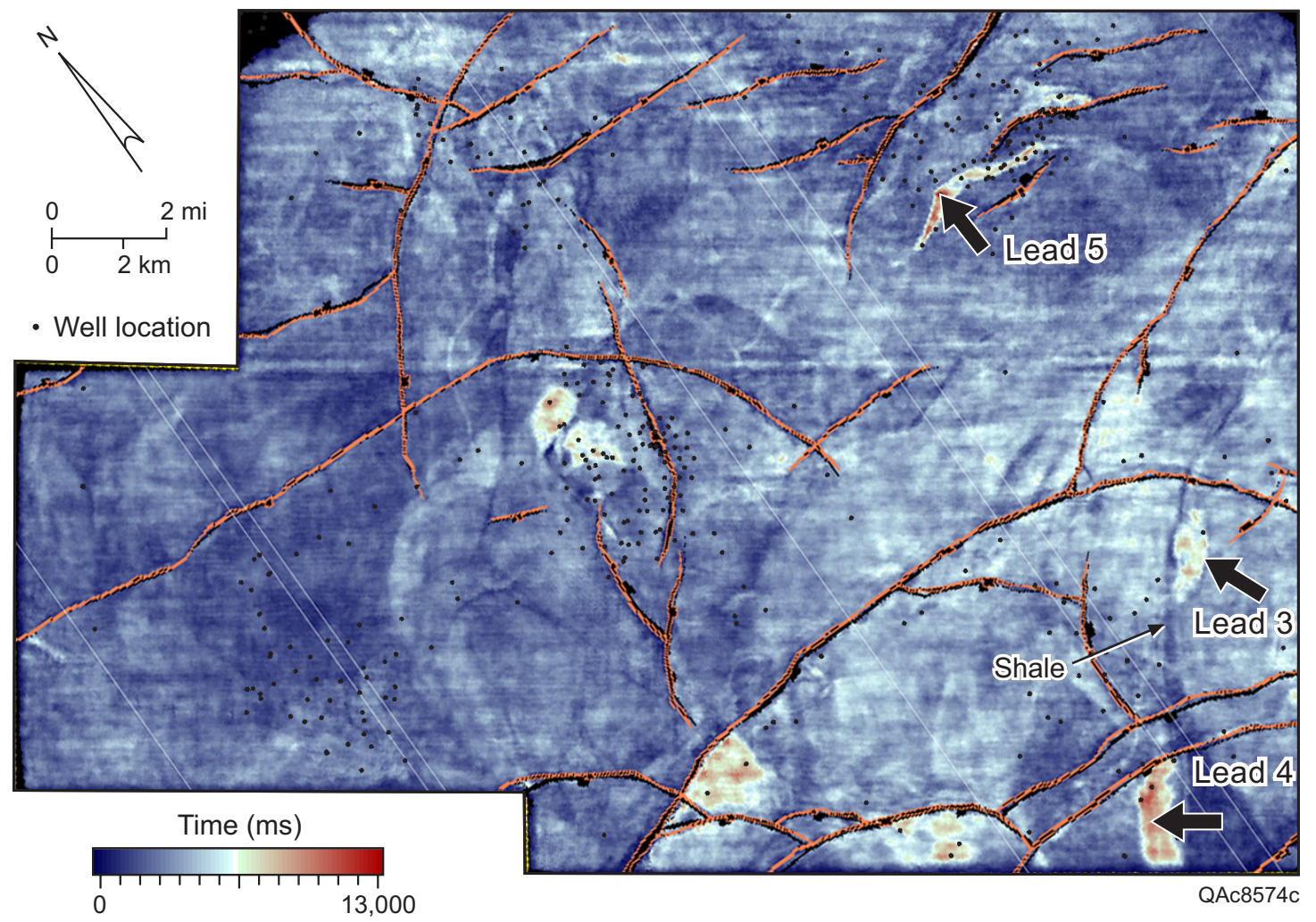

Figure 153. Root-mean-squared (RMS) amplitude map from F-sand interval extracted from 3-D seismic data set over the study area. The thin orange lines are down-to-the-southeast normal faults. Several stratigraphic fluvial- or distributary-channel leads are pointed out, including Opportunity 50 (Lead 3). This accumulation (bright red) is limited on its west side by shaly (dark) facies. 


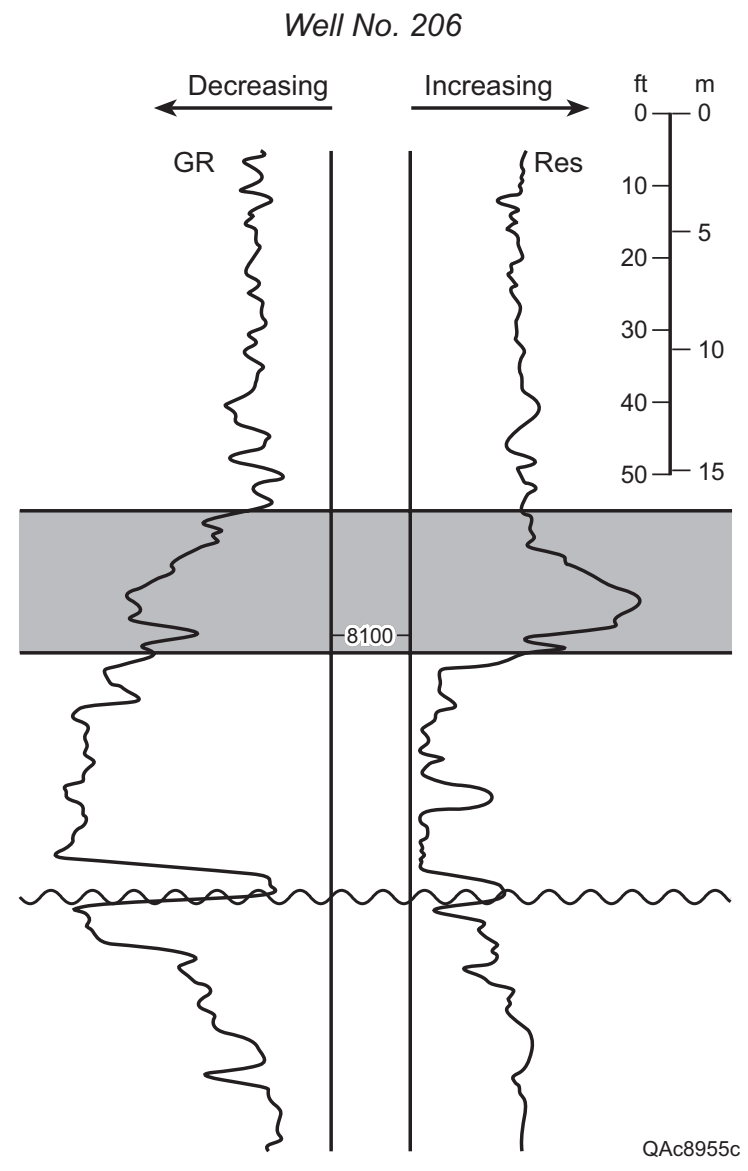

Figure 154. Gamma-ray and resistivity log from well 206 drilled by Texaco in 2001 to test the Opportunity 50 stratigraphic trap. Note the sharp-based upward-fining signature of the stacked channel-fill sandstones (incisedvalley fill) and the high resistivity in the top of the unit denoting gas saturation. 


\section{Structural-Trap Opportunity}

Early in the research design, it was proposed by the research team, in consultation with Texaco, to explore the resource potential that might lie in the structural saddle between the existing four-way structural closures that form exploited Starfak and Tiger Shoal fields. Many such structural saddles occur in the Gulf of Mexico, but management is commonly reluctant to explore for resources away from the structural crests because of uncertainty surrounding migration and trapping in these regional lows. Proving the viability of these saddle-perched opportunities would reduce industry's uncertainty and open up entire new regions for resource exploitation from this play type.

Integrated well log and seismic sequence-stratigraphic analysis provided the key surfaces that enabled the mapping from Starfak, through the structural saddle, and across into Tiger Shoal. Several saddle-perched, brightspot anomalies were identified from the seismic data as being potential targets for testing this play type. Opportunity 8 was one such opportunity, characterized by high amplitudes truncating against a northbounding, first-order normal fault (figs. 155, 156). It was predicted, on the basis of the sequence-stratigraphic framework integrated with seismic geomorphologic interpretation, that the area probably had experienced a significant development of third-order lowstand deposits of the Y sand interval (third-order Sequence 8). However, the location of the opportunity was clearly within the structural saddle (low) between the producing fields (fig. 155).

Texaco spudded a well to test the viability of this saddle-perched trap. Four predicted target-sand zones were found, about $75 \mathbf{f t}$ of total potential pay. These sands are (in ascending order) the $12000 \mathrm{~A}$ and B sands, the Y sand, and the X-1 sand. The 12000 A and B sands fall within the third-order LST of Sequence 9, and X-1 and Y sands are in the Sequence 8 LST. The Y sand is a thick ( 180-ft), fourth-order, incised-valley fill; the X-1 sand caps a fourth-order HST; and the $12000 \mathrm{~A}$ and B sands are fourth-order incised-valley fills and prograding wedges. The Y and X-1 sands were successfully completed; however, the deeper two sands were not productive. The $12000 \mathrm{~B}$ sand flowed gas far a short time, but it was found to be sitting on top of a large water column that quickly flooded the reservoir. The next sand, $12000 \mathrm{~A}$, did not flow at all.

Total resources for this stratigraphic trap are calculated by Texaco to be $3 \mathrm{Bcf}$ of original gas in place ( 2 Bcf from the $Y$ sand, 1 Bcf from the $X-1$ sand) and calculated reserves of $1.5 \mathrm{Bcf}(1 \mathrm{Bcf}$ from the $\mathrm{Y}$ sand, 0.5 Bcf from the X-1 sand) (B. Bergquist, personal communication, 2002). Through the success of this well, numerous saddle-perched traps can now be proposed for resource additions across this area and more regionally throughout the shelf province.

\section{Combination-Trap Opportunity}

Opportunity 29, a combination structural/stratigraphic trap, targets the $\mathbf{N}$ sand in Mound Point field (fig. 5). It is characterized by a three-way closure, with high amplitudes truncating against a west-bounding (sealing) first-order fault. Although the area has been heavily exploited, the RMS amplitude map (fig. 157) clearly shows that a significant sweet spot that had been bypassed. 


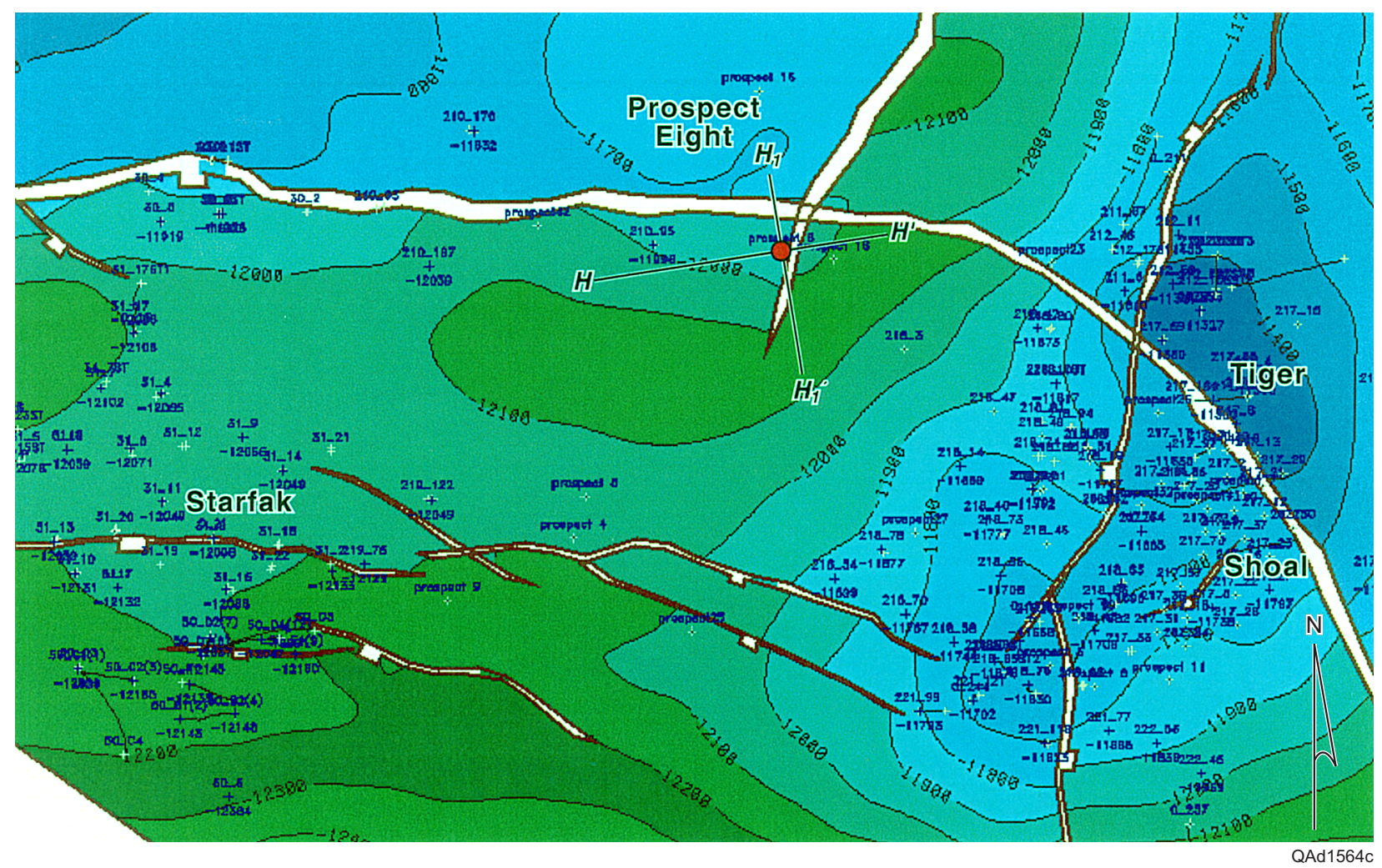

Figure 155. Depth-structure map of MFS 42, showing location of Opportunity 8 within the structural saddle between Starfak and Tiger Shoal fields. This opportunity type is typical of thousands of similar traps in the shelfal, betweenfield areas of the Gulf of Mexico. 


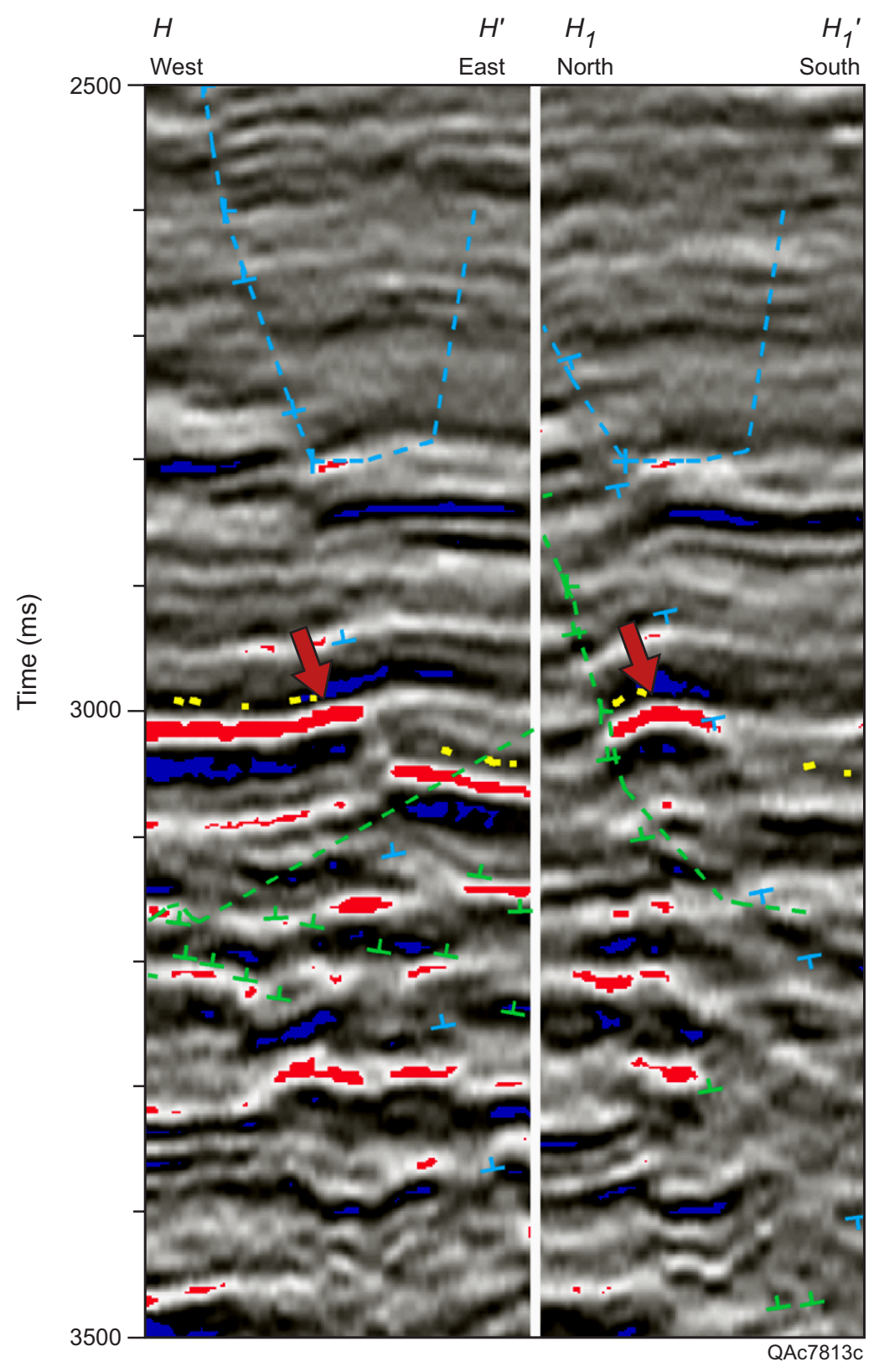

Figure 156. Two arbitrary seismic lines, $\mathrm{H}-\mathrm{H}^{\prime}$ and $\mathrm{H}_{1}-\mathrm{H}_{1}{ }^{\prime}$, through the Opportunity 8 structural closure, showing the high-amplitude anomaly associated with the target. Location of seismic line shown in figure 155. 


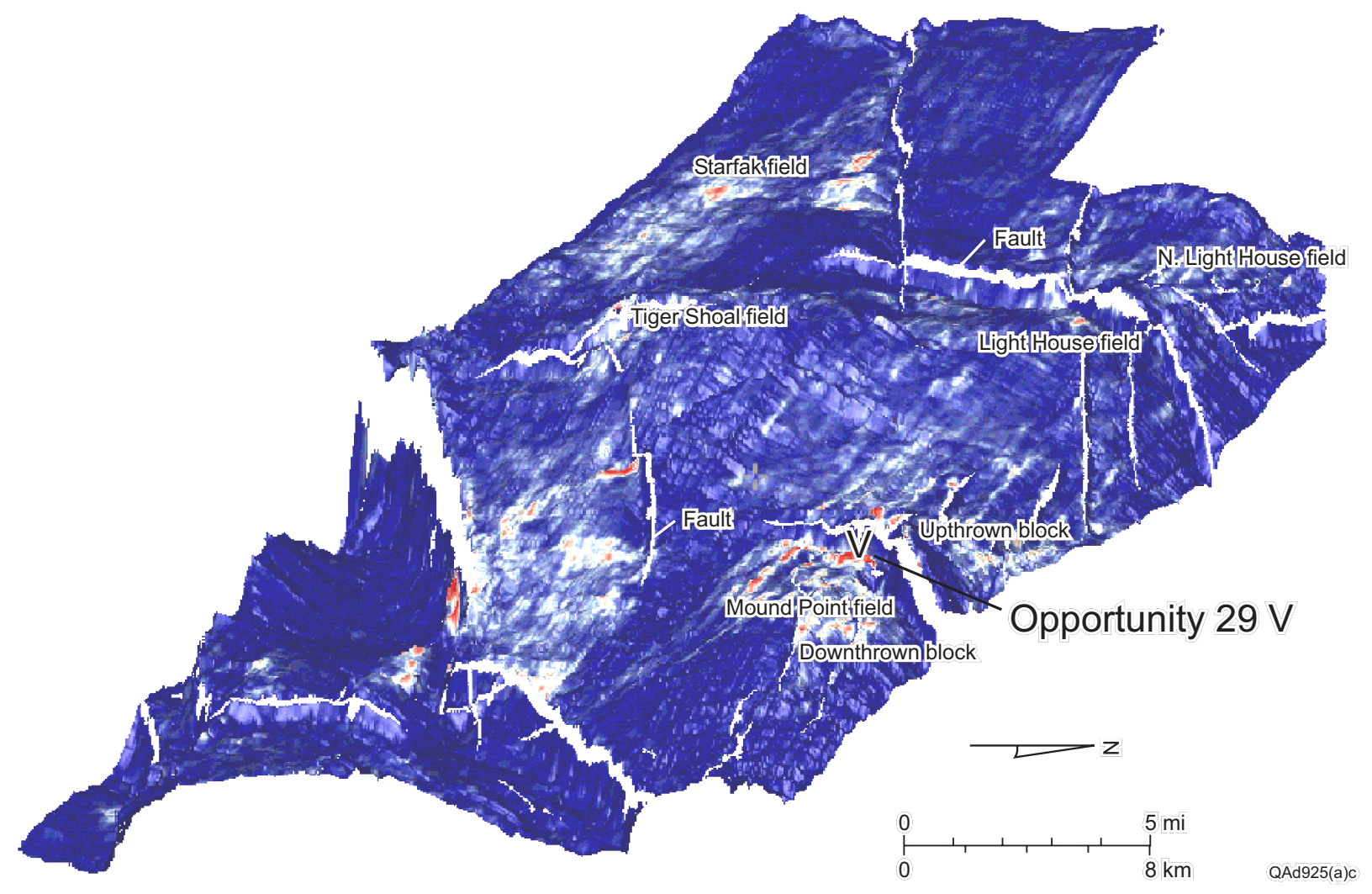

Figure 157. A 3-D RMS amplitude map of the N-sand reservoir interval (Opportunity 29). High amplitude (red) depicts sandstone-prone areas. Note the sandy area on the downthrown side of Mound Point field characterized by a topographic high (three-way closure) flanked on the west by a major normal growth fault. 
Texaco spudded a well to test the viability of the Opportunity 29 combination trap. The predicted target-sand zone (N sand) was found, containing gas in $\sim 32 \mathbf{f t}$ of pay. The N sand is in the Sequence 5 LST and forms a fourth-order incised-valley fill. Total resources for this stratigraphic trap are calculated by Texaco to be 5.5 Bcf of original gas in place and calculated reserves of $\mathbf{3} \mathbf{B c f}$ (B. Bergquist, personal communication, 2002).

\section{Deep-Reserve Opportunities}

Deep gas provides the most promise for stemming the decline in gas reserves across the Gulf of Mexico region. The Minerals Management Service (2001) estimates that there could be 5 to 20 Tcf, with the most likely value at 10.5 Tcf of deep-gas recoverable resources located below 15,000 ft stratal depth on the U.S. Gulf of Mexico shelf. To date, industry has drilled only 140 wells to a depth between 18,000 and 20,000 ft on the shelf. In 2000-2001, 15 successful discovery wells were drilled below 15,000 ft in the Gulf of Mexico that resulted in nearly 1 Tcf of gas resources discovered. Only three of those wells had resources of greater than $100 \mathrm{Bcf}$, with the largest being a 200-Bcf well drilled by Spinnaker in the High Island Block.

The current success of completing such wells has been only 4 percent $(\mathrm{W}$. Rosenbusch, written communication, 2000). Higher drilling costs dictate that for deep wells to be successful they must penetrate larger structures with reservoirs that have higher flow rates. Much of the projected higher drilling cost in tapping into this deep resource lies in the anticipation of problems associated with high geopressure at depth. The northern Gulf of Mexico has numerous deep-reservoir fluid compartments that are overpressured (below geopressure), typically characterized by a pressure gradient that exceeds $0.5 \mathrm{psi} / \mathrm{ft}$. Such overpressured conditions in the reservoir have a significant impact on diagenesis of the reservoir rocks, production characteristics of the units, seal qualities, seismic data interpretation, $\log$ quality, and the overall economics of drilling and production. These compartments are formed when rapid deposition of sediments overtakes the ability of in situ fluids to escape, effectively trapping the fluids that in turn act to support the surrounding rock matrix. Geopressured formations can be extremely hazardous when abnormally high fluid pressures invade the borehole unexpectedly, potentially leading to loss of control of the drilling process. These transition zones are identifiable on sonic and density logs as a distinct decrease in velocity and rock matrix density, respectively. Within the transition zone itself density and velocity are relatively stable. The characteristics associated with geopressured formations make it possible to map these transition zones using seismic data. A variety of seismic attributes can be applied for trying to map the sudden change in acoustic impedance (density $\times$ velocity) at the top of geopressure, which is characterized by strong amplitudes and the associated "passive" reflectivity expected within the zone of geopressure.

A significant section of middle-to-late Miocene deep-marine facies is present across the current OSGR study area, but these strata are penetrated by relatively few wells. As part of the complete evaluation of resource addition targets across the study areas, the resource potential and trapping mechanisms for gas in these deep (below 15,000 ft subsea) sections were looked at. Table 14 shows several identified targets for resource additions in this section. Seni and others (1997) defined no plays for the lower Miocene through this interval, even though many of the recent exploration efforts have been concentrated in those deep (>15,000-ft) strata. Data from the Minerals Management Service (2001) show that an estimated 10.5 Tcf of deep-gas recoverable reserves may be regionally associated 
with this interval. Across the study area, large, deep structures exist below 3.0 s. First-order normal faults that help form closure on the shallow, large Starfak and Tiger Shoal fields are deep seated. Secondary fault swarms form multiple deep fault traps and untested fault blocks (figs. 158, 159). Reservoir facies within the central planning

area are middle-to-upper Miocene deep-marine fan and slope deposits. A critical issue to productivity in these deep traps is the quality of reservoirs sands below $15,000 \mathrm{ft}$.

\section{Reservoir Quality of the Deep Robulus "L" Sandstones}

Because only 5 percent of all wells drilled on the Gulf of Mexico shelf have penetrated strata below 15,000 ft (Minerals Management Service, 2001), lower Miocene sandstones deeper than 15,000 ft are likely to be targets of increased future exploration. As part of this project, the reservoir quality of the deep $(\mathbf{1 4 , 2 0 0 - 1 5 , 0 0 0 ~} \mathrm{ft})$ Robulus " $L$ " reservoir sandstones in the study area was examined to assess the production possibilities in this virtually unexplored zone (Dutton and Hentz, in press). Significantly, among all of the project's 54 opportunities, the Robulus "L" sandstones contain 41 percent of total OGIP (421Bcf), 40 percent of unrisked reserves (251 Bcf), and 39 percent of risked reserves ( $57 \mathbf{~ B c f ) ~ ( t a b l e ~ 1 8 ) . ~ T h u s , ~ e v e n ~ i n ~ t h e ~ s m a l l ~ p o r t i o n ~ o f ~ t h e ~ G u l f ~ o f ~ M e x i c o ~ s h e l f ~}$ that constitutes the study area, these deep targets show high potential for significant reserve additions.

Our study focused on the petrography of productive Robulus L-2 and L-5 sandstones that compose the upper part of distal third-order Sequence 10 (see section "Distal Sequences [SB 10 to SB 8]" earlier) (fig. 160). These two fourth-order prograding-wedge sandstones occur from depths of 14,292 to 14,910 ft in Starfak field. Although no whole cores taken from Starfak or Tiger Shoal fields could be located, thin sections from whole cores from Starfak wells 31-6 and 31-7 used by McBride and others (1988) for their investigation of petrography, stable isotope geochemistry, and diagenesis of Miocene sandstones could be obtained. Core descriptions and photographs were available for the 31-6 well from the operator and from published reports (Hart and others, 1984; Ferrell and Drew, 1985; Lowe and Dickerson, 1985; Hart and others, 1989). For this study, thin sections that sampled the Robulus L-2 sandstone in well 31-6 (sample from depths of 14,292-14,359 ft) and the Robulus L-5 sandstone in wells 31-6 (14,770-14,851 ft) and 31-7 (14,886-14,910 ft) (fig. 161) were used.

Composition of the sandstones was determined by standard thin-section petrography of 27 samples. Thin sections were stained for feldspars (both plagioclase and potassium feldspars) and carbonates, and a total of 200 points were counted on each thin section. Porosity and permeability values from laboratory analyses of 224 plugs collected from whole core provided additional information about reservoir quality.

The Robulus L-2 and L-5 sandstones occur within an interval of upward-coarsening, progradational shale-andsandstone units of the distal third-order LST in Sequence 10 (fig. 160) (Hentz and Zeng, in press). Thin retrogradational sections overlie these progradational units. The progradational/retrogradational pairs stack to form a progradational set (lowstand prograding complex) characterized by an upward trend of coarsening sandstones (fig. 160, 14,200-14,930 ft in the Texaco No. 3 well). 


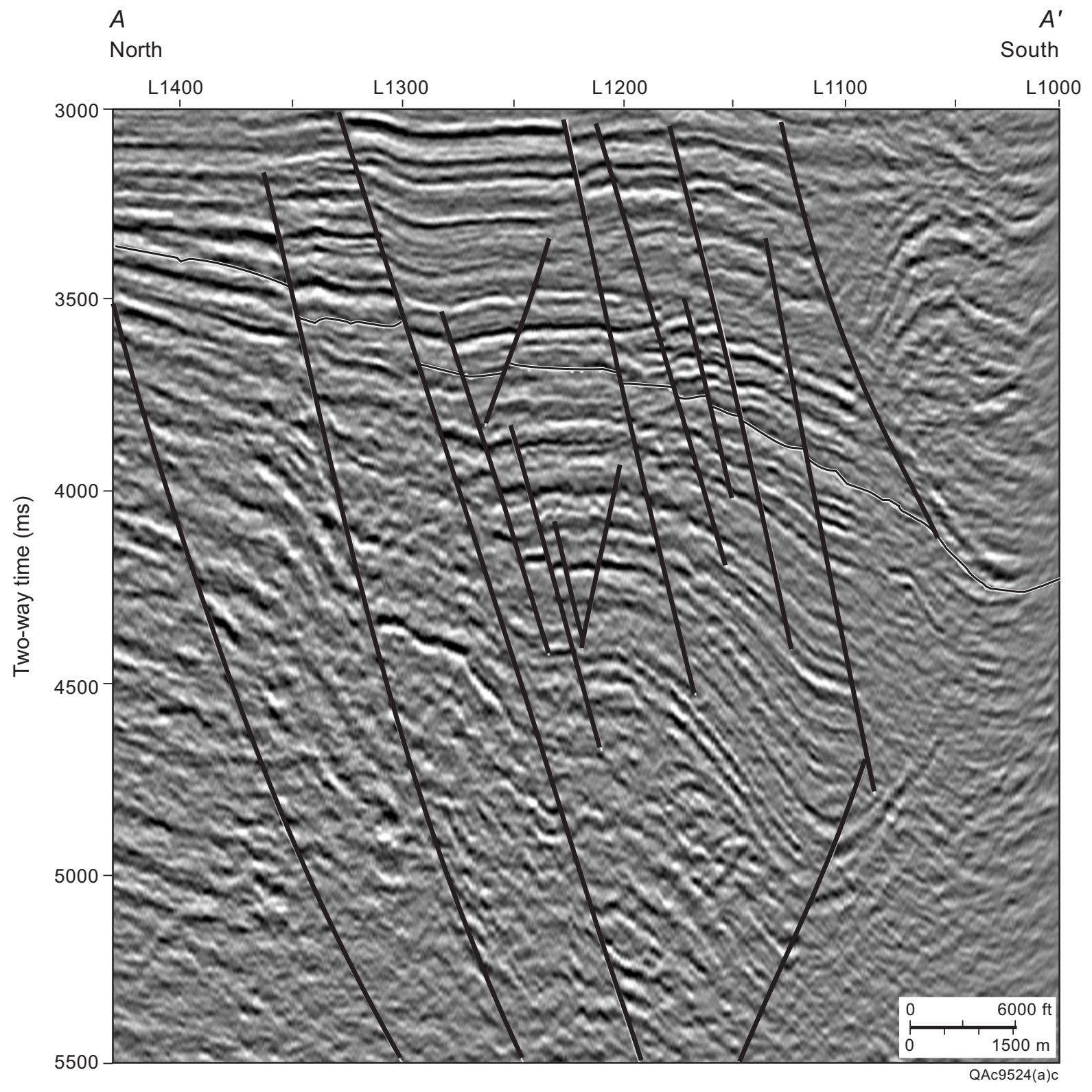

Figure 158. Seismic line that illustrates structural nature of the section below 3.0 seconds (below $\sim 15,000 \mathrm{ft}$ subsea). Several large deep structural closures exist. Reservoir facies are middle to upper Miocene deep-marine fan and slope deposits. The black horizon represents the approximate top of overpressure. Line of section shown in figure 159. 


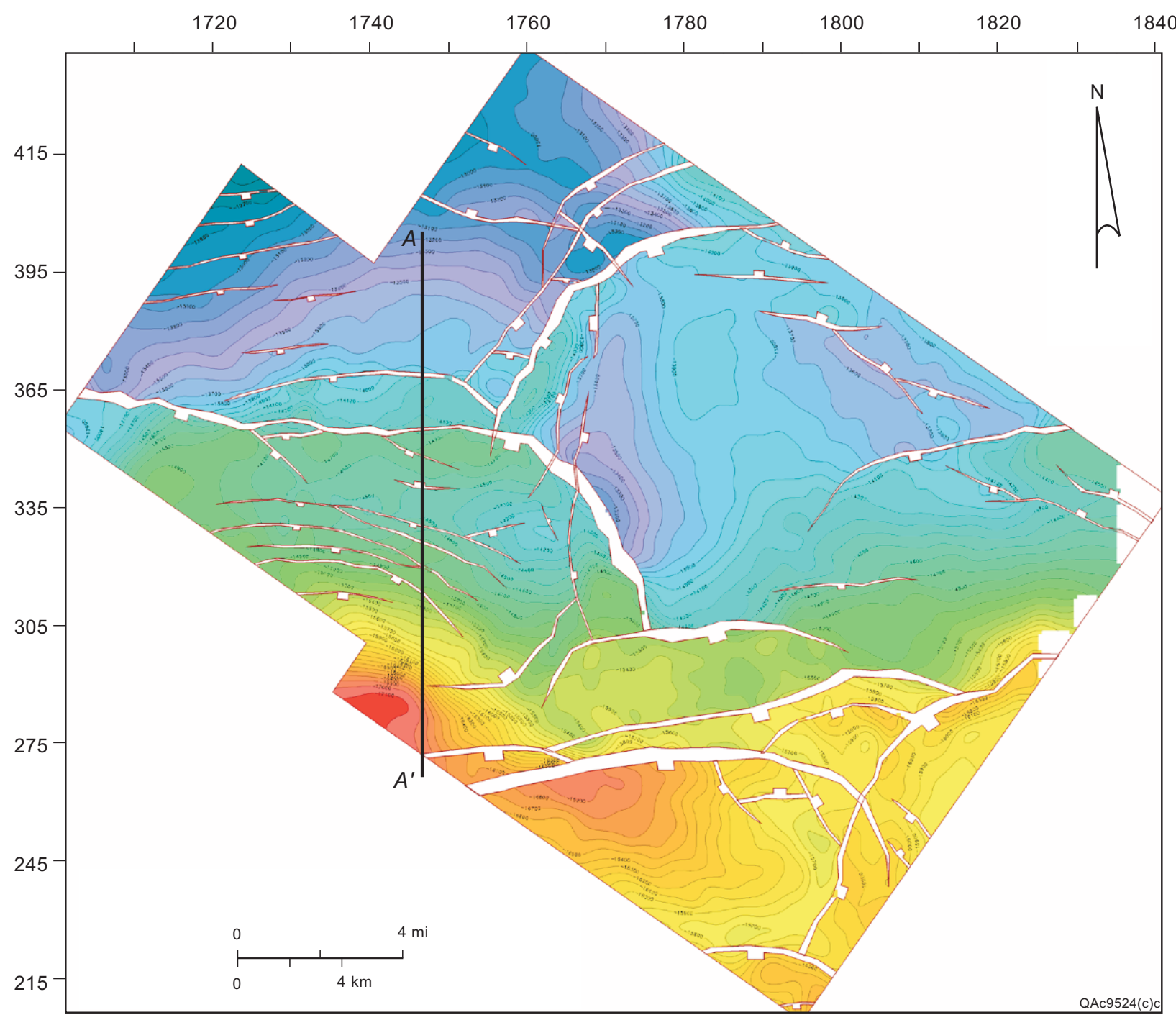

Figure 159. Structure map of MFS 48, which occurs below 15,000 ft, showing several deep structural closures. Secondary fault swarms form multiple deep fault traps and untested fault blocks. Deep portion of seismic section A$\mathrm{A}^{\prime}$ is shown in figure 158. Shallow portion of seismic section $\mathrm{A}^{-\mathrm{A}^{\prime}}$ is shown in figure 63. 


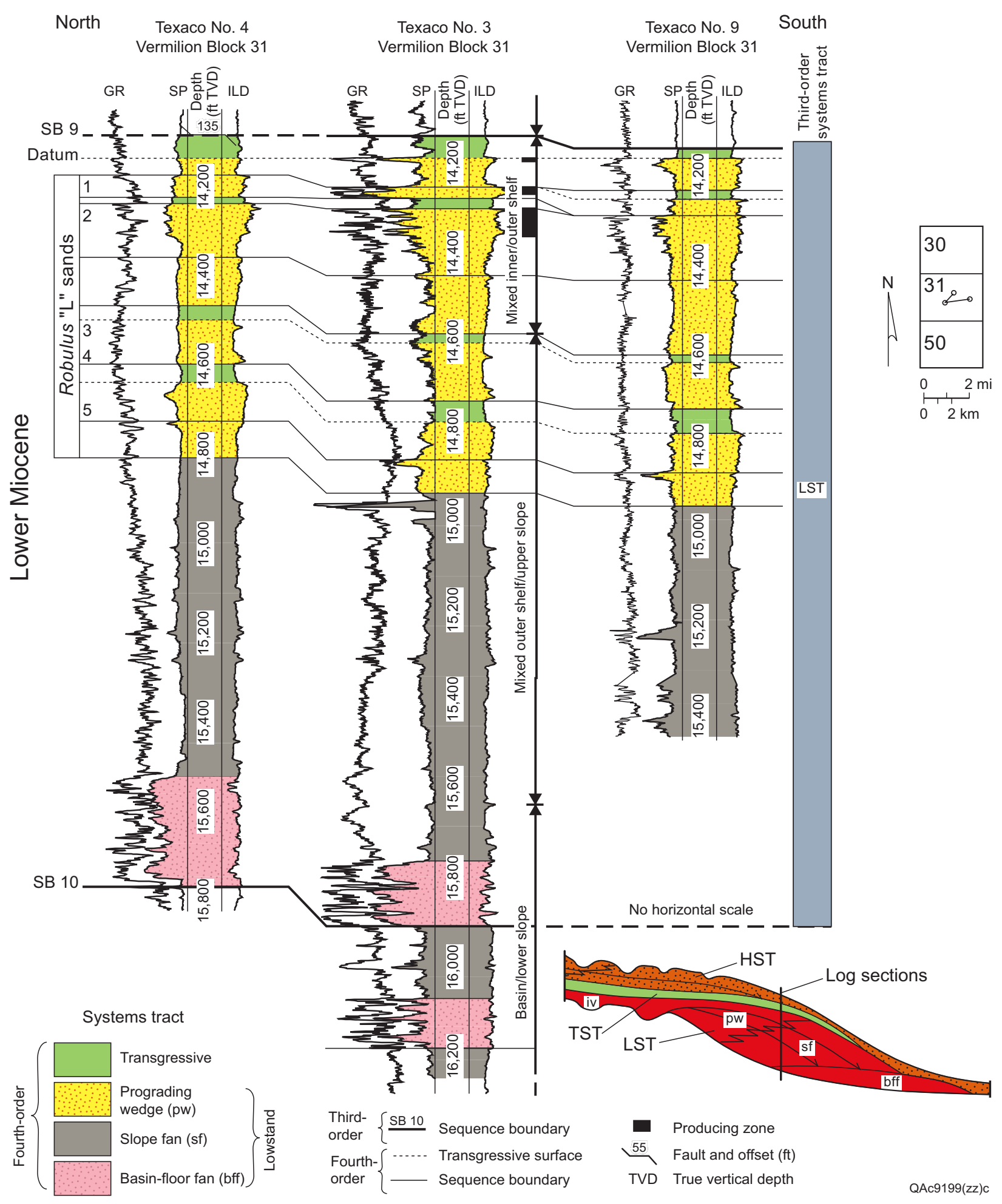

Figure 160. Cross section of Starfak field, showing distal third-order Sequence 10. The Robulus "L" sandstones occur in fourth-order prograding wedges in the upper lower Miocene. Inset diagram shows inferred position of well log sections in a schematic depositional profile. 


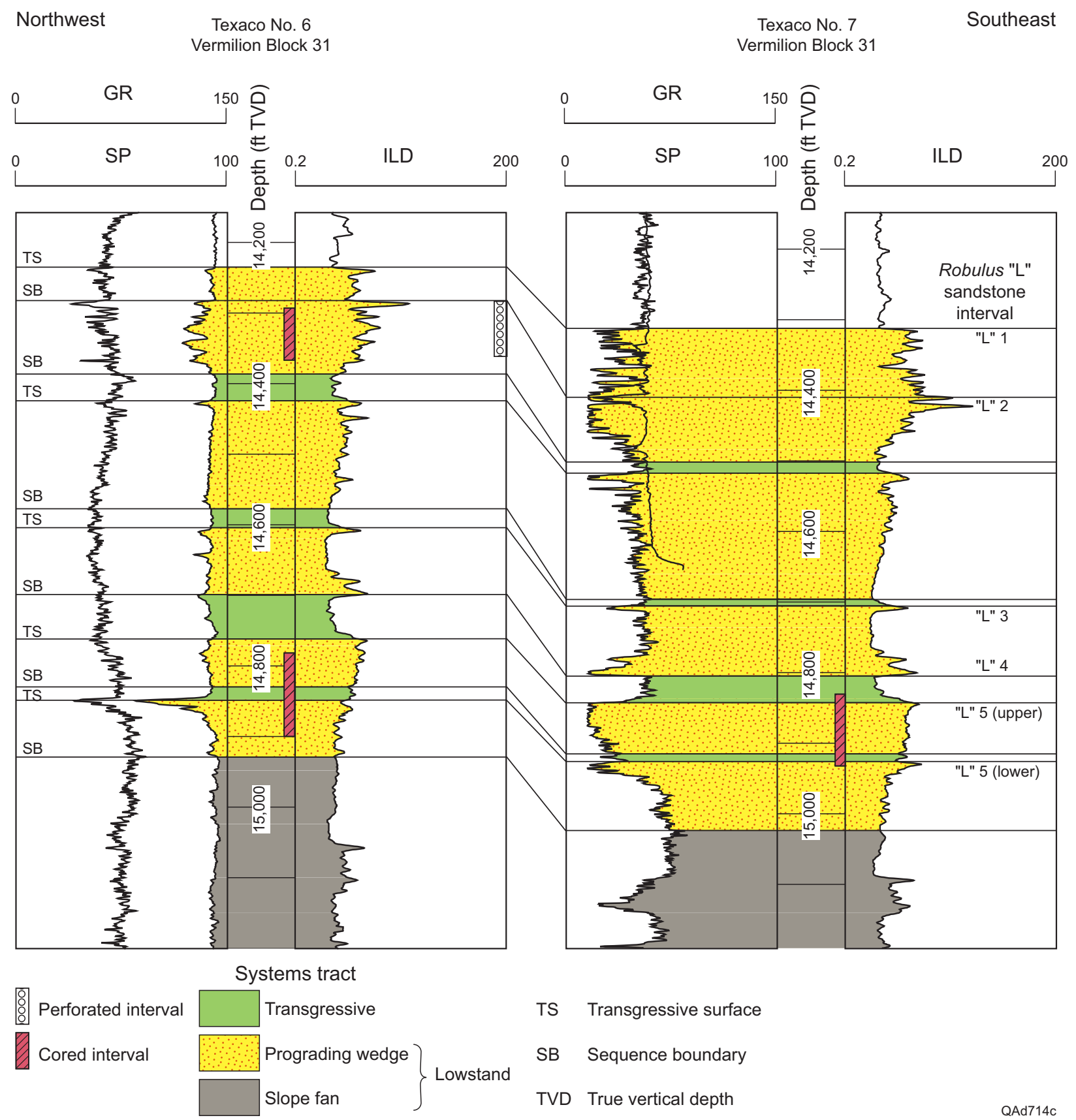

Figure 161. The Robulus "L" interval is composed of a series of lowstand prograding-wedge deposits overlain by distal portions of transgressive systems tracts. The cored intervals in the Robulus L-2 and L-5 sandstones in wells 31-6 and 31-7 are shown. The wells are $\sim 0.5 \mathrm{mi}$ apart. 
The Robulus L-5 sandstone is divided into upper and lower progradational units in both No. 6 and No. 7 wells (fig. 161). The cored intervals include upward-coarsening sandstones of the Robulus L-5 (lower) and overlying muddy sandstone and mudstone of the Robulus L-5 (upper) (figs. 161, 162). Interbedded sandstones and mudstones at the base of the cored prograding wedges are interpreted to represent the distal-delta-front deposits of each lowstand delta (or distal-shoreface deposits in interdeltaic areas) (Dutton and Hentz, in press). The good reservoir-quality sandstone at the top of the Robulus L-5 (lower) and L-2 intervals is interpreted to represent proximal-delta-front/shoreface deposits. Muddy deposits above Robulus L-5 (lower) (fig. 162) are inferred to compose a transgressive systems tract.

\section{$\underline{\text { Sandstone Composition }}$}

The comprehensive petrographic and geochemical study of the diagenesis of Miocene sandstones from Vermilion Block 31 by McBride and others (1988) provided the foundation for this investigation. On the basis of their work, 27 thin sections were selected from the lower Miocene Robulus L-2 and L-5 sandstone intervals to investigate depositional and diagenetic controls on reservoir quality. Sandstones represented in the thin sections are fine to very fine grained ( 0.074 to $0.21 \mathrm{~mm}$ ) and range from well sorted to poorly sorted. The Robulus L-2 sandstones are somewhat coarser grained than are the L-5 sandstones, $3.0 \phi(0.13 \mathrm{~mm})$ versus $3.5 \phi(0.09 \mathrm{~mm})$, respectively. Medium-grained sandstones are reported to occur in the Robulus L-2 interval (McBride and others, 1988; Hart and others, 1989).

The sandstones have an average composition of $\mathbf{Q}_{\mathbf{8 2}} \mathbf{F}_{\mathbf{1 2}} \mathbf{R}_{\mathbf{6}}$ and are mostly subarkoses (fig. 163). (Pseudomatrix and clay clasts were both counted as rock fragments in this calculation.) Plagioclase and potassium feldspars are present (figs. 164, 165), but plagioclase is more abundant ( 8 percent whole-rock volume versus 1 percent, respectively). McBride and others (1988) concluded that the original feldspar content of these sandstones was higher because both plagioclase and potassium feldspars have undergone dissolution. The most abundant lithic grains are clay clasts (fig. 165b), microcrystalline quartz, and metamorphic rock fragments. Other framework grains include fossils fragments, particularly mollusk shell fragments and foraminiferal tests (fig. 164a), glauconite, and zircon.

Detrital matrix (fig. 164b) ranges from 0 to 13 percent in the sandstones. Matrix content is highest in the burrowed distal-delta-front deposits and decreases upward in the proximal-delta-front deposits. Clay clasts and pseudomatrix, which is interpreted as having formed by deformation of soft clay clasts, are also most abundant in distal-delta-front deposits.

The main authigenic cements and replacement minerals are calcite, quartz, and chlorite; minor volumes of kaolinite, siderite, and pyrite also occur. Chlorite precipitated early as grain coats and later in primary and secondary pores and as an alteration of detrital clay (McBride and others, 1988). Chlorite volume ranges from 0 to 6.5 percent and averages 1.8 percent. Quartz overgrowths precipitated after the early chlorite rims. The volume of quartz cement ranges from 0 to 9.5 percent and averages 4.0 percent. Quartz is fairly evenly distributed and is most abundant in clean, matrix-free sandstones (fig. 164c). 

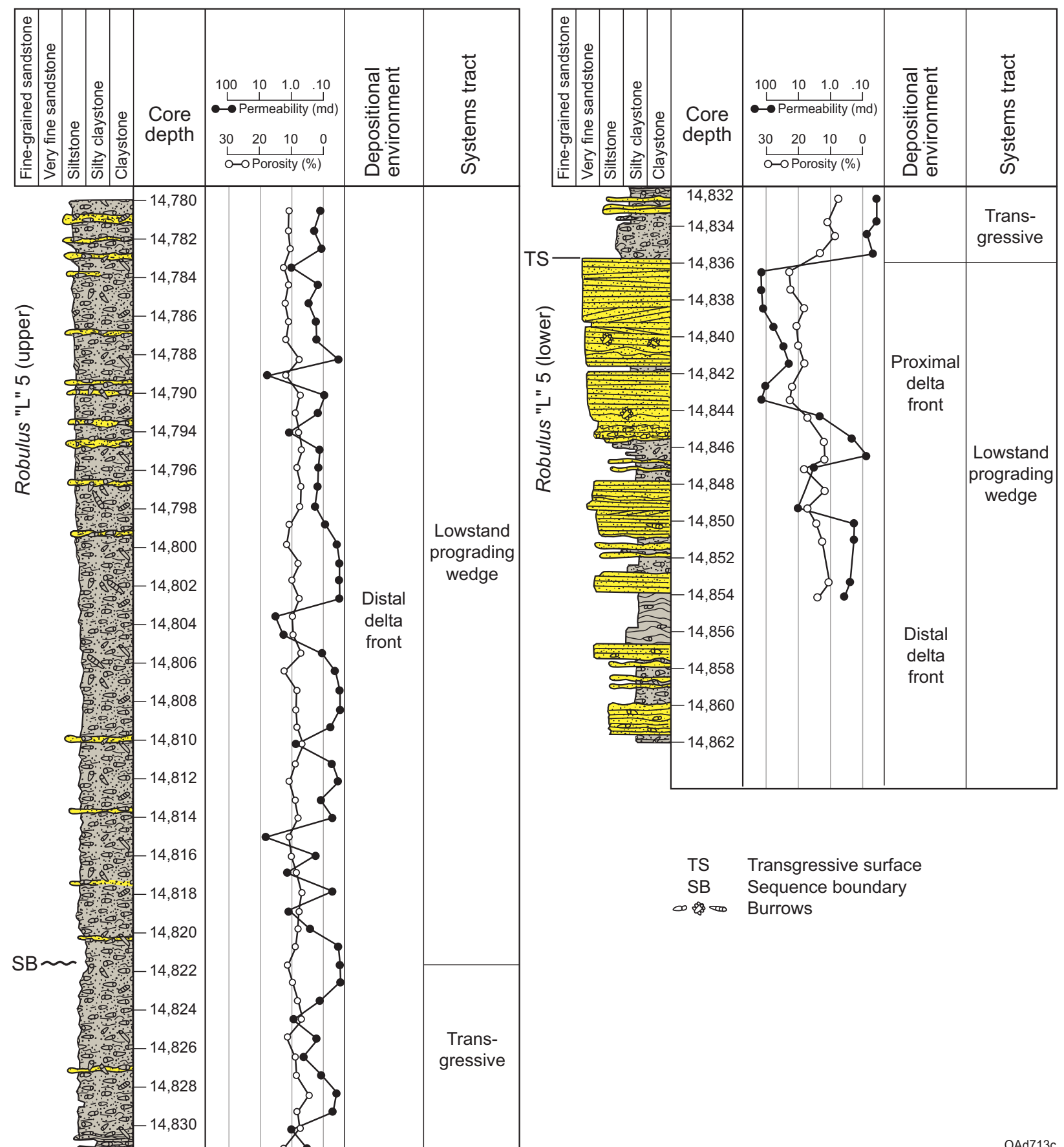

TS Transgressive surface

SB Sequence boundary

$\infty$ Burrows

QAd713c

Figure 162. Core description and interpreted depositional and systems-tract setting of the Robulus L-5 sandstone in well 31-6. 


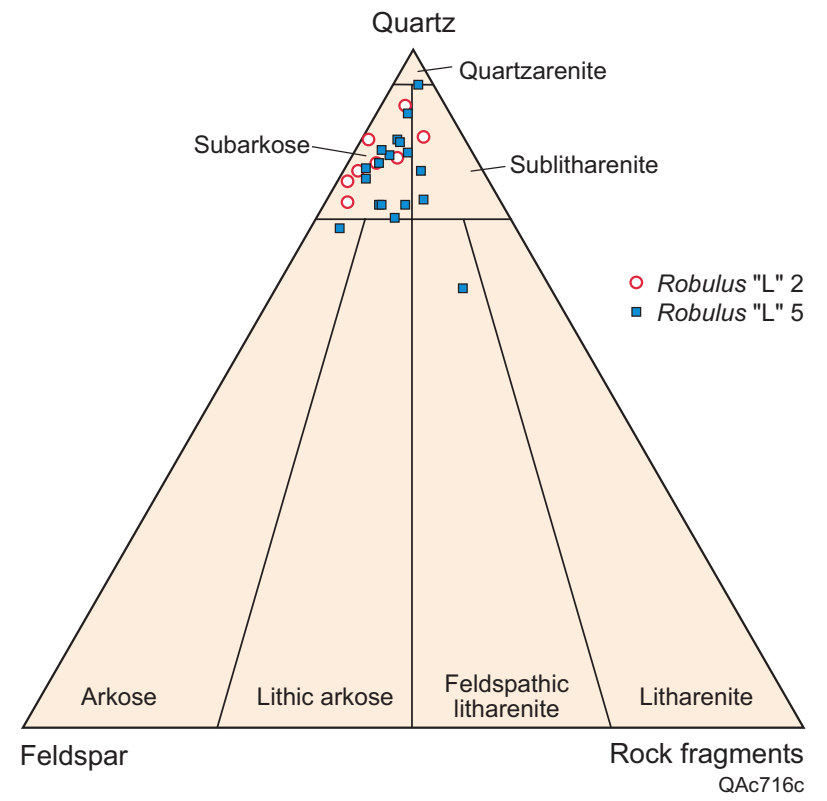

Figure 163. Compositional classification of the Robulus L-2 and L-5 sandstones; most are subarkoses according to the Folk (1974) sandstone classification triangle. 
(a)

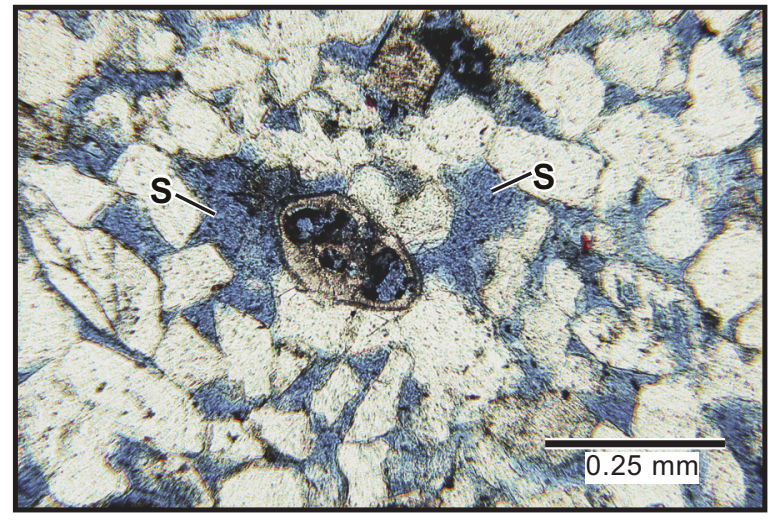

(c)

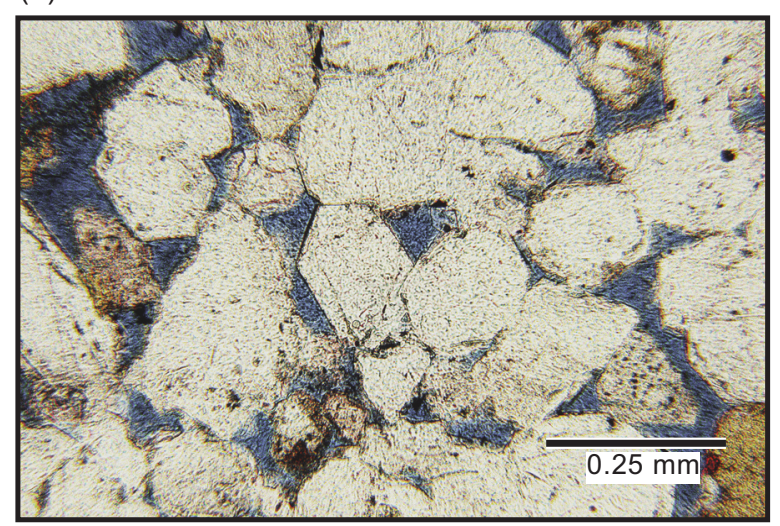

(b)

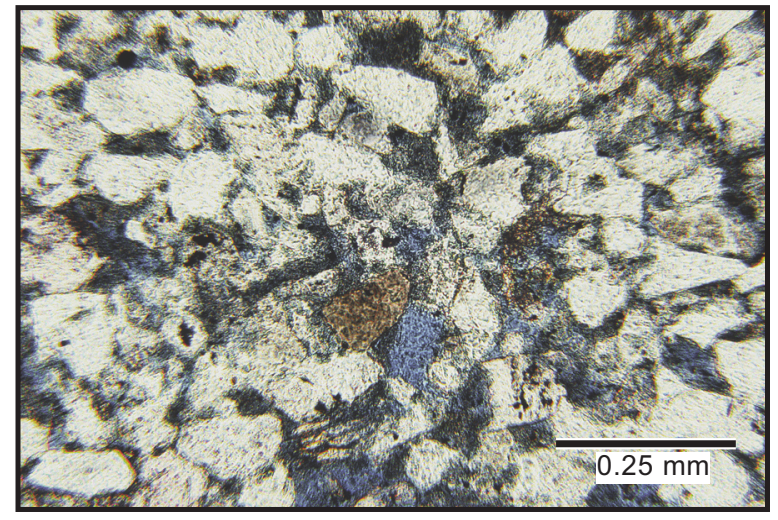

(d)

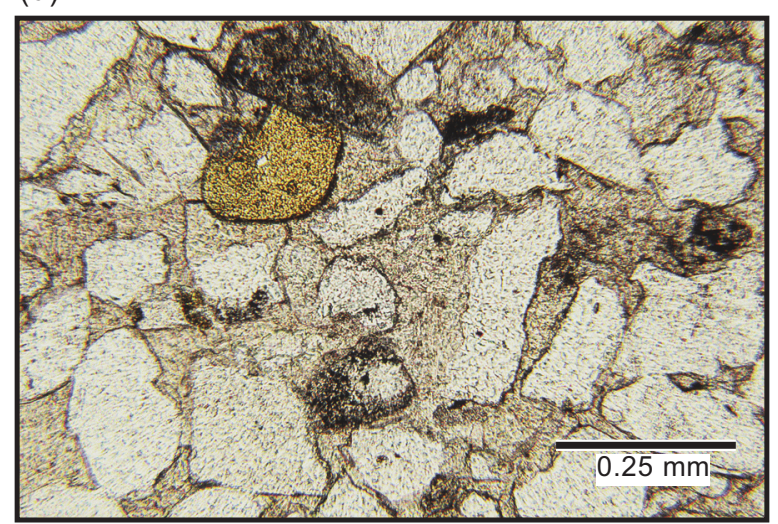

QAd717c

Figure 164. Photomicrographs of fine-grained, proximal-delta-front sandstones from the Robulus L-2 interval, well 31-6. Thin sections were stained for feldspars and carbonates. (a) Good primary and secondary (S) porosity; foraminiferal test in center. Sample porosity $(\phi)=26.6$ percent, and permeability $(\mathrm{k})=620 \mathrm{md}$. Depth 14,298 ft. (b) Matrix (dark green) introduced during bioturbation. Sample $\phi=21.0$ percent, $\mathrm{k}=15 \mathrm{md}$. Depth $14,291 \mathrm{ft}$. (c) Welldeveloped quartz overgrowths (volume $=9.5$ percent). Sample $\phi=16.0$ percent, $\mathrm{k}=200 \mathrm{md}$. Depth $14,318 \mathrm{ft}$. (d) Porosity occluded by 25.5 percent calcite cement (pink). Sample $\phi=14.8$ percent, k $=0.82 \mathrm{md}$. Depth $14,312 \mathrm{ft}$. 
(a)

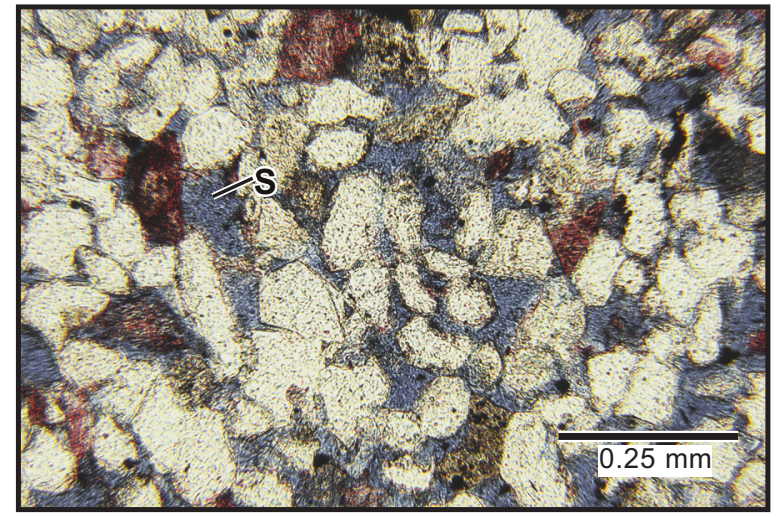

(c)

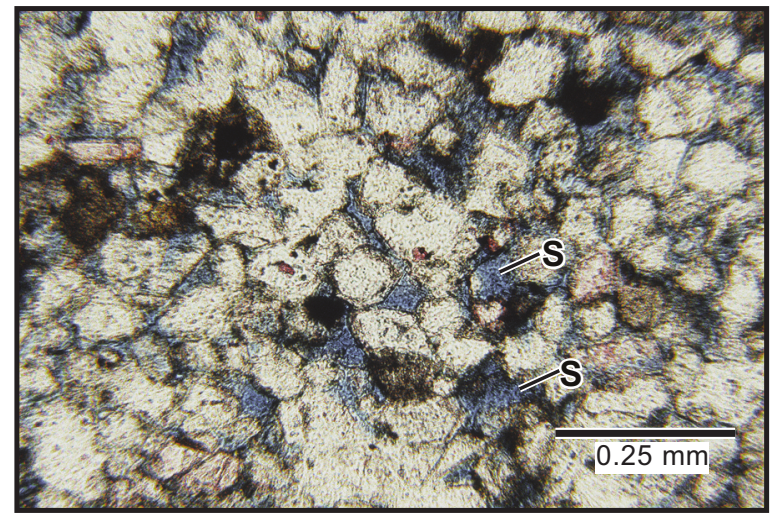

(b)

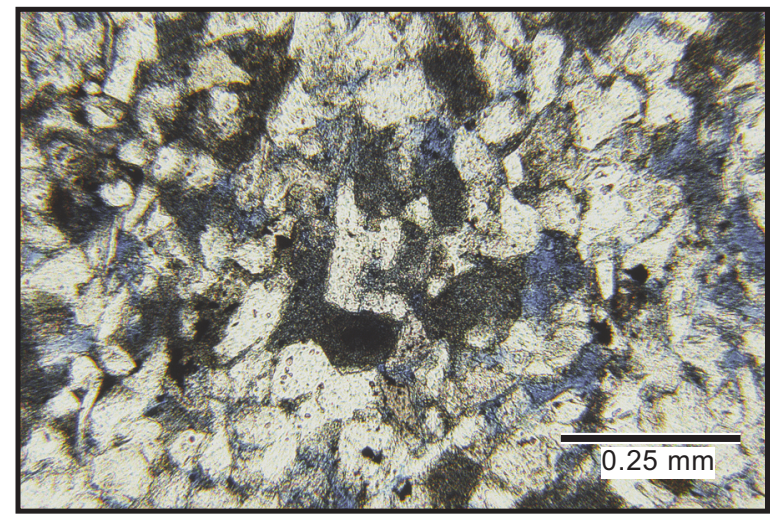

(d)

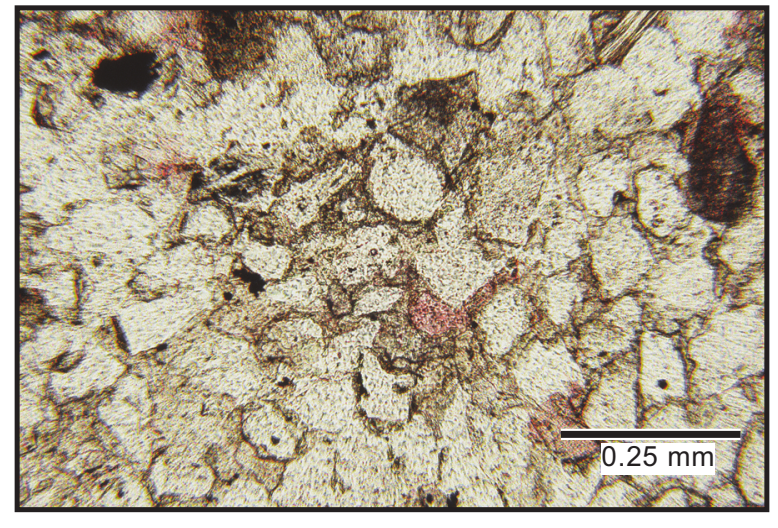

QAd718c

Figure 165. Photomicrographs of very fine grained Robulus L-5 sandstones. Thin sections were stained for feldspars and carbonates. (a) Good primary and secondary (S) porosity in proximal-delta-front sample from well 31-6, 14,843 ft. Dark-pink grains are plagioclase. Sample $\phi=23.0$ percent, $k=151 \mathrm{md}$. (b) Matrix and clay clasts in sample from lower part of the proximal-delta-front deposits, well 31-6, 14,851 ft. Sample $\phi=13.3$ percent, $\mathrm{k}=0.24 \mathrm{md}$. (c)

Primary and secondary (S) pores in proximal-delta-front sample from well 31-7, 14,910 ft. Sample $\phi=18.7$ percent, $\mathrm{k}=104 \mathrm{md}$. (d) Abundant calcite cement (21.5 percent) in lower-delta-front sample from well 31-7, 14,886 ft.

Sample $\phi=7.0$ percent, $\mathrm{k}=0.08 \mathrm{md}$. 
Calcite, which occurs as both pore-filling cement and grain replacement, ranges in volume from 0 to 34 percent. Average volume is 4.8 percent. In a few sandstones the porosity is completely occluded by calcite (fig. 164d), but most samples contain less than 5 percent calcite. Heavily bioturbated distal-delta-front facies of the overlying Robulus L-5 (upper) interval are highly calcite cemented (average 22 percent) (fig. 165d). The calcite fills primary, intergranular pores and also occurs as tiny, disseminated crystals within the matrix. Clean, proximal-deltafront sandstones in the Robulus L-5 (lower) sandstone interval contain only minor volumes of calcite cement $(<5$ percent).

Some zones in the proximal-delta-front sandstones of the Robulus L-2 interval are highly cemented by calcite (fig. 164d). The cemented intervals contain higher volumes of fossil fragments, which were probably the source of the cement. Corroded margins of some calcite are evidence of cement dissolution, but like McBride and others (1988) such dissolution is not interpreted as having been widespread or extensive. No pattern to the distribution of the calcite-cemented zones in the Robulus L-2 sandstone was observed, but the cemented zones are apparently not common. Only one calcite-cemented zone was included in the eight thin sections from the proximal-delta-front sandstones of the Robulus L-2 used in this study. McBride and others (1988) noted 5 samples that contained more than 10 percent calcite cement among the 26 thin sections from the Robulus L-2 sandstone. The thickness of the cemented zones could not be determined from the core photographs presented in Hart and others (1989).

Porosity estimated by thin-section point counts ranges from 0 to 29 percent and averages 16 percent. The average volume of primary porosity is $\mathbf{1 3}$ percent, and the average volume of secondary porosity is 3 percent. The highest porosity occurs in clean (containing $<5$ percent matrix) proximal delta-front deposits (fig. 164a, c; 165a, c), which contain an average of 17 percent primary porosity and 4 percent secondary porosity. McBride and others (1988) were correct in claiming that most oversized pores formed by dissolution of feldspars, as deduced from the size and shape of the secondary pores and the remnants of some partly dissolved feldspar grains. More rarely, the secondary pores are long and narrow and are interpreted as having formed by dissolution of a mollusk shell fragment. The interpretation of Hart and others (1989), that most intergranular pores were once filled with calcite cement that was subsequently removed in a major episode of carbonate dissolution, is incorrect.

\section{Controls on Reservoir Quality}

Core analysis data from wells 31-6 and 31-7 provide information about porosity and reservoir quality of the lower Miocene Robulus "L" reservoir sandstones. Porosity in all samples ranges from 4.9 to 27.1 percent and permeability from 0.01 to $766 \mathrm{md}$. The permeability of one sample was an anomalously high 2,180 md; it is not clear that this is a valid measurement. There is a good relationship between porosity and permeability in the Robulus "L" sandstones (fig. 166). The linear regression equation relating porosity and permeability in the entire population is

$\log$ permeability $(\mathrm{md})=-3.10+0.22 \times$ porosity $($ percent $)(\mathrm{r}=0.85)$. 


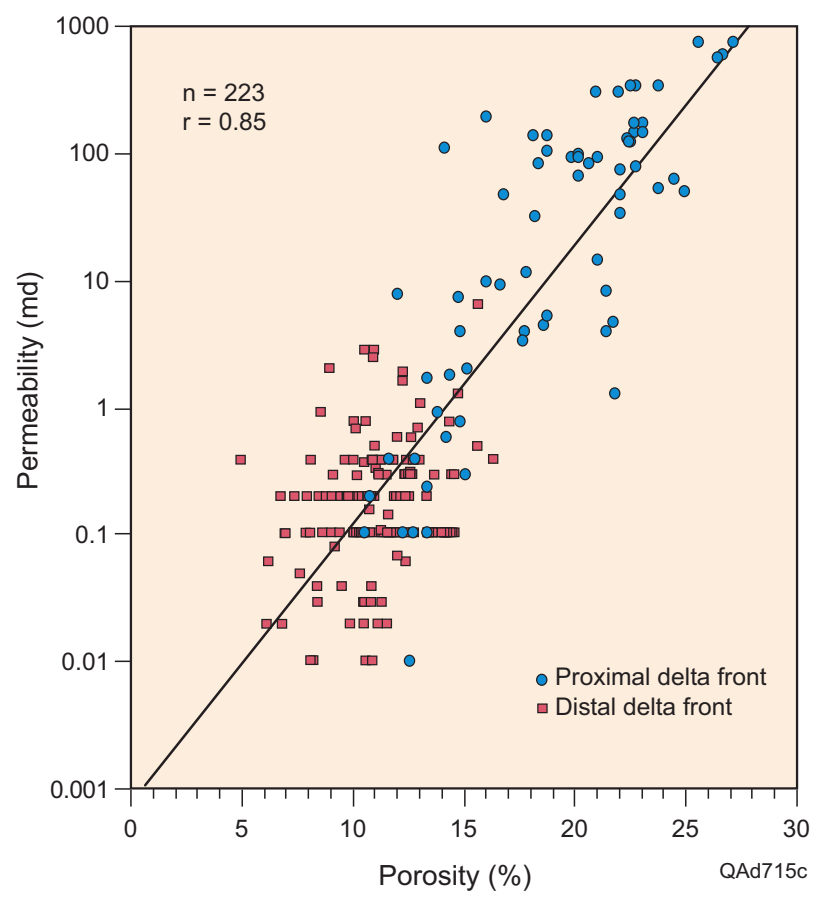

Figure 166. Plot of core-analysis porosity versus permeability for Robulus L-2 and L-5 sandstones. Proximal-deltafront deposits generally have higher porosity and permeability than distal-delta-front deposits. 
Porosity and permeability in the studied cores vary with depositional environment. Proximal-delta-front deposits have average porosity of 18.9 percent and average permeability of $107 \mathrm{md}$ (range 10.5-27.1 percent porosity and 0.01-766 md permeability). Geometric mean permeability in proximal-delta-front deposits is $16 \mathrm{md}$. In contrast, distal-delta-front deposits have average porosity of 10.9 percent (range 4.9-16.3 percent) and average permeability of $0.4 \mathrm{md}$ (range $0.01-6.7 \mathrm{md}$ ). Geometric mean permeability is $0.2 \mathrm{md}$.

Proximal-delta-front sandstones of the Robulus L-2 zone have slightly higher porosity and permeability than do proximal-delta-front sandstones of the Robulus L-5 (lower) interval. Average porosity in proximal-delta-front L-2 sandstones is 19.2 percent, and average permeability is $111 \mathrm{md}$. Geometric mean permeability is $18 \mathrm{md}$. Proximaldelta-front sandstones from the L-5 interval (all samples from the L-5 [lower]) have average porosity of 18.3 percent and average permeability of $100 \mathrm{md}$ (geometric mean $=13 \mathrm{md}$ ).

The petrographic data were used to evaluate the influence of parameters such as grain size, sorting, and volume of ductile grains and authigenic cements on reservoir quality. Two parameters emerge as the major controls on reservoir quality in Robulus L-2 and L-5 sandstones: volume of matrix and volume of calcite cement. Of less importance but also statistically significant (at the 95-percent confidence level) are volume of ductile grains, including pseudomatrix, and grain size. All of these parameters, including calcite cement volume, are largely controlled by depositional environment. This work thus supports the conclusion of previous workers that reservoir quality is a function of primary depositional characteristics and their effects on diagenesis (Hart and others, 1984, 1989; Lowe and Dickerson, 1985).

Most sands deposited in the distal-delta-front environment had relatively low initial porosity and permeability because they are very fine grained and contain abundant matrix as a result of extensive bioturbation. Ductile grains such as micas and clay clasts deformed during compaction and further lowered porosity and permeability. Finally, carbonate fossil fragments were abundant in the distal-delta-front deposits, and calcite cement derived from dissolution of these skeletal fragments filled much of the remaining intergranular porosity.

In contrast, sandstones of the proximal delta front were deposited in a higher energy environment and are somewhat coarser grained. These deposits are less bioturbated, perhaps because sedimentation was probably more rapid, contain less matrix, and are less prone to compaction. Proximal-delta-front sandstones in the Robulus L-5 (lower) interval in Texaco No. 6 contain few fossil fragments and have low volumes of calcite cement. Porosity and permeability in this interval are fairly uniform (fig. 162). Porosity and permeability in the Robulus L-2 sandstone are more heterogeneous. Porous and permeable sandstones are interbedded with low-permeability mudstones, burrowed sandstones, and calcite-cemented sandstones.

\section{Implications for Deep-Sandstone Reservoir Quality}

The fact that porosity as high as $\mathbf{2 7}$ percent and permeability as high as $\mathbf{7 6 6} \mathrm{md}$ remain in lower Miocene sandstones between $\mathbf{1 4 , 0 0 0}$ and $\mathbf{1 5 , 0 0 0} \mathrm{ft}$ in the study area suggests that deeper sandstones probably retain adequate reservoir quality for economic hydrocarbon production. Gold (1984) studied diagenesis of onshore middle and upper Miocene sandstones from southeast Louisiana (primarily Lafourche and Terrebonne Parishes) buried to depths of 20,000 ft. The volume of quartz cement in sandstones between 18,000 and 20,000 ft ranged from 0 to 6 
percent, and volume of calcite cement was less than 5 percent. His work suggests that significantly greater diagenesis has not occurred in Miocene sandstones below 15,000 ft. This finding is significant in light of the previously presented statistics that (1) 5 percent of all wells drilled on the Gulf of Mexico shelf have penetrated strata below 15,000 ft and (2) an estimated $10.5 \mathrm{Tcf}$ of deep-gas recoverable resources occurs in strata below 15,000 $\mathrm{ft}$ (Minerals Management Service, 2001). The young age and recent burial of these sandstones are important factors in their porosity preservation.

\section{CONCLUSIONS}

Significant recoverable gas resources remain undiscovered, undocumented, and unproduced in the Miocene strata of the northern Gulf of Mexico (GOM). More than 41 percent of known gas in the GOM Miocene strata remains to be produced. This 4-year, Secondary Gas Recovery research program was initiated to develop new play concepts, new processing designs, and imaging tools and to identify new resource-addition opportunities that will enable small and large companies alike to arrest the decline in capital performance and extend the life of many mature gas fields on the GOM shelf.

Significant conclusions of the study are:

- Three-dimensional seismic data enable identification of numerous additional resource opportunities in mature fields across the northern GOM region. Within the study area, these traps include

(1) structural traps located within the immediate area of production,

(2) possible deep structural closures and large stratigraphic wedges beneath existing production,

(3) structural traps that extend into the structural "saddle" between Starfak and Tiger Shoal fields, and

(4) widespread stratigraphic and combination stratigraphic/structural traps formed by (a) updip pinch-outs of incised-valley sandstones within shaly highstand strata, (b) local diagenetic pinch-outs of late highstand sandstones that are capped by tight (sealing) zones formed by possible pedogenic cementation developing during lowstand exposure, (c) a variety of potential subregional sandstone pinch-outs within lowstand prograding wedges, (d) updip pinch-outs of lowstand basin-floor-fan sandstones within slope-fan shales, and (e) updip pinch-outs of locally well-developed sandstones within channel-levee complexes of thick lowstand slope-fan successions.

- First-order, broadly arcuate, west-east-trending growth faults cut the north part of the project's two targetstudy fields (Starfak and Tiger Shoal) and act as a primary control on depositional basin geometry and depositional-systems-track development during the early Miocene.

- Structurally trapped hydrocarbons in Starfak field are being produced from rollover anticlines against the first-order growth faults and from deep zones in the rotated fault blocks. In contrast, structural traps in Tiger Shoal field are generally anticlines cut by the second-order, north-south-trending faults.

- Within the study area, there are at least five first-order normal faults ( $>500 \mathrm{ft}$ of maximum offset), extending from near the seafloor to below seismic depth coverage. These five faults have many rollover features at depth, many of which have not been exploited. 
- Seismic analysis has identified several deep (below $3.0 \mathrm{sec}, ~ 12,000 \mathrm{ft}$ ) structural closures, and petrophysical and petrographic analyses show that as much as 27 percent porosity and $766 \mathrm{md}$ of permeability exist in the Miocene units below 14,000 ft. Both observations suggest significant deepreserves potential throughout the area.

- The young age and recent burial of $<15,000$ - $\mathrm{ft}$ sandstones are important factors in their porosity preservation.

- Second-order faults generally have less maximum offset ( $<200 \mathrm{ft}$ ) compared with that of first-order faults, and significant reserve-growth opportunities are associated with these important features. In addition, hourglass features form good structural traps.

- Deep segments of first-order growth faults have significant offset (>600 ft), and they syndepositionally influenced the distribution of reservoir-quality sediments.

- The study area is dominated by extensional normal faulting, with no evidence of compression. Producing reservoir sands are on the downthrown sides of these faults, where most reservoir-quality sands also occur. Downdip deposits may define good trend plays, targeting stratigraphically trapped (pinch-out) hydrocarbon accumulations that parallel the fault line (that is, along fault strike).

- Integrated sequence-stratigraphic analysis can be used to create a framework of unparalleled utility within which to examine resource distribution, seal quality, petrophysical parameters, and reservoir presence.

- The third-order cyclicity interpreted in this study contrasts with the Haq and others (1988) generalized (global) coastal-onlap curve, with the section being an overall regressive succession that was deposited during a time of cyclic regression and transgression, as interpreted by Haq and others (1988). The difference between their well-known "average" global coastal-onlap pattern and that of offshore Louisiana is best explained by the basin-specific effects of generally high sediment flux throughout the Miocene near the ancestral Mississippi delta.

- We identified three third-order cycles between 11.70 and 9.26 m.y., a time interval of 2.44 m.y. that Haq and others (1988) identified as representing one third-order cycle. Such differences probably lie in basinspecific variations in the interaction of eustasy, sediment supply, and subsidence, which control stacking trends of third-order sequences.

- Hydrocarbons have been produced from inferred lowstand incised-valley fills, deltaic/strandplain sandstones of late highstand systems tracts (HST's), deltaic sandstones of late lowstand prograding wedges, and transgressive bayhead deltaic sandstones. Lowstand systems tracts (LST's) of the third-order sequences are the source of 92.6 percent of all gas production, 98 percent of all oil production, and 92.6 percent of total hydrocarbon production.

- Most reservoirs occur within the third-order LST's for several reasons, which are considered collectively:

(1) Prominent thick shales of the third-order transgressive systems tracts (TST's) and HST's create thick regional hydrocarbon seals over reservoirs within the third-order LST's. 
(2) Thick sealing shales above and below the productive zones minimize the risk of cross-fault juxtaposition of lowstand reservoir sandstones against third-order highstand sandstones that can act as points of leakage.

(3) Thick, third-order Miocene shales are potential source rocks for hydrocarbons in lowstand sandstones of the overlying third-order sequence.

(4) The common juxtaposition of thick incised-valley sandstones against neritic to shallow-marine shales from lowstand incision creates lateral and upper seals at valley margins.

(5) The areally restricted distribution of commonly thick, stacked, deltaic-wedge sandstones within slope and basinal shales creates ideal conditions for potential hydrocarbon migration and entrapment.

- Porosity and permeability of reservoir sandstones vary according to their occurrence within LST's, TST's, and HST's

- LST's have the highest average porosity values, especially in the shallow sections. Porosity of LST's is $\sim 28$ percent, compared with 20 percent (TST's) and 22 percent (HST's).

- The highest values of permeability also occur in LST's (average in shallow section, 300-500 md), followed by HST's (100-200 md) and TST's (<100 md).

- Average gas production rates (monthly production rate per perforated foot) are highest in HST's, followed by those in LST's.

- Thick shales of third-order TST's and overlying HST's form regional sealing units across the fields, significantly influencing hydrocarbon distribution.

- Because of their relatively similar geological, engineering, and production characteristics, reservoirs within the same play tend to have similar production and ultimate recovery growth (URG) patterns. Therefore, when couched within this play concept, the observations and processes defined within the SGR study area are broadly applicable to regional resource-addition issues. The study section in the two fields comprises seven middle and upper Miocene plays, five progradational and two retrogradational.

- Several seismic-analysis methodologies and tools can assist significantly in targeting new resource opportunities in 3-D seismic data:

(1) coherency analysis primarily for fault identification;

(2) surface-mapping methods for deducing regional structure at different stratigraphic levels;

(3) analysis of root-mean-squared (RMS) amplitudes for identifying stratigraphic, depositional, and hydrocarbon-bearing features;

(4) amplitude stratal slicing for imaging regional depositional systems along single genetic surfaces;

(5) neural-network-assisted multiattribute analysis for automated depositional-facies recognition and for prediction of log properties from seismic attributes; and

(6) analysis of seismic-lithology relationships.

- RMS amplitudes are sensitive to sandstone-bearing depositional systems tracts within the reservoir-bearing successions and help define the spatial distribution of genetically related depositional successions. RMS- 
amplitude maps can also image stratigraphic leads that have been missed by previous exploitation programs.

- Neural networks are superior to standard statistical classifiers for this study because they do not assume class distribution and can better handle the nonlinearity of seismic data. Neural networks successfully assisted in automating the process for rapidly and accurately defining morphic elements in the 3-D data volume, which showed no distinctive differences in seismic amplitude, waveform, or texture.

- A new seismic attribute, amplitude versus frequency (AVF), when combined with neural networks can dramatically improve bright-spot prospecting in thin-bedded reservoirs by showing

(1) much less tuning effect and more vertical and horizontal thickness changes,

(2) higher resolution for very thin sandstones that are otherwise unresolved in the original data, and

(3) much better fit between shale volume (Vsh) and seismic data.

- Overpressured areas, characterized by an abrupt change in P-wave velocity and bulk density, are thought to strongly influence the quality of deep seismic data. Within the zone of overpressure, seismic attributes do not correlate well with known hydrocarbon-bearing reservoirs. Consequently, seismic-attribute data below this level are unreliable predictors of hydrocarbon trends.

- Production history of the Starfak T-1 sandstone reservoir shows that aquifer encroachment is controlling production. The reservoir has undergone four pulses of production as wells have been completed and produced in separate fault blocks within the reservoir. Only about half of the original resources in place have been produced.

- Production data indicate that significant fluid compartmentalization exists in the T1 intervals because of both near-resolution limit and subseismic-resolution faulting, as well as stratigraphic complexity. Such compartmentalization most likely exists within most of the major reservoir intervals.

- The T-1 reservoir has produced less than half of the original gas in place (OGIP). A significant volume of gas remains as residual gas. Several techniques can be applied to reduce the abandonment pressure before water encroachment kills production:

(1) increase the rate of gas production,

(2) recomplete existing wells higher in the reservoir or drill infill wells higher in the same structure and add compression and artificial lift, and/or

(3) decrease production tubing size.

- Portfolio analysis is a step beyond risk assessment of individual prospects, enabling companies to examine each resource-addition opportunity within the context of a desired portfolio.

- Fifty-four resource-addition opportunities were identified for risk analysis and portfolio assessment. Overall ranking analysis of the opportunities indicates an average geologic chance of success of 25 percent and a standard deviation of 10 percent. The minimum value was 4 percent, and the maximum was 46 percent. 
- After detailed risk assessment of these 54 identified opportunities, it was determined that a 50-percent probability exists that the study area contains 1 trillion standard cubic feet (Tscf) of mean OGIP, 623 billion standard cubic feet (Bscf) of mean unrisked reserves, and $146 \mathrm{Bscf}$ of mean risked reserves.

- Among all of the project's 54 opportunities, the Robulus "L" sandstones collectively contain the most gas reserves: 41 percent of total OGIP (421Bscf), 40 percent of unrisked reserves (251 Bscf), and 39 percent of risked reserves (57 Bscf).

\section{ACKNOWLEDGMENTS}

The authors wish to acknowledge Brian Bergquist, Steven Krause, Ellen Clark, Debra Fotsch, Ricardo Chona, and Jerry Hardouin, all formerly of the New Orleans office of Texaco Exploration and Production Inc. (now Chevron-Texaco) for their continued and invaluable assistance during the course of the 4-year project. Rome Lytton (Chevron-Texaco, Houston) provided much-appreciated guidance in deciphering the biostratigraphy of the study succession. Earle F. McBride of the Department of Geological Sciences, The University of Texas at Austin, provided the thin sections used in the petrographic study reservoir quality of the deep Robulus "L" sandstones.

This publication was prepared with the support of the U.S. Department of Energy, under Cooperative Agreement No. DE-FC26-98FT40136. However, any opinions, findings, conclusions, or recommendations expressed herein are those of the authors and do not necessarily reflect the views of the DOE. As an industry partner, Chevron-Texaco contributed the well, 3-D seismic, and production data. Landmark Graphics Corporation provided software for the 3-D seismic interpretation via the Landmark University Grant Program. Roxar ASA generously contributed the reservoir-modeling software.

Lana Dieterich edited the manuscript, and Scarlett Hurt prepared the digital file of the report. Thanks to both. Thanks also go to Patricia Alfano, John T. Ames, Paula Beard, Jamie H. Coggin, Jana S. Robinson, and David M. Stephens, under the direction of Joel Lardon (Graphics Manager), who prepared all graphics presented in this report.

Lynda Miller and Deborah Thomas are thanked for their ongoing assistance in facilitating administration of this research project and maintaining timely transfer of reports and documents between the research team and the Department of Energy.

\section{REFERENCES CITED}

Agarwal, R. G., R. Al-Hussainy, and H. J. Ramey, Jr., 1965, The importance of water influx in gas reservoirs: Journal of Petroleum Technology, v. 17, p. 1336-1342.

Ancell, K. L, and T. A. Manhart, 1987, Secondary gas recovery from a water-drive gas reservoir: a case study: Society of Petroleum Engineers Paper No. 16944.

Badescu, A. C., and Hongliu Zeng, 2001, Integrating 3-D seismic, sequence stratigraphy, and reservoir properties to enhance secondary gas recovery of two major Miocene Gulf of Mexico offshore fields (abs.): American Association of Petroleum Geologists Annual Convention, Official Program, v. 10, p. A10. Also on CDROM. 
Baker, R. A., W. R. Gehman, and D. A. White, 1984, Geologic field number and size assessments of oil and gas plays: American Association of Petroleum Geologists Bulletin, v. 68, p. 426-432.

Barba, R. E. and C. O. Kiliç, 2000, Petrophysical model development: The University of Texas at Austin, Bureau of Economic Geology, internal report, 23 p.

Bebout, D. G., W. A. White, C. M. Garrett, Jr., and T. F. Hentz, eds., 1992, Atlas of major central and eastern Gulf Coast gas reservoirs: The University of Texas at Austin, Bureau of Economic Geology, 88 p.

Berggren, W. A., D. V. Kent, C. C. Swisher III, and M.-P. Aubrey, 1995, A revised Cenozoic geochronology and chronostratigraphy, in W. A. Berggren, D. V. Kent, M.-P. Aubry, and Jan Hardenbol, eds., Geochronology, time scales and global stratigraphic correlation: SEPM (Society for Sedimentary Geology) Special Publication No. 54, p. 129-212.

Berggren, W. A., D. V. Kent, and J. A. Van Couvering, 1985, Neogene chronology and chronostratigraphy, in N. J. Snelling, ed., The chronology of the geologic record: The Geologic Society Memoir No. 10, p. 211-260.

Boettcher, S. S., and K. L. Milliken, 1994, Mesozoic-Cenozoic unroofing of the southern Appalachian basin: apatite fission track evidence from Middle Pennsylvanian sandstones: Journal of Geology, v. 102, p. 655-663.

Bowen, D. W., Paul Weimer, and A. J. Scott, 1993, The relative success of siliciclastic sequence stratigraphic concepts in exploration: examples from incised valley fill and turbidite systems reservoirs, in Paul Weimer and Henry Posamentier, eds., Siliciclastic sequence stratigraphy: recent developments and applications: American Association of Petroleum Geologists Memoir 58, p. 15-42.

Brill, J. P. and H. D. Beggs, 1974, Two-phase flow in pipes: University of Tulsa INTERCOMP Course, The Hague, $76 \mathrm{p}$.

Chatzis, I., and N. R. Morrow, 1981, Measurement and conditions for entrapment and mobilization of residual: U.S. DOE Final Report, DOE/BETC/3251-12.

Chierici, G. L., G. M. Ciucci, and G. Long, 1963, Experimental research on gas saturation behind the water front in gas reservoirs subjected to water drive, in World Petroleum Congress (Frankfurt), Proceedings, p. 483-498.

Clemen, R., and T. Reilly, 2001, Making hard decisions: an introduction to decision analysis (second edition), Duxbury Press, Pacific Grove, CA, 664 p.

Crawford, T. G., B. J. Bascle, C. J. Kinler, M. T. Prendergast, and K. M. Ross, 2000, Outer continental shelf estimated oil and gas reserves, Gulf of Mexico, December 31, 1998: Minerals Management Service, U.S. Department of the Interior, OCS Report MMS 2000-069, 26 p.

DeAngelo, M. V., T. F. Hentz, L. J. Wood, Hongliu Zeng, and R. E. Barba, Jr., 2000, Targeting reserve growth opportunities in the northern Gulf of Mexico Basin: transferring secondary gas recovery technology to the offshore environment: The University of Texas at Austin, Bureau of Economic Geology, technical progress report: year 2, prepared for U.S. Department of Energy, National Energy Technology Laboratory, under contract no. DE-FC26-98FT40136, 59 p.

DeAngelo, M. V., and L. J. Wood, 2001, 3-D seismic detection of undrilled prospective areas in a mature province, South Marsh Island, Gulf of Mexico: The Leading Edge, v. 20, p. 1282-1292.

Diegel, F. A., J. F. Karlo, D. C. Schuster, R. C. Shoup, and P. R. Tauvers, 1995, Cenozoic structural evolution and tectono-stratigraphic framework of the northern Gulf Coast continental margin, in M. P. A. Jackson, D. G. Roberts, and S. Snelson, eds., Salt tectonics: a global perspective: American Association of Petroleum Geologists Memoir 65, p. 109-151. 
DuBois, J. R., 2001, An investigation of risk and probability in a portfolio management context: Society of Petroleum Engineers Paper No. 71421, 9 p.

Dutton S. P., and T. F. Hentz, in press, Reservoir quality of lower Miocene sandstones in lowstand prograding wedge successions, Vermilion Block 31, offshore Louisiana: Gulf Coast Association of Geological Societies Transactions.

Erskine, R. D., and P. R. Vail, 1988, Seismic stratigraphy of the Exmouth Plateau, in A. W. Bally, ed., Atlas of seismic stratigraphy: American Association of Petroleum Geologists Studies in Geology 27, v. 2, p. $163-$ 173.

Ferrell, R. E., and A. Drew, 1985, Conventional core studies: microfabric of detrital and diagenetic clays, Texaco well \#6: Louisiana State University Publications in Geology and Geophysics, Gulf Coast Studies, No. 4-4, unpaginated.

Fillon, R. H., and P. N. Lawless, 1999, Paleocene-lower Miocene sequences in the northern Gulf: progradational slope salt-basin deposition and diminishing slope-bypass deposition in the deep basin: Gulf Coast Association of Geological Societies Transactions, v. 49, p. 224-241.

Fillon, R. H., and P. N. Lawless, 2000, Lower Miocene-early Pliocene deposystems in the Gulf of Mexico: regional sequence relationships: Gulf Coast Association of Geological Societies Transactions, v. 50, p. 411-428.

Firoozabadi, A., and G. Olsen, 1987, Residual gas saturation in water-drive gas reservoirs: Society of Petroleum Engineers Paper No. 16355, p. 319-327.

Fisher, W. L., 1999, Energy and environment into the twenty-first century: the challenge to technology and ingenuity: Environmental Geosciences, v. 6, no. 4, p. 191-199.

Fishlock, T. P., B. M. Smith, B. M. Soper, and R. W. Wood, 1986, Experimental studies on the waterflood residual gas saturation and its production blowdown: Society of Petroleum Engineers Paper No. 15455, 12 p.

Folk, R.L., 1974, Petrology of sedimentary rocks: Austin, Texas, Hemphill, 182 p.

Galloway, W. E., 1989, Genetic stratigraphic sequences in basin analysis II: application to northwest Gulf of Mexico basin: American Association of Petroleum Geologists Bulletin, v. 73, p. 143-154.

Galloway, W. E., T. W., Ewing, C. M. Garrett, Noel Tyler, and D. G. Bebout, 1983, Atlas of major Texas oil reservoirs: The University of Texas at Austin, Bureau of Economic Geology, 139 p.

Galloway, W. E., P. E. Ganey-Curry, Xiang Li, and R. T. Buffler, 2000, Cenozoic depositional history of the Gulf of Mexico basin: American Association of Petroleum Geologists Bulletin, v. 84, p. 1743-1774.

Galloway, W. E., L. A. Jirik, R. A. Morton, and J. R. DuBar, 1986, Lower Miocene (Fleming) depositional episode of the Texas coastal plain and continental shelf: structural framework, facies, and hydrocarbon resources: The University of Texas at Austin, Bureau of Economic Geology Report of Investigations No. 150, 50 p.

Gold, P. B., 1984, Diagenesis of Middle and Upper Miocene sandstones, Louisiana Gulf Coast: The University of Texas at Austin, Master's Thesis, $160 \mathrm{p}$.

Grab, F. A., and G. L. Smith, 1987, Estimation of oil and gas reserves, in H. B. Bradley, ed. in chief, Petroleum Engineering Handbook: Society of Petroleum Engineers, Richardson, Texas, p. 40-1-40-38.

Hampson, D. P., J. S. Schuelke, and J. A. Quirein, 2001, Use of multiattribute transform to predict log properties from seismic data: Geophysics, v. 66, no. 1, p. 220-236. 
Haq, B. U., J. Hardenbol, and P. R. Vail, 1988, Mesozoic and Cenozoic chronostratigraphy and cycles of sea-level change, in C. K. Wilgus, C. A. Ross, Henry Posamentier, and C. G. St.C. Kendall, eds., Sea-level changes: an integrated approach: Society of Economic Paleontologists and Mineralogists Special Publication No. 42, p. 71-108.

Hardenbol, Jan, Jacques Thierry, M. B. Farley, Thierry Jacquin, Pierre-Charles de Graciansky, and P. R. Vail, 1998, Mesozoic and Cenozoic sequence chronostratigraphic framework of European basins, in Pierre-Charles de Graciansky, Jan Hardenbol, Thierry Jacquin, and P. R. Vail, eds., Mesozoic and Cenozoic sequence stratigraphy of European basins: SEPM (Society for Sedimentary Geology) Special Publication No. 60, p. $3-13$.

Hart, G. F., R. E. Ferrell, Jr., D. R. Lowe, and A. E. Lenoir, 1989, Shelf sandstones of the Robulus L zone, offshore Louisiana, in R. A. Morton and Dag Nummedal, eds., Shelf sedimentation, shelf sequences and related hydrocarbon accumulation, in Gulf Coast Section of the Society of Economic Paleontologists and Mineralogists, Seventh Annual Research Conference Proceedings, p. 117-141.

Hart, G. F., R. E. Ferrell, and D. R. Peach, 1984, Conventional core studies: photolog and sampling locations, Texaco well \#6: Louisiana State University Publications in Geology and Geophysics, Gulf Coast Studies, No. 4-1 (unnumbered pages).

Hefner, R. A., 1993, New thinking about natural gas, in The future of energy gases: U.S. Geological Survey Professional Paper 1570, p. 807-829.

Hentz, T. F., S. J. Seni, and E. G. Wermund, Jr., eds., 1997, Atlas of northern Gulf of Mexico gas and oil reservoirs: volume 2. Pliocene and Pleistocene reservoirs: The University of Texas at Austin, Bureau of Economic Geology, 78 p.

Hentz, T. F., and Zeng, Hongliu, in press, High-frequency Miocene sequence stratigraphy, offshore Louisiana: cycle framework and influence on production distribution in a mature shelf province: American Association of Petroleum Geologists Bulletin.

Hentz, T. F., Hongliu Zeng, and C. O. Kiliç, 2000, Sequence stratigraphy, depositional framework, and resource potential of mature gas reservoirs, Miocene of offshore Louisiana (abs.): American Association of Petroleum Geologists Annual Convention Official Program, CD-ROM.

Hentz, T. F., Hongliu Zeng, and L. J. Wood, 2002, Sequence stratigraphy and hydrocarbon distribution of Miocene plays: a case study from Starfak and Tiger Shoal fields, offshore Louisiana (abs.): American Association of Petroleum Geologists Annual Convention Official Program, v. 11, p. A76-A77. Also on CD-ROM.

Hentz, T. F., Hongliu Zeng, L. J. Wood, A. C. Badescu, Claudia Rassi, and C. O. Kiliç, 2001, Controls on hydrocarbon distribution within a sequence-stratigraphic framework: a case study from the Miocene of offshore Louisiana (abs.): American Association of Petroleum Geologists Annual Convention Official Program, v. 10, p. A86. Also on CD-ROM.

Hightower, M. L., 1991, Portfolio modeling: a technique for sophisticated oil and gas investors: Society of Petroleum Engineers Paper No. 22016, p. 53-64.

Hilterman, F., 1990, Is AVO the seismic signature of lithology?: a case history of Ship Shoal—South Addition: The Leading Edge, v. 9, no. 6, p. 15-22.

Holtz, M. H., and D. S. Hamilton, 1998, Reservoir characterization: methodology to identify reserve growth potential: International Petroleum Conference \& Exhibition, Society of Petroleum Engineers, Proceedings, p. $473-485$. 
Holtz, M. H., and R. P. Major, 2002, Petrophysical characterization of Permian shallow-water dolostone: Society of Petroleum Engineers Paper No. 75214, 16 p.

Hower, T. L., Intera Bergeson, and D. R. Lewis, 1992, Recovery optimization in a multi-reservoir offshore gas field with water influx: Society of Petroleum Engineers Paper No. 24865, p. 9-19.

Hower, T. L., and R. E. Jones, 1991, Predicting recovery of gas reservoirs under waterdrive conditions: Society of Petroleum Engineers Paper No. 22937, p. 525-540.

Jiang, M. M., 1993, Miocene sequence biostratigraphy of the northern Gulf of Mexico: Gulf Coast Association of Geological Societies Transactions, v. 43, p. 137-143.

Jiang, M. M., and J. S. Watkins, 1992, Floral pulses, foraminiferal peaks and inferred sequences in the Miocene of the northern Gulf of Mexico: Marine and Petroleum Geology, v. 9, p. 608-622.

Katz, D. L., M. W. Legatski, M. R. Tek, L. Gorring, and R. L. Neilsen, 1966, How water displaces gas from porous media: Oil and Gas Journal, v. 13, January 10, p. 55-66.

Lake, Larry, 1996, Enhanced oil recovery: Prentice Hall, New York, 550 p

Land, C. S., 1971, Comparison of calculated with experimental imbibition relative permeability: Society of Petroleum Engineers Paper No. 3360, p. 419-425.

Lawless, P. N., R. H. Fillon, and R. G. Lytton III, 1997, Gulf of Mexico Cenozoic biostratigraphic, lithostratigraphic, and sequence stratigraphic event chronology: Gulf Coast Association of Geological Societies Transactions, v. 47, p. 271-282.

Likert, R. A., 1932, A technique for the measurement of attitudes: Archives of Psychology, no. 140, 55 p.

Lore, G. L., K. M. Ross, B. J. Bascle, L. D. Nixon, and R. J. Klazynski, 1999, Assessment of conventional recoverable hydrocarbon resources of the Gulf of Mexico and Atlantic outer continental shelf as of January 1, 1995: U.S. Department of the Interior, Minerals Management Service, Gulf of Mexico OCS Region, Office of Resource Evaluation, OCS Report MMS 99-0034, CD-ROM.

Lowe, D. R., and W. Dickerson, 1985, Conventional core studies: petrology and sedimentology, Texaco well \#6: Louisiana State University Publications in Geology and Geophysics, Gulf Coast Studies, No. 4-3, unpaginated.

Luo, Xin, 2000, 3D seismic interpretation of central offshore Louisiana, Gulf of Mexico: M.S. Thesis, Baylor University, $72 \mathrm{p}$.

Lutes, J. L., C. P. Chiang, R. H. Rossen, and M. M. Brady, 1977, Accelerated blowdown of a strong water-drive gas reservoir: Journal of Petroleum Technology, v. 29, p. 1533-1538.

MacKay, Virginia, ed., 1994, Determination of oil and gas reserves: Petroleum Society of the Canadian Institute of Mining, Metallurgy and Petroleum, Calgary Section, Petroleum Society Monograph No. 1, 361 p.

Matthes, G., R. F. Jackson, S. Schuler, and O. P. Marudiak, 1973, Reservoir evaluation and deliverability study, Bierwang field, West Germany: Journal of Petroleum Technology, v. 25, p. 23-30.

McBride, E. F., L. S. Land, T. N. Diggs, and L. E. Mack, 1988, Petrography, stable isotope geochemistry and diagenesis of Miocene sandstones, Vermilion Block 31, offshore Louisiana: Gulf Coast Association of Geological Societies Transactions, v. 38, p. 513-523. 
McGookey, D. P., 1975, Gulf Coast Cenozoic sediments and structures: an excellent example of extra-continental sedimentation: Gulf Coast Association of Geological Societies Transactions, v. 25, p. 104-120.

Megill, Robert, 1977, Risk analysis (second edition): PennWell Books, Oklahoma, Tulsa, 225 p.

Minerals Management Service, 2001, The promise of deep gas in the Gulf of Mexico: Minerals Management Service, U.S. Department of the Interior, OCS Report MMS 2001-037, 4 p.

Mink, R. M., E. A. Mancini, B. L. Bearden, and C. C. Smith, 1988, Middle and upper Miocene natural gas sands in onshore and offshore Alabama (abs.): American Association of Petroleum Geologists Bulletin, v. 72, p. 1118 .

Mitchum, R. M., J. B. Sangree, P. R. Vail, and W. W. Wornardt, 1990, Sequence stratigraphy in Late Cenozoic expanded sections, Gulf of Mexico, in J. M. Armentrout and B. F. Perkins, eds., Sequence stratigraphy as an exploration tool: concepts and practices in the Gulf Coast: Eleventh Annual Research Conference Proceedings, Gulf Coast Section of the Society of Economic Paleontologists and Mineralogists, p. 237256.

Mitchum, R. M., J. B. Sangree, P. R. Vail, and W. W. Wornardt, 1993, Recognizing sequences and systems tracts from well logs, seismic data, and biostratigraphy: examples from the Late Cenozoic of the Gulf of Mexico, in Paul Weimer and Henry Posamentier, eds., Siliciclastic sequence stratigraphy: recent developments and applications: American Association of Petroleum Geologists Memoir 58, p. 163-197.

Mitchum, R. M., and J. C. Van Wagoner, 1990, High-frequency sequences and eustatic cycles in the Gulf of Mexico basin, in J. M. Armentrout and B. F. Perkins, eds., Sequence stratigraphy as an exploration tool: concepts and practices in the Gulf Coast: Eleventh Annual Research Conference Proceedings, Gulf Coast Section of the Society of Economic Paleontologists and Mineralogists, p. 257-267.

Morton, R. A., L. A. Jirik, and W. E. Galloway, 1988, Middle-upper Miocene depositional sequences of the Texas coastal plain and continental shelf: geologic framework, sedimentary facies, and hydrocarbon plays: The University of Texas at Austin, Bureau of Economic Geology Report of Investigations No. 174, 40 p.

Murtha, James, 1995, An @ risk tutorial for the petroleum industry: James Murtha Publisher, Houston, Texas, 171 p.

Newendorp, P., and J. Schuyler, 2000, Decision analysis for petroleum exploration: Planning Press, Denver, Colorado, $668 \mathrm{p}$.

Orman, M., and T. E. Duggan, 1986, Applying modern portfolio theory to upstream investment decision-making: Society of Petroleum Engineers Paper No. 49095, p. 1-6.

Otis, R., and N. Schneidermann, 1997, A process for evaluating exploration prospects: American Association of Petroleum Geologists Bulletin, v. 81, p. 1087-1109.

Picou, E. B., Jr., B. F. Perkins, N. C. Rosen, and M. J. Nault, eds., 1999, Gulf of Mexico basin biostratigraphic index microfossils: a geoscientist's guide, foraminifers and nannofossils, Oligocene through Pleistocene: Gulf Coast Section of the Society of Economic Paleontologists and Mineralogists Foundation, Parts I and II, 215 p. +3 charts.

Posamentier, H. W., G. A. Dorn, M. J. Cole, C. W. Beierle, and S. P. Ross, 1996, Imaging elements of depositional systems with 3-D seismic data: a case study, in Gulf Coast Section of the Society of Economic Paleontologists and Mineralogists Foundation, $17^{\text {th }}$ Annual Research Conference, p. 213-228. 
Posamentier, H. W., and P. R. Vail, 1988, Eustatic controls on clastic deposition II - sequence and systems tract models, in C. K. Wilgus, C. A. Ross, Henry Posamentier, and C. G. St.C. Kendall, eds., Sea-level changes: an integrated approach: Society of Economic Paleontologists and Mineralogists Special Publication No. 42, p. $125-154$.

Principe, J. C., N. R. Euliano, and W. C. Lefebvre, 2000, Neural and adaptive systems: fundamentals through simulations: John Wiley \& Sons, Inc., New York, 656 p.

Rassi, Claudia, 2002a, in press, Assessment of production predictability of fourth-order systems tracts in the Miocene offshore Louisiana: Gulf Coast Association of Geological Societies Transactions, v. 52.

Rassi, Claudia, 2002b, in press, Influence of reservoir character and architecture on hydrocarbon distribution and production in the Miocene of Starfak and Tiger Shoal fields, offshore Louisiana: Ph.D. dissertation, The University of Texas at Austin, Department of Geological Sciences.

Rassi, Claudia, 2002c, Predicting reservoir performance through sequence stratigraphy—a viable approach? (abs.): American Association of Petroleum Geologists Annual Convention, Official Program, v. 11, p. A145. Also on CD-ROM.

Rassi, Claudia, and T. F. Hentz, 2001, Production prediction and reservoir characterization of systems tracts of fourth-order sequences in the Miocene offshore Louisiana (abs.): American Association of Petroleum Geologists Annual Convention, Official Program, v. 10, p. A164. Also on CD-ROM.

Reilly, F., and K. Brown, 1997, Investment analysis and portfolio management: Dryden Press, Fort Worth, Texas, $1090 \mathrm{p}$.

Rose, P. R., 1987, Dealing with risk and uncertainty in exploration: how can we improve?: American Association of Petroleum Geologists Bulletin, v. 71, p.1-16.

Rose, P. R., and P. J. Brown, 2001a, An overview of exploration play analysis: American Association of Petroleum Geologists short course notes, Houston, March 19-21, 294 p.

Rose, P. R., and P. J. Brown, 2001b, Plays and concessions - a straightforward method for assessing volumes, value, and chance (abs.): American Association of Petroleum Geologists Annual Convention, Official Program, v. 10, CD-ROM.

Rosen, R. N., and W. A. Hill, 1990, Biostratigraphic application to Pliocene-Miocene sequence stratigraphy of the western and central Gulf of Mexico and its integration to lithostratigraphy: Gulf Coast Association of Geological Societies Transactions, v. 40, p. 737-743.

Russell, B., D. P. Hampson, J. Schuelke, and J. Quirein, 1997, Mutiattribute seismic analysis: The Leading Edge, v. 16, p. 1439-1443.

Schafer, P. S., T. Hower, and R. W. Owens, 1993, Managing water-drive gas reservoirs: Gas Research Institute, Chicago, $193 \mathrm{p}$.

Schultz, P. S., S. Rosen, M. Hattori, and C. Corbett, 1994, Seismic guided estimation of log properties, parts 1, 2, and 3: The Leading Edge, v. 13, p. 305-310, 674-678, and 770-776.

Seni, S. J., T. F. Hentz, W. R. Kaiser, and E. G. Wermund, Jr., eds., 1997, Atlas of northern Gulf of Mexico gas and oil reservoirs: volume 1. Miocene and older reservoirs: The University of Texas at Austin, Bureau of Economic Geology, 199 p.

Styzen, M. J., compiler, 1996, A chart in two sheets of the Late Cenozoic chronostratigraphy of the Gulf of Mexico: Gulf Coast Section, Society of Economic Paleontologists and Mineralogists Foundation. 
Texaco Exploration and Production, Inc., 1996, South Marsh Island 3-D survey processing report, project number 11036-3D.

Thomas, L. K., R. W. Hankinson, and K. A. Phillips, 1970, Determination of acoustic velocities for natural gas: Journal of Petroleum Technology, v. 22, no. 7, p. 889-892.

Van Wagoner, J. C., R. M. Mitchum, K. M. Campion, and V. D. Rahmanian, 1990, Siliciclastic sequence stratigraphy in well logs, cores, and outcrops: concepts for high-resolution correlation of time and facies: American Association of Petroleum Geologists Methods in Exploration Series, No. 7, 55 p.

Wagner, J. B., B. M. Kofron, R. W. Morin, D. W. Ford, V. R. Mathur, and R. T. Mauro, 1994, A sequence stratigraphic analysis of the lower Miocene, West and East Cameron Areas, Gulf of Mexico, in Paul Weimer, A. H. Bouma, and B. F. Perkins, eds., Submarine fans and turbidite systems: sequence stratigraphy, reservoir architecture and production characteristics, Gulf of Mexico and international : Fifteenth Annual Research Conference Proceedings, Gulf Coast Section, Society of Economic Paleontologists and Mineralogists, p. 357-372.

Walters, C. C., and M. R. Cassa, 1985, Regional organic geochemistry of offshore Louisiana: Gulf Coast Association of Geological Societies Transactions, v. 35, p. 277-286.

Wang, Z. J., A. Nur, and M. L. Batzle, 1988, Acoustic velocities in petroleum oils: Society of Petroleum Engineers Paper No. 18163.

White, David, 1993, Geologic risking guide for prospects and plays: American Association of Petroleum Geologists Bulletin, v. 77, p. 2048-2061.

Winker, C. D., 1982, Cenozoic shelf margins, northwestern Gulf of Mexico: Gulf Coast Association of Geological Societies Transactions, v. 32, p. 427-448.

Wood, L. J., Hongliu Zeng, M. V. DeAngelo, T. F. Hentz, M. H. Holtz, K. Chan, A. C. Badescu, C. O. Kiliç, Claudia Rassi, and D. Zhou, 2001, Targeting reserve growth opportunities in the northern Gulf of Mexico Basin: transferring secondary gas recovery technology to the offshore environment: The University of Texas at Austin, Bureau of Economic Geology, technical progress report: year 3, prepared for U.S. Department of Energy, National Energy Technology Laboratory, under contract no. DE-FC26-98FT40136, $51 \mathrm{p}$.

Zeng, Hongliu, 1994, Facies-guided 3-dimensional seismic modeling and reservoir characterization: The University of Texas at Austin, Ph.D. dissertation, 164 p.

Zeng, Hongliu, 2001, From seismic stratigraphy to seismic sedimentology: a sensible transition: Gulf Coast Association of Geological Societies Transactions, v. 51, p. 413-420.

Zeng, Hongliu, M. M. Backus, K. T. Barrow, and Noel Tyler, 1995, Three-dimensional seismic modeling and seismic facies imaging: Gulf Coast Association of Geological Societies Transactions, v. 45, p. 621-628.

Zeng, Hongliu, M. M. Backus, K. T. Barrow, and Noel Tyler, 1998a, Stratal slicing, part I: realistic 3-D seismic model: Geophysics, v. 63, no. 2, p. 502-513.

Zeng, Hongliu, S. C. Henry, and J. P. Riola, 1998b, Stratal slicing, part II: real seismic data: Geophysics, v. 63, no. 2, p. 514-522.

Zeng, Hongliu, T. F., Hentz, and L. J. Wood, 2000a, Three-dimensional seismic facies imaging by stratal slicing of Miocene-Pleistocene sediments in the greater Vermilion Block 50-Tiger Shoal field area, offshore Louisiana (abs.): American Association of Petroleum Geologists Annual Convention, Official Program, v. 9, p. A165. Also on CD-ROM. 
Zeng, Hongliu, T. F. Hentz, and L. J. Wood, 2001a, Stratal slicing of Miocene-Pliocene sediments in Vermilion Block 50-Tiger Shoal area, offshore Louisiana: The Leading Edge, v. 20, p. 408-418.

Zeng, Hongliu, T. F. Hentz, and L. J. Wood, 2001b, 3-D seismic expression of high-frequency sequence stratigraphy in Vermilion Block 50-Tiger Shoal area, offshore Louisiana (abs.): American Association of Petroleum Geologists Annual Convention, Official Program, v. 10, p. A224-A225. Also on CD-ROM.

Zeng, Hongliu, and Charles Kerans, 2000, Amplitude versus frequency—applications to seismic stratigraphy and reservoir characterization, part I: model (exp. abs.), in 2000 technical program expanded abstracts: SEG International Exposition and Seventieth Annual Meeting, Calgary, August 6-11: Society of Exploration Geophysicists.

Zeng, Hongliu, Charles Kerans, and F. Jerry Lucia, 2000b, Amplitude versus frequency—applications to seismic stratigraphy and reservoir characterization, part II: real 3-D data in Abo reservoir, Kingdom field, West Texas (exp. abs.), in 2000 technical program expanded abstracts: SEG International Exposition and Seventieth Annual Meeting, Calgary, August 6-11: Society of Exploration Geophysicists.

Zeng, Hongliu, and L. J. Wood, 2002, Using quantitative seismic sedimentology to predict reservoir architecture and lithology: a Gulf Coast Miocene-Pliocene example (abs.): American Association of Petroleum Geologists Annual Convention, Official Program, v. 11, p. A197. Also on CD-ROM.

Zeng, Hongliu, L. J. Wood, and T. F. Hentz, 2001c, Seismic sedimentology by stratal slicing of fluvial and shallowmarine depositional systems in Pliocene, offshore Louisiana: American Association of Petroleum Geologists Annual Convention, Official Program, v. 10, p. A224. Also on CD-ROM. 


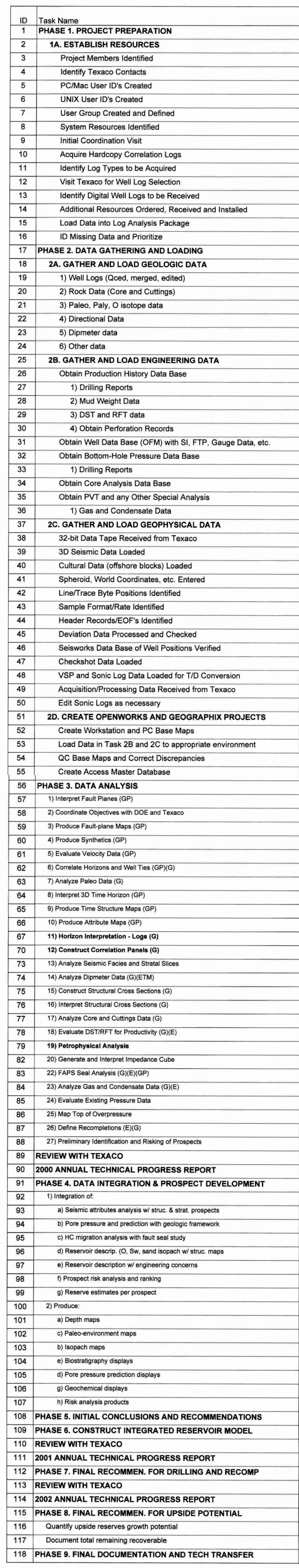

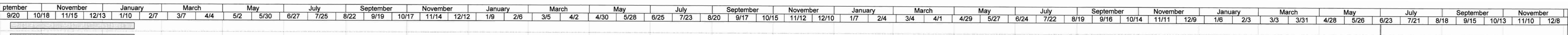
lition
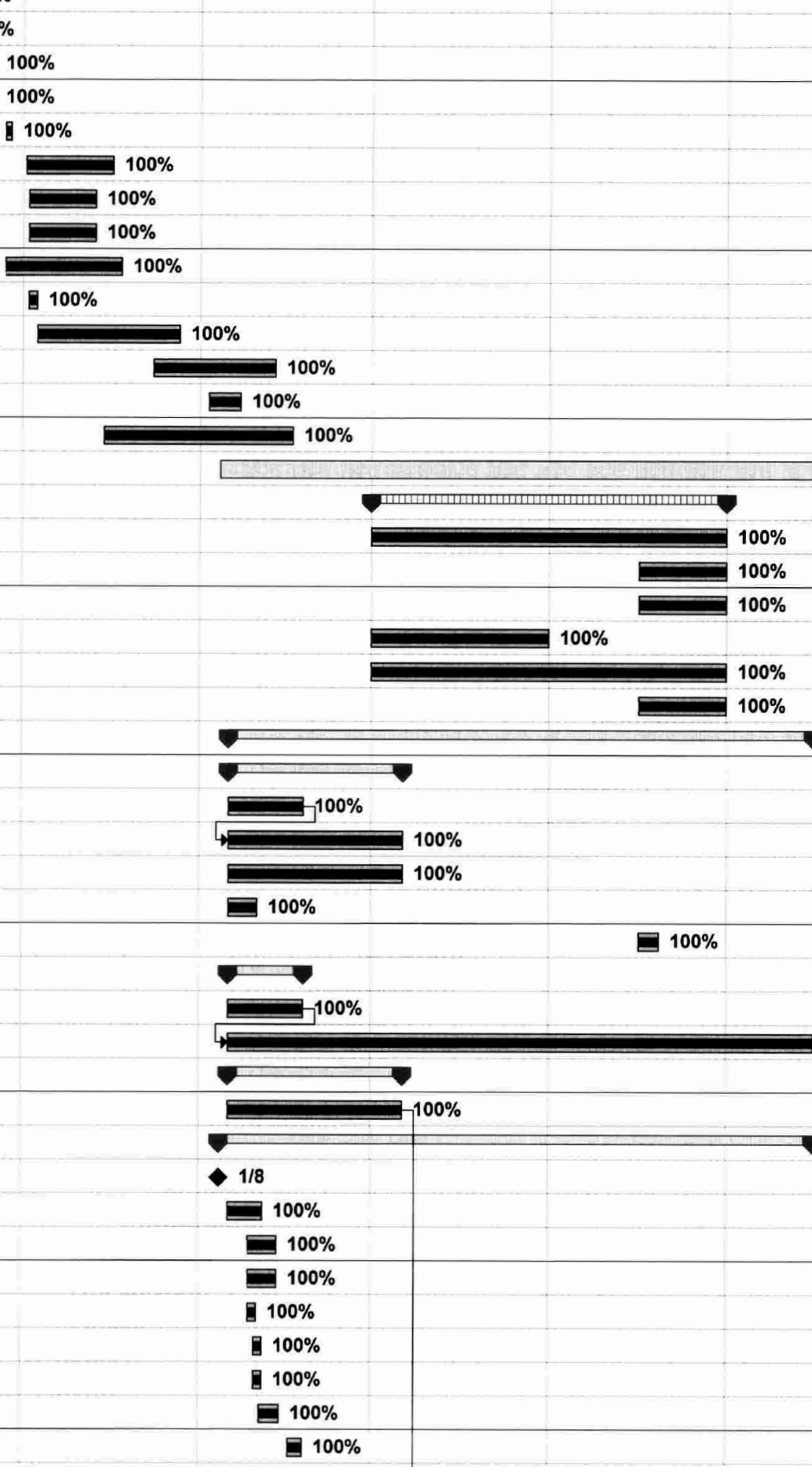

$\underbrace{100 \%}_{100 \%}$
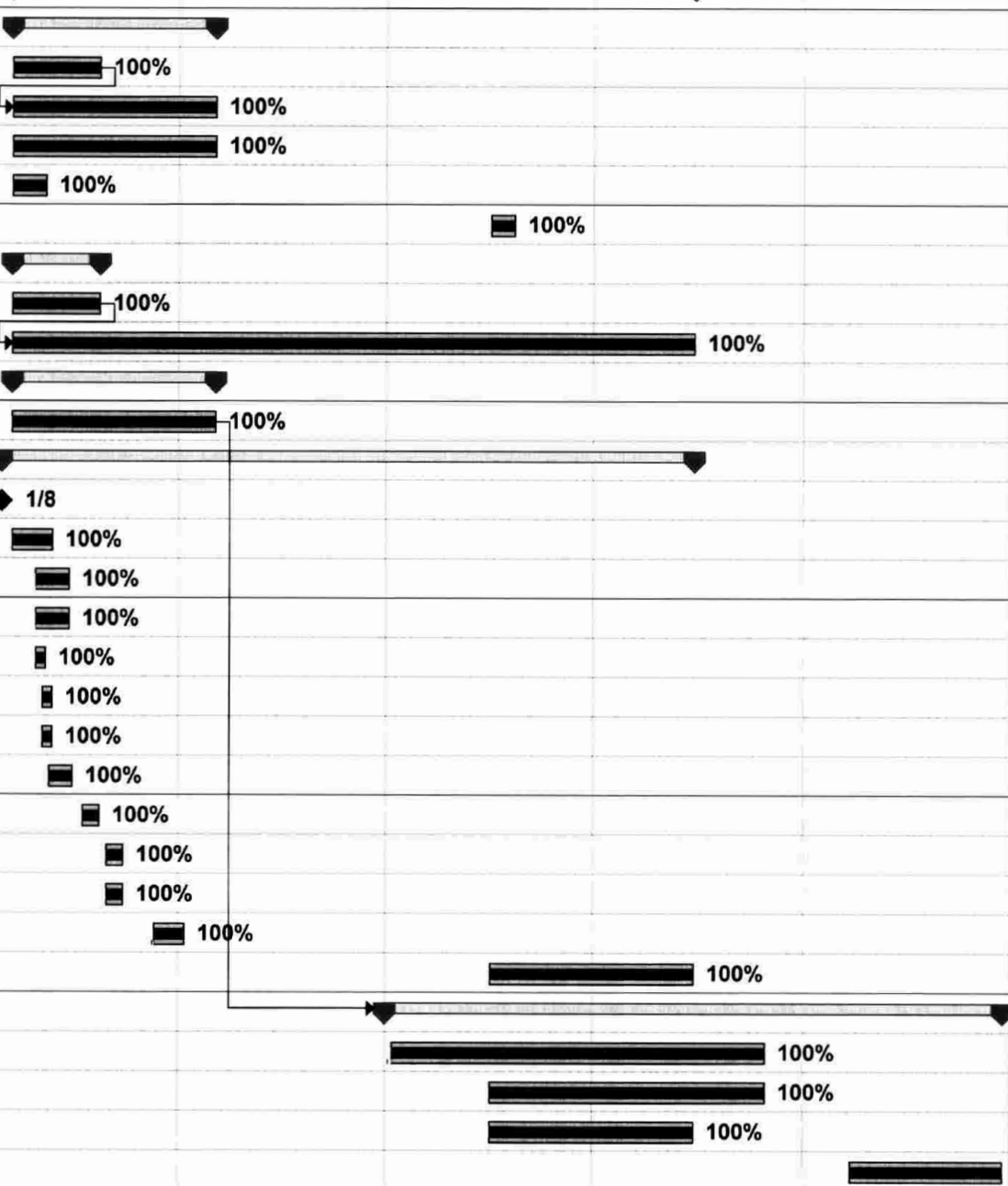

$100 \%$
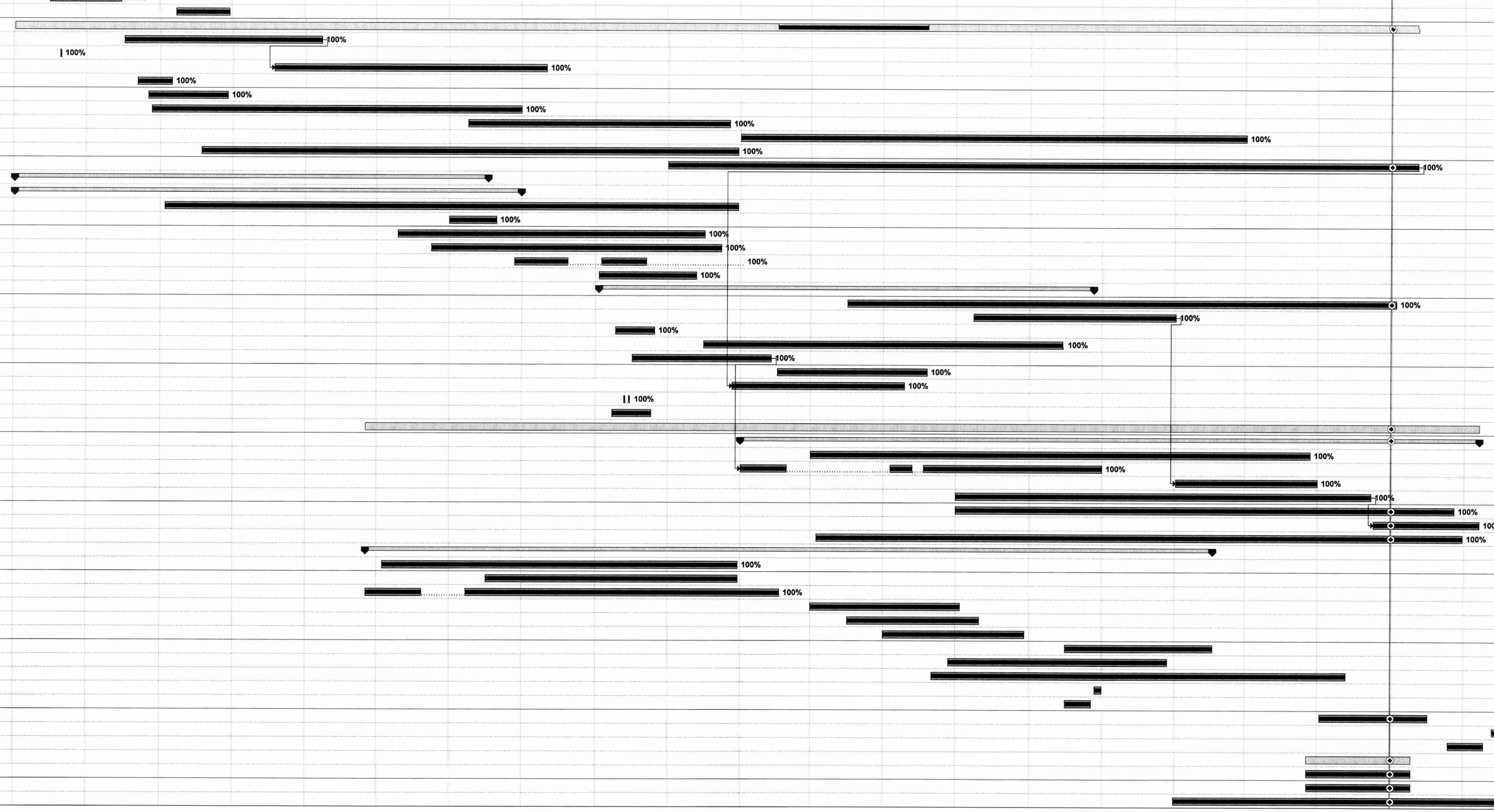

Plate 1. Gantt chart of project timeline showing key project phases and events 


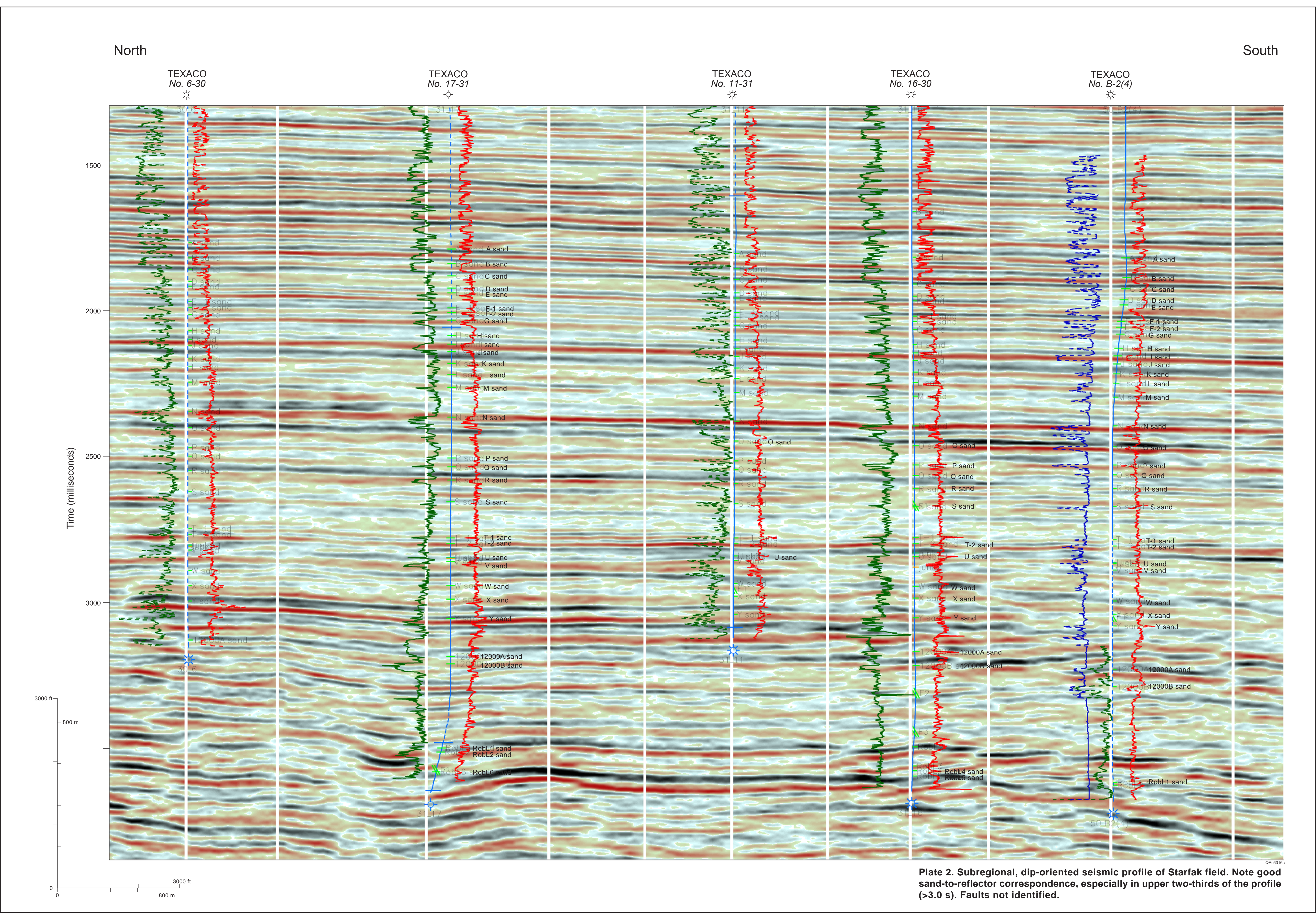

